\title{
Risk Assessment of a Water Supply System under Climate Variability: A Stochastic Approach
}

by

Beatrice Biau Yung

\author{
A thesis \\ presented to the University of Waterloo \\ in fulfillment of the
}

thesis requirement for the degree of

Master of Applied Science

in

Civil Engineering

Waterloo, Ontario, Canada, 2008

CBeatrice Biau Yung 2008 


\section{AUTHOR'S DECLARATION}

I hereby declare that I am the sole author of this thesis. This is a true copy of the thesis, including any required final revisions, as accepted by my examiners.

I understand that my thesis may be made electronically available to the public.

Beatrice Biau Yung 


\begin{abstract}
Canada has approximately $9 \%$ of the world's renewable water (Natural Resources Canada, 2006). In 2000, the Walkerton incident raised the alarm that even a modern domestic water supply can have risks associated with it. These risks can involve water contaminations or water shortage.
\end{abstract}

In this study, a model is developed to assess risk to a municipal water supply system under the influence of population growth and climate change. To incorporate the uncertainly in water use, a model which combines time series Monte Carlo simulations and a deterministic artificial neural network (ANN) is developed to simulate the daily water demand under climate variability.

The model is then expanded in two directions. One direction is to estimate the effects of demand management programs and system expansion on the reliability, resiliency, and vulnerability of the water supply system. Another direction is to capture the possible impacts of climate change on the risk of a water supply system. Twenty-six scenarios generated from different combinations of demand management programs, system expansions and Global Climate Model (GCM) scenarios were set to illustrate the risk indices: reliability, resiliency, and vulnerability. To illustrate the effects of a change of precipitation frequency and a higher population growth, twenty-five additional scenarios were evaluated.

The simulation results suggest that a rise in temperature and a change in precipitation magnitude will have a negative impact on the performance of the system. For example, under the worst case climate change scenario and the current water supply system, average 
future reliability, resilience, and vulnerability values are projected to be $0.981,0.304$, and $258.5 \mathrm{~m}^{3}$, respectively. This compares with average future reliability, resilience, and vulnerability values of the current system with no climate change $0.998,0.635$, and $172.5 \mathrm{~m}^{3}$. The results also suggest that a reduction of precipitation may worsen the system performance. Conversely, an increase of precipitation may lessen the impacts of a warmer climate.

A more rapid population growth will substantially increase the water demand, showing that expansion of the current system is required. For example, under more rapid growth and without expansion, the current system has an estimated reliability of 0.923 under the worst case climate scenario. With expansion option increasing system capacity by $20 \%$, this reliability is improved to 0.965 .

The final phase of the study involves a multiobjective analysis consisting of two objective functions: cost and overall system performance. Four feasible system improvement alternatives were evaluated. By using comprise programming, the nondominated solution of increasing the system capacity by $10 \%$ was ranked first. This compromise solution has emphasis on both aspects of cost and the overall risk performance measures.

Uncertainties exist in the GCM projections of the temperature and precipitation change. The individual effects of an increase of average temperature, a reduction in precipitation, and the fluctuations in the GCM estimates on the risk in the system is uncertain. Additional studies are needed to identify the influence of these factors. 


\section{Acknowledgements}

There are many people that I would like to thank. I would like to thank my supervisors, Professor Don Burn and Professor Bryan Tolson for giving me this exciting opportunity in conducting such interesting and relevant research. This work would not be possible without their guidance, patience, and constant encouragement.

I also want to acknowledge the financial support provided by the Ontario Graduate Study of Technology and the Natural Sciences and Engineering Research Council and data provided by the Region of Waterloo.

I owe my deepest gratitude to my friends, both far and near, and the hydrology lab people for their stimulating discussions, laughter and friendships.

This thesis is dedicated to my parents and my sister who put up with my endless babbling. For without their endless support and belief in me, I would have never made it. 


\section{Table of Contents}

AUTHOR'S DECLARATION ................................................................................... ii

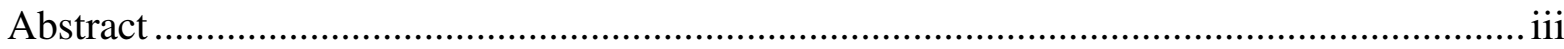

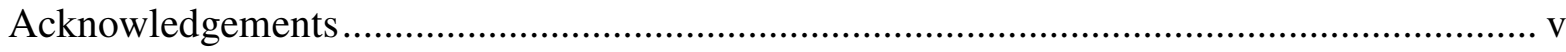

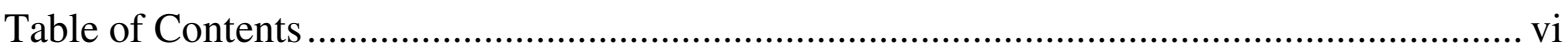

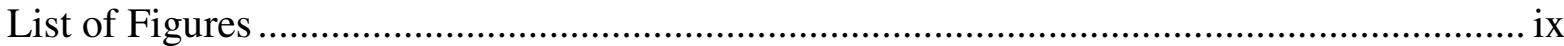

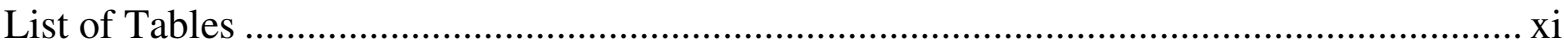

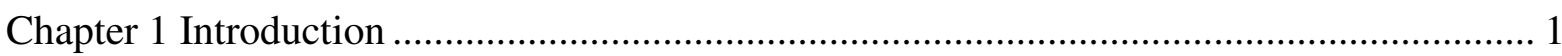

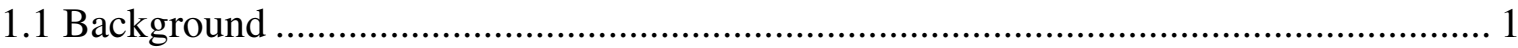

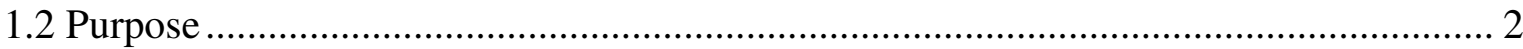

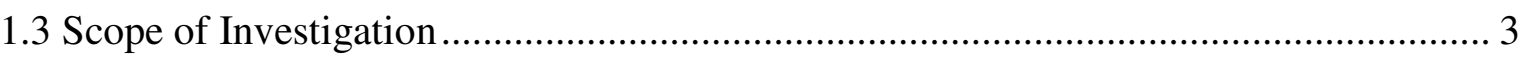

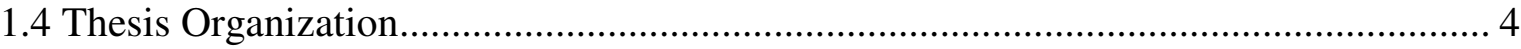

Chapter 2 Literature Review and Background................................................................ 5

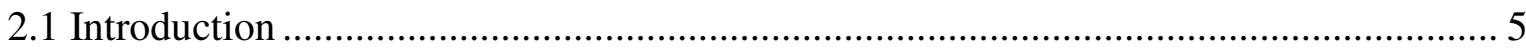

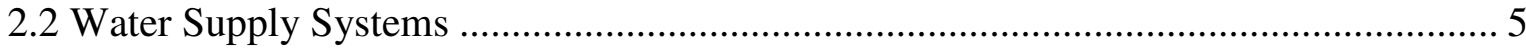

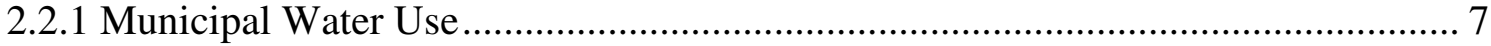

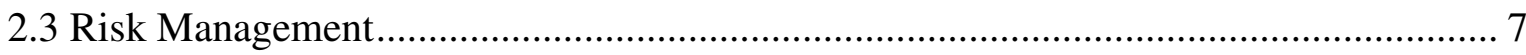

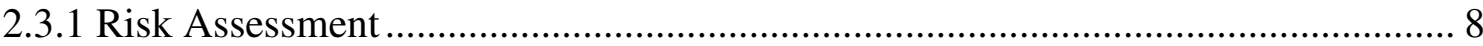

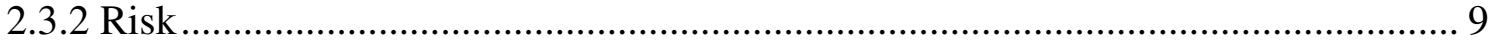

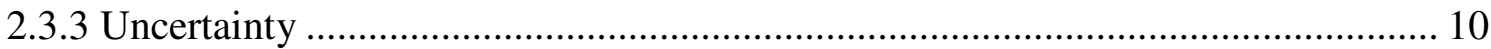

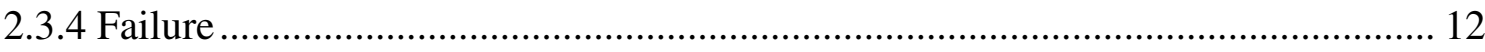

2.4 Risk in Water Supply Systems ............................................................................. 13

2.5 Stochastic Modelling and Simulation ................................................................ 14

2.5.1 Monte Carlo Simulation ....................................................................................... 15

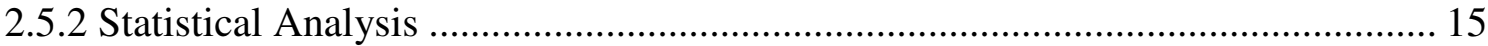

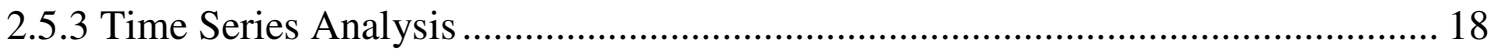

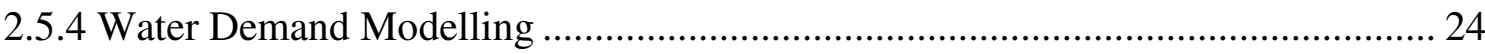

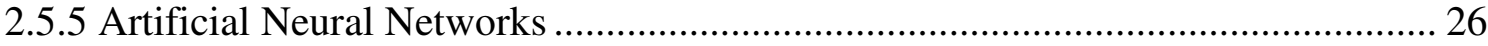

2.6 Risk Indices and Multi-objective Optimization ...................................................... 28

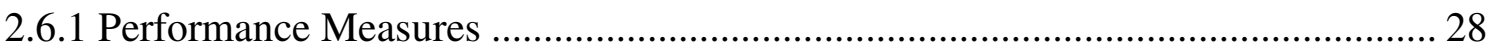

2.6.2 Multi-objective Optimization ................................................................ 33 


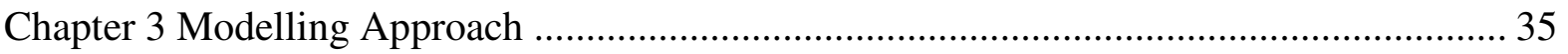

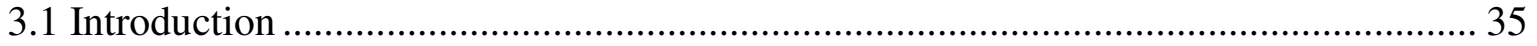

3.2 Model Architecture and Risk Measures Calculation Process ……………………….... 35

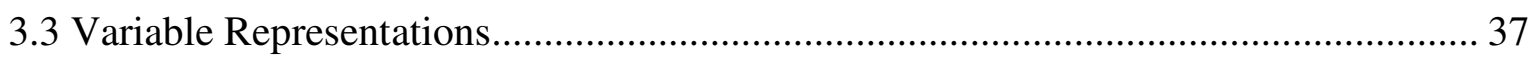

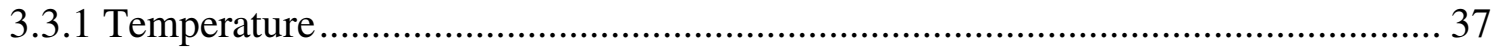

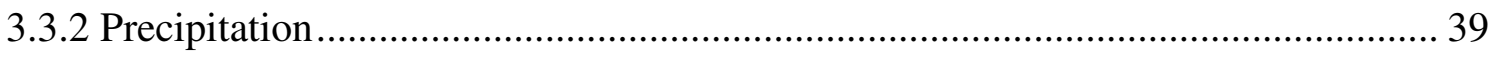

3.3.3 Global Climate Models (GCMs) Data.................................................................... 41

3.3.4 Population Growth, Demand Management and Cost ............................................. 45

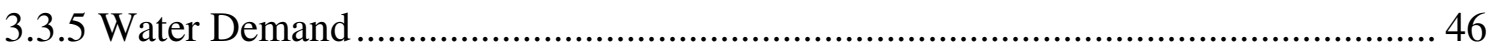

3.3.6 Prediction Model Type Selection .................................................................... 46

3.3.7 Artificial Neural Network Training .................................................................... 47

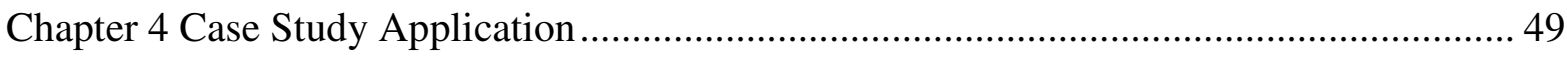

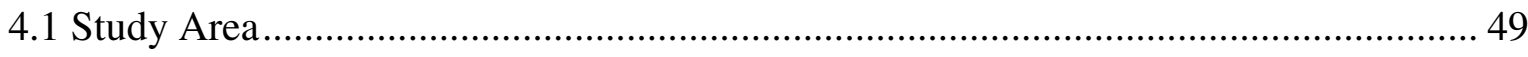

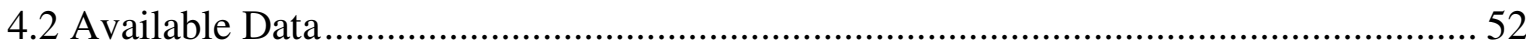

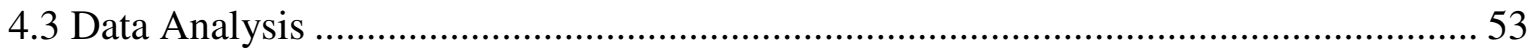

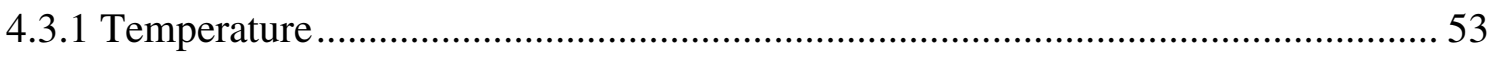

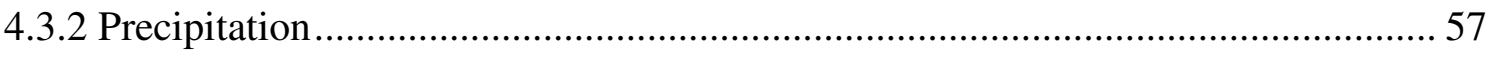

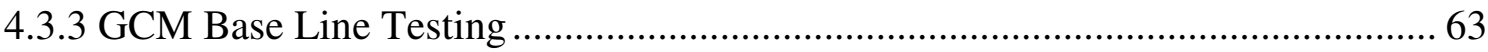

4.3.4 Artificial Neural Network Input Variable Selection.................................................. 64

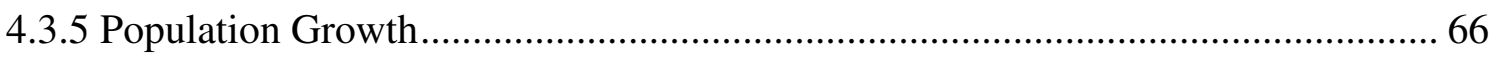

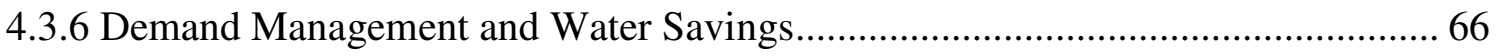

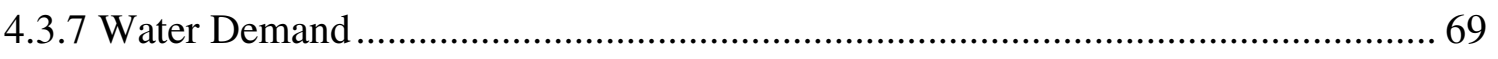

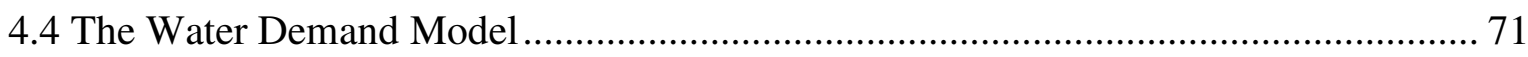

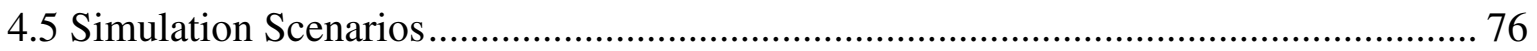

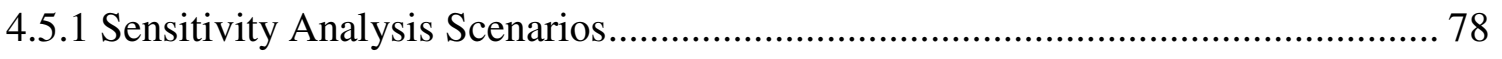

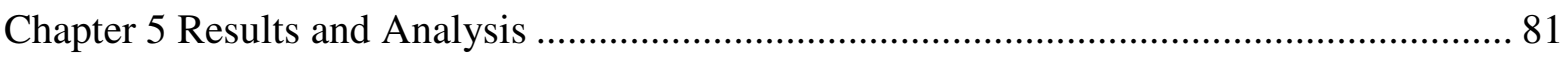

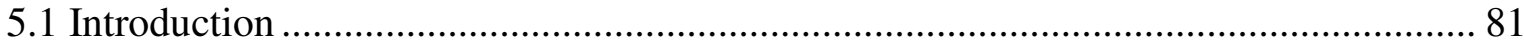

5.2 Result Analysis Approach .................................................................................. 82

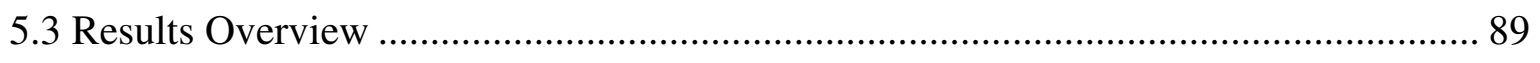

5.3.1 Sensitivity Analysis ............................................................................................. 104

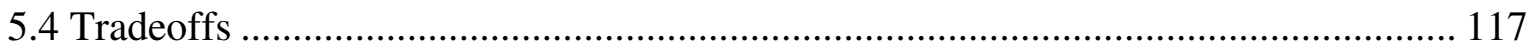




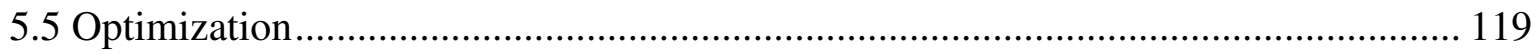

5.5.1 Optimization Results .................................................................................. 120

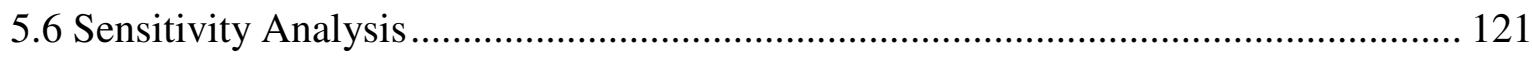

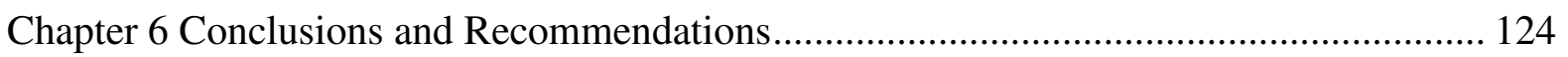

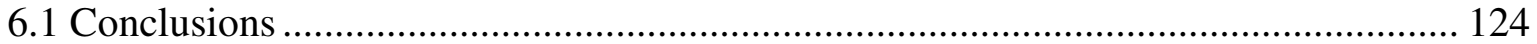

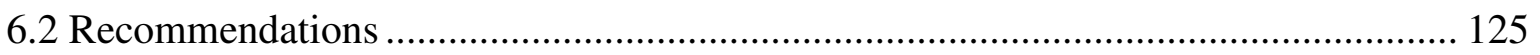

6.2.1 Direction of Future Work .............................................................................. 126

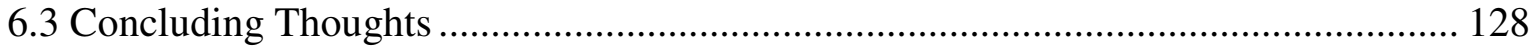

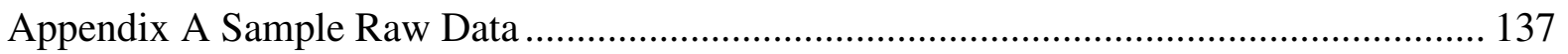

Appendix B Artificial Neural Network Input Variable Selection Experiment Results ........ 146

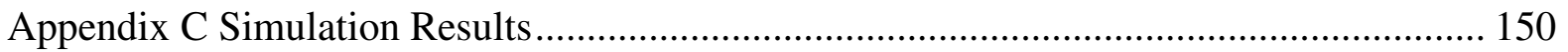

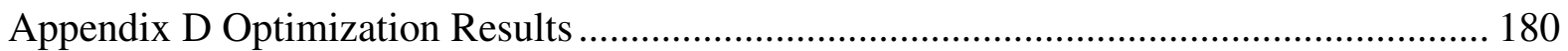




\section{List of Figures}

Figure 1. One period of N-harmonic Fourier series.......................................................... 20

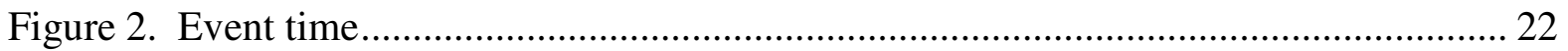

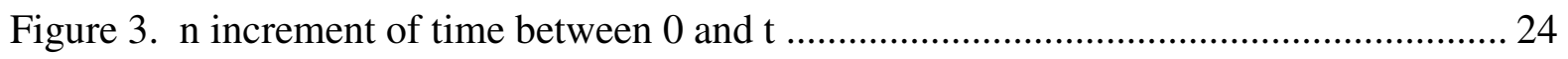

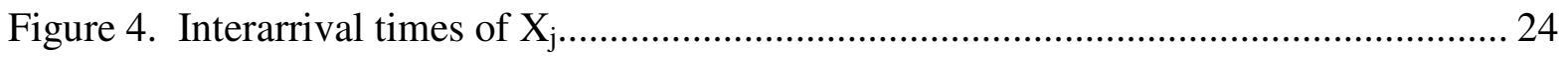

Figure 5. A fully interconnected three-layered back-propagation network ............................ 27

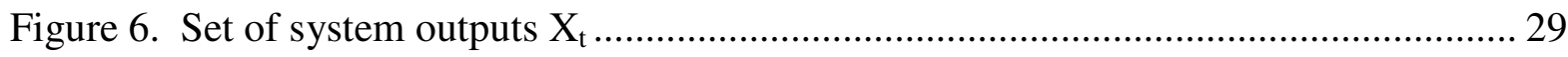

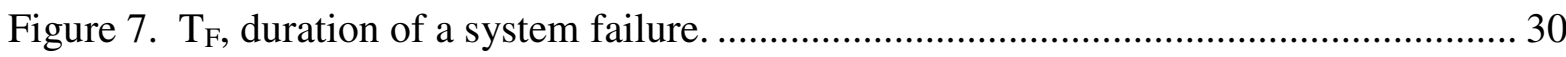

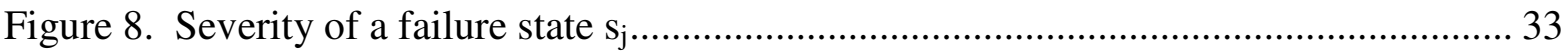

Figure 9. Structure of simulation model schematic for reliability, resilience, and vulnerability

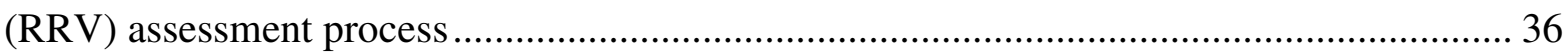

Figure 10. Components of a linear additive time series model................................................. 38

Figure 11. Poisson distributed precipitation arrival and exponential distributed precipitation

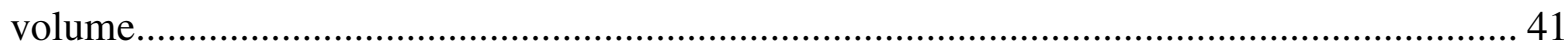

Figure 12. CCSRNIES A11 (SRES) July precipitation change 2020s ................................... 42

Figure 13. Maximum temperature change versus precipitation change for time slice 2020s scenarios.

Figure 14. Monthly maximum temperature and monthly precipitation changes projected by

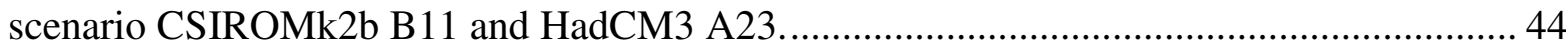

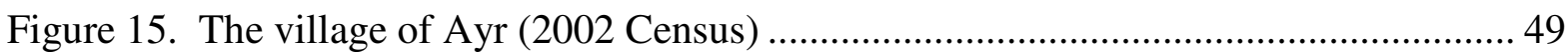

Figure 16. Area municipalities and rural municipal .......................................................... 50

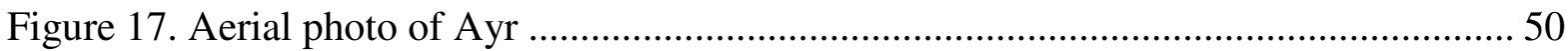

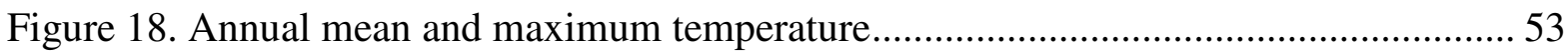

Figure 19. Maximum temperature data fitted using Matlab Curve Fitting Tool ..................... 54

Figure 20. Simulated highest maximum daily temperature with and without climate change

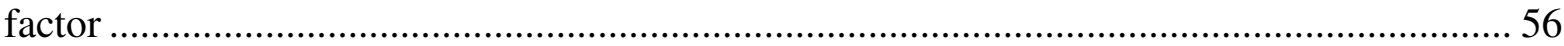

Figure 21. Annual mean and maximum precipitation …………..................................... 57

Figure 22. Comparison of Observed Frequency and Poisson Approximation with $\lambda=0.364$.

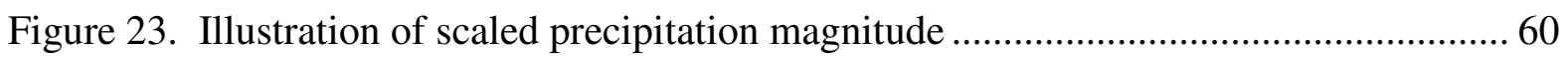


Figure 24. Example of Stochastic Precipitation generated using Poisson Process with a

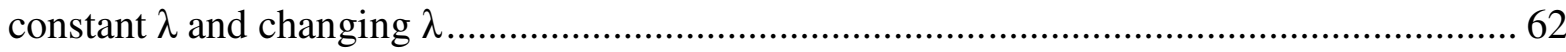

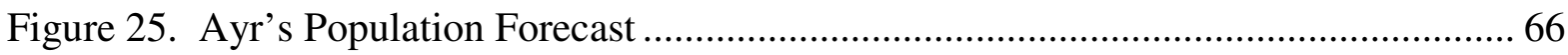

Figure 26. Suspected Erroneous Record in 2000 to 2005 Original Water Demand Data ..... 69

Figure 27. 2000 to 2005 Water Savings and Inflated Water Demand ............................... 70

Figure 28. Time Series Plot of Input Parameters ......................................................... 71

Figure 29. Maximum Temperature versus Water Demand ............................................. 74

Figure 30. Scenario 1 Results. (Top) Reliability versus Resiliency. (Middle) Reliability versus Vulnerability. (Bottom) Resiliency versus Vulnerability..................................... 84

Figure 31. Initial System State of the Example Case ................................................. 85

Figure 32. An Illustration of the Increase in Average Duration of Failure $E\left(T_{f}\right)$ with an

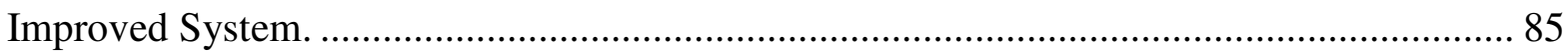

Figure 33. Illustration of the usage of typical severity of a failure state $\mathrm{s}_{\mathrm{j}} \ldots \ldots \ldots \ldots \ldots \ldots \ldots \ldots . . . . . . . . . .88$

Figure 34. Monthly Temperature and Precipitation Projected Climatic Measures in GCMs.

Figure 35. Relative Changes of System Performance as a Function of Water Savings and system expansion under Different Climate Conditions. .................................................. 103

Figure 36. Reductions of Reliability, Resiliency, and Vulnerability in scenario 1b, 3b to 6b.

Figure 37. Reductions of Reliability, Resiliency, and Vulnerability of scenario 7 to 11 , 7a to $11 \mathrm{a}$ and $7 \mathrm{c}$ to $11 \mathrm{c}$. 115

Figure 38. Reductions of Reliability, Resiliency, and Vulnerability of scenario 12 to 16, 12a

to $16 \mathrm{a}$ and $12 \mathrm{c}$ to $16 \mathrm{c}$ 116

Figure 39. Performance Indices and Costs Tradeoff 118 


\section{List of Tables}

Table 1. Average Difference Relative to Baseline in Maximum Temperature and

Precipitation of the Four Selected Scenarios. .................................................................... 44

Table 2. Fourier Series Temperature Smoothing ........................................................... 55

Table 3. Stochastic Time Series Temperature Simulation ................................................ 56

Table 4. A Summary of Recorded Precipitation Data .................................................... 58

Table 5. Summary of an Example of Simulated Time Series Precipitation ......................... 58

Table 6. Stochastic Precipitation Simulation ................................................................... 61

Table 7. ANOVA Table of Simulated Temperature Data Versus GCM Scenario Baseline

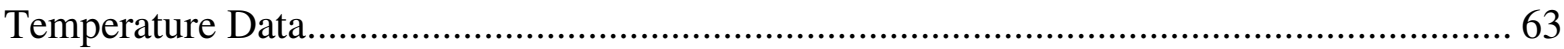

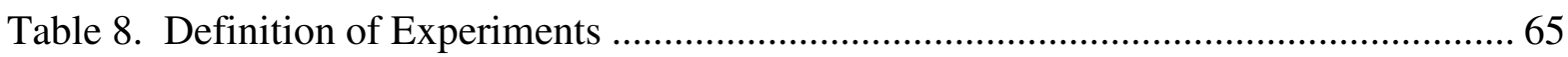

Table 9. Sensitivity Analysis of Inputs Experiment …................................................. 65

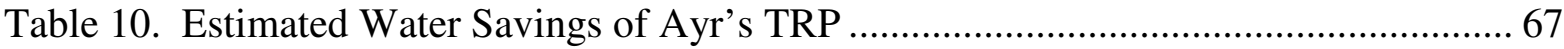

Table 11. Summary of Projected Program Costs and Water Savings from 2006 Water

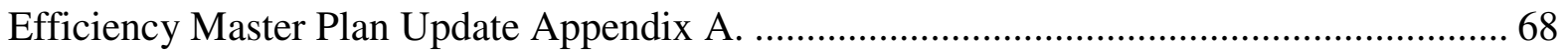

Table 12. Summary of Ayr Water Supply Expansion Costs and Capacity Increase ............. 68

Table 13. Cross-correlation coefficients of water demands and Climatic Variables............ 73

Table 14. Correlation Coefficients between Maximum Temperature and Per Capita Water

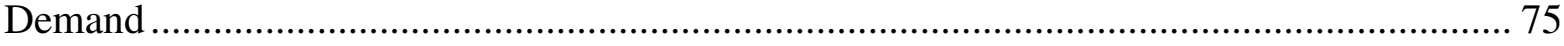

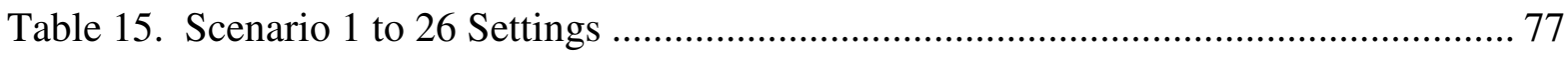

Table 16. Sensitivity Analysis Scenario to Investigate the Effect of a Change of Frequency

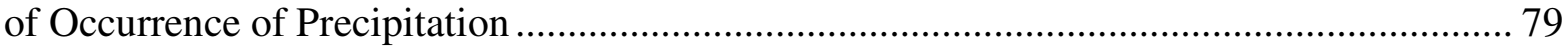

Table 17. Sensitivity Analysis Scenario to Investigate the Effect of Higher Population Growth

Table 18. Sensitivity Analysis Scenario to Investigate the Effect of Climate Change and a

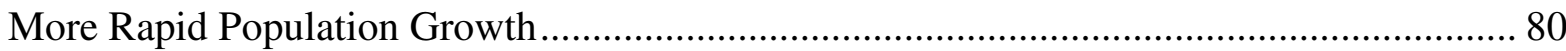

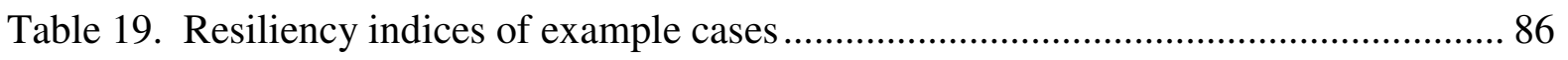

Table 20. Vulnerability Indices of Example Case ..................................................... 88

Table 21. Scenario 1 to 6 Failure Statistics and Performance Measures. In brackets are the minimum, average, and maximum values of a measure with associated standard deviation in

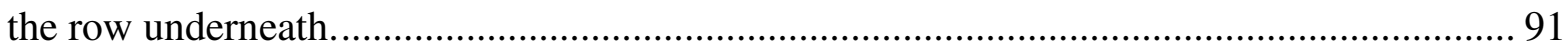


Table 22. Scenario 7 to 11 Failure Statistics and Performance Measures.

Table 23. A Comparison of the Average Number of Failure Days between Scenarios 3 to 6 and 8 to 11 in Comparison to the Base Case .................................................................. 95

Table 24. Scenario 12 to 16 Failure Statistics and Performance Measures. ......................... 96

Table 25. Scenario 17 to 21 Failure Statistics and Performance Measures......................... 98

Table 26. Scenario 22 to 26 Failure Statistics and Performance Measures. ........................ 100

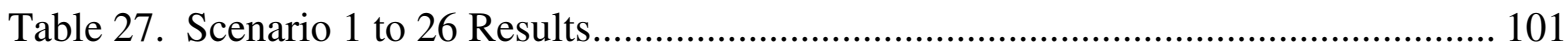

Table 28. Scenario 7a to 11a Failure Statistics and Performance Measures. ..................... 105

Table 29. Scenario 12a to 16a Failure Statistics and Performance Measures. ................... 107

Table 30. Overall System Performance in Scenario 7 to 11,7 a to 11 a, 12 to 16 , and 12a to

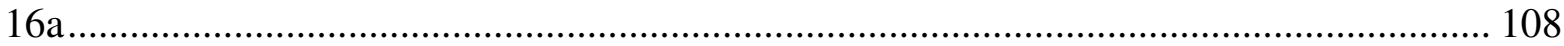

Table 31. Scenario 1b to 6b Failure Statistics and Performance Measures. ....................... 109

Table 32. Scenario 7c to 11c Failure Statistics and Performance Measures. ..................... 112

Table 33. Overall System Performance in Scenario 1, 3 to 6, 7 to 11, 7c to $11 \mathrm{c}, 12$ to 16 , and

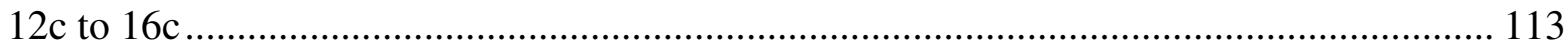

Table 34. Scenario 12c to $16 \mathrm{c}$ Failure Statistics and Performance Measures. .................... 114

Table 35. Costs and Performance Indices of Alternatives in Base Case Scenario. ............. 120

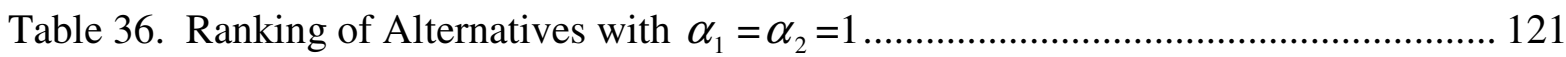

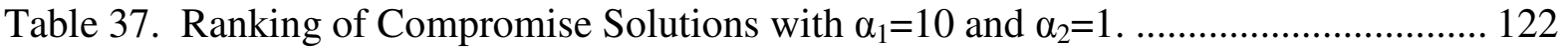

Table 38. Ranking of Compromise Solutions with $\alpha_{1}=1$ and $\alpha_{2}=10$............................ 122 


\section{Chapter 1 \\ Introduction}

\subsection{Background}

Of all of the water on Earth, only $2.5 \%$ is freshwater (Environment Canada, 2007). Two thirds are in the form of glaciers and polar ice caps, with the remaining liquid water contained in ground and surface water such as rivers, streams, and lakes. For reasons such as contamination or being too remote for human use, some of the water is not useable, leaving an approximate $0.3 \%$ of water that is available (Loucks and Van Beek, 2005).

In many parts of the world, water demand has already exceeded supply causing water stress. For example, in countries such as Australia, China, India, and Spain, etc, water resources authorities are seeking a national hydrological plan to meet the existing demands. Fueled by population growth and climate shift, more areas will likely experience the imbalance in the near future (Loucks and Van Beek, 2005).

Since Canada holds roughly $20 \%$ of the world's freshwater (Environment Canada, 2007), it may appear that water is abundant. However, this figure can be misleading, because most of the water is locked in snow and ice (Loucks and Van Beek, 2005). Discounting the water that is out-of-reach, Canada has about $9 \%$ of the world's renewable freshwater. However, over half of Canada's water flows north away from the southern population centers leaving scarce water supplies in some of these regions (Meakin, 1993). 
Humanity has depleted aquifers, diverted rivers, and polluted water bodies (Barlow and Clarke, 2002). Human activities have altered the natural water cycle and habitat causing even modern water supply systems to become dysfunctional, as can be seen in the 2000 Walkerton incident. With an increasing population and the second largest per capita water usage, Canada's municipal water supply systems may experience more downtime in the future (Ministry of Environment, 2003).

\subsection{Purpose}

Water is the essence of life. It is crucial to the health of humans and ecological systems. It is an important factor in the development of modern societies. Water is used in all aspects of our daily life. It is the most widely used resource in industrial activities. It is used in cleansing and as a carrier for household wastes to control or eliminate disease. It is used directly and indirectly in the production of energy and all of our consumable goods. As our life depends on it, as well as our society's economic growth, it is important to have a reliable water supply (Frederick, 1995).

Municipal water demand is highly variable, because water usage behaviour varies with season and weather conditions. With an increasing population and a shifting climate, making decisions in preparation for future needs can be difficult. Many water managers are now facing the challenge of planning expenditures under uncertainties and with limited resources. In preparation for climate variation, as well as ensuring sustainable growth, it is important to assess the risk to a domestic water supply. Such information would contribute to the 
development of an adaptation plan to ensure the reliability of a water supply system. Therefore, it is the purpose of this study to develop a framework for risk analysis of a water supply system under a range of uncertain conditions.

\subsection{Scope of Investigation}

This study examines the impacts of population growth and fluctuating climate conditions on the performance of a municipal water supply system. It also focuses on the approaches and methodology in developing a hybrid model which combines a data-derived stochastic component to a deterministic artificial neural network. The proposed model takes in climatic variables and water consumption patterns derived from historical records and projects future water demands under different assumed conditions. The model also estimates the effects of water efficiency management programs such as a low flow toilet replacement program, conservation efforts such as education and communication programs, and regulation implementation such as outdoor water use by-law, on improving the system.

As a separate but related goal, this study examines the impacts of future climate scenarios on the performance of a water supply system. First this study looks at the possible outcomes of a changing monthly mean temperature and precipitation magnitude as projected by a selection of Globe Climate Models (GCMs). Because future precipitation deviation may be frequency related (Zhang et al., 2007), a second approach was developed to look at the outcomes if the change of precipitation amount is converted into a change of precipitation pattern by a change of frequency of occurrence of events. 
In addition, economic analyses to determine the tradeoffs between expansion options and conservation alternatives under different scenarios are also undertaken. Multi-objective optimization analysis on different water management configurations is performed to determine the most robust water conservation alternatives.

\subsection{Thesis Organization}

This thesis is organized into six chapters. Chapter two begins with the fundamental concepts of uncertainty, risk, reliability, and robustness of a water supply system. It then reviews the relevant techniques of stochastic simulation and modelling. A summary of the risk performance indices and multi-objective optimization then follows. Chapter three illustrates the architecture of the simulation model and the risk indices calculation process. Methods used to develop the model are also presented. Chapter four briefly describes the case study area, the available data, and the simulation scenario definitions. Chapter five presents the results of the simulations and provides discussion of the findings suggested by the analysis of the results. In the last chapter, Chapter six, conclusions of the study and recommendations on future work are provided. 


\section{Chapter 2 \\ Literature Review and Background}

\subsection{Introduction}

This section begins with a brief description of a typical water supply system, its major components and their functions. Following is a review on risk and uncertainties of a water supply system and their consequences illustrated with the use of a few recent examples. This section then presents theories and techniques employed in this study, which include topics on stochastic modelling and simulation, performance measures and multi-objective optimization.

\subsection{Water Supply Systems}

Water supply systems provide the general population with water in sufficient quantity and quality. A typical water supply system comprises of three components: source, treatment and distribution.

Source Water

Source water refers to the freshwater drawn from surface water and groundwater. A water supply system draws water from the source water. In some regions where the availability of water is limited, desalination is used to generate freshwater. As this method has very high operation costs, it is not widely used. 
Surface water includes water from lakes, rivers, and reservoirs and ice and snow.

Groundwater refers to water from aquifers through springs or wells. Surface water tends to be more turbid and is more prone to contamination by external factors and to weather conditions. Groundwater usually has higher total dissolved solids because of the minerals that are dissolved from rocks and soils. Depending on the geographical location, some places without direct access to water, or if the local supplies are inadequate to fulfill existing consumption, would need to import water via pipelines, ship cargo, or water trucks. Very often a municipality can have a combination of source water (Tchobanoglous and Schroeder, 1987).

\section{Water Treatment}

The primary objective of treating source water is to ensure that the drinking water quality standards are met and water is safe for human consumption. Depending on the characteristic of the raw water quality, the treatment objectives and the costs of operation, different water treatments are provided. Typical water treatment methods include physical operations or chemical processes. Widely used water treatment methods include filtration, coagulation, and flocculation for the removal of turbidity, water colour and suspended matter; and chlorination for disinfection purposes (Tchobanoglous and Schroeder, 1987).

\section{Distribution}

The function of a water distribution system is to deliver treated water to consumers adequate in both flow and pressure. A water distribution system comprises of storage facilities, pumping stations and piping networks (Tchobanoglous and Schroeder, 1987). To ensure the 
overall system stays in operation in case of a component failure, several degrees of redundancy are usually built into the system. For example, twinning of major branches to avoid a cut-off resulting from a water main break or installation of multiple backup pumps and diesel power generators in preparation for a pump or power failure.

\subsubsection{Municipal Water Use}

Municipal water use can be subdivided into four categories: domestic, commercial and industrial, public services, and unaccounted system losses and leakage. Domestic water use includes the water used in residential areas, commercial districts, and institutional and recreational facilities. Commercial and industrial includes water supplies to canneries or cooling for power generation. Public service water use encompasses water used in public buildings, parks and fire fighting. The water used for fire fighting is small as compared to the total water consumption, but the instantaneous demand is very high and often limited by the hydraulic capacity of the supply system (Tchobanoglous and Schroeder, 1987).

\subsection{Risk Management}

Defined by the United Nations, Office of the Disaster Relief Co-ordinator (1991), risk management is to assess risk, determine a risk management policy, and communicate the policy to the public. Risk management is of particular importance for the management of water resources system. It involves the process of identifying, evaluating, and executing of all aspects of system management in accordance with other social sections. It involves the identification of loads in a system, plan for possible emergency scenarios in case of an 
operational failure, and plan for relief and rehabilitation for structural failure. It is a technical, social and economical process to balance the monetary and social costs and benefits.

Different methodologies of risk management are found in the literature. The process of risk management includes the steps: (1) identify feasible alternatives and associated risks; (2) assess all impacts for different levels of risk; (3) select acceptable option to communicate with the public with the consideration of the perception of risk, government policy and other social factors; and (4) implement the optimal choice (Simonovic, 2002). The objective of the process is to first identify the action that can be taken to reduce risk to the acceptable level and then find the available options and the corresponding tradeoffs in costs, benefits, and risks (Haimes, 1998).

\subsubsection{Risk Assessment}

The primary objective of risk assessment is to estimate risk by identifying the undesired event, the likelihood of occurrence of the unwanted event, and the consequence of such event (Kaplan and Garrick, 1981). As suggested by Biringer and Danneels (2000), there are seven basic steps to assess the risk in critical facilities: (1) Characterize the facility; (2) Identify undesired events and critical assets; (3) Determine the consequences of undesired events; (4) Define threats to the facility; (5) Analyze protection system effectiveness; (6) Estimate risks; and (7) Suggest and evaluate upgrades to the system. 


\subsubsection{Risk}

Risk is traditionally defined as a measure of the probability and severity of adverse effects (Lowrance, 1976). The concept of engineering risk is based upon load, resistance and consequence. Load, $L$ measures the behaviour of a system under external stress or loading. Resistance $R$ is a variable that describes the ability of a system to withstand a load. When the load exceeds the resistance ( $\mathrm{L}>\mathrm{R})$, a failure or an incident occurs; the associated outcome is the consequence. Depending on the problem domain, $\mathrm{L}$ and $\mathrm{R}$ are random variables and risk is defined as the product of the probability of failure and the consequences.

$$
\begin{aligned}
\text { Risk } & =\text { Probability of failure } \mathrm{x} \text { Consequence } \\
& =P(L>R) \times C_{o}
\end{aligned}
$$

In using this simplistic formulation of risk, it is assumed that there are sufficient data to capture the characteristic of $L$ and $R$. In the aspect of water resources engineering, load includes flood, pollutant load, drought, etc.; resistance includes protection level, treatment level, system capacity, etc.; and the failures are flooding, water pollution, or water shortage, etc. It is clear that uncertainties exist in water resources systems and it is rare that the uncertainties can be entirely captured by the available data.

The stochastic approach can be used to account for the uncertainties in a system with random variables. Load $L$ and resistance $R$ are random variables and can be represented by probability density functions: $f_{L}(L)$ and $f_{R}(R)$. In the probabilistic framework, risk is the probability of load exceeding the resistance multiplied by the consequence.

$$
R I S K=p_{F} \times c_{0}=P(L>R) \times c_{0}
$$


where $\mathrm{p}_{\mathrm{F}}$ is the asymptotic limit and can be obtained by integrating the joint probability density function $\mathrm{f}_{\mathrm{LR}}(\mathrm{L}, \mathrm{R})$ for $\mathrm{L}>\mathrm{R}$ (Simonovic, 2002).

\subsubsection{Types of Risk}

The subjective judgment on the source of risk is unreliability. Very often decision makers apply more weight on the perception of risk rather than the impact of actual risk (Simonovic, 2002). Therefore, it is important to understand the basics of different types of risk. There are three primary types of risk: objective, subjective, and perceived risk. Objective risk is the real or physical risk that would cause damages to properties or to the environment or endanger or kill people. For example, contaminated source water is an objective risk as the consumption of the contaminated water would endanger people's health. Subjective risk is risk that is associated with the degree of belief based on people's judgment. For example, perceived risk is based on individual's feeling of fear (Simonovic, 2002).

\subsubsection{Uncertainty}

There are different definitions of uncertainty found in the literature. Mitchell (2002) suggests that four types of uncertainty are: risk, uncertainty, ignorance, and indeterminacy, and uncertainty itself is a type of uncertainty. Ignorance is defined as the inadequate knowledge in absence or scarcity of information. Indeterminacy is contributed by the variability inherited from the process or the statistical variability because of sparse information (Bogardi et al., 2002). 
Simonovic (2002) proposed that there are two sources of uncertainty: uncertainty caused by inherent stochastic variability and uncertainty due to a fundamental lack of knowledge. The uncertainty caused by variability is a result of the intrinsic fluctuations in the quantity of interest. For example, the values of parameters in a hydrometeorological process are highly variable. The source of variability can be classified into three categories: temporal, spatial and individual heterogeneity. Temporal variability refers to the fluctuation of values with time. Spatial variability refers to the fluctuation of values because of location variation and heterogeneity variability refers to all other sources of variability (Simonovic, 2002). In the domain of water resources processes, variability of physical system inputs or response parameters such as temperature, precipitation, river flow, etc., are mostly spatial and temporal.

Uncertainty due to a fundamental lack of knowledge is more elusive. Such uncertainty exists when a value of interest cannot be presented with complete confidence because of a lack of understanding or limitation of knowledge. Uncertainty due to lack of knowledge is further broken down into three types. They are model and structural uncertainty, parameter uncertainty, and decision uncertainty (Simonovic, 2002).

Model or structural uncertainty arises when a model is oversimplified or failed to capture the important characteristics of the process under investigation. Parameter uncertainty is caused by random error in parameter estimates resulting from subjective judgement error. Decision uncertainty exists when the comparison or weighting of social objectives is controversial or ambiguous. There are three sources of decision uncertainty. They are the uncertainties in 
the selection of an index to measure risk, the social cost of risk and the quantification of social values (Simonovic, 2002).

\subsubsection{Failure}

A failure occurs when a system performs unsatisfactorily. Depending on the course of interest, failure can vary in type and magnitude (Hashimoto et al., 1982). For example, flooding in a populated area is considered as a failure of a waterway. It occurs when the volume of water exceeds the total capacity of a water body. At different geographical points, the causes of flooding include overtopping of flood defenses due to hurricanes, rapid snow melt, or extreme rainfall, etc.

The severity of a failure is defined by the extent of the damage. In the flooding example, it would be lost lives and property damage. As risk is defined as the product of the probability of failure and the associated consequence, therefore, without the consequence to a failure, risk does not exist (Smith, 2005).

In a complex system, there can be several pathways that lead to a failure. The failure of a single critical component or a combined failure of multiple components can lead to overall system failure (Pandey, 2005). 


\subsubsection{Types of Failures}

There are two major types of failures: performance failure and non-performance failure. Performance failures result from mechanistic or operational failures of a system. Nonperformance failures result from natural or anthropogenic disasters (Baxter and Lence, 2003).

\subsection{Risk in Water Supply Systems}

The two aspects in concern of a water supply system are water quantity and water quality. Water quantity refers to the availability of water. Water quality refers to the physical, chemical and biological characteristics of water. Risk in water supply systems lays in the principle components of the system or the effects of external factors. It includes mechanical, operational, or structural failure of the source, treatment, and distribution system components. These failures can be caused by aging of system components, human factors, or natural disasters (Tchobanoglous and Schroeder, 1987).

A water supply system failure occurs when the system is unable to meet the water quantity and/or quality requirements. For example, a water shortage due to increase of water usage as a result of population growth and change of land use; or external factors such as prolonged drought or heat wave causing sudden change in demand. In older distribution systems, because of corrosion of metal pipe, such as iron or copper mains, metals can be released into water. Depending on the parameter of exceedance, a drinking water that is unable to meet the water quality guideline can be viewed as a failure or deficiency. 
Most water supply storage and treatment facilities are operated based on historical data. In the wake of a changing climate, more extreme weather events and fluctuations in weather patterns may happen. Consequently, higher system failure may result.

In this thesis, the risk found in a domestic water supply system is primarily focused on the risk of water shortage due to population growth and climate change.

\subsection{Stochastic Modelling and Simulation}

When a system is subjected to new conditions in the future such as climate change or population growth, risks may increase. To forecast these future risks, one of the best methods is to construct a stochastic model to capture the statistical characteristics in the historical data and derive the future responses from available information. To do so, it is necessary to examine the raw data and identify and select the probabilistic distributions that best describe the data. Next, the probabilistic mechanism and parameters of the distributions need to be estimated. The estimates obtained should then be investigated to see if the implications are reasonable, that is, if the probability law describes a given change of the independent variable as a function of the dependent variable(s). After the assumptions and possibly the probability laws have been specified, a probability model of the system would have been built (Ross, 1997). However, prior to any data analysis, the knowledge and application of regression is required. 
Once the probabilistic model has been constructed, risk measures can be determined analytically in simple cases. However, very often these measures are difficult to derive analytically, and therefore, to estimate the risk measures, simulations are needed (Ross, 1997). The purpose of the modelling is the prediction of the behaviour of the system given a set of parameters and initial conditions. There are in general two types of simulation models: deterministic simulation and stochastic simulation. Given a particular set of input variables and initial conditions, deterministic simulation generates identical simulation results for every simulation trial. Despite the heavy computation requirements, Monte Carlo Simulation is the most robust simulation technique and is therefore employed in this study.

\subsubsection{Monte Carlo Simulation}

Monte Carlo simulation is widely used in risk assessment for its capability of modelling phenomena with uncertainties. Monte Carlo simulation involves generating random values of stochastic parameters from their corresponding probability distribution. In order to successfully estimate the probability of failure, a large number of simulation trials need to be conducted for the output to reach stability (Pandey, 2005).

\subsubsection{Statistical Analysis}

\subsubsection{Distribution Selection}

There are a number of fitting methods to determine the "best-fitting" distribution and to estimate the associated parameters (Pandey, 2005). For example, the Method of Moments, which estimates distribution moments by equating them with sample moments; Method of 
Maximum Likelihood, which assigns the distribution parameters that maximize the likelihood of the sample; Least Squares Method, which fits a theoretical function to an empirical function by regression techniques, and Graphical Methods which allow visualization of the data via diagrams, charts and plots (Burn, 2003).

The use of a probability paper plot (probability plot) is a popular way to assess if a dataset follows a specific probability distribution. By examining the plots using various goodnessof-fit tests, which will be discussed in the following section, the best-fit distributions for individual independent parameters can be selected.

Among the many probability density functions that exist, some of the more popular and widely used distributions in hydrology include: Normal, Log-Normal, Exponential, Gamma, Gumbel (Extreme Value Type I), and Weibull (Extreme Valve Type III).

\subsubsection{Goodness of Fit Tests}

Usually it is rather difficult to determine the best-fitted distribution of a data set by solely inspecting the probability plots. There are a number of statistical procedures, known as Goodness of Fit Tests, to ascertain whether a given data set follows the tested probabilistic distribution. Some of the widely used distribution measure tests include Chi-Square Test, Kolmogorov-Smirnov (K-S) Test, and Anderson-Darling (NIST, 2006). The two Goodnessof-Fit testing methods, Probability Plot Correlation Coefficient (for its simplicity) and 
Anderson-Darling (for its sensitivity as compare to K-S test and applicability to continuous set) are chosen to find the best fitting distributions and are discussed below.

\subsection{Probability Plot and Correlation Coefficient}

In a probability plot, data are plotted against a fitting distribution. If the data fits the specific distribution well, the data points would form approximately a straight line. If the data points deviate from the straight line, it indicates a deviation of the data from the fitting distribution. The goodness of the fit of the data to a distribution can be measured by the correlation coefficient of the linear best fitted line in the probability plot. As well, the location and scale parameters of the fitting distribution can also be estimated from the slope and intercept of the best fitted line. Several probability plots can be generated for different distributions to see which distribution fits the data best. A probability plot that generates the largest correlation coefficient would indicate a best fitting distribution among the competing distributions (NIST, 2006).

\subsection{Anderson-Darling Statistic}

The Anderson-Darling (AD) Statistic is a modification of the Kolmogorov-Smirnov goodness-of-fit test. It measures the area between the empirical distribution function and the assumed population distribution (Pandey, 2005). Smaller AD values are generated if there are smaller deviations between the actual and the fitted data. Therefore, by comparing the AD values of competing distributions, the distribution with the smallest deviation would indicate the best-fit distribution. 


\subsubsection{Time Series Analysis}

A time series is a sequence of data points recorded over time and is represented by the notation $X=\left\{X_{1}, X_{2}, X_{3}, \ldots X_{n}\right\}$. Time series data are typically measured at successive time and in uniform intervals; for example, the daily stock price of a company, daily temperature of a city, or unemployment rate of a city. In a time series dataset, very often, trend, seasonality and other time dependent patterns exist, making the time series nonstationary. However, in developing a model to forecast the process, some stability in the data is needed. Tools such as taking the logarithm, linear operation, or smoothing, can be used to reduce the variability and eliminate trends in the time series data, so as to introduce stationarity in the data. In addition to taking the logarithm and smoothing, Fourier series and neural networks are also used to investigate the time series data of this study and will be discussed in the following sections (Pourahmadi, 2001).

\section{Smoothing}

Smoothing is one of the techniques to eliminate trends in the time series data. By smoothing the data, the major features such as seasonal patterns in the data would be emphasized and other features such as random fluctuations would be de-emphasized. One of the smoothing techniques would be moving average, which is defined as:

$$
s_{t}=\frac{\sum_{i=0}^{n-1} x_{t-i}}{n}
$$

where $\mathrm{s}_{\mathrm{t}}$ is the new smoothed series and the residuals are defined as:

$\mathrm{y}_{\mathrm{t}}=\mathrm{x}_{\mathrm{t}}-\mathrm{s}_{\mathrm{t}}, \mathrm{t}=1,2, \ldots, \mathrm{n}$. 


\subsubsection{Fourier Series}

The Fourier series named after the physicist and mathematician, Joseph Fourier (1768-1830), was first investigated for the applications of heat flow. In a Fourier series, an arbitrary periodic function is broken down into a set of sine and cosine components. The individual sinusoidal terms can then be solved individually (Mathworld.wolfram, 2007). A generalized Fourier series of a function $\mathrm{f}(\mathrm{x})$ is given as

$$
f(x)=\frac{1}{2} a_{0}+\sum_{n=1}^{\infty} a_{n} \cos (n x)+\sum_{n=1}^{\infty} b_{n} \sin (n x),
$$

where

$$
\begin{aligned}
& a_{0}=\frac{1}{\pi} \int_{-\pi}^{\pi} f(x) d x \\
& a_{n}=\frac{1}{\pi} \int_{-\pi}^{\pi} f(x) \cos (n x) d x \\
& b_{n}=\frac{1}{\pi} \int_{-\pi}^{\pi} f(x) \sin (n x) d x
\end{aligned}
$$

and $\mathrm{n}=1,2,3$, etc. Figure 1 illustrates the $\mathrm{N}$-harmonic Fourier series for $\mathrm{N}$ equals to 1 to 4 . 

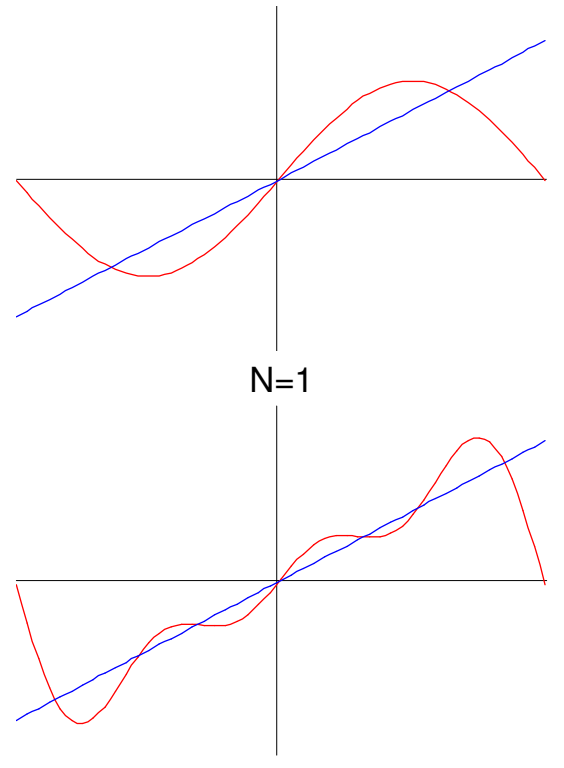

$\mathrm{N}=3$
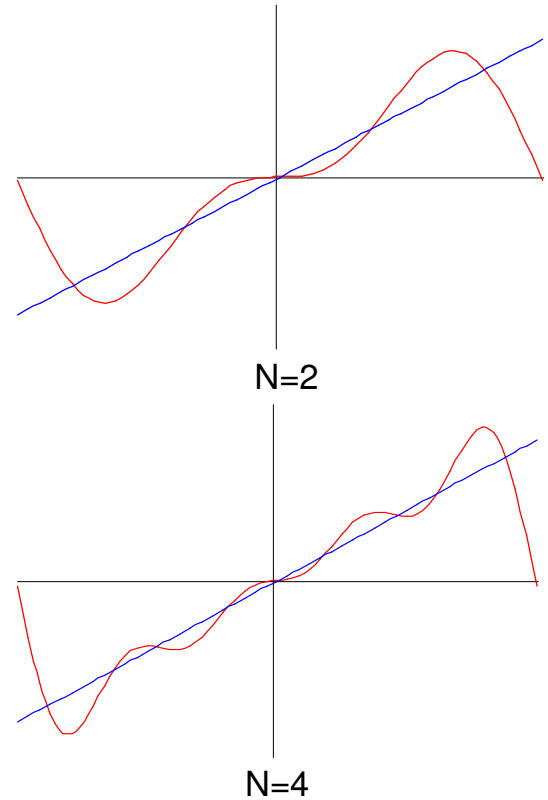

Figure 1. One period of N-harmonic Fourier series

The Fourier series has been used in water resources related area to detect periodic and cyclic components in data, to name but a few, the seasonal fluctuation elevations of lakes and wells (Kite and Adamowski, 1973). The seasonal patterns in a dataset can be approximated by the Fourier series

$x(t)=a_{o}+\sum_{m=1}^{N / 2} a_{m} \cos \left(\frac{2 \pi m t}{N}\right)+b_{m} \sin \left(\frac{2 \pi m t}{N}\right)$

where $\mathrm{a}_{0}$ is the mean of the data set, $\mathrm{m}$ is the number of harmonics, $\mathrm{N}$ is the length of the data set, and $t$ is the time. The coefficients $a_{m}$ and $b_{m}$ for $m \neq N / 2$ are defined as

$a_{m}=\frac{2}{N} \sum_{m=1}^{N} x_{t} \cos \left(\frac{2 \pi m t}{N}\right) \quad b_{m}=\frac{2}{N} \sum_{m=1}^{N} x_{t} \sin \left(\frac{2 \pi m t}{N}\right)$

whereas for $\mathrm{m}=\mathrm{N} / 2$,

$a_{m}=\frac{1}{N} \sum_{m=1}^{N} x_{t}(-1)^{t} \quad b_{m}=0$ 
The variance $C_{m}^{2}$ explained by the $m$ th harmonic is defined by

$$
C_{m}^{2}=\frac{a_{m}^{2}+b_{m}^{2}}{2 s^{2}}
$$

where $s^{2}$ is the total variance of the time series $x(t)$ (Weisstein, 2004). In this study, the Fourier series is used to mimic the seasonal pattern in the temperature data.

\subsubsection{Autoregressive Moving Average Model}

Autoregressive moving average (ARMA) models after George Box and G.M. Jenkins are one of the most popular methods for forecasting time series. There are two parts to this class of models. One is the stochastic autoregressive part, which generates random disturbance, and the other is the deterministic moving average component. In many ARMA models, it is assumed that the time series value being modelled at time $t, X_{t}$, depends only on its previous values, $\mathrm{X}_{\mathrm{t}-1}$ (Box and Gwilym, 1976). The framework of the seasonal autoregressive model was adopted and modified to simulate the daily variations of temperature.

\subsubsection{Poisson Process}

The Poisson process named after the mathematician Simeon-Denis Poisson (1781-1840) is widely used to describe the arrival of events. In introducing the Poisson process, it is always necessary to first present the concept of counting process. Thus, in this section, first the counting process is briefly described, then the description of a Poisson process is presented, and lastly the procedures to generate a Poisson process are given. 


\section{Counting Process}

Suppose that $\mathrm{N}(\mathrm{t})$ represents the total number of "events" that have occurred from time 0 to time $t$, then $\{\mathrm{N}(\mathrm{t}), \mathrm{t} \geq 0\}$ denotes a counting process. For example, let $\mathrm{N}(\mathrm{t})$ be the number of customers that have entered a restaurant at or before time $t$, then

$\{\mathrm{N}(\mathrm{t}), \mathrm{t} \geq 0\}$ is a counting process and an "event" is a customer entering the restaurant. By definition, a counting process must satisfy a few conditions (Ross, 1985).

\section{$\mathrm{N}(\mathrm{t}) \geq 0$}

$\mathrm{N}(\mathrm{t})$ is integer valued

If $\mathrm{s}<\mathrm{t}$, then $\mathrm{N}(\mathrm{s}) \leq \mathrm{N}(\mathrm{t})$.

For $s<t, N(t)-N(s)$ equals the number of events that have occurred in the interval $(s, t)$ as illustrated in Figure 2.

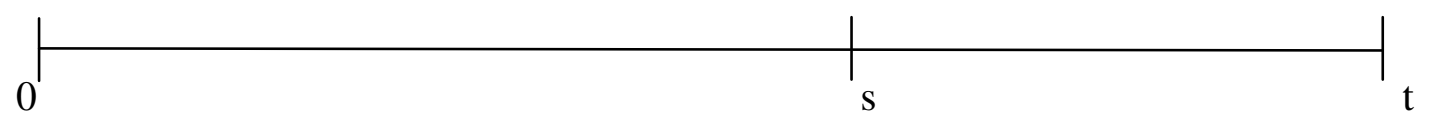

Figure 2. Event time

A counting process also has the property of independent increment. That is, the number of arrivals during a time interval is independent of the history of arrivals in other intervals. In other words, the number of events that have occurred by time s, N(s), must be independent of the number of events occurring between times s and t, (N(s) -N(t)) (Ross, 1997). 


\section{Poisson Process}

A Poisson process is a continuous-time counting process having rate parameter or intensity $\lambda, \lambda>0$, which is the expected number of "events" occurring in an interval. In a Poisson process, the number of events " $n$ " in the time interval $(0, t)$ follows a Poisson distribution

$$
\mathrm{P}(n)=\frac{(\lambda t)^{n} e^{-\lambda t}}{n !}
$$

and the interarrival time is described by the exponential distribution. A Poisson process has five associated properties:
a) $\quad \mathrm{N}(0)=0$

b) The number of events occurring in disjoint time intervals are independent.

c) The distribution of the number of events that occur in a given interval depends only on the length of the interval and not on its location.
$\lim _{h \rightarrow o} \frac{P\{N(h)=1\}}{h}=\lambda$
e $\quad \lim _{h \rightarrow o} \frac{P\{N(h) \geq 2\}}{h}=0$

Condition a) says that the process start at time 0 . Condition b) refers to the property of independent increment. Condition c) is the Stationary increment assumption, which states that the probability distribution of $\mathrm{N}(\mathrm{t}+\tau)-\mathrm{N}(\mathrm{t})$ is the same for all values of $\mathrm{t}$. Conditions $\mathrm{d}$ ) and e) state that in a small interval of length $h$, the probability of one event occurring is approximately $\lambda \tau$, and the probability of two or more events occurring is approximately 0 . In 
other words, there can only be one event occurring in any small increment of time (Ross, 1997). Figure 3 illustrate $n$ increment of time between 0 and $t$ with small interval of length.

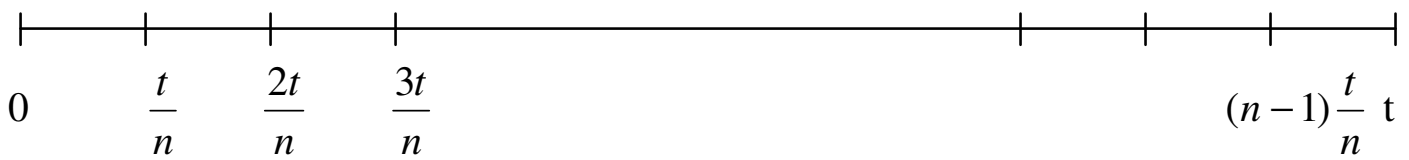

Figure 3. $\mathrm{n}$ increment of time between 0 and $\mathrm{t}$

\section{Generating a Poisson Process}

One way to generate a Poisson process for a length of time $T$ is to draw a total number of $n$ events with a sum of interarrival times exceeding $T$ (Figure 4). To do so, first generate $n$ random numbers $U_{1}, U_{2}, \ldots U_{n}$ and set $X_{i}=-1 / \lambda \log U_{i}$, where $X_{i}$ represents the time between the $(i-1)$ st and the $i$ th event and the generated values of the first $\mathrm{n}$ event times are $\sum_{i=1}^{j} X_{i}, j=1, \ldots, n$. Then, set the actual time of the $j$ th event equal to the sum of the first $j$ interarrival times (Ross, 1997). The interarrival times $X_{i}$ between successive events are independent exponential random variables each with rate $\lambda$.

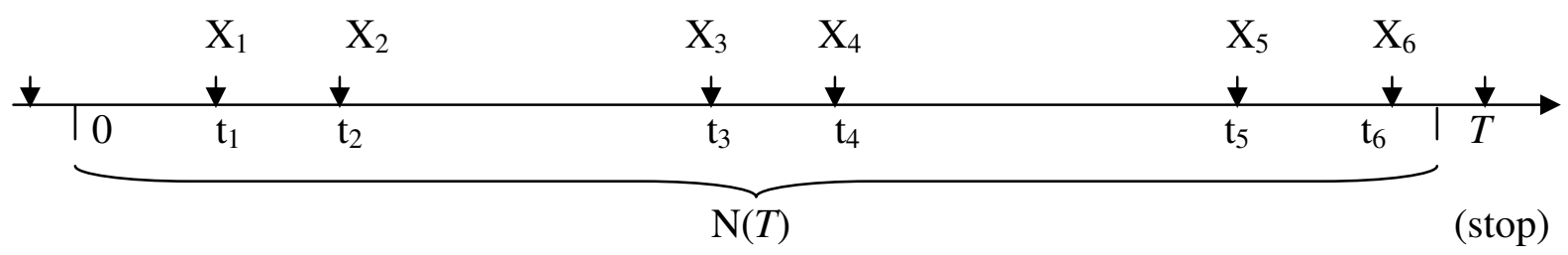

Figure 4. Interarrival times of $X_{j}$

\subsubsection{Water Demand Modelling}

In order to assess risk of the water supply system for future scenarios, it is necessary to develop a water demand forecast model. To project trends in the growth of water use for the 
need of design, operating and management of water supply system, the development of a water demand forecast model is required.

Climatic variables such as rainfall, air temperature, sunshine duration, relative humidity, wind speed, past water use and the day of the week were found related to water demand in many studies. A large collection of water use prediction methods have been investigated in various studies. Linear regression models developed by Jain et al. (2001) used weekly maximum air temperature, weekly rainfall amount, weekly past water demand, and the occurrence and non-occurrence of rainfall as dependent parameters. The linear regression models developed by Graeser (1958) have the number of previous days with maximum air temperature above $100^{\circ} \mathrm{F}$ and the number of weeks from last occurrence of one inch of rainfall as dependent variables. Howe and Linaweaver (1967) developed a collection of regression models for domestic sprinkling demands based on summer precipitation, potential evapotranspiration rates, average summer demand and irrigable area.

Another popular approach to predict water demand is the Time-series analysis. Autoregressive models were developed by Jain et al. (2001) to predict maximum water demand. Box and Jenkins models were developed by Maidment et al. (1985) to predict the daily municipal water use.

The regression and time-series models were the most popular water demand forecast methods. However, in more recent studies, artificial neural network (ANN) model are becoming prominent for water demand forecast as the neural network was found to 
outperform the regression and time-series models in some studies (Bougadis et al., 2005). The pattern of water use is sensitive to the demographic factors of the local community, therefore, a deterministic water demand forecast model needs to be tailored to predict a given water supply system demand.

\subsubsection{Artificial Neural Networks}

Artificial Neural Networks (ANNs) are a relatively new soft computing tool with architecture inspired by that of the brain. Because of its parallel data processing and learning characteristic, neural networks can detect complex relationships between inputs and outputs. Some common applications of neural networks include nonlinear functional mapping, speech and pattern recognition, categorization and data compression (Karry and De Silva, 2004).

\section{Basic Structure}

An artificial neural network comprises neurons (nodes) that are interconnected by weights to form a network of nodes (Figure 5). In each neuron, there is a threshold and an associated activation function (Karry and De Silva, 2004). 


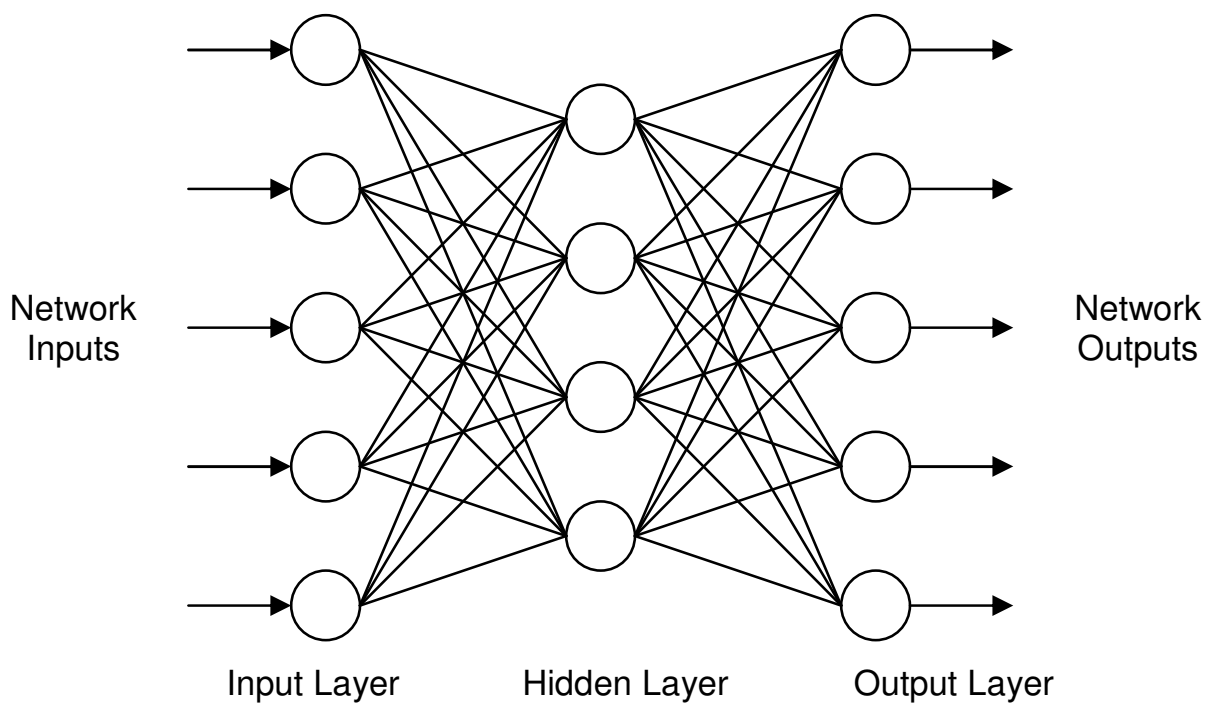

Figure 5. A fully interconnected three-layered back-propagation network

\section{Major Classes of ANNs}

There are four major classes of ANNs: Multilayer Perceptron, Radial basis function networks, Probabilistic neural network (PNN), and generalized regression neural networks (GRNN). These ANNs are different in their network topology (feedforward and recurrent), the network transfer functions, and the network learning algorithm (supervised and unsupervised). The detailed architecture of these neural networks is beyond the scope of this thesis, and therefore is not presented. Further references can be found in Bishop (1995) and Karray and De Silva (2004).

\section{Training Process}

"Neural networks learn by example". With representative data provided to the training algorithm of the neural network, the pattern in the data will be learned (StatSoft, 2003). Like other data-driven models, such as a linear regression model, an ANN model deciphers the 
relationship found between the input and output data. Much as coefficients in a regression equation need to be estimated, the interconnecting neurons in the neural network need to be trained (Solomatine, 2002). In this thesis, the ANN is used for non-linear statistical data modelling to model complex relationships between climatic variables and water demand.

\subsection{Risk Indices and Multi-objective Optimization}

\subsubsection{Performance Measures}

Under uncertainties induced by climatic shift and human behaviour, a water supply system

can encounter a wide range of possible demands and hydrological conditions. The three riskbased system performance evaluation criteria: Reliability, Resiliency, and Vulnerability, suggested by Hashimoto et al. (1982), describe the performance of a water resource system. These performance measures are especially useful for their capability in capturing possible system responses during extreme events such as drought, peak demands, or extreme weather. Further, these measures can aid decision makers in planning system capacities, selecting competing system configurations, establishing operating policies, and setting regulation targets. The following are descriptions of the system performance measures defined by Hashimoto et al. (1982).

\subsubsection{Reliability}

Reliability is the probability that a system operates within specified conditions during a specified period of time or for at least a specified duration of time. Given a system with possible outputs $X_{t}$ at time $t$ and a threshold criterion, $X_{t}$ can be divided into two sets: $S$ the 
set of outputs that satisfies the criterion and $F$ the set of outputs that fails to fulfill the criterion (Figure 6).

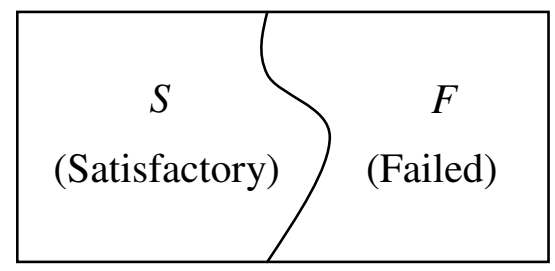

Figure 6. Set of system outputs $X_{t}$

In general, reliability is defined as the probability $\alpha$ that a system is in a satisfactory state:

$$
\alpha=\operatorname{Prob}\left[X_{t} \in S\right]
$$

which is the opposite of risk and can be calculated as one minus the probability of failure $\mathrm{P}_{\mathrm{f}}$ :

$$
\alpha=1-P_{f}
$$

Alternatively, reliability can sometimes be defined as the probability that no failure occurs during the time of interest.

\subsubsection{Resiliency}

After a failure has occurred, a system may return to the satisfactory state or remain unsatisfactory for an extended period. It is more preferable to design a system that recovers quickly as compared to one that recovers slowly. Resiliency describes how quickly a system is likely to recover after a failure occurs. Given the duration of failures $\left(T_{F}\right)$ during an nperiod experiment, resiliency can be defined as the inverse of the expected value of $\mathrm{T}_{\mathrm{F}}$ (Figure 7). 


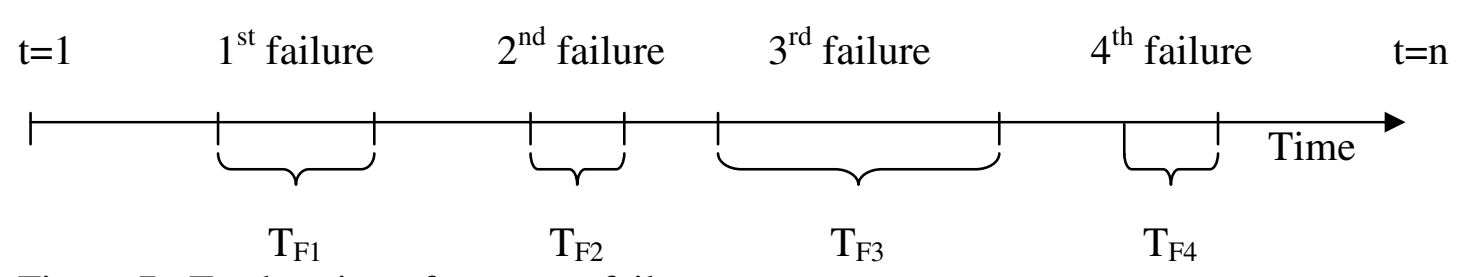

Figure 7. $\mathrm{T}_{\mathrm{F}}$, duration of a system failure.

To estimate the expected duration of a system output failure, Hashimoto et al. (1988) suggested to let

$$
\begin{array}{ll}
Z_{t}=1 & X_{t} \in S \\
Z_{t}=0 & X_{t} \in F,
\end{array}
$$

such that $(1 / \mathrm{n}) \sum_{t=1}^{n} Z_{t}$ is the fraction of time that the system performs satisfactory between $\mathrm{t}$

$=1$ to $\mathrm{n}$ time periods. As $\mathrm{n}$ approaches infinity, $\lim _{n \rightarrow \infty} \frac{1}{n} \sum_{t=1}^{n} Z_{t}$, the ratio becomes the reliability of the system $\alpha$.

To capture the transition of the system state switches from satisfactory to unsatisfactory,

Hashimoto et al. suggested to let

$$
\begin{array}{ll}
W_{t}=1 & X_{t} \in S \quad X_{t+1} \in F \\
W_{t}=0 & \text { otherwise. }
\end{array}
$$

For a long period of time, the average of $\mathrm{W}_{\mathrm{t}}$ equals the probability that the system is in the set $S$ at time period $t$ and then goes into the set $F$ at $t+1$ :

$$
\rho=\operatorname{Prob}\left\{X_{t} \in S, X_{t+1} \in F\right\}=\lim _{n \rightarrow \infty} \frac{1}{n} \sum_{t=1}^{n} W_{t}
$$


The average length of a consecutive failure $\left(T_{f}\right)$ in $n$ time steps is equal to the total time in failure divided by the number of consecutive failures:

$$
\bar{T}_{f}=\frac{1}{n} \sum_{t=1}^{n}\left(1-Z_{t}\right)\left(\frac{1}{n} \sum_{t=1}^{n} W_{t}\right)^{-1}
$$

As n approaches infinity, $\bar{T}_{f}$ approximates the mean value $(1-\alpha) / \rho$, which is the expected duration or the average duration that a system is expected to remain unsatisfactory once a failure occurred

$$
E\left[T_{F}\right]=\frac{1-\alpha}{\rho}
$$

Taking the inverse of this gives the system's average recovery rate $\gamma_{1}$

$$
\gamma_{1}=\frac{\rho}{1-\alpha}=\frac{\operatorname{Prob}\left\{X_{t} \in S \text { and } X_{t+1} \in F\right\}}{\operatorname{Prob}\left\{X_{t} \in F\right\}}
$$

For a prolonged period, the number of transitions from satisfactory to unsatisfactory and the number of transitions from unsatisfactory to satisfactory will be equal. Therefore, the probability of the two types of transitions must equal, that is

$$
\operatorname{Prob}\left\{X_{t} \in S \text { and } X_{t+1} \in F\right\}=\operatorname{Prob}\left\{X_{t} \in F \text { and } X_{t+1} \in S\right\}
$$

Hence $\gamma_{1}$ is equivalent to the average probability of a recovery from the failure set in

$$
\begin{aligned}
\gamma_{1} & =\frac{\operatorname{Prob}\left\{X_{t} \in F \text { and } X_{t+1} \in S\right\}}{\operatorname{Prob}\left\{X_{t} \in F\right\}} \\
& =\operatorname{Prob}\left\{X_{\mathrm{t}+1} \in S \mid \mathrm{X}_{\mathrm{t}} \in F\right\}
\end{aligned}
$$

This indicates that if the system fails during the current time step, $\gamma_{1}$ is the probability that the system would recover in the next time step. 
Alternatively, Moy et al. (1986) suggested another resiliency criterion based upon the maximum number of consecutive periods of deficit during the time of interest, given as

$$
\gamma_{2}=1-\frac{M D}{N S}
$$

where MD is the maximum number of consecutive time periods of failure and NS is the time of interest.

A third resiliency criterion proposed by Simonovic et al. (1992) is as follows.

$$
\gamma_{3}=\frac{1}{\left(\frac{M D}{N S} N F\right)}
$$

where NF is the number of times the system enters a failure.

\subsubsection{Vulnerability}

Vulnerability describes the likely magnitude of a failure of a system. Assuming that the system's output $\mathrm{X}_{\mathrm{t}}$ takes discrete values of $\mathrm{x}_{1}, \ldots, \mathrm{x}_{\mathrm{n}}$, the severity of a failure of each discrete

failure $x_{j}$ can be assigned a numerical indicator of the severity of the state $s_{j}$ (Figure 8 ). Let $e_{j}$ be the probability of $\mathrm{x}_{\mathrm{j}}$ corresponding to $\mathrm{s}_{\mathrm{j}}$ that is the most unsatisfactory and severe outcome that occurs in a sojourn

$$
v_{1}=\sum_{j \in F} s_{j} e_{j}
$$

Depending on the decisions makers' attitudes to the characteristic of failure, the magnitude of the most severe failure vulnerability may have more importance. Therefore, in this thesis the vulnerability is also calculated as

$$
v_{2}=\max \left(s_{j}\right)
$$


where $s_{j}$ is the magnitude of the most severe failure during the time of interest.

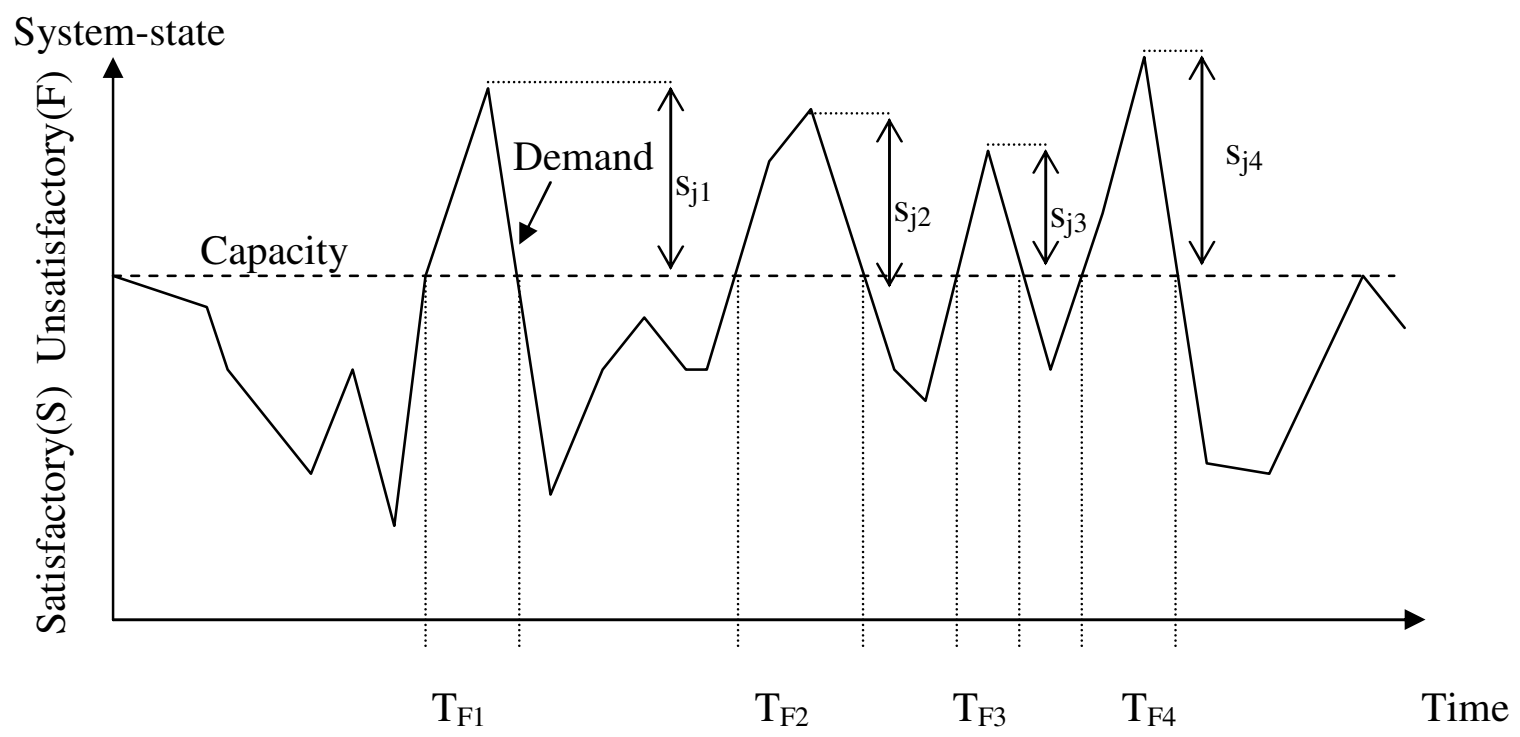

Figure 8. Severity of a failure state $s_{j}$

\subsubsection{Multi-objective Optimization}

To incorporate decision maker's attitudes toward risk and other tradeoffs between competing attributes, comprise programming is an interactive method for multi-objective analysis.

Compromise programming has the ability to deal with multiple objectives and its interactivity allows the decision maker to adjust the influence that each objective has on a final solution set. This method does not provide an absolute answer but a set of solutions that are closest to the ideal solution as determined by a measure of distance. The ideal solution is represented by vector $\mathrm{z}^{*}=\left(\mathrm{z}_{1} *, \mathrm{z}_{2} *, \ldots, \mathrm{z}_{\mathrm{p}}^{*}\right)$ where the $\mathrm{z}_{\mathrm{i}}^{*}$ are optimal objective function values of p separate single objective optimization models. For example if all were to be maximized,

$\operatorname{Max} z_{i}(x)$

subject to $\mathrm{x} € \mathrm{X}, \mathrm{i}=1,2, \ldots \ldots, \mathrm{p}$ 
The $\mathrm{z}_{\mathrm{i}}(\mathrm{x})$ in this problem can be the cost and system performance objectives. Each optimal solution, for example, for objective $\mathrm{i}$, that is $\mathrm{x}_{\mathrm{i}}{ }^{*}$, can be used to calculate values of the other objectives. If this is repeated for each objective we have a set of solutions.

A scaling function can then be applied to the resulting $\mathrm{z}_{\mathrm{i}}(\mathrm{x})$ to ensure the objective functions are evaluated over the same range. This scaling function is defined by:

$$
\mathrm{S}_{\mathrm{i}}(\mathrm{Di})=\left(\mathrm{z}_{\mathrm{i}}^{*}-\mathrm{z}_{\mathrm{i}}(\mathrm{x})\right) /\left(\mathrm{z}_{\mathrm{i}}^{*}-\mathrm{z}_{\mathrm{i}}^{* *}\right)
$$

where $\mathrm{z}_{\mathrm{i}}^{*}$ is the best solution in the set and $\mathrm{z}_{\mathrm{i}}{ }^{* *}$ is the worst solution in the set. The scaled results are then combined to account for all objectives in the problem and ranked in accordance to the results of the following equation:

$$
\min \left[L_{s}(x)=\sum_{i=1}^{p} \alpha_{i}^{s}\left(\frac{z_{i}^{*}-z_{i}(x)}{z_{i}^{*}-z_{i}^{* *}}\right)^{s}\right]
$$

The alpha values indicate the importance of the particular objective that they are assigned to. The s values are used to exemplify the weight of a particular objective towards the final decision. For example, as s becomes larger, more weight is applied on the objective of most concern. 


\section{Chapter 3 \\ Modelling Approach}

\subsection{Introduction}

In order to assess risks of a water supply system, a water demand simulation model is needed to mimic the response of the water supply system under different conditions so as to facilitate the assessment of risk in relation to the impacts of population growth and climate change. In this section, an overview of the model architecture is first provided to introduce the overall stochastic approach. More in-depth descriptions of the methodology in representing the influencing parameters and the construction of the subcomponents follows.

\subsection{Model Architecture and Risk Measures Calculation Process}

A computer-based model is constructed to estimate the performance indices of a water supply system. The model employs the Monte Carlo method to generate two time series measures (temperature and precipitation) characterized by probability distributions derived from historical data and utilizes a deterministic artificial neural network (ANN) to calculate the daily water demand. The advantage of this setting is that the stochastic approach is able to capture the uncertainties found in natural climate variability, while the deterministic ANN has the ability to map out and reproduce the complex relationships underlying the water consumption data. Figure 9 illustrates the framework of the proposed model. 


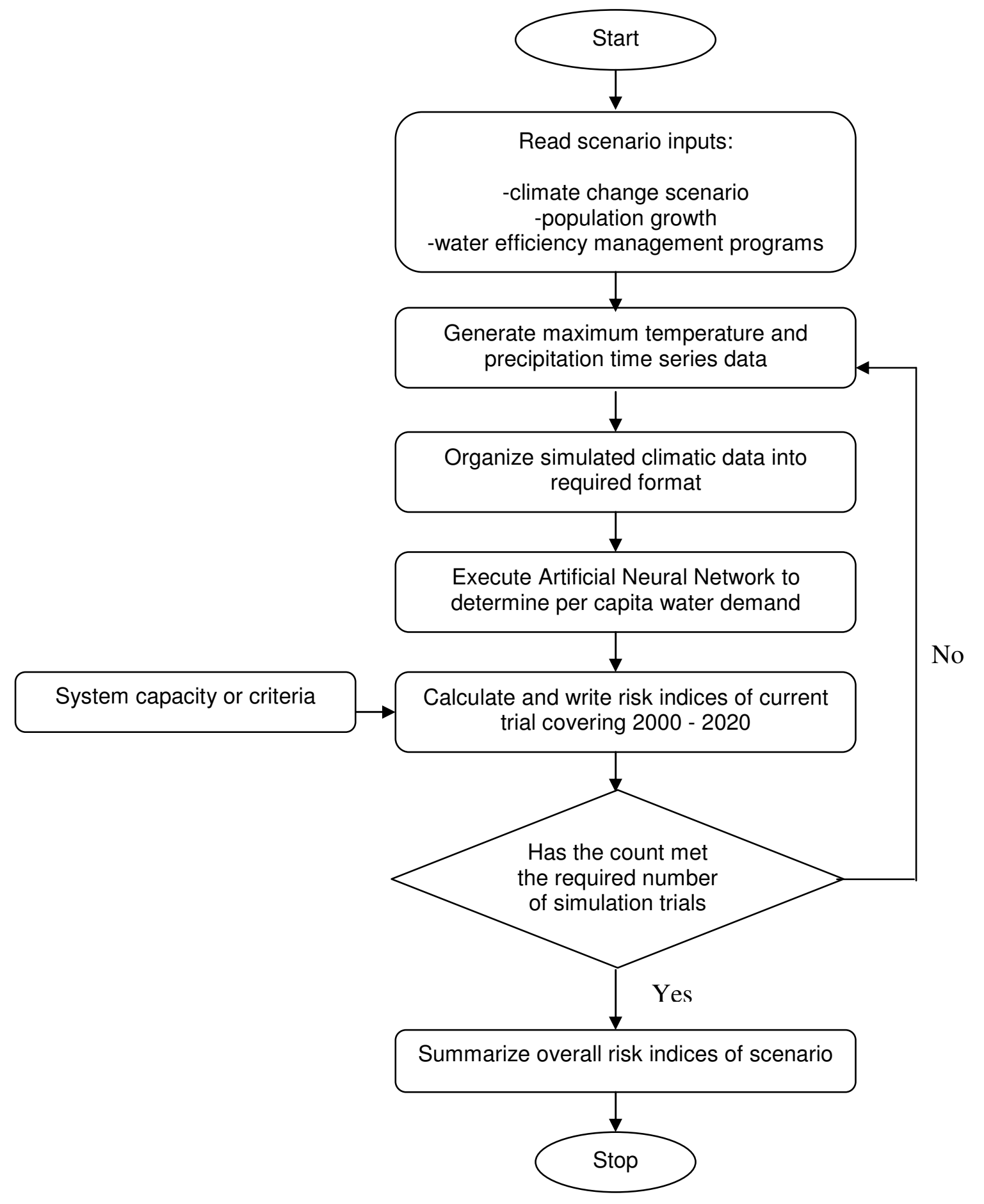

Figure 9. Structure of simulation model schematic for reliability, resilience, and vulnerability (RRV) assessment process 
The model begins by reading in input parameters that define the setting of a simulation scenario. These time series input parameters include population growth, water efficiency program configurations, system capacities, outdoor watering by law implementation threshold, and GCM scenario projections, etc. The model then starts the Monte Carlo submodels to generate the time series temperature and precipitation data for the intervening years. Next, the simulated maximum temperature and precipitation data are organized into the required format and fed into the Neural Network Simulation Tool. The water demand is then calculated. The risk measures of the current simulation trial are calculated by using the prescribed system capacity and operation criteria. This process represents one simulation trial and is repeated until the required number of simulation trials is reached, which then completes one simulation cycle.

\subsection{Variable Representations}

\subsubsection{Temperature}

To represent the random variations in daily temperature using a stochastic method, the time series temperature $T_{t}$ is represented by a three-component linear additive model (Figure 10):

$$
T_{t}=U_{t}+P_{t}+R_{t}
$$

where $U_{t}$ is a linear persistence, $P_{t}$ is the periodicity component, and $R_{t}$ is the random residual. 


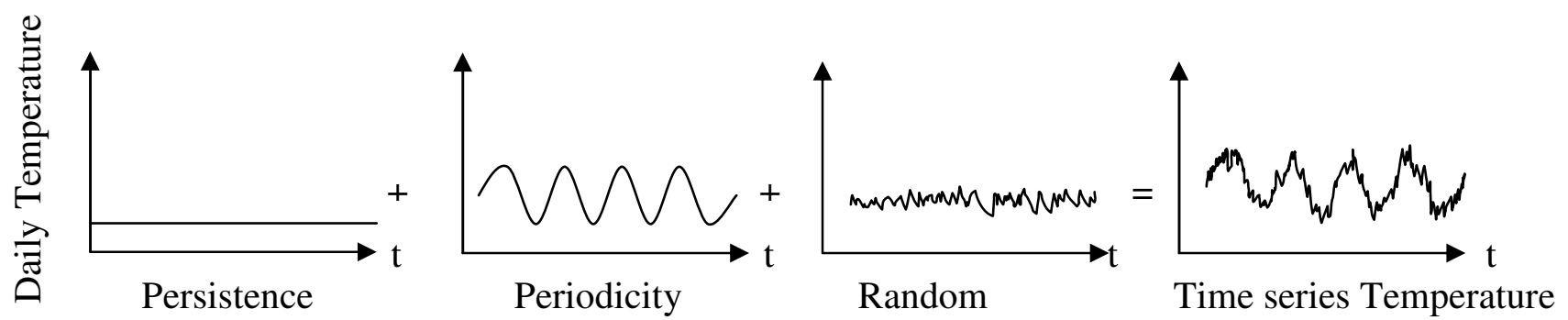

Figure 10. Components of a linear additive time series model

\subsubsection{Long Term Trends}

The annual maximum temperature and annual mean temperature over a long period are used to determine if a linear long-term temperature trend exists. The annual maximum temperature is defined as the average of the daily maximum temperature in a year and the annual mean temperature is the average of the daily mean temperature.

\subsubsection{Periodic}

The temperature data are fitted by the Fourier series to remove the daily random variations to reveal more clearly the seasonal temperature patterns. The coefficients to the series are estimated using the Matlab Curve Fitting Toolbox (C) 2007.

\subsubsection{Stochastic Residual}

The seasonal autoregressive model is chosen to simulate the random variations of the daily maximum ambient temperature. This procedure captures the daily temperature fluctuations that are known to be strongly correlated. The daily autoregressive model allows a different 
mean and variance for daily temperature and represents it as a function of the Julian day and is defined as:

$$
R_{i, j}=\bar{R}_{j}+r_{j} \frac{S_{j}}{S_{j-1}}\left(R_{i, j-1}-\bar{R}_{j-1}\right)+t_{i, j} S_{j} \sqrt{1-r_{j}^{2}}
$$

where $R_{i, j}$ are the residuals calculated by subtracting the actual daily highest temperature from the Fourier series, $\mathrm{i}$ is the year $(\mathrm{i}=1,2, \ldots, \mathrm{n}), \mathrm{j}$ is the Julian $\operatorname{day}(\mathrm{j}=1,2, \ldots, 365), \bar{R}_{j}$ is the average of the daily temperature residuals across $n$ years, $r_{j}$ is the correlation coefficient between $R_{j}$ and $R_{j-1}, S_{j}$ is the standard deviation of $T_{i, j}$ across $n$ years, $t_{i, j}$ is a normal random variate $t_{i, j} \sim N\left(0,1^{2}\right)$ (Burn, 2003).

\subsubsection{Time Series Temperature Simulation}

To complete the linear addictive model, the stochastic residuals generated from the autoregressive model are added to the results generated from the fitted Fourier series and also added to any persistence.

\subsubsection{Precipitation}

The use of a combination of a point process and an intensity function to simulate the occurrence of precipitation has a long history. Several rainfall models were formulated by Todorovic and Woolhiser (1974) with the use of point probability model. Marien and Vandewiele (1986 ) developed a point rainfall generator with internal storm structure. Guttorp (1986) used a continuous time point process to describe rainfall. 
In this study, the nature of frequency and duration of precipitation events from the data records were analyzed. The occurrence of precipitation events is assumed to be random and follow a Poisson arrival process:

$$
\mathrm{P}[(N(t+\tau)-N(t))=k]=\frac{e^{-\lambda \tau}(\lambda \tau)^{k}}{k !}
$$

where $\lambda$ is the occurrence rate during a time interval. During a time interval of $t$, the expected number of occurrences is $\lambda t$. Hence, $\lambda$ could be the number of days with precipitation over the length of the time period.

Adopted from Ross (1997), the following is an algorithm to generate the first $T$ time units of a Poisson Process with rate $\lambda$. In this algorithm, $t$ is time, $I$ is the number of events that have occurred by time $t$, and $\mathrm{S}(I)$ is the previous event arrival time.

\section{Steps}

1. set $\mathrm{t}=0, \mathrm{I}=0$

2. Generate a random number $U$.

3. $t=t-\frac{1}{\lambda} \log U$. If $t<T$, stop

4. $I=I+1, S(I)=t$.

5. Go to step 2.

The interarrival time $-\frac{1}{\lambda} \log U$ is continuous and can sometimes have values less than one.

These interarrival times when summed together would allow more than one event to occur on the same day. For example, if $t_{1}=0.5$ and $t_{2}=0.3$, then both event one and two would occur in day one. Since the desired time interval is one day, the algorithm needs to be modified to allow a maximum of one event in any day. That is, interarrival times less than one are 
rounded up to one, whereas interarrival times greater than one are rounded to the nearest integer value.

The historic daily precipitation volume is found best fitted by the exponential distribution and simulated using the typical Monte Carlo method. Therefore, the time series precipitation is simulated using the Poisson process to described the arrival time and the exponential distribution for the precipitation volume (Figure 11).

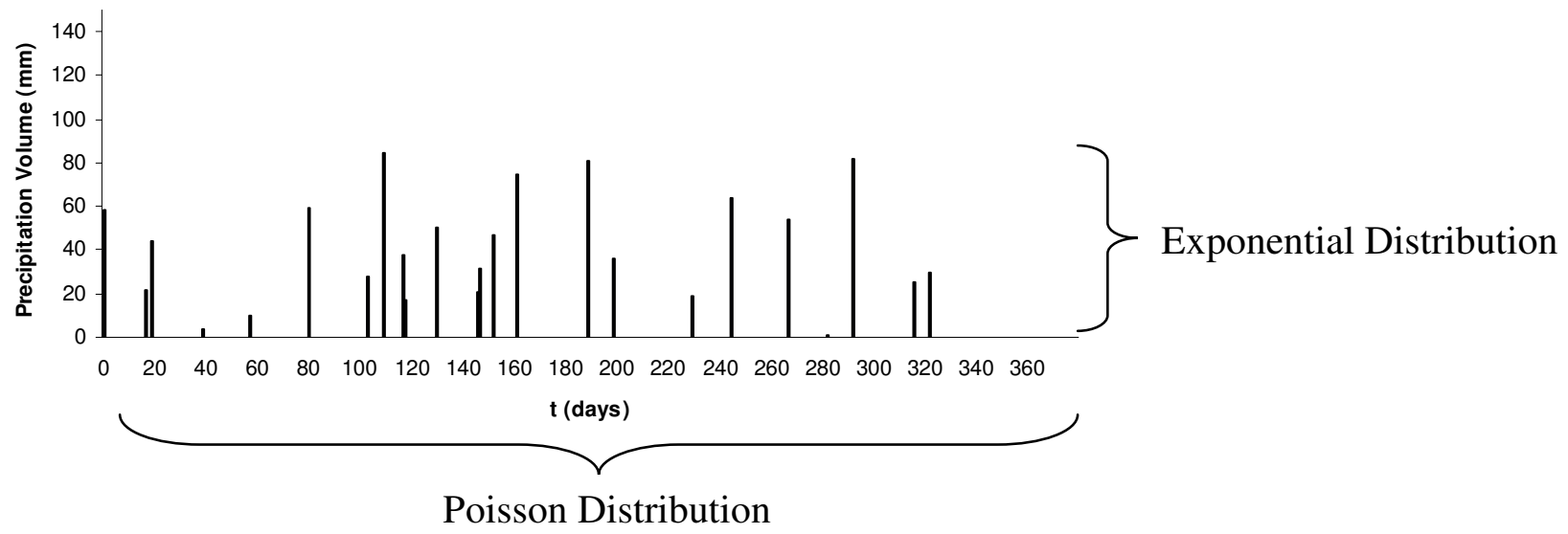

Figure 11. Poisson distributed precipitation arrival and exponential distributed precipitation volume

\subsubsection{Global Climate Models (GCMs) Data}

General Circulation Models (GCMs) commonly known as Global Climate Models are a class of computer models developed primarily for weather forecasting and climate change projections. These numerical models consist of a variety of integrated physical models such as atmospheric, oceanic, chemical, and biological models. In a GCM, the planet is divided 
into a 3-dimensional grid and differential equations describe the interactions of ocean and atmosphere. The results of each grid are estimated and interactions with neighboring points are evaluated (NOAA, 2007).

The Canadian Climate Impacts Scenarios (CCIS) Group Scenario Access Website provides climate scenario outputs that were derived from different GCMs and emission scenarios (Figure 12). These outputs illustrate the likely spatial characteristics of future climate change in Canada and North America (Canadian Climate Impacts Scenarios Group, 2003).

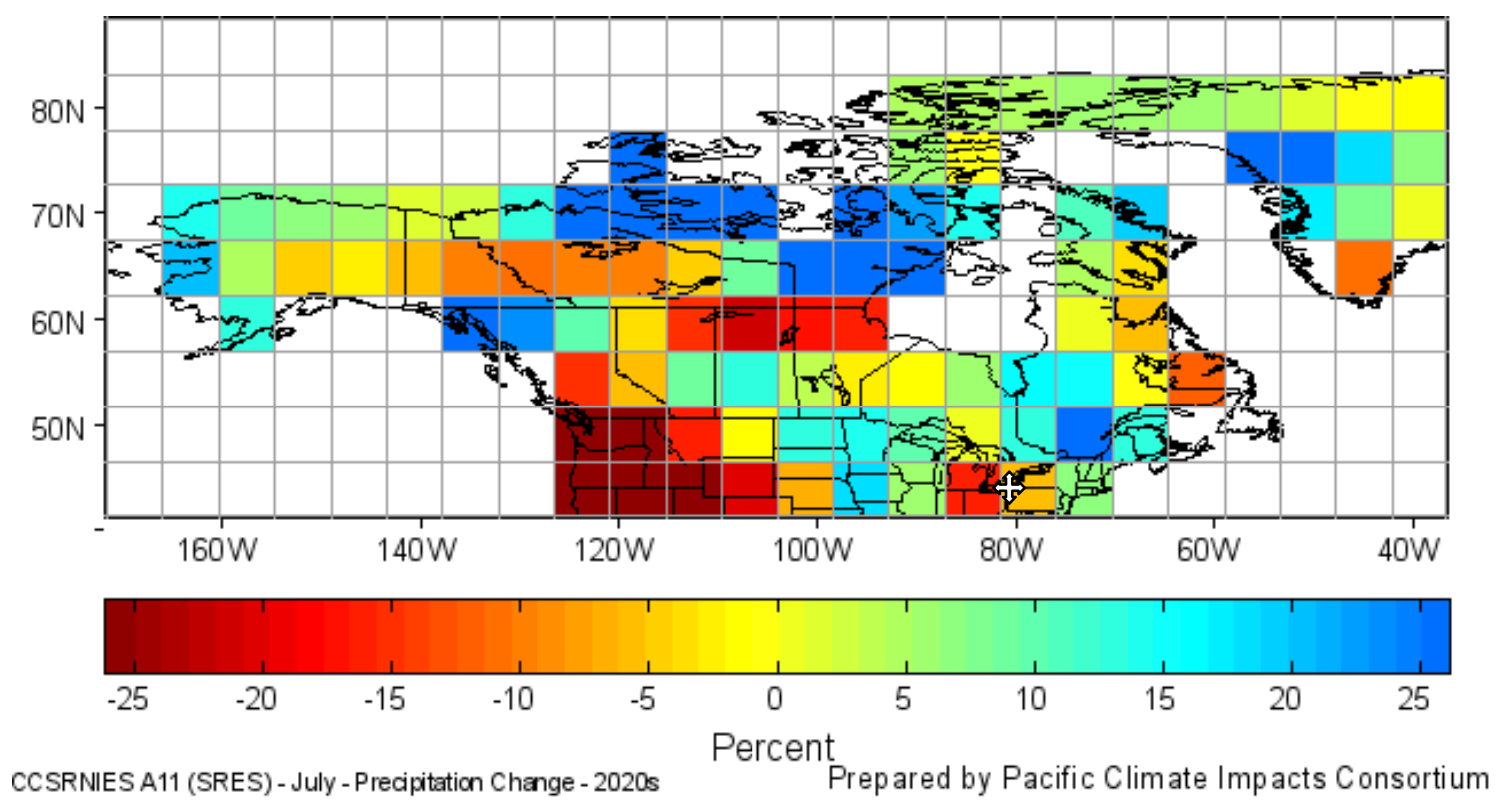

Figure 12. CCSRNIES A11 (SRES) July precipitation change 2020s

Source: CCIS Group Scenario Access Web Page (2004)

There are 63 different GCMs and emission scenarios prepared by the Pacific Climate Impacts Consortium. These GCMs envelope a range of climatology projections. As there are considerable uncertainties in magnitude, timing and spatial details (grid size) among different 
GCM forecasts, to understand the potential impact of climate change on a water supply system, different GCMs should be utilized (Weart, 2007). Since the SRES are the more recent scenarios that incorporate future emission projections, they are included in the preliminary selection.

The annual-maximum temperature and annual-precipitation for the 1960-1990 baseline, as well as the annual-maximum temperature change and annual-precipitation change for the 2020s of the SRES GCMs are tabulated in Appendix A. The scenarios associated with the most extreme temperature and precipitation changes are indicated in Figure 13.

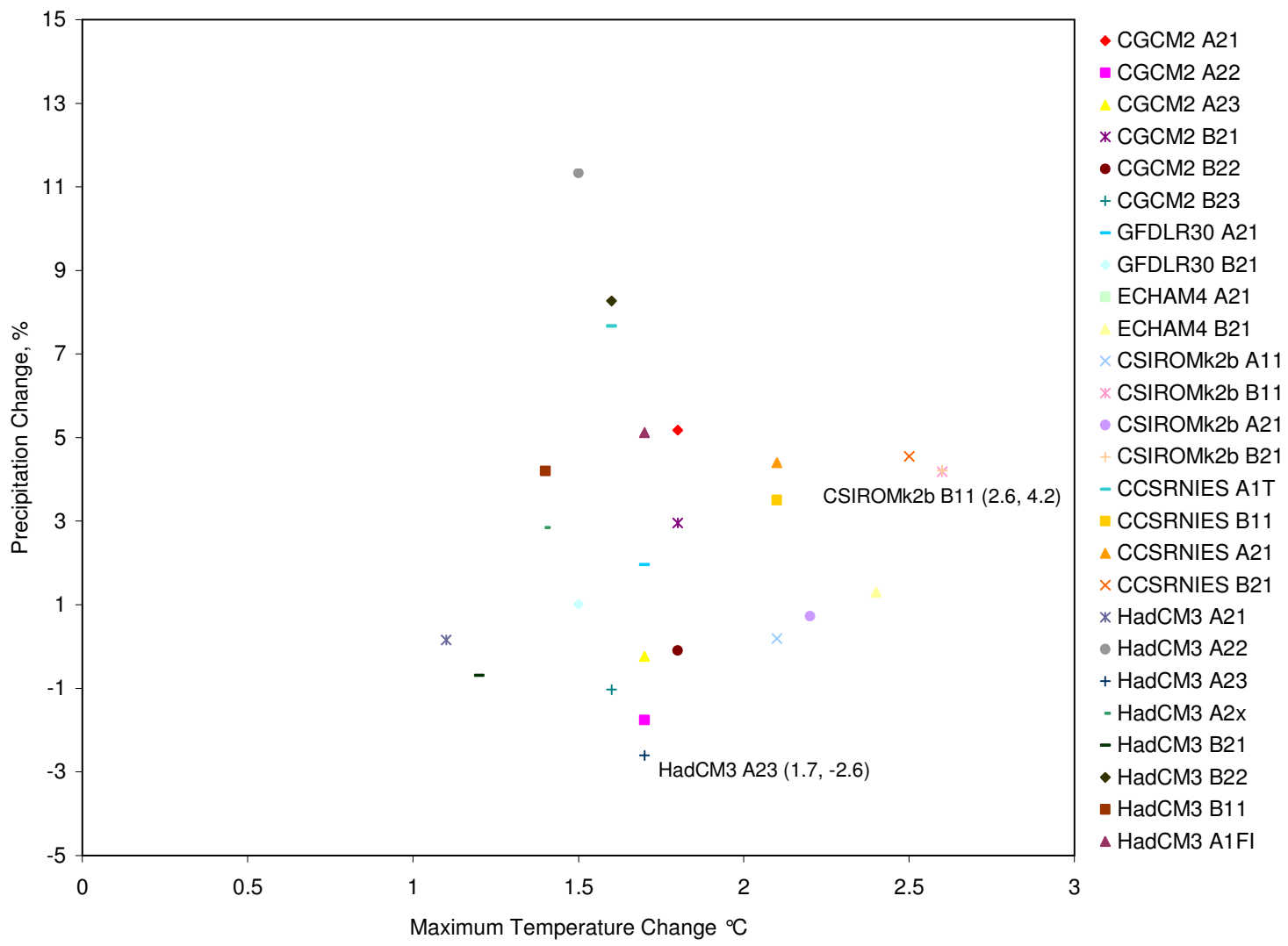

Figure 13. Maximum temperature change versus precipitation change for time slice 2020s scenarios. 
HadCM3 A23 projects the largest decrease in precipitation and CSIROMk2b B11 suggests the largest increase in temperature. Two other average case scenarios are also considered. They are CGCM2 A22, and CCSRNIES A21. The monthly absolute differences of temperature and precipitation of the two most extreme scenarios CSIROMK2b B11 and HadCM3 A23 are shown in Figure 14.
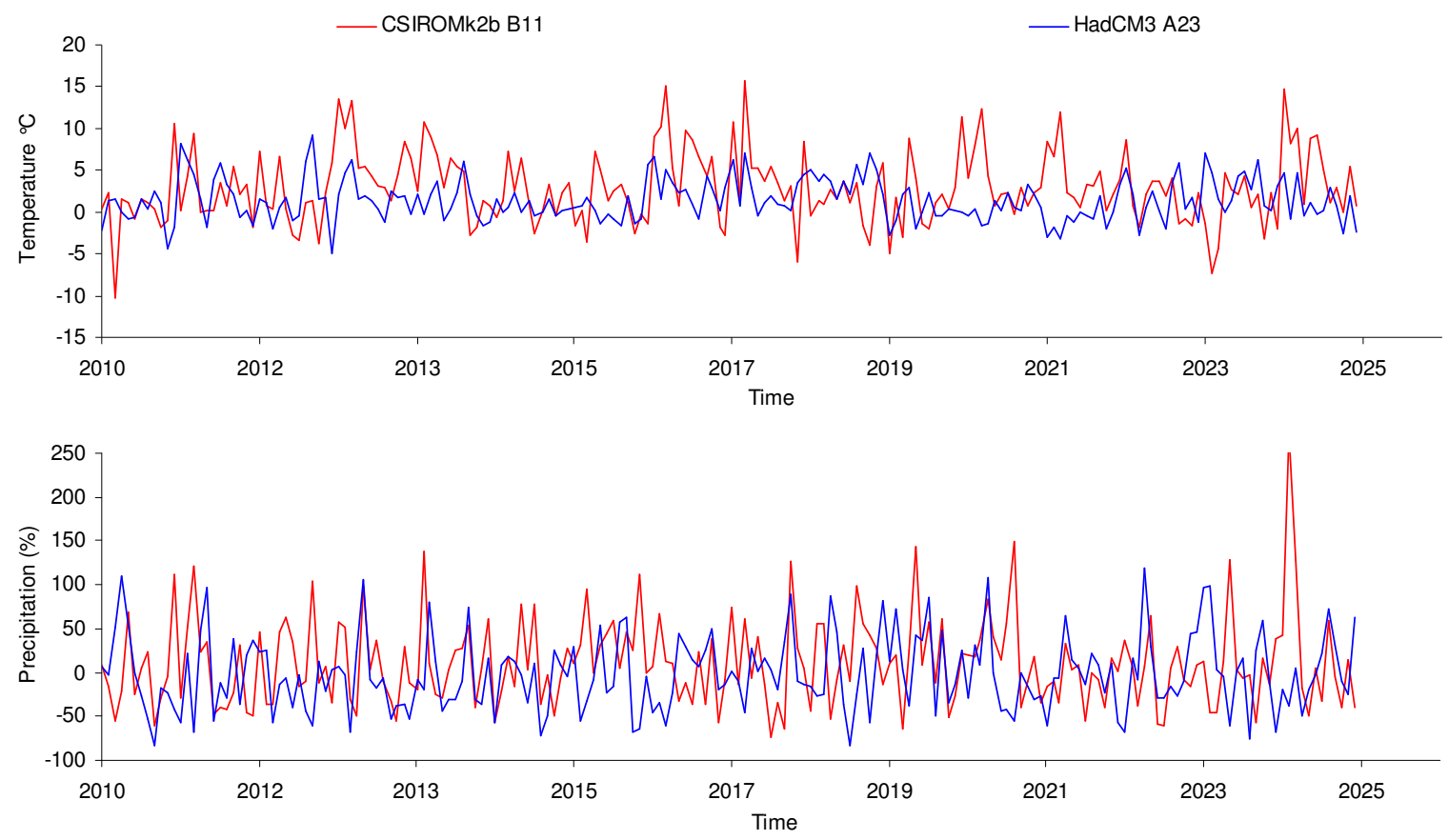

Figure 14. Monthly maximum temperature and monthly precipitation changes projected by scenario CSIROMk2b B11 and HadCM3 A23.

Table 1. Average Difference Relative to Baseline in Maximum Temperature and Precipitation of the Four Selected Scenarios.

\begin{tabular}{|c|c|c|}
\hline & \multicolumn{2}{|c|}{ Average Difference } \\
\cline { 2 - 3 } GCM Scenario & Maximum Temperature & Precipitation \\
\hline HadCM3 A23 & ${ }^{\circ} \mathrm{C}$ & -2.6 \\
CSIROMk2b B11 & 1.7 & 4.2 \\
CGCM2 A22 & 2.6 & -1.8 \\
CCSRNIES A21 & 1.7 & 4.4 \\
\hline
\end{tabular}


In measuring the estimated contribution of risk to the water supply system in future climate change scenarios, anomalies in temperature and precipitation are incorporated into the stochastic time series climate generation. As the anomaly data values are in monthly bases, the values were added to the monthly average values. For temperature:

$$
\boldsymbol{T}_{i, j}=\boldsymbol{P}_{i, j}+\boldsymbol{R}_{i, j}+\boldsymbol{A}_{i, j}
$$

where $T_{i, j}$ is the simulated daily temperature, $P_{i, j}$ is the simulated periodic component, $R_{i, j}$ is the simulated residual, and $\mathrm{A}_{\mathrm{i}, \mathrm{j}}$ is the monthly maximum temperature anomaly value projected by a GCM. For precipitation:

$$
P_{i, j}=X_{i, j} \times\left(1+B_{i, j} / 100\right)
$$

where $P_{i, j}$ is the simulated daily precipitation, $X_{i, j}$ is the simulated precipitation magnitude and $\mathrm{B}_{\mathrm{i}, \mathrm{j}}$ is the percentage of monthly mean precipitation increase or decrease projected by a GCM. Note that in equation 28 and 29 , the uncertainty of future climate change impact is handled parametrically

\subsubsection{Population Growth, Demand Management and Cost}

Population growth and water demand management are two major factors that define the performance of a water supply system. To meet the future water demands, many municipalities are aware of the need to conserve water and better manage their water supplies. Therefore, this study estimates the impacts of different population growth rate and demand management programs on future residential water demand. 


\subsubsection{Water Demand}

Many studies report the variation of water demand is weather related (Chen et al., 2005).

Research has been conducted to capture the nonlinear relationships between water demand and other exogenous variables. However, the randomly fluctuating daily water demand is also influenced by local behaviour and regulations. As such, the risks and uncertainty of water consumption related to climate change are dependent on the local climatic features (Downing et al., 2003). With a changing climate and increase of population, water demand may become more variable.

\subsubsection{Prediction Model Type Selection}

To develop a model that best describes the observed water demand pattern, a preliminary model was developed using linear regression and autoregressive method. The linear regression model was developed by using the forward fitting method and has a coefficient of determination $\mathrm{R}^{2}$ of 0.22 which indicates poor prediction accuracy. The seasonal autoregressive time series is stochastic and does not represent the data well.

In a few recent studies, it was found that the ANN models outperformed traditional modelling methods, in particular in predicting complex functions (Bowden et al., 2005). Therefore, in this study the ANN model was selected to develop a deterministic daily demand prediction model. The Excel add-in program, Palisade NeuralTools @ 2007 was chosen for such purpose. 


\subsubsection{Artificial Neural Network Training}

Like other data-driven based models, such as a linear regression model, an ANN model deciphers the relationship found between the input and output data. Just as the coefficients in a regression equation need to be estimated, the interconnecting neurons in the neural networks need to be trained (Solomatine, 2002) and thus learn based on available system input and output data.

By providing representative data to the training algorithms of the neural network, the pattern in the data will be learned (StatSoft, 2003). The network training process involves three major steps: data selection, input variable selection, and best net selection. Details of these steps are discussed in the following sub-sections.

\subsubsection{Data Selection}

Since we are most interested in the extreme demand, it is more important to focus on the training of the performance of the neural network in predicting the extreme demands. To screen a data set that is of most interest, and therefore representative, the data set is divided into two subsets delineated by a threshold temperature.

\subsubsection{Input Variable Selection}

Selection of appropriate input variables is crucial to the design of a neural network. Before starting the use of neural networks, prescreening is required to determine the set of most representative input variables. A combination of expert knowledge of the problem domain and statistical tests were used to select the variables (StatSoft, 2003). 


\subsubsection{Best Net Selection}

After the input variables are identified, a number of steps are required in determining the best network design. First, an initial network configuration is selected. The typical initial setting would be a network with one hidden layer and hidden nodes set to half as many as the number of inputs. Next, different network configurations are evaluated. Depending on the nature of the dataset, networks with different number of hidden layers and hidden nodes would have different prediction abilities. In evaluating each of these configurations, to avoid convergence to a local minimum, a number of experiments are required. The configuration that has the best prediction ability would be the best network design.

In assessing the prediction ability of the neural network, the model is tested by a test set. Ideally, the test set should be a set independent from the train set and should only be used once. However, we usually have less data than we would desire. To accommodate, a subset randomly sampled from the original dataset can be used as the test set. With the use of resamplings, the results would be more reliable (StatSoft, 2003). 


\section{Chapter 4}

\section{Case Study Application}

\subsection{Study Area}

The Village of Ayr is a rural farming community located within the Township of North Dumfries in the Region of Waterloo, Ontario, Canada. Land use in the community is primarily agricultural with some residential. The Village of Ayr covers an area of approximately 2.5 kilometers square and has a population of 4500 as of 2006 (Figure 15 to Figure 17). Situated approximately two kilometers south of a major highway (Highway 401), Ayr is growing into the suburban center within the Township (Region of Waterloo, 2001).

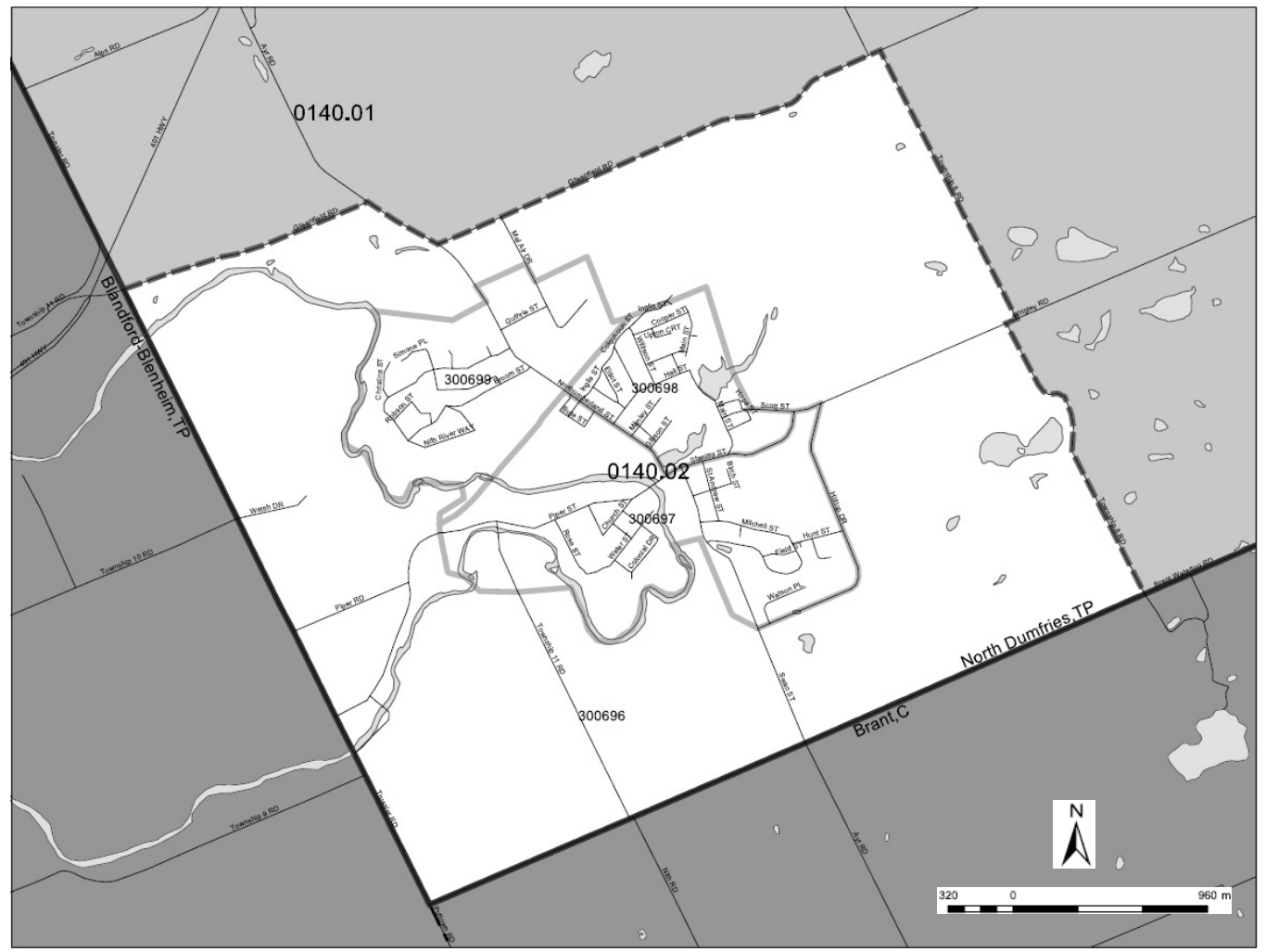

Figure 15. The village of Ayr (2002 Census) 


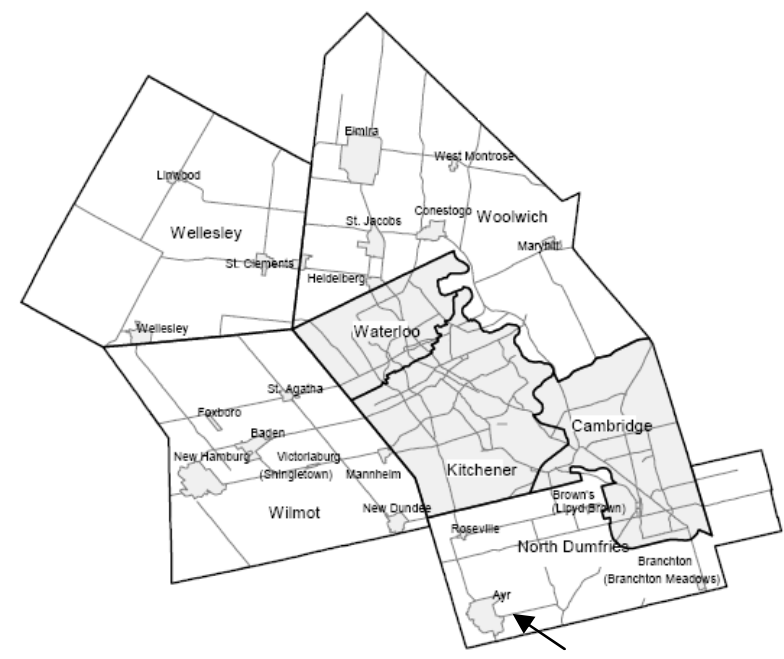

Figure 16. Area municipalities and rural municipal

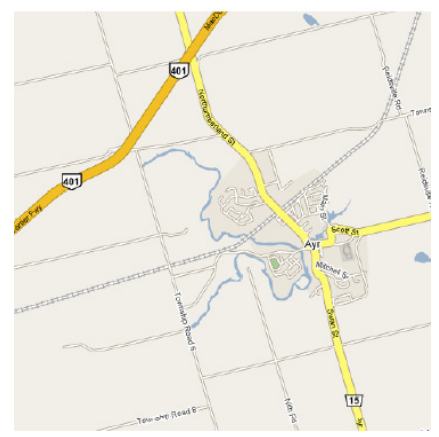

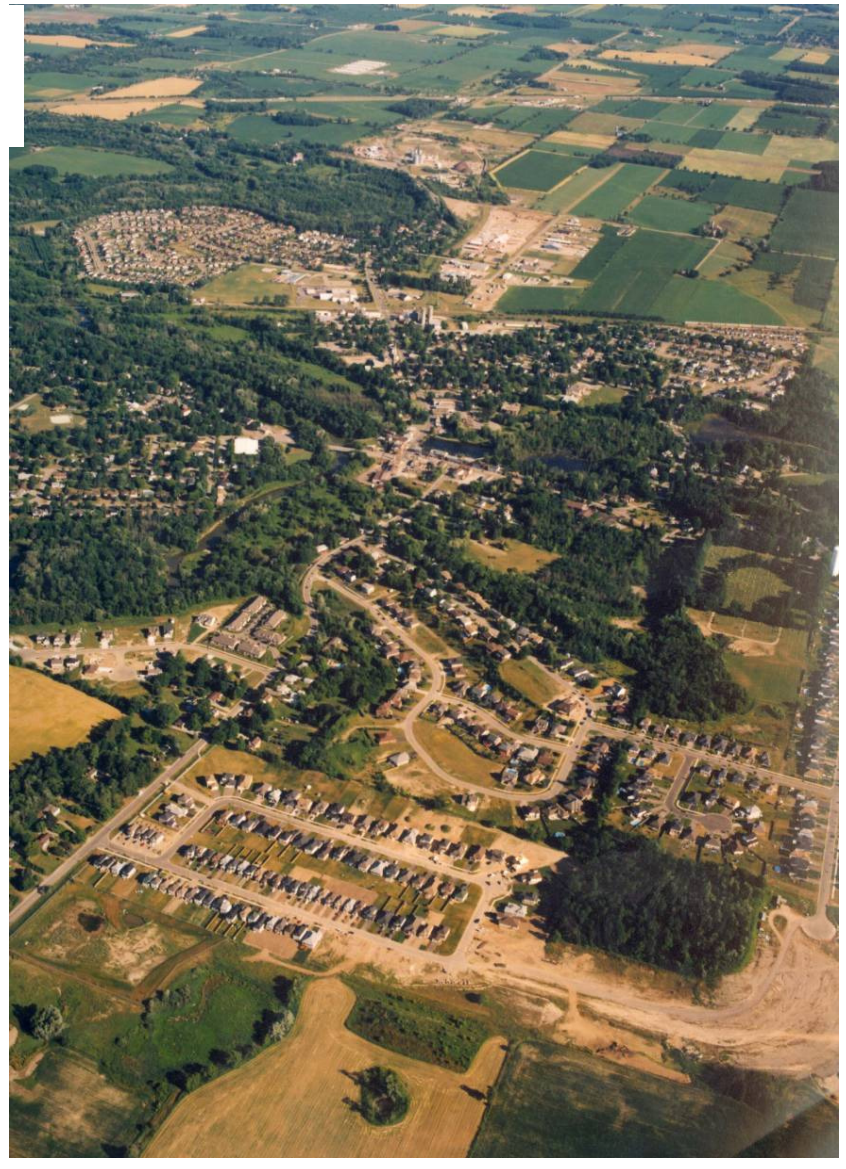

Figure 17. Aerial photo of Ayr

(Source:

http://www.region.waterloo.on.ca/web/region.nsf/ DocID/99C287F72ABA2D8685256AF70055320 8?OpenDocument\#)

Ayr's water supply comes exclusively from groundwater. The water supply system consists of two wells, a treatment facility and an above ground storage tank. Water extracted from the two wells is treated by two filtration components for the removal of iron and is disinfected by the use of hypochlorite. The two wells each can produce up to $2770 \mathrm{~m}^{3} /$ day and the pressure 
filter components can treat up to $2470 \mathrm{~m}^{3} /$ day in fulfillment of the aesthetic objective for iron of less than $0.3 \mathrm{mg} / \mathrm{L}$. The two wells can be operated in parallel or alternate to meet the water demand (Regional Municipality of Water Services, 2003).

Ayr's water supply system is owned and operated by the Region of Waterloo. As documented in the 2006 Water and Wastewater Monitoring Report, the 2005 daily average water use was $1160 \mathrm{~m}^{3} /$ day and the maximum day water use during the May-September peak demand period was recorded as $4100 \mathrm{~m}^{3} /$ day.

In recent years, the Ayr water supply system has operated at its design capacity and during hot and dry days has exceeded its allowable maximum daily instantaneous taking rate. Therefore, the Region has implemented and considered a number of alternative management options.

Several assumptions on the water savings from water use restrictions and conservation programs and the population growth rate of Ayr are made. These assumptions are combined in different ways to create an ensemble of scenarios for the studied time horizon in the study.

In this case study, when the simulated daily water demand exceeds the system capacity ( 2470 $\mathrm{m}^{3}$ ), the system is considered to have entered the failure state. In reality some storage would mitigate some failure events. However, for simplicity, it is assumed that there is no storage in the simulated supply system. 


\subsection{Available Data}

In order to assess risks and provide projections of future system performance, the construction of a model is required. To build a representative model, it is necessary to collect a large quantity of valid and high-quality data. Data collected for this study include climate data, water demand records, water sampling records, and water conservation programs and system expansion cost-figures acquired from the Region of Waterloo Water Services Office. Samples of the collected raw data are included in Appendix A.

Climate data were downloaded from the Environment Canada climate service's website. Daily weather records consist of daily high, average, and low temperature and precipitation for the period January 1, 2000 to December 30, 2006 recorded at the Roseville weather station, which is located at latitude $43^{\circ} 21^{\prime} \mathrm{N}$, longitude $80^{\circ} 28^{\prime} \mathrm{W}$, and has an elevation of $328 \mathrm{~m}$. A separate set of climate data from the University of Waterloo Weather Station was used to in-fill missing data and correct erroneous records found in the Roseville dataset.

The water sampling data include bi-weekly testing results at the raw, treated, and distribution points in the water system. The summary of the results of microbiological, inorganic, and organic parameters concentration showed that iron was the only exceedance. Iron is an aesthetic parameter and the sampling is not frequent enough to provide a complete data set to conduct a representative analysis on Ayr's water supply system water quality. Therefore, in this study, the primary focus of the risk assessment is on water quantity. 


\subsection{Data Analysis}

\subsubsection{Temperature}

\subsubsection{Long Term Trends}

The annual maximum temperature and annual mean temperature over the seven year period are used to determine if a linear temperature trend exists. The average annual maximum temperature and the average annual mean temperature between 2000 to 2006 are $7.7^{\circ} \mathrm{C}$ and $12.6^{\circ} \mathrm{C}$ respectively. There is no apparent linear increasing or decreasing trend observed in the available historical temperature data (see Figure 18).

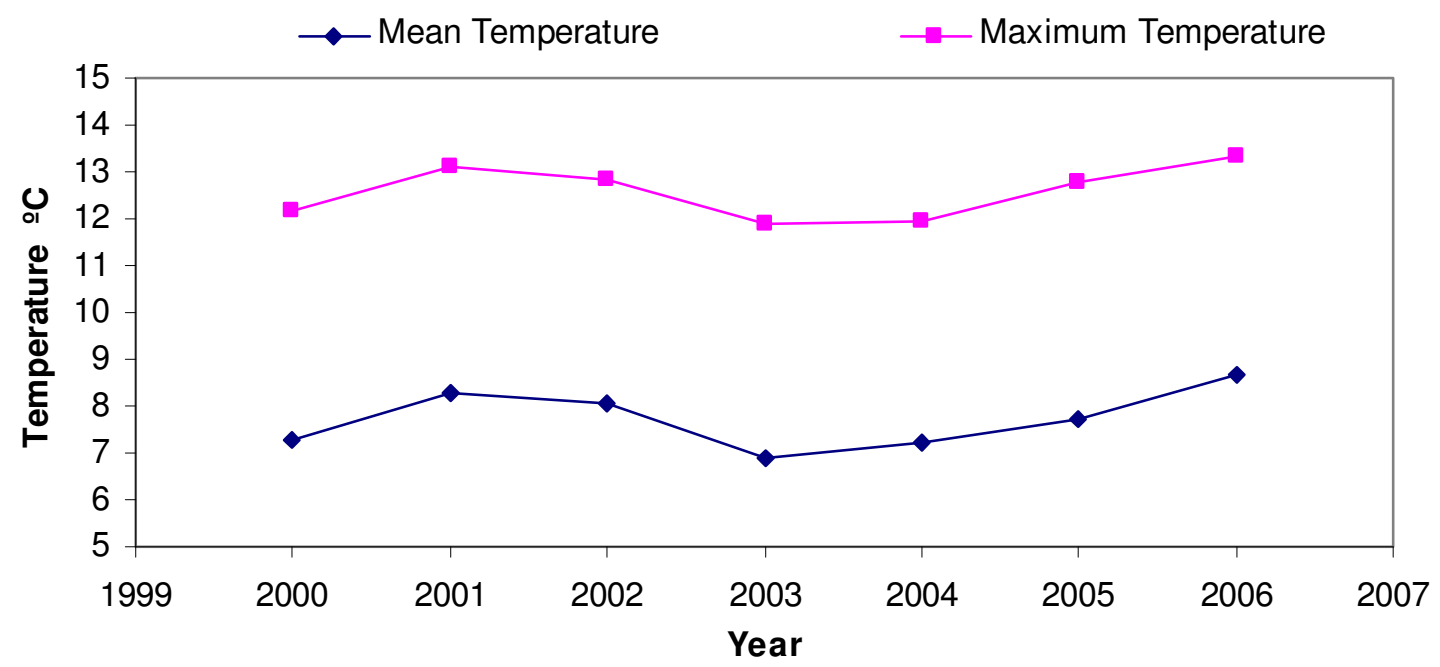

Figure 18. Annual mean and maximum temperature 


\subsubsection{Periodic}

The correlation coefficient, $\mathrm{R}^{2}$, indicates that the Fourier series with one harmonic is sufficient in describing the seasonal pattern in the data. The general Fourier model with one harmonic is given as:

$$
f(t)=a_{0}+a_{1} \cos (t \times w)+b_{1} \sin (t \times w)
$$

where the coefficients (with $95 \%$ confidence bounds) values are $\mathrm{a}_{0}=12.58(12.39,12.77), \mathrm{a}_{1}$ $=-13.65(-13.97,-13.33), \mathrm{b}_{1}=-5.139(-5.659,-4.619), \mathrm{w}=0.0172(0.01717,0.01722)$, and $\mathrm{t}$ is time from 1 to 2555 day. The coefficients $a_{0}$ represents the overall average temperature, $a_{1}$ and $\mathrm{b}_{1}$ represent the amplitude deviation from $\mathrm{a}_{0}$ and $w$ represents the width of the period.

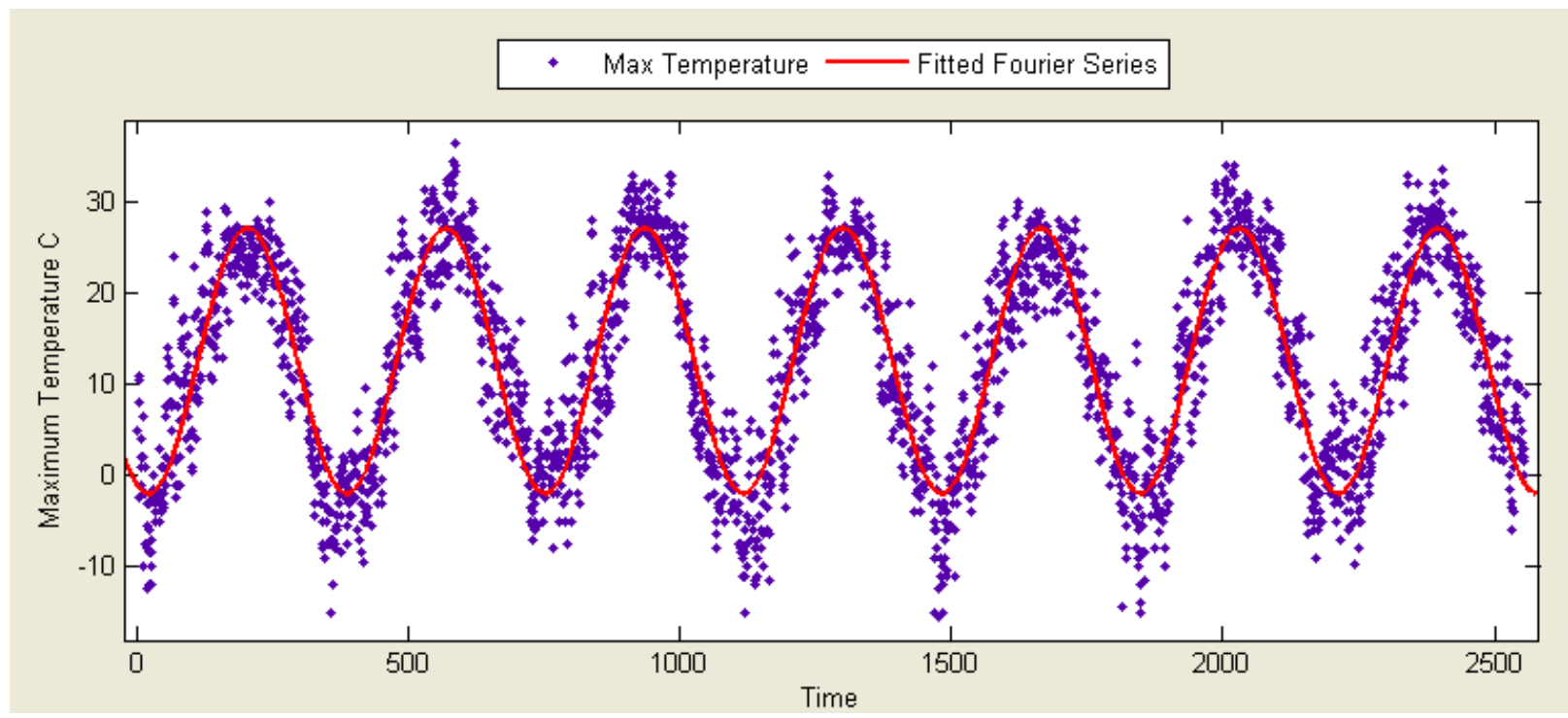

Figure 19. Maximum temperature data fitted using Matlab Curve Fitting Tool 
Table 2 shows the first ten days of the cycle component of the temperature generated from the fitted Fourier series (second last column in Table 2). Residuals were calculated by subtracting the Fourier series data from the actual temperature data. The calculated residuals are inputs of the seasonal autoregressive model described in the following section.

Table 2. Fourier Series Temperature Smoothing

\begin{tabular}{|c|c|c|c|c|c|c|c|c|}
\hline Date & $\begin{array}{c}\text { Recorded } \\
\text { Maximum } \\
\text { Temperature, } \\
X_{i}\end{array}$ & $\mathrm{t}$ & $\begin{array}{l}\mathrm{a} 0+\mathrm{dT}_{\text {Climate }} \\
\text { Change }\end{array}$ & urier Series & $b 1^{*} \sin \left(t^{*} w\right)$ & $\begin{array}{c}\text { Without } \\
\text { Climate } \\
\text { Change } \\
\text { Factor } \\
\mathrm{P}_{\mathrm{ij}}=\mathrm{x}(\mathrm{t})\end{array}$ & $\begin{array}{c}\text { With } \\
\text { Climate } \\
\text { Change } \\
\mathrm{P}_{\mathrm{ij}}=\mathrm{x}(\mathrm{t})\end{array}$ & $\begin{array}{c}\text { Residual, } \\
\text { R }\end{array}$ \\
\hline 01-Jan-00 & 5 & 1 & 12.58 & -14 & -0.1 & -1.2 & -1.16 & 6.16 \\
\hline 02-Jan-00 & 11 & 2 & 12.58 & -14 & -0.2 & -1.2 & -1.24 & 12.24 \\
\hline 03-Jan-00 & 10.5 & 3 & 12.58 & -14 & -0.3 & -1.3 & -1.32 & 11.82 \\
\hline 04-Jan-00 & 8 & 4 & 12.58 & -14 & -0.4 & -1.4 & -1.39 & 9.39 \\
\hline 05-Jan-00 & -2.5 & 5 & 12.58 & -14 & -0.4 & -1.5 & -1.46 & -1.04 \\
\hline 06-Jan-00 & 1 & 6 & 12.58 & -14 & -0.5 & -1.5 & -1.53 & 2.53 \\
\hline 07-Jan-00 & -1 & 7 & 12.58 & -14 & -0.6 & -1.6 & -1.59 & 0.59 \\
\hline 08-Jan-00 & 4 & 8 & 12.58 & -14 & -0.7 & -1.6 & -1.65 & 5.65 \\
\hline 09-Jan-00 & 2 & 9 & 12.58 & -13 & -0.8 & -1.7 & -1.70 & 3.70 \\
\hline 10-Jan-00 & 6.5 & 10 & 12.58 & -13 & -0.9 & -1.7 & -1.75 & 8.25 \\
\hline
\end{tabular}

\subsubsection{Time Series Temperature Simulation}

The autoregressive model set up in Excel spreadsheet is as shown in Table 3. The column headings are labeled with the same conventions as in equation (27) under section 3.3.1.3. A randomly selected value from the last recorded values was used as the starting value of the simulation and is highlighted in the table. Figure 20 shows the seven years of actual daily temperature data and the first four years of simulated temperature data. It shows that the simulated value follows the general trends as shown in the actual data. 
Table 3. Stochastic Time Series Temperature Simulation

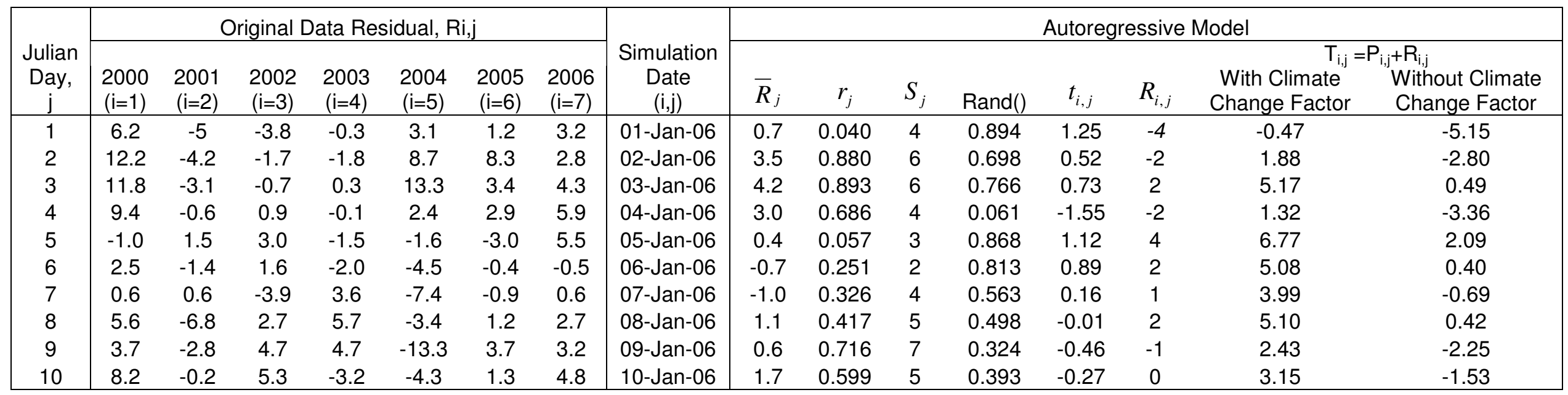

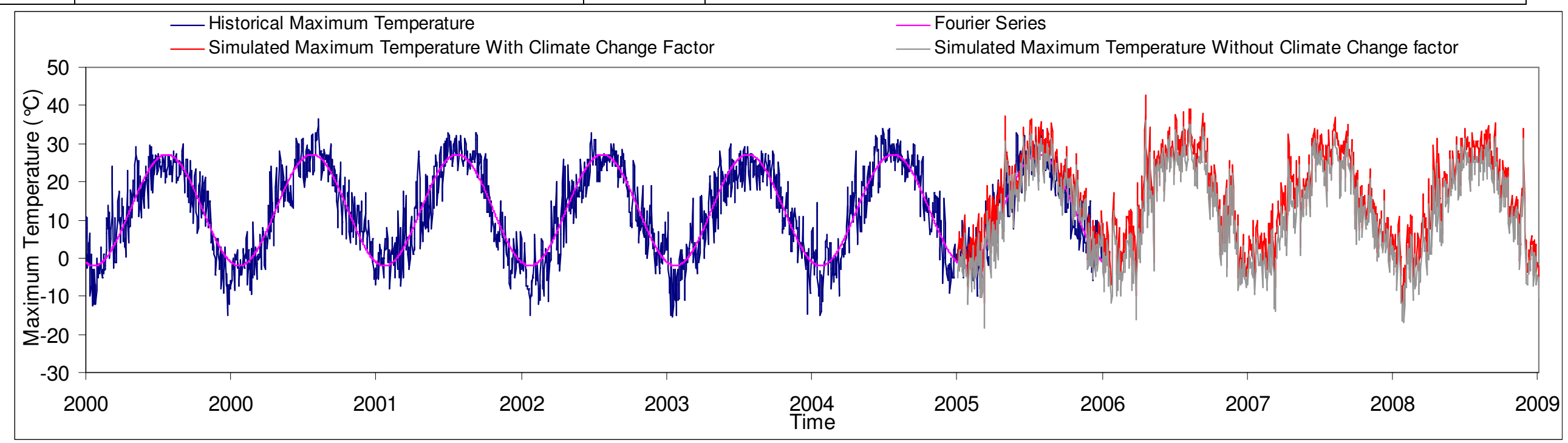

Figure 20. Simulated highest maximum daily temperature with and without climate change factor 


\subsubsection{Precipitation}

The annual total precipitation and maximum day precipitation of Ayr over the seven year period are plotted in Figure 21. The overall averages of annual total precipitation and maximum day precipitation between 2000 to 2006 are $957.8 \mathrm{~mm}$ and $51.3 \mathrm{~mm}$ respectively. As shown, there is no apparent linear increasing or decreasing trend observed in the available historical precipitation data.

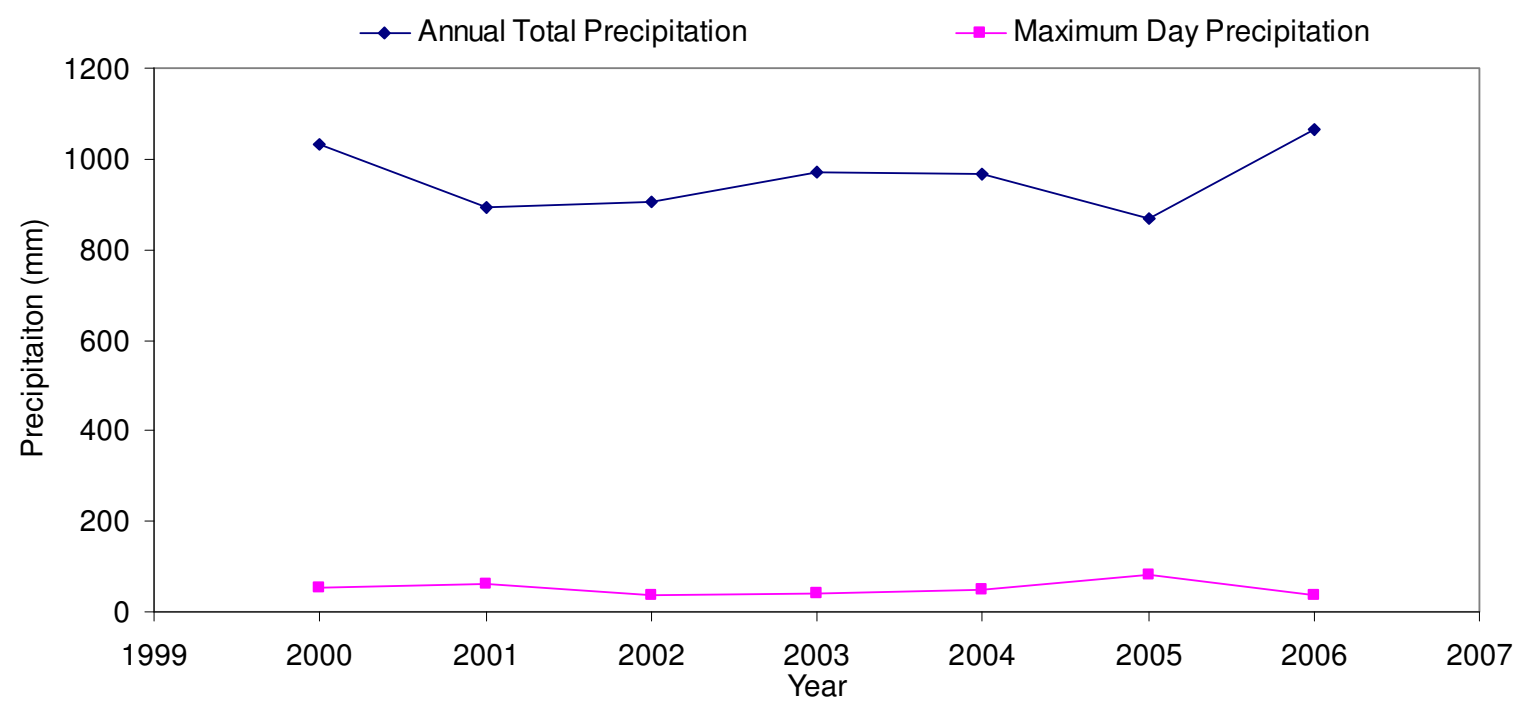

Figure 21. Annual mean and maximum precipitation

The magnitude of the precipitation appears to follow the exponential distribution and was fitted to the corresponding distribution using the software program Bestfit. The fitted distribution has parameters $\mu=0.192, \beta=7.017$, A-D statistic of 6.00 . There is no one simple statistical test to validate the theoretical properties of a point process, therefore the adequacy of the Poisson process is difficult to evaluate. Hence, most time series analysis are empirical. One of the sensible methods is to verify if the properties observed in the input data are 
preserved in the simulated process (Pourahmadi, 2001). Daily precipitation magnitude is highly variable. Therefore, for model validation, the observed annual total precipitation is compared with the results of the fitted distributions. The observed frequencies and the corresponding annual total precipitation simulated by the fitted Poisson distribution are compared in Table 4 and Table 5, which illustrate that the properties observed in the data are preserved in the simulated data.

Table 4. A Summary of Recorded Precipitation Data

\begin{tabular}{|cccc|}
\hline Year & no. of days with rain & Probability of having rain & Total Precipitation $(\mathrm{mm})$ \\
\hline 2000 & 140 & 0.384 & 1032 \\
2001 & 127 & 0.348 & 893 \\
2002 & 127 & 0.348 & 906 \\
2003 & 126 & 0.345 & 972 \\
2004 & 149 & 0.408 & 967 \\
2005 & 115 & 0.315 & 869 \\
2006 & 145 & 0.397 & 1065 \\
\hline Total & 929 & 0.364 & 6704 \\
\hline Average & 133 & 0.364 & 958 \\
\hline
\end{tabular}

Table 5. Summary of an Example of Simulated Time Series Precipitation

\begin{tabular}{|cccc|}
\hline Year & no. of days with rain & Probability of having rain & Total Precipitation $(\mathrm{mm})$ \\
\hline 1 & 146 & 0.400 & 780 \\
2 & 134 & 0.367 & 981 \\
3 & 101 & 0.277 & 728 \\
4 & 118 & 0.323 & 805 \\
5 & 130 & 0.356 & 1022 \\
6 & 153 & 0.419 & 949 \\
7 & 130 & 0.356 & 900 \\
\hline Total & 912 & 0.357 & 6165 \\
\hline Average & 130 & 0.357 & 881 \\
\hline
\end{tabular}

A second model validation, the adequacy of the point process models is evaluated. As listed in Table 4, the probability of having precipitation for any day ranges between 0.315 to 0.408 , and has an overall average of 0.364 . Therefore, to allow simple comparison, the interarrival 
times between precipitation events were simulated for a duration of seven years (2557 days) with $\lambda$ set to 0.364 . In addition to temporal comparison, the duration between precipitation events of the simulated and actual data are also found to be similar (Figure 22).

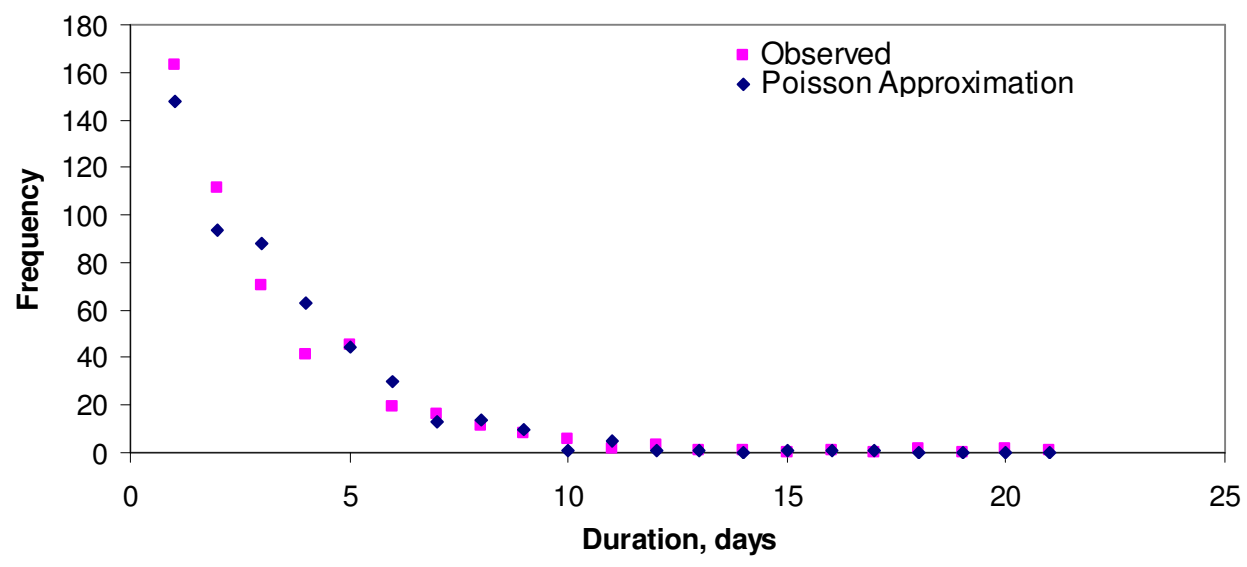

Figure 22. Comparison of Observed Frequency and Poisson Approximation with $\lambda=0.364$.

\subsubsection{Precipitation Changes}

Garbrech et al. (2002) identified that there is a recent change in seasonal pattern of precipitation normals. Changes of precipitation pattern involves changes in both magnitude and occurrence rate. In a GCM, deviations of monthly mean precipitation are projected. There are two ways in representing these precipitation changes in simulation.

One way is to represent these changes by adjusting the simulated precipitation magnitude. To simulate this effect, the time series precipitation is first generated using the process described in section 3.3.2 (see left section of upper Table 6). The time series data are then scaled by the monthly average changes projected by a GCM (columns 3 to 5 of the bottom 
half of Table 6). In this example, the GCM projects an $8 \%$ increase of precipitation for March 2006. Therefore, on March 10, 2006, the simulated precipitation with GCM effect is equal to $12.43 \mathrm{~mm} \times 1.08=13.46 \mathrm{~mm}$. Figure 23 illustrate the changes.

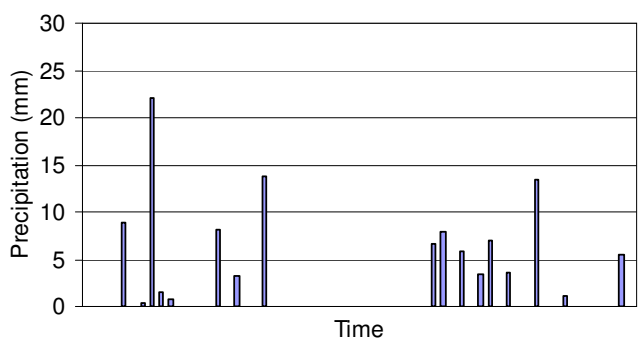

Original

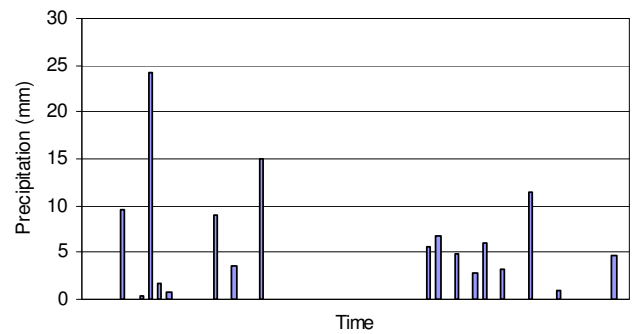

Magnitude scaled

Figure 23. Illustration of scaled precipitation magnitude

Another way to reflect a change of precipitation pattern is by converting the changes of magnitude into changes of event arrival rate. To simulate this effect, the time series precipitation is first generated using a process similar to that previously described but with $\lambda$ varying monthly. These $\lambda$ s are obtained by scaling the historical $\lambda$ to the GCM projected monthly mean precipitation deviations (see right section of upper Table 6). As the precipitation pattern generated by using this process would be different from that solely with magnitude scaled, to introduce some consistencies, the precipitation magnitude is post processed. In post processing, the total precipitation volume in time horizon of interest generated by frequency change is adjusted such that it equals the scaled magnitudes (see Table 6). Figure 24 illustrates the time series precipitation generated using the three processes: original, the original with scaled magnitude, and varying $\lambda \mathrm{s}$ with post processing. 
Table 6. Stochastic Precipitation Simulation

\begin{tabular}{|c|c|c|c|c|c|c|}
\hline \multirow[b]{2}{*}{$\begin{array}{l}\text { Random } \\
\text { Number } \\
\mathbf{U}\end{array}$} & \multicolumn{3}{|c|}{ Constant $\lambda$} & \multicolumn{3}{|c|}{ Changing $\lambda$} \\
\hline & $\begin{array}{c}\text { Time between (i-1)th and } \\
\text { ith event } \\
\mathbf{X} \mathbf{~ i}\end{array}$ & $\begin{array}{c}\text { Event time } \\
\mathbf{t}\end{array}$ & Event Date & $\begin{array}{c}\text { Time between }(\mathbf{i}-1) \text { th and } \\
\text { ith event } \\
\mathbf{X ~ i}\end{array}$ & $\begin{array}{c}\text { Event time } \\
\mathbf{t}\end{array}$ & Event Date \\
\hline 0.834 & 7 & 68 & $10 / 03 / 2006$ & 6 & 65 & $07 / 03 / 2006$ \\
\hline 0.425 & 1 & 69 & $11 / 03 / 2006$ & 1 & 66 & 08/03/2006 \\
\hline 0.324 & 2 & 71 & $13 / 03 / 2006$ & 2 & 68 & $10 / 03 / 2006$ \\
\hline 0.047 & 3 & 74 & $16 / 03 / 2006$ & 3 & 71 & $13 / 03 / 2006$ \\
\hline 0.312 & 8 & 82 & $24 / 03 / 2006$ & 8 & 79 & $21 / 03 / 2006$ \\
\hline 0.151 & 3 & 85 & $27 / 03 / 2006$ & 3 & 82 & 24/03/2006 \\
\hline
\end{tabular}

\begin{tabular}{|c|c|c|c|c|c|c|c|}
\hline \multirow[b]{3}{*}{ Time } & \multicolumn{7}{|c|}{ Simulation Outputs } \\
\hline & \multirow[b]{2}{*}{$p=r a n d()$} & \multicolumn{3}{|c|}{ Constant $\lambda$} & \multicolumn{3}{|c|}{ Changing $\lambda$} \\
\hline & & $\begin{array}{c}\text { Precipitation } \\
>0(\mathrm{Y} / \mathrm{N})\end{array}$ & $\begin{array}{l}\text { Precipitation } \\
(\mathrm{mm}) \\
\text { without Climate } \\
\text { Change Effects } \\
\mathbf{F}^{-1}(\mathbf{p})\end{array}$ & $\begin{array}{c}\begin{array}{c}\text { Precipitation } \\
(\mathrm{mm})\end{array} \\
\text { with } \mathrm{GCM} \text { scaled } \\
\text { Magnitude } \\
\mathbf{F}^{-1}(\mathbf{p}) \times \mathbf{G C M} \text { Data }\end{array}$ & $\begin{array}{l}\text { Precipitation } \\
>0(\mathrm{Y} / \mathrm{N})\end{array}$ & $\begin{array}{c}\text { Precipitation } \\
(\mathrm{mm}) \\
\text { with change } \\
\text { of frequency } \\
\mathbf{F}^{-1}(\mathbf{p})\end{array}$ & $\begin{array}{l}\text { Scaled Precipitation } \\
(\mathrm{mm})\end{array}$ \\
\hline $07 / 03 / 2006$ & 0.325 & 0 & 0.00 & 0.00 & 1 & 2.95 & 2.98 \\
\hline 08/03/2006 & 0.438 & 0 & 0.00 & 0.00 & 1 & 4.23 & 4.29 \\
\hline 09/03/2006 & 0.394 & 0 & 0.00 & 0.00 & 0 & 0.00 & 0.00 \\
\hline $10 / 03 / 2006$ & 0.825 & 1 & 12.43 & 13.46 & 1 & 12.43 & 12.59 \\
\hline $11 / 03 / 2006$ & 0.071 & 1 & 0.71 & 0.77 & 0 & 0.00 & 0.00 \\
\hline $12 / 03 / 2006$ & 0.401 & 0 & 0.00 & 0.00 & 0 & 0.00 & 0.00 \\
\hline $13 / 03 / 2006$ & 0.143 & 1 & 1.28 & 1.39 & 1 & 1.28 & 1.30 \\
\hline $14 / 03 / 2006$ & 0.907 & 0 & 0.00 & 0.00 & 0 & 0.00 & 0.00 \\
\hline
\end{tabular}



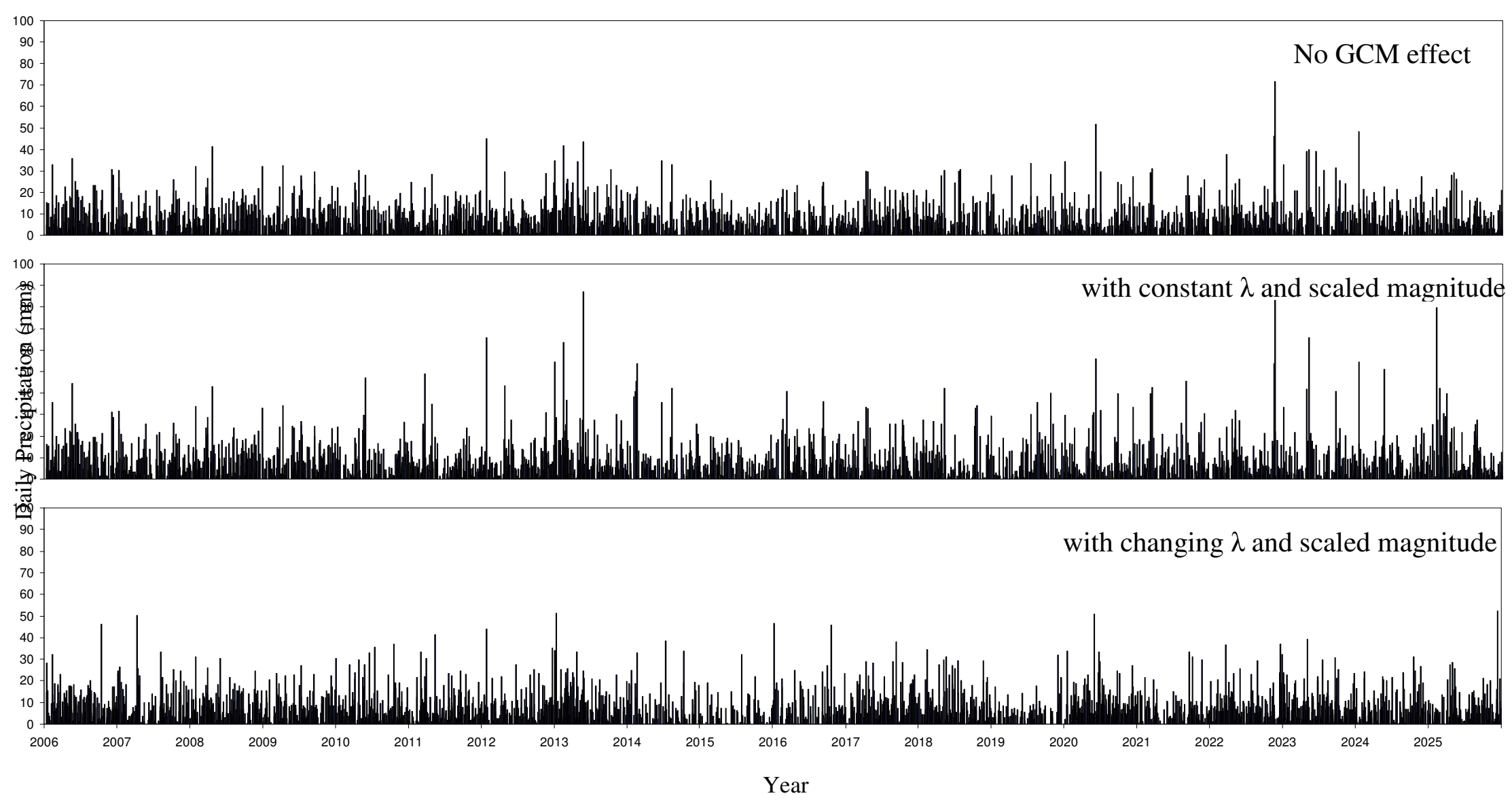

Figure 24. Example of Stochastic Precipitation generated using Poisson Process with a constant $\lambda$ and changing $\lambda$ 


\subsubsection{GCM Base Line Testing}

\subsubsection{Temperature}

To see if the GCM baseline and the simulated temperature based upon records are statistically different, the one-way Analysis of Variance Analysis (ANOVA) was performed to test the null hypothesis $\left(\mathrm{H}_{0}: \sigma_{1}^{2}=\sigma_{2}^{2}\right)$. Table 7 is a summary of the ANOVA.

Table 7. ANOVA Table of Simulated Temperature Data Versus GCM Scenario Baseline Temperature Data

\begin{tabular}{cc} 
ANOVA Summary & \\
\hline \hline Total Sample Size & 1440 \\
Grand Mean & 12.33 \\
Pooled Std Dev & 11.12 \\
Pooled Variance & 123.65 \\
Number of Samples & 2 \\
Confidence Level & $95.00 \%$
\end{tabular}

\begin{tabular}{cccccc} 
& Temperature & $\begin{array}{c}\text { Temperature } \\
\text { Simulated } \\
\text { based on } \\
\text { recorded } \\
\text { temperature }\end{array}$ & & & \\
ANOVA Sample Stats & GCM Baseline & & & \\
\hline Sample Size & 720 & 720 & & & \\
Sample Mean & 12.03 & 12.64 & & & \\
Sample Std Dev & 11.78 & 10.42 & & & \\
Sample Variance & 138.76 & 108.55 & & & \\
Pooling Weight & 0.5000 & 0.5000 & & & \\
& Sum of & Degrees of & Mean & F-Ratio & p-Value \\
One Way ANOVA Table & Squares & Freedom & Squares & & \\
\hline Between Variation & 137.09 & 1 & 137.09 & 1.11 & 0.2926 \\
Within Variation & 177813.95 & 1438 & 123.65 & & \\
Total Variation & 177951.03 & 1439 & & &
\end{tabular}

Since $F=1.11$ does not exceed the critical $F\left(F_{0.05(720,720)}=1.38\right)$, the null hypothesis $\left(\mathrm{H}_{0}\right.$ :

$\sigma_{1}^{2}=\sigma_{2}^{2}$ ) cannot be rejected. As well since the p-value is greater than 0.05 , there is insufficient evidence against the null hypothesis. Thus, scaling is not required to adjust the GCMs monthly temperature anomaly data for the use of simulation. The data can be added 
to the simulated temperature data to mimic the possible raising or lowering of temperature predicted by the GCMs.

\subsubsection{Artificial Neural Network Input Variable Selection}

The ANN model was selected to develop a deterministic daily demand prediction model. A set of 24 possible input variables was included in the initial prescreening. After different combinations of variables were tested, sensitivity analysis was also conducted to determine the relative importance of variables (StatSoft Inc., 2003). Screening experiments were conducted in the described fashion to iterate through the possible combination of variables. The experiment settings and description are defined in Table 8. To avoid network training convergence to locate a poor local minimum, 12 trials were conducted on each experiment configuration. In each experiment a different $20 \%$ randomly selected samples were used as the testing set to examine the predicting ability of the neural network. In Table $8, T(t)$ refers to the maximum temperature of current day and $T(t-i)$ refers to the maximum temperature of $i$ days ago. Similarly, $P(t)$ represents the precipitation amount of current day and $P(t-i)$ refers to the precipitation $i$ days ago. $P(t)>0$ ?, $P(t)>5$ ?, $P(t)>10$ ?, and $P(t)>25$ ? are binary flags indicating if the precipitation amount exceeded $0 \mathrm{~mm}, 5 \mathrm{~mm}, 10 \mathrm{~mm}$, and $25 \mathrm{~mm}$ respectively. $D(t-1)$ is the previous day demand and Weekend? is a binary flag indicating if the current day is in a weekend. The Root Mean Square Error and the percentage of bad predictions for the training and testing sets are included in Table 9. Detailed results are included in Appendix B. 
Table 8. Definition of Experiments

\begin{tabular}{|c|c|}
\hline Experiment no. & Input Variables \\
\hline 1 & $\begin{array}{c}\mathrm{T}(\mathrm{t}), \mathrm{T}(\mathrm{t}-1), \mathrm{T}(\mathrm{t}-2), \mathrm{T}(\mathrm{t}-3), \mathrm{T}(\mathrm{t}-4), \mathrm{T}(\mathrm{t}-5), \mathrm{T}(\mathrm{t}-6), \mathrm{T}(\mathrm{t}-7), \mathrm{P}(\mathrm{t}), \mathrm{P}(\mathrm{t}-1), \mathrm{P}(\mathrm{t}-2), \mathrm{P}(\mathrm{t}-3), \mathrm{P}(\mathrm{t}-4), \\
\mathrm{P}(\mathrm{t}-5), \mathrm{P}(\mathrm{t}-6), \mathrm{P}(\mathrm{t}-7), \mathrm{P}(\mathrm{t})>0 \text { ? }, \mathrm{P}(\mathrm{t})>5 \text { ? }, \mathrm{P}(\mathrm{t})>10 \text { ? }, \mathrm{P}(\mathrm{t})>25 \text { ? }, \mathrm{D}(\mathrm{t}-1) \text {, Day of Week, } \\
\text { Weekend?, Random Variable }\end{array}$ \\
\hline 2 & $\begin{array}{c}\mathrm{T}(\mathrm{t}), \mathrm{T}(\mathrm{t}-1), \mathrm{T}(\mathrm{t}-2), \mathrm{T}(\mathrm{t}-3), \mathrm{T}(\mathrm{t}-4), \mathrm{T}(\mathrm{t}-5), \mathrm{T}(\mathrm{t}-6), \mathrm{T}(\mathrm{t}-7), \mathrm{P}(\mathrm{t}), \mathrm{P}(\mathrm{t}-1), \mathrm{P}(\mathrm{t}-2), \mathrm{P}(\mathrm{t}-3), \mathrm{P}(\mathrm{t}-4) \text {, } \\
\mathrm{P}(\mathrm{t}-5), \mathrm{P}(\mathrm{t}-6), \mathrm{P}(\mathrm{t}-7), \mathrm{P}(\mathrm{t})>0 \text { ?, } \mathrm{D}(\mathrm{t}-1) \text {, Day of Week, Weekend?, Random Variable }\end{array}$ \\
\hline 3 & $\begin{array}{c}\mathrm{T}(\mathrm{t}), \mathrm{T}(\mathrm{t}-1), \mathrm{T}(\mathrm{t}-2), \mathrm{T}(\mathrm{t}-3), \mathrm{P}(\mathrm{t}), \mathrm{P}(\mathrm{t}-1), \mathrm{P}(\mathrm{t}-2), \mathrm{P}(\mathrm{t}-3), \mathrm{P}(\mathrm{t})>0 \text { ?, } \mathrm{D}(\mathrm{t}-1) \text {, Random Variable, } \\
\text { Day of Week, Weekend? }\end{array}$ \\
\hline 4 & $\begin{array}{l}T(t) \text {, Average }[T(t-1) \text { to } T(t-3)], P(t), \text { Sum }[P(t-1) \text { to } P(t-3)], P(t)>0 \text { ?, } D(t-1) \text {, Day of } \\
\text { Week, Weekend? }\end{array}$ \\
\hline
\end{tabular}

Table 9. Sensitivity Analysis of Inputs Experiment

\begin{tabular}{|c|c|c|c|c|}
\hline \multirow{2}{*}{$\begin{array}{c}\text { Experiment } \\
\text { Configuration }\end{array}$} & \multicolumn{2}{|c|}{ Training set } & \multicolumn{2}{|c|}{ Testing set } \\
\hline & RMSE & $\begin{array}{c}\% \text { Bad Predictions } \\
\text { (20\% Tolerance) }\end{array}$ & RMSE & $\begin{array}{c}\text { \% Bad Predictions } \\
\text { (20\% Tolerance) }\end{array}$ \\
\hline 1 & 0.0457 & $11.6 \%$ & 0.0650 & $24.6 \%$ \\
\hline 2 & 0.0437 & $12.6 \%$ & 0.0676 & $25.3 \%$ \\
\hline 3 & 0.0459 & $12.3 \%$ & 0.0687 & $25.2 \%$ \\
\hline 4 & 0.0440 & $11.2 \%$ & 0.0677 & $24.9 \%$ \\
\hline
\end{tabular}

During the training section of the ANN, variable screening was conducted to prune the initial set of 25 time series input variables into a final set of eight, while preserving the prediction ability of the network.

The final set of input parameters to the neural network consists the follows: Per Capita Inflated Demand (t-1), Maximum Temperature (t), Average Maximum Temperature (t-1 to t3), Precipitation (t) $>0$ ? (Y/N), Precipitation (t), Total Precipitation (t-1 to t-3), Day of Week (Monday=1), Weekend (Y/N). 


\subsubsection{Population Growth}

To properly approximate the future water demand, two population forecasts were collected. The 2001 Statistics Canada census forecast adopted by the Region in early studies suggested that the village of Ayr's population was expected to reach 5900 by 2025 (ROW, 2001). In the more recent 2006 population projection prepared by the Region of Waterloo Planning Information and Research Section, it was shown that the rate of increase would be more than that previously anticipated (Figure 25).

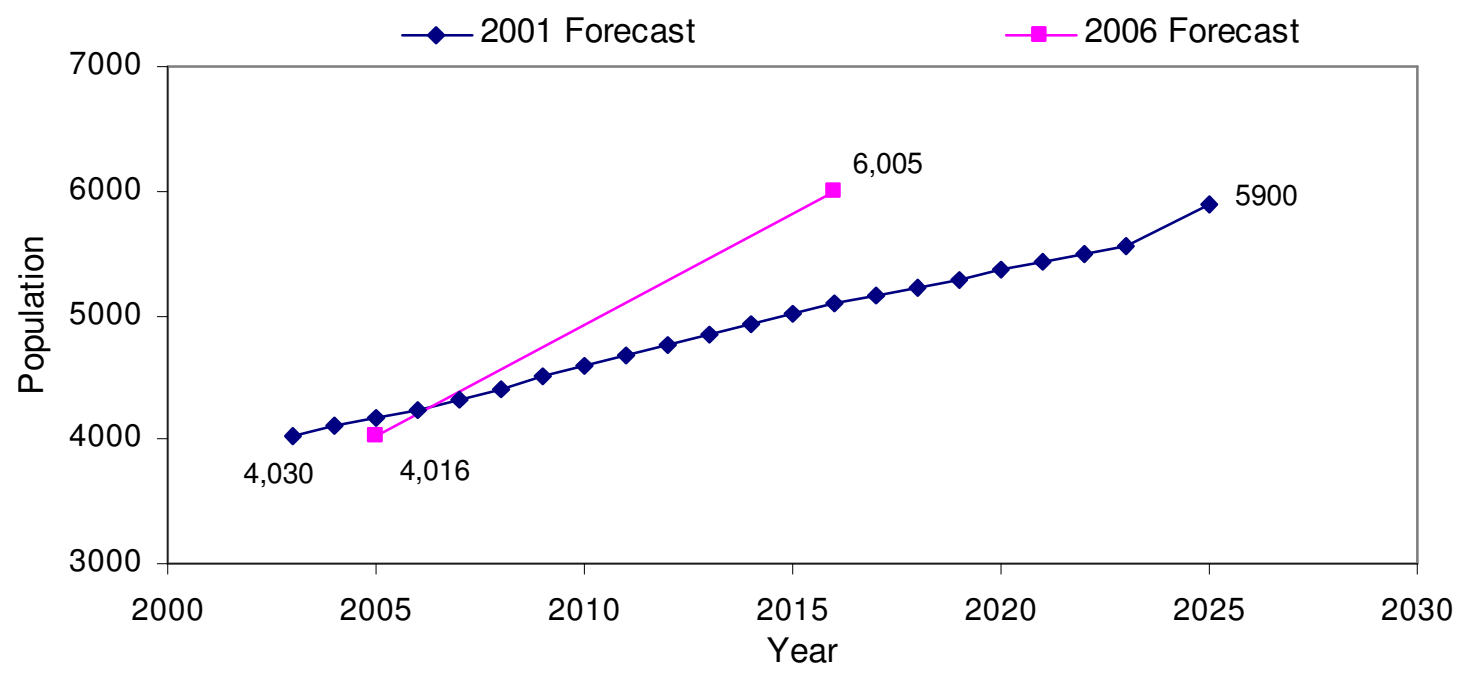

Figure 25. Ayr's Population Forecast

\subsubsection{Demand Management and Water Savings}

The Region of Waterloo initiated and implemented extensive water efficiency programs to reduce water consumption (ROW, 2006). In 2001, the Toilet Replacement Program (TRP) was implemented in Ayr to alleviate pressure on the water supply system, which was operating close to capacity. The TRP program provided rebates to encourage the replacement of inefficient toilets with 6-liter low flush models. When the TRP ended in 
2003 , it was estimated over $70 \%$ of residential units had toilets replaced with more water efficient models (ROW, 2004). Water savings achieved during the TRP program were estimated using an equation from "Final Report - Ayr Water Efficient Toilet Replacements, June 2003" and estimated water savings are tabulated in Table 10 and were calculated using

4 flushes/person/day x avg. 12 liters/flush saved $\mathrm{x} 2.926$ people per unit $\mathrm{x} \#$ toilets/ $1000=$ TRP water savings $\left(\mathrm{m}^{3} /\right.$ day $)$

Table 10. Estimated Water Savings of Ayr's TRP

\begin{tabular}{|c|cc|}
\hline Date & Number of Toilets Installed & Water Savings $\left(\mathrm{m}^{3} /\right.$ day $)$ \\
\hline $01 / 11 / 2001$ & 22 & 4 \\
$01 / 01 / 2002$ & 155 & 27 \\
$01 / 05 / 2002$ & 293 & 51 \\
$01 / 09 / 2002$ & 359 & 63 \\
$27 / 02 / 2003$ & 634 & 111 \\
$31 / 03 / 2003$ & 711 & 125 \\
\hline
\end{tabular}

As part of the Region's Water Supply Master Plan, the Region also incorporated water efficiency programs including subsidized rain barrel distribution, Outdoor Water Use ByLaw, and increasing public awareness of water conservation. Suggested in the Proposed Water Efficiency Master Plan, 2007-2015 prepared by the Region, it was estimated that the Outdoor Water Use By-Law water savings during the Maximum Week Demand is approximately 50 Liters/day per capita during the months June, July, and August. An additional of 5 Liter per capita per day was estimated to be achieved via the general education program. The water consumption reduction efforts were evident by a decreasing wastewater flow trend in the wastewater monitor program (ROW, 2003). 


\subsubsection{Costs}

In accordance to cost figures included in the Water Efficient Management Programs

(WEMPs) Master Plan, each WEMP has a different associated cost. Each cost includes the material and operating costs for executing the program for a year. The costs were estimated as a lump sum for the entire region. In Table 11, the costs were proportionally adjusted to reflect the share that the Ayr population would bear.

Table 11. Summary of Projected Program Costs and Water Savings from 2006 Water Efficiency Master Plan Update Appendix A.

\begin{tabular}{|c|c|c|}
\hline WEMPs & Estimated Water Savings & Cost \\
\hline Ayr's TRP & $125 \mathrm{~m}^{3} /$ day & $\$ 185,200$ \\
\hline $\begin{array}{c}\text { Education and } \\
\text { Communication Programs }\end{array}$ & 5 Liters/capita/day & $\begin{array}{c}(\$ 110598) / 450000 \text { people } \times 4300 \text { people } \\
=\$ 1056\end{array}$ \\
\hline Outdoor By-Law & $\begin{array}{l}50 \text { Liters/day/capita during } \\
\text { maximum week demand }\end{array}$ & $\begin{array}{c}(\$ 80,000) / 450000 \text { people } \times 4300 \text { people } \\
=\$ 764\end{array}$ \\
\hline
\end{tabular}

*The Regional Municipality of Waterloo is responsible for water supply to approximately 450,000 people in the Cities of Cambridge, Kitchener and Waterloo.

Cost estimates for Ayr Water Supply System Expansion are provided by the Regional Office. The breakdowns of the expansion are tabulated below.

Table 12. Summary of Ayr Water Supply Expansion Costs and Capacity Increase

\begin{tabular}{|c|c|c|}
\hline Expansion Components & Capacity Increase & Cost \\
\hline Additional Well Installation & & $\$ 250,000$ \\
Expansion Contract & $2500 \mathrm{~m}^{3}$ & $\$ 5725,000$ \\
Consulting Costs & & $\$ 500,000$ \\
Total & & $\$ 6,475,000$ \\
\hline
\end{tabular}


In accordance with the ROW Water Efficiency Master Plan, it is proposed to continue the implementation of the WEMPs and the charges tabulated should be inflated based on the estimated rate of inflation in the Master Plan, which is $2.5 \%$ and is adopted in this study.

\subsubsection{Water Demand}

The case study area land usage is primarily residential and commercial. Therefore, it is assumed that most of the water demand in the study encompasses domestic water use as described in section 2.2.1.

Six years of daily water consumption records for the period January 1, 2000 to December 31, 2005 were collected from the Region. In accordance with the compliance reports, discharges from the Ayr Water Treatment Plant were consistently exceeding the maximum allowable discharge from June 2001 to January 2002, which was contributed to erroneous pump settings (Figure 26).

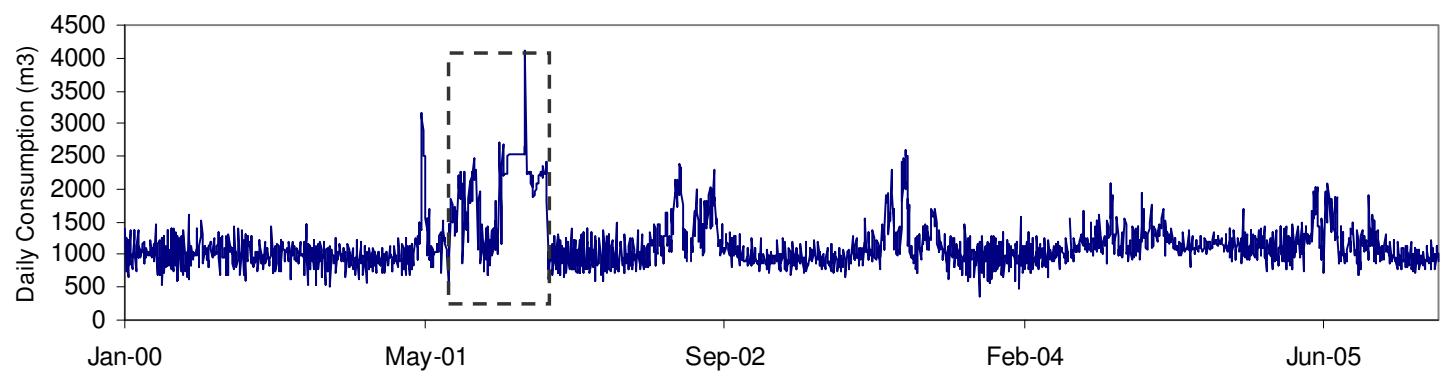

Figure 26. Suspected Erroneous Record in 2000 to 2005 Original Water Demand Data 
To understand the relationship between water demands and the exogenous variables, influences of regulations, conservation, and population growth needed to be removed from the daily water demands (Figure 27). Therefore, the daily demand was inflated by the estimated water savings as described in section 4.4.3 to approximate the actual demand if WEMPs were not implemented. The inflated water demand was then divided by the population of the year to determine the per capita water demand. The inflated per capita water demand varies between 106 to 708 L/day with an average of 301L/day, which agrees with the typical domestic water use in Canada which has an average of $638 \mathrm{~L} /$ capita/day (MOE, 2005).

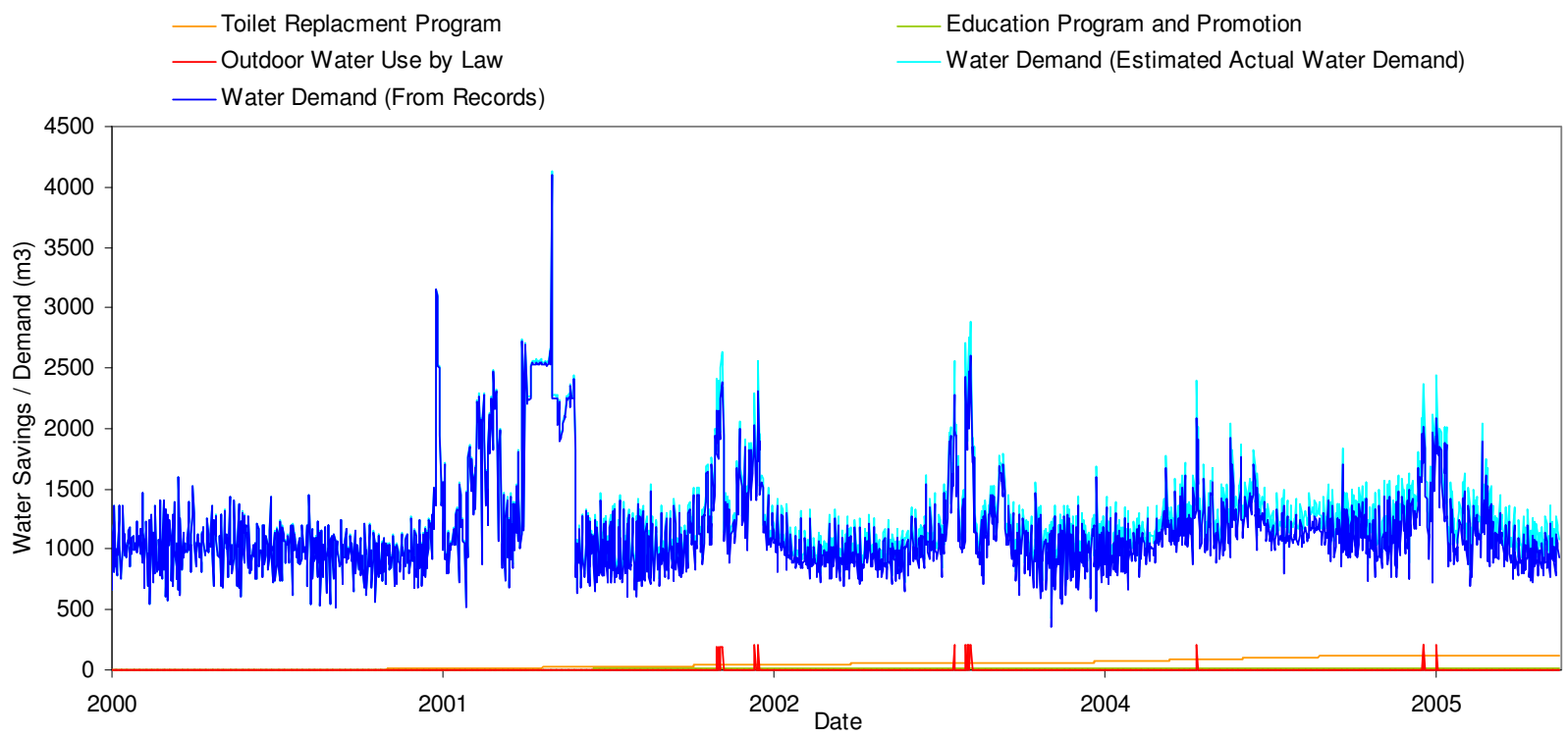

Figure 27. 2000 to 2005 Water Savings and Inflated Water Demand 


\subsection{The Water Demand Model}

Figure 28 is a plot of the observed daily water use, temperature and precipitation data aligned on the same time axis. The water use departs from the base water use $\left(800 \mathrm{~m}^{3} /\right.$ day $)$ most evidently during the warm and dry season (May to August). The plot also indicates that there is a tendency for these data to have water demand double or triple the average water use. On the contrary, cool and wet days show the opposite pattern (with a quarter to a half reduction).
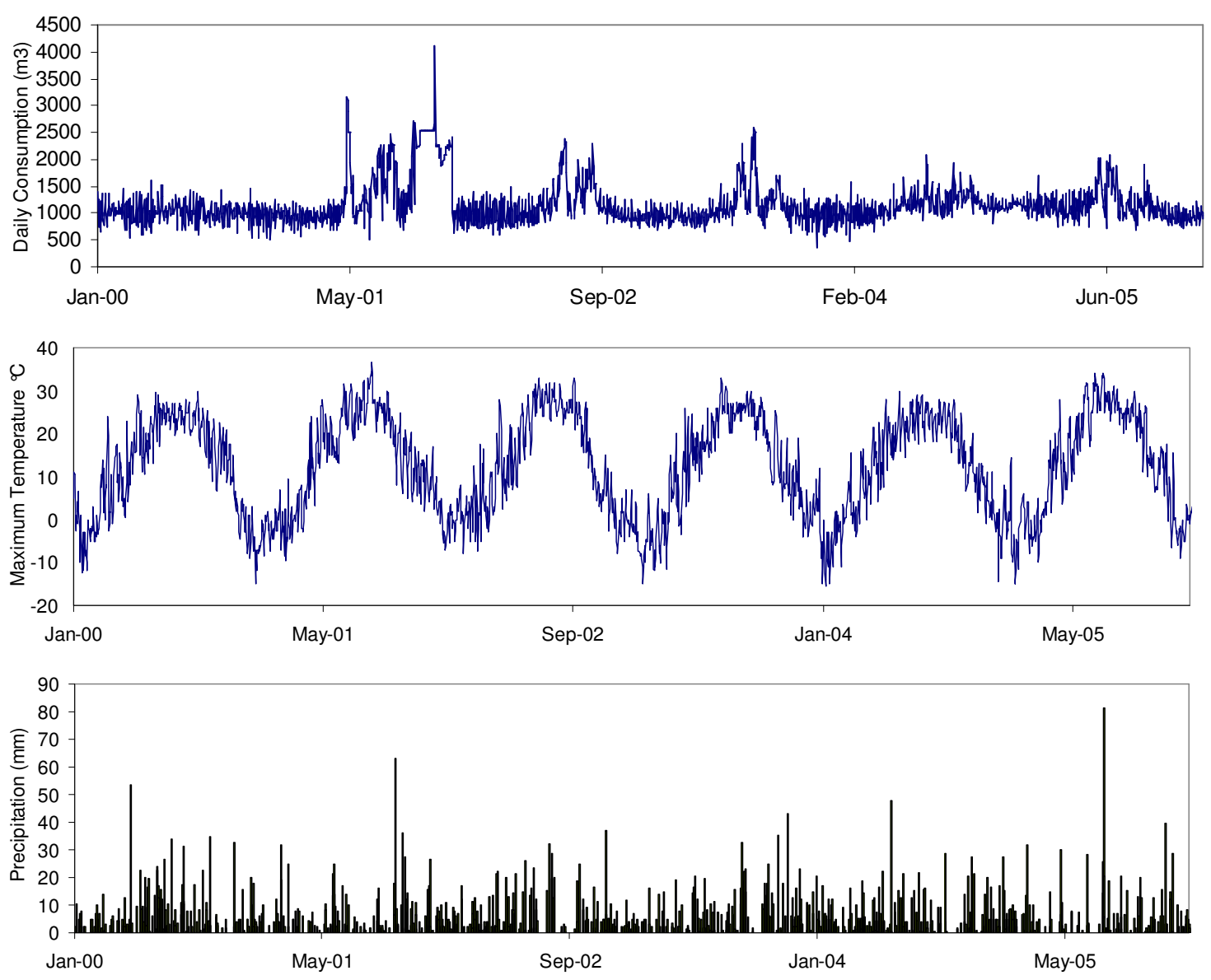

Figure 28. Time Series Plot of Input Parameters 
An initial set of testing variables for predicting daily water demand was hypothesized to include the previous day water demand, current day minimum, mean, maximum temperature, current day precipitation, the day of week, and a binary flag which indicates if the current day is in a weekend or not. Maximum temperature and precipitation with $\mathrm{n}$ days of lagging where $\mathrm{n}$ ranges from one to seven were also included in the set to investigate if past weather conditions have impacts on current water demand. The occurrence of a rainfall exceeding 0 , 5,10 , and $25 \mathrm{~mm}$ were also included in the testing set for a total of 25 independent parameters.

The days of the week were denoted by integers from one to seven with one representing Mondays and seven representing Sundays. The occurrence of rainfall above a particular amount was represented by a binary series, with one indicating days with rainfall and zero indicating days without rainfall. The Weekend $(\mathrm{Y} / \mathrm{N})$ parameter flags Saturdays and Sundays with ones and the rest of the days with zeros. For preliminary investigation, the crosscorrelation coefficients of water demand and the above-noted variables were calculated (Table 13).

As shown in Table 13, the previous day demand is strongly correlated to the current day demand with a positive correlation coefficient of 0.589 . The current day minimum, mean, and maximum temperatures are also correlated to the current day demand where maximum temperature at time $t$ is the most correlated and has a correlation of 0.431 . In the set of lagged maximum temperature, there is an almost linear decreasing trend in correlation as 
lagging duration increases. Similar to temperature, for precipitation, the current day precipitation has the strongest relation and a diminishing correlation was observed. The correlation value of -0.110 means that water use decreases with an increase of rainfall.

Table 13. Cross-correlation coefficients of water demands and Climatic Variables

\begin{tabular}{|cc|}
\hline Variable & Per Capita Inflated Water Demand $(\mathrm{t})$ \\
\hline Per Capita Inflated Water Demand $(\mathrm{t}-1)$ & 0.559 \\
Minimum Temperature $(\mathrm{t})$ & 0.343 \\
Mean Temperature $(\mathrm{t})$ & 0.399 \\
Maximum Temperature $(\mathrm{t})$ & 0.431 \\
Maximum Temperature $(\mathrm{t}-1)$ & 0.415 \\
Maximum Temperature $(\mathrm{t}-2)$ & 0.404 \\
Maximum Temperature $(\mathrm{t}-3)$ & 0.396 \\
Maximum Temperature $(\mathrm{t}-4)$ & 0.387 \\
Maximum Temperature $(\mathrm{t}-5)$ & 0.380 \\
Maximum Temperature $(\mathrm{t}-6)$ & 0.372 \\
Maximum Temperature $(\mathrm{t}-7)$ & 0.373 \\
Precipitation $(\mathrm{t})$ & -0.110 \\
Precipitation $(\mathrm{t}-1)$ & -0.108 \\
Precipitation $(\mathrm{t}-2)$ & -0.085 \\
Precipitation $(\mathrm{t}-3)$ & -0.077 \\
Precipitation $(\mathrm{t}-4)$ & -0.056 \\
Precipitation $(\mathrm{t}-5)$ & -0.042 \\
Precipitation $(\mathrm{t}-6)$ & -0.030 \\
Precipitation $(\mathrm{t}-7)$ & -0.056 \\
Precipitation $(\mathrm{t})>0 ?(\mathrm{Y} / \mathrm{N})$ & -0.154 \\
Precipitation $(\mathrm{t})>5 ?(\mathrm{Y} / \mathrm{N})$ & -0.101 \\
Precipitation $(\mathrm{t})>10 ?(\mathrm{Y} / \mathrm{N})$ & -0.071 \\
Precipitation $(\mathrm{t})>25 ?(\mathrm{Y} / \mathrm{N})$ & -0.033 \\
Day of Week $($ Monday $=1)$ & 0.128 \\
Weekend $(\mathrm{Y} / \mathrm{N})$ & 0.184 \\
&
\end{tabular}

However, the occurrence of rainfall appears to be even more significant than the magnitude of the rainfall as shown with a large negative value of -0.154 . The day of week also has impacts on daily demand. The value of 0.128 means that water demand increases for the 
later part of the week. However, this pattern may be contributed by the weekend effects as can be seen from the larger correlation of the binary weekend flag.

There is a close relationship between maximum temperature and water demand. To gain a sense of the type of relationship between daily demand and temperature, trend lines were fitted between the two variables (Figure 29). The fitted functions are linear (orange), exponential (green) and polynomial (red). As indicated by the $\mathrm{R}^{2}$, the polynomial function has the largest regression coefficient among the fitted functions, which suggests that there is a non-linear relationship between the daily water demand and the maximum temperature.

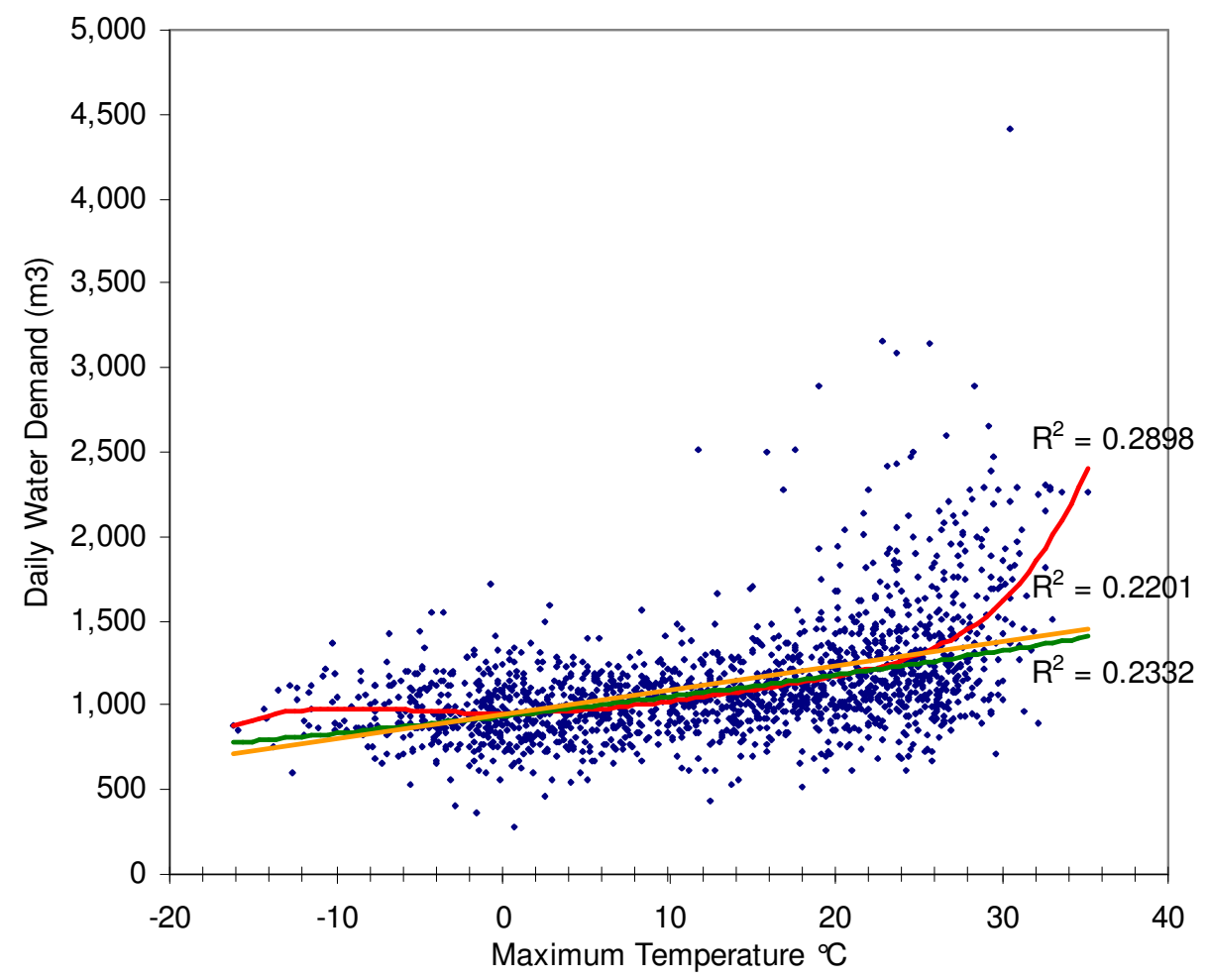

Figure 29. Maximum Temperature versus Water Demand 
Akuoko-Asibey et al. (1993) found that if the mean weekly temperatures exceeded $10^{\circ} \mathrm{C}$, the municipal water consumption would dramatically increase. It is clear, from Figure 29, a threshold temperature exists in the data. When the maximum temperature gets above around $22^{\circ} \mathrm{C}$, the data points become more dispersed. To determine the critical temperature, a simple correlation analysis was performed. Correlations between the per capita demand and the maximum temperature at $22 \pm 1{ }^{\circ} \mathrm{C}$ are calculated. The correlation coefficients confirm the hypothesized critical temperature of $22^{\circ} \mathrm{C}$ (Table 14).

Table 14. Correlation Coefficients between Maximum Temperature and Per Capita Water Demand

\begin{tabular}{|cc|}
\hline Maximum Temperature & $\begin{array}{c}\text { Correlation Coefficients between Maximum } \\
\text { Temperature and Per Capita Inflated Water }\end{array}$ \\
\hline $21^{\circ} \mathrm{C}$ & 0.456 \\
$22^{\circ} \mathrm{C}$ & 0.462 \\
$23^{\circ} \mathrm{C}$ & 0.456 \\
\hline
\end{tabular}

By using the $22^{\circ} \mathrm{C}$ cutoff point, the data set is delineated into two data sets. One for warm weather with maximum temperature at or above $22^{\circ} \mathrm{C}$ and another one for cool weather. The first set consists of 510 days of daily water demand, temperature, rainfall, and data related variables derived from the warm weather 2000, 2002, 2003, 2004, and 2005 data set. The latter set consists of 1347 days of data. 


\subsection{Simulation Scenarios}

Water demand under a shifting climate and an uncertain population growth can be highly variable. An increase of system capacity or a decrease of demand, or both, can decrease the system failure rate. Twenty-six scenarios generated from different combinations of demand management programs, system expansions levels and four Global Climate Model (GCM) scenarios were set up to illustrate the impacts of these three factors on the Reliability, Resiliency, and Vulnerability (RRV) indices. Assumptions were made on the WEMPs implementation and the level of system expansion. It is assumed that there are two levels of WEMPs implementation: normal and intensive, representing 5\% and 15\% of additional water savings as according to the 2007 Region of Waterloo's estimation. It is also assumed that there are two levels of system expansion. They are 10\% and 20\% of the proposed expansion capacity, as the preliminary analysis indicates that an expansion of $2500 \mathrm{~m}^{3}$ is not required for short-term needs. The costs of the WEMPs programs and the system expansion were estimated base upon the total implementation cost of the programs. The scenarios are defined in Table 15. 
Table 15. Scenario 1 to 26 Settings

\begin{tabular}{|c|l|}
\hline Scenario number & Description \\
\hline 1 & Base Case \\
2 & Base Case with no WEMPs implemented \\
3 & Base Case with $5 \%$ additional WEMPs savings \\
4 & Base Case with 15\% additional WEMPs savings \\
5 & Base Case with 10\% additional system capacity \\
\hline 7 & Base Case with 20\% additional system capacity \\
\hline 8 & Had CM3 A23 with base case settings \\
9 & Had CM3 A23 with $5 \%$ additional WEMPs savings \\
10 & Had CM3 A23 with $15 \%$ additional WEMPs savings \\
11 & Had CM3 A23 with $20 \%$ additional system capacity \\
\hline 12 & CSIROMk2b B11 with base case settings \\
13 & CSIROMk2b B11 with 5\% additional WEMPs savings \\
15 & CSIROMk2b B11 with 15\% additional WEMPs savings \\
16 & CSIROMk2b B11 with 10\% additional system capacity \\
\hline 17 & CSIROMk2b B11 with 20\% additional system capacity \\
\hline 18 & CCSRNIES A21 with base case settings \\
20 & CCSRNIES A21 with $5 \%$ additional WEMPs savings \\
21 & CCSRNIES A21 with 15\% additional WEMPs savings \\
\hline 22 & CCSRNIES A21 with 10\% additional system capacity \\
23 & CCSRNIES A21 with 20\% additional system capacity \\
24 & CGCM2 A22 with base case settings \\
25 & CGCM2 A22 with 5\% additional WEMPs savings \\
26 & CGCM2 A22 with 15\% additional WEMPs savings \\
\hline & CGCM2 A22 with 10\% additional system capacity \\
\hline
\end{tabular}

The first scenario describes the existing condition of the water supply system, which includes the estimated water savings incurred from the Toilet Replace Program and Outdoor Water Use By-Law. The toilet replace program involves the replacement of older 18-liter toilet with six-liter ultra-low flush toilet. The outdoor water use by-law involves water use restrictions on non-essential residential water uses, such as lawn and garden watering, and car washing. Scenario 2 is a separate scenario in the set that describes the system condition if no WEMPs were implemented. The next four scenarios (3-6) describe the base case settings with two levels of WEMPs implemented and two system capacity expansions. Scenarios 7 to 
10,12 to 16,17 to 21 , and 22 to 25 are parallel to scenario 1 and 3 to 6 with each set of five consisting of different climatic realizations projected by the four selected GCM scenarios (see section 3.3.3). These scenarios were set up to illustrate the possible impact of climate change on the system performance.

\subsubsection{Sensitivity Analysis Scenarios}

Initially the simulation model was set up to determine the effects of climate change on the case study system using the GCM projections that project deviations of temperature and precipitation magnitudes from the historical norms. However, a recent study led by the Climate Research Division, Environment Canada found that there are changing precipitation patterns. The same study projects that over most regions, the precipitation pattern is likely to be intensified with "less frequent but more intense events, and precipitation extremes are very likely to increase" (Zhang et al., 2007). Therefore, in this study, as a separate but related goal, the effect of a change in precipitation magnitude by means of changing the precipitation occurrence frequency was investigated. For this purpose, a subset of scenarios are selected from the original set of 26 . The configurations of this set of scenarios are defined in Table 16. 
Table 16. Sensitivity Analysis Scenario to Investigate the Effect of a Change of Frequency of Occurrence of Precipitation

\begin{tabular}{|c|l|}
\hline $\begin{array}{c}\text { Scenario } \\
\text { no. }\end{array}$ & \multicolumn{1}{c|}{ Description } \\
\hline $7 a$ & Had CM3 A23 with base case settings \\
$8 \mathrm{a}$ & Had CM3 A23 with $5 \%$ additional WEMPs savings \\
$9 \mathrm{a}$ & Had CM3 A23 with $15 \%$ additional WEMPs savings \\
$10 \mathrm{a}$ & Had CM3 A23 with $10 \%$ additional system capacity \\
$11 \mathrm{a}$ & Had CM3 A23 with $20 \%$ additional system capacity \\
\hline $12 \mathrm{a}$ & CSIROMk2b B11 with base case settings \\
$13 \mathrm{a}$ & CSIROMk2b B11 with $5 \%$ additional WEMPs savings \\
$14 \mathrm{a}$ & CSIROMk2b B11 with $15 \%$ additional WEMPs savings \\
$15 \mathrm{a}$ & CSIROMk2b B11 with $10 \%$ additional system capacity \\
$16 \mathrm{a}$ & CSIROMk2b B11 with $20 \%$ additional system capacity \\
\hline
\end{tabular}

The impact of a higher population growth on the performance of the water supply system is of interest. Therefore, a second set of sensitivity analysis scenarios is set up (Table 17). A third set of scenarios is established to estimate the possible combined effects of climate change and a more rapid growth of population on the supply system (Table 18).

Table 17. Sensitivity Analysis Scenario to Investigate the Effect of Higher Population Growth

\begin{tabular}{|c|l|}
\hline $\begin{array}{c}\text { Scenario } \\
\text { no. }\end{array}$ & \multicolumn{1}{c|}{ Description } \\
\hline $1 \mathrm{~b}$ & Base Case with higher population projection \\
$3 \mathrm{~b}$ & Base Case with $5 \%$ additional WEMPs savings with higher population projection \\
$4 \mathrm{~b}$ & Base Case with $15 \%$ additional WEMPs savings with higher population projection \\
$5 \mathrm{~b}$ & Base Case with 10\% additional system capacity with higher population projection \\
$6 \mathrm{~b}$ & Base Case with $20 \%$ additional system capacity with higher population projection \\
\hline
\end{tabular}


Table 18. Sensitivity Analysis Scenario to Investigate the Effect of Climate Change and a More Rapid Population Growth

\begin{tabular}{|c|l|}
\hline $\begin{array}{c}\text { Scenario } \\
\text { no. }\end{array}$ & \multicolumn{1}{|c|}{ Description } \\
\hline $7 c$ & Had CM3 A23 with base case settings with higher population projection \\
$8 c$ & Had CM3 A23 with 5\% additional WEMPs savings \\
$9 c$ & Had CM3 A23 with 15\% additional WEMPs savings \\
$10 c$ & Had CM3 A23 with 10\% additional system capacity \\
$11 c$ & Had CM3 A23 with 20\% additional system capacity \\
\hline $12 c$ & CSIROMk2b B11 with base case settings \\
$13 c$ & CSIROMk2b B11 with $5 \%$ additional WEMPs savings \\
$14 c$ & CSIROMk2b B11 with 15\% additional WEMPs savings \\
$15 c$ & CSIROMk2b B11 with 10\% additional system capacity \\
$16 c$ & CSIROMk2b B11 with 20\% additional system capacity \\
\hline
\end{tabular}




\section{Chapter 5 \\ Results and Analysis}

\subsection{Introduction}

The three factors, system capacity, water demands, and GCM projections of climate change are combined to produce an ensemble of predictions on extreme events. In each simulation scenario, the performance indices are calculated and compared against the base case. The objective of evaluating the performance indices of these scenarios is twofold. One is to demonstrate the use of the performance indices, together with the capability in capturing the assumptions and uncertainty of the impacts of climate change and human behaviour to the water supply system. The set of results can also be used as a tool to assess the effectiveness of system expansion and water conservation alternatives under different climatic scenarios to ensure that the water supply system operates satisfactorily and ultimately aid the decision maker in selecting the optimal expenditure scheme.

In conducting the simulations, 100 trials were run for each scenario to assure that a representative sample is drawn while considering the constraints of computation time and computer memory. Note that each of the 100 simulation trials represents one random climatic realization of the future and the corresponding water usage response to that particular climatic condition.

To allow parallel comparison, the stochastic climatic realization of a particular simulation trial is kept the same within the set of scenarios subjected to the influence of a particular GCM. For example, the climatic realization of all trial number ones are the same throughout 
scenario 1 to 6 . Plots illustrating an example of these climatic realizations along with the associated simulated water demand are included in Appendix C.

\subsection{Result Analysis Approach}

In most failure mode or risk analysis studies, the potential failure to a system is first determined and analyzed. A simulation model is then created to mimic the potential failure settings and the Monte Carlo simulation is left to run over a long enough horizon to allow eventual convergence. However, in this study, to account for the stochastic nature of the climate process and to incorporate the GCM time series projection, the simulation is allowed to run for the study time horizon (2006 to 2025) with multiple trials. Because of this nature, there are a few challenges in interpreting the simulation results. The following describes the issues and the approach taken to resolve them.

Too much data

The simulation comprises 26 scenarios with each scenario consisting of 100 trials to distinguish the system performance under a particular climatic scenario. The large quantity of results makes organizing or summarizing all details a challenge. The common approach for such situations is to examine the expected value or the average, such that the general trend can be observed and the overall performance of the system can be measured. However, by solely relying on the use of the average, details may be overlooked and anomalies that may be of interest may be omitted. 


\section{Multi-criteria Evaluation}

Alternatively the best and worst trial of each scenario can be compared to determine the significance a certain climatic scenario poses on the simulated system. However, there is no one criterion that can be used to identify the best or the worst trial in a scenario. For instance, the worst trial can be defined as the trial that has the highest total number of failure days or with the greatest total severity. Furthermore, because of the nature of the system response, the best scenario does not necessarily have the best performance across all performance criteria. To illustrate, consider the following example.

In Figure 30 (top) plotted the reliability and vulnerability of the 100 trials of scenario 1 . The figure indicates that there is only one best trial (in solid circle). This trial has the highest reliability and the lowest vulnerability. However, the figure also indicates that there are two worst trials (in dash circles). The worst trial on the left has a lower reliability but a lower vulnerability as compared to the one on the right. In terms of reliability and resiliency (middle Figure 30), there are also one best trial and two worst trials. However, in the context of resiliency and vulnerability, there are one best and four worst trials (bottom Figure 30).

No one best or worst trial

Under a specific performance criterion, such as the number of failure days, there is usually a best trial and a worst case trial in a scenario. However, as observed in the results, because of the system's responses, in some cases the best or worst case trial is not consistent within the 

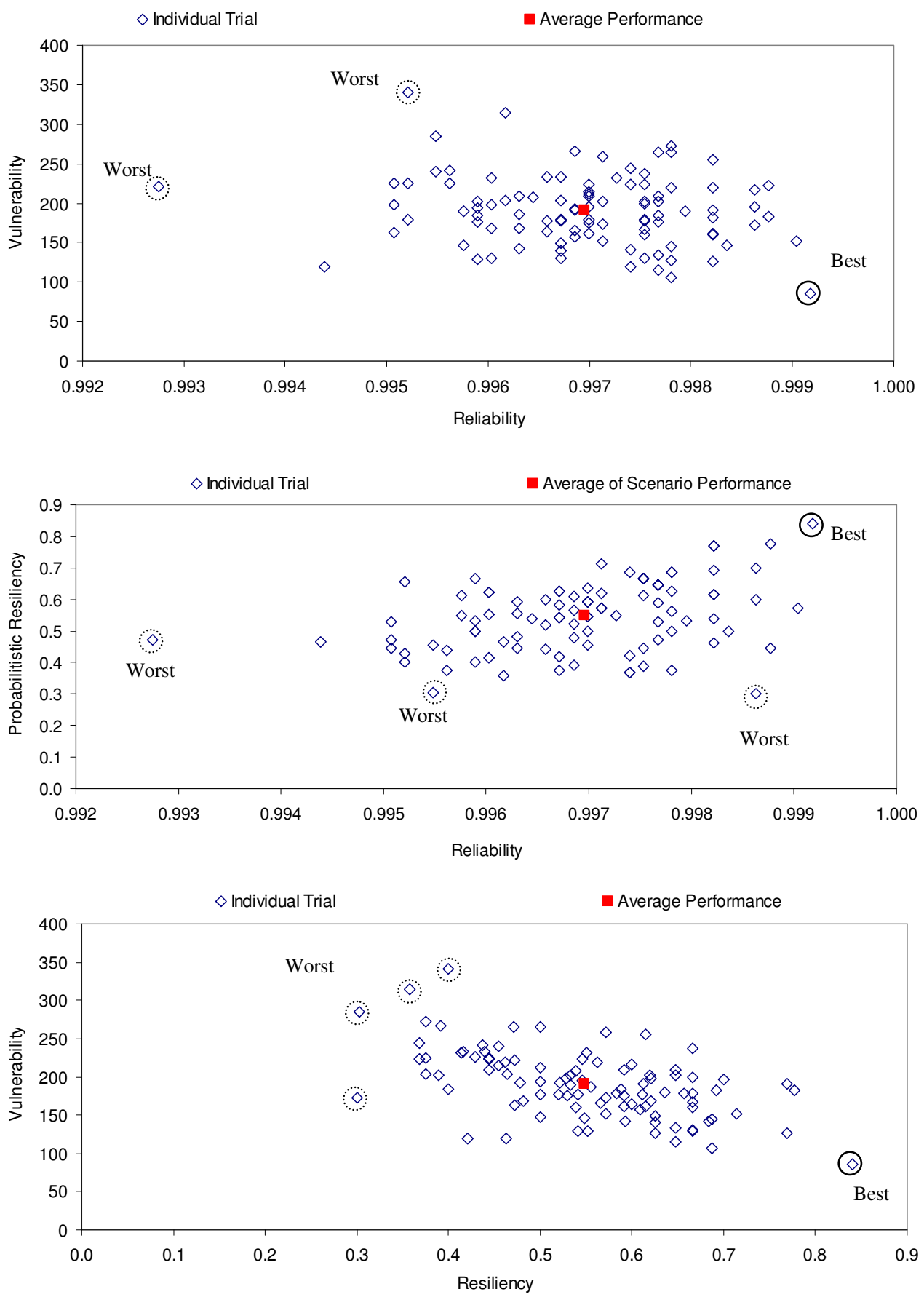

Figure 30. Scenario 1 Results. (Top) Reliability versus Resiliency. (Middle) Reliability versus Vulnerability. (Bottom) Resiliency versus Vulnerability. 
set of scenarios under the same climate projection. For example, in scenario 1, the climate realization of trial 87 has the least number of failure days. However, in scenario 2, the climate realizations of trial 4 and 38 have the least number of failure days. A detailed summary table of the best and worst trials of the scenarios are included in Appendix C.

\section{Limitation of Traditional Probabilistic Resiliency Measures}

In section 2.6.1.2, the probability based resiliency index $\left(\gamma_{1}=\frac{1}{E\left[T_{F}\right]}\right)$ suggested by

Hashimoto et al. is described. There may be a disadvantage in using $\gamma_{1}$, as follows.

Consider a system has initial and improved failure states as shown in Figure 31 and Figure 32 respectively.

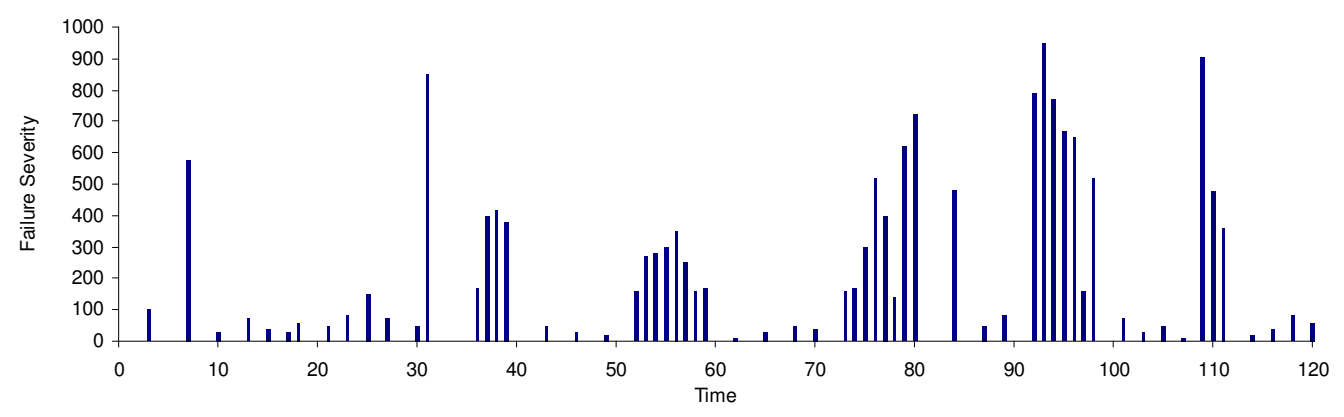

Figure 31. Initial System State of the Example Case.

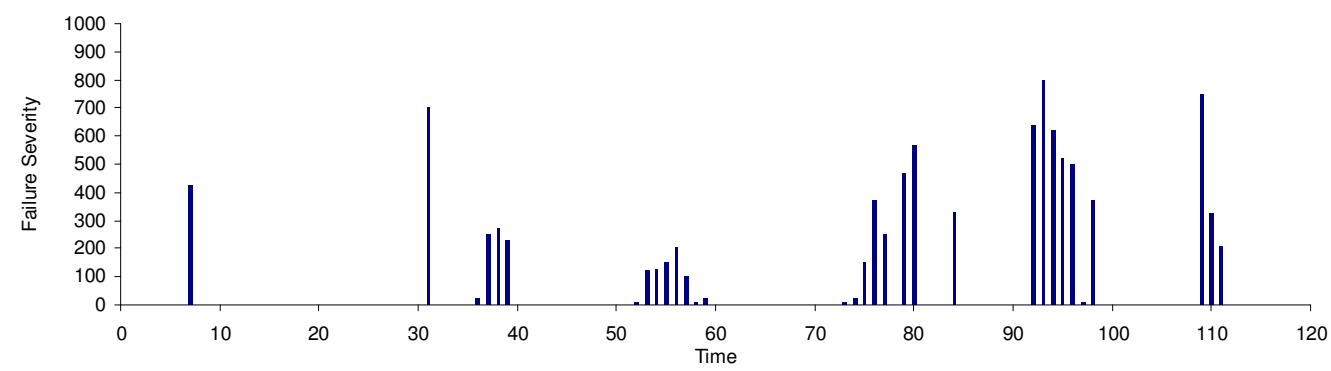

Figure 32. An Illustration of the Increase in Average Duration of Failure $E\left(T_{f}\right)$ with an Improved System. 
Initially, the system has 61 days of failure and entered into failure 34 times. After the system is improved, the number of failure days and the number of times the system enters into failure decreased (Table 19).

Table 19. Resiliency indices of example cases

\begin{tabular}{|c|cc|}
\hline & Initial State & Improved State \\
\hline No. of failure days & 61 & 24 \\
No. of times the system enters into failure & 34 & 10 \\
Average Duration of failure & 1.79 & 2.40 \\
System resiliency, $\gamma_{1}=\frac{1}{E\left[T_{F}\right]}$ & & \\
& 0.56 & 0.42 \\
\hline
\end{tabular}

One would expect system resiliency to improve after an obvious improvement in the system. Instead, the resiliency decreased from 0.56 to 0.42 . This was due to longer average failure duration. Looking closely at the system-state figures, a number of small events are mitigated by the improvement made to the system, leaving the improved system with only severe and prolonged failures. These prolonged failures contribute to a larger average time of failure. Because of the formulation of resiliency, $\gamma_{1}=\frac{1}{E\left[T_{F}\right]}$ (see section 2.6.1.2), it leads to a smaller resiliency. A smaller resiliency usually implies that if a system is in failure in the current time step, it is less likely to recover in the next time step. However, in the above example, the implication of a smaller resiliency conflicts with the fact that the system has indeed improved, which shows that $\gamma_{1}$ should not be used alone.

The simplified resilience index suggested by Moy et al. (1986) was derived for optimization purposes only and is solely based on the maximum number of consecutive periods of deficit. 
Depending on the relative duration of MD to NS, as NS increases, the ratio MD/NS approaches 0 and $\gamma_{2}$ consequently approaches 1 . Therefore, for a very long time of interest $\mathrm{NS}, \gamma_{2}$ may not be a good indicator of system resiliency. For this reason, $\gamma_{2}$ is not used in this thesis.

Because of the limitation of the probabilistic resiliency, to avoid possible misleading results, the resiliency index $\left(\gamma_{3}\right)$ suggested by Burn et al. can be used for evaluation purposes.

However, there is one potential draw back to using $\gamma_{3}$. Recall that $\gamma_{3}=\frac{1}{\left(\frac{M D}{N S} N F\right)}$ where MD is the maximum number of consecutive days of failure, NS is the time of interest, and $\mathrm{NF}$ is the number of times the system enters a failure. When MD approaches zero, $\gamma_{3}$ approaches infinity. Therefore, a system that is performing well would have a very large $\gamma_{3}$, but a poorly performing system would have a small $\gamma_{3}$. Hence $\gamma_{3}$ can be very different in magnitude, which renders a comparison across all scenarios difficult. Therefore, $\gamma_{1}$ and $\gamma_{3}$ are both employed in the results analysis and used together as a two-tier indicator.

Use of Maximum Vulnerability and Average Vulnerability

In this thesis, the average vulnerability of a failure is calculated as follows:

$$
v_{3}=\frac{\sum_{t=1}^{n} s_{t}}{n}
$$


where $s_{t}$ is the severity of a failure at time $\mathrm{t}$ and $n$ is the total duration of the system in failure state. To illustrate the usage difference of $v_{1}$ and $v_{3}$, consider the following example case (Figure 33 and Table 20). The maximum severity of the sojourn and the number of failures are the same in the two systems. System 1 has a vulnerability $\left(v_{1}\right)$ of 325 and an average vulnerability $\left(v_{3}\right)$ of 235 . System 2 has a vulnerability of 325 and an average vulnerability of 343. Note that system 2's vulnerability $\left(v_{1}\right)$, which describes the likely most unsatisfactory outcome in a sojourn, is less than the average vulnerability $\left(v_{3}\right)$. Therefore, to be conservative, the average vulnerability could be used for making decisions in concerning system 2 .

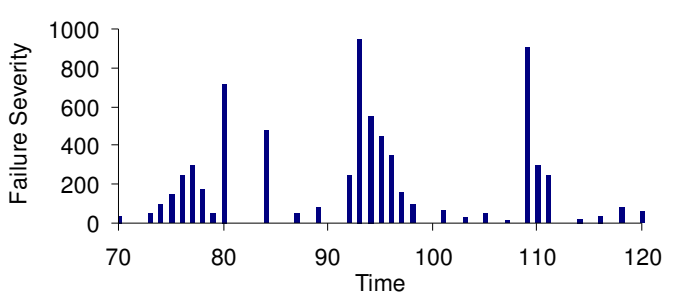

System 1

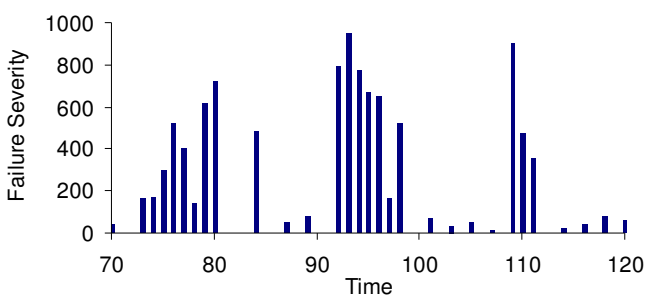

System 2

Figure 33. Illustration of the usage of typical severity of a failure state $s_{j}$

Table 20. Vulnerability Indices of Example Case

\begin{tabular}{|c|c|c|}
\hline & System 1 & System 2 \\
\hline Vulnerability, $v_{1}$ & 325 & 325 \\
Average Vulnerability, $v_{3}$ & 235 & 343 \\
\hline
\end{tabular}


Standardization

The average vulnerability is standardized by the existing system capacity $\left(v_{3}^{\prime}=v_{3} / 2500 \mathrm{~m}^{3}\right)$. The purpose of standardization is to facilitate comparison, in particular because the other two indices, reliability, $\alpha$ and resilience, $\gamma_{1}$, range between 0 and 1 .

To allow comparison of the performance indices across all scenarios, the minimum, average, maximum values and the standard deviation of the performance indices of the 100 trials in a scenario are calculated.

\subsection{Results Overview}

In this section, the results of scenarios 1 to 26 are first reported with discussions immediately following. The findings in the 26 scenarios are then summarized. Next, the results of the sensitivity analysis scenarios are presented. Accompanying are the interpretations of the trends observed. The final section offers general conclusions on the findings of all of the scenarios. Detailed results of individual scenarios are included in Appendix C. Unless indicated otherwise, the discussions on the results are centered on the averages of all of the trials in a scenario.

Scenario 1: Base case

To represent Ayr's existing water supply and demand conditions, in scenario 1, the simulated system capacity and demand management implementations are set to the 2006 levels. The results indicate that under the simulated climatic conditions derived from the seven years of 
historical records, the existing system would have an average reliability of 0.9987 , resiliency of 0.5477 , and a vulnerability of $212 \mathrm{~m}^{3}$ over the simulation horizon (2006 to 2025). See Table 21 for the results of scenario 1 to 6 . As scenarios 1 to 6 represent the base case condition, the indices are used as a benchmark in analysing the results for the rest of the base case scenarios.

Scenario 2: If no WEMPs were implemented

In scenario 2, the discounts of the system demands from the water efficiency management programs (WEMP) are taken out. The results show that despite the relatively small WEMPs savings ( $180 \mathrm{~m}^{3}$ out of $2500 \mathrm{~m}^{3}$ of system capacity), without the implementation of the demand management programs, the system would have twice as many failure days, almost twice as many consecutive failures, 50\% longer failure, and 50\% higher failure severity. As well, the lower bound of the failure statistics, for example number of days failed, would also increase (from 6 to 21). Similar conclusions can be reached for other indices and the associated standard deviations.

Scenario 3: Additional 5\% WEMPs savings

In scenario 3, the WEMPs are hypothesised to have an additional 5\% effect as that indicated in the ROW's 2007 estimates. Comparing the results of scenario 3 to those of scenario 1 shows that the additional water savings would not significantly influence the overall system performance. 
Table 21. Scenario 1 to 6 Failure Statistics and Performance Measures. In brackets are the minimum, average, and maximum values of a measure with associated standard deviation in the row underneath.

\begin{tabular}{|c|c|c|c|c|c|c|c|}
\hline $\begin{array}{c}\text { Scenario } \\
\text { no. }\end{array}$ & $\begin{array}{l}\text { No. of Days } \\
\text { Failed } \\
\text { (days) }\end{array}$ & $\begin{array}{c}\text { No. of Consecutive } \\
\text { Failures }\end{array}$ & $\begin{array}{l}\text { Max. Failure } \\
\text { Duration } \\
\text { (days) }\end{array}$ & $\begin{array}{l}\text { Avg. Failure } \\
\text { Duration } \\
\text { (days) }\end{array}$ & $\begin{array}{c}\text { Max Severity of } \\
\text { Failure } \\
\left(\mathrm{m}^{3}\right)\end{array}$ & $\begin{array}{l}\text { tal Maximum Severity of } \\
\text { Sojourn } \\
\left(\mathrm{m}^{3}\right)\end{array}$ & $\begin{array}{l}\text { Total Severity of Failure } \\
\qquad\left(\mathrm{m}^{3}\right)\end{array}$ \\
\hline \multirow[t]{2}{*}{1} & $(6,22.3,53)$ & $(3,11.9,25)$ & $(2,4.7,10)$ & $(1.2,1.9,3.3)$ & $(210,553,888)$ & $(450,2459,5695)$ & $(515,4310,11925)$ \\
\hline & 7.99 & 3.96 & 1.88 & 0.43 & 127.3 & 863.2 & 2043.6 \\
\hline \multirow[t]{2}{*}{2} & $(21,46.2,84)$ & $(9,22.2,37)$ & $(3,6.7,14)$ & $(1.3,2.1,3.3)$ & $364,706,1043)$ & $(1789,4885,10224)$ & $(2896,9370,22033)$ \\
\hline & 12.55 & 5.20 & 2.51 & 0.36 & 127.9 & 1423.8 & 3380.4 \\
\hline \multirow[t]{2}{*}{3} & $(6,21.6,53)$ & $(3,11.6,25)$ & $(2,4.6,10)$ & $(1.2,1.9,3.3)$ & $(202,545,880)$ & $(412,2371,5504)$ & $(469,4143,11655)$ \\
\hline & 7.89 & 3.90 & 1.87 & 0.44 & 127.2 & 839.2 & 1991.63 \\
\hline \multirow[t]{2}{*}{4} & $(5,20.1,50)$ & $(3,10.8,24)$ & $(2,4.5,10)$ & $(1.3,1.9,3.6)$ & $(187,530,865)$ & $(347,2205,5137)$ & $(388,3824,11135)$ \\
\hline & 7.42 & 3.74 & 1.85 & 0.44 & 127.2 & 797.0 & 1891.2 \\
\hline \multirow[t]{2}{*}{5} & $(0,6.9,23)$ & $(0,4.3,11)$ & $(0,2.8,9)$ & $(0,1.6,3.3)$ & $(0,306,641)$ & $(0,684,2337)$ & $(0,1104,5554)$ \\
\hline & 3.79 & 1.89 & 1.62 & 0.56 & 126.3 & 373.5 & 869.6 \\
\hline \multirow[t]{2}{*}{6} & $(0,1.4,10)$ & $(0,1,4)$ & $(0,1.1,7)$ & $(0,1,7)$ & $(0,80,394)$ & $(0,96,899)$ & $(0,151,2228)$ \\
\hline & 1.7 & 0.9 & 1.2 & 1.0 & 101.5 & 137.4 & 312.5 \\
\hline $\begin{array}{l}\text { Scenario } \\
\text { no. }\end{array}$ & \multicolumn{2}{|l|}{ Reliability, $\alpha$} & $\begin{array}{l}\text { Resiliency, } \gamma_{1} \\
\mathrm{~F}(\mathrm{E}(\mathrm{Tf}))\end{array}$ & $\begin{array}{l}\text { Resiliency, } \gamma_{3} \\
1 /\left(\mathrm{MD} / \mathrm{NS}{ }^{*} \mathrm{NF}\right)\end{array}$ & $\begin{array}{l}\text { Vulnerability, } v_{1} \\
\left(\mathrm{~m}^{3}\right)\end{array}$ & $\begin{array}{c}\text { Average } \\
\text { Vulnerability, } v_{3} \\
\left(\mathrm{~m}^{3}\right)\end{array}$ & $\begin{array}{l}\text { Normalized Average } \\
\text { Vulnerability, } v_{3}{ }^{\prime}\end{array}$ \\
\hline \multirow[t]{2}{*}{1} & $(0.9927,0.9987,0.9992)$ & \multicolumn{2}{|c|}{$(0.3,0.5477,0.8333)$} & $(17.2,103.6,608.8)$ & $(90,212,347)$ & $(86,191,341)$ & $(0.1346,0.2994,0.5349)$ \\
\hline & 0.0011 & \multicolumn{2}{|c|}{0.1105} & 92.7 & 50 & 45 & 0.0706 \\
\hline 2 & $(0.9885,0.9937,0.9971)$ & ( 0.3061 & $4911,0.7419)$ & $(6.2,30.4,116)$ & $(145,220,312)$ & $(121,200,313)$ & $(0.1895,0.3147,0.4921)$ \\
\hline & 0.0017 & & 801 & 18.2 & 37 & 36 & 0.0571 \\
\hline 3 & $(0.9927,0.997,0.9992)$ & $(0.3,0$ & $02,0.8333)$ & $(17.2,109.7,608.8)$ & $(82,211,343)$ & $(78,189,333)$ & $(0.1226,0.2959,0.5228)$ \\
\hline & 0.0011 & & 151 & 96.8 & 51 & 44 & 0.0696 \\
\hline 4 & $(0.9932,0.9972,0.9993)$ & $(0.281$ & $0.554,0.8)$ & $(18.3,123.8,730.5)$ & $(87,210,379)$ & $(78,188,359)$ & $(0.1219,0.2944,0.5639)$ \\
\hline & 0.0010 & & 135 & 112.5 & 53 & 48 & 0.0754 \\
\hline 5 & $(0.9969,0.9991,1)$ & $(0.307$ & $0.6832,1)$ & $(47.7,842.7,7305)$ & $(0,161,405)$ & $(0,149,326)$ & $(0,0.234,0.512)$ \\
\hline & 0.0005 & & 2041 & 1077.2 & 65 & 55 & 0.0868 \\
\hline 6 & $(0.9986,0.9998,1)$ & $(0.14$ & $0.838,1)$ & $(146.1,4719.8,7305$ & $(0,69,388)$ & $(0,62,297)$ & $(0,0.0981,0.466)$ \\
\hline & 0.0002 & & 2601 & 2864.3 & 91 & 77 & 0.1206 \\
\hline
\end{tabular}


Scenario 4: Additional 15\% WEMPs savings

In scenario 4 , the hypothesised increase in water savings is further increased to $15 \%$. It shows that with an additional $15 \%$ savings, the overall performance of the system would improve slightly. The average reliability would increase by 0.002 , resiliency by 0.006 and vulnerability by $2 \mathrm{~m}^{3}$.

Scenario 5: Additional 10\% system capacity

When the system capacity increased by $10 \%\left(250 \mathrm{~m}^{3}\right)$, there is a significant increase in the system's reliability. Of interest, by examining the entries in Table 21, one may wonder why the improved system has a greater upper bound vulnerability than the unimproved system. The total severity and average vulnerability confirm that the system did experience less water shortage. However, in the improved conditions, some small failures would disappear and only the severe failures are left behind. As the traditional vulnerability calculates the expected maximum severity of a failure, therefore, without the small but frequent failures to balance out the large but infrequent failures, a higher vulnerability results.

Scenario 6: Additional 20\% system capacity

When the system capacity expanded by $20 \%$, further improvement is observed. In general, similar system response as in scenario 5 is observed.

Scenario 7-11: HadCM3 A23

In scenarios 7 to 11 , the climatic condition projected by HadCM3 A23 defines climate inputs. HadCM3 A23 projects the highest precipitation reduction among all GCMs. It estimates an 
overall increase of $1.7^{\circ} \mathrm{C}$ in average annual maximum temperature and a decrease of $2.6 \%$ in average annual precipitation. The settings of water efficiency programs, system capacity, and population growth in this set of scenarios are parallel to that in scenario 1, and 3 to 6 .

Comparing the results of the two sets of scenarios (Table 21 and Table 22) indicates that if the system is subjected to the projected climate condition, the average number of failure days would increase by approximately six fold; the number of consecutive failures and the average failure duration would double and the average maximum severity would increase by twothirds. Translating the failure statistics into performance measures, the reliability of the system on average would decrease by 0.019 , the resiliency would also decrease by 0.33 , and the vulnerability would increase by $135.6 \mathrm{~m}^{3}$.

Another noteworthy feature is observed in the results. Although the extreme climate exerts higher water demands on the water supply system, the $20 \%$ system expansion would make the system's reliability go up by 0.012 , resiliency up by 26.3 , and vulnerability go down by $149 \mathrm{~m}^{3}$ to $182 \mathrm{~m}^{3}$, and results in system performance similar to the base case conditions. Apparently, in more adverse climate, the benefits provided by WEMPs and system expansion may become more prominent. To illustrate, in scenario 8 , the increase of $5 \%$ of water savings means a reduction of 2.4 failure days; in scenario 3 , it only means a reduction of 0.7 days. Table 23 illustrates the rest of the pair wise comparisons. 
Table 22. Scenario 7 to 11 Failure Statistics and Performance Measures.

\begin{tabular}{|c|c|c|c|c|c|c|c|c|c|}
\hline \multirow{2}{*}{$\begin{array}{c}\begin{array}{c}\text { Scenario } \\
\text { no. }\end{array} \\
7\end{array}$} & \multirow{2}{*}{$\begin{array}{c}\begin{array}{c}\text { No. of Days Failed } \\
\text { (days) }\end{array} \\
(79,122.1,170)\end{array}$} & \multicolumn{2}{|c|}{$\begin{array}{c}\text { No. of } \\
\text { Consecutive } \\
\text { Failures } \\
\end{array}$} & \multirow{2}{*}{$\begin{array}{c}\begin{array}{c}\text { Max. Failure } \\
\text { Duration } \\
\text { (days) }\end{array} \\
(10,23.8,49)\end{array}$} & \multirow{2}{*}{$\begin{array}{c}\begin{array}{c}\text { Avg. Failure } \\
\text { Duration } \\
\text { (days) }\end{array} \\
(2.3,3.4,5.4)\end{array}$} & $\begin{array}{c}\text { Max Severity of } \\
\text { Failure } \\
\left(\mathrm{m}^{3}\right)\end{array}$ & \multicolumn{2}{|c|}{$\begin{array}{c}\text { Total Maximum Severity of } \\
\text { Sojourn } \\
\left(\mathrm{m}^{3}\right)\end{array}$} & $\begin{array}{l}\text { Total Severity of Failure } \\
\qquad\left(\mathrm{m}^{3}\right)\end{array}$ \\
\hline & & $(20$, & $6.1,54)$ & & & $(782,827,1112)$ & & $312,9980,14637$ ) & $(22435,40419,58651)$ \\
\hline & 17.9 & & .7 & 8.3 & 0.5 & 43.3 & & 1701.6 & 7131.9 \\
\hline \multirow[t]{2}{*}{8} & $(78,119.7,168)$ & $(20$, & $5.4,51)$ & $(9,23.2,49)$ & $(2.3,3.4,5.6)$ & $(775,820,1104)$ & & $162,9772,14796$ ) & $(21834,39496,57529)$ \\
\hline & 17.8 & & .7 & 8.2 & 0.5 & 43.3 & & 1686.4 & 7021.4 \\
\hline \multirow[t]{2}{*}{9} & $(73,114.6,155)$ & ( 18, & $3.8,49)$ & $(8,22.5,49)$ & $(2.4,3.4,5.1)$ & $(759,804,1089)$ & & $785,9357,14708$ ) & $(20674,37706,55311)$ \\
\hline & 17.0 & & 6 & 8.3 & 0.5 & 43.3 & & 1647.9 & 6806.8 \\
\hline \multirow[t]{2}{*}{10} & $(35,64.9,92)$ & ( 12, & $8.9,30)$ & $(6,14.9,28)$ & $(2.1,3.5,5.8)$ & $(535,580,865)$ & & $2731,4779,7133$ ) & $(9763,18518,29728)$ \\
\hline & 12.5 & & 6 & 5.0 & 0.7 & 43.3 & & 1003.4 & 4055.7 \\
\hline \multirow[t]{2}{*}{11} & $(15,33.9,52)$ & $(5$ & $.5,17)$ & $(3,10.8,24)$ & $(1.7,3.4,7)$ & $(288,333,618)$ & & $751,1678,2856$ ) & $(1900,6167,10337)$ \\
\hline & 8.5 & & 8 & 4.3 & 1.0 & 43.3 & & 481.0 & 1782.4 \\
\hline $\begin{array}{c}\text { Scenario } \\
\text { no. }\end{array}$ & \multicolumn{2}{|l|}{ Reliability, $\alpha$} & \multicolumn{2}{|c|}{$\begin{array}{l}\text { Resiliency, } \gamma_{1} \\
\mathrm{~F}(\mathrm{E}(\mathrm{Tf}))\end{array}$} & \multicolumn{3}{|c|}{$\begin{array}{c}\text { Vulnerability, } v_{1} \\
\left(\mathrm{~m}^{3}\right)\end{array}$} & $\begin{array}{c}\text { Average } \\
\text { Vulnerability, } v_{3} \\
\left(\mathrm{~m}^{3}\right)\end{array}$ & $\begin{array}{l}\text { Normalized Average } \\
\text { Vulnerability, } v_{3}{ }^{\prime}\end{array}$ \\
\hline \multirow[t]{2}{*}{7} & \multicolumn{2}{|c|}{$(0.9767,0.9833,0.9892)$} & \multicolumn{2}{|c|}{$(0.1864,0.2982,0.43)$} & \multicolumn{3}{|c|}{$(187,278,378)$} & $(246,331,419)$ & $(0.3856,0.5198,0.6579)$ \\
\hline & \multicolumn{2}{|l|}{0.0024} & \multicolumn{2}{|r|}{0.0442} & 1.3 & \multicolumn{2}{|l|}{34} & 35 & 0.0545 \\
\hline \multirow[t]{2}{*}{8} & \multicolumn{2}{|c|}{$(0.977,0.9836,0.9893)$} & \multicolumn{2}{|c|}{$(0.1795,0.2982,0.4286)$} & $(1,3.1,7.9)$ & \multicolumn{2}{|c|}{$(184,278,383)$} & $(245,330,429)$ & $(0.3851,0.5181,0.6731)$ \\
\hline & \multicolumn{2}{|l|}{0.0024} & \multicolumn{2}{|r|}{0.0451} & 1.4 & \multicolumn{2}{|l|}{35} & 35 & 0.0555 \\
\hline \multirow[t]{2}{*}{9} & $(0.9788,0.9843,0$ & 99 ) & ( 0.1947 & $0.2976,0.4255)$ & $(1,3.4,8.5)$ & $(206,279$, & 57 ) & $(243,329,418)$ & $(0.3819,0.5164,0.6559)$ \\
\hline & 0.0023 & & & 0.0467 & 1.5 & 34 & & 35 & 0.0553 \\
\hline 10 & $(0.9874,0.9911,0.9$ & 952 ) & $(0.1739$ & $0.2963,0.4717$ ) & $(3.1,9.1,26.5)$ & $(178,255$, & 41) & $(210,285,354)$ & $(0.3289,0.4481,0.5558)$ \\
\hline & 0.0017 & & & 0.0555 & 4.8 & 37 & & 32 & 0.0508 \\
\hline 11 & $(0.9929,0.9954,0.9$ & 979 ) & $(0.142$ & $9,0.3216,0.6)$ & $(7.1,29.3,162.3)$ & $(74,162$ & 43 ) & $(118,182,256)$ & $(0.185,0.2863,0.4026)$ \\
\hline & 0.0012 & & & 0.0880 & 25.8 & 34 & & 31 & 0.0481 \\
\hline
\end{tabular}


Table 23. A Comparison of the Average Number of Failure Days between Scenarios 3 to 6 and 8 to 11 in Comparison to the Base Case

\begin{tabular}{|l|ll|}
\hline & $\begin{array}{l}\text { Base Case } \\
\text { Scenarios 3 to 6 }\end{array}$ & $\begin{array}{l}\text { HadCM3 A23 } \\
\text { Scenarios 8 to 11 }\end{array}$ \\
\hline 5\% of water savings & 0.7 & 2.4 \\
15\% of water savings & 2.2 & 7.5 \\
10\% system capacity & 15.4 & 57.2 \\
20\% system capacity & 20.9 & 88.2 \\
\hline
\end{tabular}

This finding can further be interpreted as under different climatic conditions, the effects of system improvements may vary. Further discussions on this variation are provided at the end of this section.

\section{Scenario 12-16: CSIROMK2b B11}

For scenario 12 to 16 , the climatic projecting is based upon the CSIROMK2b B11. This model projects the highest temperature change in the four GCMs integrated in this study. It approximates an overall increase of $2.6^{\circ} \mathrm{C}$ in average annual maximum temperature and an increase of $4.2 \%$ in average annual precipitation.

To minimize the comparison effort, averages of measures are taken across scenario 1,3 to 6 and scenario 12 to 16. By comparing the averages in Table 21 and Table 24, as compared to the base case scenarios, in scenario 12 to 16 , the number of failure days increases almost ten times (from 14.5 to 138.6 days); the maximum failure duration increases five fold (from 3.54 to 18.64 days); the maximum severity of failure increases $81 \%$ (from 403 to $730 \mathrm{~m}^{3}$ ). In terms of performance indices, the reliability of the system would decrease from 0.998 to 0.961 , resiliency $\gamma_{1}$ would 
Table 24. Scenario 12 to 16 Failure Statistics and Performance Measures.

\begin{tabular}{|c|c|c|c|c|c|c|c|c|c|}
\hline $\begin{array}{c}\text { Scenario } \\
\text { no. }\end{array}$ & $\begin{array}{c}\text { No. of Days Failed } \\
\text { (days) }\end{array}$ & $\begin{array}{r}1 \\
\text { Con } \\
\mathrm{F} \\
\end{array}$ & $\begin{array}{l}\text { lo. of } \\
\text { secutive } \\
\text { ilures }\end{array}$ & $\begin{array}{l}\text { Max. Failure } \\
\text { Duration } \\
\text { (days) }\end{array}$ & $\begin{array}{l}\text { Avg. Failure } \\
\text { Duration } \\
\text { (days) }\end{array}$ & $\begin{array}{c}\text { Max Severity of } \\
\text { Failure } \\
\left(\mathrm{m}^{3}\right)\end{array}$ & \multicolumn{2}{|c|}{$\begin{array}{c}\text { Total Maximum Severity of } \\
\text { Sojourn } \\
\left(\mathrm{m}^{3}\right)\end{array}$} & $\begin{array}{l}\text { Total Severity of Failure } \\
\qquad\left(\mathrm{m}^{3}\right)\end{array}$ \\
\hline \multirow[t]{2}{*}{12} & $(135,190.1,244)$ & ( 36 , & $53.8,68)$ & $(11,23.4,53)$ & $(2.7,3.6,5.2)$ & $(613,884,951)$ & $(10$ & $21,15583,20140)$ & $(33725,59186,81593)$ \\
\hline & 20 & & 6 & 8 & 0 & 37 & & 2077 & 9959 \\
\hline \multirow[t]{2}{*}{13} & $(134,186.8,240)$ & ( 36, & $53.1,67$ ) & $(11,22.9,53)$ & $(2.6,3.6,5.2)$ & $(606,876,943)$ & $(10$ & $85,15276,19728)$ & $(32582,57752,79965)$ \\
\hline & 20 & & 6 & 8 & 0 & 37 & & 2079 & 9829 \\
\hline \multirow[t]{2}{*}{14} & $(129,179.8,231)$ & ( 34 , & $51.3,66)$ & $(11,22,52)$ & $(2.6,3.5,5.4)$ & $(590,861,927)$ & $(10$ & $22,14658,18907$ ) & $(30408,54961,76773)$ \\
\hline & 20 & & 6 & 8 & 0 & 37 & & 1988 & 9570 \\
\hline \multirow[t]{2}{*}{15} & $(59,106.4,146)$ & ( 23, & $31.9,43)$ & $(8,15.8,38)$ & $(2.2,3.4,5)$ & $(366,637,704)$ & & $677,6876,9723$ ) & $(8248,23981,39395)$ \\
\hline & 18 & & 5 & 6 & 1 & 37 & & 1232 & 5914 \\
\hline \multirow[t]{2}{*}{16} & $(3,30.1,54)$ & (3, & $9.9,17)$ & $(1,9.3,19)$ & $(1,3,6)$ & $(119,390,457)$ & & $87,2074,3899$ ) & $(187,7007,15747)$ \\
\hline & 10 & & 3 & 4 & 1 & 37 & & 633 & 2906 \\
\hline $\begin{array}{l}\text { Scenario } \\
\text { no. }\end{array}$ & \multicolumn{2}{|l|}{ Reliability, $\alpha$} & \multicolumn{2}{|c|}{$\begin{array}{l}\text { Resiliency, } \gamma_{1} \\
F(E(T f))\end{array}$} & $\begin{array}{l}\text { Resiliency, } \gamma_{3} \\
1 /\left(\mathrm{MD} / \mathrm{NS}{ }^{\star} \mathrm{NF}\right)\end{array}$ & \multicolumn{2}{|c|}{$\begin{array}{l}\text { Vulnerability, } v_{1} \\
\qquad\left(\mathrm{~m}^{3}\right)\end{array}$} & $\begin{array}{c}\text { Average } \\
\text { Vulnerability, } v_{3} \\
\left(\mathrm{~m}^{3}\right)\end{array}$ & $\begin{array}{l}\text { Normalized Average } \\
\text { Vulnerability, } v_{3}{ }^{\prime}\end{array}$ \\
\hline \multirow[t]{2}{*}{12} & \multicolumn{2}{|c|}{$(0.9666,0.974,0.9815)$} & \multicolumn{2}{|c|}{$(0.1915,0.2852,0.3654)$} & $(0.6,1.9,4.1)$ & \multicolumn{2}{|c|}{$(230,290,366)$} & $(220,310,380)$ & $(0.346,0.4869,0.5958)$ \\
\hline & \multicolumn{2}{|l|}{0.0028} & \multicolumn{2}{|r|}{0.0354} & 0.7 & \multicolumn{2}{|l|}{28} & 31 & 0.0494 \\
\hline \multirow[t]{2}{*}{13} & \multicolumn{2}{|c|}{$(0.9671,0.9744,0.9817)$} & \multicolumn{2}{|c|}{$(0.1915,0.2861,0.3787)$} & $(0.6,1.9,4.1)$ & \multicolumn{2}{|c|}{$(224,289,365)$} & $(220,308,377)$ & $(0.3456,0.4835,0.5921)$ \\
\hline & \multicolumn{2}{|l|}{0.0028} & \multicolumn{2}{|r|}{0.0364} & 0.7 & \multicolumn{2}{|l|}{29} & 31 & 0.0490 \\
\hline \multirow[t]{2}{*}{14} & \multicolumn{2}{|c|}{$(0.9684,0.9754,0.9823)$} & \multicolumn{2}{|c|}{$(0.1848,0.2875,0.3836)$} & $(0.7,2.1,4.3)$ & \multicolumn{2}{|c|}{$(215,287,359)$} & $(219,304,371)$ & $(0.3434,0.4779,0.5822)$ \\
\hline & \multicolumn{2}{|l|}{0.0028} & \multicolumn{2}{|r|}{0.0379} & 0.8 & \multicolumn{2}{|l|}{29} & 31 & 0.0485 \\
\hline \multirow[t]{2}{*}{15} & \multicolumn{2}{|c|}{$(0.98,0.9854,0.9919)$} & \multicolumn{2}{|c|}{$(0.1985,0.3046,0.4576)$} & $(1.4,5.1,15.5)$ & $(138,216$ & 303 ) & $(116,223,293)$ & $(0.1824,0.3508,0.4606)$ \\
\hline & 0.0024 & & & 0.0518 & 2.3 & 27 & & 32 & 0.0508 \\
\hline 16 & $(0.9926,0.9959,0.99$ & 996 ) & $(0.166$ & $57,0.3566,1)$ & $(8.5,66.9,2435)$ & $(62,211$, & 45 ) & $(62,227,306)$ & $(0.0981,0.357,0.4809)$ \\
\hline & 0.0014 & & & 0.1164 & 244.7 & 45 & & 41 & 0.0650 \\
\hline
\end{tabular}


decrease from 0.63 to 0.30 , and the average vulnerability would increase from 155.8 to $274 \mathrm{~m}^{3}$. This result reflects that the system performance as a whole, when subjected to the CSIROMK2b B11 climate projection, would result in more frequent failures that are more severe and would last longer. One would expect that the increase in precipitation would achieve some outdoor water savings and therefore counteract some of the impacts caused by an increase of temperature. However, as previously described in section 3.3.7, precipitation magnitude by itself does not have substantial impacts on water demands. Therefore, the increase of precipitation does not have substantial effect in relieving water strain due to heat stress.

\section{Scenario 17-21: CCSRNIES A21}

The future climate scenario CCSRNIES A21 projects a milder climate change as compared to CSIROMk2b B11 in both changes in temperature and precipitation. It projects a $1.7^{\circ} \mathrm{C}$ increase in annual average temperature and $1.8 \%$ decrease in average precipitation.

As compared to the base case scenarios (Table 21 and Table 25), on average in scenario 17 to 21, the number of failure days would increase almost five times (from 14.46 to 75.32 days), the maximum failure duration would increase by three fold (from 3.54 to 9.62 days), the maximum severity of failure would increase by $31 \%$ (from 403 to $530 \mathrm{~m}^{3}$ ). In representation of performance indices, the reliability of the system on average would decrease from 0.99802 to 0.98968, resiliency would decrease from 0.6346 to 0.423 , and the average vulnerability would increase from 155.8 to $202 \mathrm{~m}^{3}$. The results show that the system performance in CCSRNIES A21 scenario follows a similar trend as in CSIROMk2b B11. 
Table 25. Scenario 17 to 21 Failure Statistics and Performance Measures.

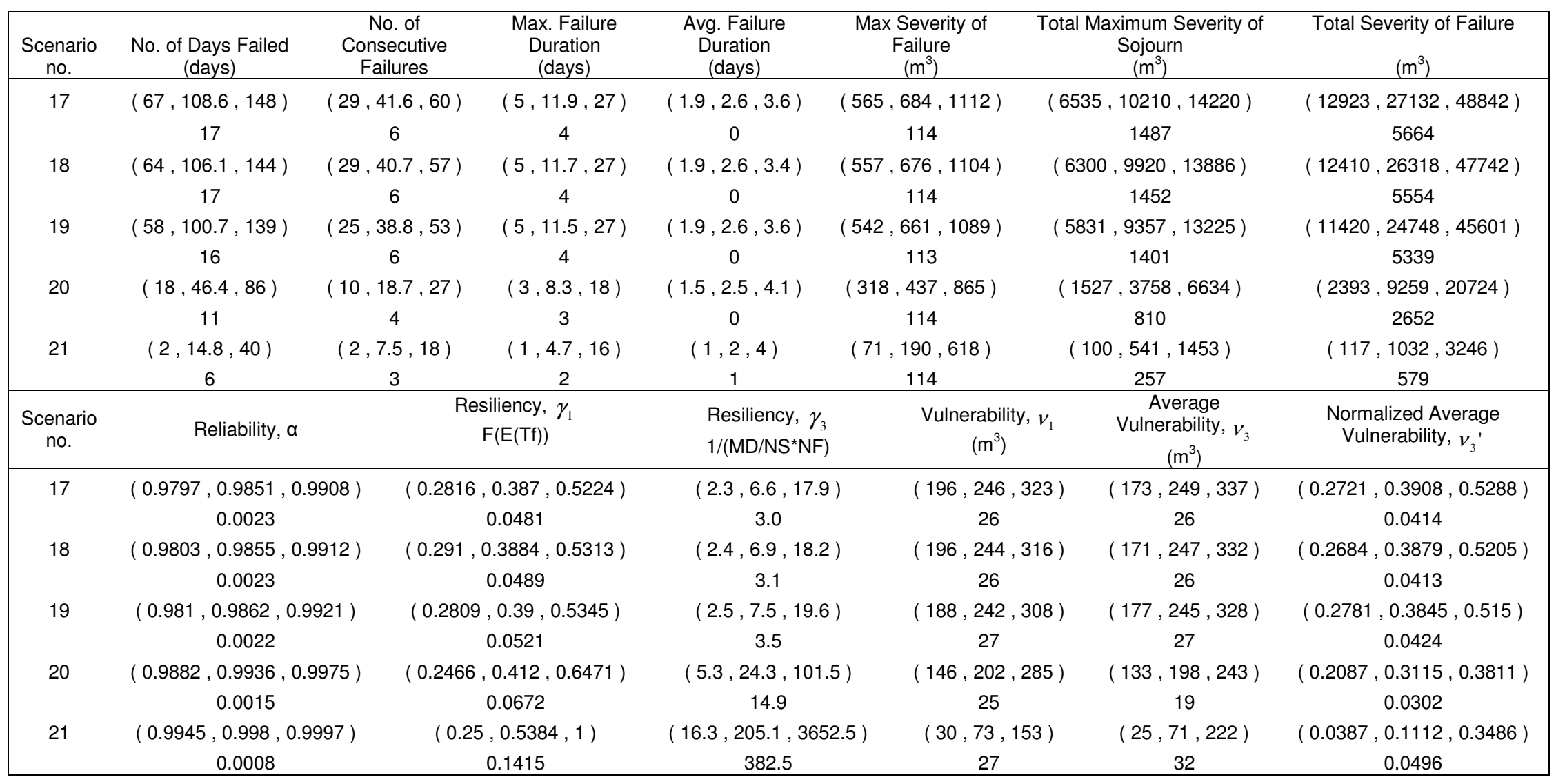


Scenario 22-26: CGCM2 A22

CGCM2 A22 projects a $2.1^{\circ} \mathrm{C}$ increase in temperature and $4.4 \%$ increase in precipitation. As compared to the base case scenario, on average the system in this set of scenarios has five times as many failure days (from 14.46 to 36.96 days), twice as long maximum failure duration (from 3.54 to 5.74 days), $31 \%$ as severe failures (from 403 to $565 \mathrm{~m}^{3}$ ) (see Table 26). In terms of performance indices, the reliability of the system on average would decrease from 0.99802 to 0.98968 , resiliency would decrease from 0.6346 to 0.423 , and the average vulnerability would increase from 155.8 to $202 \mathrm{~m}^{3}$. The results show that the system performance in CGCM2 A22 scenario follows a similar trend as in HadCM3 A23.

Summary of scenario 1 to 26 results

Overall, the simulation results suggest that a rise in temperature and a change in precipitation magnitude will have negative impact on the performance of the system. Shown in Table 27 are averages of system performance taken across a set of five scenarios of a particular climate scenario. Therefore, each entry in the table in fact is the average of 500 trials ( 5 scenarios x 100 trials). For reference, the GCM projected change in average maximum temperature and average precipitation are also included. Ranking the system by the overall performance, the order from best-case scenario to worst-case climate scenario is: Base Case, CGCM2 A22, CCSRNIES A21, HadCM3 A23 and CSIROMK2b B11. 
Table 26. Scenario 22 to 26 Failure Statistics and Performance Measures.

\begin{tabular}{|c|c|c|c|c|c|c|c|c|c|}
\hline \multirow{2}{*}{$\begin{array}{c}\begin{array}{c}\text { Scenario } \\
\text { no. }\end{array} \\
22\end{array}$} & \multirow{2}{*}{$\begin{array}{c}\text { No. of Days Failed } \\
\text { (days }\end{array}$} & \multicolumn{2}{|c|}{$\begin{array}{l}\text { No. of } \\
\text { Consecutive } \\
\text { Failures }\end{array}$} & \multirow{2}{*}{$\begin{array}{c}\begin{array}{c}\text { Max. Failure } \\
\text { Duration } \\
\text { (days) }\end{array} \\
(3,7.4,15) \\
\end{array}$} & \multirow{2}{*}{$\begin{array}{c}\begin{array}{c}\text { Avg. Failure } \\
\text { Duration } \\
\text { (days) }\end{array} \\
(1.5,2.2,3) \\
\end{array}$} & $\begin{array}{c}\text { Max Severity of } \\
\text { Failure } \\
\left(\mathrm{m}^{3}\right)\end{array}$ & \multicolumn{2}{|c|}{$\begin{array}{c}\text { Total Maximum Severity of } \\
\text { Sojourn } \\
\left(\mathrm{m}^{3}\right)\end{array}$} & $\begin{array}{l}\text { Total Severity of Failure } \\
\qquad\left(\mathrm{m}^{3}\right)\end{array}$ \\
\hline & & $(14$, & $26.1,38)$ & & & $(411,719,945)$ & & $458,5964,9274)$ & $(4035,12075,24583)$ \\
\hline & 12 & & 6 & 2 & 0 & 128 & & 1538 & 3778 \\
\hline \multirow[t]{2}{*}{23} & $(27,53.8,86)$ & $(14$, & $25.4,36)$ & $(3,7.1,15)$ & $(1.4,2.1,3)$ & $404,711,937)$ & & $352,5763,9053)$ & $(3822,11658,24031)$ \\
\hline & 12 & & 5 & 2 & 0 & 128 & & 1482 & 3699 \\
\hline \multirow[t]{2}{*}{24} & $(24,50,82)$ & $(11$, & $23.6,34)$ & $(3,6.8,12)$ & $(1.5,2.1,3.1)$ & $388,696,922)$ & & $168,5405,8612)$ & $(3430,10866,22959)$ \\
\hline & 12 & & 5 & 2 & 0 & 128 & & 1415 & 3545 \\
\hline \multirow[t]{2}{*}{25} & $(6,19.9,46)$ & $(3,1$ & $0.4,17)$ & $(2,4.7,10)$ & $(1.2,1.9,3.3)$ & $164,472,698)$ & & $314,1977,3984$ ) & $(480,3764,11792)$ \\
\hline & 7 & & 3 & 2 & 0 & 128 & & 728 & 1756 \\
\hline \multirow[t]{2}{*}{26} & $(0,5.5,20)$ & $(0$, & $3.1,8)$ & $(0,2.7,8)$ & $(0,1.8,8)$ & $(0,226,451)$ & & $(0,398,1335)$ & $(0,742,4710)$ \\
\hline & 3 & & 2 & 2 & 1 & 126 & & 273 & 693 \\
\hline $\begin{array}{c}\text { Scenario } \\
\text { no. }\end{array}$ & \multicolumn{2}{|l|}{ Reliability, $\alpha$} & \multicolumn{2}{|c|}{$\begin{array}{l}\text { Resiliency, } \gamma_{1} \\
F(E(T f))\end{array}$} & $\begin{array}{l}\text { Resiliency, } \gamma_{3} \\
1 /\left(\mathrm{MD} / \mathrm{NS}^{*} \mathrm{NF}\right)\end{array}$ & \multicolumn{2}{|c|}{$\begin{array}{l}\text { Vulnerability, } v_{1} \\
\qquad\left(\mathrm{~m}^{3}\right)\end{array}$} & $\begin{array}{c}\text { Average } \\
\text { Vulnerability, } v_{3} \\
\left(\mathrm{~m}^{3}\right)\end{array}$ & $\begin{array}{l}\text { Normalized Average } \\
\text { Vulnerability, } v_{3}{ }^{\prime}\end{array}$ \\
\hline \multirow[t]{2}{*}{22} & \multicolumn{2}{|l|}{$(0.988,0.9924,0.996)$} & \multicolumn{2}{|c|}{$(0.3333,0.4745,0.6757)$} & $(7.8,21.6,64.1)$ & \multicolumn{2}{|c|}{$(128,229,337)$} & $(114,215,341)$ & $(0.1791,0.3372,0.536)$ \\
\hline & \multicolumn{2}{|l|}{0.0017} & \multicolumn{2}{|r|}{0.0711} & 11.9 & \multicolumn{2}{|l|}{39} & 39 & 0.0606 \\
\hline \multirow[t]{2}{*}{23} & \multicolumn{2}{|c|}{$(0.9882,0.9926,0.9963)$} & \multicolumn{2}{|c|}{$(0.3333,0.4787,0.6944)$} & $(8.3,23.2,67.6)$ & \multicolumn{2}{|c|}{$(129,227,330)$} & $(114,214,334)$ & $(0.1793,0.3363,0.524)$ \\
\hline & \multicolumn{2}{|l|}{0.0017} & \multicolumn{2}{|r|}{0.0713} & 12.8 & 39 & & 38 & 0.0600 \\
\hline 24 & $(0.9888,0.9932,0.996$ & 67 ) & ( 0.3188 & $0.4776,0.6765)$ & $(8.9,26.4,97.4)$ & $(146,230$ & 322 ) & $(127,214,333)$ & $(0.1995,0.3364,0.5224)$ \\
\hline & 0.0016 & & & 0.0734 & 15.1 & 38 & & 38 & 0.0592 \\
\hline 25 & $(0.9937,0.9973,0.999$ & 92 ) & ( 0.3077 & $0.5438,0.8571)$ & $(19.9,114.8,521.8)$ & $(77,189$, & 32 ) & $(69,184,319)$ & $(0.1077,0.2895,0.5003)$ \\
\hline & 0.0010 & & & 0.1152 & 102.8 & 42 & & 44 & 0.0687 \\
\hline 26 & $(0.9973,0.9992,1)$ & & $(0.12$ & $, 0.6397,1)$ & $(60.9,1399.8,7305)$ & $(0,133$, & & $(0,122,365)$ & $(0,0.1916,0.5732)$ \\
\hline & 0.0005 & & & 0.2480 & 2007.0 & 89 & & 77 & 0.1208 \\
\hline
\end{tabular}


Table 27. Scenario 1 to 26 Results

\begin{tabular}{|c|c|c|c|c|c|}
\hline & \multicolumn{5}{|c|}{ Scenario Descriptions } \\
\hline & $\begin{array}{l}\text { Base } \\
\text { Case } \\
1,3 \text { to } 6\end{array}$ & $\begin{array}{l}\text { Had CM3 } \\
\text { A23 } \\
7 \text { to } 11\end{array}$ & $\begin{array}{l}\text { CSIROMk2b } \\
\text { B11 } \\
12 \text { to } 16\end{array}$ & $\begin{array}{l}\text { CCSRNIES } \\
\text { A21 } \\
17 \text { to } 21\end{array}$ & $\begin{array}{l}\text { CGCM2 } \\
\text { A22 } \\
22 \text { to } 26\end{array}$ \\
\hline Number of failure days & 14 & 91 & 139 & 83 & 37 \\
\hline Number of consecutive failures & 7.9 & 26.9 & 40.0 & 31.1 & 17.7 \\
\hline Maximum failure duration & 4 & 19 & 19 & 12 & 6 \\
\hline Maximum severity of failure & 402.8 & 672.8 & 729.5 & 615.2 & 564.7 \\
\hline Reliability & 0.998 & 0.988 & 0.981 & 0.990 & 0.995 \\
\hline Resiliency & 0.635 & 0.302 & 0.304 & 0.005 & 0.004 \\
\hline Vulnerability & 172.5 & 250.4 & 258.5 & 218.3 & 201.6 \\
\hline $\begin{array}{l}\text { GCMs projected change in average } \\
\text { maximum temperature }\left({ }^{\circ} \mathrm{C}\right)\end{array}$ & $0^{\mathrm{A}}$ & 1.7 & 2.6 & 1.7 & 2.1 \\
\hline $\begin{array}{l}\text { GCMs projected change in average } \\
\text { precipitation }(\%)\end{array}$ & $0^{\mathrm{A}}$ & -2.6 & 4.2 & -1.8 & 4.4 \\
\hline
\end{tabular}

A- not applicable. No climate change assumed. Therefore GCM projections are not used.

The simulation model is sensitive to a change in temperature but not particularly sensitive to a change in precipitation magnitude. However, as reflected in the rankings, CSIROMK2b

B11 has the highest projection in temperature increase and is the worst-case scenario.

Instead of CGCM2 A22, which projects the second highest temperature increase, the

HadCM3 A23 which has a precipitation reduction of $2.6 \%$, is the second worst-case scenario.

This shows that a reduction of precipitation may worsen the system performance.

Conversely, an increase of precipitation may lessen the impact from a warmer climate.

However, uncertainties exist in the projections of the temperature and precipitation change

(see Figure 34). The individual effects of an increase of average temperature, a reduction in

precipitation, and the fluctuations in the GCM estimates, on the system is uncertain. If an

estimate of the individual effects these two factors were desired, additional studies would be

needed to identify the influence of these factors. As noted earlier, the efficiency of system 
improvements towards the performance of a system may vary under different climatic conditions.
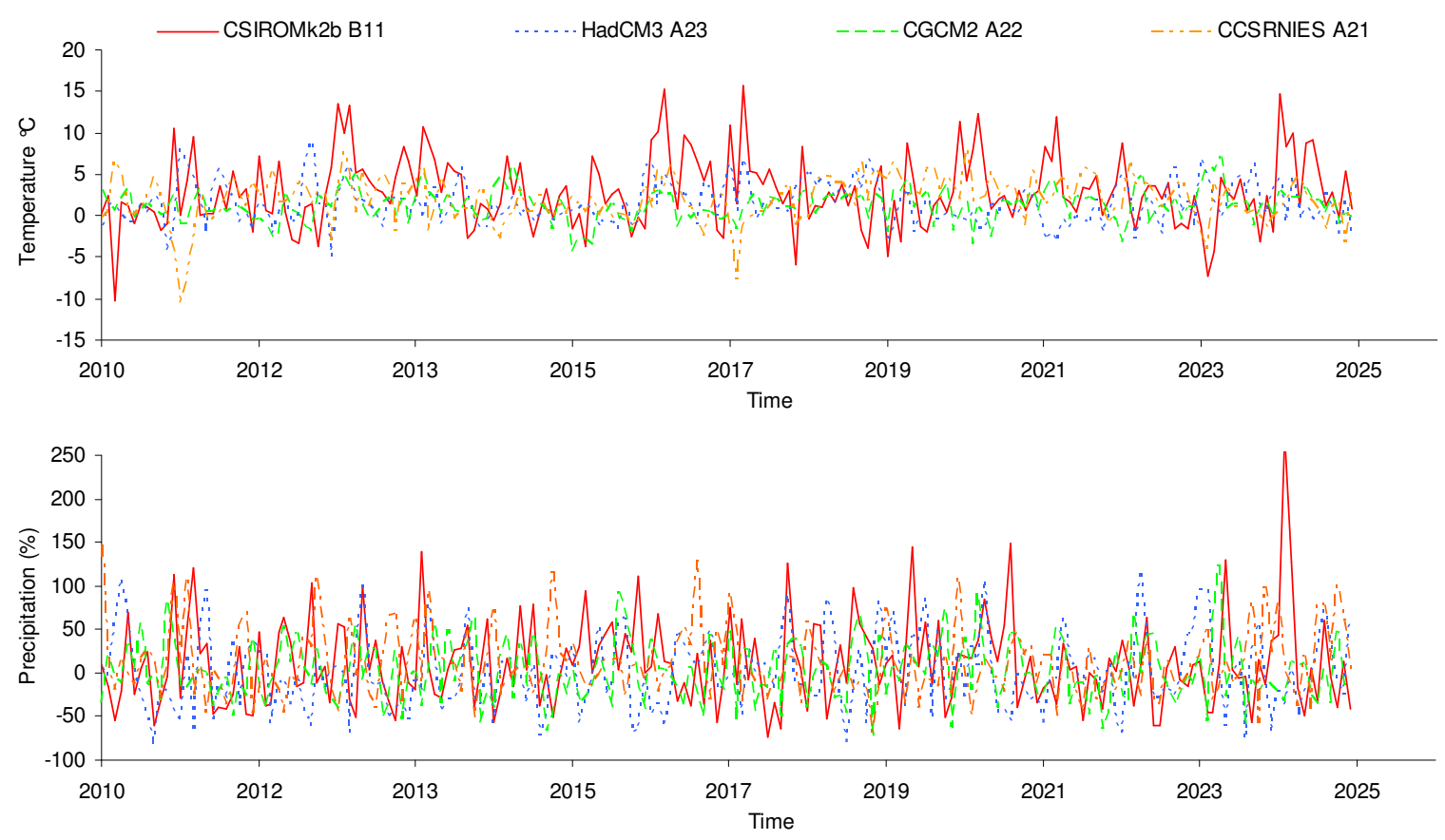

Figure 34. Monthly Temperature and Precipitation Projected Climatic Measures in GCMs.

Figure 35 illustrates the relative changes of system performance as a function of water savings and system expansion under different climatic scenarios. Further, this might explain why a distribution exists in the water savings of conservation actions. A possible explanation of this variation would be: the additional capacity introduced by reduction in water demand or via capacity expansion are being fully utilized when there is a severe failure caused by extreme climate. However, this explanation cannot be proven true until a closer look at the detailed data is made. It is important to point out that the results presented here only give 
several points of the response curve. The relationship in between points can only be defined by more simulations.
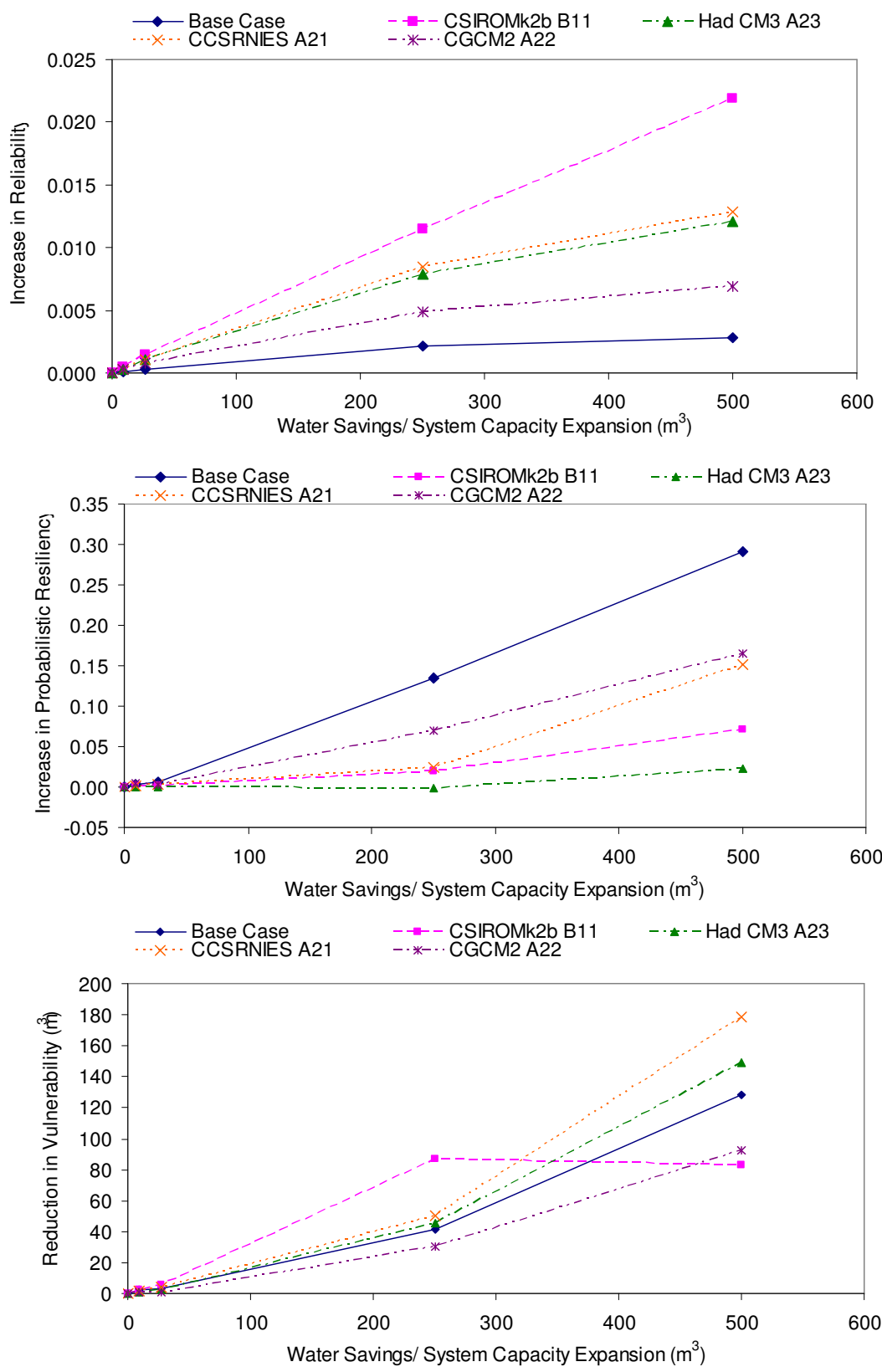

Figure 35. Relative Changes of System Performance as a Function of Water Savings and system expansion under Different Climate Conditions. 


\subsubsection{Sensitivity Analysis}

The overall objective of the sensitivity analysis is to identify the impacts of: (i) a changing precipitation pattern; and (ii) a more rapid population growth on the performance of the water supply system. This section first describes the performance of the water supply system subjected to the GCM scenarios HadCM3 A23 (scenario 7a to 11a) and CSIROMK2b B11 (scenario 12a to 16a) with the change of precipitation value converted into a change of precipitation event occurrence. Discussions of the impacts of a doubling population growth rate in base case condition (scenario 1c to 6c) are then provided. Lastly, the combined effects of a higher population growth and a change of precipitation occurrence simulated in scenario $7 \mathrm{c}$ to $11 \mathrm{c}$ and scenario $12 \mathrm{c}$ to $16 \mathrm{c}$ are presented. The information generated in this sensitivity analysis can be used to provide information for managing the water supply system.

Scenario 7a to 11a versus Scenario 7 to 11 (Had CM3 A23)

In scenarios $7 \mathrm{a}$ to $11 \mathrm{a}$, the change of precipitation value projected by HadCM3 A23 is produced by a varying frequency of occurrence (see section 3.3.2 for methodology). Recall that scenario HadCM3 A23 predicts an overall decrease of $0.83 \%$ of precipitation. Therefore, a small reduction in the number of precipitation events would result. 
Table 28. Scenario 7a to 11a Failure Statistics and Performance Measures.

\begin{tabular}{|c|c|c|c|c|c|c|c|c|}
\hline $\begin{array}{c}\text { Scenario } \\
\text { no. }\end{array}$ & $\begin{array}{l}\text { No. of Days Failed } \\
\text { (days) }\end{array}$ & $\begin{array}{l}\text { No. of } \\
\text { Consecutive } \\
\text { Failures }\end{array}$ & $\begin{array}{l}\text { Max. Failure } \\
\text { Duration } \\
\text { (days) }\end{array}$ & $\begin{array}{l}\text { Avg. Failure } \\
\text { Duration } \\
\text { (days) }\end{array}$ & $\begin{array}{l}\text { Max Severity of } \\
\text { Failure } \\
\left(\mathrm{m}^{3}\right)\end{array}$ & \multicolumn{2}{|c|}{$\begin{array}{c}\text { Total Maximum Severity of } \\
\text { Sojourn } \\
\left(\mathrm{m}^{3}\right)\end{array}$} & $\begin{array}{l}\text { Total Severity of Failure } \\
\qquad\left(\mathrm{m}^{3}\right)\end{array}$ \\
\hline \multirow[t]{2}{*}{$7 a$} & $(73,126.6,172)$ & $27,39.2,52$ ) & $(8,21.4,61)$ & $(2.3,3.3,4.6)$ & $(769,826,942)$ & & $65,10867,16355$ ) & $(22063,39355,51397)$ \\
\hline & 18.5 & 6.1 & 9.1 & 0.5 & 39.3 & & 1822.0 & 6646.4 \\
\hline \multirow[t]{2}{*}{$8 a$} & $(70,123.6,165)$ & $26,38.5,53$ ) & $(8,21,61)$ & $(2.3,3.2,4.6)$ & $(761,819,935)$ & & $59,10664,16000)$ & $(21513,38399,50306)$ \\
\hline & 18.2 & 6.2 & 9.0 & 0.5 & 39.3 & & 1806.9 & 6533.7 \\
\hline \multirow[t]{2}{*}{$9 a$} & $(65,117.9,159)$ & $24,37,53)$ & $(8,20.1,49)$ & $(2.3,3.2,4.8)$ & $(746,803,919)$ & & $86,10208,15312$ ) & $(20467,36554,48189)$ \\
\hline & 18.1 & 6.2 & 8.5 & 0.5 & 39.3 & & 1769.5 & 6311.4 \\
\hline \multirow[t]{2}{*}{$10 a$} & $(35,63.2,89)$ & $13,20.4,33$ ) & $(5,13.5,26)$ & $(2,3.1,4.5)$ & $(522,579,695)$ & & $753,5038,8482$ ) & $(8577,17390,24939)$ \\
\hline & 11.3 & 4.0 & 4.3 & 0.5 & 39.3 & & 1066.0 & 3779.5 \\
\hline \multirow[t]{2}{*}{$11 \mathrm{a}$} & $(12,31.5,48)$ & $5,10.4,18)$ & $(3,10.1,23)$ & $(1.3,3.2,6)$ & $(275,332,448)$ & & ;87 , 1691, 2941) & $(1534,5661,9430)$ \\
\hline & 7.7 & 2.8 & 3.9 & 1.0 & 39.3 & & 504.5 & 1815.8 \\
\hline $\begin{array}{l}\text { Scenario } \\
\text { no. }\end{array}$ & Reliability, $\alpha$ & \multicolumn{2}{|c|}{$\begin{array}{l}\text { Resiliency, } \gamma_{1} \\
F(E(T f))\end{array}$} & \multicolumn{3}{|c|}{$\begin{array}{l}\text { Vulnerability, } v_{1} \\
\qquad\left(\mathrm{~m}^{3}\right)\end{array}$} & $\begin{array}{c}\text { Average } \\
\text { Vulnerability, } v_{3} \\
\left(\mathrm{~m}^{3}\right) \\
\end{array}$ & $\begin{array}{l}\text { Normalized Average } \\
\text { Vulnerability, } v_{3}^{\prime}\end{array}$ \\
\hline \multirow[t]{2}{*}{$7 a$} & $(0.9765,0.9827,0.99)$ & \multicolumn{2}{|c|}{$(0.218,0.3123,0.4273)$} & $(0.7,3.2,8.3)$ & \multicolumn{2}{|c|}{$(206,279,351)$} & $(236,311,380)$ & $(0.3703,0.4887,0.5964)$ \\
\hline & 0.0025 & \multicolumn{2}{|r|}{0.0440} & 1.5 & \multicolumn{2}{|l|}{36} & 32 & 0.0509 \\
\hline \multirow[t]{2}{*}{$8 a$} & $(0.9774,0.9831,0.9904)$ & \multicolumn{2}{|c|}{$(0.2154,0.3142,0.4407)$} & $(0.7,3.4,8.5)$ & \multicolumn{2}{|c|}{$(208,278,354)$} & $(237,311,383)$ & $(0.3716,0.4884,0.601)$ \\
\hline & 0.0025 & \multicolumn{2}{|r|}{0.0439} & 1.5 & \multicolumn{2}{|l|}{34} & 33 & 0.0512 \\
\hline \multirow[t]{2}{*}{$9 a$} & $(0.9782,0.9839,0.9911)$ & \multicolumn{2}{|c|}{$(0.2063,0.3166,0.4312)$} & $(1,3.7,8.9)$ & \multicolumn{2}{|c|}{$(212,277,349)$} & $(232,311,392)$ & $(0.364,0.4877,0.6157)$ \\
\hline & 0.0025 & \multicolumn{2}{|r|}{0.0457} & 1.7 & \multicolumn{2}{|l|}{33} & 33 & 0.0520 \\
\hline $10 a$ & $(0.9878,0.9914,0.9952$ & $(0.223$ & $, 0.3273,0.5)$ & $(3.7,10.3,33.2)$ & $(160,248$, & 16 ) & $(195,275,369)$ & $(0.306,0.4313,0.5794)$ \\
\hline & 0.0015 & & 0.0564 & 5.6 & 30 & & 34 & 0.0531 \\
\hline $11 a$ & $(0.9934,0.9957,0.9984$ & ( 0.1667 & $0.3459,0.75)$ & $(9.3,33.6,202.9)$ & $(83,165$, & 19) & $(91,178,268)$ & $(0.1423,0.2793,0.4214)$ \\
\hline & 0.0011 & & 0.1103 & 31.2 & 39 & & 35 & 0.0550 \\
\hline
\end{tabular}


Overall, subjected to the small reduction in the number of precipitation events, the system performance is slightly degraded. By comparing the results of scenario 7 to 11 and scenario 7a to 11a (Table 28), it is found that there is a small increase in the number of failure days (from 91.04 to 92.56 days) and the number of consecutive failures (from 26.94 to 29.1). Interestingly, there is also a small decrease in maximum failure duration (from 19.04 to 17.22 days) and maximum severity of failure (from 673 to $672 \mathrm{~m}^{3}$ ). In representation of performance measures, the system reliability would decrease from 0.98754 to 0.98736 , resiliency would increase from 0.30238 to 0.32326 , and the average vulnerability would decrease from 291.4 to $277.2 \mathrm{~m}^{3}$.

Scenario 12 to 16 versus scenario 12 a to $16 \mathrm{a}$ (CSIROMk2b B11) Similar to scenarios $7 \mathrm{a}$ to $11 \mathrm{a}$, the change of precipitation value projected by CSIROMK2b B11 is also produced by a varying frequency of occurrence. Recall that scenario CSIROMK2b B11 predicts an overall increase of $4.2 \%$ of precipitation. Therefore, an approximately $4.2 \%$ increase in the number of precipitation events would result.

Comparing the results of scenario 12 to 16 to scenario 12a to 16a (Table 29) shows that the reliability of the system would decrease from 0.99102 to 0.98238 , resiliency would increase from 0.304 to 0.301 , and the average vulnerability would decrease from 258.6 to $255.2 \mathrm{~m}^{3}$. The results indicate that with an increase of precipitation events, the system is likely to have fewer failures while the system's resiliency and vulnerability level would remain more or less the same. 
Table 29. Scenario 12a to 16a Failure Statistics and Performance Measures.

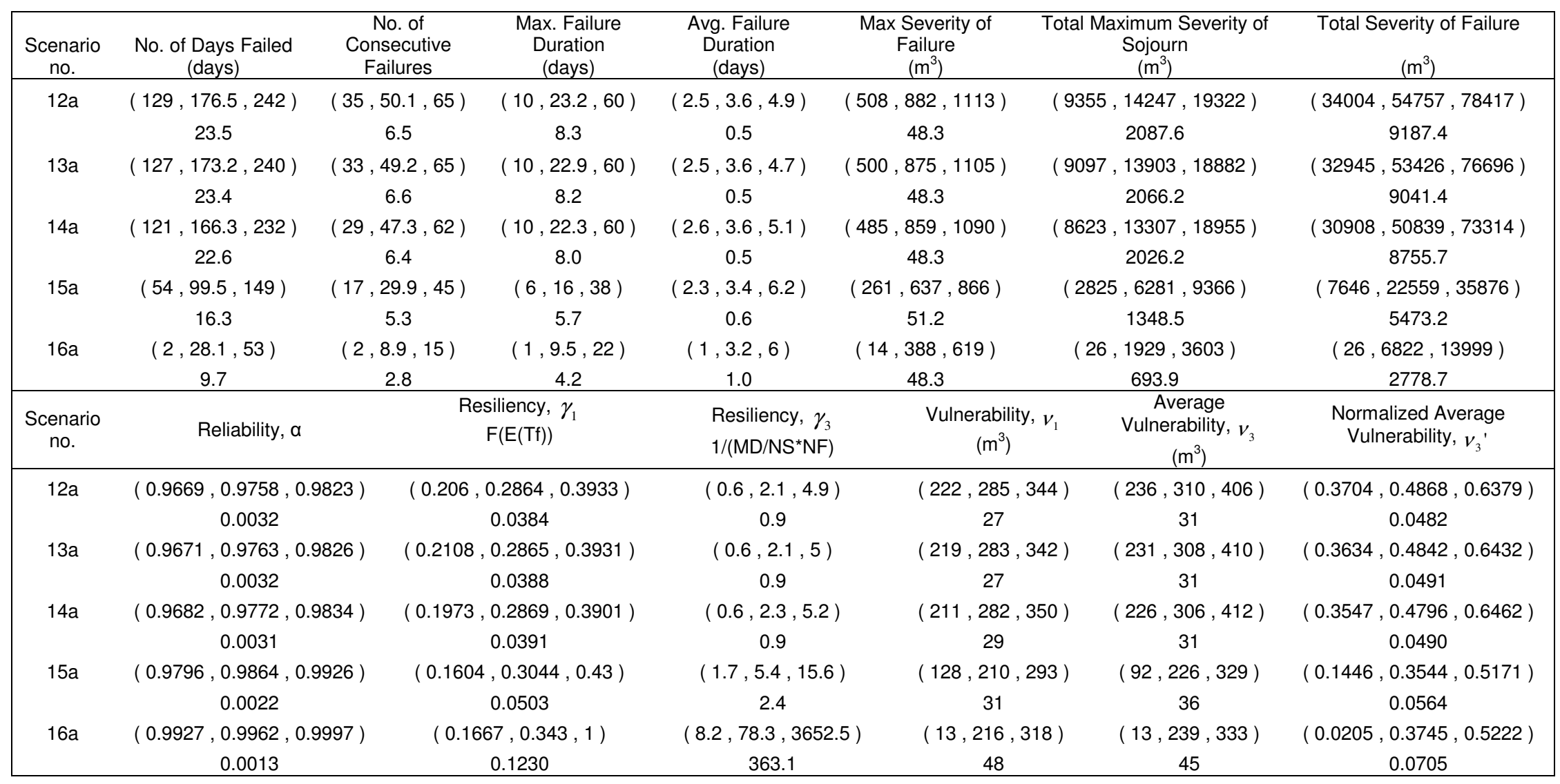


The two sets of scenarios, $7 \mathrm{a}$ to $11 \mathrm{a}$ and $12 \mathrm{a}$ to $16 \mathrm{a}$, present the possible outcomes of a change of precipitation value through a change of event frequency. The average system performance of scenario 7 to 11,7 a to $11 \mathrm{a}, 12$ to 16 , and 12 a to 16 a are summarized in Table 27. The results suggest that a change of event frequency may amplify the effects of an increase or reduction of precipitation, which can be described by "Dry drier, wet wetter".

Table 30. Overall System Performance in Scenario 7 to 11,7 a to $11 \mathrm{a}, 12$ to 16 , and 12 a to $16 \mathrm{a}$

\begin{tabular}{|l|l|l|l|l|}
\hline \multirow{2}{*}{} & \multicolumn{2}{|l|}{ Had CM3 A23 } & \multicolumn{2}{l|}{ CSIROMk2b B11 } \\
\cline { 2 - 5 } & 7 to 11 & $7 \mathrm{a}$ to $11 \mathrm{a}$ & 12 to 16 & $12 \mathrm{a}$ to 16a \\
\hline Number of failure day & 91 & 93 & 139 & 129 \\
Number of consecutive failures & 26.9 & 29.1 & 40.0 & 37.1 \\
Maximum failure duration & 19 & 17 & 19 & 19 \\
Maximum severity of failure & 672.8 & 672.1 & 729.5 & 728.4 \\
Reliability & 0.988 & 0.987 & 0.981 & 0.982 \\
Resiliency & 0.302 & 0.323 & 0.304 & 0.301 \\
Vulnerability & 250.4 & 249.6 & 258.5 & 255.4 \\
\hline
\end{tabular}

Scenario $1 b, 3 b$ to $6 b$ (Base Case with more rapid population growth)

In these scenarios, the population input is set to the 2006 estimates to describe a faster growth rate. The more rapid growth rate is approximately double that in scenario 1 to 6 $(180.82 / 80.4219=2.24)$. By comparing the results of scenario 1 to 6 to scenario $1 \mathrm{~b}$ to $6 \mathrm{~b}$ (Table 31), it can be seen that doubling the population growth will significantly reduce the resiliency of the system. With the higher population growth, Ayr's water supply system may experience seven times more down time (number of failure days from 22.2 to 193). 
Table 31. Scenario $1 \mathrm{~b}$ to $6 \mathrm{~b}$ Failure Statistics and Performance Measures.

\begin{tabular}{|c|c|c|c|c|c|c|c|c|}
\hline $\begin{array}{c}\text { Scenario } \\
\text { no. }\end{array}$ & $\begin{array}{c}\text { No. of Days Failed } \\
\text { (days) }\end{array}$ & $\begin{array}{r}1 \\
\text { Con } \\
\mathrm{Fa}\end{array}$ & $\begin{array}{l}\text { of } \\
\text { ecutive } \\
\text { lures }\end{array}$ & $\begin{array}{c}\text { Max. Failure } \\
\text { Duration } \\
\text { (days) }\end{array}$ & $\begin{array}{c}\text { Avg. Failure } \\
\text { Duration } \\
\text { (days) }\end{array}$ & $\begin{array}{c}\text { Max Severity of } \\
\text { Failure } \\
\left(\mathrm{m}^{3}\right)\end{array}$ & $\begin{array}{c}\text { Total Maximum Severity of } \\
\text { Sojourn } \\
\left(\mathrm{m}^{3}\right)\end{array}$ & $\begin{array}{l}\text { Total Severity of Failure } \\
\qquad\left(\mathrm{m}^{3}\right)\end{array}$ \\
\hline \multirow[t]{2}{*}{$1 b$} & $(139,196,243)$ & $(52$, & $0.7,85)$ & $(7,13.8,29)$ & $(2.2,2.8,3.4)$ & $(1042,1442,1898)$ & $(15654,23534,31235)$ & $(38525,64184,98380)$ \\
\hline & 23.7 & & .0 & 4.0 & 0.3 & 189.0 & 3336.9 & 12105.7 \\
\hline \multirow[t]{2}{*}{$3 b$} & $(137,191.8,238)$ & $(52$, & $9.3,84)$ & $(7,13.7,29)$ & $(2.2,2.8,3.4)$ & $(1034,1434,1889)$ & $(15238,23010,30667)$ & $(37235,62635,96469)$ \\
\hline & 23.7 & & .1 & 3.9 & 0.3 & 189.0 & 3309.3 & 11951.0 \\
\hline \multirow[t]{2}{*}{$4 b$} & $(130,183,224)$ & $(49$ & $6.1,83)$ & $(7,13.6,29)$ & $(2.2,2.8,3.3)$ & $(1018,1418,1873)$ & $(14439,22059,29588)$ & $(34788,59639,92841)$ \\
\hline & 23.1 & & .0 & 3.9 & 0.3 & 188.9 & 3247.1 & 11643.5 \\
\hline \multirow[t]{2}{*}{$5 b$} & $(61,98.2,141)$ & $(22$, & $7.3,50)$ & $(5,10.8,22)$ & $(2.1,2.6,3.5)$ & $(795,1195,1651)$ & $(6862,12038,18464)$ & $(13553,29244,52694)$ \\
\hline & 18.9 & & 8 & 3.5 & 0.3 & 189.0 & 2475.8 & 7791.4 \\
\hline \multirow[t]{2}{*}{$6 b$} & $(21,45.5,88)$ & $(9,1$ & $.7,33)$ & $(3,7.2,18)$ & $(1.5,2.3,4.1)$ & $(548,948,1404)$ & $(2296,5917,11971)$ & $(4067,12197,26499)$ \\
\hline & 12.9 & & 0 & 2.7 & 0.5 & 189.0 & 1747.0 & 4496.5 \\
\hline $\begin{array}{l}\text { Scenario } \\
\text { no. }\end{array}$ & \multicolumn{2}{|l|}{ Reliability, $\alpha$} & \multicolumn{2}{|c|}{$\begin{array}{l}\text { Resiliency, } \gamma_{1} \\
\mathrm{~F}(\mathrm{E}(\mathrm{Tf}))\end{array}$} & $\begin{array}{l}\text { Resiliency, } \gamma_{3} \\
1 /\left(\mathrm{MD} / \mathrm{NS}^{*} \mathrm{NF}\right)\end{array}$ & $\begin{array}{l}\text { Vulnerability, } v_{1} \\
\qquad\left(\mathrm{~m}^{3}\right)\end{array}$ & $\begin{array}{c}\text { Average } \\
\text { Vulnerability, } v_{3} \\
\left(\mathrm{~m}^{3}\right) \\
\end{array}$ & $\begin{array}{l}\text { Normalized Average } \\
\text { Vulnerability, } v_{3}{ }^{\prime}\end{array}$ \\
\hline \multirow[t]{2}{*}{$1 b$} & \multicolumn{2}{|c|}{$(0.9667,0.9732,0.981)$} & \multicolumn{2}{|c|}{$(0.2963,0.3634,0.4573)$} & $(1.2,3,6.2)$ & $(238,333,440)$ & $(236,326,421)$ & $(0.371,0.512,0.6602)$ \\
\hline & 0.0032 & & & 0.0354 & 0.9 & 38 & 38 & 0.0594 \\
\hline \multirow[t]{2}{*}{$3 b$} & \multicolumn{2}{|c|}{$(0.9674,0.9737,0.9812)$} & \multicolumn{2}{|c|}{$(0.2983,0.3637,0.4459)$} & $(1.2,3,6.3)$ & $(243,332,433)$ & $(236,325,424)$ & $(0.37,0.5106,0.6662)$ \\
\hline & \multicolumn{2}{|l|}{0.0032} & & 0.0341 & 0.9 & 37 & 38 & 0.0591 \\
\hline \multirow[t]{2}{*}{$4 b$} & \multicolumn{2}{|c|}{$(0.9693,0.975,0.9822)$} & \multicolumn{2}{|c|}{$(0.2986,0.3635,0.4528)$} & $(1.2,3.2,6.6)$ & $(251,334,448)$ & $(238,324,423)$ & $(0.3741,0.5094,0.6635)$ \\
\hline & \multicolumn{2}{|l|}{0.0032} & & 0.0343 & 1.0 & 37 & 38 & 0.0597 \\
\hline \multirow[t]{2}{*}{$5 b$} & \multicolumn{2}{|c|}{$(0.9807,0.9866,0.9916)$} & \multicolumn{2}{|c|}{$(0.2837,0.3854,0.4878)$} & $(2.7,8,24)$ & $(205,323,462)$ & $(193,296,430)$ & $(0.3025,0.4645,0.6749)$ \\
\hline & \multicolumn{2}{|l|}{0.0026} & \multicolumn{2}{|r|}{0.0467} & 3.4 & 46 & 44 & 0.0686 \\
\hline \multirow[t]{2}{*}{$6 b$} & \multicolumn{2}{|c|}{$(0.988,0.9938,0.9971)$} & \multicolumn{2}{|c|}{$(0.2453,0.4452,0.6667)$} & $(4.6,28.9,116)$ & $(195,302,485)$ & $(178,266,414)$ & $(0.2797,0.4179,0.65)$ \\
\hline & \multicolumn{2}{|l|}{0.0} & & 0.0813 & 17.7 & 56 & 52 & 0.0810 \\
\hline
\end{tabular}


By comparing the averages, relative to the base case scenarios, in scenario 1,3 to 6 , the number of failure days increases almost ten times (from 14.5 to 142.9 days); the maximum failure duration increases three fold (from 3.54 to 11.82 day); the maximum severity of

failure increases $81 \%$ (from 403 to $1287 \mathrm{~m}^{3}$ ). In terms of performance indices, the reliability of the system would decrease from 0.998 to 0.98046 , resiliency would decrease from 0.6346 to 0.38424 , and the average vulnerability would increase from 155.8 to $324.8 \mathrm{~m}^{3}$. Figure 36 illustrates the reduction of the RRVs for the base case scenarios and the base case scenarios with double population growth.

\section{Scenario 7-11 versus 7c to 11c (Had CM3 A23)}

To investigate the possible outcomes from the combined effect of climate change and rapid population growth, scenarios $7 \mathrm{c}$ to $11 \mathrm{c}$ determine the system performance subject to future climate scenario Had CM3 A23 with a changing precipitation occurrence rate and a higher population growth rate.

As compared to scenarios 7 to 11 , all of the failure measures would increase for the $7 \mathrm{c}$ to $11 \mathrm{c}$ settings (Table 22 and Table 32). The number of failure days would increase almost four times from 91.04 to 377.84 days; the number of consecutive failures will increase from 26.94 to 84.68; the maximum failure duration would also increase from 19.04 to 41.1 days; and the maximum severity of failure would increase from 673 to $1670 \mathrm{~m}^{3}$. 

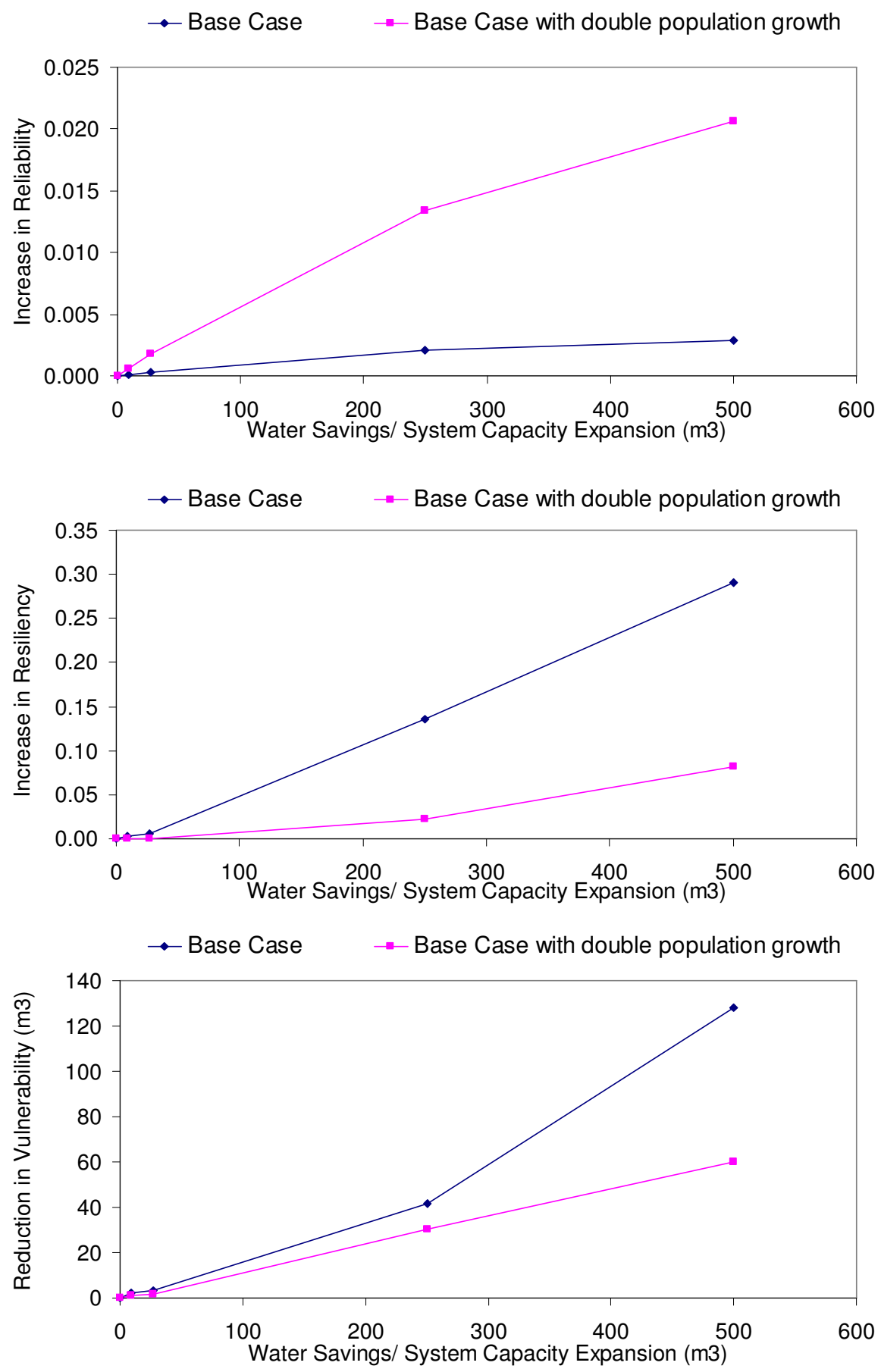

Figure 36. Reductions of Reliability, Resiliency, and Vulnerability in scenario $1 b, 3 b$ to $6 b$. 
Table 32. Scenario 7c to 11c Failure Statistics and Performance Measures.

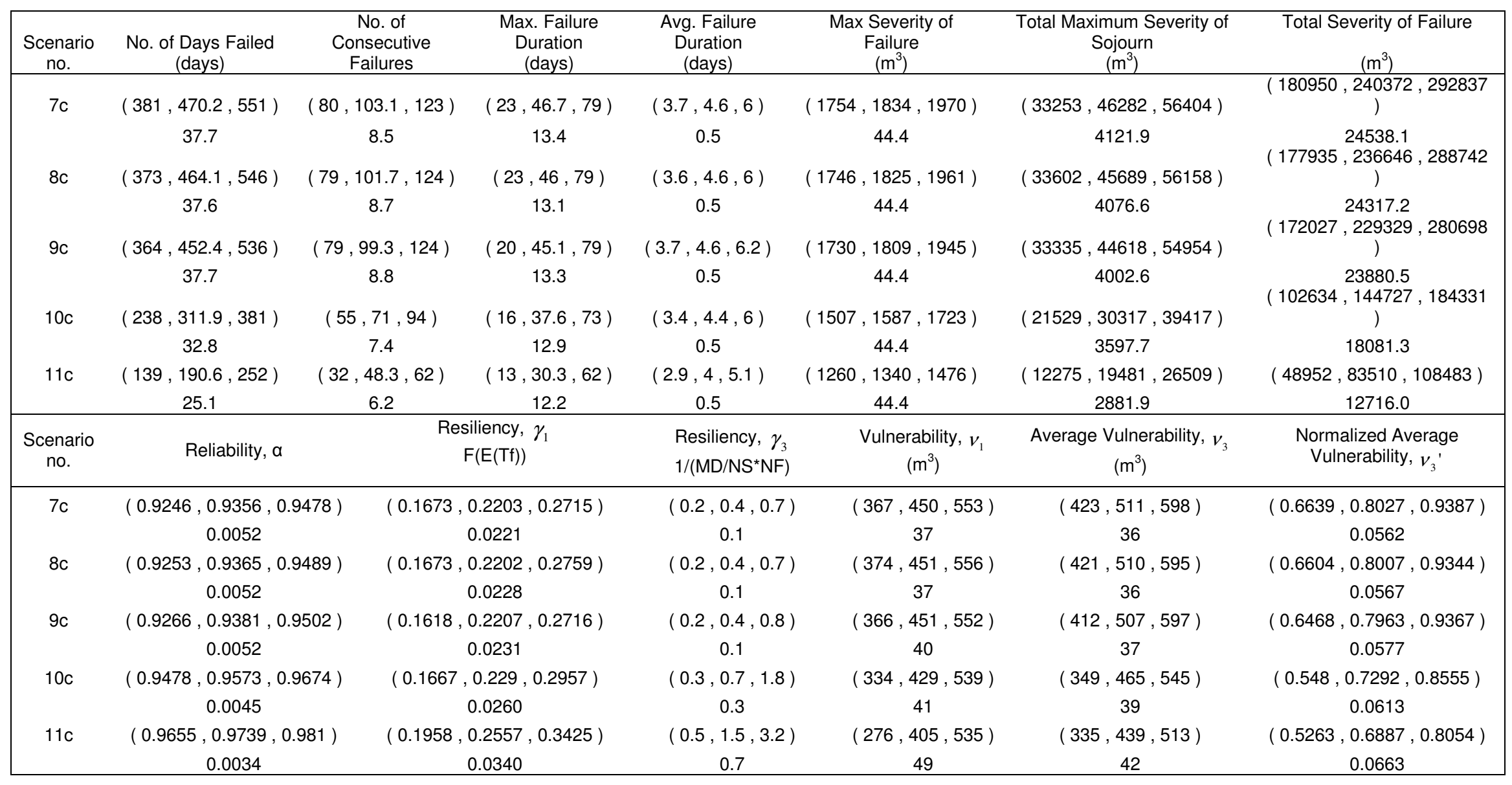


Consequently, the reliability of the system on average decreased from 0.97926 to 0.94828 , resiliency decreased from 0.30238 to 0.22918 , and the average vulnerability increased from 291.4 to $437.2 \mathrm{~m}^{3}$. The results show that a larger population and a changing climate will substantially increase the water demand and therefore lead to a substantial degradation of the system performance.

Scenario 12-16 versus Scenario 12c and 16c (CSIROMk2b B11)

Scenarios $12 \mathrm{c}$ to $16 \mathrm{c}$ have a similar arrangement as in scenarios $7 \mathrm{c}$ to $11 \mathrm{c}$ (Table 34 ). This scenario setting describes the worst-case scenario among all simulation scenarios. Table 33 provides a comparison of the overall average system performance in scenario 7 to $11,7 \mathrm{c}$ to $11 \mathrm{c}, 12$ to 16 , and $12 \mathrm{c}$ and $16 \mathrm{c}$. The base case results are also included for reference. As shown, under the combined influence of climate change and rapid population growth, the system's operation can be subjected to substantial failure. Figure 37 and Figure 38 illustrates the influences of the combined factors on the system's RRVs in scenario 7 to 11 , 12 to 16 and the corresponding sensitivity analysis scenarios.

Table 33. Overall System Performance in Scenario 1, 3 to 6,7 to $11,7 \mathrm{c}$ to $11 \mathrm{c}, 12$ to 16 , and $12 \mathrm{c}$ to $16 \mathrm{c}$

\begin{tabular}{|l|l|l|l|l|l|}
\hline & Base Case & \multicolumn{2}{|l|}{ Had CM3 A23 } & \multicolumn{2}{l|}{ CSIROMk2b B11 } \\
\cline { 2 - 6 } & 1,3 to 6 & 7 to 11 & $7 \mathrm{c}$ to $11 \mathrm{c}$ & 12 to 16 & $12 \mathrm{c}$ to $16 \mathrm{c}$ \\
\hline Number of failure day & 14 & 91 & 378 & 139 & 462 \\
Number of consecutive failures & 7.9 & 26.9 & 84.7 & 40.0 & 100.5 \\
Maximum failure duration & 4 & 19 & 41 & 19 & 43 \\
Maximum severity of failure & 402.8 & 672.8 & 1678.8 & 729.5 & 1739.4 \\
Reliability & 0.998 & 0.988 & 0.948 & 0.981 & 0.937 \\
Resiliency & 0.635 & 0.302 & 0.229 & 0.304 & 0.223 \\
Vulnerability & 172.5 & 250.4 & 437.1 & 258.5 & 462.0 \\
\hline
\end{tabular}


Table 34. Scenario 12c to 16c Failure Statistics and Performance Measures.

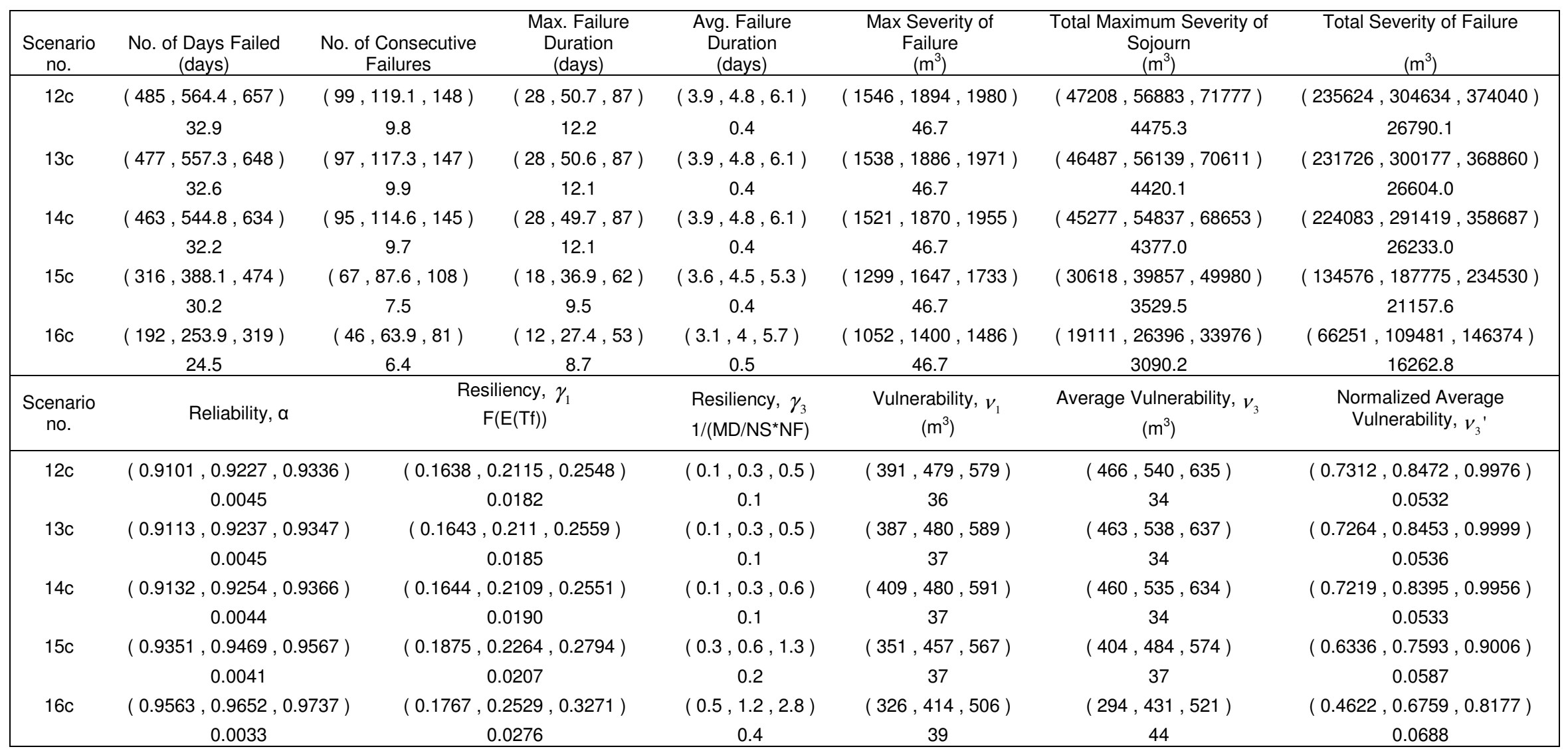



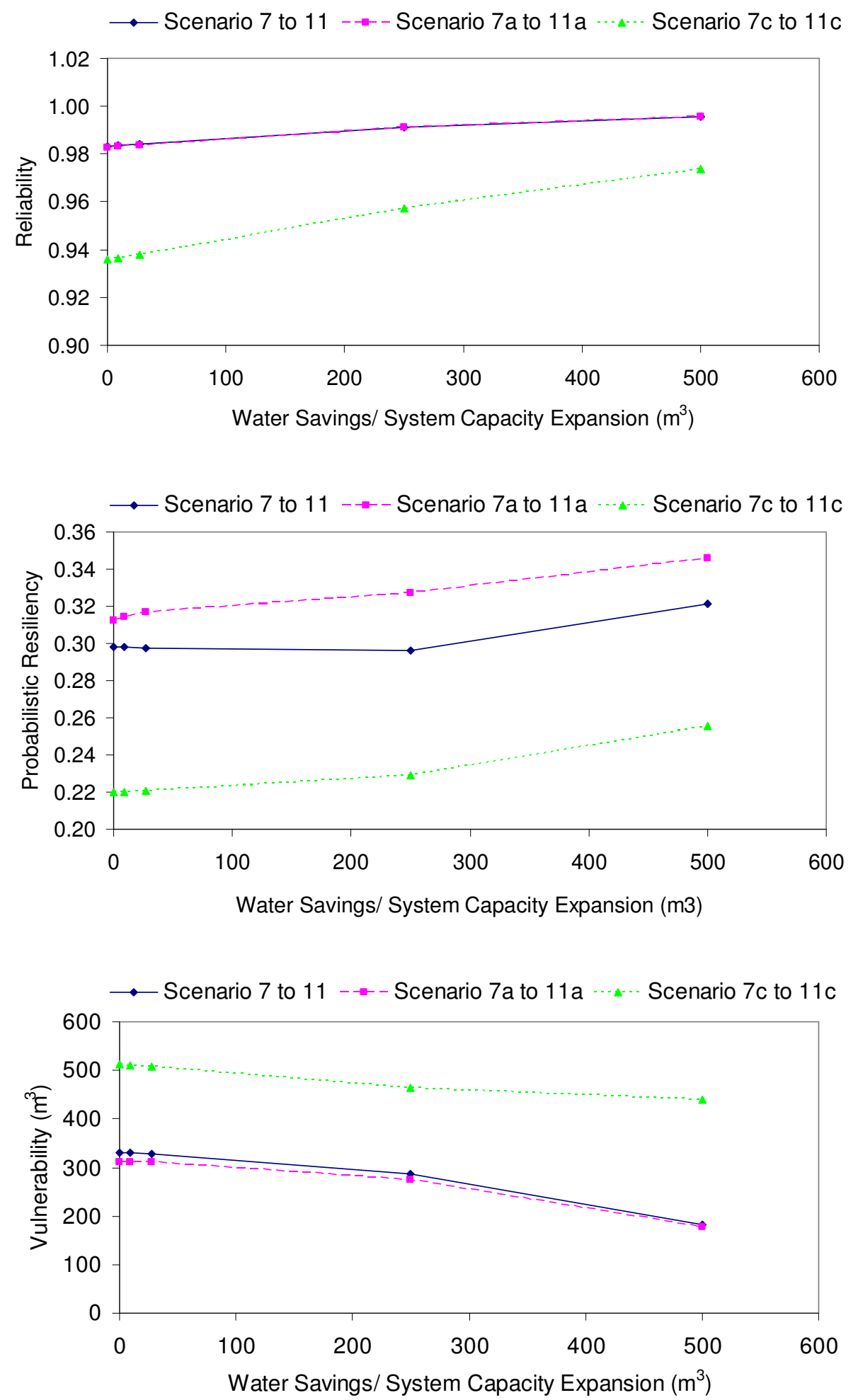

Figure 37. Reductions of Reliability, Resiliency, and Vulnerability of scenario 7 to 11,7 a to $11 \mathrm{a}$ and $7 \mathrm{c}$ to $11 \mathrm{c}$. 

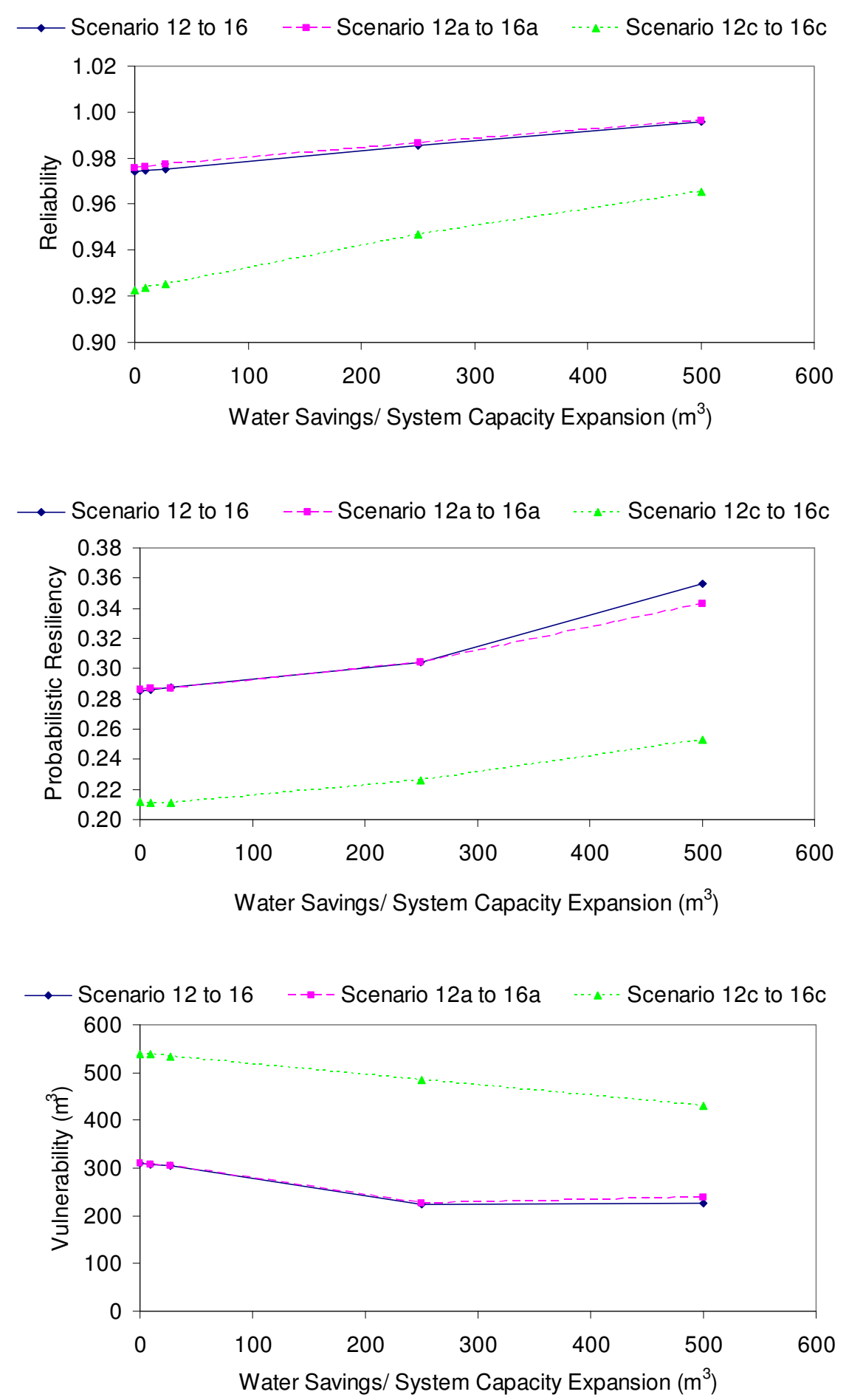

Figure 38. Reductions of Reliability, Resiliency, and Vulnerability of scenario 12 to $16,12 \mathrm{a}$ to $16 \mathrm{a}$ and $12 \mathrm{c}$ to $16 \mathrm{c}$. 


\subsection{Tradeoffs}

In many municipalities, water supply systems are operating close to capacity, such that the systems must be expanded and/or conservation actions must be taken. The simulation results were used to derive tradeoff relationships between spending and risk measures with different system configurations, climatic conditions and population growth rate settings. These relationships can be used to conduct cost-benefit analysis to aid decision makers in allocating resources to prepare for future needs.

In this study, vulnerability is calculated as the expected magnitude of water shortage during a failure and is measured in $\mathrm{m}^{3}$. To have all of three indices on the same magnitude of axis, the vulnerability measures is standardized by the existing system capacity.

Tradeoff relationships between costs and system performance are found in the simulation results and are plotted in Figure 39. In Figure 39, each point represents the average of a scenario and linear relationships are assumed between any two points in the same set of scenarios. As illustrated, more spending would lead to greater improvement. However, the tradeoffs vary under different climatic conditions. For example, to provide for the level of protection, as illustrated in the top figure, a spending of $\$ 1,100,000$ is required to achieve a reliability of 0.99 in HadCM3 A23, but in CSIROMK2b B11 spending \$1,460,000 is required to reach the same level of reliability. 

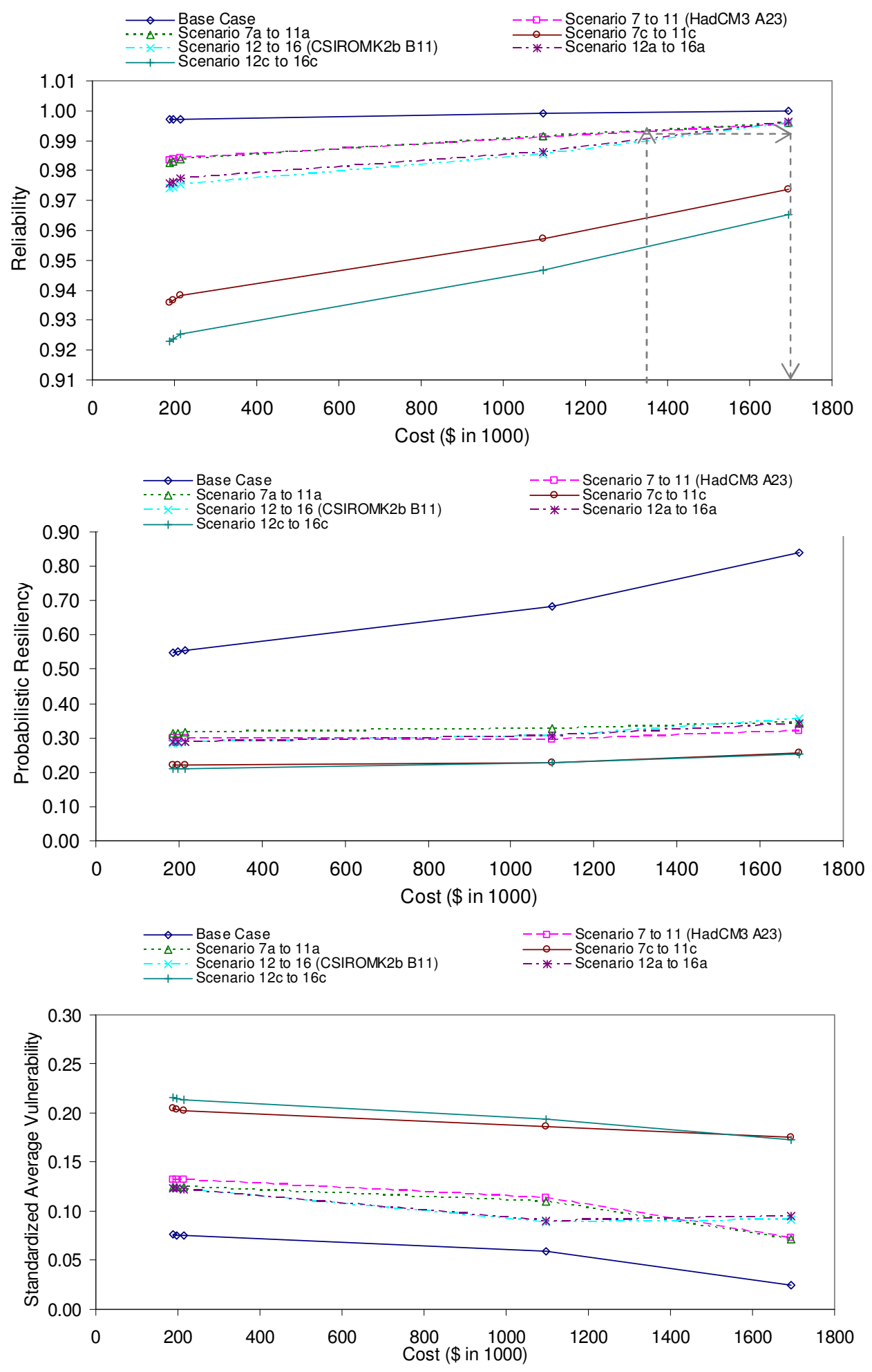

Figure 39. Performance Indices and Costs Tradeoff 


\subsection{Optimization}

In making the decision for a water supply system expansion, many factors come into play. Upon reviewing the features of the four alternatives evaluated in the risk assessment, each alternative is assigned a number of characteristic measures to account for cost and associated performance.

Compromise programming was used to account for all of the characteristic variables and possible combinations of alternatives, to produce an objective decision aid for decision makers to reconfigure the existing water management systems.

The Euclidean distance, $\mathrm{d}_{\mathrm{i}}$, from the ideal point in objective space to a scenario $\mathrm{i}$ is calculated using

$$
d_{i}=\sqrt{\left(p_{1}-q_{1 i}\right)^{2}+\left(p_{2}-q_{2 i}\right)^{2}+\left(p_{3}-q_{3 i}\right)^{2}}
$$

where $\mathrm{p}_{1}, \mathrm{p}_{2}, \mathrm{p}_{3}$ are the ideal reliability, $\mathrm{a}^{*}$, resiliency, $\gamma_{1}^{*}$, and the normalized vulnerability indices, $v_{3} *(1,1,0)$ and $\mathrm{q}_{1 \mathrm{i}}, \mathrm{q}_{2 \mathrm{i}}$, and $\mathrm{q}_{3 \mathrm{i}}$ are the $\mathrm{RRV}$ indices of scenario $\mathrm{i}$. Table 35 lists the costs and performance indices of the existing conditions and the four alternatives. Note that the cost for the existing conditions is for the continuation of the toilet replacement program, the implementation of outdoor water use by-law, and other educational water efficiency management programs. 
Table 35. Costs and Performance Indices of Alternatives in Base Case Scenario.

\begin{tabular}{|c|c|c|c|c|c|}
\hline \multirow{4}{*}{ System Performance } & \multicolumn{5}{|c|}{ Alternatives } \\
\hline & (1) & (2) & (3) & (4) & (5) \\
\hline & Existing & $5 \%$ additional & $15 \%$ & $10 \%$ & $20 \%$ \\
\hline & Conditions & $\begin{array}{l}\text { WEMPs } \\
\text { savings }\end{array}$ & $\begin{array}{l}\text { additional } \\
\text { WEMPs } \\
\text { savings }\end{array}$ & $\begin{array}{l}\text { additional } \\
\text { system } \\
\text { capacity }\end{array}$ & $\begin{array}{l}\text { additional } \\
\text { system } \\
\text { capacity }\end{array}$ \\
\hline Reliability (maximize) & 0.99695 & 0.99704 & 0.99725 & 0.99905 & 0.99981 \\
\hline Resiliency (maximize) & 0.548 & 0.550 & 0.554 & 0.683 & 0.838 \\
\hline Vulnerability & & & & & \\
\hline (minimize) & 0.076 & 0.075 & 0.075 & 0.060 & 0.025 \\
\hline Euclidean Distance & 0.458 & 0.456 & 0.452 & 0.322 & 0.164 \\
\hline Costs (\$ in 1000) & 187.02 & 196.371 & 215.073 & 1097.5 & 1695 \\
\hline
\end{tabular}

When evaluating the use of a combination of alternatives, there are two objective functions that must be formulated to solve this problem: Cost and the Euclidean distance based on the three performance measures. Given the four possible improvement alternatives, a set of feasible solutions was generated, as below.

\subsubsection{Optimization Results}

In ranking the alternatives using comprise programming, it was first assumed that the two categories, cost and system performance, are of equivalent importance. Detailed results of the comprise programming are included in Appendix D. Table 36 shows the rankings of the alternatives with $\alpha_{1}=\alpha_{2}=1$, thus the two objectives are weighted equally (see equation 24 for objective function formulation). 
Table 36. Ranking of Alternatives with $\alpha_{1}=\alpha_{2}=1$

\begin{tabular}{|c|cc|cc|cc|}
\hline & $\mathrm{S}=$ & 1 & $\mathrm{~S}=$ & 2 & $\mathrm{~S}=$ & 100 \\
Alternative Implementation & $\mathrm{L}_{\mathrm{s}}(\mathrm{x})$ & Rank & $\mathrm{L}_{\mathrm{s}}(\mathrm{x})$ & Rank & $\mathrm{L}_{\mathrm{s}}(\mathrm{x})$ & Rank \\
\hline Alterative 1 & 1.000 & 3 & 1.000 & 4 & 1.00 & 4 \\
Alterative 2 & 0.999 & 2 & 0.985 & 3 & 0.46 & 3 \\
Alterative 3 & 0.998 & 1 & 0.960 & 2 & 0.13 & 2 \\
Alterative 4 & 1.142 & 5 & 0.655 & 1 & 0.00 & 1 \\
Alterative 5 & 1.000 & 3 & 1.000 & 4 & 1.00 & 4 \\
\hline
\end{tabular}

For $\mathrm{s}=1$, all deviations are weighted equally. For $\mathrm{s}=2$, each deviation is weighted in proportion to its magnitude. As s becomes larger and larger, the largest deviation receives more and more weight, which shows that the decision maker's concern on the maximal deviation can be reflected on the choice of $\mathrm{s}$, that is, the larger the value of $\mathrm{s}$, the greater the concern. As shown in the ranking table alternative 3 is ranked first if $s=1$. Interestingly if $s$ $=2$ or 100, alternative 4 becomes the best alternative.

\subsection{Sensitivity Analysis}

Alphas represent the relative importance of the objectives and can be adjusted to reflect the decision maker's weighting on the objectives. Two weighting assignments are selected to illustrate the nondominated set rankings with emphasis on the two objectives, as follows.

Emphasis on Cost:

Emphasis on System Performance: $\alpha_{1}=10 ; \alpha_{2}=1$;

$\alpha_{1}=1 ; \quad \alpha_{2}=10$; 
The ranked alternatives with s equals to 1,2 , and 100 for the two weight assignment schemes are shown in Table 37 and Table 38. The detailed ranking results are also included in Appendix D.

Table 37. Ranking of Compromise Solutions with $\alpha_{1}=10$ and $\alpha_{2}=1$.

\begin{tabular}{|c|cc|cc|cc|}
\hline & $\mathrm{S}=$ & 1 & $\mathrm{~S}=$ & 2 & $\mathrm{~S}=$ & 100 \\
Alternative Implementation & $\mathrm{L}_{\mathrm{s}}(\mathrm{x})$ & Rank & $\mathrm{L}_{\mathrm{s}}(\mathrm{x})$ & Rank & $\mathrm{L}_{\mathrm{s}}(\mathrm{x})$ & Rank \\
\hline Alterative 1 & 1.000 & 1 & 1.000 & 3 & 1.000 & 4 \\
Alterative 2 & 1.055 & 2 & 0.985 & 2 & 0.463 & 3 \\
Alterative 3 & 1.166 & 3 & 0.963 & 1 & 0.126 & 2 \\
Alterative 4 & 6.579 & 4 & 3.939 & 4 & 0.000 & 1 \\
Alterative 5 & 10.000 & 5 & 10.000 & 5 & 10.00 & 5 \\
\hline
\end{tabular}

Table 38. Ranking of Compromise Solutions with $\alpha_{1}=1$ and $\alpha_{2}=10$.

\begin{tabular}{|c|cc|cc|cc|}
\hline & $\mathrm{S}=$ & 1 & $\mathrm{~S}=$ & 2 & $\mathrm{~S}=$ & 100 \\
Alternative Implementation & $\mathrm{L}_{\mathrm{s}}(\mathrm{x})$ & Rank & $\mathrm{L}_{\mathrm{s}}(\mathrm{x})$ & Rank & $\mathrm{L}_{\mathrm{s}}(\mathrm{x})$ & Rank \\
\hline Alterative 1 & 10.000 & 5 & 10.000 & 5 & 10.00 & 5 \\
Alterative 2 & 0.999 & 2 & 9.847 & 4 & 4.625 & 4 \\
Alterative 3 & 0.998 & 1 & 9.594 & 3 & 1.258 & 3 \\
Alterative 4 & 1.142 & 4 & 3.261 & 2 & 0.000 & 1 \\
Alterative 5 & 1.000 & 3 & 1.000 & 1 & 1.000 & 2 \\
\hline
\end{tabular}

The rankings show that the first three ranked implementation schemes with emphasis on cost and system performance are identical to that with the two objectives equally weighted. With emphasis on cost, the first ranked implementation scheme would be alternative 1 for $s=1$ and alternative 3 for $s=2$. Interestingly, if $s=100$, the first comprise solutions are identical in all three weighting schemes. Therefore, it is concluded that alternative 4 is the ultimate 
comprise solution. It is not a coincidence to have alternative 4 reappearing in all of the first three ranked comprise solutions. This ranking result is attributed by the performance of the alternative, which is relatively high as compared to alternatives 1,2 , and 3 and a lower cost than alternative 5 . 


\section{Chapter 6 \\ Conclusions and Recommendations}

\subsection{Conclusions}

This study aimed to assess the impacts of population growth and fluctuating climate conditions on the performance of a municipal water supply system. A hybrid model was developed which combines a data-derived stochastic component with a deterministic artificial neural network. The simulation model takes in climatic variables and water consumption patterns derived from historical records and projects future water demands under different assumptions. The model was used to estimate the effects of water efficiency management programs and system expansion on improving the system.

The impact of future climate change was assessed in two ways and compared. First, the possible outcomes of a changing monthly mean temperature and precipitation magnitude as projected by a selection of Globe Climate Models (GCMs) is estimated. Second, the possible outcomes of a change in precipitation amount represented by a change of precipitation pattern is investigated.

The simulation results suggest that a rise in temperature and a change in precipitation magnitude will have a negative impact on the performance of the system. For example, under the worst case climate change scenario and the current water supply system, average future reliability, resilience, and vulnerability values are projected to be $0.981,0.304$, and 
$258.5 \mathrm{~m}^{3}$, respectively. This compares with average future reliability, resilience, and vulnerability values of the current system with no climate change $0.998,0.635$, and $172.5 \mathrm{~m}^{3}$. The results also suggest that a reduction of precipitation may worsen the system performance. Conversely, an increase of precipitation may lessen the impacts of a warmer climate.

A more rapid population growth will substantially increase the water demand, showing that expansion of the current system is required. For example, under more rapid growth and without expansion, the current system has an estimated reliability of 0.923 under the worst case climate scenario. With expansion option increasing system capacity by $20 \%$, this reliability is improved to 0.965 .

To complete the analysis, a multiobjective optimization problem consisting of two objectives was formulated to help identify a recommended management alternative. Four feasible system improvement alternatives were generated. By using compromise programming, the alternative to increase system capacity by $10 \%$ was ranked first. This compromise solution has emphasis on the aspects of cost and the overall performance measures.

\subsection{Recommendations}

It was attempted to introduce source water quality parameters into the risk assessment. Because of the lack of representative data, such analysis was not possible. It is 
recommended that more frequent water sampling be conducted by the Region of Waterloo to provide continuous water quality monitoring.

The effect of conservation is hard to estimate and substantial savings are difficult to achieve. However, the conservation technology is readily available and more intense water efficiency management program is recommended.

\subsubsection{Direction of Future Work}

Additional research could be done in a few areas, as follows:

Analysis on the required insurance capacity for fire protection was not conducted. The existing model can be modified to incorporate such analysis. By using the following equation in the National Board of Fire Underwriters, the required fire demand can be estimated.

$F=320 C \sqrt{A}$

where $\mathrm{F}$ is the required fire flow in $\mathrm{m}^{3} / \mathrm{d}, \mathrm{C}$ is a coefficient depending on the type of construction, and A is the total building floor area in the municipality (Tchobanoglous and Schroeder, 1987)

As reported in the literature, a reduction of 10 to 25 percent in water consumption can be achieved without significantly changing people's life-style (Droste, 1997). It would be interesting to see the temporal effects of an intensive water efficiency management program 
on the water demand. In particular, of interest is the relative benefit on the system performance of such seasonal savings as compared to a fixed increase of capacity. In this study, water savings are assumed to be fixed. However, there are many factors affecting water use. These factors include geographic location, type of community, economic status, water pressure, cost and need for conservation. To carry the study one step further, investigation on the actual effectiveness of water conservation is needed. Alternatively, effectiveness can be considered uncertain.

To make the optimization weighting scheme more relevant, a survey of decision makers' perceptions can be conducted.

Risk is simply defined as a product of probability of failure and the consequence of a failure. The hidden costs and loss of revenue for residences and businesses due to a water supply system shut down was not estimated. A more thorough risk management study can be conducted by building on the current risk assessment process and by incorporating study on the social, environmental, economical impacts. With sufficient data, the risk assessment can be expanded to cover risks in all basic components of the water supply system.

Of interest is to take into account the possible impacts of climate change on water infiltration as a result of a reduction in precipitation and an increase of evaporation potential. As pointed out in 2001 Groundwater Monitoring Report, the water taking rate in the Region of Waterloo is less than $25 \%$ of the recharge rate. However, with a rapid population growth and change 
of land use, an assessment on the risk of over-exploitation of underground water sources is needed.

In conducting the risk assessment simulation, to compromise with the time and computation constraints, 100 trials were run for each scenario. More analysis on the simulation results is needed to assess the number of simulation trials required for a particular confidence level.

The GCM precipitation scaling algorithm for a changing occurrence rate needs to be revised to reflect monthly scaling of precipitation. Currently, the scaling is done once by matching the total precipitation volume generated by frequency change to that with scaled magnitudes for the entire time horizon of interest (see section 4.3.2.1).

Uncertainties exist in the GCM projections of the temperature and precipitation change. The individual effects of an increase of average temperature, a reduction in precipitation, and the fluctuations in the GCM estimates, on the risk in the system is unclear. Additional studies are needed to if the independent influence of these two factors are desired.

\subsection{Concluding Thoughts}

Concerns regarding of the reliability of water supply systems to meet the future needs are growing in the Kitchener and Waterloo area in spite of the on-going research to monitor and recharging of aquifers. Further studies are needed to identify the possible shortage of water to aid the local authority in allocating their resources to the most pressing problem. In 
addition, the current communication between municipalities and public can be improved to give greater emphasis on the water saving strategies such as alternative landscaping techniques, recycle use of water, or reduction of leakage loss from the point of conservation. In summary, with improved management of source water, understanding of the effects of climate change on water supply demands and reduction of water uses in response to conservation efforts, and cost-effective approaches to optimize the performance of water supplies system, a sustainable reliable water supply will be available to the future public. 


\section{References}

Akuoko-Asibey, A., Nkemdirim, L.C. and Draper, D.L. (1993). The impacts of climatic variables on seasonal water consumption in Calgary, Alberta. Canadian Water Resources Journal 18 (2), 107-16.

Barlow, M. and Clarke, T. (2002). Blue Gold, Stoddart Publishing Co. Limited, Toronto.

Baxter, C. W. and Lence, B. J. (2003). A Framework for Risk Analysis in Potable Water Supply. Pages 721-730 in Paul Bizier and Paul DeBarry (eds.) Proceedings of World Water and Environmental Resources Congress, Held in Philadelphia, Pennsylvania, June 23-26, 2003: American Society of Civil Engineers.

Biringer, B. and Danneels, J. J. (2001). Risk Assessment Methodology for Protecting Our Critical Physical Infrastructures. Pages 33-43 in Yacov Y. Haimes, David A. Moser, and Eugene Z. Stakhiv (eds). Risks-Based Decision Making in Water Resources IX, Reston: VA: American Society of Civil Engineers.

Bishop, C. M. (1995). Neural Networks for Pattern Recognition. Oxford University Press. Bogardi, J., and Kundzewicz, Z. (2002). Risk, Reliability, Uncertainty, and Robustness of Water Resources Systems. Cambridge University Press, Cambridge, United Kingdom.

Bougadis, J., Adamowski, K., and Diduch, R. (2005). Short-term municipal water demand forecasting. Hydrological Processes 19, pp. 137-148

Box, G. and Gwilym, J. (1970). Time Series Analysis: Forecasting and Control. San Francisco, California. Holden-Day. 
Bowden. G. J., Dandy. G. C., and Maier H. R (2005). Input determination for neural network models in water resources applications. Part 1-background and methodology. Journal of Hydrology 301, 75-92.

Bowden, G.J., Holger, R. M., and Graeme, C. D. (2005). Input determination for neural network models in water resources applications. Part 2. Case study: forecasting salinity in a river. Journal of Hydrology 301, 93-107.

Burn, D.H. (2003). Notes for CIV E 486 Hydrology, Department of Civil Engineering, University of Waterloo.

Canadian Climate Impacts Scenarios (CCIS) Group (2003). Canadian Institute for Climate Studies: Scenario Access. http://www.cics.uvic.ca/scenarios/data/select.cgi\#map

Chen, Z., Grasby, S. and Osadetz, K. (2004). Relation between climate variability and groundwater levels in the upper carbonate aquifer, southern Manitoba, Canada. Journal of Hydrology, 290, 43-62.

Downing, T. and Butterfield, R. (2003). CCDeW: Climate Change and Demand for Water Final Report. Climate Change and the Demand for Water, Research Report, Stockholm Environment Institute Oxford Office, Oxford.

Droste, R. L. (1997). Theory and Practice of Water and Wastewater Treatment. John Wiley \& Sons. Canada.

Environment Canada. (2007). How much do we have? Environment Canada. http://www.ec.gc.ca/WATER/en/info/facts/e_quantity.htm

Frederick, D. K. America's Water Supply: Status and Prospects for the Future 
http://www.gcrio.org/CONSEQUENCES/spring95/frederick.html. The Nature and Implications of Environmental Change. Consequences Vol.1, No. 1, Spring 1995.

Garbrech, J.D., Schneider, J.M. and Zhang, J.X. (2002). The Seasonal Pattern of Recent Change in Precipitation Normals. American Meteorological Society. http://ams.confex.com/ams/annual2003/techprogram/paper_52788.htm

Graser, H.J. (1958). Meter records in system planning. Journal of American Water Works Association 50(11): 1395-1402.

Guttorp, P. (1986). On Binary Time Series Obtained From Continuous Time Point Processes Describing Rainfall. Water Resources Research, Vol. 22, No. 6, Pages 897-904, June 1986.

Haimes, Y.Y., (1998). Risk Modelling, Assessment, and Management, Wiley Inter-Science, John Wiley \& Sons, Inc., New York.

Hashimoto, T., Stedinger, J.R. and Loucks, D. P. (1982). Reliability, Resiliency, and Vulnerability Criteria for Water Resource System Performance Evaluation, Water Resources Research, Vol. 18, p14-20.

Howe, C.W., and Linaweaver, F.P. (1967). The impact of price on residential water demands and its relation to system design and price structure. Water Resources Research 3(1): 13-32.

Jain, A., Varshney, A.K., and Joshi, U.C. (2001). Short-term water demand forecast modeling at IIT Kanpur using artificial neural networks. Water Resources Management 15: 299-321. 
Kaplan, S., and B.J. Carrick, (1981). "On the quantitative definition of risk", Risk Analysis, Vol. 1, No.1.

Karry, F.O. and De Silva C. (2004). Soft Computing and Intelligent Systems Design. Theory, Tools and Applications. Pearson Education Limited 2004. England.

Kite, G.W. and Adamwski, K. (1973) Stochastic analysis of Lake Superior Elevations for Computation of Relative Crustal Movement. Journal of Hydrology 18, 163-175.

Loucks, D. P. and Van Beek E., et al (2005). Water Resources Systems Planning and Management an Introduction to Methods, Models, and Applications, United Nations Educational, Scientific and Cultural Organization 7.

Lowrance, W.W., (1976). Of Acceptable Risk, William Kaufman, Inc., Los Altos, CA. Marien J.L. and Vandewiele G.L. (1986). A Point Rainfall Generator with Internal Storm Structure. Water Resources Research, Vol. 22, No.4, Pages 475-482.

Maidment, D.R., Miaou, S.P., and Crawford M.M. (1985). Transfer function models of daily urban water use. Water Resources Research 21(4): 425-432.

Mathworld.wolfram (2007). http://mathworld.wolfram.com/FourierSeries.html

Meakin, S. (1993). Municipal Water Issues in Canada. Government of Canada. Science and Technology Division.

Ministry of Environment (2003). Threats to Water Availability in Canada- A Perspective. Des O’Neill DONMEC Consulting Inc. http://www.nwri.ca/threats2full/perspectivee.html

Ministry of Environment (2005). Technical Supplements. http://www.ec.gc.ca/soer-ree/English/Indicator_series/techs.cfm?tech_id=25\&issue_id=6 
Mitchell, B. (2002). Resource and Environmental Management. $2^{\text {nd }}$ edition, Prentice Hall, Essex.

Moy, W. E., Cohon, J. L. and Revelle, C. S. (1986). A Programming Model for Analysis of the Reliability, Resilience, and Vulnerability of a Water Supply Reservoir. Water Resources Research, Vol. 22, p489-497.

National Institute of Standards and Technology (NIST) (2006). NIST/SEMATECH eHandbook of Statistical Methods, http://www.itl.nist.gov/div898/handbook/, date.

National Oceanic and Atmospheric Administration (NOAA) (2007). The First Climate Model.

http://celebrating200years.noaa.gov/breakthroughs/climate_model/welcome.html Natural Resources Canada (2006). Freshwater. http://atlas.nrcan.gc.ca/site/english/maps/freshwater/1

Pandey, M. D. (2005). Civ E 601 Engineering Risk and Reliability Course Notes, University of Waterloo.

Pourahmadi, M. (2001). Foundations of Times Series Analysis and Prediction Theory. John Wiley \& Sons, Inc., New York.

ROW (2004). Development Charges Background Study 2004, Region of Waterloo

ROW (2003). Development Charges Background Study 2003, Region of Waterloo

ROW (2004) Water Efficiency Master Plan Update Terms of Reference, Region of Waterloo. ROW (2001). Regional Development Charges Background Study Service Category: Water Appendix 1-1.a., Region of Waterloo ROW (2006). Proposed Water Efficiency Master Plan, 2007-2015, Region of Waterloo. 
Ross, S. M. (1997). Simulation Second Edition, Department of Industrial Engineering and Operations Research, University of California, Berkeley. California.

Ross, S. M. (1985). Introduction to Probability Models Third Edition, University of California, Berkeley.

Simonovic, S.P., Venema, H.D., and Burn, D.H. (1992). Risk-based parameter selection for short-term reservoir operation. Journal of Hydrology 131, 269-291.

Simonovic, S.P. (2002). Understanding Risk Management. Annual Conference of the Canadian Society for Civil Engineering, Montreal, Quebec, June 5-8, 2002.

Smith, S.K. (2005). A Probabilistic Approach for Assessing Risk to a Domestic Water Supply System. MASc Thesis. Civil Engineering. University of Waterloo, Ontario, Canada.

Solomatine, D.P.(2002). Data-driven Modelling: Paradigm, Methods, Experiences. Proc. 5th Int. Conference on Hydroinformatics. Cardiff, UK, July 2002, pp.757-763.

StatSoft Inc. (2003). Neural Networks. Electronic Textbook StatSoft.

Tchobanoglous, G. and Schroeder, E.D. (1987). Water Quality. University of California at Davis. Addison-Wesley Publishing Company, Inc. 1985.

Todorovic, P. and Woolhiser, D.A. (1974). Stochastic model of daily rainfall. Proceedings of the Symposium on Statistical Hydrology. U.S. Dep. Agric. Misc. Publ. 1275, 232246.

UNDRO (1991). "Mitigation of natural disasters: phenomena, effects, and options", A Manual for Policy Makers and Planners, United Nations, Office of the Disaster Relief Co-ordinator, New York. 
Weart S. (2007). The Discovery of Global Warming. http://www.aip.org/history/climate/GCM.htm

Weisstein, E.W. (2004). “Fourier Series.” MathWorld--A Wolfram Web Resource. http://mathworld.wolfram.com/FourierSeries.html

Zhang, X., Zwiers F.W., Hegerl G.C., Lambert F.H., Gillett N. P., Solomon S., Stott P.A., and Nozawa, T. (2007). Detection of Human Influence on Twentieth-century Precipitation Trends. Nature advance online publication 23 July 2007. 
Appendix A

Sample Raw Data 


\begin{tabular}{|c|c|c|c|c|c|c|c|}
\hline \multirow{2}{*}{$\begin{array}{l}\text { Date } \\
\qquad \text { 01-Jan-06 }\end{array}$} & \multicolumn{3}{|c|}{ Low temperat High tempera Precipitation } & \multirow{2}{*}{$\begin{array}{l}\text { Date } \\
\text { 01-Mar-06 }\end{array}$} & \multicolumn{3}{|c|}{ Low temperat High tempera Precipitation } \\
\hline & -3.6 & 1.8 & 0.5 & & -13 & -3.6 & 0 \\
\hline 02-Jan-06 & -0.4 & 1.4 & 4.5 & 02-Mar-06 & -12 & -3.3 & 0 \\
\hline 03-Jan-06 & -0.2 & 1.2 & 0.1 & 03-Mar-06 & -14 & -5.1 & 0 \\
\hline 04-Jan-06 & 0.8 & 4.6 & 3 & 04-Mar-06 & -9.1 & 0 & 0 \\
\hline 05-Jan-06 & -3.7 & 3.1 & 4.4 & 05-Mar-06 & -8.9 & 1.3 & 0 \\
\hline 06-Jan-06 & -9.9 & -3.9 & 0.1 & 06-Mar-06 & -10.3 & 0.4 & 0 \\
\hline 07-Jan-06 & -7.1 & -1.4 & 2.8 & 07-Mar-06 & -12.4 & -0.1 & 0 \\
\hline 08-Jan-06 & -4.3 & 0.1 & 0.2 & 08-Mar-06 & -8.8 & 2.1 & 0 \\
\hline 09-Jan-06 & -0.4 & 1.6 & 0.5 & 09-Mar-06 & 1.2 & 9.3 & 24 \\
\hline 10-Jan-06 & -3 & 0.3 & 0 & 10-Mar-06 & -1.1 & 9.5 & 5.6 \\
\hline 11-Jan-06 & -0.4 & 7.6 & 2.9 & 11-Mar-06 & -2.9 & 10.7 & 0 \\
\hline 12-Jan-06 & 1.6 & 7 & 0 & 12-Mar-06 & 2.2 & 12.5 & 6.4 \\
\hline 13-Jan-06 & 4.5 & 8.4 & 3.2 & 13-Mar-06 & 2.3 & 15.6 & 14.1 \\
\hline 14-Jan-06 & -7 & 6.1 & 0.8 & 14-Mar-06 & -3.4 & 4 & 2.4 \\
\hline 15-Jan-06 & -11.3 & -5.9 & 0 & 15-Mar-06 & -3.7 & 1.1 & 1.1 \\
\hline 16-Jan-06 & -11.6 & -5.6 & 0 & 16-Mar-06 & -4.8 & 2.5 & 0.2 \\
\hline 17-Jan-06 & -5.8 & 4.7 & 14.6 & 17-Mar-06 & -7.1 & -1 & 0 \\
\hline 18-Jan-06 & -4.6 & 4.5 & 7.9 & 18-Mar-06 & -6.6 & -2.6 & 0.1 \\
\hline 19-Jan-06 & -5.5 & 5.8 & 0.1 & 19-Mar-06 & -4.8 & -1.8 & 1.3 \\
\hline 20-Jan-06 & 0.3 & 8.3 & 3.4 & 20-Mar-06 & -7.6 & -2.6 & 0 \\
\hline 21-Jan-06 & -6.4 & 0.2 & 16.6 & 21-Mar-06 & -9.6 & -1.1 & 0 \\
\hline 22-Jan-06 & -9.1 & 1.7 & 0 & 22-Mar-06 & -3.3 & -0.3 & 0 \\
\hline 23-Jan-06 & -4.8 & 0.2 & 0.1 & 23-Mar-06 & -3.4 & 1.4 & 0 \\
\hline 24-Jan-06 & -3.9 & 1.3 & 3.1 & 24-Mar-06 & -1.3 & 2.5 & 0 \\
\hline 25-Jan-06 & -10.7 & -0.2 & 1.1 & 25-Mar-06 & -1.4 & 3.6 & 6.3 \\
\hline 26-Jan-06 & -15.5 & -7.9 & 0 & 26-Mar-06 & -1.9 & 6.1 & 0 \\
\hline 27-Jan-06 & -15.6 & 2.9 & 0.2 & 27-Mar-06 & -4.4 & 9.3 & 0 \\
\hline 28-Jan-06 & 1.6 & 7.5 & 0 & 28-Mar-06 & -2.5 & 10.5 & 0 \\
\hline 29-Jan-06 & 2.1 & 7.5 & 20 & 29-Mar-06 & -3.5 & 13 & 0 \\
\hline 30-Jan-06 & 1.7 & 6.9 & 0.2 & 30-Mar-06 & -1.3 & 15.9 & 0 \\
\hline 31-Jan-06 & -2.3 & 1.6 & 0 & 31-Mar-06 & 2.5 & 19.3 & 2.5 \\
\hline 01-Feb-06 & -3.5 & 2.6 & 0.2 & 01-Apr-06 & 0.7 & 12.2 & 3.8 \\
\hline 02-Feb-06 & 1.1 & 3.1 & 2.4 & 02-Apr-06 & -2.7 & 11.4 & 0.2 \\
\hline 03-Feb-06 & 0.2 & 2.3 & 10.1 & 03-Apr-06 & 0.6 & 17 & 1.8 \\
\hline 04-Feb-06 & 0.2 & 2.7 & 28.1 & 04-Apr-06 & -3.8 & 4.6 & 0.2 \\
\hline 05-Feb-06 & -5.9 & 0.5 & 5.9 & 05-Apr-06 & -4 & 3.3 & 1.2 \\
\hline 06-Feb-06 & -7.4 & -3.6 & 4.2 & 06-Apr-06 & 0.4 & 12.3 & 0 \\
\hline 07-Feb-06 & -7 & -3 & 1.8 & 07-Apr-06 & -0.5 & 6.4 & 11.8 \\
\hline 08-Feb-06 & -15.7 & -6.6 & 0 & 08-Apr-06 & -4.5 & 2.8 & 0 \\
\hline 09-Feb-06 & -17.8 & -6.7 & 0.5 & 09-Apr-06 & -4.9 & 8.2 & 0 \\
\hline 10-Feb-06 & -9.2 & -1.8 & 1 & 10-Apr-06 & -1.6 & 13.7 & 0 \\
\hline 11-Feb-06 & -16.7 & -3.5 & 0 & 11-Apr-06 & -0.5 & 18.6 & 0 \\
\hline 12-Feb-06 & -18.3 & -5.5 & 0 & 12-Apr-06 & 7.8 & 15.3 & 15.4 \\
\hline 13-Feb-06 & -8.8 & -4.3 & 0.9 & 13-Apr-06 & 6.2 & 19.7 & 0 \\
\hline 14-Feb-06 & -5.1 & 2.2 & 0 & 14-Apr-06 & 9.2 & 15 & 2.4 \\
\hline 15-Feb-06 & 0.4 & 3.9 & 0 & 15-Apr-06 & 5 & 14 & 0.2 \\
\hline 16-Feb-06 & -3.7 & 6.9 & 25.7 & 16-Apr-06 & 2.9 & 13.9 & 0 \\
\hline 17-Feb-06 & -9.2 & 7.5 & 12.8 & 17-Apr-06 & 2.9 & 13.4 & 0 \\
\hline 18-Feb-06 & -15 & -9.8 & 0 & 18-Apr-06 & 1.4 & 18.6 & 0 \\
\hline 19-Feb-06 & -14.4 & -9.8 & 0 & 19-Apr-06 & 3.1 & 21.7 & 0 \\
\hline 20-Feb-06 & -11.3 & -5.3 & 1.2 & 20-Apr-06 & 4.6 & 23.5 & 0 \\
\hline 21-Feb-06 & -12.5 & -1.6 & 0 & 21-Apr-06 & 10.4 & 18.4 & 0.4 \\
\hline 22-Feb-06 & -12.7 & 3.9 & 0 & 22-Apr-06 & 7.2 & 11.4 & 6 \\
\hline 23-Feb-06 & -7.1 & 3.2 & 0.3 & 23-Apr-06 & 6.4 & 8.5 & 26.6 \\
\hline 24-Feb-06 & -10.5 & -2.7 & 0.5 & 24-Apr-06 & 5.8 & 11.6 & 0.6 \\
\hline 25-Feb-06 & -8.9 & 0.9 & 0 & 25-Apr-06 & -0.8 & 10.5 & 0.4 \\
\hline 26-Feb-06 & -17.2 & -8.2 & 0.2 & 26-Apr-06 & -1.2 & 15.6 & 0 \\
\hline 27-Feb-06 & -19.7 & -5.1 & 1.1 & 27-Apr-06 & 1.5 & 12 & 0 \\
\hline 28-Feb-06 & -18.6 & -5.6 & 0 & 28-Apr-06 & -2.3 & 13.8 & 0 \\
\hline & & & & 29-Apr-06 & -0.5 & 14.7 & 0 \\
\hline & & & & 30-Apr-06 & 7.8 & 18.3 & 0 \\
\hline
\end{tabular}




\begin{tabular}{|c|c|c|c|}
\hline Date & \multicolumn{3}{|c|}{ Low temperat High tempera Precipitation } \\
\hline 01-May-06 & 7.4 & 19 & 0 \\
\hline 02-May-06 & 3 & 19.8 & 0 \\
\hline 03-May-06 & 3.9 & 23.3 & 0 \\
\hline 04-May-06 & 7.9 & 21.1 & 0 \\
\hline 05-May-06 & 4.4 & 15.2 & 1 \\
\hline 06-May-06 & 0.7 & 9.9 & 2.4 \\
\hline 07-May-06 & -1.1 & 17.2 & 0 \\
\hline 08-May-06 & 2.3 & 21.7 & 0 \\
\hline 09-May-06 & 6.6 & 21.2 & 0 \\
\hline 10-May-06 & 5.8 & 23.9 & 0 \\
\hline 11-May-06 & 10.8 & 16.3 & 29.2 \\
\hline 12-May-06 & 9.3 & 13.6 & 5.6 \\
\hline 13-May-06 & 9.2 & 17.1 & 0.2 \\
\hline 14-May-06 & 10.5 & 16.1 & 0.2 \\
\hline 15-Мау-06 & 9.9 & 15.3 & 1.8 \\
\hline 16-May-06 & 9.5 & 14.8 & 11.8 \\
\hline 17-May-06 & 8.5 & 19 & 0.2 \\
\hline 18-May-06 & 6.1 & 11.9 & 19.2 \\
\hline 19-May-06 & 6 & 12.8 & 0.4 \\
\hline 20-May-06 & 6.2 & 15 & 0.2 \\
\hline 21-May-06 & 2.7 & 10.7 & 3.2 \\
\hline 22-May-06 & 1.1 & 7.8 & 0 \\
\hline 23-May-06 & 2.1 & 16.1 & 0 \\
\hline 24-May-06 & 4 & 22.3 & 0 \\
\hline 25-May-06 & 13.9 & 23.5 & 0 \\
\hline 26-May-06 & 14.2 & 18.9 & 4 \\
\hline 27-May-06 & 12.2 & 24.7 & 0.2 \\
\hline 28-May-06 & 11.8 & 27.6 & 0 \\
\hline 29-May-06 & 20.3 & 32.7 & 0 \\
\hline 30-May-06 & 19.1 & 31.4 & 0 \\
\hline 31-May-06 & 19.2 & 27.9 & 33.8 \\
\hline 01-Jun-06 & 17.1 & 23.3 & 0 \\
\hline 02-Jun-06 & 15 & 22.9 & 4.2 \\
\hline 03-Jun-06 & 13.3 & 20.7 & 3.4 \\
\hline 04-Jun-06 & 12.9 & 21.2 & 0 \\
\hline 05-Jun-06 & 11.7 & 25.1 & 0 \\
\hline 06-Jun-06 & 11 & 27.2 & 0 \\
\hline 07-Jun-06 & 12.9 & 26.9 & 0 \\
\hline 08-Jun-06 & 13.1 & 24.7 & 8.6 \\
\hline 09-Jun-06 & 8.7 & 16.6 & 0 \\
\hline 10-Jun-06 & 7.1 & 15.1 & 0 \\
\hline 11-Jun-06 & 6 & 16.4 & 0 \\
\hline 12-Jun-06 & 10.9 & 20.4 & 0 \\
\hline 13-Jun-06 & 8.7 & 20.7 & 0 \\
\hline 14-Jun-06 & 10.2 & 23.3 & 0 \\
\hline 15-Jun-06 & 9.6 & 23.9 & 0 \\
\hline 16-Jun-06 & 9.7 & 26.7 & 0 \\
\hline 17-Jun-06 & 20.7 & 31.1 & 0 \\
\hline 18-Jun-06 & 20.7 & 28.8 & 0 \\
\hline 19-Jun-06 & 18.2 & 26.6 & 3.6 \\
\hline 20-Jun-06 & 12.1 & 21.4 & 0.2 \\
\hline 21-Jun-06 & 10.4 & 22.8 & 0 \\
\hline 22-Jun-06 & 17.5 & 27.8 & 0 \\
\hline 23-Jun-06 & 14.5 & 24.7 & 0 \\
\hline 24-Jun-06 & 10.4 & 25.4 & 0 \\
\hline 25-Jun-06 & 12.4 & 26 & 0 \\
\hline 26-Jun-06 & 17.6 & 22.6 & 0 \\
\hline 27-Jun-06 & 17.7 & 25.6 & 1 \\
\hline 28-Jun-06 & 15.1 & 26.2 & 10.2 \\
\hline 29-Jun-06 & 13.7 & 21.1 & 1.4 \\
\hline 30-Jun-06 & 13.7 & 24.6 & 0.2 \\
\hline
\end{tabular}

\begin{tabular}{|c|c|c|c|}
\hline Date & \multicolumn{3}{|c|}{ Low temperat High tempera Precipitation } \\
\hline 01-Jul-06 & 15.9 & 26.6 & 0.8 \\
\hline 02-Jul-06 & 21.3 & 28 & 0.4 \\
\hline 03-Jul-06 & 19.5 & 28.2 & 0 \\
\hline 04-Jul-06 & 14.1 & 26.2 & 11.2 \\
\hline 05-Jul-06 & 11.4 & 20.6 & 0 \\
\hline 06-Jul-06 & 10.1 & 22.6 & 0 \\
\hline 07-Jul-06 & 10.5 & 26.4 & 0 \\
\hline 08-Jul-06 & 13 & 26.6 & 0 \\
\hline 09-Jul-06 & 17.2 & 26.4 & 0 \\
\hline 10-Jul-06 & 17.2 & 22.9 & 24 \\
\hline 11-Jul-06 & 16.2 & 26.9 & 0.4 \\
\hline 12-Jul-06 & 17.8 & 22 & 47 \\
\hline 13-Jul-06 & 15.6 & 29.1 & 0 \\
\hline 14-Jul-06 & 17 & 29.5 & 2.4 \\
\hline 15-Jul-06 & 20 & 28.7 & 3 \\
\hline 16-Jul-06 & 19.4 & 31.5 & 0 \\
\hline 17-Jul-06 & 20 & 31.2 & 0 \\
\hline 18-Jul-06 & 17.2 & 26.9 & 0 \\
\hline 19-Jul-06 & 13.9 & 27.6 & 0 \\
\hline 20-Jul-06 & 15.9 & 26.9 & 26.2 \\
\hline 21-Jul-06 & 18.8 & 26.8 & 0 \\
\hline 22-Jul-06 & 15.6 & 21.9 & 0 \\
\hline 23-Jul-06 & 12.1 & 23 & 18.4 \\
\hline 24-Jul-06 & 12.8 & 26.2 & 0 \\
\hline 25-Jul-06 & 20.3 & 27.5 & 0.2 \\
\hline 26-Jul-06 & 20.4 & 26.8 & 8 \\
\hline 27-Jul-06 & 20.4 & 28.5 & 0.8 \\
\hline 28-Jul-06 & 19.9 & 27.5 & 9.4 \\
\hline 29-Jul-06 & 21.1 & 30.2 & 0 \\
\hline 30-Jul-06 & 18.8 & 28.1 & 0 \\
\hline 31-Jul-06 & 20 & 31.9 & 0 \\
\hline 01-Aug-06 & 25.3 & 33.7 & 0 \\
\hline 02-Aug-06 & 20.9 & 32.7 & 12.4 \\
\hline 03-Aug-06 & 17.6 & 22.1 & 17 \\
\hline 04-Aug-06 & 14.8 & 26.9 & 0.2 \\
\hline 05-Aug-06 & 12.7 & 26.4 & 0 \\
\hline 06-Aug-06 & 16.4 & 27.5 & 0 \\
\hline 07-Aug-06 & 16.6 & 26.3 & 0 \\
\hline 08-Aug-06 & 11.8 & 23.5 & 0 \\
\hline 09-Aug-06 & 9.3 & 25.6 & 0 \\
\hline 10-Aug-06 & 14.7 & 25.6 & 0 \\
\hline 11-Aug-06 & 10.9 & 22.3 & 0 \\
\hline 12-Aug-06 & 7.7 & 23.6 & 0 \\
\hline 13-Aug-06 & 7.8 & 24.8 & 0 \\
\hline 14-Aug-06 & 12.2 & 24.2 & 7 \\
\hline 15-Aug-06 & 13.5 & 23.1 & 0.2 \\
\hline 16-Aug-06 & 11.9 & 24.8 & 0 \\
\hline 17-Aug-06 & 10.3 & 25.4 & 0 \\
\hline 18-Aug-06 & 15 & 28.5 & 0 \\
\hline 19-Aug-06 & 19.4 & 23.4 & 4.8 \\
\hline 20-Aug-06 & 13.2 & 20.5 & 0.2 \\
\hline 21-Aug-06 & 10.4 & 24.6 & 0.2 \\
\hline 22-Aug-06 & 12.7 & 25 & 0 \\
\hline 23-Aug-06 & 11.2 & 24.7 & 0 \\
\hline 24-Aug-06 & 14.6 & 21.9 & 0 \\
\hline 25-Aug-06 & 15.3 & 17.9 & 8 \\
\hline 26-Aug-06 & 14.7 & 20.8 & 1 \\
\hline 27-Aug-06 & 17.1 & 25.1 & 0.2 \\
\hline 28-Aug-06 & 15.4 & 22.9 & 0.8 \\
\hline 29-Aug-06 & 14.9 & 23.8 & 0.4 \\
\hline 30-Aug-06 & 12.1 & 22.3 & 0 \\
\hline 31-Aug-06 & 10.3 & 20.2 & 0 \\
\hline
\end{tabular}




\begin{tabular}{|c|c|c|c|c|c|c|c|}
\hline Date & \multicolumn{3}{|c|}{ Low temperat High tempera Precipitation } & \multirow{2}{*}{$\begin{array}{l}\text { Date } \\
\text { 01-Nov-06 }\end{array}$} & \multicolumn{3}{|c|}{ Low temperat High tempera Precipitation } \\
\hline 01-Sep-06 & 10.9 & 22 & 0 & & -1.6 & 6.2 & 0 \\
\hline 02-Sep-06 & 12.4 & 16.9 & 8.8 & 02-Nov-06 & -2.6 & 1.5 & 0 \\
\hline 03-Sep-06 & 11.5 & 16.8 & 4 & 03-Nov-06 & -2.5 & 2 & 0.6 \\
\hline 04-Sep-06 & 12.1 & 20.6 & 0.2 & 04-Nov-06 & -3.7 & 3.7 & 0 \\
\hline 05-Sep-06 & 12.1 & 20.4 & 0 & 05-Nov-06 & 2.6 & 9.6 & 0 \\
\hline 06-Sep-06 & 12.5 & 22.9 & 0 & 06-Nov-06 & -2.1 & 14.1 & 0 \\
\hline 07-Sep-06 & 9.3 & 23.3 & 0 & 07-Nov-06 & 6.8 & 9.6 & 10.8 \\
\hline 08-Sep-06 & 15.2 & 25.7 & 0.2 & 08-Nov-06 & 7.1 & 12 & 0.4 \\
\hline 09-Sep-06 & 7.5 & 17.2 & 0.8 & 09-Nov-06 & 4.6 & 14.9 & 0 \\
\hline 10-Sep-06 & 6.1 & 16.6 & 0.2 & 10-Nov-06 & 3.1 & 6.9 & 0 \\
\hline 11-Sep-06 & 8 & 16.8 & 0 & 11-Nov-06 & 0.9 & 5.4 & 5.6 \\
\hline 12-Sep-06 & 13.8 & 15.7 & 15.2 & 12-Nov-06 & -0.4 & 1.8 & 0 \\
\hline 13-Sep-06 & 14.9 & 22.8 & 14.4 & 13-Nov-06 & 1.4 & 4.2 & 0.2 \\
\hline 14-Sep-06 & 14.7 & 18 & 0.2 & 14-Nov-06 & 3.5 & 5 & 0 \\
\hline 15-Sep-06 & 11.4 & 19.6 & 0.4 & 15-Nov-06 & 1 & 9 & 4 \\
\hline 16-Sep-06 & 9.9 & 20.4 & 0 & 16-Nov-06 & 4.3 & 12 & 21.6 \\
\hline 17-Sep-06 & 12.7 & 23.4 & 0.2 & 17-Nov-06 & 1.7 & 4.1 & 2 \\
\hline 18-Sep-06 & 13 & 22.2 & 23 & 18-Nov-06 & -1.4 & 3.7 & 0 \\
\hline 19-Sep-06 & 11.6 & 16.3 & 0.2 & 19-Nov-06 & -0.7 & 1.1 & 0 \\
\hline 20-Sep-06 & 7.4 & 12.9 & 0.4 & 20-Nov-06 & -2 & 0.4 & 0 \\
\hline 21-Sep-06 & 5.9 & 16.1 & 0.4 & 21-Nov-06 & -4.7 & 4.9 & 0 \\
\hline 22-Sep-06 & 4.4 & 16.2 & 1.4 & 22-Nov-06 & -5.4 & 7 & 0.2 \\
\hline 23-Sep-06 & 15.4 & 22.6 & 10.6 & 23-Nov-06 & -2.2 & 10.8 & 0 \\
\hline 24-Sep-06 & 9.7 & 18.9 & 5 & 24-Nov-06 & -3.6 & 10.3 & 0 \\
\hline 25-Sep-06 & 6.7 & 17.3 & 0.4 & 25-Nov-06 & -3.4 & 12.8 & 0 \\
\hline 26-Sep-06 & 7.6 & 17.8 & 0.2 & 26-Nov-06 & 6.5 & 13.3 & 0.2 \\
\hline 27-Sep-06 & 9.7 & 21.3 & 19.4 & 27-Nov-06 & 6.6 & 13.1 & 0 \\
\hline 28-Sep-06 & 4.8 & 12.1 & 0 & 28-Nov-06 & 4.9 & 10.6 & 0 \\
\hline 29-Sep-06 & 2.3 & 12.1 & 0 & 29-Nov-06 & 5.1 & 15 & 1.2 \\
\hline 30-Sep-06 & 7.6 & 12.1 & 11.6 & 30-Nov-06 & 0.9 & 14.9 & 21.8 \\
\hline 01-Oct-06 & 5.2 & 15.3 & 0.2 & 01-Dec-06 & -1.1 & 4.2 & 35.1 \\
\hline 02-Oct-06 & 4.1 & 20.8 & 0 & 02-Dec-06 & -2.5 & 0.1 & 0.4 \\
\hline 03-Oct-06 & 14.1 & 22.6 & 3.4 & 03-Dec-06 & -6.3 & -1.5 & 0.3 \\
\hline 04-Oct-06 & 6.3 & 18.9 & 23.8 & 04-Dec-06 & -7.1 & -3.6 & 1.6 \\
\hline 05-Oct-06 & 2.2 & 12 & 0 & 05-Dec-06 & -8.7 & -2.8 & 0.5 \\
\hline 06-Oct-06 & 1.3 & 13.9 & 0 & 06-Dec-06 & -4.1 & 2.1 & 5.3 \\
\hline 07-Oct-06 & -0.2 & 17.9 & 0.2 & 07-Dec-06 & -15.4 & -1.6 & 1.5 \\
\hline 08-Oct-06 & 1.3 & 21 & 0 & 08-Dec-06 & -15.5 & -3.9 & 1.1 \\
\hline 09-Oct-06 & 9 & 18.4 & 0.2 & 09-Dec-06 & -6.4 & 0.6 & 0.3 \\
\hline 10-Oct-06 & 8.4 & 16.5 & 1.4 & 10-Dec-06 & -1.5 & 5.9 & 0.2 \\
\hline 11-Oct-06 & 8.4 & 16.7 & 20.8 & 11-Dec-06 & 1.7 & 4.1 & 1.1 \\
\hline 12-Oct-06 & -0.6 & 8.5 & 0.8 & 12-Dec-06 & 3.1 & 8.6 & 1.7 \\
\hline 13-Oct-06 & -0.3 & 4.8 & 1.2 & 13-Dec-06 & 0 & 7.2 & 6.7 \\
\hline 14-Oct-06 & 2.1 & 7.1 & 1.8 & 14-Dec-06 & 1.5 & 9.7 & 0.1 \\
\hline 15-Oct-06 & 1.1 & 10 & 0 & 15-Dec-06 & 0.9 & 7.7 & 0.2 \\
\hline 16-Oct-06 & -1.1 & 14.3 & 0 & 16-Dec-06 & -1.2 & 5.6 & 0.1 \\
\hline 17-Oct-06 & 8.3 & 13.9 & 27.2 & 17-Dec-06 & 4.1 & 10.1 & 0 \\
\hline 18-Oct-06 & 10 & 14.8 & 0 & 18-Dec-06 & -0.3 & 4.9 & 0 \\
\hline 19-Oct-06 & 2.3 & 13.6 & 6.6 & 19-Dec-06 & -1.9 & 1.4 & 0 \\
\hline 20-Oct-06 & 1.9 & 7.2 & 0.4 & 20-Dec-06 & -1.4 & 5.5 & 0.1 \\
\hline 21-Oct-06 & 2.2 & 8.6 & 0 & 21-Dec-06 & -1 & 5.3 & 0 \\
\hline 22-Oct-06 & 2.4 & 9.9 & 10.8 & 22-Dec-06 & 2 & 8.5 & 17.3 \\
\hline 23-Oct-06 & 0.9 & 5.2 & 0.2 & 23-Dec-06 & 2 & 8.1 & 1.4 \\
\hline 24-Oct-06 & 0.9 & 6.2 & 0.6 & 24-Dec-06 & -0.5 & 4.2 & 0.1 \\
\hline 25-Oct-06 & 1.8 & 6.3 & 0 & 25-Dec-06 & -0.2 & 2.7 & 1.5 \\
\hline 26-Oct-06 & 0 & 6.3 & 0 & 26-Dec-06 & -2.1 & 2.8 & 1.7 \\
\hline 27-Oct-06 & 0 & 4.2 & 14.6 & 27-Dec-06 & -1.9 & 0.7 & 0.2 \\
\hline 28-Oct-06 & 1.2 & 4.5 & 10.6 & 28-Dec-06 & 0.3 & 2.6 & 0.1 \\
\hline 29-Oct-06 & 0.5 & 5.2 & 5.8 & 29-Dec-06 & -2.9 & 0.7 & 0 \\
\hline 30-Oct-06 & 1.2 & 15.3 & 0 & 30-Dec-06 & -3.3 & 1.2 & 0.4 \\
\hline 31-Oct-06 & 2.6 & 14.3 & 0.8 & 31-Dec-06 & -3.4 & 4.9 & 7.4 \\
\hline
\end{tabular}


Ayr Daily Water Demand

\begin{tabular}{|c|c|c|c|c|}
\hline DATE & $\begin{array}{l}\text { A1 Pumpage } \\
(\mathrm{m} 3)\end{array}$ & $\begin{array}{c}\text { A2 Pumpage } \\
(\mathrm{m} 3)\end{array}$ & $\begin{array}{c}\text { Ayr Tank Level (@6:00 am) } \\
\text { (Metre) }\end{array}$ & $\begin{array}{l}\text { Daily Consumption } \\
\text { (m3) }\end{array}$ \\
\hline $1 / 1 / 00$ & 0 & 1217 & 348.62 & 1406 \\
\hline $1 / 2 / 00$ & 0 & 967 & 347.13 & 744 \\
\hline $1 / 3 / 00$ & 0 & 1108 & 348.79 & 1263 \\
\hline $1 / 4 / 00$ & 685 & 438 & 347.51 & 1022 \\
\hline $1 / 5 / 00$ & 743 & 0 & 348.32 & 670 \\
\hline $1 / 6 / 00$ & 1034 & 0 & 348.8 & 1086 \\
\hline $1 / 7 / 00$ & 1144 & 0 & 348.37 & 1224 \\
\hline $1 / 8 / 00$ & 859 & 0 & 347.83 & 820 \\
\hline $1 / 9 / 00$ & 1326 & 0 & 348.1 & 1356 \\
\hline $1 / 10 / 00$ & 843 & 0 & 347.77 & 861 \\
\hline $1 / 11 / 00$ & 276 & 731 & 347.66 & 896 \\
\hline $1 / 12 / 00$ & 0 & 841 & 348.42 & 789 \\
\hline $1 / 13 / 00$ & 0 & 1014 & 348.69 & 1012 \\
\hline $1 / 14 / 00$ & 0 & 965 & 348.64 & 942 \\
\hline $1 / 15 / 00$ & 0 & 1145 & 348.89 & 1237 \\
\hline $1 / 16 / 00$ & 0 & 1263 & 348.12 & 1368 \\
\hline $1 / 17 / 00$ & 0 & 1076 & 347.37 & 1040 \\
\hline $1 / 18 / 00$ & 668 & 199 & 347.63 & 754 \\
\hline $1 / 19 / 00$ & 828 & 0 & 348.49 & 764 \\
\hline $1 / 20 / 00$ & 1000 & 0 & 348.78 & 985 \\
\hline $1 / 21 / 00$ & 1038 & 0 & 348.97 & 1127 \\
\hline $1 / 22 / 00$ & 1224 & 0 & 348.34 & 1364 \\
\hline $1 / 23 / 00$ & 1107 & 0 & 347.11 & 941 \\
\hline $1 / 24 / 00$ & 1190 & 0 & 348.47 & 1121 \\
\hline $1 / 25 / 00$ & 994 & 43 & 348.86 & 1059 \\
\hline $1 / 26 / 00$ & 1003 & 0 & 348.61 & 1016 \\
\hline $1 / 27 / 00$ & 1016 & 0 & 348.53 & 939 \\
\hline $1 / 28 / 00$ & 1001 & 0 & 348.92 & 1086 \\
\hline $1 / 29 / 00$ & 1055 & 0 & 348.23 & 1045 \\
\hline $1 / 30 / 00$ & 1224 & 0 & 348.34 & 1160 \\
\hline $1 / 31 / 00$ & 416 & 717 & 348.69 & 1180 \\
\hline $2 / 1 / 00$ & 0 & 943 & 348.27 & 861 \\
\hline $2 / 2 / 00$ & 0 & 1022 & 348.79 & 1008 \\
\hline $2 / 3 / 00$ & 0 & 1062 & 348.75 & 1087 \\
\hline $2 / 4 / 00$ & 9 & 922 & 348.53 & 962 \\
\hline $2 / 5 / 00$ & 0 & 1186 & 348.27 & 1099 \\
\hline $2 / 6 / 00$ & 0 & 1028 & 348.86 & 1115 \\
\hline $2 / 7 / 00$ & 0 & 1041 & 348.3 & 991 \\
\hline $2 / 8 / 00$ & 105 & 948 & 348.58 & 1007 \\
\hline $2 / 9 / 00$ & 0 & 1049 & 348.89 & 1052 \\
\hline $2 / 10 / 00$ & 0 & 1015 & 348.83 & 1001 \\
\hline $2 / 11 / 00$ & 0 & 984 & 348.79 & 982 \\
\hline $2 / 12 / 00$ & 0 & 1128 & 348.79 & 1233 \\
\hline $2 / 13 / 00$ & 0 & 1038 & 348.1 & 982 \\
\hline $2 / 14 / 00$ & 0 & 1140 & 348.43 & 1080 \\
\hline $2 / 15 / 00$ & 672 & 402 & 348.73 & 1109 \\
\hline $2 / 16 / 00$ & 942 & 0 & 348.42 & 965 \\
\hline $2 / 17 / 00$ & 1185 & 0 & 348.1 & 1163 \\
\hline $2 / 18 / 00$ & 977 & 0 & 348.24 & 1070 \\
\hline $2 / 19 / 00$ & 1045 & 0 & 347.57 & 881 \\
\hline $2 / 20 / 00$ & 1309 & 0 & 348.68 & 1466 \\
\hline $2 / 21 / 00$ & 1143 & 0 & 347.6 & 1141 \\
\hline $2 / 22 / 00$ & 390 & 757 & 347.42 & 1049 \\
\hline $2 / 23 / 00$ & 0 & 767 & 348.21 & 675 \\
\hline $2 / 24 / 00$ & 0 & 927 & 348.83 & 899 \\
\hline $2 / 25 / 00$ & 0 & 997 & 348.96 & 1149 \\
\hline $2 / 26 / 00$ & 0 & 1238 & 347.81 & 1226 \\
\hline $2 / 27 / 00$ & 0 & 830 & 347.83 & 694 \\
\hline $2 / 28 / 00$ & 0 & 960 & 348.83 & 961 \\
\hline $2 / 29 / 00$ & 0 & 929 & 348.86 & 919 \\
\hline $3 / 1 / 00$ & 9 & 972 & 348.86 & 990 \\
\hline $3 / 2 / 00$ & 0 & 1134 & 348.64 & 1239 \\
\hline $3 / 3 / 00$ & 0 & 689 & 347.88 & 545 \\
\hline $3 / 4 / 00$ & 0 & 1098 & 348.9 & 1188 \\
\hline $3 / 5 / 00$ & 0 & 1162 & 348.11 & 1285 \\
\hline $3 / 6 / 00$ & 0 & 861 & 347.22 & 724 \\
\hline $3 / 7 / 00$ & 11 & 1051 & 348.2 & 1144 \\
\hline $3 / 8 / 00$ & 331 & 611 & 347.44 & 826 \\
\hline $3 / 9 / 00$ & 851 & 0 & 348.38 & 796 \\
\hline
\end{tabular}




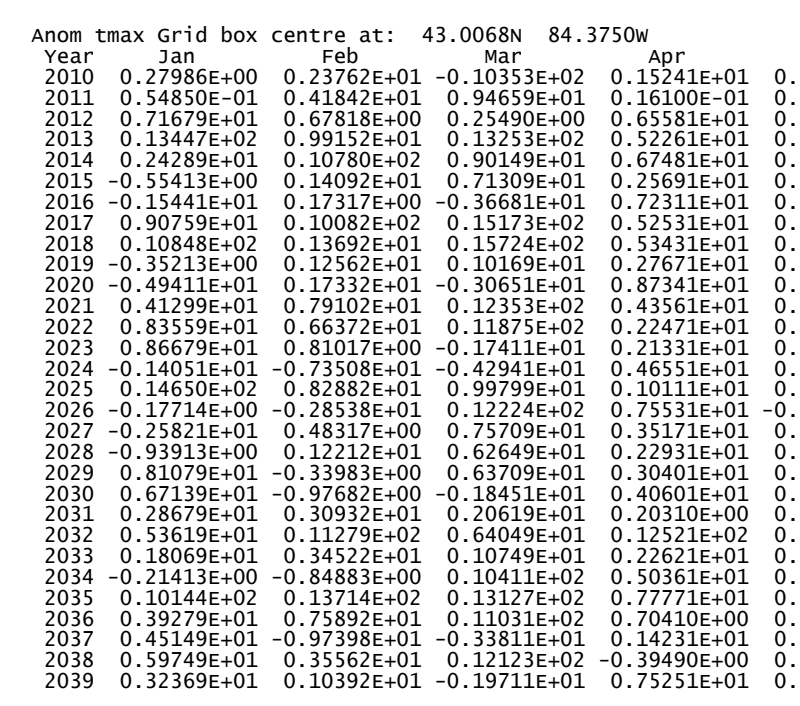

csiromk2b_B11_2010_2039_tmax_anom_7ong16_7at15

\begin{tabular}{|c|c|c|c|c|c|c|c|}
\hline & & & & & & & \\
\hline & & & $\begin{array}{l}1096 \\
1096 \\
\text { a }\end{array}$ & 0.35 & 0 & (10057 & $056-2 \quad-5$ \\
\hline $\begin{array}{l}5900 \\
9900\end{array}$ & & $\begin{array}{l}0.3537 \\
0.3358\end{array}$ & 0.7693 & & & & $\begin{array}{l}554 \mathrm{E}+01 \\
046 \mathrm{E}+01\end{array}$ \\
\hline 01 & & 0.31 & $0.28283 \mathrm{E}+01$ & 0. & $\begin{array}{l}35 \\
45\end{array}$ & & $6 \mathrm{E}+$ \\
\hline +01 & 0. & $0.54180 \mathrm{E}+01$ & $0.49023 \mathrm{E}+\mathrm{C}$ & $7171 \mathrm{E}+$ & $17645 \mathrm{E}+$ & 0 & 1 \\
\hline $\begin{array}{l}20 E+01 \\
50 E+01\end{array}$ & $\begin{array}{l}0.8754 \\
0.1400\end{array}$ & $\begin{array}{r}-0.26000 \mathrm{E}+01 \\
0.25670 \mathrm{E}+01\end{array}$ & $\begin{array}{l}0.17930 \mathrm{E}+00 \\
0.32093 \mathrm{E}+01\end{array}$ & $\begin{array}{l}0.32569 \mathrm{E}+01 \\
0.10579 \mathrm{E}+01\end{array}$ & & & \\
\hline & 0 & $0.85220 \mathrm{E}+01$ & $0.66463 \mathrm{E}+01$ & $0.42019 \mathrm{E}+01$ & $55445 \mathrm{E}+01$ & 01 & $244 \mathrm{E}+$ \\
\hline & $0.37114 \mathrm{E}+01$ & & 0.3 & $13659 \mathrm{E}+01$ & & & \\
\hline $\begin{array}{l}+01 \\
+01 \\
+1\end{array}$ & $0.36914 \mathrm{E}+01$ & $0.11510 \mathrm{E}+01$ & & & $\begin{array}{l}E+01 \\
E+00\end{array}$ & & $6 \mathrm{E}+01$ \\
\hline+00 & 0.209 & $\begin{array}{l}-0.230901 \\
0.2301\end{array}$ & 0.245 & $\begin{array}{ll}9 E+01 \\
0.01\end{array}$ & & & $E+01$ \\
\hline $\begin{array}{l}+01 \\
+01 \\
\end{array}$ & $\begin{array}{l}0.4984 \\
0.3613\end{array}$ & $\begin{array}{l}0.33120 \mathrm{E}+01 \\
0.19860 \mathrm{E}+01\end{array}$ & $\begin{array}{l}0.316 \\
0.397\end{array}$ & $\begin{array}{l}. .48619 \mathrm{E}+01 \\
-0.15051 \mathrm{E}+01\end{array}$ & $\begin{array}{r}0.10350 \\
-0.88150\end{array}$ & 01 & $\begin{array}{l}E+01 \\
+01 \\
+01\end{array}$ \\
\hline $7620 \mathrm{E}+01$ & $0.20144 \mathrm{E}+01$ & $0.43610 \mathrm{E}+01$ & $0.59430 \mathrm{E}+00$ & & & & \\
\hline & 01 & & 0130 & & & & \\
\hline & $37114 \mathrm{E}+01$ & $\begin{array}{l}0.53080 \mathrm{E}+01 \\
0.32800 \mathrm{E}+01\end{array}$ & $0.32343 \mathrm{E}+01$ & $0.39249 \mathrm{E}$ & $\begin{array}{l}0.15499 \mathrm{E}-01 \\
0.21005 \mathrm{E}+01\end{array}$ & 0.36923 & $\begin{array}{l}0.17234 \mathrm{E}+\mathrm{C} \\
0.39436 \mathrm{E}\end{array}$ \\
\hline & 3036401 & . & 07737 & $0.31249 \mathrm{E}$ & 12165 & & 063146 \\
\hline & 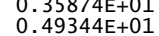 & $\begin{array}{l}537 \\
554\end{array}$ & 30 & $\begin{array}{l}0.95119 \\
0.26509\end{array}$ & 0.22450 & 0.87 & 0.24 \\
\hline & & 0. & 0.26 & $0.6190 \mathrm{~s}$ & 1 & & \\
\hline & & & & & 1 & & \\
\hline & $\mathrm{E}+01$ & $\begin{array}{l}0.47610 \mathrm{E}+01 \\
0.26200 \mathrm{E}+00\end{array}$ & $\begin{array}{l}0.39453 \mathrm{E}+01 \\
0.92830 \mathrm{E}+00\end{array}$ & $\begin{array}{l}0.572 \\
0.570\end{array}$ & $\begin{array}{r}0.21675 \mathrm{E}+01 \\
-0.1415 \mathrm{E}+01\end{array}$ & $\begin{array}{l}01 \\
00\end{array}$ & +01 \\
\hline & & & & & & & \\
\hline & & $0.15090 \mathrm{E}$ & 031 & & & & \\
\hline & & & 0 & & & & \\
\hline & & & & & & & \\
\hline
\end{tabular}




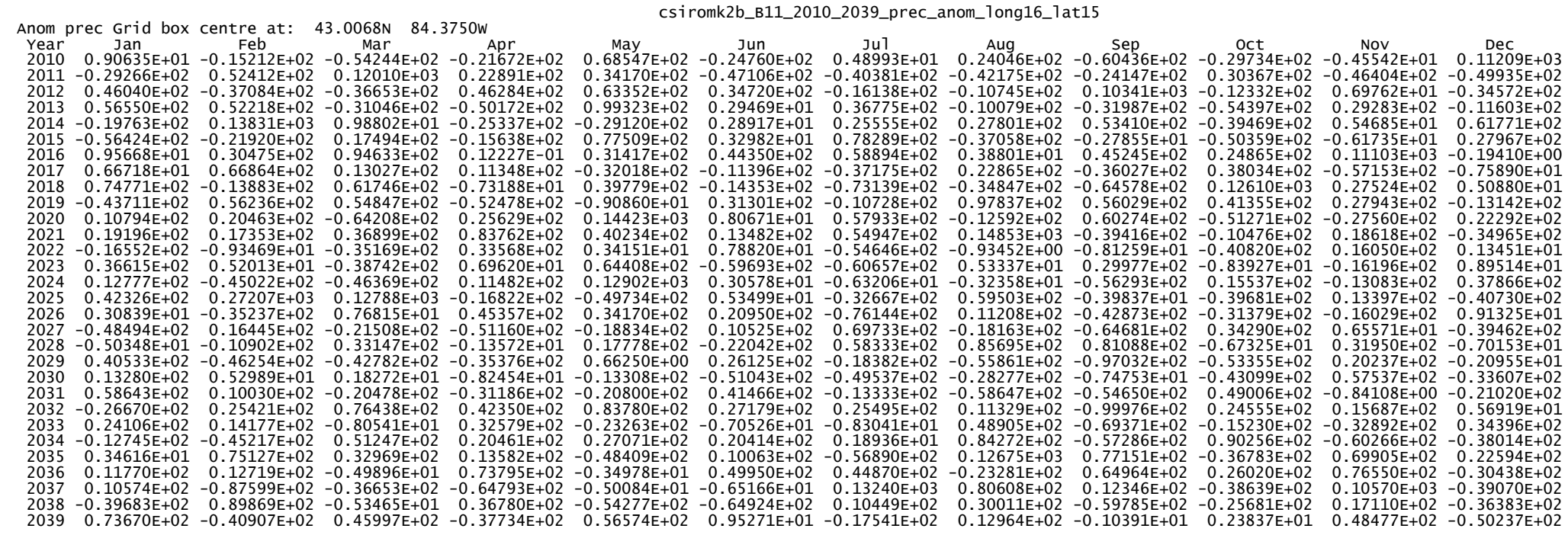




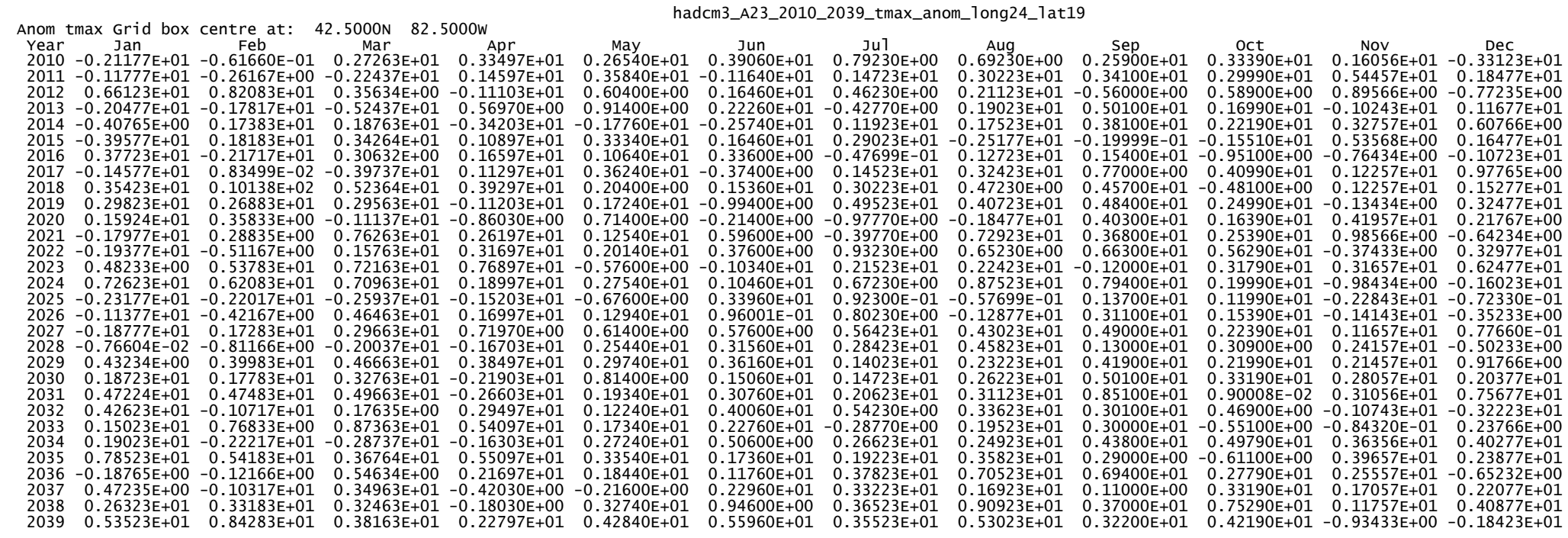


Anom prec Grid box centre at: 42.5000N $82.5000 \mathrm{~W}$

hadcm3_A23_2010_2039_prec_anom_7ong24_7at19

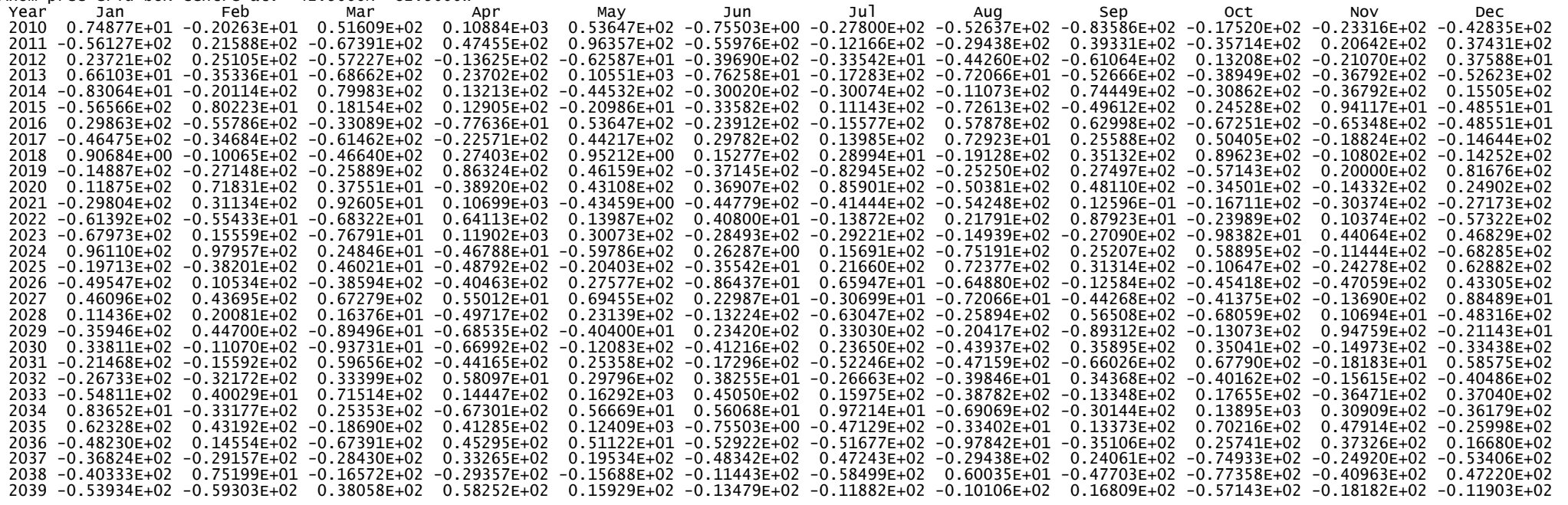




\section{Appendix B \\ Artificial Neural Network Input Variable Selection Experiment Results}


Training 1 Initial Training

Set up training tags, and see relative importance of variables.

Training 2 Insert Random Variable

Training 3 Relative importance of Max Temp (t-n) and Total Prec (t-n)

Training 4 Delete Max Temp (t-1) to $(\mathrm{t}-3)$, Precp $(\mathrm{t}-1)$ to $(\mathrm{t}-3)$

Training 5-2 Avg. Max Temp (t-1 to $t-3)$ and Total Prec (t-1 to $t-3)$ to see if it perfer one or another 


\begin{tabular}{|c|c|c|c|c|c|c|}
\hline \multirow[t]{2}{*}{ Number of Trials in each Training: 6} & \multicolumn{6}{|c|}{ Training } \\
\hline & 1(i) & 2(i) & 3(i) & 4(i) & $5(\mathrm{i})$ & 6(i) \\
\hline \multicolumn{7}{|l|}{ Training } \\
\hline \% Bad Predictions (20\% Tolerance) & $13.2 \%$ & $12.4 \%$ & $22.4 \%$ & $13.1 \%$ & $12.1 \%$ & $11.5 \%$ \\
\hline Root Mean Square Error & 0.0461 & 0.0451 & 0.0624 & 0.0462 & 0.0449 & 0.0444 \\
\hline Mean Absolute Error & 0.0310 & 0.0302 & 0.0459 & 0.0320 & 0.0304 & 0.0299 \\
\hline Change of Mean Abs. Err. as compared to 1 (i) & & $-3 \%$ & $33 \%$ & $3 \%$ & $-2 \%$ & $-4 \%$ \\
\hline Std. Deviation of Abs. Error & 0.0340 & 0.0334 & 0.0421 & 0.0333 & 0.0330 & 0.0327 \\
\hline \multicolumn{7}{|l|}{ Testing } \\
\hline$\%$ Bad Predictions (20\% Tolerance) & $24.6 \%$ & $22.6 \%$ & $26.0 \%$ & $25.6 \%$ & $25.3 \%$ & $26.9 \%$ \\
\hline Root Mean Square Error & 0.0683 & 0.0684 & 0.0685 & 0.0705 & 0.0698 & 0.0694 \\
\hline Mean Absolute Error & 0.0486 & 0.0483 & 0.0492 & 0.0498 & 0.0494 & 0.0489 \\
\hline Change of Mean Abs. Err. as compared to 1 (i) & & $-1 \%$ & $2 \%$ & $2 \%$ & $2 \%$ & $1 \%$ \\
\hline Std. Deviation of Abs. Error & 0.0479 & 0.0483 & 0.0476 & 0.0498 & 0.0494 & 0.0491 \\
\hline
\end{tabular}

\begin{tabular}{|c|c|c|c|c|c|c|}
\hline \multirow[t]{2}{*}{ Number of Trials in each Training: 6} & \multicolumn{6}{|c|}{ Training } \\
\hline & 1(ii) & 2(ii) & 3(ii) & 4(ii) & 5(ii) & 6(ii) \\
\hline \multicolumn{7}{|l|}{ Training } \\
\hline$\%$ Bad Predictions (20\% Tolerance) & $11.8 \%$ & $10.5 \%$ & $19.2 \%$ & $11.4 \%$ & $10.5 \%$ & $10.9 \%$ \\
\hline Root Mean Square Error & 0.0440 & 0.0422 & 0.0567 & 0.0456 & 0.0427 & 0.0436 \\
\hline Mean Absolute Error & 0.0295 & 0.0275 & 0.0400 & 0.0303 & 0.0288 & 0.0287 \\
\hline Change of Mean Abs. Err. as compared to 1 (ii) & & $-7 \%$ & $26 \%$ & $3 \%$ & $-2 \%$ & $-3 \%$ \\
\hline Std. Deviation of Abs. Error & 0.0325 & 0.0319 & 0.0402 & 0.0341 & 0.0314 & 0.0327 \\
\hline \multicolumn{7}{|l|}{ Testing } \\
\hline$\%$ Bad Predictions (20\% Tolerance) & $23.3 \%$ & $22.9 \%$ & $23.5 \%$ & $24.7 \%$ & $23.8 \%$ & $22.9 \%$ \\
\hline Root Mean Square Error & 0.0667 & 0.0668 & 0.0644 & 0.0669 & 0.0658 & 0.0659 \\
\hline Mean Absolute Error & 0.0469 & 0.0474 & 0.0475 & 0.0476 & 0.0468 & 0.0463 \\
\hline Change of Mean Abs. Err. as compared to 1 (ii) & & $1 \%$ & $0 \%$ & $2 \%$ & $0 \%$ & $-1 \%$ \\
\hline Std. Deviation of Abs. Error & 0.0473 & 0.0469 & 0.0434 & 0.0470 & 0.0462 & 0.0467 \\
\hline
\end{tabular}

Note: A decrease of Mean Abs Err indicates that there is an improvement of model prediction.

Comparisons made to $1(\mathrm{i})$ :

2(i) There is a small decrease of Mean Abs Err in training, which is odd. However, this may have be caused by the selection of training and testing points.

3(i) There is a significant increase of Mean Abs Err from 1 (i) to 3(i), which illustrates that an elimination of the variables of precipitation would significantly degraded the net.

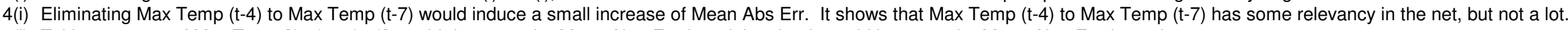

5(i) Taking average of Max Temp [(t-1) to (t-3)] would decrease the Mean Abs. Err. in training, but it would increase the Mean Abs. Err. in testing.

6(i) Taking average of Max Temp [(t-1) to (t-3)] and total of Precp [(t-1) to (t-3)] would decrease the Mean Abs. Err. in training and increase the Mean Abs. Err. in testing.

Comparisons made to 1 (ii):

2(ii) There is a decrease of Mean Abs Err in training but an small increase of Mean Abs Err in testing.

3(ii) There is a significant increase of Mean Abs Err from 1(i) to 3(i), which illustrates that an elimination of the variables of precipitation would significantly degraded the net.

4(ii) Eliminating Precp (t-4) to Precp (t-7) would induce a small increase of Mean Abs Err. It shows that Max Temp (t-4) to Max Temp (t-7) has some relevancy in the net, but not a lot.

5 (ii) Totaling Precp[(t-1) to (t-3)] would decrease the Mean Abs. Err in training and would leave the Mean Abs. Err. in testing unchange.

6(ii) Totaling Precp[(t-1) to (t-3)] would decrease the Mean Abs. Err in training and testing. It will result in the best configurations.

Final note: If one takes the average of the results of 6(i) and 6(ii), the Change of Mean Abs. Err. From 1 (i) and 1 (ii) is $-3.5 \%$ and $0 \%$ for training and testing respectively.

This illustrates that the pruning of the input variables indeed improved the prediction of the training set a bit and leaving the prediction on the testing set unchange.

Therefore, it can be concluded that the pruned input variable set is just as good, if not slightly better than the orginial set.

However, it dimensions on which the neural network need to train on has reduced significantly, and therefore would benefit the efficiency of the computation time. 


\begin{tabular}{|c|c|c|c|c|c|c|}
\hline & 1(i) & 2(i) & 3(i) & 4(i) & 5(i) & $6(i)$ \\
\hline & $\operatorname{Max}$ & $\operatorname{Max}$ & $\operatorname{Max}$ & $\operatorname{Max}$ & $\operatorname{Max}$ & $\operatorname{Max}$ \\
\hline \% Bad Predictions (20\% Tolerance) & $18.3 \%$ & $18.3 \%$ & $24.5 \%$ & $19.0 \%$ & $14.6 \%$ & \\
\hline Root Mean Square Error & 0.0527 & 0.0541 & 0.0647 & 0.0520 & 0.0501 & 0.0475 \\
\hline Mean Absolute Error & 0.0363 & 0.0376 & 0.0475 & 0.0375 & 0.0340 & 0.0330 \\
\hline Std. Deviation of Abs. Error & 0.0383 & 0.0390 & 0.0443 & 0.0371 & 0.0368 & 0.0342 \\
\hline$\%$ Bad Predictions (20\% Tolerance) & $31.1 \%$ & $27.3 \%$ & $29.5 \%$ & $32.3 \%$ & $29.3 \%$ & $33.3 \%$ \\
\hline Root Mean Square Error & 0.0794 & 0.0818 & 0.0750 & 0.0715 & 0.0727 & 0.0767 \\
\hline Mean Absolute Error & 0.0556 & 0.0554 & 0.0521 & 0.0516 & 0.0518 & 0.0524 \\
\hline Std. Deviation of Abs. Error & 0.0567 & 0.0602 & 0.0545 & 0.0527 & 0.0520 & 0.0560 \\
\hline & 1(ii) & 2(ii) & 3(ii) & 4(ii) & 5(ii) & 6(ii) \\
\hline & $\operatorname{Max}$ & $\operatorname{Max}$ & $\operatorname{Max}$ & $\operatorname{Max}$ & Max & $\operatorname{Max}$ \\
\hline & $20.8 \%$ & $19.1 \%$ & $21.2 \%$ & $14.8 \%$ & $14.8 \%$ & $16.7 \%$ \\
\hline & 0.0547 & 0.0529 & 0.0594 & 0.0496 & 0.0482 & 0.0514 \\
\hline & 0.0396 & 0.0377 & 0.0430 & 0.0335 & 0.0325 & 0.0355 \\
\hline & 0.0378 & 0.0371 & 0.0414 & 0.0368 & 0.0356 & 0.0373 \\
\hline & $27.7 \%$ & $28.4 \%$ & $29.3 \%$ & $31.4 \%$ & $29.7 \%$ & $27.7 \%$ \\
\hline & 0.0732 & 0.0739 & 0.0713 & 0.0732 & 0.0701 & 0.0694 \\
\hline & 0.0520 & 0.0540 & 0.0510 & 0.0519 & 0.0508 & 0.0495 \\
\hline & 0.0515 & 0.0517 & 0.0499 & 0.0536 & 0.0512 & 0.0513 \\
\hline
\end{tabular}

this slightly increase, because of the addition of an random variable

b. comparing $3(i)$ and $4(i)$, it shows that the general quality of training and testing improved

\section{Aumber of Trials in each Training: 6}

\begin{tabular}{|c|c|c|c|c|c|c|}
\hline Training no. & 1(i) & 2 (i) & $3($ (i) & 4 (i) & 5 (i) & $6(i)$ \\
\hline \multicolumn{7}{|l|}{ Training } \\
\hline$\%$ Bad Predictions (20\% Tolerance) & $13.2 \%$ & $12.4 \%$ & $22.4 \%$ & $13.1 \%$ & $12.1 \%$ & $11.5 \%$ \\
\hline Root Mean Square Error & 0.0461 & 0.0451 & 0.0624 & 0.0462 & 0.0449 & 0.0444 \\
\hline Mean Absolute Error & 0.0310 & 0.0302 & 0.0459 & 0.0320 & 0.0304 & 0.0299 \\
\hline Std. Deviation of Abs. Error & 0.0340 & 0.0334 & 0.0421 & 0.0333 & 0.0330 & 0.0327 \\
\hline \multicolumn{7}{|l|}{ Testing } \\
\hline \% Bad Predictions (20\% Tolerance) & $24.6 \%$ & $22.6 \%$ & $26.0 \%$ & $25.6 \%$ & $25.3 \%$ & $26.9 \%$ \\
\hline Root Mean Square Error & 0.0683 & 0.0684 & 0.0685 & 0.0705 & 0.0698 & 0.0694 \\
\hline Mean Absolute Error & 0.0486 & 0.0483 & 0.0492 & 0.0498 & 0.0494 & 0.0489 \\
\hline Std. Deviation of Abs. Error & 0.0479 & 0.0483 & 0.0476 & 0.0498 & 0.0494 & $\overrightarrow{0.0491}$ \\
\hline
\end{tabular}

\begin{tabular}{|c|c|c|c|c|c|c|}
\hline Training no. & 1(i) & 2(i) & $3(i)$ & 4(i) & $5(\mathrm{i})$ & 6(i) \\
\hline \multicolumn{7}{|l|}{ Training } \\
\hline \% Bad Predictions (20\% Tolerance) & $11.8 \%$ & $10.5 \%$ & $19.2 \%$ & $11.4 \%$ & $10.5 \%$ & $10.9 \%$ \\
\hline Root Mean Square Error & 0.0440 & 0.0422 & 0.0567 & 0.0456 & 0.0427 & 0.0436 \\
\hline Mean Absolute Error & 0.0295 & 0.0275 & 0.0400 & 0.0303 & 0.0288 & 0.0287 \\
\hline Std. Deviation of Abs. Error & 0.0325 & 0.0319 & 0.0402 & 0.0341 & 0.0314 & 0.0327 \\
\hline \multicolumn{7}{|l|}{ Testing } \\
\hline$\%$ Bad Predictions (20\% Tolerance) & $23.3 \%$ & $22.9 \%$ & $23.5 \%$ & $24.7 \%$ & $23.8 \%$ & $22.9 \%$ \\
\hline Root Mean Square Error & 0.0667 & 0.0668 & 0.0644 & 0.0669 & 0.0658 & 0.0659 \\
\hline Mean Absolute Error & 0.0469 & 0.0474 & 0.0475 & 0.0476 & 0.0468 & 0.0463 \\
\hline Std. Deviation of Abs. Error & 0.0473 & 0.0469 & 0.0434 & $0.04 \overline{70}$ & 0.0462 & 0.0467 \\
\hline \multicolumn{7}{|l|}{ this slightly increased } \\
\hline $\begin{array}{l}\text { of Bad Prediction of Training incr } \\
\text { is is not an identical comparsion. } \\
\text { lative importance and show that b } \\
\text { le RMS and \% Bad Prediction wo }\end{array}$ & & & & & & \\
\hline
\end{tabular}

\begin{tabular}{|c|c|c|c|c|c|c|c|c|c|c|}
\hline & 1 & 1(i) & 2 & 2(i) & 3 (all) & 3(i) & 4(all) & 4(i) & 5(i) & $6(i)$ \\
\hline & Min & Min & Min & Min & Min & Min & Min & Min & Min & $\begin{array}{c}\text { Min } \\
8.4 \%\end{array}$ \\
\hline \% Bad Predictions (20 & $2.7 \%$ & $5.7 \%$ & $4.0 \%$ & $4.7 \%$ & $15.6 \%$ & $21.4 \%$ & $6.4 \%$ & $6.4 \%$ & $7.9 \%$ & \\
\hline Root Mean Square Er & 0.0269 & 0.0336 & 0.0294 & 0.0303 & 0.0517 & 0.0589 & 0.0360 & 0.0360 & 0.0383 & 0.04 \\
\hline Mean Absolute Error & 0.0161 & 0.0195 & 0.0171 & 0.0172 & 0.0352 & 0.0441 & 0.0240 & 0.0240 & 0.0237 & 0.02 \\
\hline Std. Deviation of Abs. & 0.0216 & 0.0273 & 0.0238 & 0.0250 & 0.0380 & 0.0390 & 0.0268 & 0268 & 0.0300 & 0.0 \\
\hline \% Bad Predictions (20 & $15.8 \%$ & $15.8 \%$ & $16.1 \%$ & $17.8 \%$ & $18.0 \%$ & $22.5 \%$ & $18.4 \%$ & $20.5 \%$ & $19.8 \%$ & 21. \\
\hline Root Mean Square Er & 0.0572 & 0.0578 & 0.0602 & 0.0602 & 0.0564 & 0.0630 & 0.0580 & 0.0686 & 0.063376 & 0.0 \\
\hline Mean $A b$ & 0.0397 & 0.0437 & 0.0433 & 0.0449 & 0.0423 & 0.0452 & 0.0411 & 0.0483 & 0.045323 & 0.0 \\
\hline Std. Deviation of Abs. & 0.0379 & 0.0379 & 0.0391 & 0.0391 & 0.0373 & 0.0440 & 0.0410 & 0.0465 & 0.044298 & \\
\hline & & 1(ii) & & 2(i) & & 3(ii) & & 4( & 5(ii) & \\
\hline & & Min & & Min & & Min & & Min & Min & \\
\hline & & $2.7 \%$ & & $4.0 \%$ & & $16 \%$ & & 7.7 & $6.7 \%$ & \\
\hline & & 0.0269 & & 0.0294 & & 0.0517 & & 0.0419 & 0.0363 & 0.0 \\
\hline & & 0.0161 & & 0.0171 & & 0.0352 & & 0.0258 & 0.0237 & \\
\hline & & 0.0216 & & 0.0238 & & 0.0380 & & 0.0321 & 0.0275 & \\
\hline & & $19.5 \%$ & & $16.1 \%$ & & $18.0 \%$ & & $18.4 \%$ & $16 \%$ & 15. \\
\hline & & 0.05716 & & 0.0604 & & 0.0564 & & 0.0580 & 0.0556 & \\
\hline & & 0.03969 & & 0.0433 & & 0.0423 & & 0.0411 & 0.0390 & \\
\hline & & 0.04071 & & 0.0398 & & 0.0373 & & 0.0410 & 0.0396 & 0.03 \\
\hline
\end{tabular}

$\begin{array}{lcccc} & \begin{array}{c}1 \\ \text { Stdev }\end{array} & \begin{array}{c}1(i) \\ \text { Stdev }\end{array} & \begin{array}{c}2 \\ \text { Stdev }\end{array} & \begin{array}{c}2(i) \\ \text { Stdev }\end{array} \\ \text { \% Bad Predictions (20 } & 5.3 \% & 4.8 \% & 4.9 \% & 4.6 \% \\ \text { Root Mean Square Erl } & 0.0082 & 0.0072 & 0.0080 & 0.0081 \\ \text { Mean Absolute Error } & 0.0071 & 0.0066 & 0.0070 & 0.0071 \\ \text { Std. Deviation of Abs. } & 0.0048 & 0.0039 & 0.0046 & 0.0046 \\ & & & & \\ \text { \% Bad Predictions (20 } & 5 \% & 6 \% & 4.0 \% & 4.1 \% \\ \text { Root Mean Square Er } & 0.0064 & 0.0075 & 0.0061 & 0.0076 \\ \text { Mean Absolute Error } & 0.0041 & 0.0042 & 0.0036 & 0.0038 \\ \text { Std. Deviation of Abs. } & 0.0057 & 0.0067 & 0.0059 & 0.0071\end{array}$

$\begin{array}{ccccc}3(i) & 4(\text { all }) & 4(\text { i) } & 5(i) & 6(i) \\ \text { Stdev } & \text { Stdev } & \text { Stdev } & \begin{array}{c}\text { Stdev } \\ \text { Stdev }\end{array} \\ 1 \% & 3 \% & 4.2 \% & 2.3 \% & 1.63 \% \\ 0.002 & 0.0045 & 0.0060 & 0.0039 & 0.003 \\ 0.002 & 0.0038 & 0.0046 & 0.0035 & 0.003 \\ 0.0018 & 0.0031 & 0.0041 & 0.0026 & 0.002 \\ & & & \\ 2 \% & 4 \% & 4.6 \% & 3.9 \% & 4.35 \% \\ 0.004 & 0.0042 & 0.001 & 0.0036 & 0.005 \\ 0.003 & 0.0029 & 0.001 & 0.0024 & 0.002 \\ 0.0040 & 0.0042 & 0.002 & 0.0031 & 0.005\end{array}$

$\begin{array}{cc} & 2 \text { (ii) } \\ \text { Stdev } & \text { Stdev } \\ 6.1 \% & 5.4 \% \\ 0.0097 & 0.0084 \\ 0.0082 & 0.0073 \\ 0.0059 & 0.0049 \\ 3.6 \% & 4.4 \% \\ 0.0057 & 0.0049 \\ 0.0041 & 0.0036 \\ 0.0052 & 0.0050\end{array}$

$\begin{array}{ccc}4 \text { (ii) } & 5 \text { (ii) } & 6 \text { (ii) } \\ \text { Stdev } & \text { Stdev } & \text { Stdev } \\ 2.5 \% & 3.2 \% & 4.74 \% \\ 0.0031 & 0.0042 & 0.006 \\ 0.0030 & 0.0036 & 0.005 \\ 0.0021 & 0.0026 & 0.004 \\ 4.8 \% & 5.3 \% & 5.84 \% \\ 0.0054 & 0.0052 & 0.005 \\ 0.0037 & 0.0044 & 0.004 \\ 0.0053 & 0.0042 & 0.004\end{array}$


Appendix C

Simulation Results 


\begin{tabular}{ccc}
$\begin{array}{c}\text { Scenario } \\
\text { no. }\end{array}$ & $\begin{array}{c}\text { Corresponding } \\
\text { trial no. }\end{array}$ & $\begin{array}{c}\text { No. of Days } \\
\text { Failed }\end{array}$ \\
\hline 1 & 87 & 6 \\
& 82 & 53 \\
\hline 2 & 4,38 & 21 \\
& 99 & 84 \\
\hline 3 & 87 & 6 \\
& 82 & 53 \\
\hline 4 & 87 & 5 \\
& 82 & 50 \\
\hline 5 & 87 & 0 \\
& 82 & 23 \\
\hline 6 & more than 1 & 0 \\
& 34 & 10 \\
\hline $1 \mathrm{~b}$ & 40 & 139 \\
& 82 & 243 \\
\hline $3 \mathrm{~b}$ & 40 & 137 \\
& 82 & 238 \\
\hline $4 \mathrm{~b}$ & 40 & 130 \\
& 43 & 224 \\
\hline $5 \mathrm{~b}$ & 4 & 61 \\
& 82 & 141 \\
\hline $6 \mathrm{~b}$ & 4 & 21 \\
& 99 & 88 \\
\hline & &
\end{tabular}

\begin{tabular}{|c|c|c|}
\hline $\begin{array}{c}\text { Scenario } \\
\text { no. }\end{array}$ & $\begin{array}{c}\text { Corresponding } \\
\text { trial no. }\end{array}$ & $\begin{array}{l}\text { No. of Days } \\
\text { Failed }\end{array}$ \\
\hline \multirow[t]{2}{*}{7} & 7 & 79 \\
\hline & 99 & 170 \\
\hline \multirow[t]{2}{*}{8} & 7 & 78 \\
\hline & 99 & 168 \\
\hline \multirow[t]{2}{*}{9} & 7 & 73 \\
\hline & 99 & 155 \\
\hline \multirow[t]{2}{*}{10} & 7 & 35 \\
\hline & 9 & 92 \\
\hline \multirow[t]{2}{*}{11} & 7,70 & 15 \\
\hline & 30,78 & 52 \\
\hline \multirow[t]{2}{*}{$7 a$} & 7 & 73 \\
\hline & 99 & 172 \\
\hline \multirow[t]{2}{*}{$8 a$} & 7 & 70 \\
\hline & 99 & 165 \\
\hline \multirow[t]{2}{*}{$9 a$} & 7 & 65 \\
\hline & 99 & 159 \\
\hline \multirow[t]{2}{*}{$10 a$} & 7 & 35 \\
\hline & 56 & 89 \\
\hline \multirow[t]{2}{*}{$11 a$} & 70 & 12 \\
\hline & 56 & 48 \\
\hline \multirow[t]{2}{*}{$7 c$} & 54 & 381 \\
\hline & 35 & 551 \\
\hline \multirow[t]{2}{*}{$8 c$} & 54 & 373 \\
\hline & 35 & 546 \\
\hline \multirow[t]{2}{*}{$9 \mathrm{c}$} & 54 & 364 \\
\hline & 78 & 536 \\
\hline \multirow[t]{2}{*}{$10 \mathrm{c}$} & 54 & 238 \\
\hline & 99 & 381 \\
\hline \multirow[t]{2}{*}{$11 \mathrm{c}$} & 19 & 139 \\
\hline & 61 & 252 \\
\hline
\end{tabular}

\begin{tabular}{|c|c|c|}
\hline $\begin{array}{c}\text { Scenario } \\
\text { no. }\end{array}$ & $\begin{array}{c}\text { Corresponding } \\
\text { trial no. }\end{array}$ & $\begin{array}{l}\text { No. of Days } \\
\text { Failed }\end{array}$ \\
\hline \multirow[t]{2}{*}{12} & 4 & 135 \\
\hline & 85 & 244 \\
\hline \multirow[t]{2}{*}{13} & 4 & 134 \\
\hline & 85 & 240 \\
\hline \multirow[t]{2}{*}{14} & 4 & 129 \\
\hline & 85 & 231 \\
\hline \multirow[t]{2}{*}{15} & 4 & 59 \\
\hline & 45 & 146 \\
\hline \multirow[t]{2}{*}{16} & 40 & 3 \\
\hline & 99 & 54 \\
\hline \multirow[t]{2}{*}{$12 a$} & 56 & 129 \\
\hline & 89 & 242 \\
\hline \multirow[t]{2}{*}{$13 a$} & 56 & 127 \\
\hline & 89 & 240 \\
\hline \multirow[t]{2}{*}{$14 a$} & 41 & 121 \\
\hline & 89 & 232 \\
\hline \multirow[t]{2}{*}{$15 a$} & 4 & 54 \\
\hline & 75 & 149 \\
\hline \multirow[t]{2}{*}{$16 a$} & 40 & 2 \\
\hline & 37 & 53 \\
\hline \multirow[t]{2}{*}{$12 \mathrm{c}$} & 41 & 485 \\
\hline & 85 & 657 \\
\hline \multirow[t]{2}{*}{$13 \mathrm{c}$} & 41 & 477 \\
\hline & 85 & 648 \\
\hline \multirow[t]{2}{*}{$14 \mathrm{c}$} & 41 & 463 \\
\hline & 85 & 634 \\
\hline \multirow[t]{2}{*}{$15 c$} & 93 & 316 \\
\hline & 85 & 474 \\
\hline \multirow[t]{2}{*}{$16 c$} & 41 & 192 \\
\hline & 77 & 319 \\
\hline
\end{tabular}

\begin{tabular}{ccc}
$\begin{array}{c}\text { Scenario } \\
\text { no. }\end{array}$ & $\begin{array}{c}\text { Corresponding } \\
\text { trial no. }\end{array}$ & $\begin{array}{c}\text { No. of Days } \\
\text { Failed }\end{array}$ \\
\hline 17 & 40 & 67 \\
& 62 & 148 \\
\hline 18 & 40 & 64 \\
& 85 & 144 \\
\hline 19 & 40 & 58 \\
& 85 & 139 \\
\hline 20 & 76 & 18 \\
& 85 & 86 \\
\hline 21 & 76 & 2 \\
& 85 & 40 \\
\hline 22 & 16 & 29 \\
& 75 & 88 \\
\hline 23 & 87 & 27 \\
& 75 & 86 \\
\hline 24 & 16 & 24 \\
& 75 & 82 \\
\hline 25 & 16 & 6 \\
& 75 & 46 \\
\hline 26 & 27 & 0 \\
& 34 & 20 \\
\hline
\end{tabular}




\begin{tabular}{|c|c|c|c|c|c|c|c|c|c|c|c|c|c|c|c|c|c|c|c|c|c|c|c|}
\hline Trial No. & $\begin{array}{l}\text { Total no. of } \\
\text { Days }\end{array}$ & $\begin{array}{l}\text { No. of } \\
\text { Days } \\
\text { Failed }\end{array}$ & $\begin{array}{l}\text { No. of } \\
\text { Consecutive } \\
\text { Failures }\end{array}$ & $\begin{array}{l}\text { Max. } \\
\text { Failure } \\
\text { Duration }\end{array}$ & $\begin{array}{c}\text { Min. } \\
\text { Failure } \\
\text { Duration }\end{array}$ & $\begin{array}{c}\text { Avg. } \\
\text { Failure } \\
\text { Duration }\end{array}$ & $\begin{array}{l}\text { Max } \\
\text { Severity of } \\
\text { Failure }\end{array}$ & $\begin{array}{l}\text { Min } \\
\text { Severity of } \\
\text { Failure }\end{array}$ & $\begin{array}{l}\text { Avg. } \\
\text { Severity of } \\
\text { a Failure }\end{array}$ & $\begin{array}{l}\text { Total } \\
\text { Severity of } \\
\text { Failure }\end{array}$ & $\begin{array}{l}\text { Total Maximum } \\
\text { Severity of } \\
\text { Sojourn }\end{array}$ & Reliability, $\alpha$ & $\begin{array}{c}\text { Resiliency, } \\
F\left(E\left[T_{\mathrm{f}}\right]\right)\end{array}$ & $\begin{array}{l}\text { Resiliency, } \\
\text { 1/(MD/NS*NF) }\end{array}$ & Vulnerability 1 & Vulnerability 2 & $0-500$ & 501-1000 & $1001-150 \mathrm{C}$ & $1501-2000$ & 2001-2500 & $>2500$ & $\begin{array}{l}\text { Eculidean } \\
\text { Distance }\end{array}$ \\
\hline 1 & 7305 & 21 & 12 & 6 & 1 & 1.8 & 461 & 19 & 173 & 3639 & 2510 & 0.9971 & 0.5714 & 58 & 209 & 173 & 0 & 526 & 5531 & 1058 & 170 & 20 & 0.3894 \\
\hline 2 & 7305 & 19 & 13 & 3 & 1 & 1.5 & 384 & 11 & 142 & 2690 & 2138 & 0.9974 & 0.6842 & 128 & 164 & 142 & 0 & 550 & 5405 & 1174 & 162 & 14 & 0.5050 \\
\hline 3 & 7305 & 28 & 13 & 5 & 1 & 2.2 & 532 & 30 & 203 & 5695 & 2982 & 0.9962 & 0.4643 & 52 & 229 & 203 & 0 & 561 & 5426 & 1148 & 145 & 25 & 0.3399 \\
\hline 4 & 7305 & 7 & 4 & 2 & 1 & 1.8 & 479 & 23 & 152 & 1065 & 928 & 0.9990 & 0.5714 & 522 & 232 & 152 & 0 & 537 & 5518 & 1126 & 118 & 6 & 0.5388 \\
\hline 5 & 7305 & 17 & 11 & 3 & 1 & 1.5 & 296 & 24 & 115 & 1959 & 1442 & 0.9977 & 0.6471 & 143 & 131 & 115 & 0 & 534 & 5437 & 1158 & 160 & 16 & 0.4689 \\
\hline 6 & 7305 & 24 & 15 & 4 & 1 & 1.6 & 644 & 17 & 149 & 3567 & 2725 & 0.9967 & 0.6250 & 76 & 182 & 149 & 0 & 551 & 5469 & 1090 & 175 & 20 & 0.6164 \\
\hline 7 & 7305 & 13 & 6 & 4 & 1 & 2.2 & 558 & 2 & 219 & 2850 & 1652 & 0.9982 & 0.4615 & 140 & 275 & 219 & 0 & 575 & 5428 & 1130 & 159 & 13 & 0.6314 \\
\hline $\begin{array}{l}8 \\
9\end{array}$ & $\begin{array}{l}7305 \\
7305\end{array}$ & 13 & & 2 & 1 & 1.3 & 419 & 14 & 191 & 2480 & 2021 & 0.9982 & 0.7692 & 281 & 202 & 191 & 0 & 542 & 5470 & 1146 & 137 & 10 & 0.4554 \\
\hline $\begin{array}{c}9 \\
10\end{array}$ & $\begin{array}{l}7305 \\
7305\end{array}$ & 31 & $\begin{array}{l}19 \\
16\end{array}$ & $\begin{array}{l}5 \\
5\end{array}$ & 1 & $\begin{array}{l}1.6 \\
1.6\end{array}$ & $\begin{array}{l}489 \\
525\end{array}$ & 13 & $\begin{array}{l}190 \\
130\end{array}$ & $\begin{array}{l}5900 \\
3756\end{array}$ & 3776 & 0.9958 & 0.6129 & 47 & 199 & $\begin{array}{l}190 \\
190\end{array}$ & 0 & 548 & $\begin{array}{l}5436 \\
5509\end{array}$ & 1103 & 193 & 25 & 0.5034 \\
\hline 11 & 7305 & 22 & 11 & 4 & 1 & $\begin{array}{l}.8 \\
2.0\end{array}$ & $\begin{array}{l}525 \\
487\end{array}$ & $\begin{array}{l}6 \\
4\end{array}$ & $\begin{array}{l}130 \\
212\end{array}$ & $\begin{array}{l}3756 \\
4661\end{array}$ & $\begin{array}{l}1923 \\
2576\end{array}$ & $\begin{array}{l}0.9960 \\
0.9970\end{array}$ & $\begin{array}{l}0.5517 \\
0.5000\end{array}$ & $\begin{array}{l}50 \\
83\end{array}$ & $\begin{array}{l}120 \\
234\end{array}$ & $\begin{array}{r}130 \\
212\end{array}$ & 0 & $\begin{array}{l}547 \\
561\end{array}$ & & $\begin{array}{l}1090 \\
1158\end{array}$ & $\begin{array}{l}134 \\
153\end{array}$ & $\begin{array}{l}25 \\
21\end{array}$ & 0.3409 \\
\hline 12 & 7305 & 30 & 15 & 6 & 1 & 2.0 & 425 & 3 & 194 & 5818 & 3248 & $\begin{array}{l}0.9970 \\
0.9959\end{array}$ & $\begin{array}{l}0.5000 \\
0.5000\end{array}$ & $\begin{array}{l}83 \\
41\end{array}$ & $\begin{array}{l}234 \\
217\end{array}$ & $\begin{array}{l}212 \\
194\end{array}$ & $\begin{array}{l}0 \\
0\end{array}$ & $\begin{array}{l}561 \\
542\end{array}$ & $\begin{array}{l}5412 \\
5490\end{array}$ & $\begin{array}{l}1158 \\
1062\end{array}$ & $\begin{array}{l}153 \\
184\end{array}$ & $\begin{array}{l}21 \\
27\end{array}$ & $\begin{array}{l}0.4638 \\
0.3559\end{array}$ \\
\hline 13 & 7305 & 28 & 10 & 10 & 1 & 2.8 & 876 & 11 & 314 & 8801 & 2826 & 0.9962 & 0.3571 & 26 & 283 & 314 & 0 & 514 & 5449 & 1140 & 174 & 28 & 0.3953 \\
\hline 15 & 7305 & 30 & 15 & 4 & 1 & 2.0 & 517 & 5 & 176 & 5292 & 3377 & $\begin{array}{l}0.9959 \\
0.9988\end{array}$ & $\begin{array}{l}0.5000 \\
0.4444\end{array}$ & 61 & $\begin{array}{l}225 \\
220\end{array}$ & $\begin{array}{l}176 \\
223\end{array}$ & $\begin{array}{l}0 \\
0\end{array}$ & $\begin{array}{l}539 \\
537\end{array}$ & $\begin{array}{l}5422 \\
5491\end{array}$ & $\begin{array}{l}1128 \\
1129\end{array}$ & $\begin{array}{l}189 \\
142\end{array}$ & 27 & $\begin{array}{l}0.3570 \\
07563\end{array}$ \\
\hline $\begin{array}{l}16 \\
17\end{array}$ & $\begin{array}{l}7305 \\
7305\end{array}$ & $\begin{array}{c}9 \\
27\end{array}$ & $\begin{array}{c}4 \\
12\end{array}$ & $\begin{array}{l}4 \\
6\end{array}$ & $\begin{array}{l}1 \\
1\end{array}$ & $\begin{array}{l}2.3 \\
2.3\end{array}$ & $\begin{array}{l}507 \\
711\end{array}$ & $\begin{array}{l}2 \\
9\end{array}$ & $\begin{array}{l}223 \\
209\end{array}$ & $\begin{array}{l}2004 \\
5654\end{array}$ & $\begin{array}{c}993 \\
2728\end{array}$ & $\begin{array}{l}0.9988 \\
0.9963\end{array}$ & $\begin{array}{l}0.4444 \\
0.4444\end{array}$ & $\begin{array}{c}203 \\
45\end{array}$ & $\begin{array}{l}248 \\
227\end{array}$ & $\begin{array}{l}223 \\
209\end{array}$ & $\begin{array}{l}0 \\
0\end{array}$ & $\begin{array}{l}537 \\
522\end{array}$ & $\begin{array}{l}5491 \\
5419\end{array}$ & $\begin{array}{l}1129 \\
1130\end{array}$ & $\begin{array}{l}142 \\
213\end{array}$ & $\begin{array}{c}6 \\
21\end{array}$ & $\begin{array}{l}0.7063 \\
0.4728\end{array}$ \\
\hline $\begin{array}{l}17 \\
18\end{array}$ & 7305 & 18 & 12 & 4 & 1 & 1.5 & 519 & 12 & 237 & 4262 & 2590 & 0.9975 & 0.6667 & $\begin{array}{l}45 \\
101\end{array}$ & 216 & 237 & 0 & 551 & 5532 & 1055 & 152 & 15 & 0.5419 \\
\hline 19 & 7305 & 12 & 6 & 4 & 1 & 2.0 & 423 & 2 & 147 & 1763 & 1170 & 0.9984 & 0.5000 & 152 & 195 & 147 & 0 & 543 & 5528 & 1100 & 123 & 11 & 0.6045 \\
\hline 20 & 7305 & 16 & 8 & 5 & 1 & 2.0 & 733 & 19 & 265 & 4237 & 2133 & 0.9978 & 0.5000 & 91 & 267 & 265 & 0 & 571 & 5474 & 1110 & 135 & 15 & 0.5060 \\
\hline 21 & 7305 & 23 & 14 & 2 & 1 & 1.6 & 508 & 9 & 158 & 3626 & 2715 & 0.9969 & 0.6087 & 159 & 194 & 158 & 0 & 549 & 5508 & 1068 & 157 & 23 & 0.2921 \\
\hline 22 & 7305 & 23 & 11 & 8 & 1 & 2.1 & 561 & 34 & 192 & 4406 & 2146 & 0.9969 & 0.4783 & 40 & 195 & 192 & 0 & 551 & 5453 & 1106 & 172 & 23 & 0.5111 \\
\hline 23 & $\begin{array}{l}7305 \\
7305\end{array}$ & 17 & $\begin{array}{l}11 \\
11\end{array}$ & $\begin{array}{l}4 \\
5\end{array}$ & 1 & $\begin{array}{l}1.5 \\
16\end{array}$ & $\begin{array}{l}440 \\
532\end{array}$ & 3 & 209 & $\begin{array}{r}3549 \\
3366\end{array}$ & $\begin{array}{l}2108 \\
2113\end{array}$ & 0.9977 & 0.6471 & 107 & 192 & 209 & 0 & 529 & 5539 & 1066 & 155 & 16 & 0.5522 \\
\hline $\begin{array}{l}24 \\
25\end{array}$ & $\begin{array}{l}7305 \\
7305\end{array}$ & $\begin{array}{l}24 \\
35 \\
35\end{array}$ & $\begin{array}{l}15 \\
15\end{array}$ & $\begin{array}{l}5 \\
5\end{array}$ & $\begin{array}{l}1 \\
1\end{array}$ & $\begin{array}{l}1.6 \\
2.3\end{array}$ & $\begin{array}{l}532 \\
565\end{array}$ & $\begin{array}{l}0 \\
5\end{array}$ & $\begin{array}{l}140 \\
225\end{array}$ & $\begin{array}{l}3366 \\
7886\end{array}$ & $\begin{array}{l}2113 \\
3639\end{array}$ & $\begin{array}{l}0.9967 \\
\end{array}$ & 0.6250 & 61 & $\begin{array}{l}141 \\
243\end{array}$ & $\begin{array}{l}140 \\
225\end{array}$ & 0 & $\begin{array}{l}559 \\
558\end{array}$ & 5455 & 1105 & $\begin{array}{l}165 \\
154\end{array}$ & $\begin{array}{l}21 \\
31\end{array}$ & 0.3465 \\
\hline $\begin{array}{l}25 \\
26 \\
26\end{array}$ & $\begin{array}{l}3305 \\
7305\end{array}$ & $\begin{array}{l}35 \\
17\end{array}$ & $\begin{array}{c}15 \\
9\end{array}$ & $\begin{array}{l}5 \\
3\end{array}$ & $\begin{array}{l}1 \\
1\end{array}$ & $\begin{array}{l}2.3 \\
1.9\end{array}$ & $\begin{array}{l}565 \\
417\end{array}$ & $\begin{array}{c}5 \\
13\end{array}$ & $\begin{array}{l}225 \\
176\end{array}$ & $\begin{array}{l}886 \\
2992\end{array}$ & $\begin{array}{l}\begin{array}{l}3639 \\
2304\end{array}\end{array}$ & $\begin{array}{l}0.99525 \\
0.9977\end{array}$ & $\begin{array}{l}0.4286 \\
0.5294\end{array}$ & $\begin{array}{l}42 \\
143\end{array}$ & $\begin{array}{l}243 \\
256\end{array}$ & $\begin{array}{l}225 \\
176\end{array}$ & 0 & $\begin{array}{l}558 \\
556\end{array}$ & $\begin{array}{l}5458 \\
5484\end{array}$ & $\begin{array}{l}\begin{array}{l}1104 \\
1110\end{array} \\
\end{array}$ & $\begin{array}{l}154 \\
140\end{array}$ & $\begin{array}{l}31 \\
15\end{array}$ & $\begin{array}{l}0.3900 \\
0.4852\end{array}$ \\
\hline 27 & 7305 & 9 & 7 & 3 & 1 & 1.3 & 507 & 14 & 182 & 1642 & 1172 & 0.9988 & 0.7778 & 271 & 167 & 182 & 0 & 542 & 5438 & 1202 & 116 & 7 & 0.5935 \\
\hline 28 & 7305 & 30 & 16 & 5 & 1 & 1.9 & 627 & 3 & 202 & 6054 & 3651 & 0.9959 & 0.5333 & 49 & 228 & 202 & 0 & 531 & 5422 & 1152 & 174 & 26 & 0.4758 \\
\hline 31 & 7305 & 30 & 20 & 4 & 1 & 1.5 & 589 & 1 & 128 & 3854 & 2854 & 0.9959 & 0.6667 & 61 & 143 & 128 & 0 & 551 & 5468 & 1082 & 177 & 27 & 0.3621 \\
\hline 32 & 7305 & 16 & 6 & 5 & 1 & 2.7 & 846 & 2 & 273 & 4366 & 1757 & 0.9978 & 0.3750 & 91 & 293 & 273 & 0 & 549 & 5489 & 1135 & 117 & 15 & 0.5318 \\
\hline 33 & 7305 & 20 & 11 & 4 & 1 & 1.8 & 519 & 22 & 231 & 4628 & 2663 & 0.9973 & 0.5500 & 91 & 242 & 231 & 0 & 546 & 5461 & 1103 & 176 & 19 & 0.4114 \\
\hline 34 & 7305 & 35 & 14 & 7 & 1 & 2.5 & 888 & 13 & 341 & 11925 & $\begin{array}{l}4864 \\
2\end{array}$ & 0.9952 & 0.4000 & 30 & 347 & 341 & 0 & 525 & 5477 & 1080 & 193 & 30 & 0.5627 \\
\hline 35 & 7305 & 25 & 15 & 4 & 1 & 1.7 & $\begin{array}{l}418 \\
517\end{array}$ & 18 & 164 & 4090 & 2395 & 0.9966 & 0.6000 & 73 & $\begin{array}{l}160 \\
\end{array}$ & $\begin{array}{l}164 \\
164\end{array}$ & 0 & 542 & 5493 & 1116 & 130 & 24 & 0.4151 \\
\hline $\begin{array}{l}36 \\
37 \\
37\end{array}$ & $\begin{array}{l}7305 \\
7305\end{array}$ & $\begin{array}{l}18 \\
26\end{array}$ & $\begin{array}{c}7 \\
14\end{array}$ & $\begin{array}{l}4 \\
6\end{array}$ & $\begin{array}{l}1 \\
1 \\
1\end{array}$ & $\begin{array}{l}2.6 \\
1.9\end{array}$ & $\begin{array}{l}517 \\
615\end{array}$ & $\begin{array}{l}41 \\
13\end{array}$ & $\begin{array}{l}202 \\
207\end{array}$ & $\begin{array}{l}3637 \\
5389\end{array}$ & $\begin{array}{l}1988 \\
2489\end{array}$ & $\begin{array}{l}0.9975 \\
0.9964\end{array}$ & $\begin{array}{l}0.3889 \\
0.5389\end{array}$ & $\begin{array}{l}101 \\
47\end{array}$ & $\begin{array}{l}284 \\
178\end{array}$ & $\begin{array}{l}202 \\
207\end{array}$ & $\begin{array}{l}0 \\
0 \\
0\end{array}$ & $\begin{array}{l}526 \\
553\end{array}$ & $\begin{array}{l}5542 \\
5373\end{array}$ & $\begin{array}{l}1056 \\
1169\end{array}$ & $\begin{array}{l}163 \\
186\end{array}$ & $\begin{array}{l}18 \\
24\end{array}$ & $\begin{array}{l}0.4507 \\
0.4462\end{array}$ \\
\hline $\begin{array}{l}37 \\
38\end{array}$ & $\begin{array}{l}7305 \\
7305\end{array}$ & $\begin{array}{l}26 \\
10\end{array}$ & $\begin{array}{c}14 \\
3 \\
3\end{array}$ & $\begin{array}{l}6 \\
7\end{array}$ & $\begin{array}{l}1 \\
1\end{array}$ & $\begin{array}{l}1.9 \\
3.3\end{array}$ & $\begin{array}{l}615 \\
303\end{array}$ & $\begin{array}{l}13 \\
73\end{array}$ & $\begin{array}{l}207 \\
173\end{array}$ & $\begin{array}{l}5389 \\
1726\end{array}$ & $\begin{array}{l}2489 \\
858\end{array}$ & $\begin{array}{l}0.9964 \\
0.9986\end{array}$ & $\begin{array}{l}0.5385 \\
0.3000\end{array}$ & $\begin{array}{c}47 \\
104\end{array}$ & $\begin{array}{l}178 \\
286\end{array}$ & $\begin{array}{l}207 \\
173\end{array}$ & 0 & $\begin{array}{l}553 \\
556\end{array}$ & $\begin{array}{l}5373 \\
5443\end{array}$ & $\begin{array}{l}1169 \\
1145\end{array}$ & $\begin{array}{l}186 \\
151\end{array}$ & $\begin{array}{l}24 \\
10\end{array}$ & $\begin{array}{l}0.4462 \\
06552\end{array}$ \\
\hline 39 & 7305 & 16 & 11 & 3 & 1 & 1.5 & 317 & 9 & 106 & $\begin{array}{l}1 / 26 \\
1700\end{array}$ & $\begin{array}{l}858 \\
1153\end{array}$ & $\begin{array}{l}0.9986 \\
0.9978\end{array}$ & $\begin{array}{l}0.3000 \\
0.6875\end{array}$ & $\begin{array}{l}104 \\
152\end{array}$ & $\begin{array}{l}286 \\
105\end{array}$ & 106 & 0 & $\begin{array}{l}556 \\
552\end{array}$ & $\begin{array}{l}5443 \\
5423\end{array}$ & $\begin{array}{r}1145 \\
1127\end{array}$ & 191 & 12 & $\begin{array}{l}0.6550 \\
0.3503\end{array}$ \\
\hline 40 & 7305 & 10 & 7 & 2 & 1 & 1.4 & 415 & 35 & 196 & 1959 & 1621 & 0.9986 & 0.7000 & 365 & 232 & 196 & 0 & 570 & 5484 & 1122 & 119 & 10 & 0.4789 \\
\hline 41 & 7305 & 19 & 7 & 10 & 1 & 2.7 & 882 & 4 & 224 & 4250 & 1583 & 0.9974 & 0.3684 & 38 & 226 & 224 & 0 & 535 & 5556 & 1083 & 113 & 18 & 0.3853 \\
\hline 42 & 7305 & 24 & 14 & 5 & 1 & 1.7 & 490 & 20 & 179 & 4286 & 2184 & 0.9967 & 0.5833 & 61 & 156 & 179 & 0 & 551 & 5484 & 1114 & 135 & 21 & 0.7034 \\
\hline 43 & 7305 & 23 & 13 & 3 & 1 & 1.8 & 479 & 9 & 166 & 38 & 2617 & 0.9969 & 0.5652 & 106 & 201 & 166 & 0 & 531 & 5499 & 1071 & 185 & 19 & 0.6345 \\
\hline 44 & 7305 & 36 & 19 & 7 & 1 & 1.9 & 571 & 16 & 198 & 71 & 4213 & & 0.5 & 29 & 222 & 198 & 0 & 577 & 5458 & 1078 & 162 & 30 & 0.2431 \\
\hline 45 & 7305 & 22 & 14 & 4 & 1 & 1.6 & 529 & 17 & 179 & 394 & 2747 & 0.9970 & 0.6364 & 83 & 196 & 179 & 0 & 561 & 5477 & 1091 & 157 & 19 & 0.6303 \\
\hline 46 & 7305 & 29 & 18 & 4 & 1 & 1.6 & 474 & 2 & 169 & 485 & 3330 & 0.9960 & 0.6207 & 63 & 185 & 160 & 0 & 532 & 5485 & 1125 & 141 & 22 & 0.3162 \\
\hline 47 & 7305 & 33 & 10 & 9 & 1 & 3.3 & 544 & 11 & 285 & 941 & 2762 & 0.9955 & 0.3030 & 25 & 276 & 285 & 0 & 545 & 5448 & 1120 & 160 & 32 & 0.2362 \\
\hline 48 & 7305 & 24 & 13 & 5 & 1 & 1.8 & $\begin{array}{l}449 \\
707\end{array}$ & 2 & $\begin{array}{l}130 \\
150\end{array}$ & 311 & 1890 & 0.9967 & 0.5417 & 61 & $\begin{array}{l}145 \\
159\end{array}$ & $\begin{array}{l}130 \\
150\end{array}$ & 0 & 552 & 5435 & 1176 & 123 & 19 & 0.4398 \\
\hline 49 & $\begin{array}{l}7305 \\
7305\end{array}$ & 21 & $\begin{array}{l}15 \\
17\end{array}$ & 4 & 1 & $\begin{array}{l}1.4 \\
2.1\end{array}$ & 727 & 2 & $\begin{array}{l}152 \\
163\end{array}$ & $\begin{array}{l}3198 \\
5855\end{array}$ & $\begin{array}{l}2366 \\
3409\end{array}$ & 0.9971 & 0.7143 & 87 & $\begin{array}{l}158 \\
021\end{array}$ & $\begin{array}{l}152 \\
153\end{array}$ & 0 & 550 & 5404 & 1173 & 159 & 19 & 0.4409 \\
\hline $\begin{array}{l}50 \\
51\end{array}$ & $\begin{array}{l}7305 \\
7305\end{array}$ & $\begin{array}{l}36 \\
18\end{array}$ & $\begin{array}{c}17 \\
8\end{array}$ & $\begin{array}{l}5 \\
5\end{array}$ & 1 & $\begin{array}{l}2.1 \\
2.3\end{array}$ & 658 & ${ }_{14}^{6}$ & $\begin{array}{l}163 \\
163\end{array}$ & 5855 & $\begin{array}{l}3409 \\
1805\end{array}$ & 0.9951 & $\begin{array}{l}0.4722 \\
0\end{array}$ & $\begin{array}{l}41 \\
81\end{array}$ & 201 & $\begin{array}{l}163 \\
224\end{array}$ & 0 & 571 & 5465 & 1099 & 139 & 31 & 0.3101 \\
\hline $\begin{array}{l}51 \\
52\end{array}$ & $\begin{array}{l}\begin{array}{l}7305 \\
7305\end{array} \\
7305\end{array}$ & $\begin{array}{l}18 \\
16\end{array}$ & $\begin{array}{c}8 \\
10\end{array}$ & $\begin{array}{l}5 \\
4\end{array}$ & $\begin{array}{l}1 \\
1\end{array}$ & $\begin{array}{l}2.3 \\
1.6\end{array}$ & $\begin{array}{l}682 \\
312\end{array}$ & $\begin{array}{c}14 \\
3\end{array}$ & $\begin{array}{l}224 \\
127\end{array}$ & $\begin{array}{l}4025 \\
2029\end{array}$ & $\begin{array}{l}1805 \\
1500\end{array}$ & $\begin{array}{l}0.9975 \\
0.9978\end{array}$ & $\begin{array}{l}0.44444 \\
0.6250\end{array}$ & $\begin{array}{l}81 \\
114\end{array}$ & $\begin{array}{l}226 \\
150\end{array}$ & 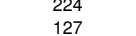 & $\begin{array}{l}0 \\
0 \\
0\end{array}$ & $\begin{array}{l}560 \\
565\end{array}$ & $\begin{array}{l}5462 \\
5397\end{array}$ & $\begin{array}{l}1092 \\
1161\end{array}$ & $\begin{array}{l}176 \\
169\end{array}$ & $\begin{array}{l}15 \\
13\end{array}$ & $\begin{array}{l}0.6391 \\
0.5785\end{array}$ \\
\hline 53 & 7305 & 23 & 12 & 3 & 1 & 1.9 & 572 & 4 & 19 & 44 & 3029 & 0.9 & 0.5 & 106 & 252 & 19 & 0 & 533 & 54 & 1164 & 166 & 22 & 0.4594 \\
\hline 54 & 73 & 25 & 13 & 6 & 1 & 1.9 & 507 & 17 & 17 & 44 & 2577 & 0.9 & 0.5 & 49 & 198 & 17 & 0 & 549 & 5402 & 1197 & 134 & 23 & 0.4176 \\
\hline 55 & 73 & 16 & 9 & 4 & 1 & 1.8 & 496 & 9 & 219 & 35 & 2153 & 0.9 & 0.5 & 114 & 239 & 21 & 0 & 54 & 5459 & 1145 & 141 & 13 & 0.5229 \\
\hline 56 & 73 & 10 & 6 & 2 & 1 & 1.7 & 467 & 46 & 2 & 21 & 1557 & 0.9 & 0. & 365 & 260 & 21 & 0 & 544 & 5516 & 1080 & 155 & 10 & 0.6153 \\
\hline 57 & 7305 & 32 & 12 & 7 & 1 & 2.7 & 749 & 1 & 224 & 71 & 3248 & 0.9956 & 0.3750 & 33 & 271 & 224 & 0 & 550 & 5450 & 1099 & 178 & 28 & 0.3179 \\
\hline 58 & 7305 & 17 & 11 & 3 & 1 & 1.5 & 610 & 4 & 134 & 2275 & 1787 & 0.9977 & 0.6471 & 143 & 162 & 134 & 0 & 553 & 5503 & 1053 & 181 & 15 & 0.5678 \\
\hline 59 & 7305 & 18 & 12 & 3 & 1 & 1.5 & 513 & 0 & 131 & 2351 & 1777 & 0.9975 & 0.6667 & 135 & 148 & 131 & 0 & 544 & 5457 & 1120 & 170 & 14 & 0.4341 \\
\hline 60 & 7305 & 31 & 17 & 7 & 1 & 1.8 & 432 & 4 & 146 & 4521 & 2755 & 0.9958 & 0.5484 & 34 & 162 & 146 & 0 & 564 & 5442 & 1102 & 169 & 28 & 0.3154 \\
\hline
\end{tabular}




\begin{tabular}{|c|c|c|c|c|c|c|c|c|c|c|c|c|c|c|c|c|c|c|c|c|c|c|c|}
\hline 61 & 7305 & 27 & 15 & 5 & 1 & 1.8 & 566 & 4 & 186 & 5029 & 2782 & 0.9963 & 0.5556 & 54 & 185 & 186 & 0 & 579 & 5389 & 1161 & 152 & 24 & 0.3208 \\
\hline 62 & 7305 & 16 & 11 & 3 & 1 & 1.5 & 536 & 9 & 145 & 2323 & 1915 & 0.9978 & 0.6875 & 152 & 174 & 145 & 0 & 544 & 5449 & 1145 & 154 & 13 & 0.5618 \\
\hline 63 & 7305 & 24 & 10 & 4 & 1 & 2.4 & 535 & 11 & 233 & 5593 & 3252 & 0.9967 & 0.4167 & 76 & 325 & 233 & 0 & 545 & 5469 & 1102 & 170 & 19 & 0.4844 \\
\hline 64 & 7305 & 19 & 7 & 7 & 1 & 2.7 & 609 & 22 & 244 & 4634 & 2103 & 0.9974 & 0.3684 & 55 & 300 & 244 & 0 & 536 & 5472 & 1153 & 126 & 18 & 0.3875 \\
\hline 65 & 7305 & 22 & 12 & 4 & 1 & 1.8 & 568 & 15 & 195 & 4299 & 2256 & 0.9970 & 0.5455 & 83 & 188 & 195 & 0 & 554 & 5460 & 1097 & 178 & 16 & 0.5907 \\
\hline 66 & 7305 & 33 & 15 & 6 & 1 & 2.2 & 591 & 36 & 241 & 7941 & 3588 & 0.9955 & 0.4545 & 37 & 239 & 241 & 0 & 551 & 5497 & 1054 & 170 & 33 & 0.4659 \\
\hline 67 & 7305 & 21 & 13 & 5 & 1 & 1.6 & 596 & 8 & 202 & 4233 & 3017 & 0.9971 & 0.6190 & 70 & 232 & 202 & 0 & 560 & 5429 & 1135 & 161 & 20 & 0.4053 \\
\hline 68 & 7305 & 27 & 13 & 6 & 1 & 2.1 & 582 & 2 & 168 & 4538 & $\begin{array}{l}2368 \\
3117\end{array}$ & 0.9963 & 0.4815 & $\begin{array}{l}45 \\
83\end{array}$ & 182 & $\begin{array}{l}168 \\
224\end{array}$ & 0 & 533 & 5462 & 1080 & 207 & 23 & 0.3374 \\
\hline 69 & $\begin{array}{l}7305 \\
7305\end{array}$ & $\begin{array}{l}22 \\
1\end{array}$ & $\begin{array}{l}12 \\
9\end{array}$ & $\begin{array}{l}4 \\
4 \\
4\end{array}$ & 1 & 1.8 & $\begin{array}{l}710 \\
51\end{array}$ & $\begin{array}{l}24 \\
37\end{array}$ & $\begin{array}{l}224 \\
\end{array}$ & 4917 & 3117 & 0.9970 & 0.5455 & 83 & $\begin{array}{l}260 \\
221\end{array}$ & $\begin{array}{l}224 \\
\end{array}$ & 0 & 554 & 5425 & 1136 & 170 & $\begin{array}{l}20 \\
13\end{array}$ & 0.5627 \\
\hline $\begin{array}{l}70 \\
71\end{array}$ & $\begin{array}{l}7305 \\
7305\end{array}$ & $\begin{array}{l}13 \\
23\end{array}$ & $\begin{array}{l}9 \\
9\end{array}$ & $\begin{array}{l}4 \\
6\end{array}$ & $\begin{array}{l}1 \\
1\end{array}$ & $\begin{array}{l}1.4 \\
2.6\end{array}$ & $\begin{array}{l}157 \\
786\end{array}$ & $\begin{array}{l}37 \\
30\end{array}$ & $\begin{array}{l}882 \\
266\end{array}$ & $\begin{array}{l}2370 \\
6126\end{array}$ & $\begin{array}{l}1987 \\
3009\end{array}$ & $\begin{array}{l}0.9982 \\
0.9969\end{array}$ & $\begin{array}{l}0.6923 \\
0.3913\end{array}$ & $\begin{array}{l}140 \\
53\end{array}$ & 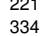 & $\begin{array}{l}182 \\
266\end{array}$ & $\begin{array}{l}0 \\
0\end{array}$ & $\begin{array}{l}532 \\
553\end{array}$ & $\begin{array}{l}5516 \\
5405\end{array}$ & $\begin{array}{l}1120 \\
1143\end{array}$ & $\begin{array}{l}124 \\
184\end{array}$ & $\begin{array}{l}13 \\
20\end{array}$ & $\begin{array}{l}0.5628 \\
0.3428\end{array}$ \\
\hline 72 & 7305 & 18 & 11 & 3 & 1 & 1.6 & 490 & 20 & 177 & 3185 & 2351 & 0.9975 & 0.6111 & 135 & 214 & 177 & 0 & 525 & 5514 & 1080 & 171 & 15 & 0.4613 \\
\hline 73 & 7305 & 22 & 13 & 3 & 1 & 1.7 & 518 & 20 & 176 & 3862 & 2806 & 0.9970 & 0.5909 & 111 & 216 & 176 & 0 & 547 & 5492 & 1089 & 157 & 20 & 0.3707 \\
\hline 74 & 7305 & 21 & 12 & 5 & 1 & 1.8 & 520 & 13 & 259 & 5432 & 2849 & 0.9971 & 0.5714 & 70 & 237 & 259 & 0 & 548 & 5456 & 1108 & 177 & 16 & 0.3797 \\
\hline 75 & 7305 & 27 & 16 & 4 & 1 & 1.7 & 637 & 9 & 142 & 3833 & 2772 & 0.9963 & 0.5926 & 68 & 173 & 142 & 0 & 555 & 5440 & 1110 & 178 & 22 & 0.3394 \\
\hline 76 & 7305 & 13 & 8 & 3 & 1 & 1.6 & 569 & 1 & 161 & 2095 & 1548 & 0.9982 & 0.6154 & 187 & 193 & 161 & 0 & 513 & 5489 & 1112 & 183 & 8 & 0.5539 \\
\hline 77 & 7305 & 36 & 16 & 6 & 1 & 2.3 & 657 & 6 & 225 & 8093 & 3483 & 0.9951 & 0.4444 & 34 & 218 & 225 & 0 & 557 & 5459 & 1095 & 160 & 34 & 0.4093 \\
\hline 78 & 7305 & 19 & 8 & 10 & 1 & 2.4 & 720 & 3 & 119 & 2270 & 1368 & 0.9974 & 0.4211 & 38 & 171 & 119 & 0 & 550 & 5494 & 1108 & 137 & 16 & 0.4141 \\
\hline 79 & 7305 & 13 & 10 & 3 & 1 & 1.3 & 555 & 2 & 126 & 1634 & 1326 & 0.9982 & 0.7692 & 187 & 133 & 126 & 0 & 555 & 5463 & 1124 & 152 & 11 & 0.5708 \\
\hline 80 & 7305 & 18 & 12 & 3 & 1 & 1.5 & 455 & 8 & 159 & 2870 & 2186 & 0.9975 & 0.6667 & 135 & 182 & 159 & 0 & 553 & 5431 & 1106 & 198 & 17 & 0.3792 \\
\hline 81 & 7305 & 15 & 8 & 4 & 1 & 1.9 & 558 & 3 & 190 & 2844 & 1718 & 0.9979 & 0.5333 & 122 & 215 & 190 & 0 & 541 & 5453 & 1142 & 158 & 11 & 0.5273 \\
\hline 82 & 7305 & 53 & 25 & 8 & 1 & 2.1 & 624 & 8 & 221 & 11716 & 5695 & 0.9927 & 0.4717 & 17 & 228 & 221 & 0 & 561 & 5396 & 1119 & 180 & 49 & 0.1702 \\
\hline 83 & 7305 & $\begin{array}{l}24 \\
17\end{array}$ & 13 & 4 & 1 & 1.8 & $\begin{array}{l}455 \\
589\end{array}$ & $\begin{array}{l}16 \\
12\end{array}$ & 177 & 4253 & 3018 & 0.9967 & 0.5417 & 76 & 232 & 177 & 0 & 548 & 5443 & 1120 & 174 & 20 & 0.3627 \\
\hline 84 & 7305 & $\begin{array}{l}17 \\
35\end{array}$ & $\begin{array}{l}10 \\
03\end{array}$ & $\begin{array}{l}3 \\
5\end{array}$ & 1 & $\begin{array}{l}1.7 \\
15\end{array}$ & $\begin{array}{l}588 \\
58\end{array}$ & 12 & $\begin{array}{l}184 \\
179\end{array}$ & 3135 & $\begin{array}{l}2156 \\
3973\end{array}$ & 0.9977 & 0.5882 & 143 & $\begin{array}{l}216 \\
173\end{array}$ & $\begin{array}{l}184 \\
179\end{array}$ & 0 & 546 & 5554 & 1069 & 124 & 12 & 0.4736 \\
\hline $\begin{array}{l}85 \\
86\end{array}$ & $\begin{array}{l}7305 \\
7305\end{array}$ & $\begin{array}{l}35 \\
17\end{array}$ & $\begin{array}{c}23 \\
8\end{array}$ & $\begin{array}{l}5 \\
4\end{array}$ & $\begin{array}{l}1 \\
1\end{array}$ & $\begin{array}{l}1.5 \\
2.1\end{array}$ & $\begin{array}{l}528 \\
563\end{array}$ & $\begin{array}{l}3 \\
28\end{array}$ & $\begin{array}{l}179 \\
265\end{array}$ & $\begin{array}{l}6262 \\
4503\end{array}$ & $\begin{array}{l}3973 \\
2512\end{array}$ & $\begin{array}{l}0.9952 \\
0.9977\end{array}$ & $\begin{array}{l}0.6571 \\
0.4706\end{array}$ & $\begin{array}{c}42 \\
107\end{array}$ & $\begin{array}{r}173 \\
314\end{array}$ & $\begin{array}{l}179 \\
265\end{array}$ & $\begin{array}{l}0 \\
0\end{array}$ & $\begin{array}{l}539 \\
527\end{array}$ & $\begin{array}{l}5447 \\
5513\end{array}$ & $\begin{array}{l}1096 \\
1099\end{array}$ & $\begin{array}{l}194 \\
153\end{array}$ & $\begin{array}{l}29 \\
13\end{array}$ & $\begin{array}{l}0.2339 \\
0.4513\end{array}$ \\
\hline 87 & 7305 & 6 & 5 & 2 & 1 & 1.2 & 210 & 11 & 86 & 515 & 450 & 0.9992 & 0.8400 & 609 & 90 & 86 & 0 & 575 & 5493 & 1076 & 157 & 4 & 0.5357 \\
\hline 88 & 7305 & 18 & 12 & 4 & 1 & 1.5 & 510 & 3 & 200 & 3592 & 2128 & 0.9975 & 0.6667 & 101 & 177 & 200 & 0 & 570 & 5428 & 1145 & 145 & 17 & 0.4228 \\
\hline 89 & 7305 & 29 & 18 & 4 & 1 & 1.6 & 612 & 4 & 197 & 5725 & 4139 & 0.9960 & 0.6207 & 63 & 230 & 197 & 0 & 566 & 5444 & 1108 & 164 & 23 & 0.5456 \\
\hline 90 & 7305 & 25 & 11 & 6 & 1 & 2.3 & 569 & 1 & 234 & 5839 & 2415 & 0.9966 & 0.4400 & 49 & 220 & 234 & 0 & 565 & 5399 & 1153 & 167 & 21 & 0.3784 \\
\hline 91 & 7305 & 24 & 9 & 4 & 1 & 2.7 & 767 & 11 & 203 & 4872 & 2810 & 0.9967 & 0.3750 & 76 & 312 & 203 & 0 & 557 & 5524 & 1070 & 131 & 23 & 0.5399 \\
\hline 92 & 7305 & 13 & 7 & 3 & 1 & 1.9 & 652 & 13 & 159 & 2073 & 1235 & 0.9982 & 0.5385 & 187 & 176 & 159 & 0 & 548 & 5509 & 1052 & 187 & 9 & 0.5809 \\
\hline 93 & 7305 & 29 & 12 & 10 & 1 & 2.4 & 861 & 5 & 232 & 6721 & 2707 & 0.9960 & 0.4138 & 25 & 226 & 232 & 0 & 552 & 5546 & 1039 & 144 & 24 & 0.3979 \\
\hline 94 & 7305 & 18 & 12 & 3 & 1 & 1.5 & 412 & 2 & 178 & 3210 & 2132 & 0.9975 & 0.6667 & 135 & 178 & 178 & 0 & 571 & 5408 & 1130 & 180 & 16 & 0.3373 \\
\hline 95 & 7305 & 13 & 8 & 4 & 1 & 1.6 & 492 & 79 & 255 & 3318 & 1627 & 0.9982 & 0.6154 & 140 & 203 & 255 & 0 & 548 & 5489 & 1074 & 182 & 12 & 0.6379 \\
\hline 96 & 7305 & 22 & $\begin{array}{l}10 \\
13\end{array}$ & 7 & 1 & 2.2 & 748 & 21 & 214 & 4717 & 2483 & 0.9970 & 0.4545 & 47 & 248 & 214 & 0 & 544 & 5507 & 1058 & 175 & 21 & 0.4612 \\
\hline 97 & 7305 & $\begin{array}{l}22 \\
32\end{array}$ & $\begin{array}{l}13 \\
14\end{array}$ & 3 & 1 & $\begin{array}{l}1.7 \\
2.3\end{array}$ & $\begin{array}{l}452 \\
552\end{array}$ & $\begin{array}{l}22 \\
22\end{array}$ & 209 & $\begin{array}{l}4603 \\
7731\end{array}$ & $\begin{array}{l}3268 \\
3837\end{array}$ & 0.9970 & 0.5909 & $\begin{array}{l}111 \\
38\end{array}$ & $\begin{array}{l}251 \\
274\end{array}$ & 209 & 0 & 535 & 5484 & 1123 & 142 & 21 & 0.5071 \\
\hline $\begin{array}{l}98 \\
99\end{array}$ & 7305 & 32 & $\begin{array}{l}14 \\
19\end{array}$ & & & $\begin{array}{l}2.3 \\
2 ?\end{array}$ & 552 & 32 & $\begin{array}{l}242 \\
\end{array}$ & 7731 & $\begin{array}{l}3837 \\
2737\end{array}$ & 0.9956 & 0.4375 & $\begin{array}{l}38 \\
22\end{array}$ & $\begin{array}{l}274 \\
146\end{array}$ & $\begin{array}{r}242 \\
\end{array}$ & 0 & 533 & 5496 & 1063 & 181 & 32 & 0.3964 \\
\hline $\begin{array}{l}99 \\
100\end{array}$ & $\begin{array}{l}7305 \\
7305\end{array}$ & $\begin{array}{l}41 \\
22\end{array}$ & $\begin{array}{l}19 \\
13\end{array}$ & $\begin{array}{l}8 \\
5\end{array}$ & $\begin{array}{l}1 \\
1\end{array}$ & $\begin{array}{l}2.2 \\
1.7\end{array}$ & $\begin{array}{l}613 \\
619\end{array}$ & $\begin{array}{l}3 \\
15\end{array}$ & $\begin{array}{l}120 \\
161\end{array}$ & $\begin{array}{l}4918 \\
3542\end{array}$ & $\begin{array}{l}\begin{array}{l}2769 \\
2449\end{array} \\
2409\end{array}$ & $\begin{array}{l}0.99444 \\
0.9970\end{array}$ & $\begin{array}{l}0.4634 \\
0.5909\end{array}$ & $\begin{array}{l}22 \\
66\end{array}$ & $\begin{array}{l}146 \\
188\end{array}$ & $\begin{array}{l}120 \\
161\end{array}$ & $\begin{array}{l}0 \\
0\end{array}$ & $\begin{array}{l}566 \\
540\end{array}$ & $\begin{array}{l}5475 \\
5478\end{array}$ & $\begin{array}{l}1059 \\
1119\end{array}$ & $\begin{array}{l}174 \\
147\end{array}$ & $\begin{array}{l}31 \\
21\end{array}$ & $\begin{array}{l}0.4329 \\
0.4633\end{array}$ \\
\hline Minimum & & 6 & 3 & 2 & 1 & 1.2 & 210 & 0 & 86 & 515 & 450 & 0.9927 & 0.300 & 17 & 90 & 86 & 0 & 513 & 5373 & 1039 & 113 & 4 & 0.1702 \\
\hline Average & & 22 & 12 & 5 & 1 & 1.9 & 553 & 13 & 191 & 4310 & 2459 & 0.9970 & 0.548 & 104 & 212 & 191 & 0 & 548 & 5466 & 1111 & 161 & 20 & 0.4590 \\
\hline Maximum & & 53 & 25 & 10 & 1 & 3.3 & 888 & 79 & 341 & 11925 & 5695 & 0.9992 & 0.840 & 609 & 347 & 341 & 0 & 579 & 5556 & 1202 & 213 & 49 & 0.7063 \\
\hline Stdddev & & 8 & 4 & 2 & 0 & 0.4 & 127 & 14 & 45 & 2044 & 863 & 0.0011 & 0.111 & 92.7 & 50.1 & 44.9 & 0 & 13.8 & 40.3 & 35.2 & 22.5 & 7.4 & 0.1106 \\
\hline
\end{tabular}




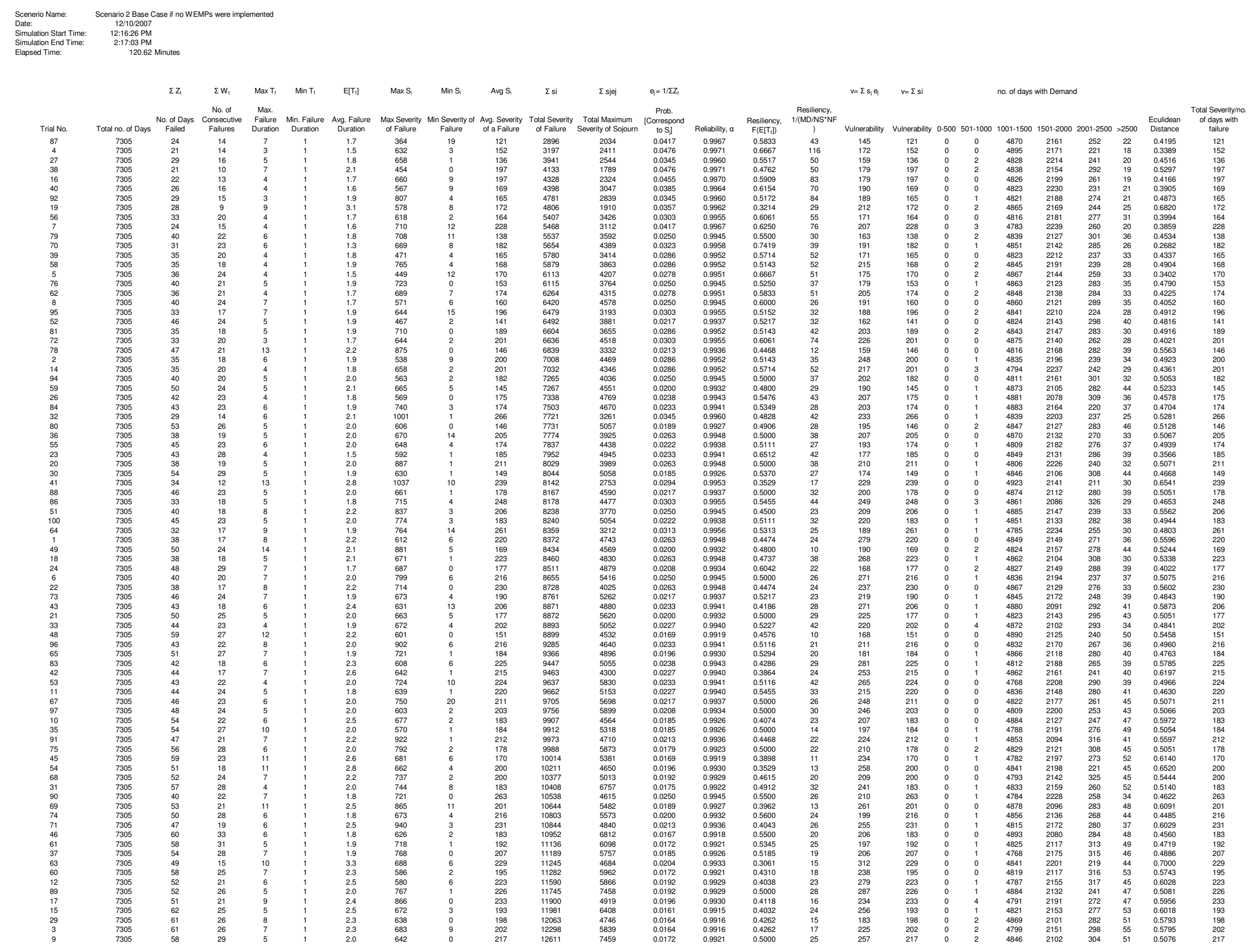




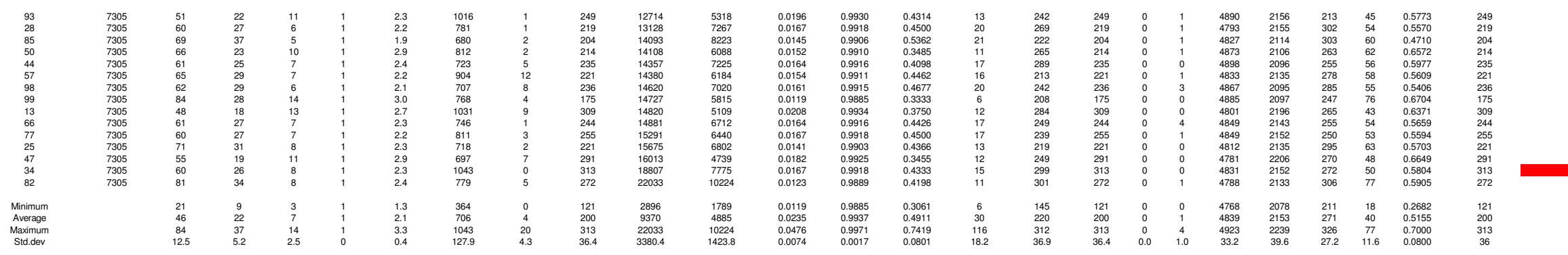


Elapsed Tir $\quad 88.51$ Minutes

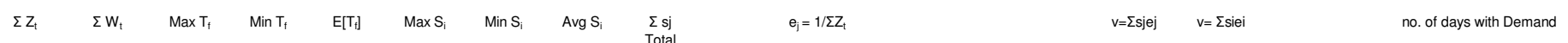

\begin{tabular}{|c|c|c|c|c|c|c|c|c|c|c|c|c|c|c|c|c|c|c|c|c|c|c|c|c|}
\hline Trial No. & $\begin{array}{c}\text { Total no. } 0 \\
\text { Days }\end{array}$ & $\begin{array}{l}\text { No. of Days } \\
\text { Failed }\end{array}$ & $\begin{array}{l}\text { No. of } \\
\text { Consecutive } \\
\text { Failures }\end{array}$ & $\begin{array}{c}\text { Max. } \\
\text { Failure } \\
\text { Duration }\end{array}$ & $\begin{array}{l}\text { Min. Failure } \\
\text { Duration }\end{array}$ & $\begin{array}{c}\text { Avg. } \\
\text { Failure } \\
\text { Duration }\end{array}$ & $\begin{array}{l}\text { Max } \\
\text { Severity of } \\
\text { Failure }\end{array}$ & $\begin{array}{l}\text { Min } \\
\text { Severity of } \\
\text { Failure }\end{array}$ & $\begin{array}{l}\text { Avg. } \\
\text { Severity of } \\
\text { a Failure }\end{array}$ & $\begin{array}{l}\text { Total } \\
\text { Maximum } \\
\text { Severity of } \\
\text { Sojourn }\end{array}$ & $\begin{array}{l}\text { Total } \\
\text { Severity of } \\
\text { Failure }\end{array}$ & $\begin{array}{l}\text { Prob. } \\
\text { [Correspon } \\
\text { d to } S \text { ] }\end{array}$ & $\begin{array}{l}\text { Reliability, } \\
\alpha\end{array}$ & $\begin{array}{l}\text { Resiliency, } \\
\text { F(ETTI) }\end{array}$ & $\begin{array}{l}\text { Resiliency, } \\
1 /(\mathrm{MD} / \mathrm{NSS} \\
\mathrm{NF})\end{array}$ & $\begin{array}{c}\text { Vulnerability } \\
1\end{array}$ & $\begin{array}{l}\text { Vulnerability } \\
2\end{array}$ & $0-500$ & $501-1000$ & $1001-1500$ & $1501-2000$ & & & \\
\hline 87 & 7305 & 6 & 5 & 2 & 1 & 1.2 & 202 & 4 & 78 & 412 & 469 & 0.1667 & 0.9992 & 0.8333 & 609 & 82 & 78 & 0 & 622 & 5493 & $\begin{array}{l}1501-20000 \\
1035\end{array}$ & $\begin{array}{l}2001-2500 \\
151\end{array}$ & $>2500$ & $\begin{array}{c}\text { Eculidean Distanc } \\
0.1696\end{array}$ \\
\hline 4 & 7305 & 7 & 4 & 2 & 1 & 1.8 & 471 & 16 & 145 & 898 & 1012 & 0.1429 & 0.9990 & 0.5714 & 522 & 224 & 145 & 0 & 589 & 5518 & 1075 & 118 & $\begin{array}{l}4 \\
5\end{array}$ & $\begin{array}{l}0.1696 \\
0.4325\end{array}$ \\
\hline 79 & 7305 & 10 & 8 & 2 & 1 & 1.3 & 548 & 1 & 155 & 1259 & 1549 & 0.1000 & 0.9986 & 0.8000 & 365 & 157 & 155 & 0 & 569 & 5473 & 1077 & 178 & 8 & 0.2094 \\
\hline 27 & 7305 & 9 & 7 & 3 & 1 & 1.3 & 499 & 7 & 175 & 1119 & 1574 & 0.1111 & 0.9988 & 0.7778 & 271 & 160 & 175 & 0 & 601 & 5427 & 1158 & 113 & 6 & 0.2330 \\
\hline 39 & 7305 & 16 & 11 & 3 & 1 & 1.5 & $\begin{array}{l}309 \\
295\end{array}$ & $\stackrel{2}{65}$ & $\begin{array}{l}99 \\
165\end{array}$ & $\begin{array}{l}1069 \\
835\end{array}$ & 1577 & 0.0625 & 0.9978 & 0.6875 & 152 & 97 & $\begin{array}{l}99 \\
165\end{array}$ & 0 & 592 & 5442 & $\begin{array}{l}1125 \\
1107\end{array}$ & $\begin{array}{l}134 \\
114\end{array}$ & 12 & 0.3150 \\
\hline $\begin{array}{l}38 \\
19\end{array}$ & $\begin{array}{l}7305 \\
7305\end{array}$ & $\begin{array}{l}10 \\
11\end{array}$ & $\begin{array}{l}3 \\
5\end{array}$ & $\begin{array}{l}7 \\
4\end{array}$ & $\begin{array}{l}1 \\
1\end{array}$ & $\begin{array}{l}3.3 \\
2.2\end{array}$ & $\begin{array}{l}295 \\
415\end{array}$ & $\begin{array}{l}65 \\
39 \\
39\end{array}$ & $\begin{array}{l}165 \\
152\end{array}$ & $\begin{array}{l}835 \\
1130\end{array}$ & $\begin{array}{l}1649 \\
1677\end{array}$ & $\begin{array}{l}0.1000 \\
0.0909\end{array}$ & $\begin{array}{l}0.9986 \\
0.9985\end{array}$ & $\begin{array}{l}0.3000 \\
0.4545\end{array}$ & $\begin{array}{l}104 \\
166\end{array}$ & $\begin{array}{l}278 \\
226\end{array}$ & $\begin{array}{l}165 \\
152\end{array}$ & $\begin{array}{l}0 \\
0\end{array}$ & $\begin{array}{l}616 \\
602\end{array}$ & $\begin{array}{l}5428 \\
5516\end{array}$ & $\begin{array}{l}1107 \\
1059\end{array}$ & $\begin{array}{l}{ }_{144}^{144} \\
117\end{array}$ & $\begin{array}{l}10 \\
11\end{array}$ & $\begin{array}{l}0.7031 \\
0.5489\end{array}$ \\
\hline 5 & $\begin{array}{l}7305 \\
7305\end{array}$ & 17 & $\begin{array}{c}5 \\
11\end{array}$ & $\begin{array}{l}4 \\
3\end{array}$ & 1 & $\begin{array}{l}2.2 \\
1.5\end{array}$ & $\begin{array}{l}415 \\
289\end{array}$ & $\begin{array}{l}39 \\
16\end{array}$ & $\begin{array}{l}152 \\
108\end{array}$ & $\begin{array}{l}1130 \\
1358\end{array}$ & $\begin{array}{l}1629 \\
1829\end{array}$ & $\begin{array}{l}0.0589 \\
0.0588\end{array}$ & $\begin{array}{l}0.9985 \\
0.9977\end{array}$ & $\begin{array}{l}0.4545 \\
0.6471\end{array}$ & $\begin{array}{l}766 \\
143\end{array}$ & $\begin{array}{l}226 \\
123\end{array}$ & $\begin{array}{l}152 \\
108\end{array}$ & 0 & $\begin{array}{l}602 \\
587\end{array}$ & $\begin{array}{l}5516 \\
5529\end{array}$ & $\begin{array}{l}1059 \\
1022\end{array}$ & 153 & $\begin{array}{l}11 \\
14\end{array}$ & $\begin{array}{l}0.5489 \\
0.3556\end{array}$ \\
\hline 40 & 7305 & 10 & 7 & 2 & 1 & 1.4 & 407 & 27 & 188 & 1568 & 1883 & 0.1000 & 0.9986 & 0.7000 & 365 & 224 & 188 & 0 & 618 & 5474 & 1087 & 117 & 9 & 0.3093 \\
\hline $\begin{array}{l}52 \\
16\end{array}$ & $\begin{array}{l}7305 \\
7305\end{array}$ & $\begin{array}{l}14 \\
8 \\
8\end{array}$ & $\begin{array}{c}11 \\
3\end{array}$ & $\begin{array}{l}4 \\
4\end{array}$ & $\begin{array}{l}1 \\
2\end{array}$ & $\begin{array}{l}1.3 \\
2.7\end{array}$ & $\begin{array}{l}304 \\
499\end{array}$ & $\begin{array}{l}6 \\
6\end{array}$ & $\begin{array}{l}137 \\
243\end{array}$ & $\begin{array}{l}1442 \\
968\end{array}$ & $\begin{array}{l}1915 \\
1941\end{array}$ & $\begin{array}{l}0.0714 \\
0.1250\end{array}$ & $\begin{array}{l}0.9981 \\
0.9989\end{array}$ & $\begin{array}{l}0.7857 \\
0.3750\end{array}$ & $\begin{array}{l}130 \\
228 \\
228\end{array}$ & $\begin{array}{l}131 \\
323\end{array}$ & $\begin{array}{l}137 \\
243 \\
243\end{array}$ & $\begin{array}{l}0 \\
0 \\
0\end{array}$ & $\begin{array}{l}611 \\
591\end{array}$ & $\begin{array}{l}5396 \\
5485\end{array}$ & $\begin{array}{l}1096 \\
1091\end{array}$ & $\begin{array}{l}190 \\
132\end{array}$ & 12 & 0.2212 \\
\hline $\begin{array}{l}16 \\
92\end{array}$ & $\begin{array}{l}7305 \\
7305\end{array}$ & $\begin{array}{l}8 \\
13 \\
\end{array}$ & $\begin{array}{l}3 \\
7\end{array}$ & $\begin{array}{l}4 \\
3 \\
\end{array}$ & $\begin{array}{l}2 \\
1\end{array}$ & $\begin{array}{l}2.7 \\
1.9\end{array}$ & $\begin{array}{l}499 \\
644\end{array}$ & $\begin{array}{l}6 \\
5\end{array}$ & $\begin{array}{l}243 \\
152\end{array}$ & $\begin{array}{l}968 \\
1182\end{array}$ & $\begin{array}{l}\begin{array}{l}1941 \\
1974\end{array} \\
\text {. }\end{array}$ & $\begin{array}{l}0.1250 \\
0.0769\end{array}$ & $\begin{array}{l}0.9989 \\
0.9982\end{array}$ & $\begin{array}{l}0.5380 \\
0.5385\end{array}$ & $\begin{array}{l}228 \\
187\end{array}$ & $\begin{array}{l}323 \\
169\end{array}$ & $\begin{array}{l}243 \\
152\end{array}$ & 0 & $\begin{array}{l}591 \\
613\end{array}$ & $\begin{array}{l}5485 \\
5449\end{array}$ & $\begin{array}{l}1091 \\
1083\end{array}$ & $\begin{array}{l}\begin{array}{l}132 \\
149\end{array} \\
1\end{array}$ & $\begin{array}{l}6 \\
11\end{array}$ & $\begin{array}{l}0.6325 \\
0.4655\end{array}$ \\
\hline 76 & 7305 & 12 & 7 & 3 & 1 & 1.7 & 561 & 2 & 167 & 1493 & 2003 & 0.0833 & 0.9984 & 0.5833 & 203 & 213 & 167 & 0 & 605 & 5495 & 1020 & 176 & 9 & 0.4220 \\
\hline 56 & 7305 & 10 & 6 & 2 & 1 & 1.7 & 459 & 39 & 209 & 1512 & 2093 & 0.1000 & 0.9986 & 0.6000 & $\begin{array}{l}365 \\
57\end{array}$ & $\begin{array}{l}252 \\
166\end{array}$ & 209 & 0 & 592 & 5522 & 1029 & 152 & 10 & 0.4087 \\
\hline $\begin{array}{l}78 \\
58\end{array}$ & $\begin{array}{l}7305 \\
7305\end{array}$ & $\begin{array}{l}16 \\
16\end{array}$ & $\begin{array}{c}8 \\
11\end{array}$ & $\begin{array}{l}8 \\
3\end{array}$ & $\begin{array}{l}1 \\
1\end{array}$ & $\begin{array}{l}2.0 \\
1.5\end{array}$ & $\begin{array}{l}713 \\
603\end{array}$ & $\begin{array}{l}20 \\
16 \\
16\end{array}$ & $\begin{array}{l}133 \\
134 \\
134\end{array}$ & $\begin{array}{l}1330 \\
1703\end{array}$ & $\begin{array}{l}2130 \\
2148\end{array}$ & $\begin{array}{l}0.0625 \\
0.0625\end{array}$ & $\begin{array}{l}0.9978 \\
0.9978\end{array}$ & $\begin{array}{l}0.5000 \\
0.6875\end{array}$ & $\begin{array}{l}57 \\
152\end{array}$ & $\begin{array}{l}166 \\
155 \\
155\end{array}$ & $\begin{array}{l}133 \\
134\end{array}$ & $\begin{array}{l}0 \\
0\end{array}$ & $\begin{array}{l}617 \\
603\end{array}$ & 5386 & $\begin{array}{l}1129 \\
1071\end{array}$ & $\begin{array}{l}160 \\
138\end{array}$ & 13 & 0.5028 \\
\hline $\begin{array}{l}58 \\
62\end{array}$ & $\begin{array}{l}7305 \\
7305\end{array}$ & $\begin{array}{l}16 \\
16\end{array}$ & $\begin{array}{l}11 \\
11\end{array}$ & $\begin{array}{l}3 \\
3\end{array}$ & $\begin{array}{l}1 \\
1\end{array}$ & $\begin{array}{l}1.5 \\
1.5\end{array}$ & $\begin{array}{l}603 \\
528\end{array}$ & $\begin{array}{c}16 \\
1\end{array}$ & $\begin{array}{l}134 \\
138\end{array}$ & $\begin{array}{l}1703 \\
1832\end{array}$ & $\begin{array}{l}2148 \\
2202\end{array}$ & $\begin{array}{l}0.0625 \\
0.0625\end{array}$ & $\begin{array}{l}0.99 / 8 \\
0.9978\end{array}$ & $\begin{array}{l}0.68 / 5 \\
0.6875\end{array}$ & $\begin{array}{l}152 \\
152 \\
152\end{array}$ & $\begin{array}{l}l_{155} \\
167\end{array}$ & $\begin{array}{l}134 \\
138\end{array}$ & 0 & $\begin{array}{l}603 \\
615\end{array}$ & $\begin{array}{l}5478 \\
5421\end{array}$ & $\begin{array}{l}70 / 7 \\
1104\end{array}$ & $\begin{array}{l}138 \\
153\end{array}$ & $\begin{array}{l}15 \\
12\end{array}$ & $\begin{array}{l}0.3171 \\
0.3171\end{array}$ \\
\hline 59 & 7305 & 17 & 11 & 3 & 1 & 1.5 & 506 & 14 & 131 & 1693 & 2220 & 0.0588 & 0.9977 & 0.6471 & 143 & 154 & 131 & 0 & 603 & 5440 & 1080 & 168 & 14 & 0.3568 \\
\hline 70 & 7305 & 13 & 9 & 4 & 1 & 1.4 & 509 & 29 & 175 & 1919 & 2271 & 0.0769 & 0.9982 & 0.6923 & 140 & 213 & 175 & 0 & 62 & 5419 & 1097 & 155 & 12 & 0.3155 \\
\hline 8 & 7305 & 13 & 10 & 2 & 1 & 1.3 & 411 & 7 & 183 & 1944 & 2381 & 0.0769 & 0.9982 & 0.7692 & 281 & 194 & 183 & 0 & 600 & 5472 & 1044 & 177 & 12 & 0.2421 \\
\hline 2 & 7305 & 19 & 13 & ${ }^{3}$ & & 1.5 & 376 & & 134 & 2039 & 2545 & 0.0526 & 0.9974 & 0.6842 & 128 & 157 & 134 & 0 & 623 & 5461 & 1072 & 134 & 15 & 0.3203 \\
\hline 80 & 7305 & 18 & 12 & 3 & 1 & 1.5 & 447 & 0 & 152 & 2095 & 2733 & 0.0556 & 0.9975 & 0.6667 & 135 & 175 & 152 & 0 & 582 & 5499 & 1042 & 168 & 14 & 0.3388 \\
\hline 81 & $\begin{array}{l}7305 \\
7305\end{array}$ & $\begin{array}{l}13 \\
12 \\
12\end{array}$ & 7 & $\begin{array}{l}4 \\
4\end{array}$ & 1 & $\begin{array}{l}1.9 \\
2.9\end{array}$ & 550 & 0 & 211 & 1661 & $\begin{array}{l}27788 \\
27757\end{array}$ & 0.0769 & 0.9982 & 0.5385 & $\begin{array}{l}140 \\
152\end{array}$ & 237 & 211 & 0 & 59 & 5446 & 1101 & 154 & 11 & 0.4692 \\
\hline 26 & $\begin{array}{l}7305 \\
7305\end{array}$ & $\begin{array}{l}12 \\
17\end{array}$ & $\begin{array}{l}6 \\
9\end{array}$ & $\begin{array}{l}4 \\
3 \\
3\end{array}$ & 1 & $\begin{array}{l}2.0 \\
1.9\end{array}$ & $\begin{array}{l}550 \\
410\end{array}$ & $\begin{array}{l}0 \\
5\end{array}$ & 230 & $\begin{array}{l}1606 \\
1606\end{array}$ & $\begin{array}{l}2757 \\
2860\end{array}$ & $\begin{array}{l}0.0833 \\
0.0558\end{array}$ & 0.9984 & $\begin{array}{l}0.5000 \\
0.5294\end{array}$ & $\begin{array}{l}152 \\
143\end{array}$ & 208 & 年 & 0 & $\begin{array}{l}618 \\
615\end{array}$ & $\begin{array}{l}5432 \\
5{ }_{5}^{5} 48\end{array}$ & 1112 & 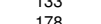 & 10 & $\begin{array}{l}0.5084 \\
0757\end{array}$ \\
\hline $\begin{array}{l}20 \\
30\end{array}$ & 7305 & 17 & $\begin{array}{c}9 \\
11\end{array}$ & 3 & $\begin{array}{l}1 \\
1\end{array}$ & $\begin{array}{l}1.9 \\
1.5\end{array}$ & $\begin{array}{l}410 \\
470\end{array}$ & $\begin{array}{l}5 \\
25\end{array}$ & $\begin{array}{l}168 \\
169\end{array}$ & 2291 & $\begin{array}{l}2002 \\
2865\end{array}$ & $\begin{array}{l}0.0500 \\
0.0588\end{array}$ & 0.9977 & $\begin{array}{l}0.5294 \\
0.6471\end{array}$ & $\begin{array}{l}143 \\
143\end{array}$ & $\begin{array}{l}240 \\
208\end{array}$ & $\begin{array}{l}100 \\
169\end{array}$ & 0 & 616 & 5420 & 1056 & $\begin{array}{l}110 \\
197\end{array}$ & 16 & $\begin{array}{l}0.4 / 54 \\
0.3593\end{array}$ \\
\hline 48 & 7305 & 23 & 13 & 4 & 1 & 1.8 & 441 & 4 & 128 & 1791 & 2937 & 0.0435 & 0.9969 & 0.5652 & 79 & 138 & 128 & 0 & 620 & 5437 & 1061 & 169 & 18 & 0.4378 \\
\hline 84 & 7305 & 17 & 10 & 3 & 1 & 1.7 & 580 & 4 & 177 & 2080 & 3005 & 0.0588 & 0.9977 & 0.5882 & 143 & 208 & 177 & 0 & 599 & 5534 & & 121 & 12 & 0.4178 \\
\hline 72 & $\begin{array}{l}7305 \\
7305\end{array}$ & $\begin{array}{l}18 \\
18\end{array}$ & 11 & $\begin{array}{l}3 \\
3 \\
3\end{array}$ & 1 & $\begin{array}{l}1.6 \\
1.4\end{array}$ & $\begin{array}{l}482 \\
719\end{array}$ & 13 & $\begin{array}{l}169 \\
170\end{array}$ & $\begin{array}{l}2267 \\
2262\end{array}$ & 3048 & 0.0556 & 0.9975 & 0.6111 & 135 & 206 & 169 & 0 & 620 & & 1103 & 141 & 15 & 0.3948 \\
\hline $\begin{array}{l}49 \\
94\end{array}$ & $\begin{array}{l}7305 \\
7305\end{array}$ & $\begin{array}{l}18 \\
16\end{array}$ & $\begin{array}{l}13 \\
11\end{array}$ & $\begin{array}{l}3 \\
3 \\
3\end{array}$ & $\begin{array}{l}1 \\
1\end{array}$ & $\begin{array}{l}1.4 \\
1.5\end{array}$ & $\begin{array}{l}719 \\
404\end{array}$ & $\begin{array}{l}13 \\
37 \\
37\end{array}$ & $\begin{array}{l}170 \\
192\end{array}$ & $\begin{array}{l}2262 \\
2041\end{array}$ & $\begin{array}{l}3054 \\
3079\end{array}$ & & 0.9975 & $\begin{array}{l}0.7222 \\
06875\end{array}$ & $\begin{array}{l}135 \\
152\end{array}$ & $\begin{array}{l}174 \\
186\end{array}$ & $\begin{array}{l}170 \\
192\end{array}$ & $\begin{array}{l}0 \\
0\end{array}$ & 597 & 5456 & 1064 & 174 & 14 & 0.2860 \\
\hline 24 & 7305 & $\begin{array}{l}16 \\
22\end{array}$ & 13 & $\begin{array}{l}3 \\
5\end{array}$ & 1 & $\begin{array}{l}1.5 \\
1.7\end{array}$ & $\begin{array}{l}404 \\
524\end{array}$ & $\begin{array}{l}3 / \\
16\end{array}$ & $\begin{array}{l}192 \\
145\end{array}$ & $\begin{array}{r}2041 \\
2014\end{array}$ & $\begin{array}{l}30 / 9 \\
3197\end{array}$ & $\begin{array}{l}0.0025 \\
0.0455\end{array}$ & $\begin{array}{l}0.99 / 8 \\
0.9970\end{array}$ & $\begin{array}{l}0.08 / 5 \\
0.5909\end{array}$ & $\begin{array}{l}152 \\
66\end{array}$ & $\begin{array}{l}186 \\
155\end{array}$ & $\begin{array}{l}192 \\
145\end{array}$ & $\begin{array}{l}0 \\
0\end{array}$ & $\begin{array}{l}623 \\
609\end{array}$ & $\begin{array}{l}5395 \\
5447\end{array}$ & & 175 & 16 & $\begin{array}{l}0.3218 \\
044132\end{array}$ \\
\hline 95 & 7305 & 13 & 8 & 4 & 1 & 1.6 & $\begin{array}{l}5<4 \\
484\end{array}$ & 71 & 248 & 1566 & 3219 & $\begin{array}{l}0.0455 \\
0.0769\end{array}$ & 0.9982 & 0.6154 & $\begin{array}{l}100 \\
140\end{array}$ & $\begin{array}{l}150 \\
196\end{array}$ & 248 & 0 & $\begin{array}{l}60 \\
57\end{array}$ & 55 & & $\begin{array}{l}160 \\
118\end{array}$ & 0 & $\begin{array}{l}0.4132 \\
0.3972\end{array}$ \\
\hline 14 & 7305 & 16 & 11 & 2 & 1 & 1.5 & 499 & 3 & 207 & 2287 & 3309 & 0.0625 & 0.9978 & 0.6875 & 228 & 208 & 207 & 0 & 580 & & & 118 & $\begin{array}{l}13 \\
12 \\
12\end{array}$ & $\begin{array}{l}0.39 / 2 \\
0.3233\end{array}$ \\
\hline 100 & 7305 & 22 & 13 & 5 & 1 & 1.7 & 611 & 7 & 153 & 2350 & 3374 & 0.0455 & 0.9970 & 0.5909 & 66 & 181 & 153 & 0 & 627 & 5446 & 10 & 147 & $\begin{array}{l}12 \\
19\end{array}$ & $\begin{array}{l}0.32137 \\
0.413\end{array}$ \\
\hline 6 & 7305 & 24 & 15 & 4 & 1 & 1.6 & 636 & 9 & 141 & 2610 & 3383 & 0.0417 & 0.9967 & 0.6250 & 76 & 174 & 141 & 0 & 615 & 5411 & 11 & 119 & 19 & 0.3792 \\
\hline 55 & 7305 & 16 & 9 & 4 & 1 & 1.8 & 489 & 1 & 212 & 2084 & 6 & 0.0625 & 0.9978 & 0.5625 & 114 & 232 & 212 & 0 & 631 & 6 & & & 12 & 0.4456 \\
\hline 23 & 7305 & 16 & 10 & 4 & 1 & 1.6 & 433 & 37 & 214 & 2029 & 3425 & 0.0625 & 0.9978 & 0.6250 & 114 & 203 & 214 & 0 & 587 & & & 58 & 16 & 0.3847 \\
\hline $\begin{array}{l}21 \\
88 \\
88\end{array}$ & 7305 & $\begin{array}{l}23 \\
17 \\
17\end{array}$ & $\begin{array}{l}14 \\
11\end{array}$ & 2 & 1 & $\begin{array}{l}1.6 \\
1.6\end{array}$ & $\begin{array}{l}50 \\
50\end{array}$ & 1 & $\begin{array}{l}150 \\
203\end{array}$ & 2608 & 3450 & & 0.9969 & 0.6087 & 159 & 186 & 150 & 0 & 610 & & & & 19 & 0.3959 \\
\hline $\begin{array}{c}88 \\
1\end{array}$ & $\begin{array}{l}7305 \\
7305\end{array}$ & $\begin{array}{l}17 \\
21\end{array}$ & $\begin{array}{l}11 \\
12\end{array}$ & $\begin{array}{l}4 \\
6 \\
6\end{array}$ & 1 & $\begin{array}{l}1.5 \\
1.8\end{array}$ & $\begin{array}{l}502 \\
454\end{array}$ & $\begin{array}{l}11 \\
11\end{array}$ & $\begin{array}{l}203 \\
166\end{array}$ & $\begin{array}{l}2041 \\
2419\end{array}$ & $\begin{array}{l}3459 \\
3480\end{array}$ & & 0.9977 & 0.64 & $\begin{array}{l}107 \\
58\end{array}$ & 186 & $\begin{array}{l}203 \\
166\end{array}$ & $\begin{array}{l}0 \\
0\end{array}$ & $\begin{array}{l}588 \\
585\end{array}$ & $\begin{array}{l}54 \\
55\end{array}$ & & 2 & 14 & $\begin{array}{l}0.3622 \\
0.4333\end{array}$ \\
\hline 36 & 7305 & $\begin{array}{l}21 \\
18\end{array}$ & 7 & $\begin{array}{l}0 \\
4\end{array}$ & 1 & $\begin{array}{l}.0 \\
2.6\end{array}$ & $\begin{array}{l}454 \\
510\end{array}$ & 33 & $\begin{array}{l}100 \\
194\end{array}$ & 1935 & 3500 & & & & $\begin{array}{l}50 \\
101\end{array}$ & 276 & $\begin{array}{l}100 \\
194\end{array}$ & 0 & 578 & & & 161 & $\begin{array}{l}19 \\
18\end{array}$ & $\begin{array}{l}0.4337 \\
0.6160\end{array}$ \\
\hline 10 & 7305 & 27 & 14 & 5 & 1 & 1.9 & 517 & 2 & 131 & 1803 & 3536 & 0.0370 & 0.9963 & 0.5185 & 54 & 129 & 131 & 0 & 598 & & & 1 & $\begin{array}{l}18 \\
19\end{array}$ & $\begin{array}{l}0.6160 \\
0.4843\end{array}$ \\
\hline 75 & 7305 & 27 & 16 & 4 & 1 & 1.7 & 629 & 2 & 134 & 2650 & 3626 & & 0.9963 & 0.5926 & 68 & 66 & 134 & 0 & 607 & & & 9 & 21 & 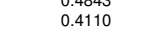 \\
\hline 43 & 73 & 23 & 13 & 3 & 1 & 1.8 & 472 & 1 & 15 & 2519 & 3641 & & 0.9 & 0.5 & 106 & 194 & 158 & 0 & $58 \%$ & & & & 18 & 0.4394 \\
\hline 31 & 730 & ${ }^{27}$ & 10 & 3 & 1 & 17 & 51 & 10 & 100 & 2706 & & & & & 11 & 208 & No & 0 & 59 & 5 & & 180 & 24 & 0.0071 \\
\hline $\begin{array}{l}73 \\
45\end{array}$ & $\begin{array}{l}7305 \\
7305\end{array}$ & $\begin{array}{l}22 \\
22 \\
22\end{array}$ & $\begin{array}{l}13 \\
14 \\
14\end{array}$ & $\begin{array}{l}3 \\
4 \\
4\end{array}$ & $\begin{array}{l}1 \\
1\end{array}$ & $\begin{array}{l}1.7 \\
16\end{array}$ & $\begin{array}{l}510 \\
522\end{array}$ & $\begin{array}{l}13 \\
10 \\
10\end{array}$ & $\begin{array}{l}168 \\
172\end{array}$ & & & & 0.9970 & 0.5909 & 111 & 208 & $\begin{array}{l}168 \\
172\end{array}$ & 0 & 593 & 4 & $\begin{array}{l}1080 \\
1051\end{array}$ & $\begin{array}{l}137 \\
177\end{array}$ & $\begin{array}{l}21 \\
15\end{array}$ & $\begin{array}{l}0.4146 \\
03701\end{array}$ \\
\hline $\begin{array}{l}45 \\
51\end{array}$ & $\begin{array}{l}7305 \\
7305\end{array}$ & $\begin{array}{l}22 \\
18\end{array}$ & $\begin{array}{c}14 \\
8\end{array}$ & $\begin{array}{l}4 \\
5\end{array}$ & 1 & $\begin{array}{l}1.6 \\
2.3\end{array}$ & $\begin{array}{l}522 \\
674\end{array}$ & $\begin{array}{l}10 \\
7\end{array}$ & $\begin{array}{l}1 / 2 \\
216\end{array}$ & $\begin{array}{l}2640 \\
1744\end{array}$ & 3887 & $\begin{array}{l}.0455 \\
0.0556\end{array}$ & 0.9975 & $\begin{array}{l}0.6364 \\
0.4444\end{array}$ & $\begin{array}{l}83 \\
81\end{array}$ & $\begin{array}{l}789 \\
218\end{array}$ & $\begin{array}{l}1 / 2 \\
216\end{array}$ & 0 & $\begin{array}{l}613 \\
609\end{array}$ & $\begin{array}{l}5450 \\
5503\end{array}$ & $\begin{array}{l}1035 \\
1035\end{array}$ & $\begin{array}{l}1 / 6 \\
143\end{array}$ & $\begin{array}{l}15 \\
15\end{array}$ & $\begin{array}{l}0.3701 \\
0.5622\end{array}$ \\
\hline & 730 & 25 & 15 & 4 & & . & 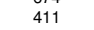 & 10 & 21 & $1 / 44$ & $500 \%$ & & 0.9966 & $\begin{array}{l}0.4444 \\
0.6000\end{array}$ & $\begin{array}{l}01 \\
73\end{array}$ & & & 0 & 00 & & & & 15 & 0.4049 \\
\hline 3 & 730 & 24 & 13 & 4 & & 1. & 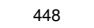 & 8 & 17 & 29 & & & 0.9967 & 0.5417 & 76 & 28 & 17 & 0 & & & & & 18 & \\
\hline & 73 & 21 & 13 & 5 & & 1. & 58 & 0 & 19 & 29 & & & & 0. & 70 & & 19 & 0 & & & & & 18 & 0.3888 \\
\hline & 730 & 24 & 14 & 5 & 1 & 1. & 48 & 12 & 17 & & 41 & & 0.9 & 0. & 61 & 148 & 17 & 0 & 60 & & 1069 & 132 & 21 & 0.4223 \\
\hline 41 & 730 & 18 & 7 & 10 & 1 & 2. & 875 & 27 & 22 & 1530 & & & & 0. & 41 & & 8 & 0 & 58 & & & 2 & 17 & 0.6179 \\
\hline & 7305 & 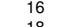 & 8 & 5 & 1 & $\begin{array}{l}2.0 \\
1.5\end{array}$ & 72 & 5 & 25 & (2) & 5 & & & & 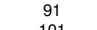 & 2 & 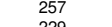 & 0 & & & & 131 & 15 & 0.5105 \\
\hline & $\begin{array}{l}7305 \\
7305\end{array}$ & $\begin{array}{l}18 \\
12 \\
22\end{array}$ & $\begin{array}{l}12 \\
12 \\
12\end{array}$ & $\begin{array}{l}4 \\
4 \\
4\end{array}$ & 1 & $\begin{array}{l}1.5 \\
1.5\end{array}$ & 561 & $\begin{array}{l}5 \\
8\end{array}$ & $\begin{array}{l}225 \\
188\end{array}$ & $\begin{array}{r}2499 \\
2165\end{array}$ & 5 & $\begin{array}{l}0.0556 \\
0.0455\end{array}$ & 0.9975 & 0.6667 & $\begin{array}{l}101 \\
83\end{array}$ & 208 & 9 & 0 & 628 & & 5 & 5 & $\begin{array}{l}14 \\
14\end{array}$ & $\begin{array}{l}0.3457 \\
0.4607\end{array}$ \\
\hline & $\begin{array}{l}7305 \\
7305\end{array}$ & 23 & $\begin{array}{l}12 \\
11\end{array}$ & $\begin{array}{l}4 \\
8 \\
8\end{array}$ & 1 & 1.8 & $\begin{array}{l}56 \\
55\end{array}$ & 8 & $\begin{array}{l}18 \\
18 \\
18\end{array}$ & $\begin{array}{r}2165 \\
2063\end{array}$ & $42 \quad-1$ & $\begin{array}{l}0.0455 \\
0.0435\end{array}$ & $\begin{array}{l}0.9970 \\
0.9969\end{array}$ & $\begin{array}{l}0.5455 \\
0.4783\end{array}$ & 83 & 8 & 8 & $\begin{array}{l}0 \\
0 \\
0\end{array}$ & & 0 & 4 & $\begin{array}{l}165 \\
154\end{array}$ & $\begin{array}{l}19 \\
22\end{array}$ & $\begin{array}{l}0.4607 \\
0.5269\end{array}$ \\
\hline 2 & $\begin{array}{l}7305 \\
7305\end{array}$ & ${ }_{25}^{23}$ & $\begin{array}{l}11 \\
13\end{array}$ & $\begin{array}{l}8 \\
6\end{array}$ & $\begin{array}{l}1 \\
1\end{array}$ & $\begin{array}{l}2.1 \\
1.9\end{array}$ & $\begin{array}{l}554 \\
499\end{array}$ & $\begin{array}{l}26 \\
10\end{array}$ & $\begin{array}{l}184 \\
170\end{array}$ & $\begin{array}{l}2063 \\
2478\end{array}$ & $\begin{array}{l}4230 \\
4241\end{array}$ & $\begin{array}{l}0.0435 \\
0.0400\end{array}$ & $\begin{array}{l}0.9969 \\
0.9966\end{array}$ & $\begin{array}{l}0.4783 \\
0.5200\end{array}$ & $\begin{array}{l}40 \\
49\end{array}$ & $\begin{array}{l}\text { 188 } \\
191\end{array}$ & $\begin{array}{l}184 \\
170\end{array}$ & 0 & $\begin{array}{l}611 \\
591\end{array}$ & $\begin{array}{l}5495 \\
5491\end{array}$ & $\begin{array}{l}1023 \\
1072\end{array}$ & $\begin{array}{l}154 \\
127\end{array}$ & $\begin{array}{ll}22 \\
24\end{array}$ & 0.4848 \\
\hline & 7305 & 15 & 5 & 5 & 1 & 3.0 & 838 & 25 & 283 & 1716 & 4250 & 0.0667 & 0.9979 & 0.3333 & 97 & 343 & 283 & 0 & 602 & 5483 & 1093 & 113 & 14 & 0.6762 \\
\hline & 7305 & 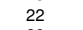 & 12 & 3 & & 18 & 564 & 26 & 193 & 2027 & 4251 & 0.0 & 0 & 0.5455 & 111 & 245 & 193 & 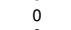 & 59 & 5407 & 11 & 163 & 21 & 0.4611 \\
\hline & 730 & 29 & 16 & 7 & 1 & 1. & $4 c$ & 2 & 148 & 2629 & 91 & & 0. & 0.5 & 36 & 16 & 148 & 0 & 60 & 543 & 1062 & 189 & 2 & 0.4522 \\
\hline 86 & $\begin{array}{l}7305 \\
7305\end{array}$ & $\begin{array}{l}24 \\
17\end{array}$ & $\begin{array}{l}11 \\
8\end{array}$ & $\begin{array}{l}6 \\
4\end{array}$ & 1 & $\begin{array}{l}2.2 \\
2.1\end{array}$ & $\begin{array}{l}575 \\
555\end{array}$ & $\begin{array}{c}0 \\
20\end{array}$ & $\begin{array}{l}181 \\
257\end{array}$ & $\begin{array}{l}777 \\
51\end{array}$ & $\begin{array}{l}4343 \\
4373\end{array}$ & 0.0588 & $\begin{array}{l}0.9967 \\
0.9977\end{array}$ & $\begin{array}{l}0.4583 \\
0.4703\end{array}$ & $\begin{array}{c}51 \\
107\end{array}$ & $\begin{array}{l}207 \\
306\end{array}$ & $\begin{array}{l}181 \\
257\end{array}$ & $\begin{array}{l}0 \\
0\end{array}$ & $\begin{array}{l}578 \\
616\end{array}$ & $\begin{array}{l}5417 \\
5426\end{array}$ & $\begin{array}{l}1081 \\
1050\end{array}$ & $\begin{array}{l}209 \\
197\end{array}$ & $\begin{array}{l}20 \\
16\end{array}$ & $\begin{array}{l}0.5465 \\
0.5393\end{array}$ \\
\hline
\end{tabular}




\begin{tabular}{|c|c|c|c|c|c|c|c|c|c|c|c|c|c|c|c|c|c|c|c|c|c|c|c|c|}
\hline 97 & 7305 & 22 & 13 & 3 & 1 & 1.7 & 444 & 15 & 202 & 3169 & 4436 & 0.0455 & 0.9970 & 0.5909 & 111 & 244 & 202 & 0 & 591 & 5465 & 1084 & 145 & 20 & 0.4170 \\
\hline 33 & 7305 & 20 & 11 & 4 & 1 & 1.8 & 511 & 15 & 224 & 2579 & 4476 & 0.0500 & 0.9973 & 0.5500 & 91 & 234 & 224 & 0 & 604 & $5+42$ & 1067 & 173 & 19 & 0.4588 \\
\hline 64 & & 19 & 7 & 7 & 1 & & 601 & 14 & 236 & 2050 & 4489 & 0.0526 & 0.9974 & 0.3684 & 55 & 293 & 236 & 0 & 591 & 5468 & 1108 & 120 & 18 & 0.6386 \\
\hline 11 & 7305 & 21 & 11 & 4 & 1 & 1.9 & 480 & 4 & 214 & 2492 & 4497 & 0.0476 & 0.9971 & 0.5238 & 87 & 227 & 214 & 0 & 610 & 5469 & 1054 & 152 & 20 & 0.4838 \\
\hline 96 & 7305 & 22 & 10 & 7 & 1 & 2.2 & 741 & 14 & 207 & 2407 & 4549 & 0.0455 & 0.9970 & 0.4545 & 47 & 241 & 207 & 0 & 609 & 5417 & 1109 & 150 & 20 & 0.5517 \\
\hline 99 & 7305 & 39 & 19 & 8 & 1 & 2.1 & 605 & 2 & 118 & 2623 & 4609 & 0.0256 & 0.9947 & 0.4872 & 23 & 138 & 118 & 0 & 621 & 5469 & 1016 & 169 & 30 & 0.5150 \\
\hline 46 & $\begin{array}{l}7305 \\
7705\end{array}$ & 28 & 18 & 4 & 1 & 1.6 & $\begin{array}{l}466 \\
779\end{array}$ & 3 & 167 & 3193 & 4678 & 0.0357 & 0.9962 & 0.6429 & 65 & 177 & 167 & 0 & 626 & 5425 & 1069 & 163 & 22 & 0.3634 \\
\hline $\begin{array}{l}91 \\
69\end{array}$ & $\begin{array}{l}7305 \\
7305\end{array}$ & $\begin{array}{l}24 \\
22\end{array}$ & 9 & $\begin{array}{l}4 \\
4\end{array}$ & $\stackrel{1}{1}$ & $\begin{array}{l}2.7 \\
18\end{array}$ & $\begin{array}{l}759 \\
703\end{array}$ & $\begin{array}{l}4 \\
17\end{array}$ & $\begin{array}{l}195 \\
216\end{array}$ & $\begin{array}{l}2741 \\
3025\end{array}$ & $\begin{array}{l}4688 \\
4749\end{array}$ & $\begin{array}{l}0.0417 \\
0.0455\end{array}$ & $\begin{array}{l}0.9967 \\
0.9970\end{array}$ & $\begin{array}{l}0.3750 \\
0\end{array}$ & $\begin{array}{l}76 \\
83\end{array}$ & $\begin{array}{l}305 \\
252\end{array}$ & $\begin{array}{l}195 \\
{ }_{216}\end{array}$ & ${ }_{0}^{0}$ & $\begin{array}{l}621 \\
603\end{array}$ & $\begin{array}{l}5414 \\
5478\end{array}$ & $\begin{array}{l}1081 \\
1034\end{array}$ & $\begin{array}{l}171 \\
119\end{array}$ & 18 & $\begin{array}{l}0.6299 \\
\end{array}$ \\
\hline $\begin{array}{l}69 \\
61\end{array}$ & $\begin{array}{l}7305 \\
7305\end{array}$ & $\begin{array}{l}22 \\
26\end{array}$ & $\begin{array}{l}12 \\
14\end{array}$ & $\begin{array}{l}4 \\
5\end{array}$ & $\begin{array}{l}1 \\
1\end{array}$ & $\begin{array}{l}1.8 \\
1.9\end{array}$ & $\begin{array}{l}703 \\
558\end{array}$ & $\begin{array}{l}17 \\
0\end{array}$ & $\begin{array}{l}216 \\
186\end{array}$ & $\begin{array}{r}3025 \\
2672\end{array}$ & $\begin{array}{l}4449 \\
4827\end{array}$ & $\begin{array}{l}0.0455 \\
0.0385\end{array}$ & $\begin{array}{l}0.9990 \\
0.9964\end{array}$ & $\begin{array}{l}0.54555 \\
0.5385\end{array}$ & $\begin{array}{l}83 \\
56\end{array}$ & $\begin{array}{l}252 \\
191\end{array}$ & $\begin{array}{l}216 \\
186\end{array}$ & $\begin{array}{l}0 \\
0 \\
0\end{array}$ & $\begin{array}{l}603 \\
593\end{array}$ & $\begin{array}{l}5478 \\
5437\end{array}$ & $\begin{array}{l}1034 \\
1051\end{array}$ & 169 & $\begin{array}{l}21 \\
23\end{array}$ & $\begin{array}{l}0.4627 \\
0.467\end{array}$ \\
\hline 15 & 7305 & $\begin{array}{l}20 \\
29\end{array}$ & $\begin{array}{l}15 \\
15\end{array}$ & 4 & 1 & 1.9 & $\begin{array}{l}558 \\
510\end{array}$ & 3 & $\begin{array}{l}186 \\
175\end{array}$ & $\begin{array}{l}26 / 2 \\
3263\end{array}$ & $\begin{array}{l}8827 \\
5067\end{array}$ & $\begin{array}{l}0.0385 \\
0.0345\end{array}$ & $\begin{array}{l}.99694 \\
0.9960\end{array}$ & $\begin{array}{l}.53855 \\
0.5172\end{array}$ & & $\begin{array}{l}911 \\
218\end{array}$ & 175 & 0 & $\begin{array}{l}593 \\
613\end{array}$ & $\begin{array}{r}5437 \\
5454\end{array}$ & $\begin{array}{l}1051 \\
1038\end{array}$ & 174 & $\begin{array}{l}206 \\
26\end{array}$ & $\begin{array}{l}0.46 / 5 \\
0.4878\end{array}$ \\
\hline 37 & 7305 & 26 & 14 & 6 & 1 & 19 & 607 & 5 & 200 & 20383 & 55191 & 0.0385 & 09964 & 0.0585 & 47 & $\begin{array}{l}170 \\
170\end{array}$ & 200 & 0 & 605 & 5368 & 1129 & 182 & 21 & 0.4688 \\
\hline 74 & 7305 & 21 & 12 & 5 & 1 & 1.8 & 512 & 5 & 251 & 2758 & 5273 & 0.0476 & 0.9971 & 0.5714 & 70 & 230 & 251 & 0 & 599 & 5444 & 1090 & 152 & 20 & $\begin{array}{l}0.4004 \\
0.4402\end{array}$ \\
\hline 29 & 7305 & 30 & 12 & 8 & 1 & 2.5 & 479 & 6 & 177 & 1977 & 5306 & 0.0333 & 0.9959 & 0.4000 & 30 & 165 & 177 & 0 & 601 & 5460 & 1038 & 182 & 24 & 0.6042 \\
\hline 63 & 7305 & 24 & 10 & 4 & 1 & 2.4 & 527 & 4 & 225 & 3175 & 5409 & 0.0417 & 0.9967 & 0.4167 & 76 & 318 & 225 & 0 & 616 & 5503 & 1036 & 127 & 23 & 0.5903 \\
\hline 17 & $\begin{array}{l}7305 \\
7705\end{array}$ & 27 & 12 & 6 & 1 & 2.3 & $\begin{array}{l}703 \\
554\end{array}$ & 2 & 202 & 2637 & $\begin{array}{r}5448 \\
5583\end{array}$ & 0.0370 & 0.9963 & 0.4444 & 45 & 220 & 202 & 0 & 630 & 5388 & 1115 & 148 & 24 & 0.5614 \\
\hline $\begin{array}{c}3 \\
89\end{array}$ & $\begin{array}{l}7305 \\
7305\end{array}$ & $\begin{array}{l}28 \\
26\end{array}$ & $\begin{array}{l}13 \\
17\end{array}$ & $\begin{array}{l}5 \\
4\end{array}$ & 1 & $\begin{array}{l}2.2 \\
15\end{array}$ & $\begin{array}{l}524 \\
604\end{array}$ & $\begin{array}{l}23 \\
14\end{array}$ & $\begin{array}{l}196 \\
{ }_{2}\end{array}$ & $\begin{array}{l}2884 \\
44006\end{array}$ & $\begin{array}{l}5483 \\
5513\end{array}$ & 0.0357 & $\begin{array}{l}0.9962 \\
0.964\end{array}$ & $\begin{array}{l}0.4643 \\
0\end{array}$ & $\begin{array}{l}52 \\
70\end{array}$ & $\begin{array}{r}222 \\
236\end{array}$ & $\begin{array}{l}196 \\
192\end{array}$ & ${ }_{0}^{0}$ & $\begin{array}{l}574 \\
604\end{array}$ & $\begin{array}{r}5430 \\
5535\end{array}$ & $\begin{array}{l}1104 \\
1002\end{array}$ & 170 & 27 & 0.5414 \\
\hline 50 & 7305 & $\begin{array}{l}26 \\
35\end{array}$ & 16 & $\begin{array}{l}4 \\
5\end{array}$ & $\begin{array}{l}1 \\
1\end{array}$ & $\begin{array}{l}1.5 \\
2.2\end{array}$ & $\begin{array}{l}604 \\
650\end{array}$ & $\begin{array}{l}14 \\
12\end{array}$ & $\begin{array}{l}212 \\
159\end{array}$ & $\begin{array}{l}4306 \\
3281\end{array}$ & $\begin{array}{l}5513 \\
5581\end{array}$ & $\begin{array}{l}0.0385 \\
0.0286\end{array}$ & $\begin{array}{l}0.9964 \\
0.9952\end{array}$ & $\begin{array}{l}0.6538 \\
0.4571\end{array}$ & $\begin{array}{l}70 \\
42\end{array}$ & $\begin{array}{l}\begin{array}{l}236 \\
205\end{array} \\
\end{array}$ & $\begin{array}{l}212 \\
159\end{array}$ & $\begin{array}{l}0 \\
0 \\
0\end{array}$ & $\begin{array}{l}604 \\
625\end{array}$ & $\begin{array}{l}5535 \\
5446\end{array}$ & $\begin{array}{l}1002 \\
1047\end{array}$ & $\begin{array}{l}140 \\
157\end{array}$ & $\begin{array}{l}24 \\
30\end{array}$ & $\begin{array}{l}0.3564 \\
0.5466\end{array}$ \\
\hline 12 & 7705 & 29 & 15 & 5 & 1 & $\begin{array}{l}2.2 \\
19\end{array}$ & 447 & 7 & $\begin{array}{l}1093 \\
193\end{array}$ & 3134 & 5594 & $\begin{array}{l}0.0286 \\
0.0345\end{array}$ & $\begin{array}{l}.99562 \\
0.9960\end{array}$ & $\begin{array}{l}0.45172 \\
0.51\end{array}$ & $\begin{array}{l}42 \\
50\end{array}$ & $\begin{array}{l}205 \\
209\end{array}$ & $\begin{array}{l}159 \\
193\end{array}$ & $\begin{array}{l}0 \\
0\end{array}$ & $\begin{array}{l}625 \\
612\end{array}$ & $\begin{array}{l}5446 \\
5388\end{array}$ & $\begin{array}{l}104 / \\
1096\end{array}$ & $\begin{array}{l}157 \\
182\end{array}$ & $\begin{array}{l}30 \\
27\end{array}$ & $\begin{array}{l}0.5466 \\
0.4889\end{array}$ \\
\hline 90 & 705 & 24 & 11 & 6 & 1 & 22 & $\begin{array}{l}5611 \\
561\end{array}$ & 13 & $\begin{array}{l}230 \\
236\end{array}$ & $\begin{array}{l}234 \\
231\end{array}$ & $\begin{array}{l}5594 \\
5557\end{array}$ & 0.0417 & $\begin{array}{l}.05067 \\
09967\end{array}$ & 0.4583 & 51 & $\begin{array}{l}2012 \\
212\end{array}$ & $\begin{array}{l}230 \\
236\end{array}$ & 0 & 601 & 5381 & 1170 & 130 & 23 & $\begin{array}{l}0.4889 \\
0.5498\end{array}$ \\
\hline 9 & 7305 & 31 & 19 & 5 & 1 & 1.6 & 481 & 6 & $\begin{array}{l}183 \\
183\end{array}$ & 3631 & 5664 & 0.0323 & 0.9958 & 0.6129 & 47 & 191 & 183 & 0 & 622 & 5422 & 1068 & 165 & 28 & 0.3940 \\
\hline 28 & 7305 & 28 & 15 & 5 & 1 & 1.9 & 619 & 14 & 208 & 3532 & 5834 & 0.0357 & 0.9962 & 0.5357 & 52 & 235 & 208 & 0 & 590 & 5399 & 1123 & 168 & 25 & 0.4717 \\
\hline 71 & 7305 & 23 & 9 & 6 & 1 & 2.6 & 779 & 23 & 259 & 2940 & 5950 & 0.0435 & 0.9969 & 0.3913 & 53 & 327 & 259 & 0 & 605 & 5440 & 1073 & 166 & 21 & 0.6174 \\
\hline 85 & 7305 & 34 & 23 & 5 & 1 & 1.5 & 520 & 0 & 176 & 3798 & 6001 & 0.0294 & 0.9953 & 0.6765 & 43 & 165 & 176 & 0 & 588 & 5456 & 1049 & 182 & 30 & 0.3312 \\
\hline 93 & 7305 & 27 & 11 & 10 & 1 & 2.5 & 853 & 4 & 241 & 2618 & 6501 & 0.0370 & 0.9963 & 0.4074 & 27 & 238 & 241 & 0 & 608 & 5492 & 1049 & 131 & 25 & 0.6004 \\
\hline 44 & 7305 & 36 & 19 & 7 & 1 & 1.9 & 563 & 8 & 191 & 4068 & 6858 & 0.0278 & 0.9951 & 0.5278 & 29 & 214 & 191 & 0 & 623 & & 1030 & 164 & & 0.4784 \\
\hline 57 & 7305 & 30 & 11 & 7 & 1 & 2.7 & 742 & 5 & 232 & 3162 & 6949 & 0.0333 & 0.9959 & 0.3667 & 35 & 287 & 232 & 0 & 606 & 5429 & 1069 & 173 & 28 & 0.6401 \\
\hline 98 & 7305 & 32 & 14 & 6 & 1 & 2.3 & 544 & 24 & 234 & 3731 & 7486 & 0.0313 & 0.9956 & 0.4375 & 38 & 266 & 234 & 0 & 594 & & 1036 & 177 & 31 & 0.5702 \\
\hline${ }^{25}$ & 7305 & 33 & 14 & 5 & 1 & 2.4 & $\begin{array}{l}558 \\
588\end{array}$ & 4 & ${ }^{231}$ & $\begin{array}{l}3528 \\
524\end{array}$ & $\begin{array}{l}7723 \\
7620\end{array}$ & 0.0303 & 0.9955 & 0.4242 & 44 & 252 & 231 & 0 & 595 & 5427 & 1063 & 193 & 27 & 0.5831 \\
\hline $\begin{array}{l}66 \\
77\end{array}$ & (305 & $\begin{array}{l}33 \\
35\end{array}$ & $\begin{array}{l}15 \\
15\end{array}$ & 6 & 1 & $\begin{array}{l}2.2 \\
2,2\end{array}$ & $\begin{array}{l}583 \\
583\end{array}$ & 28 & $\begin{array}{l}233 \\
320\end{array}$ & $\begin{array}{l}3744 \\
3200\end{array}$ & $\begin{array}{l}1689 \\
7898\end{array}$ & 0.0303 & $\begin{array}{l}.99555 \\
\end{array}$ & 0.0445 & 37 & 232 & 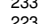 & 0 & 600 & & 1003 & 165 & 32 & 0.5534 \\
\hline 13 & 705 & & $\begin{array}{l}13 \\
10\end{array}$ & $\begin{array}{l}0 \\
1\end{array}$ & 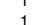 & $\begin{array}{l}2.5 \\
28\end{array}$ & $\begin{array}{l}649 \\
868\end{array}$ & 2 & 307 & 2750 & 886 & $\begin{array}{l}.02006 \\
0.0357\end{array}$ & $\begin{array}{l}.09532 \\
0.9692\end{array}$ & $\begin{array}{l}.4460 \\
03751\end{array}$ & 26 & $\begin{array}{l}2124 \\
275\end{array}$ & 30 & 0 & $\begin{array}{l}618 \\
627\end{array}$ & & 1110 & 138 & 24 & $\begin{array}{l}0.5784 \\
0.6545\end{array}$ \\
\hline 47 & 705 & 28 & 10 & o & 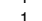 & 33 & $\begin{array}{l}6080 \\
57\end{array}$ & 4 & 278 & 268 & (158 & 00307 & 0995 & . & 25 & 年 & (3) & 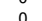 & $\begin{array}{l}521 \\
507\end{array}$ & & 10 & 150 & 32 & $\begin{array}{l}0.6545 \\
070\end{array}$ \\
\hline $\begin{array}{l}41 \\
82\end{array}$ & 7705 & 53 & 25 & 8 & 1 & $\begin{array}{l}3.0 \\
21\end{array}$ & $\begin{array}{l}617 \\
617\end{array}$ & $\begin{array}{l}4 \\
1\end{array}$ & 213 & 5004 & $\begin{array}{l}11302 \\
11312\end{array}$ & $\begin{array}{l}0.0303 \\
0.0189\end{array}$ & $\begin{array}{l}.995952 \\
0.9927\end{array}$ & $\begin{array}{l}.303030 \\
0.4717\end{array}$ & $\begin{array}{l}25 \\
17\end{array}$ & $\begin{array}{l}269 \\
220\end{array}$ & $\begin{array}{l}278 \\
213\end{array}$ & $\begin{array}{l}0 \\
0\end{array}$ & $\begin{array}{l}59 / \\
613\end{array}$ & $\begin{array}{l}5434 \\
5385\end{array}$ & $\begin{array}{l}1092 \\
1081\end{array}$ & $\begin{array}{l}150 \\
178\end{array}$ & $\begin{array}{l}32 \\
48\end{array}$ & $\begin{array}{l}0.1058 \\
0.5352\end{array}$ \\
\hline 34 & 7305 & 35 & 14 & 7 & 1 & 2.5 & 880 & 6 & 333 & 4756 & 11655 & 0.0286 & 0.9952 & 0.4000 & 30 & 340 & 333 & 0 & 613 & 5439 & 1069 & 153 & 31 & 0.6146 \\
\hline ninimum & & & 3 & 2 & 1 & 1.2 & 202 & 0 & 78 & 412 & 469 & 0.0189 & 0.9927 & 0.3000 & 17 & 82 & 78 & 0 & 569 & 5368 & 1002 & 112 & 4 & 0 \\
\hline age & & 22 & 12 & 5 & 1 & 1.9 & 545 & 12 & 189 & 2371 & 4143 & 0.0539 & 0.9970 & 0.5502 & 110 & 211 & 189 & 0 & 605 & & 1073 & 7 & 9 & 0 \\
\hline mum & & 53 & 25 & 10 & 2 & 3 & 880 & 71 & 333 & 5504 & 11655 & 0 & & & 609 & 343 & 333 & 0 & 631 & 4 & 1170 & 209 & 48 & 1 \\
\hline i.dev & & 7.9 & 3.9 & 1.9 & 0.1 & 0.4 & 127.2 & 12.7 & 44.3 & 839.2 & 1991.6 & 0.0248 & 0.0011 & 0.1151 & 96.8 & 51.3 & 44.3 & & 14.2 & 41.8 & 34.8 & 22.3 & 7.2 & 0.1 \\
\hline
\end{tabular}


Scenerio N Scenario 4 Base Case with $15 \%$ additional WEMPs savings
$1210 / 2007$ $\begin{array}{ll}\text { Date. } & \text { 12/10/2007 } \\ \text { Simulation } & 4: 32: 21 \mathrm{PM} \\ \text { Simmulation } & 5: 40: 37 \mathrm{PM}\end{array}$

$\begin{array}{ll}\text { Elimulation } & \text { 5:40:37 PM } \\ \text { Elapsed Til } & 68.27 \text { Minutes }\end{array}$

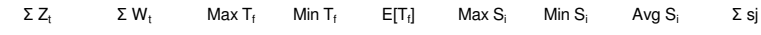

$e_{j}=1 / \Sigma Z_{1}$

$v=S$ sjej $\quad v=$ Ssiei

no. of days with Demand

\begin{tabular}{|c|c|c|c|c|c|c|c|c|c|c|c|c|c|c|c|c|c|c|c|c|c|c|c|c|}
\hline Trial No. & $\begin{array}{c}\text { Total no. of } \\
\text { Days }\end{array}$ & $\begin{array}{l}\text { No. of } \\
\text { Days } \\
\text { Failed }\end{array}$ & $\begin{array}{l}\text { No. of } \\
\text { Consecutive } \\
\text { Failures }\end{array}$ & $\begin{array}{c}\text { Max. } \\
\text { Failure } \\
\text { Duration }\end{array}$ & $\begin{array}{c}\text { Min. } \\
\text { Faulure } \\
\text { Duration }\end{array}$ & $\begin{array}{c}\text { Avg. } \\
\text { Failure } \\
\text { Duration }\end{array}$ & $\begin{array}{l}\text { Max } \\
\text { Severity of } \\
\text { Failure }\end{array}$ & $\begin{array}{c}\text { Min } \\
\text { Severity of } \\
\text { Failure }\end{array}$ & $\begin{array}{l}\text { Avg. } \\
\text { Severity of } \\
\text { a Failure }\end{array}$ & $\begin{array}{l}\text { Total } \\
\text { Maximum } \\
\text { Severity of } \\
\text { Sojourn }\end{array}$ & $\begin{array}{c}\text { Total } \\
\text { Severity of } \\
\text { Failure }\end{array}$ & $\begin{array}{l}\text { Prob. } \\
\text { [Correspo } \\
\text { nd to } \mathrm{S}_{\mathrm{j}}\end{array}$ & $\begin{array}{c}\text { Reliability, } \\
\alpha\end{array}$ & $\begin{array}{l}\text { Resiliency, } \\
F\left(E\left[T_{1}\right]\right)\end{array}$ & $\begin{array}{c}\text { Resiliency, } \\
\text { 1/(MD/NS'NF) }\end{array}$ & Vulnerability 1 & Vulnerability 2 & $0-500$ & 501-1000 & $\begin{array}{l}1001- \\
1500\end{array}$ & $\begin{array}{l}1501- \\
2000\end{array}$ & $\begin{array}{l}2001- \\
2500\end{array}$ & $>2500$ & $\begin{array}{l}\text { Eculidean } \\
\text { Distance }\end{array}$ \\
\hline 87 & 7305 & 5 & 4 & 2 & 1 & 1.3 & 187 & 1 & 78 & 347 & 388 & 0.2000 & 0.9993 & 0.8000 & 731 & 87 & 78 & 0 & 731 & 5470 & 962 & 138 & 4 & 0.2024 \\
\hline 4 & 7305 & 7 & 4 & 2 & 1 & 1.8 & 456 & 0 & 129 & 837 & 905 & 0.1429 & 0.9990 & 0.5714 & 522 & 209 & 129 & 0 & 719 & 5473 & 1005 & 103 & 5 & 0.4317 \\
\hline 39 & 7305 & 13 & 8 & 3 & 1 & 1.6 & & 8 & & 920 & 1352 & 0.0769 & 0.9982 & 0.6154 & 187 & 115 & 104 & 0 & 716 & 5403 & 1051 & 125 & 10 & 0.3869 \\
\hline 79 & $\begin{array}{l}7305 \\
7305\end{array}$ & 8 & $\begin{array}{l}6 \\
5\end{array}$ & $\begin{array}{l}2 \\
3\end{array}$ & 1 & $\begin{array}{l}1.3 \\
1.4\end{array}$ & $\begin{array}{l}533 \\
484\end{array}$ & 34 & 178 & 1165 & 1424 & 0.1250 & 0.9989 & 0.7500 & 457 & & 178 & 0 & 691 & $\begin{array}{l}5438 \\
545\end{array}$ & $\begin{array}{r}997 \\
1077\end{array}$ & 171 & 8 & 0.2599 \\
\hline $\begin{array}{l}27 \\
38\end{array}$ & $\begin{array}{l}7305 \\
7305\end{array}$ & $\begin{array}{c}7 \\
10\end{array}$ & $\begin{array}{l}5 \\
3\end{array}$ & $\begin{array}{l}3 \\
7\end{array}$ & $\begin{array}{l}1 \\
1\end{array}$ & $\begin{array}{l}1.4 \\
3.3\end{array}$ & $\begin{array}{l}484 \\
280\end{array}$ & $\begin{array}{l}12 \\
50\end{array}$ & $\begin{array}{l}207 \\
149\end{array}$ & $\begin{array}{l}1024 \\
789\end{array}$ & $\begin{array}{l}1449 \\
1495\end{array}$ & $\begin{array}{l}0.1429 \\
0.1000\end{array}$ & $\begin{array}{l}0.9990 \\
0.9986\end{array}$ & $\begin{array}{l}0.7143 \\
0.3000\end{array}$ & $\begin{array}{l}348 \\
104\end{array}$ & $\begin{array}{l}205 \\
263\end{array}$ & $\begin{array}{l}207 \\
149\end{array}$ & $\begin{array}{l}0 \\
0 \\
0\end{array}$ & $\begin{array}{l}713 \\
740\end{array}$ & $\begin{array}{l}5405 \\
5369\end{array}$ & $\begin{array}{l}1077 \\
1052\end{array}$ & $\begin{array}{l}104 \\
134\end{array}$ & 6 & 0.2975 \\
\hline $\begin{array}{l}38 \\
19\end{array}$ & $\begin{array}{l}7305 \\
7305\end{array}$ & 11 & $\begin{array}{l}3 \\
5\end{array}$ & 4 & $\begin{array}{l}1 \\
1\end{array}$ & $\begin{array}{l}3.3 \\
2.2\end{array}$ & $\begin{array}{l}280 \\
400\end{array}$ & $\begin{array}{l}50 \\
23\end{array}$ & 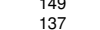 & $\begin{array}{l}899 \\
1053\end{array}$ & $\begin{array}{l}1495 \\
1507\end{array}$ & $\begin{array}{l}0.1000 \\
0.0909\end{array}$ & $\begin{array}{l}0.9986 \\
0.9985\end{array}$ & $\begin{array}{l}0.3000 \\
0.4545\end{array}$ & $\begin{array}{l}104 \\
166\end{array}$ & $\begin{array}{l}263 \\
211\end{array}$ & $\begin{array}{l}149 \\
137\end{array}$ & 0 & $\begin{array}{l}470 \\
704\end{array}$ & $\begin{array}{l}5699 \\
5478\end{array}$ & $\begin{array}{l}1052 \\
1007\end{array}$ & $\begin{array}{l}134 \\
107\end{array}$ & $\begin{array}{c}10 \\
9\end{array}$ & $\begin{array}{l}0.7026 \\
0.5482\end{array}$ \\
\hline $\begin{array}{l}19 \\
5\end{array}$ & 7305 & 17 & 11 & $\begin{array}{l}4 \\
3\end{array}$ & 1 & $\begin{array}{l}2.2 \\
1.5\end{array}$ & 274 & 1 & 92 & $\begin{array}{l}1053 \\
1190\end{array}$ & 1570 & $\begin{array}{l}0.0909 \\
0.0588\end{array}$ & $\begin{array}{l}0.9985 \\
0.9977\end{array}$ & $\begin{array}{l}0.4545 \\
0.6471\end{array}$ & $\begin{array}{l}166 \\
143\end{array}$ & $\begin{array}{l}211 \\
108\end{array}$ & $\begin{array}{l}137 \\
92\end{array}$ & $\begin{array}{l}0 \\
0\end{array}$ & $\begin{array}{l}704 \\
704\end{array}$ & $\begin{array}{l}5478 \\
5486\end{array}$ & $\begin{array}{l}1007 \\
955\end{array}$ & $\begin{array}{l}107 \\
147\end{array}$ & $\begin{array}{c}9 \\
13\end{array}$ & $\begin{array}{l}0.5482 \\
0.3549\end{array}$ \\
\hline 52 & 7305 & 13 & 10 & 4 & 1 & 1.3 & 289 & 2 & 132 & 1284 & 1710 & $\begin{array}{l}0.0769 \\
0.0769\end{array}$ & 0.9982 & 0.7692 & 140 & 128 & 132 & 0 & $\begin{array}{l}104 \\
722\end{array}$ & $\begin{array}{l}5386 \\
5366\end{array}$ & $\begin{array}{l}955 \\
1030\end{array}$ & $\begin{array}{l}14 / \\
176\end{array}$ & 11 & $\begin{array}{l}0.3549 \\
0.2367\end{array}$ \\
\hline 40 & 7305 & 10 & 7 & 2 & 1 & 1.4 & 392 & 12 & 173 & $\begin{array}{l}1461 \\
1461\end{array}$ & 1731 & 0.1000 & 0.9986 & 0.7000 & 365 & $\begin{array}{l}200 \\
209\end{array}$ & $\begin{array}{l}178 \\
173\end{array}$ & 0 & 736 & 5423 & 1025 & 112 & 9 & 0.3079 \\
\hline 92 & 7305 & 11 & 7 & 3 & 1 & 1.6 & 629 & 34 & 162 & 1134 & 1787 & 0.0909 & 0.9985 & 0.6364 & 221 & 162 & 162 & 0 & 720 & 5424 & 1012 & 138 & 11 & 0.3694 \\
\hline 16 & 7305 & 6 & 3 & 3 & 1 & 2.0 & 484 & 23 & 306 & 922 & 1834 & 0.1667 & 0.9992 & 0.5000 & 406 & 307 & 306 & 0 & 721 & 5438 & & 122 & 5 & 0.5147 \\
\hline 76 & & & & & & & & 16 & 206 & & & & & & & & & & 705 & & & & 8 & 0.4520 \\
\hline 78 & 7305 & 16 & 8 & 8 & 1 & 2.0 & 697 & 5 & 118 & 1207 & 1884 & 0.0625 & 0.9978 & 0.5000 & 57 & 151 & 118 & 0 & 726 & 5346 & 1005 & 157 & 11 & $\begin{array}{l}0.452<0 \\
0.5022\end{array}$ \\
\hline 58 & 7305 & 16 & 11 & 3 & 1 & 1.5 & 587 & 0 & 119 & 1536 & 1903 & 0.0625 & 0.9978 & 0.6875 & 152 & 140 & 119 & 0 & 738 & 5429 & 990 & 134 & 14 & 0.3161 \\
\hline 56 & 7305 & 10 & 6 & 2 & 1 & 1.7 & 444 & 24 & 194 & 1422 & 1942 & 0.1000 & 0.9986 & 0.6000 & 365 & 237 & 194 & 0 & 703 & 5479 & 971 & 144 & 8 & 0.4075 \\
\hline 59 & 7305 & 15 & 10 & 3 & 1 & 1.5 & 491 & 0 & 131 & 1526 & 1962 & 0.0667 & 0.9979 & 0.6667 & 162 & 153 & 131 & 0 & 699 & 5417 & 1018 & 159 & 12 & 0.3374 \\
\hline 62 & 7305 & 13 & 9 & 3 & 1 & 1.4 & 513 & 11 & 152 & 1673 & 1980 & 0.0769 & 0.9982 & 0.6923 & 187 & 186 & 152 & 0 & 728 & 5379 & 1041 & 147 & 10 & 0.3137 \\
\hline 70 & 7305 & 13 & 9 & 4 & 1 & 1.4 & 494 & 13 & 159 & 1782 & 2072 & 0.0769 & 0.9982 & 0.6923 & 140 & & 159 & 0 & 731 & 5392 & 1030 & 141 & 11 & 0.3142 \\
\hline 8 & 7305 & 12 & 9 & 2 & 1 & 1.3 & 396 & & 183 & 1799 & 2190 & 0.0833 & 0.9984 & 0.7500 & 304 & 200 & 183 & & 716 & 5432 & 975 & 172 & 10 & 0.2604 \\
\hline 2 & 7305 & 18 & 13 & 3 & 1 & 1.4 & 361 & 0 & 126 & 1840 & 2267 & 0.0556 & 0.9975 & 0.7222 & 135 & 142 & 126 & 0 & 753 & 5 & 1001 & 132 & 14 & 0.2823 \\
\hline 80 & 7305 & 17 & 12 & 3 & 1 & 1.4 & $\begin{array}{l}432 \\
432\end{array}$ & 0 & 146 & 1912 & 2474 & 0.0588 & 0.9977 & 0.7059 & 143 & 159 & 146 & 0 & 704 & & 6 & 156 & 12 & 0.2998 \\
\hline $\begin{array}{l}81 \\
7\end{array}$ & $\begin{array}{l}7305 \\
7305\end{array}$ & $\begin{array}{l}12 \\
10\end{array}$ & $\begin{array}{l}6 \\
5 \\
5\end{array}$ & $\begin{array}{l}4 \\
4\end{array}$ & 1 & $\begin{array}{l}2.0 \\
2.0\end{array}$ & $\begin{array}{l}535 \\
535\end{array}$ & 3 & $\begin{aligned} 213 \\
213 \\
259\end{aligned}$ & $\begin{array}{l}{ }_{1570} \\
1530\end{array}$ & $\begin{array}{r}2555 \\
2591\end{array}$ & 0.0833 & 0.9984 & $\begin{array}{l}0.5000 \\
0.5000\end{array}$ & $\begin{array}{l}152 \\
1183\end{array}$ & 262 & $\begin{array}{l}213 \\
259\end{array}$ & 0 & 718 & & $\begin{array}{l}1042 \\
1021\end{array}$ & 145 & 10 & 0.5072 \\
\hline 30 & 7305 & 17 & $\begin{array}{c}5 \\
11\end{array}$ & $\begin{array}{l}4 \\
3\end{array}$ & 1 & $\begin{array}{l}2.0 \\
1.5\end{array}$ & $\begin{array}{l}530 \\
455\end{array}$ & 9 & $\begin{array}{l}259 \\
153\end{array}$ & $\begin{array}{r}21530 \\
2124\end{array}$ & $\begin{array}{l}2591 \\
2607\end{array}$ & $\begin{array}{l}0.1000 \\
0.0588\end{array}$ & $\begin{array}{l}0.9986 \\
0.9977\end{array}$ & $\begin{array}{l}0.00000 \\
0.6471\end{array}$ & $\begin{array}{l}183 \\
143\end{array}$ & $\begin{array}{l}300 \\
193\end{array}$ & $\begin{array}{l}259 \\
153\end{array}$ & 0 & (150 & $\begin{array}{l}5420 \\
5355\end{array}$ & 085 & 184 & 15 & $\begin{array}{l}0.5106 \\
0.3582\end{array}$ \\
\hline $\begin{array}{l}30 \\
48\end{array}$ & $\begin{array}{l}7305 \\
7305\end{array}$ & 20 & 110 & $\begin{array}{l}3 \\
4\end{array}$ & 1 & $\begin{array}{l}1.5 \\
20\end{array}$ & $\begin{array}{l}455 \\
426\end{array}$ & 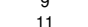 & $\begin{array}{l}153 \\
130\end{array}$ & $\begin{array}{l}2124 \\
1617\end{array}$ & 2607 & $\begin{array}{l}0.0588 \\
0.0500\end{array}$ & $\begin{array}{l}0.99 / 7 \\
0.9973\end{array}$ & $\begin{array}{l}0.04 / 1 \\
0.5000\end{array}$ & $\begin{array}{l}143 \\
91\end{array}$ & 193 & $\begin{array}{l}753 \\
130\end{array}$ & 0 & . & & & 187 & 15 & $\begin{array}{l}0.3582 \\
05027\end{array}$ \\
\hline $\begin{array}{l}40 \\
26\end{array}$ & 7305 & 16 & 9 & $\begin{array}{l}4 \\
3\end{array}$ & 1 & 1.8 & $\begin{array}{l}420 \\
395\end{array}$ & 7 & 163 & 2098 & 2613 & $\begin{array}{l}0.0500 \\
0.0625\end{array}$ & 0.9978 & $\begin{array}{l}0.50000 \\
0.5625\end{array}$ & $\begin{array}{l}91 \\
152\end{array}$ & $\begin{array}{l}162 \\
233\end{array}$ & $\begin{array}{l}130 \\
163\end{array}$ & 0 & $\begin{array}{l}735 \\
728\end{array}$ & & 12 & 165 & $\begin{array}{l}15 \\
15\end{array}$ & $\begin{array}{l}0.5027 \\
0.4424\end{array}$ \\
\hline 84 & 7305 & $\begin{array}{l}10 \\
15\end{array}$ & $\begin{array}{l}9 \\
9\end{array}$ & 3 & 1 & $\begin{array}{l}1.0 \\
1.7\end{array}$ & 565 & 1 & $\begin{array}{l}103 \\
184\end{array}$ & $\begin{array}{l}1938 \\
1938\end{array}$ & 2760 & $\begin{array}{l}0.0667 \\
0.067\end{array}$ & 0.9979 & 0.6000 & $\begin{array}{l}152 \\
162\end{array}$ & 215 & $\begin{array}{l}103 \\
184\end{array}$ & 0 & $\begin{array}{l}713 \\
713\end{array}$ & $\begin{array}{l}54903 \\
5496\end{array}$ & $\begin{array}{l}904 \\
968\end{array}$ & $\begin{array}{l}105 \\
116\end{array}$ & 12 & $\begin{array}{l}0.4424 \\
0.4067\end{array}$ \\
\hline 72 & 7305 & 17 & 11 & 2 & 1 & 1.5 & 467 & 12 & 163 & 2101 & 2777 & 0.0588 & 0.9977 & 0.6471 & 215 & 191 & 163 & 0 & 732 & 5385 & 1044 & 131 & 13 & 0.3589 \\
\hline 49 & 7305 & 16 & 12 & 3 & 1 & 1.3 & 704 & 10 & 174 & 2066 & 2782 & 0.0625 & 0.9978 & 0.7500 & 152 & 172 & 174 & 0 & 720 & 5413 & 995 & 164 & 13 & 0.2595 \\
\hline 94 & 7305 & 16 & 11 & 3 & 1 & 1.5 & 389 & 22 & 177 & 1874 & 2836 & 0.0625 & 0.9978 & 0.6875 & 152 & 170 & 177 & 0 & 749 & 5352 & 1024 & 167 & 13 & 0.3205 \\
\hline 24 & 7305 & 22 & 13 & 5 & 1 & 1.7 & 509 & 0 & 130 & 1815 & 2861 & 0.0455 & 0.9970 & 0.5909 & 66 & 140 & 130 & 0 & 738 & & & 161 & 15 & 0.4124 \\
\hline 95 & 7305 & 13 & 8 & 4 & 1 & 1.6 & 469 & 56 & $\begin{array}{l}232 \\
\end{array}$ & 1444 & 3022 & 0.0769 & 0.9982 & 0.6154 & 140 & 180 & 232 & 0 & 701 & & 1002 & & 13 & 0.3957 \\
\hline 6 & $\begin{array}{l}7305 \\
7305\end{array}$ & 20 & 年 & 3 & 1 & 1.5 & $\begin{array}{l}621 \\
{ }_{20}\end{array}$ & 2 & 152 & $\begin{array}{l}2387 \\
{ }_{2387}\end{array}$ & 3031 & 0.0500 & 0.9973 & 0.6500 & 122 & 184 & 152 & 0 & 726 & & 1065 & 114 & 16 & 0.3552 \\
\hline 100 & $\begin{array}{l}7305 \\
7335\end{array}$ & ${ }^{21}$ & 12 & 5 & 1 & 1.8 & 596 & 4 & 145 & 2159 & 3047 & 0.0476 & 0.9971 & 0.5714 & 70 & 180 & 145 & 0 & 743 & & & 10 & 18 & 0.4325 \\
\hline 14 & $\begin{array}{l}7305 \\
7335\end{array}$ & 13 & 8 & 2 & 1 & 1.6 & 484 & 8 & 238 & 2146 & 3091 & 0.0769 & 0.9982 & 0.6154 & 281 & 268 & 238 & 0 & 702 & & & 15 & 12 & 0.3962 \\
\hline $\begin{array}{l}21 \\
10\end{array}$ & $\begin{array}{l}7305 \\
7305\end{array}$ & $\begin{array}{r}21 \\
23 \\
23\end{array}$ & $\begin{array}{l}14 \\
114\end{array}$ & $\begin{array}{l}2 \\
5\end{array}$ & 1 & $\begin{array}{l}1.5 \\
21\end{array}$ & $\begin{array}{l}485 \\
502 \\
502\end{array}$ & $\begin{array}{l}5 \\
6\end{array}$ & $\begin{array}{l}149 \\
137\end{array}$ & $\begin{array}{l}2395 \\
1657\end{array}$ & $\begin{array}{l}3121 \\
3162\end{array}$ & $\begin{array}{l}0.0476 \\
0.0435\end{array}$ & $\begin{array}{l}0.9971 \\
0.9969\end{array}$ & 0.6667 & 174 & 171 & $\begin{array}{l}149 \\
137\end{array}$ & 0 & $\begin{array}{l}712 \\
716\end{array}$ & & 1038 & 172 & $\begin{array}{l}19 \\
15\end{array}$ & 0.3386 \\
\hline 10 & $\begin{array}{l}7305 \\
7305\end{array}$ & $\begin{array}{l}23 \\
20 \\
20\end{array}$ & $\begin{array}{l}11 \\
11\end{array}$ & 5 & 1 & $\begin{array}{l}2.1 \\
1.8\end{array}$ & $\begin{array}{l}502 \\
438\end{array}$ & $\begin{array}{l}6 \\
9\end{array}$ & $\begin{array}{l}137 \\
158\end{array}$ & & $\begin{array}{l}\begin{array}{l}3162 \\
3165\end{array} \\
3165\end{array}$ & 0.0435 & 0.9969 & 0.4783 & 64 & $\begin{array}{l}148 \\
204\end{array}$ & $\begin{array}{l}137 \\
158\end{array}$ & 0 & $\begin{array}{l}71 \\
71\end{array}$ & & $\begin{array}{l}1020 \\
9057\end{array}$ & $\begin{array}{l}133 \\
152\end{array}$ & $\begin{array}{l}15 \\
19\end{array}$ & $\begin{array}{l}0.5246 \\
0.4544\end{array}$ \\
\hline 55 & $\begin{array}{l}73005 \\
7305\end{array}$ & $\begin{array}{l}20 \\
13\end{array}$ & $\begin{array}{c}11 \\
8\end{array}$ & $\begin{array}{l}6 \\
4\end{array}$ & 1 & $\begin{array}{l}1.8 \\
1.6\end{array}$ & $\begin{array}{l}\begin{array}{r}438 \\
474\end{array} \\
47\end{array}$ & $\begin{array}{c}9 \\
11\end{array}$ & $\begin{array}{l}158 \\
244\end{array}$ & $\begin{array}{l}2240 \\
1953\end{array}$ & $\begin{array}{l}3165 \\
3166\end{array}$ & $\begin{array}{l}0.0500 \\
0.0769\end{array}$ & $\begin{array}{l}0.9973 \\
0.9982\end{array}$ & $\begin{array}{l}0.55000 \\
0.6154\end{array}$ & $\begin{array}{l}61 \\
140\end{array}$ & $\begin{array}{l}204 \\
244\end{array}$ & $\begin{array}{l}158 \\
244\end{array}$ & 0 & 7) & & $\begin{array}{l}957 \\
1050\end{array}$ & $\begin{array}{l}152 \\
152\end{array}$ & 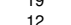 & $\begin{array}{l}0.4544 \\
0.3968\end{array}$ \\
\hline 23 & 7305 & 16 & 10 & 4 & 1 & $\begin{array}{l}1.6 \\
1.6\end{array}$ & $\begin{array}{l}\text { t/4 } \\
417\end{array}$ & 22 & $\begin{array}{l}244 \\
199\end{array}$ & 1877 & 3181 & 0.0625 & $\begin{array}{l}. .9982 \\
0.9978\end{array}$ & $\begin{array}{l}0.0154 \\
0.6250\end{array}$ & $\begin{array}{l}140 \\
114\end{array}$ & $\begin{array}{l}244 \\
188\end{array}$ & $\begin{array}{l}244 \\
199\end{array}$ & 0 & $\begin{array}{l}358 \\
698\end{array}$ & 5406 & 1033 & 152 & 15 & $\begin{array}{l}0.39606 \\
0.3833\end{array}$ \\
\hline 88 & 7305 & 16 & 10 & 4 & 1 & 1.6 & 487 & 10 & 200 & 1877 & 3204 & 0.0625 & 0.9978 & 0.6250 & 114 & 188 & 200 & 0 & $\begin{array}{l}690 \\
698\end{array}$ & & 1 & 173 & 14 & 0.3835 \\
\hline 36 & 7305 & 18 & 7 & 4 & 1 & 2.6 & 494 & 18 & 179 & 1829 & 3227 & 0.0556 & 0.9975 & 0.3889 & 101 & 261 & 179 & 0 & 680 & 5496 & 956 & 157 & 16 & 0.6153 \\
\hline 31 & 7305 & 26 & 18 & 3 & 1 & 1.4 & 565 & 2 & 124 & 2435 & 3232 & 0.0385 & 0.9964 & 3 & 94 & 135 & 124 & 0 & 16 & & 1005 & 67 & 22 & 0.3117 \\
\hline 75 & 7305 & 24 & 15 & 4 & 1 & 1.6 & 614 & 2 & 136 & $\begin{array}{r}2419 \\
2325\end{array}$ & 32 & 7 & 0.9967 & 0. & 76 & 195 & 13 & 0 & 10 & 5 & 1006 & 156 & 19 & 0.3789 \\
\hline $\begin{array}{l}43 \\
73\end{array}$ & & $\begin{array}{r}20 \\
21\end{array}$ & $\begin{array}{l}12 \\
13\end{array}$ & $\begin{array}{l}3 \\
3 \\
3\end{array}$ & 1 & $\begin{array}{l}1.7 \\
16\end{array}$ & $\begin{array}{l}4_{456} \\
495\end{array}$ & $\begin{array}{c}5 \\
16\end{array}$ & $\begin{array}{l}166 \\
160\end{array}$ & $\begin{array}{l}2335 \\
2508\end{array}$ & $\begin{array}{l}3328 \\
3359\end{array}$ & $\begin{array}{l}0.0500 \\
0.047\end{array}$ & $\begin{array}{l}0.9973 \\
0.9973\end{array}$ & $\begin{array}{l}0.6000 \\
0\end{array}$ & $\begin{array}{l}122 \\
116\end{array}$ & 193 & 160 & $\begin{array}{l}0 \\
0 \\
0\end{array}$ & 706 & & $\begin{array}{l}964 \\
9095\end{array}$ & 131 & $\begin{array}{l}18 \\
18\end{array}$ & 0.4055 \\
\hline $\begin{array}{l}73 \\
45\end{array}$ & $\begin{array}{l}7305 \\
7305\end{array}$ & $\begin{array}{l}21 \\
20\end{array}$ & $\begin{array}{l}13 \\
12\end{array}$ & $\begin{array}{l}3 \\
4\end{array}$ & $\begin{array}{l}1 \\
1\end{array}$ & $\begin{array}{l}1.6 \\
1.7\end{array}$ & $\begin{array}{l}495 \\
507\end{array}$ & $\begin{array}{c}16 \\
3 \\
3\end{array}$ & $\begin{array}{l}\text { 160 } \\
173\end{array}$ & $\begin{array}{l}2508 \\
2434\end{array}$ & $\begin{array}{l}3359 \\
3451\end{array}$ & $\begin{array}{l}0.0476 \\
0.0500\end{array}$ & $\begin{array}{l}0.9971 \\
0.9973\end{array}$ & $\begin{array}{l}0.6190 \\
0.6000\end{array}$ & $\begin{array}{c}116 \\
91\end{array}$ & $\begin{array}{l}193 \\
203\end{array}$ & $\begin{array}{l}160 \\
173\end{array}$ & $\begin{array}{l}0 \\
0\end{array}$ & $\begin{array}{l}706 \\
726\end{array}$ & $\begin{array}{l}5555 \\
5398\end{array}$ & $\begin{array}{l}995 \\
999\end{array}$ & $\begin{array}{l}131 \\
171\end{array}$ & $\begin{array}{l}18 \\
11\end{array}$ & 0.3863 \\
\hline $\begin{array}{l}45 \\
35 \\
35\end{array}$ & $\begin{array}{l}7305 \\
7305\end{array}$ & $\begin{array}{l}20 \\
23 \\
23\end{array}$ & $\begin{array}{l}12 \\
14\end{array}$ & $\begin{array}{l}4 \\
4\end{array}$ & $\begin{array}{l}1 \\
1\end{array}$ & $\begin{array}{l}1.7 \\
1.6\end{array}$ & $\begin{array}{l}507 \\
396\end{array}$ & $\begin{array}{l}3 \\
3 \\
3\end{array}$ & $\begin{array}{l}173 \\
153\end{array}$ & $\begin{array}{l}2434 \\
2057\end{array}$ & $\begin{array}{l}34 \\
35\end{array}$ & $\begin{array}{l}0.0500 \\
0.0435\end{array}$ & $\begin{array}{l}0.9973 \\
0.9969\end{array}$ & $\begin{array}{l}0.60000 \\
0.6087\end{array}$ & 91 & 203 & $\begin{array}{l}173 \\
153\end{array}$ & $\begin{array}{l}0 \\
0\end{array}$ & $\begin{array}{l}726 \\
726\end{array}$ & $\begin{array}{l}5398 \\
5334\end{array}$ & $\begin{array}{r}999 \\
1070\end{array}$ & $\begin{array}{l}171 \\
157\end{array}$ & $\begin{array}{l}11 \\
18\end{array}$ & $\begin{array}{l}0.4059 \\
0.3961\end{array}$ \\
\hline 51 & 7305 & $\begin{array}{l}20 \\
16\end{array}$ & $\begin{array}{l}8 \\
8\end{array}$ & $\begin{array}{l}4 \\
5\end{array}$ & 1 & 2.0 & $\begin{array}{l}650 \\
658\end{array}$ & $\begin{array}{l}3 \\
2\end{array}$ & $\begin{array}{l}153 \\
227\end{array}$ & $\begin{array}{l}205 / \\
1622\end{array}$ & $\begin{array}{l}3526 \\
3627\end{array}$ & 25 & $\begin{array}{l}0.9969 \\
0.9978\end{array}$ & 10 & $\begin{array}{l}99 \\
91\end{array}$ & $\begin{array}{l}74 / \\
203\end{array}$ & $\begin{array}{l}153 \\
227\end{array}$ & 0 & $\begin{array}{l}726 \\
724\end{array}$ & & 1070 & $\begin{array}{l}15 / \\
137\end{array}$ & $\begin{array}{l}18 \\
13 \\
\end{array}$ & $\begin{array}{l}0.3961 \\
0.5082\end{array}$ \\
\hline 83 & 7305 & 23 & 14 & 3 & 1 & 1.6 & 432 & 0 & 161 & 2769 & 3711 & 0.0435 & 0.9969 & 0.6087 & 106 & 198 & 161 & 0 & $\begin{array}{l}724 \\
724\end{array}$ & 5420 & 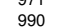 & 155 & 16 & 0.3966 \\
\hline 42 & 7305 & 23 & 13 & 5 & 1 & 1.8 & 467 & 2 & 163 & 18 & 37 & 0.0 & 0.9969 & 2 & 64 & 144 & 163 & 0 & 710 & & 7 & 130 & 18 & 0.4396 \\
\hline 67 & 73 & 19 & 13 & 3 & 1 & 1.5 & 57 & 9 & 199 & 27 & 37 & 0.0 & 0. & 0. & 28 & & 15 & 0 & & & & 19 & 17 & 0.3256 \\
\hline 65 & 7305 & 21 & 12 & 4 & 1 & 1.8 & 54 & 5 & 181 & 15 & 38 & & & & 87 & 65 & $1 \varepsilon$ & 0 & & & 9 & 158 & 17 & 0.4347 \\
\hline $\begin{array}{l}41 \\
54\end{array}$ & $\begin{array}{r}7305 \\
7705\end{array}$ & $\begin{array}{l}18 \\
24\end{array}$ & 7 & 10 & 1 & 2.6 & $\begin{array}{l}859 \\
484\end{array}$ & 15 & 16 & 14 & 38 & 0.0 & 0.9975 & 0.3889 & $\begin{array}{l}41 \\
51\end{array}$ & 10 & 21 & 0 & 689 & & & 109 & 17 & 0.6170 \\
\hline $\begin{array}{l}54 \\
18 \\
18\end{array}$ & $\begin{array}{l}7305 \\
7305\end{array}$ & $\begin{array}{l}24 \\
16\end{array}$ & $\begin{array}{l}12 \\
10\end{array}$ & $\begin{array}{l}6 \\
4\end{array}$ & $\begin{array}{l}1 \\
1\end{array}$ & $\begin{array}{l}2.0 \\
16\end{array}$ & $\begin{array}{l}484 \\
496\end{array}$ & $\begin{array}{c}15 \\
3 \\
3\end{array}$ & $\begin{array}{l}161 \\
242\end{array}$ & 22 & 38 & 0.0 & $\begin{array}{l}0.9967 \\
0.9978\end{array}$ & 0.5 & $\begin{array}{c}51 \\
114\end{array}$ & $\begin{array}{l}190 \\
233 \\
233\end{array}$ & $\begin{array}{l}161 \\
242\end{array}$ & 0 & $\begin{array}{l}701 \\
730\end{array}$ & 54 & $\begin{array}{l}1003 \\
987\end{array}$ & $\begin{array}{l}126 \\
164\end{array}$ & $\begin{array}{l}21 \\
13\end{array}$ & $\begin{array}{l}0.5041 \\
0.3873\end{array}$ \\
\hline 20 & $\begin{array}{l}7305 \\
7305\end{array}$ & $\begin{array}{l}16 \\
15\end{array}$ & $\begin{array}{l}100 \\
7\end{array}$ & $\begin{array}{l}4 \\
5\end{array}$ & 1 & $\begin{array}{l}1.6 \\
2.1\end{array}$ & $\begin{array}{l}496 \\
710\end{array}$ & $\begin{array}{l}3 \\
15 \\
\end{array}$ & $\begin{array}{l}242 \\
258 \\
258\end{array}$ & $\begin{array}{l}2331 \\
1953\end{array}$ & $\begin{array}{l}3867 \\
3874\end{array}$ & $\begin{array}{l}0.0625 \\
0.0667\end{array}$ & $\begin{array}{l}0.9978 \\
0.9979\end{array}$ & $\begin{array}{l}0.6250 \\
0.4667\end{array}$ & $\begin{array}{l}114 \\
97\end{array}$ & $\begin{array}{l}\begin{array}{r}233 \\
279\end{array} \\
279\end{array}$ & $\begin{array}{l}242 \\
258\end{array}$ & 0 & $\begin{array}{l}730 \\
735\end{array}$ & & $\begin{array}{l}987 \\
1012\end{array}$ & $\begin{array}{l}164 \\
126\end{array}$ & $\begin{array}{l}73 \\
12\end{array}$ & $\begin{array}{l}0.3873 \\
0.5433\end{array}$ \\
\hline 22 & 7305 & 23 & 11 & 8 & 1 & 2.1 & 539 & 11 & $\begin{array}{l}160 \\
169\end{array}$ & 1895 & 3878 & 0.0435 & 0.9969 & 0.4783 & 40 & $\begin{array}{l}172 \\
\end{array}$ & 160 & 0 & 74 & & & 146 & 12 & 0.5261 \\
\hline 60 & 7305 & 26 & 4 & . & 1 & 1.9 & 408 & 2 & 149 & 2403 & 3879 & 0.0385 & 0.9964 & 0.5385 & 40 & 172 & $\begin{array}{l}149 \\
149\end{array}$ & 0 & 71 & & 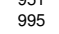 & $\begin{array}{l}170 \\
179\end{array}$ & 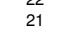 & 0.4654 \\
\hline 53 & 7305 & 22 & 12 & 3 & 1 & 1.8 & 549 & 11 & 178 & 27 & 39 & 0. & 0 & 0. & 111 & 22 & 178 & 0 & 72 & & 4 & 147 & 21 & 0.4601 \\
\hline 68 & 7305 & 21 & 10 & 5 & 1 & 2.1 & 559 & 7 & 191 & 2124 & 4007 & 0.0476 & 0.9971 & 0.4762 & 70 & 212 & 191 & 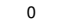 & 69 & 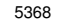 & 1033 & 92 & 20 & 0.5293 \\
\hline 32 & 7305 & 15 & 5 & 5 & 1 & 3.0 & 823 & 10 & 268 & 1640 & 4020 & 0.0667 & 0.9979 & 0.3333 & 97 & 328 & 268 & 0 & 711 & 5446 & 1027 & 108 & 13 & 0.6752 \\
\hline
\end{tabular}




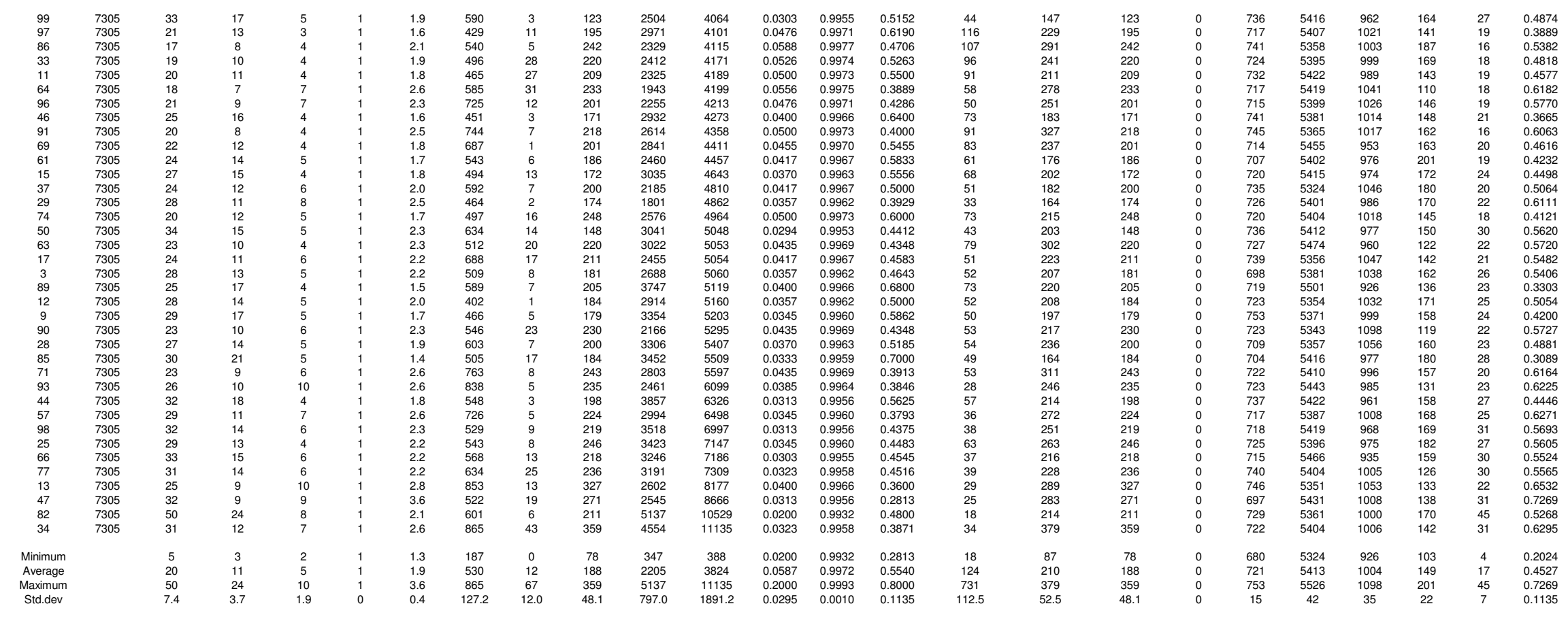


Scenerio NScenario 5 Base Case with 10\% additional system capacity
$12110 / 2007$

$\begin{array}{ll}\text { Date: } & 12 / 110 / 2007 \\ \text { Simulation } & 6: 28: 51 \mathrm{PM} \\ \text { Simulation } & 7 \cdot 05 \cdot 09\end{array}$

\begin{tabular}{|c|c|c|c|c|c|c|c|c|c|c|c|c|c|c|c|c|c|c|c|c|c|c|c|c|c|}
\hline & & $\begin{array}{l}\sum Z_{1} \\
\text { No. of }\end{array}$ & $\begin{array}{l}\sum W_{1} \\
\text { No. of }\end{array}$ & $\begin{array}{l}\text { Max } T_{t} \\
\text { Max. }\end{array}$ & $\begin{array}{l}\text { Min } T_{1} \\
\text { Min. }\end{array}$ & $\begin{array}{l}E\left[T_{1}\right] \\
\text { Avg }\end{array}$ & $\begin{array}{c}\operatorname{Max} S_{i} \\
\operatorname{Max}\end{array}$ & $\underset{\operatorname{Min}}{\operatorname{Min} S_{i}}$ & $\begin{array}{l}\text { Avg } S_{i} \\
\text { Avg. }\end{array}$ & $\begin{array}{l}\sum \mathrm{sj} \\
\text { al Maximum }\end{array}$ & & $e_{1}=1 / \Sigma Z_{1}$ & & & & $v=S s j e j$ & $v=S$ siei & & & & & & & & \\
\hline Trial №. & Total no. of Days & $\begin{array}{l}\text { Days } \\
\text { Failed }\end{array}$ & $\begin{array}{c}\text { Consecutive } \\
\text { Failures }\end{array}$ & $\begin{array}{l}\text { Failure } \\
\text { Duration }\end{array}$ & $\begin{array}{l}\text { Failure } \\
\text { Duration }\end{array}$ & $\begin{array}{l}\text { Failure } \\
\text { Duration }\end{array}$ & $\begin{array}{l}\text { Severity of } \\
\text { Failure }\end{array}$ & $\begin{array}{l}\text { Severity of } \\
\text { Failure }\end{array}$ & $\begin{array}{l}\text { f Severity of } \\
\text { a Failure }\end{array}$ & $\begin{array}{l}\text { Severity of } \\
\text { Sojourn }\end{array}$ & $\begin{array}{l}\text { Severity of } \\
\text { Failure }\end{array}$ & Correspo & eliability, & Resilien & (MDNNS" & Inerat & nerab & 500 & 1.1000 & 1001 - & $1501-$ & 2001 - & & Eculidean & of days with \\
\hline 87 & 7305 & 0 & 0 & 0 & 0 & 0.0 & 0 & 0 & 0 & 0 & 0 & 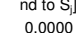 & $\begin{array}{l}a \\
1.0000\end{array}$ & $\begin{array}{l}F(E[T]\}) \\
1.0000\end{array}$ & NF) & 1 & $\begin{array}{l}2 \\
0\end{array}$ & 0 & $\begin{array}{l}501-1000 \\
575\end{array}$ & $\begin{array}{l}1500 \\
5493\end{array}$ & 2000 & $\begin{array}{l}2500 \\
157\end{array}$ & $>2500$ & Distance & failure \\
\hline 39 & & & & & & & & & & 70 & 70 & $\begin{array}{l}1.0000 \\
1.000\end{array}$ & $\begin{array}{l}0.9999 \\
0.9909\end{array}$ & 1.0000 & 7305 & 70 & 70 & 0 & $\begin{array}{l}545 \\
547\end{array}$ & 5459 & $\begin{array}{l}1006 \\
1145\end{array}$ & $\begin{array}{l}15 / \\
141\end{array}$ & $\begin{array}{l}4 \\
13\end{array}$ & 0.0278 & 70 \\
\hline 5 & 7305 & 2 & 2 & 1 & 1 & 1.0 & 49 & 49 & 49 & 98 & 98 & 0.5000 & 0.9997 & 1.0000 & 3653 & 49 & 49 & 0 & 529 & 5539 & 10 & 155 & 16 & 0.0197 & $\begin{array}{l}10 \\
49\end{array}$ \\
\hline 52 & 7305 & 3 & 2 & 2 & 1 & 1.5 & 65 & & 33 & 93 & 100 & 0.3333 & 0.9996 & 0.6667 & 1218 & 46 & 33 & 0 & 552 & 5423 & 1127 & 191 & 12 & 0.3336 & 33 \\
\hline 38 & 7305 & 4 & 3 & 2 & 1 & 1.3 & 56 & 15 & 33 & 117 & 132 & 0.2500 & 0.9995 & 0.7500 & 913 & 39 & 33 & 0 & 556 & 5443 & 1145 & 151 & 10 & 0.2503 & 33 \\
\hline 8 & $\begin{array}{l}7305 \\
7305\end{array}$ & $\begin{array}{l}2 \\
3\end{array}$ & $\begin{array}{l}2 \\
3\end{array}$ & $\begin{array}{l}1 \\
1\end{array}$ & 1 & $\begin{array}{l}1.0 \\
1.0\end{array}$ & $\begin{array}{l}232 \\
172\end{array}$ & $\begin{array}{c}4 \\
45\end{array}$ & $\begin{array}{l}118 \\
99\end{array}$ & $\begin{array}{l}236 \\
297\end{array}$ & $\begin{array}{l}236 \\
297\end{array}$ & $\begin{array}{l}0.5000 \\
0.3333\end{array}$ & $\begin{array}{l}0.9997 \\
0.996\end{array}$ & $\begin{array}{l}1.0000 \\
10000\end{array}$ & $\begin{array}{l}3653 \\
2435 \\
2435\end{array}$ & 118 & $\begin{array}{l}118 \\
99\end{array}$ & 0 & ${ }_{548}^{537}$ & $\begin{array}{l}5518 \\
5489\end{array}$ & & $\begin{array}{l}118 \\
182\end{array}$ & 6 & 0.0472 & 118 \\
\hline $\begin{array}{lll}40 & \end{array}$ & $\begin{array}{l}7305 \\
7305\end{array}$ & $\begin{array}{l}3 \\
4\end{array}$ & $\begin{array}{l}3 \\
4\end{array}$ & $\begin{array}{l}1 \\
1\end{array}$ & $\begin{array}{l}1 \\
1\end{array}$ & $\begin{array}{l}1.0 \\
1.0\end{array}$ & $\begin{array}{l}1 / 2 \\
168\end{array}$ & $\begin{array}{l}45 \\
11\end{array}$ & $\begin{array}{l}99 \\
78\end{array}$ & $\begin{array}{l}297 \\
313\end{array}$ & $\begin{array}{l}297 \\
313\end{array}$ & $\begin{array}{l}0.3333 \\
0.2500\end{array}$ & $\begin{array}{l}0.9996 \\
0.9995\end{array}$ & $\begin{array}{l}1.0000 \\
1.0000\end{array}$ & ${ }_{1826}^{2435}$ & $\begin{array}{l}99 \\
78\end{array}$ & $\begin{array}{l}99 \\
78\end{array}$ & $\begin{array}{l}0 \\
0\end{array}$ & $\begin{array}{l}548 \\
570\end{array}$ & $\begin{array}{l}5499 \\
548\end{array}$ & $\begin{array}{l}1014 \\
1102\end{array}$ & $\begin{array}{l}182 \\
119\end{array}$ & 12 & $\begin{array}{l}0.0396 \\
0.0313\end{array}$ & 99 \\
\hline $\begin{array}{l}40 \\
19\end{array}$ & 7305 & $\begin{array}{l}4 \\
3\end{array}$ & $\begin{array}{l}4 \\
3\end{array}$ & 1 & 1 & $\begin{array}{l}7.0 \\
1.0\end{array}$ & $\begin{array}{l}768 \\
176\end{array}$ & 54 & 104 & 313 & $\begin{array}{l}313 \\
313\end{array}$ & $\begin{array}{l}0.25300 \\
0.3333\end{array}$ & $\begin{array}{l}0.99956 \\
0.9996\end{array}$ & 1.0000 & $\begin{array}{l}\begin{array}{l}1826 \\
2435\end{array} \\
-\end{array}$ & $\begin{array}{l}18 \\
104\end{array}$ & $\begin{array}{l}10 \\
104\end{array}$ & 0 & 543 & $\begin{array}{l}5484 \\
5528\end{array}$ & 100 & ${ }_{123}$ & 11 & $\begin{array}{l}0.0313 \\
0.0418\end{array}$ & $\begin{array}{l}18 \\
104\end{array}$ \\
\hline 1 & 7305 & 4 & 3 & 2 & 1 & 1.3 & 214 & 2 & 91 & 362 & 364 & 0.2500 & 0.9995 & 0.7500 & 913 & 121 & 91 & 0 & 526 & 5531 & 1058 & 170 & 20 & 0.2526 & 91 \\
\hline 58 & 7305 & 2 & 2 & 1 & 1 & 1.0 & 363 & 2 & 183 & 366 & 366 & 0.5000 & 0.9997 & 1.0000 & 3653 & 183 & 183 & 0 & 556 & 5484 & 1110 & 140 & 15 & 0.0732 & 183 \\
\hline $\begin{array}{c}79 \\
2\end{array}$ & $\begin{array}{l}7305 \\
7305\end{array}$ & $\begin{array}{l}2 \\
4\end{array}$ & $\begin{array}{l}2 \\
4\end{array}$ & $\begin{array}{l}1 \\
1\end{array}$ & $\begin{array}{l}1 \\
1\end{array}$ & $\begin{array}{l}1.0 \\
1.0\end{array}$ & $\begin{array}{l}308 \\
137\end{array}$ & $\begin{array}{l}{ }_{58}^{64} \\
58\end{array}$ & $\begin{array}{l}186 \\
98\end{array}$ & $\begin{array}{l}373 \\
394\end{array}$ & $\begin{array}{l}373 \\
394\end{array}$ & $\begin{array}{l}0.5000 \\
0.2500\end{array}$ & $\begin{array}{l}0.9997 \\
0.9995\end{array}$ & $\begin{array}{l}1.0000 \\
10000\end{array}$ & $\begin{array}{l}3653 \\
1826\end{array}$ & $\begin{array}{l}186 \\
08\end{array}$ & 186 & ${ }_{0}^{0}$ & $\begin{array}{l}513 \\
550\end{array}$ & $\begin{array}{l}5489 \\
5494\end{array}$ & $\begin{array}{l}1112 \\
\end{array}$ & $\begin{array}{l}183 \\
137\end{array}$ & 8 & $\begin{array}{l}0.0746 \\
0\end{array}$ & 186 \\
\hline $\begin{array}{l}2 \\
59\end{array}$ & $\begin{array}{l}3305 \\
7305\end{array}$ & $\begin{array}{l}4 \\
3\end{array}$ & $\begin{array}{l}4 \\
3\end{array}$ & $\begin{array}{l}1 \\
1\end{array}$ & $\begin{array}{l}1 \\
1\end{array}$ & $\begin{array}{l}1.0 \\
1.0\end{array}$ & $\begin{array}{l}137 \\
266\end{array}$ & $\begin{array}{l}58 \\
12\end{array}$ & $\begin{array}{l}98 \\
134\end{array}$ & $\begin{array}{l}394 \\
401\end{array}$ & $\begin{array}{l}394 \\
401\end{array}$ & $\begin{array}{l}0.2500 \\
0.3333\end{array}$ & $\begin{array}{l}0.9995 \\
0.9996\end{array}$ & $\begin{array}{l}1.00000 \\
1.00000\end{array}$ & $\begin{array}{l}1826 \\
2435\end{array}$ & $\begin{array}{c}98 \\
134\end{array}$ & $\begin{array}{c}98 \\
134\end{array}$ & $\begin{array}{l}0 \\
0\end{array}$ & $\begin{array}{l}550 \\
544\end{array}$ & $\begin{array}{l}5494 \\
5457\end{array}$ & $\begin{array}{l}11108 \\
1120\end{array}$ & $\begin{array}{l}137 \\
170\end{array}$ & $\begin{array}{l}16 \\
14\end{array}$ & $\begin{array}{l}0.0394 \\
0.0534\end{array}$ & $\begin{array}{c}98 \\
134\end{array}$ \\
\hline 27 & 7305 & 3 & $\begin{array}{l}0 \\
2\end{array}$ & 2 & 1 & 1.5 & $\begin{array}{l}260 \\
260\end{array}$ & 34 & 137 & 294 & 411 & 0.3333 & 0.9996 & 0.6667 & 1218 & $\begin{array}{l}134 \\
147\end{array}$ & $\begin{array}{l}134 \\
137\end{array}$ & 0 & $\begin{array}{l}544 \\
542\end{array}$ & 5438 & 1202 & 116 & $\begin{array}{l}144 \\
7\end{array}$ & 0.3378 & $\begin{array}{l}134 \\
137\end{array}$ \\
\hline 70 & 7305 & 3 & 3 & 1 & 1 & 1.0 & 270 & $\begin{array}{l}\text { S4 } \\
13\end{array}$ & 142 & $\begin{array}{l}425 \\
425\end{array}$ & 425 & 0.3333 & 0.9996 & 1.0000 & $\begin{array}{l}2435 \\
2435\end{array}$ & $\begin{array}{l}174 \\
142\end{array}$ & 142 & 0 & 575 & 5428 & 1130 & $\begin{array}{l}159 \\
159\end{array}$ & 13 & $\begin{array}{l}0.0570 \\
0.0566\end{array}$ & 142 \\
\hline 76 & $\begin{array}{l}7305 \\
73025\end{array}$ & 4 & 4 & 1 & 1 & 1.0 & 322 & 4 & 108 & 433 & 433 & 0.2500 & 0.9995 & 1.0000 & 1826 & 108 & 108 & 0 & 548 & 5509 & 1052 & 187 & 9 & 0.0433 & 108 \\
\hline $\begin{array}{l}30 \\
94\end{array}$ & $\begin{array}{l}7305 \\
73305\end{array}$ & $\begin{array}{l}5 \\
4\end{array}$ & $\begin{array}{l}5 \\
2\end{array}$ & $\begin{array}{l}1 \\
3\end{array}$ & ${ }_{1}^{1}$ & $\begin{array}{l}1.0 \\
2.0\end{array}$ & $\begin{array}{l}231 \\
165\end{array}$ & $\begin{array}{l}2 \\
20\end{array}$ & 88 & $\begin{array}{l}440 \\
15\end{array}$ & $\begin{array}{l}440 \\
443\end{array}$ & $\begin{array}{l}0.2000 \\
0.2500\end{array}$ & $\begin{array}{l}0.9993 \\
0.9995\end{array}$ & 1.0000 & $\begin{array}{l}1461 \\
609\end{array}$ & $\begin{array}{l}88 \\
92\end{array}$ & ${ }^{88}$ & 0 & $\begin{array}{l}553 \\
571\end{array}$ & 5431 & $\begin{array}{l}1106 \\
1100\end{array}$ & 198 & 17 & 0.0352 & 88 \\
\hline $\begin{array}{l}44 \\
31\end{array}$ & $\begin{array}{l}3305 \\
7305\end{array}$ & $\begin{array}{l}4 \\
3\end{array}$ & $\begin{array}{l}2 \\
2\end{array}$ & $\begin{array}{l}3 \\
2 \\
2\end{array}$ & $\begin{array}{l}1 \\
1\end{array}$ & $\begin{array}{l}2.0 \\
1.5\end{array}$ & $\begin{array}{l}165 \\
342\end{array}$ & $\begin{array}{l}20 \\
49\end{array}$ & $\begin{array}{l}111 \\
155\end{array}$ & $\begin{array}{l}185 \\
416\end{array}$ & $\begin{array}{l}443 \\
464\end{array}$ & $\begin{array}{l}0.2500 \\
0.3333\end{array}$ & $\begin{array}{l}0.9995 \\
0.9996\end{array}$ & $\begin{array}{l}0.5000 \\
0.6667\end{array}$ & $\begin{array}{l}6699 \\
1218\end{array}$ & $\begin{array}{r}92 \\
208\end{array}$ & $\begin{array}{l}111 \\
155\end{array}$ & $\begin{array}{l}0 \\
0\end{array}$ & $\begin{array}{l}571 \\
541\end{array}$ & $\begin{array}{l}54088 \\
5456\end{array}$ & $\begin{array}{l}1130 \\
1101\end{array}$ & $\begin{array}{l}180 \\
182\end{array}$ & $\begin{array}{l}16 \\
25\end{array}$ & $\begin{array}{l}0.502020 \\
0.3390\end{array}$ & $\begin{array}{l}111 \\
1155\end{array}$ \\
\hline 80 & $\begin{array}{l}73005 \\
7305\end{array}$ & 6 & 6 & $\begin{array}{l}2 \\
1\end{array}$ & 1 & $\begin{array}{l}1.0 \\
1.0\end{array}$ & $\begin{array}{l}242 \\
208\end{array}$ & $\begin{array}{l}49 \\
16\end{array}$ & 77 & $\begin{array}{l}110 \\
464\end{array}$ & $\begin{array}{l}{ }^{664} \\
464\end{array}$ & $\begin{array}{l}0.33333 \\
0.1667\end{array}$ & $\begin{array}{l}0.9996 \\
0.9992\end{array}$ & $\begin{array}{l}.06667 \\
1.0000\end{array}$ & $\begin{array}{l}1218 \\
1218\end{array}$ & $\begin{array}{l}208 \\
77\end{array}$ & $\begin{array}{l}155 \\
77\end{array}$ & 0 & $\begin{array}{l}541 \\
525\end{array}$ & $\begin{array}{l}5400 \\
5514\end{array}$ & 1080 & $\begin{array}{l}102 \\
171\end{array}$ & $\begin{array}{l}25 \\
15\end{array}$ & 0.0310 & $\begin{array}{l}155 \\
77\end{array}$ \\
\hline 56 & 7305 & 4 & 3 & 2 & 1 & 1.3 & 220 & $\begin{array}{l}18 \\
28\end{array}$ & 121 & $\begin{array}{l}454 \\
452\end{array}$ & $\begin{array}{l}404 \\
486\end{array}$ & 0.2500 & 0.9995 & 0.7500 & 913 & 151 & 121 & 0 & 544 & $\begin{array}{l}5516 \\
5516\end{array}$ & 1080 & 155 & 10 & 0.2547 & 121 \\
\hline 48 & 7305 & 4 & 3 & 2 & 1 & 1.3 & 202 & 46 & 123 & 302 & 490 & 0.2500 & 0.9995 & 0.7500 & 913 & 101 & 123 & 0 & 551 & 5469 & 1090 & 175 & 20 & 0.2548 & 123 \\
\hline $\begin{array}{l}35 \\
78\end{array}$ & $\begin{array}{l}7305 \\
73305\end{array}$ & $\begin{array}{l}5 \\
3\end{array}$ & 3 & 2 & 1 & $\begin{array}{l}1.7 \\
1.5\end{array}$ & $\begin{array}{l}171 \\
473\end{array}$ & $\begin{array}{r}9 \\
14\end{array}$ & $\begin{array}{l}98 \\
177\end{array}$ & $\begin{array}{l}372 \\
557\end{array}$ & $\begin{array}{l}490 \\
551\end{array}$ & $\begin{array}{l}0.2000 \\
0.3333\end{array}$ & 0.9993 & 0.6000 & $\begin{array}{l}731 \\
1218\end{array}$ & $\begin{array}{l}124 \\
259\end{array}$ & $\begin{array}{c}98 \\
177\end{array}$ & $\begin{array}{l}0 \\
0\end{array}$ & $\begin{array}{l}565 \\
550\end{array}$ & $\begin{array}{r}5399 \\
5405\end{array}$ & $\begin{array}{l}1153 \\
1117\end{array}$ & 167 & 21 & 0.4019 & $\begin{array}{l}98 \\
177\end{array}$ \\
\hline $\begin{array}{l}78 \\
24\end{array}$ & $\begin{array}{l}7305 \\
7305\end{array}$ & $\begin{array}{l}3 \\
4\end{array}$ & $\begin{array}{l}2 \\
3\end{array}$ & $\begin{array}{l}2 \\
2\end{array}$ & $\begin{array}{l}1 \\
1\end{array}$ & $\begin{array}{l}.5 \\
1.3\end{array}$ & $\begin{array}{l}473 \\
285\end{array}$ & $\begin{array}{c}14 \\
7 \\
7\end{array}$ & $\begin{array}{l}177 \\
134\end{array}$ & $\begin{array}{l}517 \\
426\end{array}$ & $\begin{array}{l}531 \\
536\end{array}$ & $\begin{array}{l}0.3333 \\
0.2500\end{array}$ & $\begin{array}{l}0.9996 \\
0.9995\end{array}$ & $\begin{array}{l}0.6667 \\
0.7500\end{array}$ & $\begin{array}{l}1218 \\
913\end{array}$ & $\begin{array}{l}559 \\
142\end{array}$ & $\begin{array}{l}177 \\
134\end{array}$ & $\begin{array}{l}0 \\
0\end{array}$ & $\begin{array}{l}550 \\
559\end{array}$ & $\begin{array}{l}5405 \\
5455\end{array}$ & $\begin{array}{l}1714 \\
1105\end{array}$ & $\begin{array}{l}162 \\
165\end{array}$ & $\begin{array}{l}14 \\
21\end{array}$ & $\begin{array}{l}0.34088 \\
0.2557\end{array}$ & $\begin{array}{l}177 \\
134\end{array}$ \\
\hline $\begin{array}{l}24 \\
92\end{array}$ & & & $\begin{array}{l}3 \\
1\end{array}$ & 3 & 3 & $\begin{array}{l}3.3 \\
3.0\end{array}$ & $\begin{array}{l}280 \\
405\end{array}$ & 30 & $\begin{array}{l}134 \\
181\end{array}$ & $\begin{array}{l}246 \\
405\end{array}$ & $\begin{array}{l}536 \\
543\end{array}$ & $\begin{array}{l}0.2500 \\
0.3333\end{array}$ & $\begin{array}{l}0.9995 \\
0.9996\end{array}$ & $\begin{array}{l}0.1500 \\
0.3333\end{array}$ & $\begin{array}{l}913 \\
812\end{array}$ & $\begin{array}{l}142 \\
405\end{array}$ & $\begin{array}{l}134 \\
181\end{array}$ & $\begin{array}{l}0 \\
0\end{array}$ & $\begin{array}{l}559 \\
555\end{array}$ & $\begin{array}{l}5455 \\
5463\end{array}$ & $\begin{array}{l}1105 \\
1124\end{array}$ & $\begin{array}{l}165 \\
152\end{array}$ & $\begin{array}{l}21 \\
11\end{array}$ & $\begin{array}{l}.255 / 2 \\
0.6706\end{array}$ & $\begin{array}{l}134 \\
181\end{array}$ \\
\hline 100 & $\begin{array}{l}7305 \\
7305\end{array}$ & $\begin{array}{l}5 \\
4\end{array}$ & 3 & $\begin{array}{l}3 \\
2\end{array}$ & 1 & $\begin{array}{l}3.0 \\
1.3\end{array}$ & $\begin{array}{l}400 \\
372\end{array}$ & 45 & 137 & $\begin{array}{l}405 \\
503\end{array}$ & $\begin{array}{l}548 \\
548\end{array}$ & 0.2500 & $\begin{array}{l}0.9996 \\
0\end{array}$ & 0.7500 & 913 & $\begin{array}{l}405 \\
168\end{array}$ & $\begin{array}{l}137 \\
137\end{array}$ & 0 & $\begin{array}{l}500 \\
561\end{array}$ & 5477 & $\begin{array}{l}1124 \\
1091\end{array}$ & $\begin{array}{l}152 \\
157\end{array}$ & 19 & $\begin{array}{l}0.0760 \\
0.2559\end{array}$ & 137 \\
\hline 21 & 7305 & 6 & 5 & 2 & 1 & 1.2 & 261 & 13 & 92 & 538 & 551 & 0.1667 & 0.9992 & 0.8333 & 609 & 108 & 92 & 0 & 553 & 5405 & 1143 & 184 & 20 & 0.1707 & 92 \\
\hline 62 & $\begin{array}{l}7305 \\
73305\end{array}$ & 3 & 3 & 1 & 1 & 1.0 & $\begin{array}{l}289 \\
\end{array}$ & 42 & $\begin{array}{l}187 \\
71\end{array}$ & $\begin{array}{l}562 \\
550\end{array}$ & 562 & 0.3333 & 0.9996 & 1.0000 & $\begin{array}{r}2435 \\
\quad 575\end{array}$ & 187 & 187 & 0 & 544 & 49 & 45 & 154 & 13 & 0.0749 & 187 \\
\hline 60 & 73055 & 8 & 7 & 2 & 1 & 1.1 & 185 & 3 & 71 & $\begin{array}{l}552 \\
557\end{array}$ & 565 & 0.1250 & 0.9989 & 0.8750 & ${ }^{457}$ & 79 & 71 & 0 & 548 & 436 & 1103 & 193 & 壁 & 0.1282 & 71 \\
\hline${ }^{26}$ & $\begin{array}{l}7305 \\
7305\end{array}$ & $\begin{array}{l}4 \\
5\end{array}$ & $\begin{array}{l}4 \\
4\end{array}$ & $\begin{array}{l}1 \\
2 \\
2\end{array}$ & $\begin{array}{l}1 \\
1\end{array}$ & $\begin{array}{l}1.0 \\
1.3\end{array}$ & $\begin{array}{l}170 \\
270\end{array}$ & $\begin{array}{c}115 \\
31\end{array}$ & $\begin{array}{l}143 \\
123\end{array}$ & $\begin{array}{l}571 \\
544\end{array}$ & $\begin{array}{l}571 \\
617\end{array}$ & $\begin{array}{l}0.2500 \\
0.2000\end{array}$ & $\begin{array}{l}0.9995 \\
0.9993\end{array}$ & $\begin{array}{l}1.00000 \\
08000\end{array}$ & $\begin{array}{l}1826 \\
731\end{array}$ & $\begin{array}{l}443 \\
136\end{array}$ & $\begin{array}{l}143 \\
123\end{array}$ & $\begin{array}{l}0 \\
0\end{array}$ & $\begin{array}{l}553 \\
526\end{array}$ & $\begin{array}{l}5503 \\
5542\end{array}$ & $\begin{array}{r}1053 \\
1056\end{array}$ & $\begin{array}{l}181 \\
163\end{array}$ & $\begin{array}{l}15 \\
18\end{array}$ & 0.0571 & 143 \\
\hline $\begin{array}{l}30 \\
10\end{array}$ & $\begin{array}{l}73005 \\
7305\end{array}$ & 6 & 3 & 4 & 1 & $\begin{array}{l}2.3 \\
2.0\end{array}$ & 278 & 7 & $\begin{array}{l}109 \\
109\end{array}$ & $\begin{array}{l}344 \\
311\end{array}$ & 655 & $\begin{array}{l}0.20000 \\
0.1667\end{array}$ & 0.9992 & 0.5000 & 304 & $\begin{array}{l}104 \\
104\end{array}$ & $\begin{array}{l}109 \\
109\end{array}$ & 0 & $\begin{array}{l}560 \\
532\end{array}$ & $\begin{array}{l}5042 \\
5485\end{array}$ & $\begin{array}{l}100 \\
1125\end{array}$ & 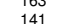 & $\begin{array}{l}10 \\
22\end{array}$ & $\begin{array}{l}.2060 \\
5019\end{array}$ & $\begin{array}{l}123 \\
109\end{array}$ \\
\hline 75 & 7305 & 6 & 5 & 2 & 1 & 1.2 & 390 & 18 & 113 & 619 & 677 & 0.1667 & 0.0992 & 0.8333 & 609 & 124 & 113 & $0_{0}$ & 555 & 5440 & 1110 & 178 & 22 & 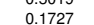 & $\begin{array}{l}109 \\
113\end{array}$ \\
\hline 16 & 7305 & 5 & 2 & 3 & 2 & 2.5 & 260 & 30 & 138 & 451 & 690 & 0.2000 & 0.0993 & 0.4000 & 487 & 225 & 138 & 0 & 537 & & & 142 & 6 & .6025 & 138 \\
\hline 72 & 7305 & 3 & 3 & 1 & 1 & 1.0 & 243 & 231 & 236 & 707 & 707 & 0.3333 & 0.9996 & 1.0000 & 2435 & ${ }_{236}^{23}$ & 236 & 0 & 570 & 8 & 1145 & 145 & 17 & 0.0942 & $\begin{array}{l}238 \\
236\end{array}$ \\
\hline 97 & 7305 & 9 & 7 & 2 & 1 & 1.3 & 205 & 3 & 79 & 638 & 711 & 0.1111 & 0.9988 & 0.7778 & 406 & 91 & 79 & 0 & 540 & & 11 & 147 & 21 & .2245 & 79 \\
\hline 14 & 7305 & 7 & 5 & 2 & 1 & 1.4 & 259 & 32 & 103 & 529 & 720 & 0.1429 & 0.9990 & 0.7143 & 522 & 106 & 103 & 0 & ${ }^{527}$ & & 1099 & 153 & 13 & 0.2887 & 103 \\
\hline 73 & 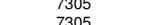 & ${ }_{5}^{6}$ & ${ }_{5}^{5}$ & ${ }_{1}^{2}$ & 1 & 1.22 & 年 & 9 & $\begin{array}{l}125 \\
115\end{array}$ & $\begin{array}{l}744 \\
774\end{array}$ & $\begin{array}{l}753 \\
774\end{array}$ & & & & $\begin{array}{l}609 \\
1491\end{array}$ & $\begin{array}{l}149 \\
155\end{array}$ & $\begin{array}{l}125 \\
1\end{array}$ & 0 & ${ }_{552}^{535}$ & & & 142 & 19 & (4) & $\begin{array}{l}125 \\
115\end{array}$ \\
\hline $\begin{array}{c}6 \\
43\end{array}$ & $\begin{array}{l}3305 \\
7305\end{array}$ & $\begin{array}{l}5 \\
7\end{array}$ & $\begin{array}{l}5 \\
6\end{array}$ & $\begin{array}{l}1 \\
2\end{array}$ & 1 & $\begin{array}{l}1.0 \\
1.2\end{array}$ & $\begin{array}{l}397 \\
232\end{array}$ & $\begin{array}{l}63 \\
59\end{array}$ & $\begin{array}{l}155 \\
114\end{array}$ & $\begin{array}{l}1 / 4 \\
733\end{array}$ & $\begin{array}{l}7 / 4 \\
795\end{array}$ & $\begin{array}{l}0.2000 \\
0.1429\end{array}$ & $\begin{array}{l}0.9993 \\
0.9990\end{array}$ & $\begin{array}{l}1.00000 \\
0.8571\end{array}$ & $\begin{array}{l}1461 \\
522\end{array}$ & $\begin{array}{l}155 \\
1.22 \\
\end{array}$ & $\begin{array}{l}155 \\
114\end{array}$ & $\begin{array}{l}0 \\
0\end{array}$ & $\begin{array}{l}552 \\
531\end{array}$ & 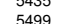 & 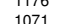 & 列 & 19 & $\begin{array}{l}.0679 \\
.1499\end{array}$ & $\begin{array}{l}155 \\
114\end{array}$ \\
\hline 23 & 7305 & 7 & 4 & 4 & 1 & 1.8 & 193 & 50 & 116 & 472 & 814 & 0.1429 & 0.9990 & 0.5714 & 261 & 118 & 116 & 0 & 534 & & & 160 & 16 & 11 & $\begin{array}{l}114 \\
116\end{array}$ \\
\hline 7 & 7305 & 6 & 3 & 3 & 1 & 2.0 & 311 & 34 & 136 & 621 & 818 & & 0.9992 & 0.5000 & 406 & 207 & 136 & 0 & 542 & & & 137 & 10 & .5030 & 136 \\
\hline 67 & 7305 & 6 & 5 & 2 & 1 & 1.2 & 349 & 5 & 140 & 832 & 838 & 0.1667 & 0.9992 & 0.8333 & - & 166 & 140 & 0 & 550 & & & 159 & 19 & 0.1758 & 140 \\
\hline $\begin{array}{l}12 \\
53\end{array}$ & $\begin{array}{l}7305 \\
7305\end{array}$ & $\begin{array}{l}9 \\
8\end{array}$ & $\begin{array}{l}5 \\
7\end{array}$ & $\begin{array}{l}5 \\
2 \\
2\end{array}$ & $\begin{array}{l}1 \\
1\end{array}$ & $\begin{array}{l}1.8 \\
1.1\end{array}$ & $\begin{array}{l}178 \\
325\end{array}$ & $\begin{array}{l}34 \\
2\end{array}$ & $\begin{array}{c}93 \\
105\end{array}$ & $\begin{array}{l}420 \\
837\end{array}$ & $\begin{array}{l}840 \\
842\end{array}$ & 50 & $\begin{array}{l}0.9988 \\
0.9899\end{array}$ & $\begin{array}{l}56 \\
50\end{array}$ & $\begin{array}{l}162 \\
45\end{array}$ & 84 & $\begin{array}{c}93 \\
105\end{array}$ & $\begin{array}{l}0 \\
0\end{array}$ & $\begin{array}{l}539 \\
533\end{array}$ & & 28 & $\begin{array}{l}189 \\
169\end{array}$ & $2 ?$ & $\begin{array}{l}0.4460 \\
0.1319\end{array}$ & $\begin{array}{l}93 \\
105\end{array}$ \\
\hline $\begin{array}{l}53 \\
54\end{array}$ & $\begin{array}{l}3305 \\
7305\end{array}$ & $\begin{array}{l}8 \\
8\end{array}$ & 5 & $\begin{array}{l}2 \\
4\end{array}$ & 1 & $\begin{array}{l}1.1 \\
16\end{array}$ & $\begin{array}{l}325 \\
260\end{array}$ & $\begin{array}{l}2 \\
28\end{array}$ & $\begin{array}{l}105 \\
107\end{array}$ & 74 & $\begin{array}{l}842 \\
853\end{array}$ & & & & $\begin{array}{l}451 \\
228\end{array}$ & $\begin{array}{l}210 \\
115\end{array}$ & $\begin{array}{l}105 \\
107\end{array}$ & $\begin{array}{l}0 \\
0\end{array}$ & $\begin{array}{l}533 \\
542\end{array}$ & & & $\begin{array}{l}166 \\
130\end{array}$ & $\begin{array}{l}22 \\
24\end{array}$ & $\begin{array}{l}1719 \\
3774\end{array}$ & $\begin{array}{l}105 \\
107\end{array}$ \\
\hline 81 & 7305 & $\begin{array}{l}\circ \\
4\end{array}$ & 3 & $\begin{array}{l}4 \\
2\end{array}$ & 1 & $\begin{array}{l}1.6 \\
1.3\end{array}$ & 311 & $\begin{array}{l}20 \\
63\end{array}$ & $\begin{array}{l}217 / \\
216\end{array}$ & $\begin{array}{l}50 / 4 \\
800\end{array}$ & $\begin{array}{l}853 \\
863\end{array}$ & $\begin{array}{l}0.12500 \\
0.2500\end{array}$ & $\begin{array}{l}.09989 \\
0.9995\end{array}$ & $\begin{array}{l}0.6650 \\
0.7500\end{array}$ & $\begin{array}{l}228 \\
913\end{array}$ & $\begin{array}{l}175 \\
267\end{array}$ & $\begin{array}{l}107 \\
216\end{array}$ & 0 & $\begin{array}{l}542 \\
541\end{array}$ & $5^{3}$ & ${ }_{11}>$ & $\begin{array}{l}130 \\
158\end{array}$ & 年 & $\begin{array}{l}0.37 / 74 \\
0.2645\end{array}$ & $\begin{array}{l}107 \\
216\end{array}$ \\
\hline 15 & 7305 & 9 & 6 & 3 & 1 & 1.5 & 270 & 3 & 98 & 649 & 881 & 0.1111 & 0.9988 & 0.6667 & 271 & 108 & 98 & 0 & 551 & 68 & 1082 & 177 & 27 & 0.3356 & 98 \\
\hline 95 & 7305 & 5 & 2 & 4 & 1 & 2.5 & 245 & 9 & 177 & 254 & 883 & 0.2000 & 0.9993 & 0.4000 & 365 & 127 & 177 & 0 & 532 & 5516 & 1120 & 124 & 13 & 6041 & 177 \\
\hline 499 & $\begin{array}{l}7305 \\
73305\end{array}$ & 4 & $\begin{array}{l}3 \\
5\end{array}$ & $\begin{array}{l}2 \\
2\end{array}$ & $\begin{array}{l}1 \\
1\end{array}$ & $\begin{array}{l}1.3 \\
1.2\end{array}$ & $\begin{array}{l}48 \\
34\end{array}$ & $\begin{array}{l}100 \\
20\end{array}$ & $\begin{array}{l}224 \\
157\end{array}$ & 14 & 94 & & $\begin{array}{r}0.9995 \\
\end{array}$ & & & 143 & $\begin{array}{l}224 \\
157\end{array}$ & ${ }^{0}$ & 546 & & & 77 & $\begin{array}{l}16 \\
11\end{array}$ & 2655 & $\begin{array}{l}224 \\
157\end{array}$ \\
\hline 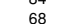 & $\begin{array}{l}3305 \\
7305\end{array}$ & $\begin{array}{lll}0 \\
9\end{array}$ & $\begin{array}{l}5 \\
4\end{array}$ & $\begin{array}{l}2 \\
3\end{array}$ & $\begin{array}{l}1 \\
1\end{array}$ & $\begin{array}{l}1.2 \\
23\end{array}$ & $\begin{array}{l}34 \\
32 \\
32\end{array}$ & $\begin{array}{l}20 \\
23\end{array}$ & $\begin{array}{l}15 / \\
107\end{array}$ & $\begin{array}{l}114 \\
653\end{array}$ & $\begin{array}{l}944 \\
964\end{array}$ & $\begin{array}{l}0.166 / 167 \\
0.1111\end{array}$ & $\begin{array}{l}0.9992 \\
0.9988\end{array}$ & & $\begin{array}{l}6099 \\
271\end{array}$ & $\begin{array}{l}143 \\
163\end{array}$ & $\begin{array}{l}157 \\
107\end{array}$ & $\begin{array}{l}0 \\
0\end{array}$ & $\begin{array}{l}546 \\
522\end{array}$ & 19 & $\begin{array}{l}1609 \\
1130\end{array}$ & 24 & $\begin{array}{l}12 \\
21\end{array}$ & $\begin{array}{l}.01782 \\
0.5572\end{array}$ & $\begin{array}{l}157 \\
107\end{array}$ \\
\hline 99 & (5000 & 5 & $\begin{array}{l}4 \\
3\end{array}$ & 3 & 1 & $\begin{array}{l}.0 .7 \\
1.7\end{array}$ & $\begin{array}{l}335 \\
366\end{array}$ & 66 & 74 & $\begin{array}{l}563 \\
619\end{array}$ & $\begin{array}{l}\text { ofu } \\
973\end{array}$ & 0.2000 & $\begin{array}{l}0.9988 \\
0.9993\end{array}$ & $\begin{array}{l}0.4444 \\
0.6000\end{array}$ & & 206 & $\begin{array}{l}107 \\
195\end{array}$ & 0 & 566 & & & 174 & 31 & 4075 & $\begin{array}{l}107 \\
195\end{array}$ \\
\hline 22 & $77^{2}+3$ & 6 & 4 & 3 & 1 & 15 & 314 & 10 & 16 & 10 & & 0.1667 & 0.9992 & 0.6667 & .06 & 111 & 169 & 0 & 549 & & 68 & 157 & 23 & 3401 & 169 \\
\hline 83 & 7305 & 9 & 7 & 2 & 1 & 1.3 & 208 & 42 & 113 & 899 & 1014 & 0.1111 & 0.9988 & 0 & .06 & 28 & 113 & 0 & 5 & 9 & 1102 & 170 & 19 & 0.2267 & 113 \\
\hline 45 & $\begin{array}{l}7305 \\
73305\end{array}$ & 8 & $\begin{array}{l}6 \\
3\end{array}$ & $\begin{array}{l}3 \\
4\end{array}$ & 1 & 1.3 & $\begin{array}{l}282 \\
243\end{array}$ & 6 & $\begin{array}{l}134 \\
154\end{array}$ & 51 & $\begin{array}{l}1074 \\
1084\end{array}$ & $\begin{array}{l}0.1250 \\
0.1420\end{array}$ & 0.9989 & 0. & $\begin{array}{l}304 \\
261\end{array}$ & 108 & $\begin{array}{l}134 \\
154\end{array}$ & ${ }^{0}$ & $\begin{array}{l}554 \\
551\end{array}$ & 0 & $\begin{array}{r}1097 \\
1114\end{array}$ & $\begin{array}{l}178 \\
175\end{array}$ & 16 & 2557 & $\begin{array}{l}134 \\
114\end{array}$ \\
\hline 42 & 73 & 9 & $\begin{array}{l}3 \\
6\end{array}$ & $\begin{array}{l}4 \\
2\end{array}$ & 1 & 2.3 & $\begin{array}{l}24 \\
27\end{array}$ & $\begin{array}{l}60 \\
8\end{array}$ & $\begin{array}{l}154 \\
123\end{array}$ & & 11 & & $\begin{array}{l}90 \\
88\end{array}$ & $\begin{array}{l}0 \\
0\end{array}$ & & $\begin{array}{l}146 \\
121\end{array}$ & 154 & 0 & $\begin{array}{l}551 \\
546\end{array}$ & & & & $\begin{array}{l}21 \\
19\end{array}$ & $\begin{array}{l}5348 \\
3369\end{array}$ & 5 \\
\hline 88 & $\begin{array}{l}7300 \\
7305\end{array}$ & 6 & $\begin{array}{l}0 \\
3\end{array}$ & 3 & 1 & $\begin{array}{l}.1 .0 \\
2.0\end{array}$ & $\begin{array}{l}21 / 2 \\
263\end{array}$ & 20 & $\begin{array}{l}123 \\
186\end{array}$ & 126 & 1104 & 0.1667 & $\begin{array}{l}.99800 \\
0.9992\end{array}$ & $\begin{array}{l}0.6667 \\
0.5000\end{array}$ & $\begin{array}{l}406 \\
406\end{array}$ & $\begin{array}{l}121 \\
214\end{array}$ & $\begin{array}{l}123 \\
186\end{array}$ & 0 & 540 & 5 & 1007 & ${ }_{183}^{118}$ & 16 & 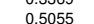 & $\begin{array}{l}123 \\
186\end{array}$ \\
\hline 55 & 7305 & 7 & 4 & 3 & 1 & 1.8 & $\begin{array}{l}240 \\
249\end{array}$ & 16 & $\begin{array}{l}100 \\
163\end{array}$ & 88 & 1 & 29 & 0.9990 & 0.5714 & 348 & 172 & 163 & 0 & 565 & 97 & 1161 & 169 & 13 & 0.4335 & $\begin{array}{l}100 \\
163\end{array}$ \\
\hline 86 & 73 & 8 & 5 & 2 & 1 & 1.6 & 31 & 41 & 144 & 870 & 1148 & 0 & 0 & 0 & 457 & 174 & 144 & 0 & 552 & 3 & 76 & 208 & 16 & 3794 & 44 \\
\hline 65 & 73 & 6 & 2 & 4 & 2 & .0 & 321 & 41 & 192 & 475 & 1 & & & & 04 & & 192 & 0 & 507 & & & 57 & 20 & & 192 \\
\hline $\begin{array}{c}11 \\
3\end{array}$ & $\begin{array}{l}7305 \\
7305\end{array}$ & $\begin{array}{l}7 \\
9\end{array}$ & $\begin{array}{l}4 \\
6\end{array}$ & $\begin{array}{l}4 \\
2 \\
2\end{array}$ & 1 & $\begin{array}{l}1.8 \\
1.5\end{array}$ & $\begin{array}{l}240 \\
285\end{array}$ & $\begin{array}{l}37 \\
19\end{array}$ & $\begin{array}{l}65 \\
130\end{array}$ & $\begin{array}{l}718 \\
795\end{array}$ & $\begin{array}{l}1153 \\
1166\end{array}$ & $\begin{array}{l}0.1429 \\
0.1111\end{array}$ & $\begin{array}{l}0.9990 \\
09988\end{array}$ & $\begin{array}{l}0.5714 \\
0.6667\end{array}$ & $\begin{array}{l}261 \\
406\end{array}$ & $\begin{array}{l}80 \\
133\end{array}$ & $\begin{array}{l}65 \\
130\end{array}$ & $\begin{array}{l}0 \\
0\end{array}$ & $\begin{array}{l}5 \\
5 \\
5\end{array}$ & & & 174 & $\begin{array}{l}20 \\
28\end{array}$ & 4336 & $\begin{array}{l}165 \\
130\end{array}$ \\
\hline 46 & 7305 & 8 & 5 & 3 & & $\begin{array}{l}1.0 \\
1.6\end{array}$ & $\begin{array}{l}220 \\
227\end{array}$ & $\frac{15}{4}$ & 147 & $\begin{array}{l}975 \\
771\end{array}$ & 1175 & 0.1250 & $\begin{array}{l}.09080 \\
09989\end{array}$ & $\begin{array}{l}0.6667 \\
0.6250\end{array}$ & $\begin{array}{l}4066 \\
304\end{array}$ & $\begin{array}{l}150 \\
154\end{array}$ & 14 & 0 & 56 & 4 & 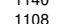 & ${ }_{164}$ & $\begin{array}{l}26 \\
23\end{array}$ & 作 & $\begin{array}{l}130 \\
147\end{array}$ \\
\hline 9 & 7305 & 9 & 6 & 3 & 1 & 1.5 & 242 & 20 & 132 & 782 & 1191 & 0.1111 & 0.9988 & 0.6667 & 271 & 130 & 132 & 5 & 564 & 5442 & 1102 & 169 & 28 & .3375 & 132 \\
\hline 61 & $\begin{array}{l}7305 \\
7305\end{array}$ & 10 & $\begin{array}{l}6 \\
5\end{array}$ & 3 & 1 & 1.7 & $\begin{array}{l}319 \\
70\end{array}$ & 31 & 124 & $\begin{array}{l}727 \\
889\end{array}$ & $\begin{array}{l}1240 \\
1269\end{array}$ & $\begin{array}{l}0.1000 \\
0.1000\end{array}$ & $\begin{array}{l}0.9986 \\
09986\end{array}$ & $\begin{array}{l}0.6000 \\
0.5000\end{array}$ & $\begin{array}{l}244 \\
244\end{array}$ & $\begin{array}{l}121 \\
172\end{array}$ & $\begin{array}{l}124 \\
1127\end{array}$ & $\begin{array}{l}0 \\
0\end{array}$ & 560 & $\begin{array}{l}5462 \\
5462\end{array}$ & $\begin{array}{l}1080 \\
1002\end{array}$ & $\begin{array}{l}207 \\
176\end{array}$ & 15 & $\begin{array}{l}0.4031 \\
0.5026\end{array}$ & 124 \\
\hline & & 10 & & 3 & & & & & & & & & & & & & & & & & & & & & \\
\hline
\end{tabular}




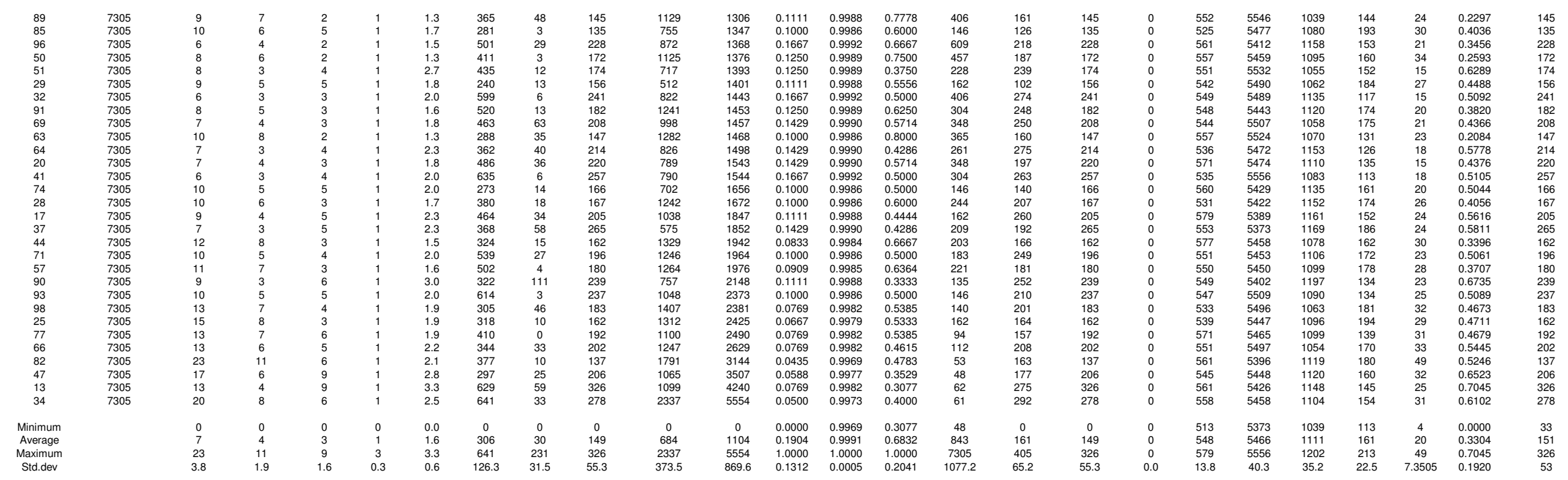




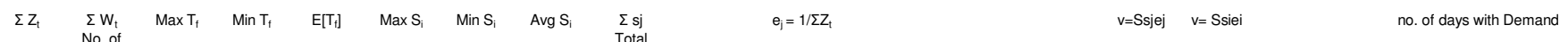

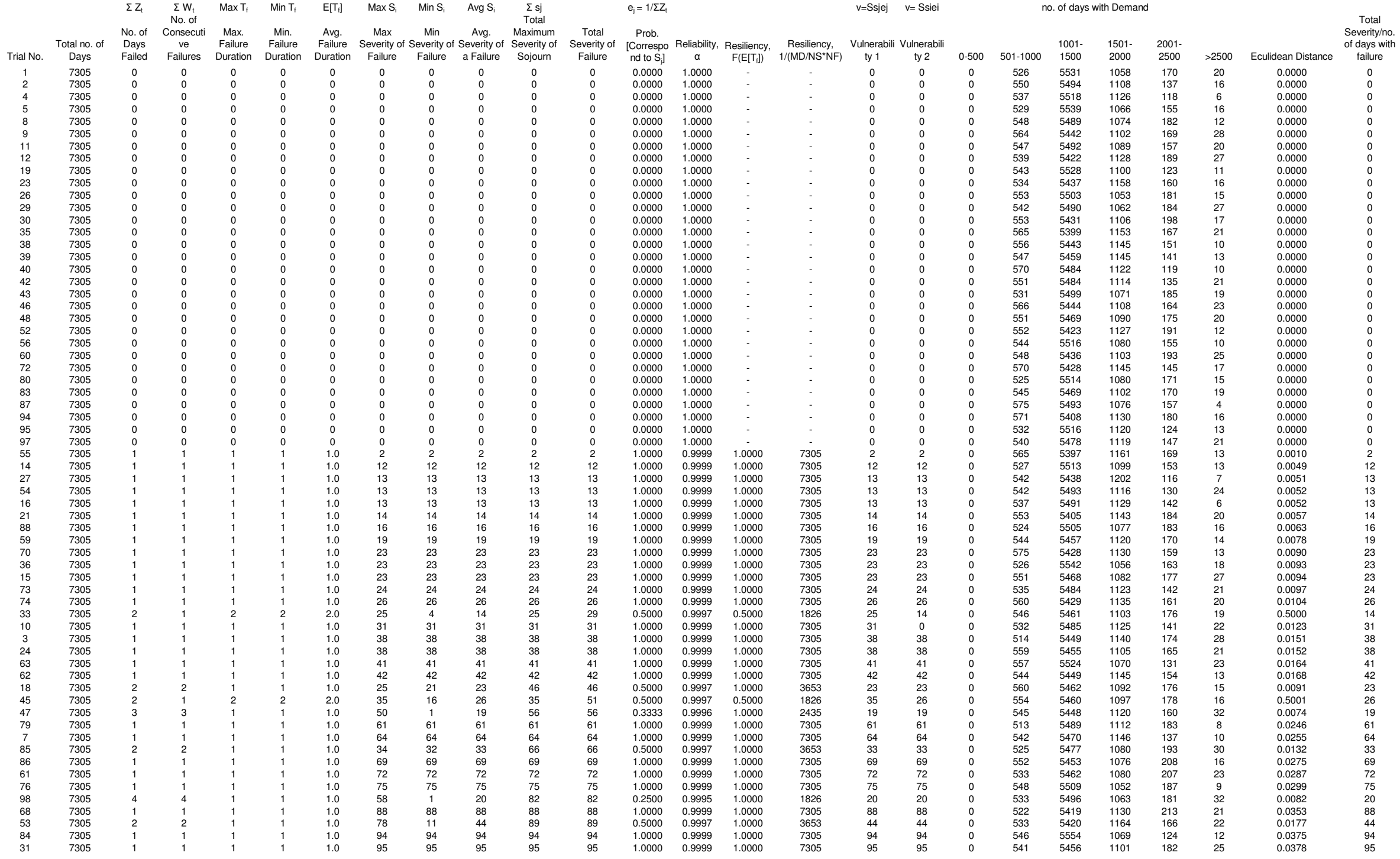


Scenerio NScenario 12 CSIROMk2b B11 with base case settings

Date: $\quad 13 / 10 / 2007$

Simulation 1.51:44 PM

$\begin{array}{ll}\text { Simulation } & 1: 31: 44 \text { PM } \\ \text { Elapsed Til } & 37.2 \text { Minutes }\end{array}$
$\Sigma Z_{1}$
$\Sigma W_{t}$
$T_{f}$
$\operatorname{Max} S_{i} \quad \operatorname{Min}_{i} \quad \operatorname{Avg} S_{i} \quad$ Ssj $\quad S_{s i} \quad e_{j}=1 / \Sigma Z_{i}$
$v=$ Ssjej $\quad v=$ Ssiei
no. of days with Demand

\begin{tabular}{|c|c|c|c|c|c|c|c|c|c|c|c|c|c|c|c|c|c|c|c|c|c|c|c|c|}
\hline Trial No. & $\begin{array}{l}\text { Total no. of } \\
\text { Days }\end{array}$ & $\begin{array}{l}\text { No. of } \\
\text { Days } \\
\text { Failed }\end{array}$ & $\begin{array}{c}\text { Consecuti } \\
\text { ve } \\
\text { Failures }\end{array}$ & $\begin{array}{c}\text { Max. } \\
\text { Failure } \\
\text { Duration }\end{array}$ & $\begin{array}{c}\text { Min. } \\
\text { Failure } \\
\text { Duration }\end{array}$ & $\begin{array}{c}\text { Avg. } \\
\text { Failure } \\
\text { Duration }\end{array}$ & $\begin{array}{c}\text { Max } \\
\text { Severity } \\
\text { of Failure }\end{array}$ & $\begin{array}{l}\text { Min } \\
\text { Severity } \\
\text { of Failure }\end{array}$ & $\begin{array}{l}\text { Severity } \\
\text { of a } \\
\text { Failure }\end{array}$ & $\begin{array}{l}\text { Maximum } \\
\text { Severity } \\
\text { of Sojourn }\end{array}$ & $\begin{array}{c}\text { Total } \\
\text { Severity } \\
\text { of Failure }\end{array}$ & $\begin{array}{l}\text { Prob. } \\
\text { [Correspo } \\
\text { nd to S]] }\end{array}$ & $\begin{array}{c}\text { Reliability, } \\
\alpha\end{array}$ & $\begin{array}{l}\text { Resiliency } \\
\text {, } F\left(E\left[T_{1}\right]\right)\end{array}$ & $\begin{array}{c}1 /(\mathrm{MD} / \mathrm{NS} \\
\left.{ }^{*} \mathrm{NF}\right)\end{array}$ & $\begin{array}{c}\text { Vulnerabili } \\
\text { ty } 1\end{array}$ & $\begin{array}{c}\text { i Vulnerabaili } \\
\text { ty } 2\end{array}$ & $0-500$ & $501-1000$ & $\begin{array}{l}1001- \\
1500\end{array}$ & $\begin{array}{l}1501- \\
2000\end{array}$ & $\begin{array}{l}2001- \\
2500\end{array}$ & $>2500$ & $\begin{array}{l}\text { Eculidean } \\
\text { Distance }\end{array}$ \\
\hline 40 & 7305 & 153 & 50 & 17 & 1 & 3.1 & 613 & 2 & 220 & 11475 & 33725 & 0.0065 & 0.9791 & 0.3268 & 3 & 230 & 220 & 0 & 471 & 5018 & 1282 & 400 & 134 & 0.6793 \\
\hline 4 & 7305 & 135 & 46 & 23 & 1 & 2.9 & 876 & 1 & 258 & 12346 & 34847 & 0.0074 & 0.9815 & 0.3407 & 2 & 268 & 258 & 0 & 493 & 5026 & 1244 & 418 & 124 & 0.6676 \\
\hline 7 & 7305 & 164 & 51 & 33 & 1 & 3.2 & 772 & 3 & 251 & 12669 & 41240 & 0.0061 & 0.9775 & 0.3110 & 1 & 248 & 251 & 0 & 469 & 4978 & 1270 & 442 & 146 & 0.6967 \\
\hline 2 & 7305 & 156 & 57 & 18 & 1 & 2.7 & 865 & 1 & 266 & 13499 & 41543 & 0.0064 & 0.9786 & 0.3654 & 3 & 237 & 266 & 0 & 475 & 5002 & 1239 & 448 & 141 & 0.6438 \\
\hline 38 & 7305 & 150 & 48 & 12 & 1 & 3.1 & 874 & 1 & 286 & 13566 & 42879 & 0.0067 & 0.9795 & 0.3200 & 4 & 283 & 286 & 0 & 485 & 4971 & 1256 & 458 & 135 & 0.6899 \\
\hline 76 & 7305 & 178 & 59 & 13 & 1 & 3.0 & 869 & 2 & 249 & 16427 & 44258 & 0.0056 & 0.9756 & 0.3315 & 3 & 278 & 249 & 0 & 484 & 5029 & 1220 & 408 & 164 & 0.6763 \\
\hline 81 & 7305 & 178 & 57 & 17 & 1 & 3.1 & 866 & 0 & 254 & 16888 & 45137 & 0.0056 & 0.9756 & 0.3202 & 2 & 296 & 254 & 0 & 474 & 5008 & 1215 & 446 & 162 & 0.6877 \\
\hline 84 & 7305 & 169 & 56 & 20 & 1 & 3.0 & 872 & 1 & 269 & 15235 & 45389 & 0.0059 & 0.9769 & 0.3314 & 2 & 272 & 269 & 0 & 468 & 4998 & 1217 & 466 & 156 & 0.6776 \\
\hline 26 & 7305 & 186 & 52 & 21 & 1 & 3.6 & 864 & 3 & 254 & 13370 & 47231 & 0.0054 & 0.9745 & 0.2796 & 2 & 257 & 254 & 0 & 480 & 4989 & 1221 & 448 & 167 & 0.7280 \\
\hline 41 & $\begin{array}{l}7305 \\
77305\end{array}$ & 147 & 51 & 17 & 1 & 2.9 & 901 & 1 & 322 & 13826 & 47318 & 0.0068 & 0.9799 & 0.3469 & 3 & 271 & 322 & 0 & 470 & 5007 & 1319 & 378 & 131 & 0.6659 \\
\hline 16 & 7305 & 176 & 51 & 16 & 1 & 3.5 & 910 & 3 & 270 & 13099 & 47586 & 0.0057 & 0.9759 & 0.2898 & 3 & 257 & 270 & 0 & 470 & 4997 & 1254 & 419 & 165 & 0.7188 \\
\hline 58 & $\begin{array}{l}7305 \\
7705\end{array}$ & $\begin{array}{l}181 \\
175\end{array}$ & $\begin{array}{l}57 \\
57\end{array}$ & 31 & 1 & 3.2 & 863 & 0 & 267 & 14775 & $\begin{array}{l}48340 \\
48250\end{array}$ & 0.0055 & 0.9752 & 0.3149 & 1 & 259 & 267 & 0 & 479 & 5001 & 1259 & 395 & 171 & 0.6938 \\
\hline $\begin{array}{l}17 \\
72\end{array}$ & $\begin{array}{l}7305 \\
7305\end{array}$ & $\begin{array}{l}175 \\
173\end{array}$ & $\begin{array}{l}57 \\
63\end{array}$ & $\begin{array}{l}14 \\
18\end{array}$ & $\begin{array}{l}1 \\
1\end{array}$ & $\begin{array}{l}3.1 \\
2.7\end{array}$ & $\begin{array}{l}874 \\
871\end{array}$ & $\begin{array}{l}4 \\
0\end{array}$ & $\begin{array}{l}276 \\
280\end{array}$ & $\begin{array}{l}16237 \\
15513\end{array}$ & $\begin{array}{l}\begin{array}{r}48358 \\
48447\end{array} \\
4\end{array}$ & $\begin{array}{l}0.0057 \\
0.0058\end{array}$ & $\begin{array}{l}0.9760 \\
0.9763\end{array}$ & $\begin{array}{l}0.3257 \\
0.3642\end{array}$ & $\begin{array}{l}3 \\
2\end{array}$ & $\begin{array}{l}285 \\
246\end{array}$ & $\begin{array}{l}276 \\
280\end{array}$ & $\begin{array}{l}0 \\
0 \\
0\end{array}$ & $\begin{array}{l}487 \\
497\end{array}$ & $\begin{array}{l}4972 \\
4963\end{array}$ & $\begin{array}{l}1255 \\
1220\end{array}$ & $\begin{array}{l}435 \\
469\end{array}$ & $\begin{array}{l}156 \\
156\end{array}$ & 0.6837 \\
\hline $\begin{array}{l}72 \\
27\end{array}$ & $\begin{array}{l}7305 \\
7305\end{array}$ & $\begin{array}{l}173 \\
161\end{array}$ & $\begin{array}{l}63 \\
49\end{array}$ & $\begin{array}{l}18 \\
28\end{array}$ & $\begin{array}{l}1 \\
1\end{array}$ & $\begin{array}{l}2.7 \\
3.3\end{array}$ & $\begin{array}{l}871 \\
873\end{array}$ & $\begin{array}{l}0 \\
0\end{array}$ & $\begin{array}{l}280 \\
302\end{array}$ & $\begin{array}{l}155513 \\
12958\end{array}$ & $\begin{array}{l}\begin{array}{r}48447 \\
48587\end{array} \\
4\end{array}$ & $\begin{array}{l}0.0058 \\
0.0062\end{array}$ & $\begin{array}{l}0.9763 \\
0.9780\end{array}$ & $\begin{array}{l}0.3642 \\
0.3043\end{array}$ & $\begin{array}{l}2 \\
2\end{array}$ & $\begin{array}{l}246 \\
264\end{array}$ & $\begin{array}{l}280 \\
302\end{array}$ & $\begin{array}{l}0 \\
0\end{array}$ & $\begin{array}{l}497 \\
481\end{array}$ & $\begin{array}{l}4963 \\
5046\end{array}$ & $\begin{array}{l}1220 \\
1216\end{array}$ & $\begin{array}{l}469 \\
409\end{array}$ & $\begin{array}{l}156 \\
153\end{array}$ & $\begin{array}{l}0.6461 \\
0.7064\end{array}$ \\
\hline $\begin{array}{l}27 \\
18\end{array}$ & 7305 & 178 & $\begin{array}{l}49 \\
57\end{array}$ & $\begin{array}{l}28 \\
13\end{array}$ & $\begin{array}{l}1 \\
1\end{array}$ & $\begin{array}{l}3.3 \\
3.1\end{array}$ & $\begin{array}{l}8 / 3 \\
881\end{array}$ & 2 & $\begin{array}{l}302 \\
273\end{array}$ & $\begin{array}{l}12958 \\
15523\end{array}$ & $\begin{array}{l}\begin{array}{r}48587 \\
48606\end{array} \\
4\end{array}$ & $\begin{array}{l}0.0062 \\
0.0056\end{array}$ & $\begin{array}{l}0.9880 \\
0.9756\end{array}$ & $\begin{array}{l}0.3043 \\
0.3202\end{array}$ & $\begin{array}{l}2 \\
3\end{array}$ & $\begin{array}{l}264 \\
272\end{array}$ & $\begin{array}{l}302 \\
273 \\
\end{array}$ & $\begin{array}{l}0 \\
0\end{array}$ & $\begin{array}{l}481 \\
476\end{array}$ & $\begin{array}{l}5046 \\
5027\end{array}$ & $\begin{array}{l}1216 \\
1197\end{array}$ & $\begin{array}{l}409 \\
441\end{array}$ & $\begin{array}{l}153 \\
164\end{array}$ & $\begin{array}{l}0.7064 \\
0.6889\end{array}$ \\
\hline 71 & 7305 & 183 & 55 & 16 & 1 & 3.3 & 865 & 0 & 277 & 14095 & 50725 & 0.0055 & 0.9749 & 0.3005 & 2 & 256 & 277 & 0 & 468 & 4961 & 1254 & 457 & $\begin{array}{l}104 \\
165\end{array}$ & 0.7086 \\
\hline 93 & 7305 & 170 & 55 & 30 & 1 & 3.1 & 891 & 5 & 299 & 16237 & 50761 & 0.0059 & 0.9767 & 0.3235 & 1 & 295 & 299 & 0 & 485 & 4978 & 1312 & 369 & 161 & 0.6873 \\
\hline 55 & 7305 & 160 & 49 & 17 & 1 & 3.3 & 894 & 0 & 319 & 14039 & 51033 & 0.0063 & 0.9781 & 0.3063 & 3 & 287 & 319 & 0 & 501 & 4950 & 1256 & 450 & 148 & 0.7057 \\
\hline 36 & 7305 & 175 & 50 & 24 & 1 & 3.5 & 869 & 3 & 292 & 13983 & 51110 & 0.0057 & 0.9760 & 0.2857 & 2 & 280 & 292 & 0 & 455 & 5007 & 1232 & 450 & 161 & 0.7242 \\
\hline 88 & 7305 & 175 & 48 & 18 & 1 & 3.6 & 873 & 3 & 292 & 14132 & 51117 & 0.0057 & 0.9760 & 0.2743 & 2 & 294 & 292 & 0 & 474 & 5060 & 1184 & 421 & 166 & 0.7354 \\
\hline 56 & 7305 & 174 & 54 & 26 & 1 & 3.2 & 907 & 1 & 294 & 13938 & 51166 & 0.0057 & 0.9762 & 0.3103 & 2 & 258 & 294 & 0 & 465 & 5026 & 1216 & 441 & 157 & 0.7000 \\
\hline 100 & 7305 & 180 & 54 & 12 & 1 & 3.3 & 897 & 0 & 285 & 16212 & 51311 & 0.0056 & 0.9754 & 0.3000 & 3 & 300 & 285 & 0 & 466 & 5046 & 1217 & 408 & 168 & 0.7097 \\
\hline 19 & 7305 & 176 & 48 & 29 & 1 & 3.7 & 945 & 0 & 292 & 12635 & 51371 & 0.0057 & 0.9759 & 0.2727 & 1 & 263 & 292 & 0 & 473 & 5007 & 1253 & 416 & 156 & 0.7370 \\
\hline 11 & 7305 & 178 & 56 & 18 & 1 & 3.2 & 888 & 0 & 296 & 15980 & 52660 & 0.0056 & 0.9756 & 0.3146 & 2 & 285 & 296 & 0 & 499 & 4946 & 1291 & 404 & 165 & 0.6960 \\
\hline 20 & 7305 & 179 & 60 & 15 & 1 & 3.0 & 859 & 2 & 296 & 16268 & 52991 & 0.0056 & 0.9755 & 0.3352 & 3 & 271 & 296 & 0 & 495 & 5010 & 1234 & 398 & 168 & 0.6757 \\
\hline 64 & 7305 & 171 & 55 & 11 & 1 & 3.1 & 930 & 2 & 310 & 16568 & 53060 & 0.0058 & 0.9766 & 0.3216 & 4 & 301 & 310 & 0 & 77 & 4960 & 1311 & 403 & 154 & 0.6900 \\
\hline 23 & 7305 & 170 & 50 & 18 & 1 & 3.4 & 1 & 2 & 314 & 14821 & & & 0.9767 & 0.2941 & 2 & 296 & 314 & 0 & 75 & 4991 & 1257 & 425 & 157 & 0.7174 \\
\hline 95 & 7305 & 188 & 53 & 17 & 1 & 3.5 & 873 & 1 & 286 & & 53678 & & 0.9743 & 0.2819 & 2 & 318 & 86 & 0 & 78 & 5013 & 1249 & 10 & 175 & 0.7276 \\
\hline 8 & 7305 & 175 & 53 & 11 & 1 & 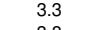 & 876 & 3 & 309 & 15732 & 54021 & & 0.9760 & 0.3029 & 4 & 7 & 09 & 0 & 7 & 4989 & 1242 & 32 & 165 & 0.7084 \\
\hline 47 & 7305 & 203 & 54 & 17 & 1 & 8 & 8 & 3 & 266 & & 54061 & 0.0049 & 0.9722 & 0.2660 & 2 & 262 & 66 & 0 & 78 & 4940 & 1297 & 7 & 183 & 0.7422 \\
\hline 65 & 7305 & 204 & $6 \varepsilon$ & 14 & 1 & 3.0 & 86 & 4 & 265 & & 54152 & 0.0049 & 0.9721 & 0.3333 & 3 & ק? & 7 & 0 & 34 & 5016 & 1161 & 54 & 190 & 0.6756 \\
\hline 74 & 7305 & 183 & 55 & 13 & 1 & 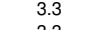 & 96 & 2 & 297 & 16583 & 54335 & & 0.9749 & 0.3005 & 3 & 302 & 97 & 0 & 73 & 5018 & 1255 & 34 & 165 & 0.7099 \\
\hline 90 & $\begin{array}{l}7305 \\
7705\end{array}$ & 172 & 52 & 25 & 1 & 3.3 & 9 & 9 & 317 & 135 & & & 0.9765 & 0.3023 & 2 & 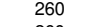 & 17 & 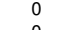 & & & 1268 & 2 & 157 & 0.7095 \\
\hline 62 & $\begin{array}{l}7305 \\
7305\end{array}$ & 200 & 57 & 23 & 1 & 3.5 & 86 & 1 & 273 & & 54581 & & 0.9726 & 0.2850 & 2 & & 3 & 0 & & 4986 & 1168 & 30 & 182 & 0.7238 \\
\hline 39 & $\begin{array}{l}7305 \\
7305\end{array}$ & $\begin{array}{l}199 \\
192\end{array}$ & $\begin{array}{l}52 \\
57\end{array}$ & $\begin{array}{l}23 \\
33\end{array}$ & 1 & 3.8 & 8 & 1 & $\begin{array}{l}278 \\
288\end{array}$ & $\begin{array}{l}15890 \\
1591\end{array}$ & 55247 & & $\begin{array}{l}0.9728 \\
0.973\end{array}$ & 0.2613 & 2 & 30 & 278 & 0 & 99 & 5048 & 1215 & 11 & 182 & 0.7475 \\
\hline 94 & $\begin{array}{l}7305 \\
7305\end{array}$ & $\begin{array}{l}192 \\
192\end{array}$ & 57 & $\begin{array}{l}33 \\
32\end{array}$ & 1 & $\begin{array}{l}3.4 \\
31\end{array}$ & 86 & 1 & 288 & $\begin{array}{l}15981 \\
1591\end{array}$ & $\begin{array}{l}55390 \\
55444\end{array}$ & $\begin{array}{l}0.0052 \\
0.005 ?\end{array}$ & $\begin{array}{l}0.9737 \\
0.9737\end{array}$ & 0.2969 & 1 & 262 & 289 & 0 & & & 1232 & 462 & 179 & 0.7130 \\
\hline $\begin{array}{l}33 \\
87\end{array}$ & $\begin{array}{l}7305 \\
7305\end{array}$ & $\begin{array}{l}192 \\
174\end{array}$ & $\begin{array}{l}61 \\
45\end{array}$ & $\begin{array}{l}32 \\
31\end{array}$ & $\begin{array}{l}1 \\
1\end{array}$ & $\begin{array}{l}3.1 \\
3.9\end{array}$ & $\begin{array}{l}889 \\
889\end{array}$ & $\begin{array}{l}2 \\
1\end{array}$ & $\begin{array}{l}289 \\
319\end{array}$ & $\begin{array}{l}15981 \\
10621\end{array}$ & $\begin{array}{l}55446 \\
55523\end{array}$ & $\begin{array}{l}0.0052 \\
0.0057\end{array}$ & $\begin{array}{l}0.9777 \\
0.9762\end{array}$ & $\begin{array}{l}0.3177 \\
0.2586\end{array}$ & $\begin{array}{l}1 \\
1\end{array}$ & $\begin{array}{l}262 \\
236\end{array}$ & $\begin{array}{l}289 \\
319\end{array}$ & 0 & $\begin{array}{l}475 \\
507\end{array}$ & $\begin{array}{l}5002 \\
5059\end{array}$ & $\begin{array}{l}1210 \\
1217\end{array}$ & $\begin{array}{l}441 \\
359\end{array}$ & $\begin{array}{l}177 \\
163\end{array}$ & $\begin{array}{l}0.6925 \\
0.7527\end{array}$ \\
\hline $\begin{array}{l}89 \\
29\end{array}$ & 7305 & $\begin{array}{l}1 / 4 \\
183\end{array}$ & 57 & 25 & 1 & $\begin{array}{l}3.9 \\
3.2\end{array}$ & $\begin{array}{l}889 \\
876\end{array}$ & $\begin{array}{l}1 \\
0\end{array}$ & $\begin{array}{l}319 \\
304\end{array}$ & $\begin{array}{l}10621 \\
16239\end{array}$ & $\begin{array}{l}55523 \\
55683\end{array}$ & $\begin{array}{l}0.0057 \\
0.0055\end{array}$ & $\begin{array}{l}0.9762 \\
0.9749\end{array}$ & $\begin{array}{l}0.2586 \\
0.3115\end{array}$ & $\begin{array}{l}1 \\
2\end{array}$ & $\begin{array}{l}236 \\
285\end{array}$ & $\begin{array}{l}319 \\
304\end{array}$ & $\begin{array}{l}0 \\
0\end{array}$ & $\begin{array}{l}507 \\
472\end{array}$ & $\begin{array}{l}5059 \\
5021\end{array}$ & $\begin{array}{l}1217 \\
1183\end{array}$ & $\begin{array}{l}359 \\
458\end{array}$ & $\begin{array}{l}163 \\
171\end{array}$ & $\begin{array}{l}0.7527 \\
0.6996\end{array}$ \\
\hline 52 & 7305 & 194 & 59 & 26 & 1 & 3.3 & 879 & 0 & 290 & 15686 & 56194 & $\begin{array}{l}0.0052 \\
0.0052\end{array}$ & 0.9734 & 0.3041 & 1 & $\begin{array}{l}280 \\
266\end{array}$ & $\begin{array}{l}394 \\
290\end{array}$ & 0 & $\begin{array}{l}467 \\
467\end{array}$ & $\begin{array}{l}5021 \\
4958\end{array}$ & $\begin{array}{l}1183 \\
1247\end{array}$ & $\begin{array}{l}458 \\
460\end{array}$ & $\begin{array}{l}1 / 1 \\
173\end{array}$ & $\begin{array}{l}0.6996 \\
0.7060\end{array}$ \\
\hline 61 & 7305 & 201 & 62 & 28 & 1 & 2 & 870 & 0 & 280 & 16562 & 56318 & 0.0050 & 0.9725 & 0.3085 & 1 & 267 & 280 & 0 & 466 & 5010 & 1208 & 437 & 184 & 0.7011 \\
\hline 83 & 7305 & 188 & 51 & 31 & 1 & 3.7 & 873 & 2 & 301 & 15320 & 56552 & 0.0053 & 0.9743 & 0.2713 & 1 & 300 & 301 & 0 & 463 & 5007 & 1215 & 445 & 175 & 0.7390 \\
\hline 97 & 7305 & 177 & 57 & 18 & 1 & 3.1 & 943 & 10 & 320 & 16002 & 56602 & 0.0056 & 0.9758 & 0.3220 & 2 & 281 & 320 & 0 & 462 & 5061 & 1213 & 404 & 165 & 0.6904 \\
\hline 24 & 7305 & 183 & 53 & 19 & 1 & 3.5 & 8 & 1 & 311 & 14463 & 56824 & 0.0055 & 0.9749 & 0.2896 & 2 & 273 & 311 & 0 & 471 & 5005 & 1306 & 356 & 167 & 0.7216 \\
\hline 86 & 7305 & 172 & 45 & 23 & 1 & 3.5 & & 1 & 332 & 14 & 57 & 0.0 & 0.9765 & 0.28 & 2 & 289 & 332 & 0 & 47 & 49 & 1217 & 460 & 165 & 0.7277 \\
\hline 53 & 73 & 186 & 55 & 20 & 1 & 4 & 8 & 4 & 308 & & 57 & & 0.9745 & 0.2 & 2 & 29 & $3 c$ & 0 & 46 & 4944 & 1241 & 47 & 172 & 0.7154 \\
\hline 43 & 73 & 180 & 62 & 24 & 1 & 2 & 9 & 0 & 31 & & 57 & & 0.9754 & 0.3 & 2 & 263 & 31 & 0 & 4 & 50 & 1176 & $4 \varepsilon$ & 163 & 0.6683 \\
\hline 78 & 73 & 177 & 4 & 43 & 1 & 3 & & 0 & 32 & & & & 0.9 & 0.2 & 1 & 239 & 32 & 0 & & & 1277 & 41 & 160 & 0.7519 \\
\hline 48 & 73 & 18 & 56 & 17 & 1 & 3 & & 1 & 32 & & & & & & 2 & 3 & 32 & 0 & 4. & & 12 & 43 & 166 & 0.7356 \\
\hline 98 & 73 & 19 & 5 & 17 & 1 & 3 & 8 & 1 & 30 & & & & & & 2 & 31 & $30-2$ & 0 & & & 1177 & & 181 & 0.7169 \\
\hline 42 & & 17 & 5 & 24 & 1 & & & 1 & 33 & & & & & & 2 & 3 & & 0 & & & 1264 & & 162 & 0.7103 \\
\hline 79 & & 19 & 62 & 15 & 1 & & 9 & 2 & 25 & & & & & & 2 & - & & 0 & & & & & 178 & 0.6960 \\
\hline 14 & & 16 & 44 & 24 & 1 & 3 & 88 & 6 & 35 & & & & & & 2 & & & 0 & & & & & 154 & 0.7490 \\
\hline $\begin{array}{c}6 \\
69 \\
69\end{array}$ & $\begin{array}{l}7305 \\
7305\end{array}$ & $\begin{array}{l}183 \\
199\end{array}$ & $\begin{array}{l}54 \\
65\end{array}$ & $\begin{array}{l}17 \\
25\end{array}$ & 1 & $\begin{array}{l}3.4 \\
3.4\end{array}$ & $\begin{array}{l}876 \\
905\end{array}$ & $\begin{array}{l}0 \\
3\end{array}$ & $\begin{array}{l}325 \\
299\end{array}$ & $\begin{array}{l}17072 \\
18429\end{array}$ & $\begin{array}{l}59503 \\
59553\end{array}$ & $\begin{array}{l}0.0055 \\
0.0050\end{array}$ & $\begin{array}{l}0.9749 \\
0.9728\end{array}$ & $\begin{array}{l}0.2951 \\
0.3266\end{array}$ & $\begin{array}{l}2 \\
1\end{array}$ & $\begin{array}{l}316 \\
284\end{array}$ & $\begin{array}{l}325 \\
299\end{array}$ & $\begin{array}{l}0 \\
0\end{array}$ & $\begin{array}{l}470 \\
487\end{array}$ & $\begin{array}{l}5006 \\
4973\end{array}$ & $\begin{array}{l}1270 \\
1246\end{array}$ & $\begin{array}{l}383 \\
415\end{array}$ & $\begin{array}{l}176 \\
184\end{array}$ & $\begin{array}{l}0.7173 \\
0.6845\end{array}$ \\
\hline & & & & & & & & & & & & & & & & & & & & & & & & \\
\hline
\end{tabular}




\begin{tabular}{|c|c|c|c|c|c|c|c|c|c|c|c|c|c|c|c|c|c|c|c|c|c|c|c|c|}
\hline 30 & 7305 & 199 & 62 & 19 & 1 & 3.2 & 915 & 2 & 301 & 20016 & 59806 & 0.0050 & 0.9728 & 0.3116 & 2 & 323 & 301 & 0 & 475 & 5014 & 1206 & 433 & 177 & 0.6994 \\
\hline 73 & 7305 & 192 & 54 & 27 & 1 & 3.6 & 879 & 1 & 312 & 13403 & 59856 & 0.0052 & 0.9737 & 0.2813 & 1 & 248 & 312 & 0 & 469 & 5048 & 1196 & 419 & 173 & 0.7300 \\
\hline 32 & 7305 & 181 & 45 & 27 & 1 & 4.0 & 880 & 4 & 332 & 13572 & 60152 & 0.0055 & 0.9752 & 0.2486 & 1 & 302 & 332 & 0 & 490 & 4981 & 1281 & 374 & 179 & 0.7635 \\
\hline 92 & 7305 & 190 & 45 & 16 & 1 & 4.2 & 872 & 2 & 318 & 15098 & 60338 & 0.0053 & 0.9740 & 0.2368 & 2 & 336 & 318 & 0 & 454 & 5057 & 1236 & 375 & 183 & 0.7741 \\
\hline 3 & 7305 & 207 & 63 & 23 & 1 & 3.3 & 878 & 0 & 292 & 19080 & 60456 & 0.0048 & 0.9717 & 0.3043 & 2 & 303 & 292 & 0 & 463 & 4955 & 1233 & 462 & 192 & 0.7060 \\
\hline 35 & 7305 & 181 & 62 & 14 & 1 & 2.9 & 911 & 1 & 334 & 17996 & 60469 & 0.0055 & 0.9752 & 0.3425 & 3 & 290 & 334 & 0 & 493 & 4956 & 1232 & 457 & 167 & 0.6714 \\
\hline 28 & 7305 & 197 & 63 & 18 & 1 & 3.1 & 877 & 0 & 311 & 18552 & 61200 & 0.0051 & 0.9730 & 0.3198 & 2 & 294 & 311 & 0 & 459 & 4937 & 1287 & 440 & 182 & 0.6920 \\
\hline 9 & 7305 & 200 & 54 & 18 & 1 & 3.7 & 868 & 2 & 307 & 18233 & 61389 & 0.0050 & 0.9726 & 0.2700 & 2 & 338 & 307 & 0 & 479 & 4975 & 1229 & 438 & 184 & 0.7408 \\
\hline 54 & 7305 & 216 & 60 & 28 & 1 & 3.6 & 876 & 1 & 287 & 15679 & 62061 & 0.0046 & 0.9704 & 0.2778 & 1 & 261 & 287 & 0 & 475 & 5050 & 1199 & 385 & 196 & 0.7319 \\
\hline 51 & 7305 & 177 & 43 & 39 & 1 & 4.1 & 899 & 0 & 353 & 11758 & 62443 & 0.0056 & 0.9758 & 0.2429 & 1 & 273 & 353 & 0 & 483 & 5034 & 1227 & 394 & 167 & 0.7705 \\
\hline 91 & 7305 & 181 & 44 & 17 & 1 & 4.1 & 877 & 2 & 345 & 14675 & 62535 & 0.0055 & 0.9752 & 0.2431 & 2 & 334 & 345 & 0 & 477 & 4979 & 1291 & 392 & 166 & 0.7698 \\
\hline 66 & 7305 & 208 & 64 & 18 & 1 & 3.3 & 860 & 1 & 302 & 19575 & 62730 & 0.0048 & 0.9715 & 0.3077 & 2 & 306 & 302 & 0 & 476 & 4969 & 1238 & 424 & 198 & 0.7033 \\
\hline 5 & 7305 & 214 & 50 & 22 & 1 & 4.3 & 868 & 0 & 306 & 16476 & 65445 & 0.0047 & 0.9707 & 0.2336 & 2 & 330 & 306 & 0 & 482 & 4993 & 1257 & 378 & 195 & 0.7766 \\
\hline 44 & 7305 & 197 & 56 & 21 & 1 & 3.5 & 918 & 1 & 333 & 16820 & 65648 & 0.0051 & 0.9730 & 0.2843 & 2 & 300 & 333 & 0 & 494 & 5025 & 1160 & 443 & 183 & 0.7285 \\
\hline 13 & 7305 & 187 & 42 & 23 & 1 & 4.5 & 894 & 5 & 352 & 14149 & 65788 & 0.0053 & 0.9744 & 0.2246 & 2 & 337 & 352 & 0 & 502 & 4963 & 1265 & 399 & 176 & 0.7885 \\
\hline 50 & 7305 & 200 & 50 & 21 & 1 & 4.0 & 906 & 1 & 330 & 16311 & 65948 & 0.0050 & 0.9726 & 0.2500 & 2 & 326 & 330 & 0 & 482 & 4980 & 1219 & 436 & 188 & 0.7620 \\
\hline 96 & 7305 & 196 & 49 & 18 & 1 & 4.0 & 931 & 0 & 339 & 16176 & 66534 & 0.0051 & 0.9732 & 0.2500 & 2 & 330 & 339 & 0 & 481 & 5011 & 1247 & 381 & 185 & 0.7627 \\
\hline 67 & 7305 & 184 & 48 & 30 & 1 & 3.8 & 875 & 2 & 364 & 15944 & 66917 & 0.0054 & 0.9748 & 0.2609 & 1 & 332 & 364 & 0 & 479 & 4951 & 1252 & 445 & 178 & 0.7537 \\
\hline 60 & 7305 & 202 & 51 & 30 & 1 & 4.0 & 875 & 5 & 333 & 14458 & 67196 & 0.0050 & 0.9723 & 0.2525 & 1 & 283 & 333 & 0 & 491 & 4973 & 1240 & 411 & 190 & 0.7598 \\
\hline 57 & 7305 & 206 & 58 & 16 & 1 & 3.6 & 875 & 2 & 328 & 18848 & 67572 & 0.0049 & 0.9718 & 0.2816 & 2 & 325 & 328 & 0 & 484 & 4936 & 1269 & 418 & 198 & 0.7309 \\
\hline 25 & 7305 & 218 & 63 & 21 & 1 & 3.5 & 903 & 1 & 310 & 17466 & 67604 & 0.0046 & 0.9702 & 0.2890 & 2 & 277 & 310 & 0 & 486 & 4985 & 1215 & 419 & 200 & 0.7224 \\
\hline 59 & 7305 & 222 & 55 & 14 & 1 & 4.0 & 878 & 1 & 306 & 20140 & 67913 & 0.0045 & 0.9696 & 0.2477 & 2 & 366 & 306 & 0 & 460 & 4999 & 1241 & 404 & 201 & 0.7627 \\
\hline 22 & 7305 & 200 & 46 & 31 & 1 & 4.3 & 945 & 2 & 342 & 13983 & 68465 & 0.0050 & 0.9726 & 0.2300 & 1 & 304 & 342 & 0 & 484 & 5031 & 1204 & 403 & 183 & 0.7826 \\
\hline 77 & 7305 & 224 & 59 & 24 & 1 & 3.8 & 868 & 2 & 306 & 18354 & 68602 & 0.0045 & 0.9693 & 0.2634 & 1 & 311 & 306 & 0 & 504 & 4957 & 1175 & 464 & 205 & 0.7474 \\
\hline 89 & 7305 & 207 & 55 & 34 & 1 & 3.8 & 951 & 3 & 333 & 15090 & 68994 & 0.0048 & 0.9717 & 0.2657 & 1 & 274 & 333 & 0 & 488 & 5047 & 1186 & 390 & 194 & 0.7468 \\
\hline 70 & 7305 & 186 & 43 & 33 & 1 & 4.3 & 895 & 5 & 374 & 11850 & 69533 & 0.0054 & 0.9745 & 0.2312 & 1 & 276 & 374 & 0 & 459 & 5044 & 1198 & 429 & 175 & 0.7836 \\
\hline 1 & 7305 & 191 & 48 & 30 & 1 & 4.0 & 878 & 0 & 364 & 14958 & 69553 & 0.0052 & 0.9739 & 0.2513 & 1 & 312 & 364 & 0 & 455 & 5031 & 1239 & 399 & 181 & 0.7632 \\
\hline 21 & 7305 & 208 & 51 & 34 & 1 & 4.1 & 876 & 3 & 337 & 17642 & 70086 & 0.0048 & 0.9715 & 0.2452 & 1 & 346 & 337 & 0 & 486 & 4914 & 1244 & 463 & 198 & 0.7673 \\
\hline 68 & 7305 & 215 & 57 & 18 & 1 & 3.8 & 883 & 2 & 326 & 17466 & 70121 & 0.0047 & 0.9706 & 0.2651 & 2 & 306 & 326 & 0 & 481 & 4918 & 1248 & 458 & 200 & 0.7470 \\
\hline 10 & 7305 & 202 & 47 & 38 & 1 & 4.3 & 913 & 7 & 348 & 14282 & 70322 & 0.0050 & 0.9723 & 0.2327 & 1 & 304 & 348 & 0 & 456 & 5053 & 1212 & 397 & 187 & 0.7803 \\
\hline 15 & 7305 & 202 & 58 & 21 & 1 & 3.5 & 879 & 2 & 349 & 17138 & 70404 & 0.0050 & 0.9723 & 0.2871 & 2 & 295 & 349 & 0 & 483 & 4953 & 1280 & 405 & 184 & 0.7269 \\
\hline 31 & 7305 & 214 & 58 & 23 & 1 & 3.7 & 933 & 0 & 330 & 18572 & 70597 & 0.0047 & 0.9707 & 0.2710 & 1 & 320 & 330 & 0 & 448 & 4987 & 1287 & 384 & 199 & 0.7414 \\
\hline 49 & 7305 & 234 & 53 & 27 & 1 & 4.4 & 878 & 4 & 302 & 16148 & 70671 & 0.0043 & 0.9680 & 0.2265 & 1 & 305 & 302 & 0 & 479 & 4965 & 1243 & 401 & 217 & 0.7835 \\
\hline 63 & 7305 & 188 & 36 & 32 & 1 & 5.2 & 869 & 9 & 379 & 11663 & 71307 & 0.0053 & 0.9743 & 0.1915 & 1 & 324 & 379 & 0 & 482 & 5018 & 1240 & 381 & 184 & 0.8230 \\
\hline 12 & 7305 & 203 & 47 & 35 & 1 & 4.3 & 918 & 2 & 353 & 13593 & 71591 & 0.0049 & 0.9722 & 0.2315 & 1 & 289 & 353 & 0 & 472 & 4989 & 1208 & 439 & 197 & 0.7818 \\
\hline 34 & 7305 & 204 & 58 & 36 & 1 & 3.5 & 880 & 3 & 354 & 16247 & 72193 & 0.0049 & 0.9721 & 0.2843 & 1 & 280 & 354 & 0 & 482 & 4991 & 1242 & 400 & 190 & 0.7301 \\
\hline 82 & 7305 & 222 & 54 & $\begin{array}{l}33 \\
53\end{array}$ & 1 & $\begin{array}{l}4.1 \\
3.7\end{array}$ & 886 & $\begin{array}{l}1 \\
5\end{array}$ & 333 & $\begin{array}{l}16713 \\
1478\end{array}$ & $\begin{array}{l}74016 \\
7516\end{array}$ & 0.0045 & 0.9696 & 0.2432 & 1 & 309 & 333 & 0 & 494 & 4958 & 1220 & 424 & 209 & 0.7690 \\
\hline 37 & 7305 & 220 & 59 & 53 & 1 & 3.7 & 881 & $\begin{array}{l}5 \\
3\end{array}$ & 343 & $\begin{array}{l}14884 \\
1\end{array}$ & 75406 & 0.0045 & 0.9699 & 0.2682 & 1 & 252 & 343 & 0 & 506 & 4893 & 1244 & 453 & 209 & 0.7452 \\
\hline 75 & $\begin{array}{l}7305 \\
7305\end{array}$ & $\begin{array}{l}226 \\
220\end{array}$ & 60 & $\begin{array}{l}21 \\
33\end{array}$ & 1 & 3.8 & 895 & ${ }_{1}^{3}$ & $\begin{array}{l}336 \\
352\end{array}$ & $\begin{array}{l}19613 \\
1760\end{array}$ & $\begin{array}{l}76022 \\
78124\end{array}$ & 0.0044 & 0.9691 & 0.2655 & 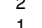 & $\begin{array}{l}327 \\
338\end{array}$ & $\begin{array}{l}336 \\
352\end{array}$ & 0 & 484 & 4929 & 1249 & 429 & 214 & $\begin{array}{l}0.7474 \\
\end{array}$ \\
\hline $\begin{array}{l}46 \\
80\end{array}$ & $\begin{array}{l}7305 \\
7305\end{array}$ & $\begin{aligned} 2222 \\
234\end{aligned}$ & $\begin{array}{l}54 \\
57\end{array}$ & $\begin{array}{l}33 \\
36\end{array}$ & 1 & $\begin{array}{l}4.1 \\
4.1\end{array}$ & $\begin{array}{l}907 \\
948\end{array}$ & 1 & $\begin{array}{l}352 \\
335 \\
335\end{array}$ & $\begin{array}{l}17701 \\
15216\end{array}$ & $\begin{array}{l}788124 \\
78344\end{array}$ & 0.0045 & 0.9696 & $\begin{array}{l}0.2432 \\
0.2436\end{array}$ & 1 & $\begin{array}{l}328 \\
267\end{array}$ & $\begin{array}{l}352 \\
335 \\
335\end{array}$ & $\begin{array}{l}0 \\
0\end{array}$ & $\begin{array}{l}489 \\
460\end{array}$ & $\begin{array}{l}5010 \\
5054\end{array}$ & 1232 & 412 & 204 & $\begin{array}{l}0.7703 \\
0.778\end{array}$ \\
\hline $\begin{array}{l}80 \\
45\end{array}$ & $\begin{array}{l}7305 \\
7305\end{array}$ & $\begin{array}{l}234 \\
228\end{array}$ & 50 & $\begin{array}{l}36 \\
29\end{array}$ & 1 & $\begin{array}{l}4.1 \\
46\end{array}$ & $\begin{array}{l}948 \\
877\end{array}$ & 4 & $\begin{array}{l}335 \\
345\end{array}$ & $\begin{array}{l}15216 \\
16213\end{array}$ & $\begin{array}{l}78344 \\
78736\end{array}$ & $\begin{array}{l}0.0043 \\
0.0044\end{array}$ & 0.9680 & $\begin{array}{l}0.2436 \\
0\end{array}$ & 1 & & $\begin{array}{l}335 \\
345\end{array}$ & 0 & $\begin{array}{l}460 \\
482\end{array}$ & $\begin{array}{l}5054 \\
4984\end{array}$ & 1241 & $\begin{array}{l}412 \\
377\end{array}$ & $\begin{array}{l}214 \\
221\end{array}$ & $\begin{array}{l}0.7688 \\
0.7634\end{array}$ \\
\hline $\begin{array}{l}45 \\
85\end{array}$ & $\begin{array}{r}3.305 \\
7305\end{array}$ & $\begin{array}{r}228 \\
244\end{array}$ & $\begin{array}{l}0 \\
63\end{array}$ & $\begin{array}{l}29 \\
19\end{array}$ & 1 & $\begin{array}{l}4.6 \\
3.9\end{array}$ & 8717 & $\begin{array}{l}4 \\
1\end{array}$ & $\begin{array}{l}345 \\
324\end{array}$ & $\begin{array}{l}16013 \\
19658\end{array}$ & $\begin{array}{r}18836 \\
79057\end{array}$ & $\begin{array}{l}0.0044 \\
0.0044\end{array}$ & 0.9666 & 0.2582 & 2 & $\begin{array}{r}280 \\
312\end{array}$ & $\begin{array}{l}540 \\
324\end{array}$ & 0 & $\begin{array}{l}482 \\
449\end{array}$ & $\begin{array}{l}4904 \\
5023\end{array}$ & 1149 & 462 & 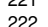 & $\begin{array}{l}0.7934 \\
0.7538\end{array}$ \\
\hline $\begin{array}{l}85 \\
99\end{array}$ & $\begin{array}{l}3305 \\
7305\end{array}$ & $\begin{array}{l}244 \\
215\end{array}$ & $\begin{array}{l}\text { os } \\
52\end{array}$ & 40 & 1 & $\begin{array}{l}3.9 \\
4.1\end{array}$ & $\begin{array}{l}896 \\
921\end{array}$ & 1 & $\begin{array}{l}5<4 \\
380\end{array}$ & $\begin{array}{l}19658 \\
15021\end{array}$ & 81593 & $\begin{array}{l}0.0041 \\
0.0047\end{array}$ & $\begin{array}{l}0.9666 \\
0.9706\end{array}$ & $\begin{array}{l}0.2582 \\
0.2419\end{array}$ & $\begin{array}{l}2 \\
1\end{array}$ & $\begin{array}{l}2812 \\
289\end{array}$ & $\begin{array}{l}3<4 \\
380\end{array}$ & 0 & $\begin{array}{l}449 \\
478\end{array}$ & 4995 & 1248 & $\begin{array}{l}402 \\
382\end{array}$ & 202 & $\begin{array}{l}0.1538 \\
0.7737\end{array}$ \\
\hline & & 135 & 36 & 11 & 1 & 2.7 & 61 & 0 & 220 & 1062 & 337 & & 196 & 0.1 & 1 & & 220 & 0 & 448 & & 114 & 356 & 124 & \\
\hline rac & & 190 & 54 & 23 & 1 & 3.6 & 884 & 2 & 310 & 155 & 591 & 0.0053 & 0.9740 & 0.2852 & 2 & 290 & 310 & 0 & 7 & & 1235 & 3 & 76 & 0.7260 \\
\hline aximum & & 244 & 68 & 53 & 1 & 5.2 & 951 & 10 & 380 & 20140 & 81593 & 0.0074 & 0.9815 & 0.3654 & 4 & 366 & 380 & 0 & 507 & 506 & 1319 & 484 & 222 & 0.8230 \\
\hline itd.dev & & 20.3 & 5.9 & 8.0 & 0 & 0.5 & 36.9 & 2.0 & 31.5 & 2077.4 & 9959.0 & 0.0006 & 0.0028 & 0.0354 & 0.7 & 27.9 & 31.5 & 0.0 & 13.1 & 37.5 & 35.6 & 30.8 & 19.9 & 0.0363 \\
\hline
\end{tabular}


Scenerio $\bigwedge$ Scenario $12 a$ CSIROMk2b B11 with Base Case Setting with change of precipitation frequency $\begin{array}{ll}\text { Date: } & \text { 29/10/2007 } \\ \text { Simulation 6:42:26 PM } & \end{array}$

$\begin{array}{ll}\text { Simulation } & \text { 9:05:51 PM } \\ \text { Elapsed Ti } & 143.42 \text { Minutes }\end{array}$

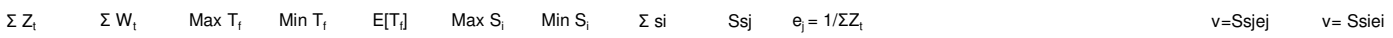
Total

\begin{tabular}{|c|c|c|c|c|c|c|c|c|c|c|c|c|c|c|c|c|c|c|c|c|c|c|c|c|}
\hline Trial No. & $\begin{array}{c}\text { Total no. of } \\
\text { Days }\end{array}$ & $\begin{array}{c}\text { No. of } \\
\text { Days } \\
\text { Failed }\end{array}$ & $\begin{array}{l}\text { No. of } \\
\text { Consecutive } \\
\text { Failures }\end{array}$ & $\begin{array}{c}\text { Max. } \\
\text { Failure } \\
\text { Duration }\end{array}$ & $\begin{array}{c}\text { Min. } \\
\text { Failure } \\
\text { Duration }\end{array}$ & $\begin{array}{c}\text { Avg. } \\
\text { Failure } \\
\text { Duration }\end{array}$ & $\begin{array}{c}\text { Max } \\
\text { Severity } \\
\text { of Failure }\end{array}$ & $\begin{array}{l}\text { Min } \\
\text { Severity } \\
\text { of Failure }\end{array}$ & $\begin{array}{l}\text { Total. } \\
\text { Severity } \\
\text { of Failure }\end{array}$ & $\begin{array}{l}\text { Total } \\
\text { Maximum } \\
\text { Severity } \\
\text { of Sojourn }\end{array}$ & $\begin{array}{l}\text { Prob. } \\
\text { [Correspo } \\
\left.\text { nd to } \mathrm{S}_{\mathrm{j}}\right]\end{array}$ & $\begin{array}{l}\text { Reliability, } \\
\alpha\end{array}$ & $\begin{array}{l}\text { Resiliency, } \\
F\left(E\left[T_{f}\right]\right)\end{array}$ & $\begin{array}{l}\text { Resiliency, } \\
1 \text { 1/(MD/NS*NF) }\end{array}$ & Vulnerability 1 & $\begin{array}{l}\text { Average } \\
\text { Vulnerability }\end{array}$ & $0-500$ & $501-1000$ & $\begin{array}{l}1001- \\
1500\end{array}$ & $\begin{array}{l}1501- \\
2000\end{array}$ & $\begin{array}{l}2001- \\
2500\end{array}$ & $>2500$ & $\begin{array}{l}\text { Eculidean } \\
\text { Distance }\end{array}$ & $\begin{array}{l}\text { Severity/n } \\
\text { o. of days } \\
\text { with } \\
\text { failure }\end{array}$ \\
\hline 56 & 7305 & 129 & 44 & 16 & 1 & 2.9 & 876 & 3 & 40159 & 11618 & 0.0078 & 0.9823 & 0.3411 & 3.5 & 264 & 311 & 0 & 445 & 5086 & 1284 & 369 & 121 & 0.67 & 0 \\
\hline 27 & 7305 & 131 & 43 & 23 & 1 & 3.0 & 873 & 8 & 46039 & 12664 & 0.0076 & 0.9821 & 0.3282 & 2.4 & 295 & 351 & 0 & 468 & 5156 & 1197 & 357 & 127 & 0.69 & 0 \\
\hline 41 & 7305 & 133 & 46 & 17 & 1 & 2.9 & 909 & 0 & 41665 & 10845 & 0.0075 & 0.9818 & 0.3459 & 3.2 & 236 & 313 & 0 & 468 & 5075 & 1240 & 403 & 119 & 0.67 & 0 \\
\hline 87 & 7305 & 134 & 36 & 19 & 1 & 3.7 & 887 & 2 & 47245 & 9947 & 0.0075 & 0.9817 & 0.2687 & 2.9 & 276 & 353 & 0 & 486 & 5039 & 1262 & 396 & 122 & 0.75 & 0 \\
\hline 38 & $\begin{array}{l}7305 \\
7305\end{array}$ & $\begin{array}{l}136 \\
141\end{array}$ & $\begin{array}{l}44 \\
44\end{array}$ & 11 & 1 & 3.1 & 898 & 3 & 40341 & 12764 & 0.0074 & 0.9814 & 0.3235 & 4.9 & 290 & 297 & 0 & 489 & 4967 & 1282 & 442 & 125 & 0.69 & 0 \\
\hline $\begin{array}{c}4 \\
66\end{array}$ & $\begin{array}{l}7305 \\
7305\end{array}$ & $\begin{array}{l}141 \\
142\end{array}$ & $\begin{array}{l}44 \\
53\end{array}$ & $\begin{array}{l}28 \\
19\end{array}$ & $\begin{array}{l}1 \\
1\end{array}$ & $\begin{array}{l}3.2 \\
2.2\end{array}$ & $\begin{array}{l}876 \\
858\end{array}$ & $\begin{array}{l}1 \\
0 \\
0\end{array}$ & $\begin{array}{l}34004 \\
42830\end{array}$ & $\begin{array}{l}11374 \\
13479\end{array}$ & $\begin{array}{l}0.0071 \\
0.0070\end{array}$ & $\begin{array}{l}0.9807 \\
0.9806\end{array}$ & $\begin{array}{l}0.3121 \\
0.3732\end{array}$ & $\begin{array}{l}1.9 \\
2.7\end{array}$ & $\begin{array}{l}258 \\
254\end{array}$ & 241 & 0 & $\begin{array}{l}478 \\
472\end{array}$ & $\begin{array}{l}5100 \\
502\end{array}$ & $\begin{array}{l}1201 \\
1212\end{array}$ & $\begin{array}{l}400 \\
444\end{array}$ & 126 & 0.69 & 0 \\
\hline $\begin{array}{l}66 \\
62\end{array}$ & $\begin{array}{l}7305 \\
7305\end{array}$ & $\begin{array}{l}142 \\
142\end{array}$ & $\begin{array}{l}53 \\
40\end{array}$ & $\begin{array}{l}19 \\
13\end{array}$ & $\begin{array}{l}1 \\
1\end{array}$ & $\begin{array}{l}2.7 \\
3.6\end{array}$ & $\begin{array}{l}858 \\
876\end{array}$ & $\begin{array}{l}0 \\
4\end{array}$ & $\begin{array}{l}42830 \\
46234\end{array}$ & $\begin{array}{l}13479 \\
13096\end{array}$ & $\begin{array}{l}0.0070 \\
0.0070\end{array}$ & $\begin{array}{l}0.9806 \\
0.9806\end{array}$ & $\begin{array}{l}0.3732 \\
0.2817\end{array}$ & $\begin{array}{l}2.7 \\
4.0\end{array}$ & $\begin{array}{l}254 \\
327\end{array}$ & $\begin{array}{l}302 \\
326\end{array}$ & $\begin{array}{l}0 \\
0\end{array}$ & $\begin{array}{l}472 \\
484\end{array}$ & $\begin{array}{l}5042 \\
4920\end{array}$ & $\begin{array}{l}1212 \\
1303\end{array}$ & $\begin{array}{l}444 \\
472\end{array}$ & $\begin{array}{l}135 \\
126\end{array}$ & $\begin{array}{l}0.64 \\
0.73\end{array}$ & $\begin{array}{l}0 \\
0\end{array}$ \\
\hline 11 & 7305 & 146 & 46 & 16 & 1 & 3.2 & 875 & 1 & 43336 & 13682 & 0.0068 & 0.9800 & 0.3151 & 3.1 & 297 & 297 & 0 & 499 & 5031 & 1276 & 366 & 133 & 0.70 & 0 \\
\hline 42 & 7305 & 146 & 49 & 14 & 1 & 3.0 & 878 & 0 & 48130 & 14044 & 0.0068 & 0.9800 & 0.3356 & 3.6 & 287 & 330 & 0 & 482 & 4955 & 1273 & 461 & 134 & 0.68 & 0 \\
\hline 36 & 7305 & 148 & 40 & 24 & 1 & 3.7 & 870 & 0 & 40508 & 10973 & 0.0068 & 0.9797 & 0.2703 & 2.1 & 274 & 274 & 0 & 456 & 4999 & 1316 & 397 & 137 & 0.74 & 0 \\
\hline 2 & 7305 & $\begin{array}{l}149 \\
150\end{array}$ & 49 & 26 & 1 & 3.0 & 868 & 3 & $\begin{array}{l}41552 \\
35387\end{array}$ & 11625 & 0.0067 & 0.9796 & 0.3289 & 1.9 & 237 & 279 & 0 & 488 & 5026 & 1281 & 380 & 130 & 0.68 & 0 \\
\hline $\begin{array}{l}40 \\
84\end{array}$ & $\begin{array}{l}7305 \\
7305\end{array}$ & $\begin{array}{l}150 \\
150\end{array}$ & $\begin{array}{l}45 \\
59\end{array}$ & $\begin{array}{l}18 \\
11\end{array}$ & $\begin{array}{l}1 \\
1\end{array}$ & $\begin{array}{l}3.3 \\
2.5\end{array}$ & $\begin{array}{l}508 \\
881\end{array}$ & $\begin{array}{l}3 \\
0\end{array}$ & $\begin{array}{l}35387 \\
39844\end{array}$ & $\begin{array}{l}9978 \\
14605\end{array}$ & $\begin{array}{l}0.0067 \\
0.0067\end{array}$ & $\begin{array}{l}0.9795 \\
0.9795\end{array}$ & $\begin{array}{l}0.3000 \\
0.3933\end{array}$ & $\begin{array}{l}2.7 \\
4.4\end{array}$ & $\begin{array}{l}222 \\
248\end{array}$ & $\begin{array}{l}236 \\
266 \\
266\end{array}$ & $\begin{array}{l}0 \\
0\end{array}$ & $\begin{array}{l}462 \\
462\end{array}$ & $\begin{array}{l}5127 \\
587\end{array}$ & $\begin{array}{l}1205 \\
1206\end{array}$ & $\begin{array}{l}371 \\
411\end{array}$ & $\begin{array}{l}140 \\
139\end{array}$ & $\begin{array}{l}0.71 \\
0.62\end{array}$ & $\begin{array}{l}0 \\
0\end{array}$ \\
\hline $\begin{array}{c}84 \\
1\end{array}$ & $\begin{array}{l}3305 \\
7305\end{array}$ & $\begin{array}{l}150 \\
150\end{array}$ & $\begin{array}{l}59 \\
37\end{array}$ & $\begin{array}{l}11 \\
27\end{array}$ & $\begin{array}{l}1 \\
1\end{array}$ & $\begin{array}{l}2.5 \\
4.1\end{array}$ & $\begin{array}{l}881 \\
1113\end{array}$ & $\begin{array}{l}0 \\
3\end{array}$ & $\begin{array}{l}398444 \\
60948\end{array}$ & $\begin{array}{l}14605 \\
10639\end{array}$ & $\begin{array}{l}0.0067 \\
0.0067\end{array}$ & $\begin{array}{l}0.9795 \\
0.9795\end{array}$ & $\begin{array}{l}0.3933 \\
0.2467\end{array}$ & $\begin{array}{l}4.4 \\
1.8\end{array}$ & $\begin{array}{l}248 \\
288\end{array}$ & $\begin{array}{l}266 \\
406\end{array}$ & $\begin{array}{l}0 \\
0\end{array}$ & $\begin{array}{l}462 \\
451\end{array}$ & $\begin{array}{l}5087 \\
5097\end{array}$ & $\begin{array}{l}1206 \\
1240\end{array}$ & $\begin{array}{l}411 \\
378\end{array}$ & $\begin{array}{l}139 \\
139\end{array}$ & $\begin{array}{l}0.62 \\
0.77\end{array}$ & $\begin{array}{l}0 \\
0 \\
0\end{array}$ \\
\hline 74 & 7305 & 151 & 49 & 14 & 1 & 3.1 & 872 & 2 & 44290 & 13712 & 0.0066 & 0.9793 & 0.3245 & $\begin{array}{l}3.0 \\
3.5\end{array}$ & $\begin{array}{l}200 \\
280\end{array}$ & 293 & 0 & 465 & $\begin{array}{l}5104 \\
5104\end{array}$ & 1218 & 374 & 144 & $\begin{array}{l}0.69 \\
0.69\end{array}$ & $\begin{array}{l}0 \\
0\end{array}$ \\
\hline 55 & 7305 & 151 & 53 & 14 & 1 & 2.8 & 919 & 1 & 48142 & 14311 & 0.0066 & 0.9793 & 0.3510 & 3.5 & 270 & 319 & 0 & 400 & 4983 & $\begin{array}{l}1238 \\
1238\end{array}$ & 462 & 134 & 0.66 & 0 \\
\hline 72 & 7305 & 151 & 48 & 21 & 1 & 3.1 & 868 & 0 & 52132 & 12620 & 0.0066 & 0.9793 & 0.3179 & 2.3 & 263 & 34 & 0 & 493 & 5014 & 1261 & 396 & 141 & 0.70 & \\
\hline 81 & 7305 & 154 & 56 & 10 & 1 & 2.8 & 871 & 3 & 39165 & 15322 & 0.0065 & 0.9789 & 0.3636 & 4.7 & 274 & 254 & & & & & & 137 & & \\
\hline 69 & 7305 & 155 & 48 & 22 & 1 & 3.2 & 868 & 3 & 46598 & 14630 & 0.0065 & 0.9788 & 0.3097 & 2.1 & 305 & 301 & 0 & 476 & 5111 & 1190 & 384 & 144 & 0.70 & 0 \\
\hline 14 & 7305 & 155 & 45 & 20 & 1 & 3.4 & 874 & 1 & 51262 & 11928 & 0.0065 & 0.9788 & 0.2903 & 2.4 & 265 & 331 & 0 & 451 & 5021 & 1241 & 447 & 145 & 0.72 & 0 \\
\hline 92 & 7305 & 157 & 35 & 19 & 1 & 4.5 & 873 & 2 & 51632 & 9355 & 0.0064 & 0.9785 & 0.2229 & 2.4 & 267 & 329 & 0 & 448 & 5093 & 1288 & 329 & 147 & 0.79 & 0 \\
\hline 78 & 7305 & 158 & 40 & 21 & 1 & 4.0 & 874 & 0 & 48071 & 12607 & 0.0063 & 0.9784 & 0.2532 & 2.2 & 315 & 304 & 0 & 497 & 5013 & 1277 & 378 & 140 & 0.76 & 0 \\
\hline 73 & 7305 & 159 & 48 & 13 & 1 & 3.3 & 870 & 6 & 51599 & 13748 & 0.0063 & 0.9782 & & 3.5 & 286 & 325 & 0 & 463 & 5060 & 1279 & 356 & 147 & 0.71 & 0 \\
\hline 86 & 7305 & 159 & 42 & 22 & 1 & 3.8 & 873 & 7 & 54352 & $\begin{array}{l}13470 \\
11105\end{array}$ & 0.0063 & 0.9782 & & 2.1 & 321 & 342 & 0 & 481 & 5091 & & 409 & 150 & 0.75 & 0 \\
\hline 17 & $\begin{array}{l}7305 \\
7305\end{array}$ & 160 & 48 & 14 & 1 & 3.3 & 869 & 0 & $\begin{array}{l}42496 \\
42697\end{array}$ & $\begin{array}{l}11625 \\
14127\end{array}$ & 0.0063 & 0.9781 & $\begin{array}{l}0.3000 \\
0.3188\end{array}$ & $\begin{array}{l}3.3 \\
17\end{array}$ & $\begin{array}{l}242 \\
277\end{array}$ & 266 & 0 & 489 & 5028 & 1266 & 379 & 143 & 0.71 & 0 \\
\hline $\begin{array}{l}76 \\
58\end{array}$ & $\begin{array}{l}7305 \\
7705\end{array}$ & $\begin{array}{l}160 \\
162\end{array}$ & $\begin{array}{l}51 \\
50\end{array}$ & $\begin{array}{l}27 \\
40\end{array}$ & 1 & $\begin{array}{l}3.1 \\
3 .\end{array}$ & $\begin{array}{l}853 \\
876\end{array}$ & 3 & $\begin{array}{l}42697 \\
46947\end{array}$ & $\begin{array}{l}14127 \\
12847\end{array}$ & $\begin{array}{l}0.0063 \\
0.0062\end{array}$ & $\begin{array}{l}0.9781 \\
0.9778\end{array}$ & $\begin{array}{l}0.3188 \\
0.3086\end{array}$ & 1.7 & $\begin{array}{l}277 \\
257\end{array}$ & 267 & $\begin{array}{l}0 \\
0\end{array}$ & $\begin{array}{l}471 \\
470\end{array}$ & $\begin{array}{l}5110 \\
501\end{array}$ & $\begin{array}{l}1190 \\
136\end{array}$ & $\begin{array}{l}386 \\
355 \\
355\end{array}$ & $\begin{array}{l}148 \\
153\end{array}$ & 0.69 & 0 \\
\hline $\begin{array}{l}58 \\
50\end{array}$ & $\begin{array}{l}7305 \\
7305\end{array}$ & $\begin{array}{l}162 \\
163\end{array}$ & $\begin{array}{l}50 \\
47\end{array}$ & $\begin{array}{l}40 \\
38\end{array}$ & $\begin{array}{l}1 \\
1\end{array}$ & $\begin{array}{l}3.2 \\
3.5\end{array}$ & $\begin{array}{l}876 \\
906\end{array}$ & $\begin{array}{l}2 \\
1\end{array}$ & $\begin{array}{l}\begin{array}{r}469477 \\
57888\end{array}\end{array}$ & $\begin{array}{l}\begin{array}{l}22887 \\
11904\end{array} \\
1\end{array}$ & $\begin{array}{l}0.0062 \\
0.0061\end{array}$ & $\begin{array}{l}0.9778 \\
0.9777\end{array}$ & $\begin{array}{l}0.3086 \\
0.2883\end{array}$ & $\begin{array}{l}1.1 \\
1.2\end{array}$ & $\begin{array}{l}257 \\
253 \\
253\end{array}$ & $\begin{array}{l}290 \\
355\end{array}$ & $\begin{array}{l}0 \\
0\end{array}$ & $\begin{array}{l}470 \\
491\end{array}$ & $\begin{array}{l}5091 \\
4989\end{array}$ & $\begin{array}{l}1236 \\
1232\end{array}$ & $\begin{array}{l}355 \\
444\end{array}$ & $\begin{array}{l}153 \\
149\end{array}$ & $\begin{array}{l}0.70 \\
0.73\end{array}$ & $\begin{array}{l}0 \\
0 \\
0\end{array}$ \\
\hline 71 & 7305 & 164 & 55 & 13 & 1 & 3.0 & 870 & 0 & 46478 & 14507 & 0.0061 & 0.9775 & 0.3354 & $\begin{array}{l}3.4 \\
3.4\end{array}$ & 264 & 283 & 0 & 477 & 4989 & 1269 & 422 & 148 & 0.67 & 0 \\
\hline 93 & 7305 & 164 & 47 & 34 & 1 & 3.5 & 891 & 6 & 53192 & 14882 & 0.0061 & 0.9775 & 0.2866 & 3 & 317 & 324 & 0 & 504 & 4996 & 1250 & 401 & 154 & 0.73 & 0 \\
\hline 88 & & 165 & 53 & ק & 1 & 3.1 & 07 & 1 & & & & 0.9774 & 0.3212 & 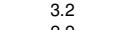 & & & 0 & 177 & & & 435 & 150 & & 0 \\
\hline 88 & $\begin{array}{l}7305 \\
7305\end{array}$ & 165 & $\begin{array}{l}45 \\
51\end{array}$ & 20 & 1 & 3.7 & 872 & 0 & $\begin{array}{l}45992 \\
556625\end{array}$ & 11493 & 0.0061 & 0.9774 & 0.2727 & 18 & $\begin{array}{l}255 \\
253\end{array}$ & 305 & 0 & 470 & 5128 & & 361 & 155 & 0.74 & 0 \\
\hline $\begin{array}{l}90 \\
18\end{array}$ & $\begin{array}{l}7305 \\
7305\end{array}$ & $\begin{array}{l}166 \\
167\end{array}$ & $\begin{array}{l}51 \\
46\end{array}$ & $\begin{array}{l}24 \\
17\end{array}$ & $\begin{array}{l}1 \\
1\end{array}$ & $\begin{array}{l}3.3 \\
3.6\end{array}$ & $\begin{array}{l}873 \\
900\end{array}$ & $\begin{array}{l}2 \\
3 \\
3\end{array}$ & $\begin{array}{l}50625 \\
45863\end{array}$ & $\begin{array}{l}12896 \\
12823\end{array}$ & $\begin{array}{l}0.0060 \\
0.0060\end{array}$ & $\begin{array}{l}0.9773 \\
0.9771\end{array}$ & $\begin{array}{l}0.3072 \\
0.2754\end{array}$ & $\begin{array}{l}1.8 \\
2.6\end{array}$ & 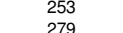 & $\begin{array}{l}305 \\
275\end{array}$ & $\begin{array}{l}0 \\
0\end{array}$ & $\begin{array}{l}470 \\
493\end{array}$ & $\begin{array}{l}5051 \\
4984\end{array}$ & $\begin{array}{l}1251 \\
1233\end{array}$ & $\begin{array}{l}386 \\
444\end{array}$ & $\begin{array}{l}147 \\
151\end{array}$ & $\begin{array}{l}0.70 \\
0.73\end{array}$ & $\begin{array}{l}0 \\
0 \\
0\end{array}$ \\
\hline $\begin{array}{l}18 \\
91\end{array}$ & $\begin{array}{l}3305 \\
7305\end{array}$ & $\begin{array}{l}16 \% \\
167\end{array}$ & $\begin{array}{l}46 \\
52\end{array}$ & $\begin{array}{l}11 \\
18\end{array}$ & $\begin{array}{l}1 \\
1\end{array}$ & $\begin{array}{l}3.6 \\
3.2\end{array}$ & $\begin{array}{l}900 \\
875\end{array}$ & $\begin{array}{l}3 \\
0\end{array}$ & $\begin{array}{l}45863 \\
52155\end{array}$ & $\begin{array}{l}18283 \\
16381\end{array}$ & $\begin{array}{l}0.0060 \\
0.0060\end{array}$ & $\begin{array}{l}0.9771 \\
0.9771\end{array}$ & $\begin{array}{l}0.2754 \\
0.3114\end{array}$ & $\begin{array}{l}2.6 \\
2.4\end{array}$ & $\begin{array}{l}279 \\
315\end{array}$ & $\begin{array}{l}275 \\
312\end{array}$ & $\begin{array}{l}0 \\
0\end{array}$ & $\begin{array}{l}493 \\
484\end{array}$ & $\begin{array}{l}4984 \\
5036\end{array}$ & $\begin{array}{l}1233 \\
1258\end{array}$ & $\begin{array}{l}444 \\
374\end{array}$ & $\begin{array}{l}151 \\
153\end{array}$ & $\begin{array}{l}0.73 \\
0.70\end{array}$ & $\begin{array}{l}0 \\
0 \\
0\end{array}$ \\
\hline 51 & 7305 & 167 & 46 & 39 & 1 & 3.6 & 875 & 0 & 56476 & 12521 & 0.0060 & 0.9771 & 0.2754 & $\begin{array}{l}2.4 \\
1.1\end{array}$ & 272 & 338 & 0 & 475 & & 1450 & & 151 & & 0 \\
\hline 48 & 7305 & 16 & 51 & 19 & 1 & 3.3 & 874 & 0 & 50880 & 9 & 59 & 0.9 & 0.3 & 3 & 244 & 30 & 0 & & & & & & & \\
\hline 7 & 7305 & 170 & 53 & 30 & 1 & 3.2 & 866 & 1 & 46285 & 15095 & 0.0059 & 0.9767 & 0.3 & 1.4 & 28 & 27 & 0 & 47 & & 125 & 407 & 153 & 0.70 & \\
\hline 64 & 7305 & 170 & 55 & 17 & 1 & 3.1 & 926 & 1 & 51209 & 13733 & 0.00 & 0.9 & & 25 & 25 & & 0 & & & & & & & \\
\hline & 7305 & & 46 & 23 & 1 & 3.7 & 872 & 3 & 57495 & 13851 & 0.0059 & 0.9767 & 0.2706 & 1.9 & 30 & 33 & 0 & 480 & & 9 & 35 & 16 & 0.74 & 0 \\
\hline os & 7305 & 171 & 55 & 30 & 1 & 3.1 & 883 & 2 & 49984 & 13822 & 0.0058 & 0.9766 & 0.3216 & 1.4 & 251 & 292 & 0 & 466 & 5060 & 1209 & 413 & 157 & 0.69 & 0 \\
\hline 43 & 730 & 171 & 54 & 25 & 1 & 3.2 & 87 & 0 & 54790 & 15231 & 8 & 0.9 & & 1.7 & 282 & 32 & 0 & 474 & & 1225 & 431 & 154 & 0.70 & 0 \\
\hline 52 & 7305 & 172 & 57 & 27 & 1 & 3.0 & 88 & 5 & 55 & 15539 & 0.0 & & & 6 & 27 & & 0 & 485 & & 3 & 43 & $15 /$ & & 0 \\
\hline 22 & 730 & 173 & 39 & 39 & 1 & 4.4 & & 2 & 63 & & & & & & & & 0 & 4 & & & 30 & 165 & 9 & 0 \\
\hline 83 & $\begin{array}{l}7305 \\
7305\end{array}$ & 174 & 49 & 28 & 1 & 3.5 & 892 & 1 & $\begin{array}{l}55729 \\
57382\end{array}$ & 16285 & 0.0057 & 0.9762 & 0.2874 & 2.1 & 6 & 32 & 0 & 450 & & 1284 & 381 & 164 & 2 & 0 \\
\hline 24 & $\begin{array}{l}7305 \\
7305\end{array}$ & $\begin{array}{l}174 \\
175\end{array}$ & $\begin{array}{l}49 \\
45\end{array}$ & 28 & 1 & $\begin{array}{l}3.6 \\
3.9\end{array}$ & $\begin{array}{l}876 \\
875\end{array}$ & 5 & 57382 & $\begin{array}{l}12435 \\
14122\end{array}$ & 0.0057 & 0.9762 & 0.2816 & $\begin{array}{l}1.5 \\
1.5\end{array}$ & $\begin{array}{l}254 \\
314\end{array}$ & $\begin{array}{l}33 \\
33 \\
35\end{array}$ & $\begin{array}{l}0 \\
0\end{array}$ & $\begin{array}{l}453 \\
469\end{array}$ & & $\begin{array}{l}1215 \\
159\end{array}$ & 3 & 160 & 3 & 0 \\
\hline $\begin{array}{l}34 \\
67\end{array}$ & $\begin{array}{l}305 \\
7305\end{array}$ & $\begin{array}{l}1 / 5 \\
175\end{array}$ & $\begin{array}{l}45 \\
50\end{array}$ & $\begin{array}{l}27 \\
21\end{array}$ & $\begin{array}{l}1 \\
1\end{array}$ & $\begin{array}{l}3.9 \\
3.5\end{array}$ & $\begin{array}{l}875 \\
874\end{array}$ & $\begin{array}{l}7 \\
5\end{array}$ & $\begin{array}{l}61420 \\
64121\end{array}$ & $\begin{array}{l}14122 \\
15453\end{array}$ & $\begin{array}{l}0.0057 \\
0.0057\end{array}$ & $\begin{array}{l}0.9760 \\
0.9760\end{array}$ & $\begin{array}{l}0.2571 \\
0.2857\end{array}$ & $\begin{array}{l}1.5 \\
2.0\end{array}$ & $\begin{array}{l}314 \\
309\end{array}$ & $\begin{array}{l}351 \\
366 \\
366\end{array}$ & $\begin{array}{l}0 \\
0\end{array}$ & $\begin{array}{l}469 \\
489\end{array}$ & $\begin{array}{l}5015 \\
5034\end{array}$ & $\begin{array}{l}1259 \\
1182\end{array}$ & $\begin{array}{l}393 \\
432\end{array}$ & $\begin{array}{l}169 \\
168\end{array}$ & $\begin{array}{l}0.76 \\
0.73\end{array}$ & 0 \\
\hline $\begin{array}{l}67 \\
47\end{array}$ & $\begin{array}{l}7305 \\
7305\end{array}$ & $\begin{array}{l}175 \\
176\end{array}$ & $\begin{array}{l}50 \\
38\end{array}$ & $\begin{array}{l}21 \\
17\end{array}$ & 1 & $\begin{array}{l}3.5 \\
4.6\end{array}$ & $\begin{array}{l}81 \\
89 \\
\end{array}$ & $\begin{array}{l}5 \\
1\end{array}$ & $\begin{array}{l}64121 \\
50454\end{array}$ & $\begin{array}{l}\text { 年 } \\
130543\end{array}$ & $\begin{array}{l}0.0055 \\
0.0057\end{array}$ & 0.9 & 9 & $\begin{array}{l}2.0 \\
2.4\end{array}$ & $\begin{array}{l}309 \\
344\end{array}$ & $\begin{array}{l}366 \\
287\end{array}$ & 0 & $\begin{array}{l}489 \\
479\end{array}$ & & $\begin{array}{l}182 \\
1230\end{array}$ & 45 & $\begin{array}{l}168 \\
166\end{array}$ & 0. & 0 \\
\hline 59 & 73 & 17 & 55 & 18 & 1 & 3.2 & 87 & 2 & 52 & & 0.0 & & & 2.3 & 29 & 29 & 0 & 454 & & & 392 & 6 & 0.10 & 0 \\
\hline 23 & 7305 & 177 & 44 & 29 & 1 & 4.0 & (1) & 1 & 54654 & 12873 & & 0.9758 & & 1.4 & & & 0 & 4 & & & 7 & 165 & & \\
\hline 79 & $\begin{array}{l}7305 \\
7305\end{array}$ & $\begin{array}{l}178 \\
178\end{array}$ & $\begin{array}{l}52 \\
55\end{array}$ & 12 & 1 & 3.4 & 871 & 1 & 53984 & $\begin{array}{l}15190 \\
15701\end{array}$ & 0.0056 & 0.9756 & 0.2921 & 3.4 & 285 & 30 & 0 & 464 & 51 & 0 & 402 & 164 & 2 & \\
\hline $\begin{array}{l}6 \\
9\end{array}$ & $\begin{array}{l}7305 \\
7305\end{array}$ & $\begin{array}{l}178 \\
179\end{array}$ & 55 & $\begin{array}{l}16 \\
11\end{array}$ & 1 & 3.2 & $\begin{array}{l}876 \\
871\end{array}$ & $\begin{array}{l}4 \\
7\end{array}$ & 54989 & $\begin{array}{l}15701 \\
1890\end{array}$ & 0.0056 & $\begin{array}{l}0.9756 \\
0756\end{array}$ & 0.3090 & $\begin{array}{l}2.6 \\
3.34\end{array}$ & $\begin{array}{l}285 \\
298\end{array}$ & $\begin{array}{l}309 \\
302\end{array}$ & 0 & $\begin{array}{l}468 \\
465\end{array}$ & 51 & $\begin{array}{l}1153 \\
103\end{array}$ & $\begin{array}{l}374 \\
370\end{array}$ & 166 & 0.70 & \\
\hline 13 & $\begin{array}{l}3305 \\
7305\end{array}$ & $\begin{array}{l}1 / 9 \\
180\end{array}$ & $\begin{array}{l}62 \\
48\end{array}$ & $\begin{array}{l}12 \\
17\end{array}$ & $\begin{array}{l}1 \\
1\end{array}$ & $\begin{array}{l}2.9 \\
3.8\end{array}$ & $\begin{array}{l}8 / 1 \\
959\end{array}$ & 1 & $\begin{array}{l}54106 \\
55871\end{array}$ & $\begin{array}{l}18440 \\
15666\end{array}$ & $\begin{array}{l}0.0056 \\
0.0056\end{array}$ & $\begin{array}{l}0.9955 \\
0.9754\end{array}$ & $\begin{array}{l}0.3464 \\
0.2667\end{array}$ & $\begin{array}{l}3.4 \\
2.4\end{array}$ & $\begin{array}{l}298 \\
326\end{array}$ & $\begin{array}{l}302 \\
310\end{array}$ & $\begin{array}{l}0 \\
0\end{array}$ & $\begin{array}{l}485 \\
487\end{array}$ & $\begin{array}{l}5067 \\
5057\end{array}$ & $\begin{array}{l}1203 \\
1158\end{array}$ & $\begin{array}{l}380 \\
436\end{array}$ & $\begin{array}{l}170 \\
167\end{array}$ & $\begin{array}{l}0.67 \\
0.74\end{array}$ & \\
\hline 60 & 73 & $\begin{array}{l}180 \\
180\end{array}$ & $\begin{array}{l}48 \\
51\end{array}$ & 38 & 1 & $\begin{array}{l}3.8 \\
3.5\end{array}$ & $\begin{array}{l}959 \\
873\end{array}$ & 3 & $\begin{array}{l}53871 \\
61564\end{array}$ & 12 & $\begin{array}{l}0.00056 \\
0.0056\end{array}$ & 0.9 & 0.8 & 1.1 & 23 & $\begin{array}{l}310 \\
342\end{array}$ & 0 & $4 \mathrm{~s}$ & & & & 168 & $\begin{array}{l}0.14 \\
0.73\end{array}$ & \\
\hline 15 & 7305 & 181 & 50 & 22 & 1 & 3.6 & 879 & 1 & 60495 & 13955 & 0.0055 & 0.9752 & 0.2762 & 1.8 & 27 & 33 & 0 & 470 & & & & & 0.14 & \\
\hline 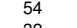 & 7305 & 182 & 47 & 30 & 1 & 3.9 & 869 & 4 & 56596 & 14412 & 0.0055 & 0.9751 & 0.2582 & 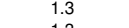 & 77 & תח & 0 & 481 & 5110 & & 371 & 72 & 0.75 & \\
\hline & & & & & & & & & & & 0.0055 & 0.9749 & & & & & & & 5053 & 1221 & 387 & 173 & & \\
\hline
\end{tabular}




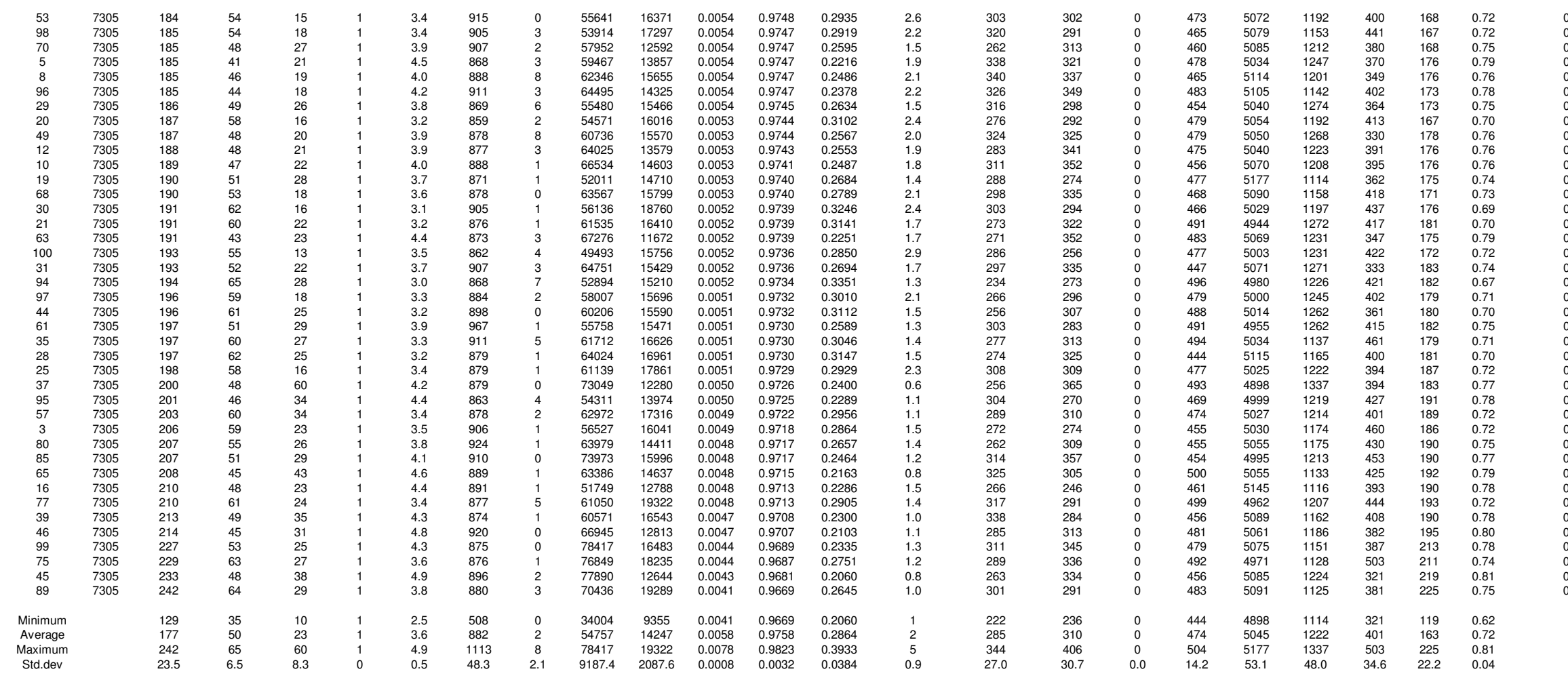


Scenerio NScenario 13 CSIROMk2b B11 with 5\% additional WEMPs savings
Date: $13 / 10 / 2007$

Simulation 1:44:15 PM

$\begin{array}{lr}\text { Simulation } & \text { 2:21:39 PM } \\ \text { Elapsed Til } & 37.4 \text { Minutes }\end{array}$

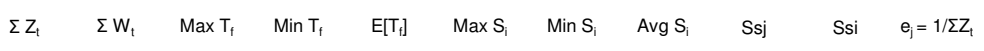

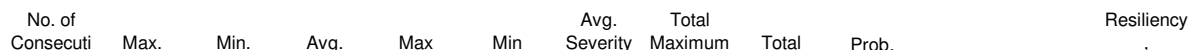

\begin{tabular}{|c|c|c|c|c|c|c|c|c|c|c|c|c|c|c|c|c|c|c|c|c|c|c|c|c|}
\hline Trial No. & $\begin{array}{l}\text { Total no. of } \\
\text { Days }\end{array}$ & $\begin{array}{l}\text { No. of } \\
\text { Days } \\
\text { Failed }\end{array}$ & $\begin{array}{l}\text { Consecuti } \\
\text { ve } \\
\text { Failures }\end{array}$ & $\begin{array}{l}\text { Max. } \\
\text { Failure } \\
\text { Duration }\end{array}$ & $\begin{array}{l}\text { Min. } \\
\text { Failure } \\
\text { Duration }\end{array}$ & $\begin{array}{l}\text { Avg. } \\
\text { Failure } \\
\text { Duration }\end{array}$ & $\begin{array}{c}\text { Max } \\
\text { Severity } \\
\text { of Failure }\end{array}$ & $\begin{array}{l}\text { Min } \\
\text { Severity } \\
\text { of Failure }\end{array}$ & $\begin{array}{l}\text { Severity } \\
\text { of a } \\
\text { Failure }\end{array}$ & $\begin{array}{l}\text { Maximum } \\
\text { Severity } \\
\text { of Sojourn }\end{array}$ & $\begin{array}{c}\text { Total } \\
\text { Severity } \\
\text { of Failure }\end{array}$ & $\begin{array}{l}\text { Prob. } \\
\text { [Correspo } \\
\left.\text { nd to } \mathrm{S}_{j}\right]\end{array}$ & $\begin{array}{l}\text { Reliability, } \\
\alpha\end{array}$ & $\begin{array}{c}\text { Resiliency } \\
, F\left(E\left[T_{f}\right]\right)\end{array}$ & $\underset{{ }^{* \mathrm{NF})}}{1 / \mathrm{MD} / \mathrm{NS}}$ & $\begin{array}{l}\text { S Vulnerabili } \\
\text { ty } 1\end{array}$ & $\begin{array}{l}\text { Vulnerabili } \\
\text { ty } 2\end{array}$ & $0-500$ & $501-1000$ & $\begin{array}{l}1001- \\
1500\end{array}$ & $\begin{array}{l}1501- \\
2000\end{array}$ & $\begin{array}{l}2001- \\
2500\end{array}$ & $>2500$ & $\begin{array}{l}\text { Eculidean } \\
\text { Distance }\end{array}$ \\
\hline 40 & 7305 & 148 & 50 & 16 & 1 & 3.0 & 606 & 1 & 220 & 11217 & 32582 & 0.0068 & 0.9797 & 0.3378 & 3 & 224 & 220 & 0 & 517 & 5012 & 1254 & 392 & 130 & 0.6683 \\
\hline 4 & 7305 & 134 & 46 & 23 & 1 & 2.9 & 868 & 1 & 252 & 11997 & 33824 & 0.0075 & 0.9817 & 0.3433 & 2 & 261 & 252 & 0 & 540 & 5026 & 1204 & 413 & 122 & 0.6647 \\
\hline 7 & 7305 & 160 & 51 & 33 & 1 & 3.1 & 764 & 1 & 250 & 12427 & 40010 & 0.0063 & 0.9781 & 0.3188 & 1 & 244 & 250 & 0 & 516 & 4978 & 1234 & 433 & 144 & 0.6889 \\
\hline 2 & 7305 & 152 & 56 & 18 & 1 & 2.7 & 857 & 1 & 266 & 13071 & 40373 & 0.0066 & 0.9792 & 0.3684 & 3 & 233 & 266 & 0 & 542 & 4986 & 1197 & 443 & 137 & 0.6408 \\
\hline 38 & 7305 & 149 & 47 & 12 & 1 & 3.2 & 866 & 1 & 280 & 13207 & 41743 & 0.0067 & 0.9796 & 0.3154 & 4 & 281 & 280 & 0 & 541 & 4952 & 1229 & 449 & 134 & 0.6940 \\
\hline 76 & 7305 & 175 & 58 & 13 & 1 & 3.0 & 861 & 2 & 245 & 15982 & 42913 & 0.0057 & 0.9760 & 0.3314 & 3 & 276 & 245 & 0 & 527 & 5025 & 1187 & 412 & 154 & 0.6762 \\
\hline 81 & 7305 & 172 & 57 & 17 & 1 & 3.0 & 859 & 1 & 255 & 16456 & 43818 & 0.0058 & 0.9765 & 0.3314 & 2 & 289 & 255 & 0 & 521 & 5011 & 1177 & 440 & 156 & 0.6767 \\
\hline 84 & 7305 & 168 & 55 & 20 & 1 & 3.1 & 864 & 1 & 263 & 14815 & 44109 & 0.0060 & 0.9770 & 0.3274 & 2 & 269 & 263 & 0 & 514 & 4996 & 1180 & 461 & 154 & 0.6812 \\
\hline 26 & 7305 & 185 & 51 & 21 & 1 & 3.6 & 856 & 1 & 248 & 12979 & 45818 & 0.0054 & 0.9747 & 0.2757 & 2 & 254 & 248 & 0 & 522 & 4993 & 1186 & 441 & 163 & 0.7315 \\
\hline 41 & 7305 & 141 & 47 & 17 & 1 & 3.0 & 893 & 1 & 328 & 13448 & 46220 & 0.0071 & 0.9807 & 0.3333 & 3 & 286 & 328 & 0 & 525 & 4994 & 1280 & 378 & 128 & 0.6797 \\
\hline 16 & 7305 & 172 & 48 & 16 & 1 & 3.6 & 902 & 0 & 269 & 12720 & 46263 & 0.0058 & 0.9765 & 0.2791 & 3 & 265 & 269 & 0 & 516 & 4990 & 1228 & 411 & 160 & 0.7293 \\
\hline 58 & 7305 & $\begin{array}{l}176 \\
172\end{array}$ & $\begin{array}{l}57 \\
57\end{array}$ & 31 & 1 & 3.1 & 855 & 5 & 267 & 14415 & 46994 & 0.0057 & 0.9759 & 0.3239 & 1 & 253 & 267 & 0 & 527 & 4987 & 1234 & 390 & 167 & 0.6849 \\
\hline 17 & $\begin{array}{l}7305 \\
7305\end{array}$ & $\begin{array}{l}172 \\
169\end{array}$ & $\begin{array}{l}57 \\
64\end{array}$ & $\begin{array}{l}14 \\
18\end{array}$ & $\begin{array}{l}1 \\
1\end{array}$ & $\begin{array}{l}3.0 \\
26\end{array}$ & $\begin{array}{l}866 \\
863 \\
863\end{array}$ & $\begin{array}{l}0 \\
2\end{array}$ & $\begin{array}{l}273 \\
279\end{array}$ & $\begin{array}{l}16228 \\
15110\end{array}$ & $\begin{array}{l}47030 \\
47152\end{array}$ & $\begin{array}{l}0.0058 \\
0.0059\end{array}$ & $\begin{array}{l}0.9765 \\
0.9669\end{array}$ & $\begin{array}{l}0.3314 \\
0.3787\end{array}$ & $\begin{array}{l}3 \\
2\end{array}$ & $\begin{array}{l}285 \\
236\end{array}$ & $\begin{array}{l}273 \\
279\end{array}$ & $\begin{array}{l}0 \\
0\end{array}$ & $\begin{array}{l}539 \\
547\end{array}$ & $\begin{array}{l}4973 \\
4951\end{array}$ & $\begin{array}{l}1206 \\
1194\end{array}$ & 436 & $\begin{array}{l}151 \\
151\end{array}$ & 0.6779 \\
\hline $\begin{array}{l}72 \\
18\end{array}$ & $\begin{array}{l}7305 \\
7305\end{array}$ & $\begin{array}{l}169 \\
175\end{array}$ & $\begin{array}{l}64 \\
58\end{array}$ & $\begin{array}{l}18 \\
13\end{array}$ & $\begin{array}{l}1 \\
1\end{array}$ & $\begin{array}{l}2.6 \\
3.0\end{array}$ & $\begin{array}{l}863 \\
874\end{array}$ & $\begin{array}{l}2 \\
4\end{array}$ & $\begin{array}{l}279 \\
270\end{array}$ & $\begin{array}{l}15510 \\
15463\end{array}$ & $\begin{array}{l}471522 \\
47268\end{array}$ & 0.0059 & $\begin{array}{l}0.9769 \\
0\end{array}$ & $\begin{array}{l}0.3787 \\
0.3314\end{array}$ & $\begin{array}{l}2 \\
3\end{array}$ & $\begin{array}{l}236 \\
267\end{array}$ & $\begin{array}{l}279 \\
270\end{array}$ & 0 & 547 & $\begin{array}{l}4951 \\
5015\end{array}$ & $\begin{array}{l}1194 \\
1164\end{array}$ & $\begin{array}{l}462 \\
444\end{array}$ & $\begin{array}{l}151 \\
161\end{array}$ & 0.6317 \\
\hline $\begin{array}{l}18 \\
27\end{array}$ & $\begin{array}{l}7305 \\
7305\end{array}$ & $\begin{array}{l}175 \\
159\end{array}$ & 49 & 28 & 1 & $\begin{array}{l}3.0 \\
3.2\end{array}$ & $\begin{array}{l}874 \\
865\end{array}$ & $\begin{array}{l}4 \\
6\end{array}$ & 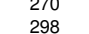 & $\begin{array}{l}15463 \\
13441\end{array}$ & $\begin{array}{l}47268 \\
47369\end{array}$ & $\begin{array}{l}0.0057 \\
0.0063\end{array}$ & $\begin{array}{l}0.9760 \\
0.9782\end{array}$ & $\begin{array}{l}0.3314 \\
0.3082\end{array}$ & $\begin{array}{l}3 \\
2\end{array}$ & $\begin{array}{l}267 \\
274\end{array}$ & $\begin{array}{l}\begin{array}{l}270 \\
298\end{array} \\
\end{array}$ & $\begin{array}{l}0 \\
0\end{array}$ & $\begin{array}{l}531 \\
520\end{array}$ & $\begin{array}{l}5015 \\
5050\end{array}$ & $\begin{array}{l}1164 \\
1184\end{array}$ & $\begin{array}{l}434 \\
409\end{array}$ & $\begin{array}{l}161 \\
142\end{array}$ & 0.6777 \\
\hline 71 & 7305 & 177 & 53 & 16 & 1 & 3.3 & 857 & 1 & 279 & 13690 & 49361 & 0.0056 & 0.9758 & 0.2994 & 3 & $\begin{array}{l}274 \\
258\end{array}$ & 279 & 0 & $\begin{array}{l}520 \\
521\end{array}$ & $\begin{array}{l}5050 \\
4960\end{array}$ & $\begin{array}{l}1184 \\
1211\end{array}$ & $\begin{array}{l}409 \\
449\end{array}$ & $\begin{array}{l}142 \\
164\end{array}$ & $\begin{array}{l}0.1023 \\
0.7098\end{array}$ \\
\hline 93 & 7305 & 169 & 55 & 30 & 1 & 3.1 & 883 & 3 & 293 & 15819 & 49469 & 0.0059 & 0.9769 & 0.3254 & 1 & 288 & 293 & 0 & 542 & 4960 & 1283 & $\begin{array}{l}449 \\
363\end{array}$ & 104 & $\begin{array}{l}0.1098 \\
0.6850\end{array}$ \\
\hline 36 & 7305 & 171 & 49 & 24 & 1 & 3.5 & 861 & 1 & 291 & 13604 & 49786 & 0.0058 & 0.9766 & 0.2865 & 2 & 278 & 291 & 0 & 501 & 5009 & 1190 & $\begin{array}{l}303 \\
449\end{array}$ & 156 & $\begin{array}{l}0.0850 \\
0.7233\end{array}$ \\
\hline 88 & 7305 & 173 & 47 & 18 & 1 & 3.7 & 865 & 7 & 288 & 13772 & 49792 & 0.0058 & 0.9763 & 0.2717 & 2 & 293 & 288 & 0 & 526 & 5053 & 1143 & 420 & 163 & $\begin{array}{l}0.7233 \\
0.7377\end{array}$ \\
\hline 55 & 7305 & 156 & 48 & 17 & 1 & 3.3 & 887 & 3 & 319 & 13673 & 49834 & 0.0064 & 0.9786 & 0.3077 & 3 & 285 & 319 & 0 & 551 & 4950 & 1218 & 444 & $\begin{array}{l}100 \\
142\end{array}$ & 0.7043 \\
\hline 56 & 7305 & 171 & 54 & 24 & 1 & 3.2 & 899 & 1 & 292 & 13535 & 49859 & 0.0058 & 0.9766 & 0.3158 & 2 & 251 & 292 & 0 & 505 & 5026 & 1189 & 433 & 152 & $\begin{array}{l}0.6943 \\
0.6945\end{array}$ \\
\hline 100 & 7305 & 174 & 52 & 12 & 1 & 3.3 & 889 & 1 & 287 & 15810 & 49972 & 0.0057 & 0.9762 & 0.2989 & 3 & 304 & 287 & 0 & 518 & 5025 & 1190 & 407 & 165 & $\begin{array}{l}0.0945 \\
0.7109\end{array}$ \\
\hline 19 & 7305 & 168 & 43 & 29 & 1 & 3.9 & 937 & 1 & 298 & 12289 & 50064 & 0.0060 & 0.9770 & 0.2560 & 1 & 286 & 298 & 0 & 514 & 4998 & 1233 & 407 & 153 & 0.7539 \\
\hline 11 & 7305 & 173 & 54 & 18 & 1 & 3.2 & 880 & 6 & 297 & 15559 & 51324 & 0.0058 & 0.9763 & 0.3121 & 2 & 288 & 297 & 0 & 553 & 4935 & 1257 & 401 & 159 & 0.6984 \\
\hline 20 & 7305 & 176 & 59 & 14 & 1 & 3.0 & 852 & 4 & 293 & 15816 & 51639 & 0.0057 & 0.9759 & 0.3352 & 3 & 268 & 293 & 0 & 538 & 5010 & 1198 & 394 & 165 & $\begin{array}{l}0.0964 \\
0.6755\end{array}$ \\
\hline 64 & 7305 & 168 & 54 & 11 & 1 & 3.1 & 922 & 0 & 308 & 16153 & 51768 & 0.0060 & 0.9770 & 0.3214 & 4 & 299 & 308 & 0 & 530 & 4959 & 1264 & 401 & 151 & 0.6901 \\
\hline 23 & 7305 & 165 & 47 & 18 & 1 & 3.5 & 893 & 2 & 316 & 14452 & 52147 & 0.0061 & 0.9774 & 0.2848 & 2 & 307 & 316 & 0 & 524 & 4988 & 1223 & 415 & 155 & 0.7266 \\
\hline 95 & 7305 & 185 & 51 & 17 & 1 & 3.6 & 865 & 1 & 283 & 16475 & 52265 & 0.0054 & 0.9747 & 0.2757 & 2 & 323 & 283 & 0 & 520 & 5022 & 1209 & 383 & 171 & 0.7335 \\
\hline 47 & 7305 & 199 & 53 & 17 & 1 & 3.8 & 864 & 0 & 264 & 13719 & 52524 & 0.0050 & 0.9728 & 0.2663 & 2 & 259 & 264 & 0 & 528 & 4933 & 1264 & 402 & 178 & 0.7417 \\
\hline 65 & 7305 & 202 & 67 & 14 & 1 & 3.0 & 860 & 1 & 260 & 18577 & 52603 & 0.0050 & 0.9723 & 0.3317 & 3 & 277 & 260 & 0 & 527 & $50 \mathrm{C}$ & 1142 & 453 & 178 & 0.6770 \\
\hline 8 & 7305 & 173 & 52 & 11 & 1 & 3.3 & 868 & 1 & 305 & 15333 & 52692 & 0.0058 & 0.9763 & 0.3006 & 4 & 295 & 305 & 0 & 531 & 497 & 12 & 429 & 159 & 0.7103 \\
\hline 74 & 7305 & 179 & 55 & 13 & 1 & 3.3 & 89 & 0 & 296 & 16711 & 52964 & 0.0056 & 0.9755 & 0.3073 & 3 & 304 & 29 & 0 & 518 & 50 & 123 & & 160 & 0.7032 \\
\hline 62 & 7305 & 197 & 55 & 23 & 1 & 3.6 & 85 & 4 & 269 & 14368 & 53075 & 0.0051 & 0.9730 & 0.2792 & 2 & 26 & 26 & 0 & 548 & 49 & 114 & 47 & 8 & 0.7293 \\
\hline 90 & 7305 & 172 & 52 & 25 & 1 & 3.3 & 90 & 1 & 309 & 1312 & 53231 & 0.0058 & 0.9765 & 0.3023 & 2 & & 30 & 0 & 51 & 49 & 12 & & 5 & 0.7090 \\
\hline 39 & 7305 & 192 & 51 & 21 & 1 & 3.8 & 86 & 2 & 280 & 1572 & 53760 & 0.0052 & 0.9737 & 0.2656 & 2 & 30 & 28 & r & 51 & 50 & 117 & 388 & 174 & 0.7433 \\
\hline 94 & 7305 & 187 & 55 & 27 & 1 & 3.4 & 86 & 2 & 288 & 159 & & 0.0053 & 0.9744 & 0.25 & 1 & & 28 & 0 & & & & & 177 & 0.7157 \\
\hline 33 & 7305 & 188 & 60 & 30 & 1 & 3.1 & 882 & 0 & 287 & 15662 & 54001 & 0.0053 & 0.9743 & 0.3191 & 1 & 261 & 287 & 0 & 523 & 4987 & 1187 & 433 & 175 & 0.6910 \\
\hline 87 & 7305 & 170 & 44 & 31 & 1 & 3.9 & 881 & 2 & 319 & 10285 & 54218 & 0.0059 & 0.9767 & 0.2588 & 1 & 234 & 319 & 0 & 557 & 5057 & 1174 & 357 & 160 & 0.7524 \\
\hline 29 & 7305 & 181 & 56 & 25 & 1 & 3.2 & 868 & 1 & 300 & 15812 & 54296 & 0.0055 & 0.9752 & 0.3094 & 2 & 282 & 300 & 0 & 523 & 5005 & 1156 & 452 & 169 & 0.7014 \\
\hline 52 & 7305 & 190 & 58 & 26 & 1 & 3.3 & 871 & 2 & 288 & 15469 & 54730 & 0.0053 & 0.9740 & 0.3053 & 1 & 267 & 288 & 0 & 528 & 4931 & 1222 & 454 & 170 & 0.7047 \\
\hline 61 & 7305 & 197 & 60 & 28 & 1 & 3.3 & 862 & 2 & 278 & 16102 & 54810 & 0.0051 & 0.9730 & 0.3046 & 1 & 268 & 278 & 0 & 523 & 4992 & 1174 & 440 & 176 & 0.7048 \\
\hline 83 & 7305 & 187 & 50 & 31 & 1 & 3.7 & 866 & 0 & 295 & 14939 & 55126 & 0.0053 & 0.9744 & 0.2674 & 1 & 299 & 295 & 0 & 510 & 5004 & 1176 & 444 & 171 & 0.7425 \\
\hline 97 & 7305 & 177 & 57 & 18 & 1 & 3.1 & 935 & 3 & 312 & 15569 & 55255 & 0.0056 & 0.9758 & 0.3220 & 2 & 273 & 312 & 0 & 519 & 5038 & 1188 & 402 & 158 & 0.6898 \\
\hline 24 & 7305 & 176 & 50 & 19 & 1 & 3.5 & 866 & 2 & 315 & 14071 & 55454 & 0.0057 & 0.9759 & 0.2841 & 2 & 281 & 315 & 0 & 523 & 4991 & 1275 & 352 & 164 & 0.7273 \\
\hline 86 & 7305 & 169 & 49 & 23 & 1 & 3.4 & 859 & 3 & 330 & 13848 & 55812 & 0.0059 & 0.9769 & 0.2899 & 2 & 283 & 330 & 0 & 539 & 4959 & 1184 & 462 & 161 & 0.7226 \\
\hline 53 & 7305 & 183 & 55 & 16 & 1 & 3.3 & 86 & 1 & 305 & 163 & 55876 & 0.0055 & 0.9749 & 0.3005 & 2 & 298 & 30 & 0 & 522 & 4938 & 1203 & 472 & 170 & 0.7105 \\
\hline 43 & 7305 & 176 & 61 & 24 & 1 & 2.9 & 85 & 2 & 318 & 15 & 56 & $0 . C$ & 0.9759 & 0.3 & 2 & 259 & 318 & 0 & 51 & 5013 & 1143 & 479 & 158 & 0.6661 \\
\hline 78 & 733 & 174 & 45 & 43 & 1 & 3.9 & 8 & 0 & 324 & & 56 & & 0.9762 & 0.2 & 1 & 237 & 32 & 0 & 55 & 49 & 1243 & 406 & 156 & 0.7530 \\
\hline 48 & 7305 & 179 & 49 & 17 & 1 & 3.7 & 86 & 3 & 318 & & & 0.0 & 0.9755 & 0.2 & 2 & 30 & 31 & 0 & 55 & 49 & 1235 & 427 & 164 & 0.7377 \\
\hline 98 & 7305 & 192 & 57 & 17 & 1 & 3.4 & 86 & 2 & 297 & & & & 0.9737 & 0.2 & 2 & 31 & 29 & 0 & 51 & 503 & 1135 & 45 & 179 & 0.7136 \\
\hline 79 & 73 & 192 & 62 & 15 & 1 & 1 & 9 & 1 & 29 & & & & 0.9737 & 0.3 & 3 & 243 & 29 & 0 & 49 & 50 & 115 & 450 & 172 & 0.6879 \\
\hline 42 & 73 & 172 & 52 & 24 & 1 & 3.3 & 86 & 1 & 333 & & 57218 & 0.0058 & 0.9765 & 0.3023 & 2 & 308 & 333 & 0 & 53 & 4959 & 1225 & 432 & 158 & 0.7106 \\
\hline 14 & 73 & 165 & 44 & $\begin{array}{l}24 \\
25\end{array}$ & 1 & 3.8 & 8 & 4 & 351 & & & 0.0061 & 0.9774 & 0.2667 & 2 & $\begin{array}{l}311 \\
211\end{array}$ & 351 & 0 & 505 & 5008 & 1219 & 420 & 153 & 0.7470 \\
\hline 69 & $\begin{array}{l}7305 \\
7305\end{array}$ & $\begin{array}{l}196 \\
180\end{array}$ & $\begin{array}{l}63 \\
54\end{array}$ & $\begin{array}{l}25 \\
1\end{array}$ & 1 & $\begin{array}{l}3.1 \\
3.3\end{array}$ & 897 & $\begin{array}{l}0 \\
6\end{array}$ & $\begin{array}{l}296 \\
323\end{array}$ & $\begin{array}{l}17941 \\
16661\end{array}$ & $\begin{array}{l}58046 \\
58121\end{array}$ & $\begin{array}{l}0.0051 \\
0.0051\end{array}$ & 0.9732 & $\begin{array}{l}0.3214 \\
0.3000\end{array}$ & $\begin{array}{l}1 \\
2 \\
2\end{array}$ & $\begin{array}{l}285 \\
309\end{array}$ & $\begin{array}{l}296 \\
323\end{array}$ & $\begin{array}{l}0 \\
0 \\
0\end{array}$ & $\begin{array}{l}531 \\
528\end{array}$ & $\begin{array}{l}4978 \\
4993\end{array}$ & $\begin{array}{l}1206 \\
1230\end{array}$ & $\begin{array}{l}412 \\
382\end{array}$ & $\begin{array}{l}178 \\
172\end{array}$ & 0.6894 \\
\hline & & & & & & & & & & & & & & 0.0000 & 2 & & & & & & & & & 0.1726 \\
\hline
\end{tabular}




\begin{tabular}{|c|c|c|c|c|c|c|c|c|c|c|c|c|c|c|c|c|c|c|c|c|c|c|c|c|}
\hline 30 & 7305 & 198 & 62 & 19 & 1 & 3.2 & 907 & 0 & 294 & 19544 & 58294 & 0.0051 & 0.9729 & 0.3131 & 2 & 315 & 294 & 0 & 520 & 5012 & 1171 & 430 & 172 & 0.6974 \\
\hline 73 & 7305 & 190 & 54 & 14 & 1 & 3.5 & 871 & 1 & 307 & 13854 & 58404 & 0.0053 & 0.9740 & 0.2842 & 3 & 257 & 307 & 0 & 512 & 5054 & 1156 & 414 & 169 & 0.7267 \\
\hline 32 & 7305 & 180 & 45 & 27 & 1 & 4.0 & 873 & 7 & 327 & 13231 & 58779 & 0.0056 & 0.9754 & 0.2500 & 2 & 294 & 327 & 0 & 536 & 4969 & 1253 & 372 & 175 & 0.7617 \\
\hline 3 & 7305 & 203 & 62 & 23 & 1 & 3.3 & 870 & 5 & 290 & 18605 & 58898 & 0.0049 & 0.9722 & 0.3054 & 2 & 300 & 290 & 0 & 506 & 4950 & 1205 & 457 & 187 & 0.7048 \\
\hline 92 & 7305 & 188 & 43 & 16 & 1 & 4.4 & 864 & 2 & 313 & 14764 & 58900 & 0.0053 & 0.9743 & 0.2287 & 2 & 343 & 313 & 0 & 497 & 5060 & 1198 & 368 & 182 & 0.7818 \\
\hline 35 & 7305 & 178 & 62 & 14 & 1 & 2.9 & 904 & 3 & 332 & 17525 & 59104 & 0.0056 & 0.9756 & 0.3483 & 3 & 283 & 332 & 0 & 554 & 4929 & 1204 & $\begin{array}{l}460 \\
\end{array}$ & 158 & 0.6655 \\
\hline 28 & 7305 & 195 & 62 & 18 & 1 & 3.1 & 869 & 1 & 306 & 18080 & 59715 & 0.0051 & 0.9733 & 0.3179 & 2 & 292 & 306 & 0 & 514 & 4931 & 1246 & 437 & 177 & 0.6935 \\
\hline 9 & $\begin{array}{l}7305 \\
7705\end{array}$ & $\begin{array}{l}192 \\
\end{array}$ & 53 & 18 & 1 & 3.6 & 860 & 7 & 312 & $\begin{array}{l}18058 \\
1520\end{array}$ & 59896 & 0.0052 & 0.9737 & 0.2760 & 2 & $\begin{array}{l}341 \\
258\end{array}$ & $\begin{array}{l}312 \\
312 \\
285\end{array}$ & 0 & 522 & $\begin{array}{l}4989 \\
5036\end{array}$ & $\begin{array}{l}1183 \\
1160\end{array}$ & $\begin{array}{l}433 \\
383\end{array}$ & $\begin{array}{l}178 \\
103\end{array}$ & $\begin{array}{l}0.7351 \\
0731\end{array}$ \\
\hline 54 & $\begin{array}{l}7305 \\
7305\end{array}$ & $\begin{array}{l}212 \\
1176\end{array}$ & 59 & $\begin{array}{l}28 \\
39\end{array}$ & 1 & $\begin{array}{l}3.6 \\
42\end{array}$ & 869 & 1 & $\begin{array}{l}285 \\
347\end{array}$ & $\begin{array}{l}15236 \\
11438\end{array}$ & 60432 & 0.0047 & 0.9710 & 0.2783 & $\stackrel{1}{1}$ & $\begin{array}{l}258 \\
272 \\
272\end{array}$ & 285 & 0 & 533 & 5036 & $\begin{array}{l}1160 \\
1107\end{array}$ & 383 & 193 & $\begin{array}{l}0.7312 \\
0.712\end{array}$ \\
\hline 51 & $\begin{array}{l}7305 \\
7305\end{array}$ & $\begin{array}{l}176 \\
206\end{array}$ & $\begin{array}{l}42 \\
63\end{array}$ & $\begin{array}{l}39 \\
18\end{array}$ & 1 & $\begin{array}{l}4.2 \\
3.2\end{array}$ & $\begin{array}{l}891 \\
853\end{array}$ & 2 & $\begin{array}{l}347 \\
297\end{array}$ & 11438 & $\begin{array}{l}61101 \\
6154\end{array}$ & 0.0057 & 0.9759 & $\begin{array}{l}0.2386 \\
03058\end{array}$ & $\begin{array}{l}1 \\
2\end{array}$ & $\begin{array}{l}272 \\
303\end{array}$ & $\begin{array}{l}347 \\
297\end{array}$ & 0 & $\begin{array}{l}521 \\
5 ? 2\end{array}$ & 5037 & $\begin{array}{l}1197 \\
1190\end{array}$ & $\begin{array}{l}384 \\
421\end{array}$ & $\begin{array}{l}166 \\
102\end{array}$ & $\begin{array}{l}0.7743 \\
0.704\end{array}$ \\
\hline $\begin{array}{l}66 \\
91\end{array}$ & $\begin{array}{l}705 \\
7305\end{array}$ & $\begin{array}{l}206 \\
177\end{array}$ & $\begin{array}{l}63 \\
44\end{array}$ & $\begin{array}{l}18 \\
17\end{array}$ & $\begin{array}{l}1 \\
1\end{array}$ & $\begin{array}{l}3.3 \\
4.0\end{array}$ & $\begin{array}{l}853 \\
869\end{array}$ & $\begin{array}{l}2 \\
3\end{array}$ & $\begin{array}{l}297 \\
346\end{array}$ & $\begin{array}{l}19094 \\
1437\end{array}$ & $\begin{array}{l}61154 \\
66173\end{array}$ & 0.0049 & $\begin{array}{l}0.9718 \\
0.0758\end{array}$ & $\begin{array}{l}0.3058 \\
0.2486\end{array}$ & $\begin{array}{l}2 \\
2 \\
2\end{array}$ & $\begin{array}{l}303 \\
327\end{array}$ & $\begin{array}{l}297 \\
346\end{array}$ & $\begin{array}{l}0 \\
0 \\
0\end{array}$ & 522 & $\begin{array}{r}4980 \\
4965\end{array}$ & $\begin{array}{l}1190 \\
1190\end{array}$ & $\begin{array}{l}421 \\
390\end{array}$ & $\begin{array}{l}192 \\
162\end{array}$ & $\begin{array}{l}0.7048 \\
0.74\end{array}$ \\
\hline $\begin{array}{c}91 \\
5\end{array}$ & $\begin{array}{l}7305 \\
7305\end{array}$ & $\begin{array}{l}17 / 7 \\
210\end{array}$ & $\begin{array}{l}44 \\
49\end{array}$ & $\begin{array}{l}11 \\
22\end{array}$ & $\begin{array}{l}1 \\
1\end{array}$ & $\begin{array}{l}4.0 \\
4.3\end{array}$ & $\begin{array}{l}869 \\
860\end{array}$ & $\begin{array}{l}3 \\
1\end{array}$ & $\begin{array}{l}346 \\
304\end{array}$ & $\begin{array}{l}143 / 7 \\
16123\end{array}$ & $\begin{array}{l}611 / 3 \\
63837\end{array}$ & $\begin{array}{l}0.0056 \\
0.0048\end{array}$ & $\begin{array}{l}0.958 \\
0.0713\end{array}$ & $\begin{array}{l}0.2486 \\
0.2333\end{array}$ & $\begin{array}{l}2 \\
2\end{array}$ & 327 & $\begin{array}{l}346 \\
304\end{array}$ & $\begin{array}{l}0 \\
0\end{array}$ & $\begin{array}{l}529 \\
530\end{array}$ & $\begin{array}{l}49655 \\
4992\end{array}$ & $\begin{array}{l}1259 \\
1220\end{array}$ & $\begin{array}{l}390 \\
372\end{array}$ & $\begin{array}{l}162 \\
191\end{array}$ & $\begin{array}{l}0.7644 \\
07776\end{array}$ \\
\hline $\begin{array}{c}5 \\
44\end{array}$ & $\begin{array}{l}7305 \\
7305\end{array}$ & 193 & 56 & 19 & 1 & $\begin{array}{l}4.3 \\
3.4\end{array}$ & 911 & 1 & $\begin{array}{l}304 \\
332\end{array}$ & $\begin{array}{l}16123 \\
16841\end{array}$ & $\begin{array}{l}63837 \\
64160\end{array}$ & 0.0048 & $\begin{array}{l}0.9713 \\
0.0736\end{array}$ & $\begin{array}{l}0.2333 \\
0.2992\end{array}$ & $\begin{array}{l}2 \\
2\end{array}$ & $\begin{array}{l}329 \\
301\end{array}$ & $\begin{array}{l}304 \\
332\end{array}$ & $\begin{array}{l}0 \\
0\end{array}$ & $\begin{array}{l}530 \\
540\end{array}$ & $\begin{array}{l}4992 \\
5013\end{array}$ & $\begin{array}{r}1220 \\
1138\end{array}$ & $\begin{array}{l}3 / 2 \\
437\end{array}$ & $\begin{array}{l}191 \\
177\end{array}$ & $\begin{array}{l}0.7768 \\
07202\end{array}$ \\
\hline 13 & 7305 & 186 & 41 & 23 & 1 & 4.5 & 886 & 4 & 346 & 13832 & 64365 & 0.0054 & 0.9745 & $\begin{array}{l}0.2902 \\
0.2204\end{array}$ & 2 & 337 & $\begin{array}{l}3.2 \\
346\end{array}$ & 0 & $\begin{array}{l}540 \\
546\end{array}$ & 4966 & 1226 & $\begin{array}{l}431 \\
398\end{array}$ & 169 & 0.7221 \\
\hline 50 & 7305 & 195 & 51 & 21 & 1 & 3.8 & 898 & 1 & 330 & 16028 & 64441 & 0.0051 & 0.9733 & 0.2615 & 2 & 314 & 330 & 0 & 540 & 4962 & 1193 & 426 & 184 & 0.7507 \\
\hline 96 & 7305 & 193 & 47 & 18 & 1 & 4.1 & 923 & 1 & 337 & 15814 & 65061 & 0.0052 & 0.9736 & 0.2435 & 2 & 336 & 337 & 0 & 541 & 4999 & 1209 & 375 & 181 & 0.7689 \\
\hline 67 & 7305 & 182 & 46 & 30 & 1 & 4.0 & 867 & 5 & 360 & 15587 & 65520 & 0.0055 & 0.9751 & 0.2527 & 1 & 339 & 360 & 0 & 532 & 4948 & 1217 & 431 & 177 & 0.7614 \\
\hline 60 & 7305 & 198 & 51 & 30 & 1 & 3.9 & 867 & 0 & 332 & 14076 & 65662 & 0.0051 & 0.9729 & 0.2576 & 1 & 276 & 332 & 0 & 536 & 4963 & 1212 & 408 & 186 & 0.7547 \\
\hline 25 & 7305 & 213 & 64 & 21 & 1 & 3.3 & 895 & 5 & 310 & 17176 & 65965 & 0.0047 & 0.9708 & 0.3005 & 2 & 268 & 310 & 0 & 523 & 4994 & 1173 & 418 & 197 & 0.7110 \\
\hline 57 & 7305 & 202 & 56 & 16 & 1 & 3.6 & 867 & 3 & 327 & 18415 & 66014 & 0.0050 & 0.9723 & 0.2772 & 2 & 329 & 327 & 0 & 531 & 4932 & 1232 & 417 & 193 & 0.7350 \\
\hline 59 & 7305 & 216 & 54 & 14 & 1 & 4.0 & 870 & 1 & 307 & 19728 & 66245 & 0.0046 & 0.9704 & 0.2500 & 2 & 365 & 307 & 0 & 514 & 4998 & 1198 & 399 & 196 & 0.7605 \\
\hline 77 & 7305 & 217 & 61 & 24 & 1 & 3.6 & 860 & 3 & 308 & 18330 & 66925 & 0.0046 & 0.9703 & 0.2811 & 1 & 300 & 308 & 0 & 559 & 4946 & 1138 & 461 & 201 & 0.7300 \\
\hline 22 & 7305 & 195 & 44 & 31 & 1 & 4.4 & 937 & 0 & 343 & 13735 & 66957 & 0.0051 & 0.9733 & 0.2256 & 1 & 312 & 343 & 0 & 532 & 5022 & 1170 & 400 & 181 & 0.7869 \\
\hline 89 & 7305 & 204 & 53 & 34 & 1 & 3.8 & 943 & 2 & 331 & 14679 & 67428 & 0.0049 & 0.9721 & 0.2598 & 1 & 277 & 331 & 0 & 533 & 5048 & 1146 & 388 & 190 & 0.7524 \\
\hline 1 & 7305 & 187 & 48 & 30 & 1 & 3.9 & 871 & 4 & 364 & 14638 & 68117 & 0.0053 & 0.9744 & 0.2567 & 1 & 305 & 364 & 0 & 515 & 5015 & 1199 & 400 & 176 & 0.7579 \\
\hline 70 & 7305 & 185 & 42 & 33 & 1 & 4.4 & 888 & 1 & 368 & 11527 & 68120 & 0.0054 & 0.9747 & 0.2270 & 1 & 274 & 368 & 0 & 516 & 5036 & 1157 & 422 & 174 & 0.7873 \\
\hline 68 & 7305 & 209 & 56 & 18 & 1 & 3.7 & 875 & 3 & 328 & 18188 & 68506 & 0.0048 & 0.9714 & 0.2679 & 2 & 325 & 328 & 0 & 517 & 4917 & 1225 & 450 & 196 & 0.7443 \\
\hline 21 & 7305 & 207 & 50 & 34 & 1 & 4.1 & 869 & 1 & 331 & 17258 & 68507 & 0.0048 & 0.9717 & 0.2415 & 1 & 345 & 331 & 0 & 531 & 4905 & 1218 & 454 & 197 & 0.7704 \\
\hline 10 & 7305 & 201 & 47 & 38 & 1 & 4.3 & 905 & 1 & 342 & 13925 & 68783 & 0.0050 & 0.9725 & 0.2338 & 1 & 296 & 342 & 0 & 512 & 5038 & 1177 & 394 & 184 & 0.7788 \\
\hline 15 & 7305 & 199 & 57 & 21 & 1 & 3.5 & 871 & 1 & 346 & 16697 & 68873 & 0.0050 & 0.9728 & 0.2864 & 2 & 293 & 346 & 0 & 528 & 4953 & 1241 & 402 & 181 & 0.7274 \\
\hline 49 & 7305 & 231 & 53 & 27 & 1 & 4.4 & 870 & 1 & 298 & 15744 & 68897 & 0.0043 & 0.9684 & 0.2294 & 1 & 297 & 298 & 0 & 522 & 4972 & 1200 & 399 & 212 & 0.7804 \\
\hline 31 & 7305 & 209 & 59 & 16 & 1 & 3.5 & 925 & 2 & 330 & 19024 & 68987 & 0.0048 & 0.9714 & 0.2823 & 2 & 322 & 330 & 0 & 498 & 4978 & 1261 & 373 & 195 & 0.7303 \\
\hline 63 & 7305 & 188 & 36 & 32 & 1 & 5.2 & 862 & 1 & 372 & 11389 & 69874 & 0.0053 & 0.9743 & 0.1915 & 1 & 316 & 372 & 0 & 526 & 5018 & 1202 & 376 & 183 & 0.8225 \\
\hline 12 & 7305 & 202 & 47 & 35 & 1 & 4.3 & 910 & 5 & 347 & 13237 & 70055 & 0.0050 & 0.9723 & 0.2327 & 1 & 282 & 347 & 0 & 535 & 4969 & 1172 & 434 & 195 & 0.7803 \\
\hline 34 & 7305 & 198 & 55 & $\begin{array}{r}33 \\
25\end{array}$ & 1 & 3.6 & 872 & 2 & 357 & 15943 & 70659 & 0.0051 & 0.9729 & 0.2778 & 1 & 290 & 357 & 0 & 532 & 4979 & 1211 & 394 & 189 & 0.7367 \\
\hline 82 & $\begin{array}{l}7305 \\
7305\end{array}$ & $\begin{array}{l}217 \\
219\end{array}$ & $\begin{array}{l}55 \\
59\end{array}$ & $\begin{array}{l}25 \\
53\end{array}$ & 1 & $\begin{array}{l}3.9 \\
3.7\end{array}$ & $\begin{array}{l}878 \\
873\end{array}$ & 2 & $\begin{array}{l}333 \\
333\end{array}$ & 16809 & $\begin{array}{l}72346 \\
77731\end{array}$ & 0.0046 & 0.9703 & 0.2535 & 1 & 306 & 333 & 0 & 544 & $\begin{array}{l}4948 \\
\end{array}$ & 1192 & 418 & 203 & 0.7589 \\
\hline 37 & $\begin{array}{l}7305 \\
7305\end{array}$ & $\begin{array}{l}219 \\
219\end{array}$ & $\begin{array}{l}59 \\
58\end{array}$ & 53 & 1 & 3.7 & 873 & $\begin{array}{l}0 \\
0 \\
2\end{array}$ & $\begin{array}{l}337 \\
332\end{array}$ & $\begin{array}{l}14436 \\
1016 ?\end{array}$ & $\begin{array}{l}73731 \\
7\end{array}$ & 0.0046 & 0.9700 & 0.2694 & 1 & 245 & $\begin{array}{l}337 \\
332\end{array}$ & ${ }^{0}$ & 550 & 4891 & 1210 & 448 & 206 & 0.7435 \\
\hline 75 & $\begin{array}{l}7305 \\
7305\end{array}$ & $\begin{array}{l}224 \\
218\end{array}$ & $\begin{array}{l}58 \\
52\end{array}$ & $\begin{array}{l}21 \\
33\end{array}$ & 1 & $\begin{array}{l}3.9 \\
42\end{array}$ & 888 & $\begin{array}{l}2 \\
3\end{array}$ & $\begin{array}{l}332 \\
351\end{array}$ & 19162 & $\begin{array}{l}74305 \\
74453\end{array}$ & 0.0045 & $\begin{array}{l}0.9693 \\
0\end{array}$ & 0.2589 & ${ }_{1}^{2}$ & $\begin{array}{l}330 \\
333\end{array}$ & $\begin{array}{l}332 \\
351\end{array}$ & ${ }_{0}^{0}$ & $\begin{array}{l}534 \\
534\end{array}$ & $\begin{array}{r}4919 \\
\end{array}$ & $\begin{array}{l}1217 \\
1211\end{array}$ & $\begin{array}{l}426 \\
366\end{array}$ & 209 & 0.7535 \\
\hline $\begin{array}{l}46 \\
80\end{array}$ & $\begin{array}{l}7305 \\
7305\end{array}$ & $\begin{array}{l}218 \\
229\end{array}$ & $\begin{array}{l}52 \\
57\end{array}$ & $\begin{array}{l}33 \\
36\end{array}$ & 1 & $\begin{array}{l}4.2 \\
4.0\end{array}$ & $\begin{array}{l}899 \\
940\end{array}$ & $\begin{array}{l}3 \\
1\end{array}$ & $\begin{array}{l}351 \\
334\end{array}$ & $\begin{array}{l}17300 \\
14867\end{array}$ & $\begin{array}{l}76453 \\
76587\end{array}$ & $\begin{array}{l}0.0046 \\
0.0044\end{array}$ & 0.9702 & $\begin{array}{l}0.2385 \\
02489\end{array}$ & 1 & $\begin{array}{l}333 \\
261\end{array}$ & $\begin{array}{l}351 \\
334\end{array}$ & o & $\begin{array}{l}534 \\
503\end{array}$ & $\begin{array}{l}4994 \\
5055\end{array}$ & $\begin{array}{l}1211 \\
1132\end{array}$ & 306 & 200 & $\begin{array}{l}0.7749 \\
0.769\end{array}$ \\
\hline $\begin{array}{l}80 \\
45\end{array}$ & $\begin{array}{l}7305 \\
7305\end{array}$ & $\begin{array}{r}229 \\
227\end{array}$ & $\begin{array}{l}57 \\
51\end{array}$ & $\begin{array}{l}36 \\
29\end{array}$ & 1 & $\begin{array}{l}4.0 \\
4.5\end{array}$ & $\begin{array}{l}940 \\
869\end{array}$ & 1 & $\begin{array}{l}334 \\
339\end{array}$ & $\begin{array}{l}14867 \\
15747\end{array}$ & $\begin{array}{l}67587 \\
7708\end{array}$ & $\begin{array}{l}0.0044 \\
0.0044\end{array}$ & $\begin{array}{l}0.9687 \\
0 \\
0\end{array}$ & $\begin{array}{l}0.2489 \\
0.2247\end{array}$ & 1 & $\begin{array}{l}261 \\
309\end{array}$ & $\begin{array}{l}334 \\
339\end{array}$ & 0 & 536 & $\begin{array}{l}5055 \\
4977\end{array}$ & 11199 & $\begin{array}{l}407 \\
373\end{array}$ & 208 & $\begin{array}{l}0.7636 \\
0.787\end{array}$ \\
\hline $\begin{array}{l}45 \\
85\end{array}$ & 7305 & $\begin{array}{l}247 \\
240\end{array}$ & 64 & $\begin{array}{l}99 \\
19\end{array}$ & 1 & $\begin{array}{l}4.5 \\
3.8\end{array}$ & $\begin{array}{l}809 \\
889\end{array}$ & 2 & $\begin{array}{l}399 \\
322\end{array}$ & 19200 & 77220 & $\begin{array}{l}0.0044 \\
0.0042\end{array}$ & $\begin{array}{l}0.9671 \\
0.9671\end{array}$ & 0.2667 & 2 & 300 & 322 & 0 & 498 & 5022 & 1111 & 459 & 215 & 0.7453 \\
\hline 99 & 7305 & 212 & 52 & 40 & 1 & 4.1 & 913 & 0 & 377 & 14626 & 79965 & 0.0047 & 0.9710 & 0.2453 & 1 & 281 & 377 & 0 & 530 & 4987 & 1209 & 380 & 199 & 0.7702 \\
\hline inim & & 134 & 36 & 11 & 1 & 2.6 & 606 & 0 & 220 & 102 & 325 & & 0.9671 & & 1 & 224 & 220 & 0 & 497 & 4891 & 11 & 352 & 122 & 0.6317 \\
\hline verage & & 187 & 53 & 23 & 1 & 3.6 & 876 & 2 & 308 & 15276 & 57752 & 0.0054 & 0.9744 & 0.2861 & 2 & 289 & 308 & 0 & 527 & 4987 & 1201 & 418 & 172 & 0.7250 \\
\hline aximum & & 240 & 67 & 53 & 1 & 5.2 & 943 & 7 & 377 & 19728 & 79965 & 0.0075 & 0.9817 & 0.3787 & 4 & 365 & 377 & 0 & 559 & 5060 & 1283 & 479 & 220 & 0.8225 \\
\hline std.dev & & 20.1 & 6.1 & 7.9 & 0 & 0.5 & 36.9 & 1.7 & 31.2 & 2078.5 & 9829.4 & 0.0006 & 0.0028 & 0.0364 & 0.7 & 28.8 & 31.2 & 0.0 & 14.0 & 38.8 & 35.8 & 30.4 & 19.8 & 0.0373 \\
\hline
\end{tabular}


Scenerio NScenario 13a CSIROMk2b B11 with 5\% additional WEMPs savings with change of precipitation frequency $\begin{array}{lr}\text { Date: } & \text { 30/10/2007 } \\ \text { Simulation } & 9: 35: 13 \mathrm{AM}\end{array}$

Elmulation 12:16:00 PM

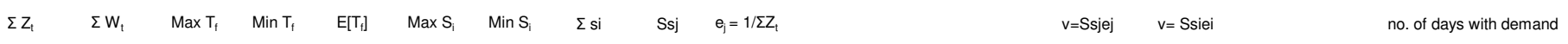

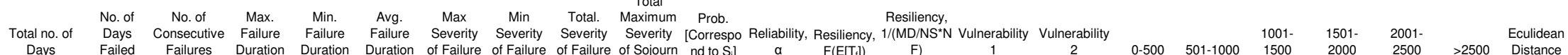

\begin{tabular}{|c|c|c|c|c|c|c|c|c|c|c|c|c|c|c|c|c|c|c|c|c|c|c|c|}
\hline Trial No. & $\begin{array}{l}\text { Total no. of } \\
\text { Days }\end{array}$ & $\begin{array}{l}\text { Days } \\
\text { Failed }\end{array}$ & $\begin{array}{l}\text { Consecutive } \\
\text { Failures }\end{array}$ & $\begin{array}{c}\text { Failure } \\
\text { Duration }\end{array}$ & $\begin{array}{l}\text { Failure } \\
\text { Duration }\end{array}$ & $\begin{array}{l}\text { Failure } \\
\text { Duration }\end{array}$ & $\begin{array}{l}\text { Severity } \\
\text { of Failure }\end{array}$ & $\begin{array}{l}\text { Severity } \\
\text { of Failure }\end{array}$ & $\begin{array}{l}\text { Severity } \\
\text { of Failure }\end{array}$ & $\begin{array}{l}\text { Severity } \\
\text { of Sojourn }\end{array}$ & $\begin{array}{l}\text { [Correspo } \\
\left.\text { nd to } \mathrm{S}_{j}\right]\end{array}$ & $\begin{array}{c}\text { Reliability } \\
a\end{array}$ & $\begin{array}{l}\text { Resiliency, } \\
F\left(E\left[T_{f}\right]\right)\end{array}$ & $\begin{array}{c}1 /\left(\mathrm{MD}_{\mathrm{N} / \mathrm{NS}} \mathrm{N}\right. \\
\mathrm{F})\end{array}$ & $\begin{array}{c}\text { Vulnerability } \\
1\end{array}$ & $\begin{array}{c}\text { Vulnerability } \\
2\end{array}$ & 0-500 & $501-1000$ & $\begin{array}{l}1001- \\
1500\end{array}$ & $\begin{array}{l}1501- \\
2000\end{array}$ & $\begin{array}{l}2001- \\
2500\end{array}$ & $>2500$ & $\begin{array}{l}\text { Eculidean } \\
\text { Distance }\end{array}$ \\
\hline 4 & 7305 & 137 & 45 & 28 & 1 & 3.0 & 868 & 0 & 32945 & 11103 & 0.0073 & 0.9812 & 0.3285 & 1.9 & 247 & 240 & 0 & 533 & 5082 & 1169 & 398 & 123 & 0.679 \\
\hline 40 & 7305 & 148 & 44 & 18 & 1 & 3.4 & 500 & 1 & 34259 & 9641 & 0.0068 & 0.9797 & 0.2973 & 2.7 & 219 & 231 & 0 & 521 & 5115 & 1169 & 361 & 139 & 0.709 \\
\hline 81 & 7305 & 148 & 55 & 10 & 1 & 2.7 & 864 & 1 & 38013 & 14900 & 0.0068 & 0.9797 & 0.3716 & 4.9 & 271 & 257 & 0 & 523 & 5045 & 1148 & 457 & 132 & 0.637 \\
\hline 84 & 7305 & 145 & 57 & 11 & 1 & 2.5 & 873 & 1 & 38725 & 14167 & 0.0069 & 0.9802 & 0.3931 & $\begin{array}{l}4.6 \\
4.6\end{array}$ & 249 & 267 & 0 & 506 & 5089 & 1166 & 410 & 134 & 0.617 \\
\hline 56 & 7305 & 127 & 42 & 16 & 1 & 3.0 & 868 & 0 & 39188 & 11293 & 0.0079 & 0.9826 & 0.3307 & 3.6 & 269 & 309 & 0 & 496 & 5084 & 1242 & 366 & 117 & 0.681 \\
\hline 38 & 7305 & 133 & 43 & 11 & 1 & 3.1 & 890 & 1 & 39317 & 12432 & 0.0075 & 0.9818 & 0.3233 & 5.0 & 289 & 296 & 0 & 537 & 4953 & 1256 & 439 & 120 & 0.687 \\
\hline 36 & 7305 & 144 & 40 & 23 & 1 & 3.6 & 862 & 5 & 39400 & 10669 & 0.0069 & 0.9803 & 0.2778 & 2.2 & 267 & 274 & 0 & 507 & 4992 & 1281 & 393 & 132 & 0.731 \\
\hline 2 & 7305 & 147 & 48 & 26 & 1 & 3.1 & 860 & 0 & 40421 & 11256 & 0.0068 & 0.9799 & 0.3265 & 1.9 & 235 & 275 & 0 & 543 & 5016 & 1251 & 367 & 128 & 0.683 \\
\hline 41 & 7305 & 129 & 46 & 17 & 1 & 2.8 & 902 & 3 & 40670 & 10685 & 0.0078 & 0.9823 & 0.3566 & 3.3 & 232 & 315 & 0 & 525 & 5061 & 1208 & 395 & 116 & 0.656 \\
\hline 17 & 7305 & 158 & 48 & 14 & 1 & 3.3 & 861 & 1 & 41288 & 11286 & 0.0063 & 0.9784 & 0.3038 & 3.3 & 235 & 261 & 0 & 530 & 5036 & 1221 & 379 & 139 & 0.704 \\
\hline 76 & 7305 & 159 & & 27 & 1 & 3.1 & 846 & 0 & 41482 & 13738 & 0.0063 & 0.9782 & 0.3208 & 1.7 & 269 & 261 & 0 & 524 & 5097 & 1161 & 377 & 146 & 0.688 \\
\hline 66 & 7305 & 141 & 52 & 19 & 1 & 2.7 & 851 & 3 & 41761 & 13084 & 0.0071 & 0.9807 & 0.3688 & 2.7 & 252 & 296 & 0 & 522 & 5038 & 1172 & 441 & 132 & 0.643 \\
\hline 11 & 7305 & 143 & 45 & 16 & 1 & 3.2 & 868 & 2 & 42240 & 13337 & 0.0070 & 0.9804 & 0.3147 & 3.2 & 296 & 295 & 0 & 550 & 5035 & 1228 & 361 & 131 & 0.696 \\
\hline 74 & 7305 & 150 & 49 & 14 & 1 & 3.1 & 864 & 2 & 43148 & 13340 & 0.0067 & 0.9795 & 0.3267 & 3.5 & 272 & 288 & 0 & 517 & 5093 & 1181 & 377 & 137 & 0.683 \\
\hline 26 & 7305 & 163 & 52 & 14 & 1 & 3.1 & 856 & 2 & 43593 & 14418 & 0.0061 & 0.9777 & 0.3190 & 3.2 & 277 & 267 & 0 & 510 & 4979 & 1237 & 430 & 149 & 0.690 \\
\hline 18 & 7305 & 163 & & 17 & 1 & 3.5 & 893 & 3 & 44608 & 12474 & 0.0061 & 0.9777 & 0.2822 & 2.6 & 271 & 274 & 0 & 543 & 4983 & 1193 & 439 & 147 & 0.726 \\
\hline 88 & 7305 & 162 & 43 & 20 & 1 & 3.8 & 865 & 2 & 44758 & 11163 & 0.0062 & 0.9778 & 0.2654 & 2.3 & 260 & 276 & 0 & 523 & 5106 & 1168 & 354 & 154 & 0.743 \\
\hline 7 & 7305 & 162 & 49 & 30 & 1 & 3.3 & 858 & 2 & 45029 & 14865 & 0.0062 & 0.9778 & 0.3025 & 1.5 & 303 & 278 & 0 & 521 & 5001 & 1231 & 401 & 151 & \\
\hline 27 & 7305 & 131 & 43 & 23 & 1 & & 865 & 0 & 45040 & 12338 & 0.0076 & 0.9821 & 0.3282 & 2.4 & 287 & 344 & 0 & 516 & 5157 & 1155 & 352 & 125 & 0.686 \\
\hline 62 & 7305 & 139 & 39 & 13 & 1 & 3.6 & 868 & 0 & 45162 & 12796 & 0.0072 & 0.9810 & 0.2806 & 4.0 & 328 & 325 & 0 & 521 & 4937 & 1255 & 466 & 126 & 0.731 \\
\hline 71 & 7305 & $\begin{array}{l}156 \\
152\end{array}$ & 49 & 13 & 1 & & 862 & 8 & 45261 & 14110 & 0.0064 & 0.9786 & 0.3141 & 3.6 & 288 & 290 & 0 & 521 & 4986 & 1237 & 415 & 146 & 0.696 \\
\hline 69 & 7305 & $\begin{array}{l}152 \\
150\end{array}$ & 48 & 22 & 1 & 3.2 & 860 & 2 & $\begin{array}{l}45426 \\
45724\end{array}$ & $\begin{array}{l}14280 \\
\end{array}$ & 0.0066 & 0.9792 & 0.3158 & 2.2 & 298 & 299 & 0 & 533 & 5093 & 1157 & 379 & 143 & 0.695 \\
\hline 58 & 7305 & 159 & 49 & 40 & 1 & 3.2 & 869 & 4 & 45734 & 12473 & 0.0063 & 0.9782 & 0.3082 & 1.1 & 255 & $\begin{array}{l}288 \\
256\end{array}$ & 0 & 529 & 5085 & 1185 & 360 & 146 & 0.702 \\
\hline 87 & $\begin{array}{l}7305 \\
70305\end{array}$ & $\begin{array}{l}130 \\
154\end{array}$ & 34 & 18 & 1 & 3.8 & 879 & 1 & 46239 & $\begin{array}{r}9679 \\
12303\end{array}$ & 0.0077 & $\begin{array}{l}0.9822 \\
0.0709\end{array}$ & 0.2615 & 3.1 & 285 & 356 & 0 & 532 & $\begin{array}{l}5028 \\
5018\end{array}$ & 1234 & 392 & 119 & 0.752 \\
\hline $\begin{array}{l}78 \\
55\end{array}$ & $\begin{array}{l}7305 \\
7305\end{array}$ & $\begin{array}{l}154 \\
144\end{array}$ & $\begin{array}{l}40 \\
53\end{array}$ & $\begin{array}{l}21 \\
14\end{array}$ & 1 & $\begin{array}{l}3.9 \\
28\end{array}$ & $\begin{array}{l}866 \\
911\end{array}$ & $\begin{array}{l}0 \\
2\end{array}$ & $\begin{array}{l}46889 \\
47015\end{array}$ & $\begin{array}{l}12303 \\
13932\end{array}$ & $\begin{array}{l}0.0065 \\
0.0068\end{array}$ & $\begin{array}{l}0.9789 \\
0.9799\end{array}$ & $\begin{array}{l}0.2597 \\
0.365\end{array}$ & $\begin{array}{l}2.3 \\
35\end{array}$ & $\begin{array}{l}308 \\
263\end{array}$ & 304 & 0 & 542 & 5018 & 1237 & 372 & 136 & 0.751 \\
\hline $\begin{array}{l}55 \\
42\end{array}$ & $\begin{array}{l}7305 \\
7305\end{array}$ & $\begin{array}{l}147 \\
141\end{array}$ & $\begin{array}{l}53 \\
47\end{array}$ & $\begin{array}{l}14 \\
14\end{array}$ & 1 & $\begin{array}{l}2.8 \\
30\end{array}$ & $\begin{array}{l}911 \\
870\end{array}$ & $\begin{array}{l}2 \\
5\end{array}$ & $\begin{array}{l}47015 \\
47012\end{array}$ & 13932 & 0.0068 & $\begin{array}{l}0.9799 \\
0.087\end{array}$ & $\begin{array}{l}0.3605 \\
0\end{array}$ & $\begin{array}{l}3.5 \\
3.5\end{array}$ & 263 & $\begin{array}{l}320 \\
334\end{array}$ & 0 & $\begin{array}{l}545 \\
557\end{array}$ & $\begin{array}{l}4970 \\
\end{array}$ & $\begin{array}{l}1200 \\
1208\end{array}$ & 459 & 131 & 0.652 \\
\hline 100 & 7305 & 189 & $\begin{array}{l}41 \\
56\end{array}$ & $\begin{array}{l}14 \\
13 \\
13\end{array}$ & 1 & $\begin{array}{l}3.0 \\
3.4\end{array}$ & $\begin{array}{l}8 / 0 \\
855\end{array}$ & $\begin{array}{l}5 \\
3\end{array}$ & $\begin{array}{l}47042 \\
48027\end{array}$ & $\begin{array}{l}13678 \\
15367\end{array}$ & $\begin{array}{l}0.0071 \\
0.0053\end{array}$ & $\begin{array}{l}0.9807 \\
0.9741\end{array}$ & $\begin{array}{l}0.3333 \\
0.2963\end{array}$ & $\begin{array}{l}3.7 \\
30\end{array}$ & & $\begin{array}{l}334 \\
254\end{array}$ & $\begin{array}{l}0 \\
0\end{array}$ & $\begin{array}{l}537 \\
530\end{array}$ & $\begin{array}{l}4951 \\
4988\end{array}$ & $\begin{array}{l}1228 \\
1201\end{array}$ & $\begin{array}{l}458 \\
422\end{array}$ & $\begin{array}{l}131 \\
164\end{array}$ & 0.680 \\
\hline 33 & 7305 & 168 & 53 & 30 & 1 & 3.2 & 875 & 1 & 48694 & $\begin{array}{l}1536 / 2 \\
13412\end{array}$ & $\begin{array}{l}0.0053 \\
0.0060\end{array}$ & $\begin{array}{l}0.9 / 411 \\
0.9770\end{array}$ & $\begin{array}{l}0.2963 \\
0.3155\end{array}$ & $\begin{array}{l}3.0 \\
1.4\end{array}$ & $\begin{array}{l}2 / 4 \\
253\end{array}$ & $\begin{array}{l}254 \\
290\end{array}$ & 0 & $\begin{array}{l}530 \\
521\end{array}$ & $\begin{array}{l}4988 \\
5048\end{array}$ & $\begin{array}{l}1201 \\
1173\end{array}$ & $\begin{array}{l}422 \\
409\end{array}$ & $\begin{array}{l}164 \\
154\end{array}$ & $\begin{array}{l}0.711 \\
0.695\end{array}$ \\
\hline 47 & 7305 & 174 & 38 & 17 & 1 & 4.6 & 883 & 2 & 49119 & 12767 & 0.0057 & 0.9762 & 0.2184 & $\begin{array}{l}2.4 \\
2.5\end{array}$ & $\begin{array}{l}330 \\
336\end{array}$ & 282 & 0 & 528 & 5000 & 1204 & 412 & 161 & 0.790 \\
\hline 90 & 7305 & 164 & 51 & 24 & 1 & 3.2 & 865 & 0 & 49367 & 12917 & 0.0061 & 0.9775 & 0.3110 & 1.9 & 253 & 301 & 0 & 521 & 5042 & 1224 & 378 & 140 & 0.700 \\
\hline 48 & 7305 & 166 & 49 & 19 & 1 & 3.4 & 866 & 4 & 49613 & 12061 & 0.0060 & 0.9773 & 0.2952 & 2.3 & 246 & 299 & 0 & 538 & 5016 & 1180 & 417 & 154 & 0.715 \\
\hline 64 & 7305 & 169 & 55 & 17 & 1 & 3.1 & 918 & 0 & 49920 & 13314 & 0.0059 & 0.9769 & 0.3254 & 2.5 & 242 & 295 & 0 & 519 & 5017 & 1185 & 442 & 142 & 0.685 \\
\hline 14 & 7305 & 148 & 43 & 19 & 1 & 3.4 & 867 & 7 & 50116 & 11598 & 0.0068 & 0.9797 & 0.2905 & 2.6 & 270 & 339 & 0 & 493 & 5027 & 1200 & 440 & 145 & 0.723 \\
\hline 16 & 7305 & 204 & 47 & 23 & 1 & 4.3 & 884 & 0 & 50174 & 12429 & 0.0049 & 0.9721 & 0.2304 & 1.6 & 264 & 246 & 0 & 512 & 5136 & 1086 & 389 & 182 & 0.776 \\
\hline 73 & 7305 & 158 & 47 & 13 & 1 & 3.4 & 862 & 2 & 50391 & 13386 & 0.0063 & 0.9784 & 0.2975 & 3.6 & 285 & 319 & 0 & 504 & 5071 & 1239 & 348 & 143 & 0.714 \\
\hline 92 & 7305 & 154 & 33 & 19 & 1 & 4.7 & 865 & 3 & 50443 & 9097 & 0.0065 & 0.9789 & 0.2143 & 2.5 & 276 & 328 & 0 & 499 & 5077 & 1259 & 326 & 144 & 0.797 \\
\hline 19 & 7305 & 184 & 49 & 28 & 1 & 3.8 & 864 & 2 & 50592 & 14444 & 0.0054 & 0.9748 & 0.2663 & 1.4 & 295 & 275 & 0 & 516 & 5181 & 1073 & 366 & 169 & 0.742 \\
\hline 59 & 7305 & 173 & 54 & 18 & 1 & 3.2 & 868 & 5 & 50735 & 15823 & 0.0058 & 0.9763 & 0.3121 & 2.3 & 293 & 293 & 0 & & 5088 & 11 & 387 & 162 & 0.698 \\
\hline 91 & 7305 & 164 & 51 & 17 & 1 & 3.2 & 867 & 1 & 50897 & 15989 & 0.0061 & 0.9775 & 0.3110 & 2.6 & 314 & 310 & 0 & 28 & 5033 & & 369 & 149 & 0.700 \\
\hline 72 & 7305 & 146 & 46 & 21 & 1 & 3.2 & 860 & 11 & 50997 & 12327 & 0.0068 & 0.9800 & 0.3151 & 2.4 & 268 & 349 & 0 & 550 & 4998 & 1229 & 392 & 136 & 0.699 \\
\hline 94 & 7305 & 193 & 65 & 28 & 1 & 3.0 & 860 & 0 & 51422 & 14716 & 0.0052 & 0.9736 & 0.3368 & 1.4 & 226 & 266 & 0 & 539 & 4976 & & 423 & 176 & 0.672 \\
\hline 93 & 7305 & 162 & 46 & 34 & 1 & 3.5 & 883 & 1 & 51942 & 14526 & 0.0062 & 0.9778 & 0.2840 & 1.3 & 316 & 321 & 0 & 551 & 4997 & 12 & 398 & 150 & 0.728 \\
\hline 98 & 7305 & 183 & 54 & 18 & 1 & 3.4 & 897 & 1 & 52512 & 16887 & 0.0055 & 0.9749 & 0.2951 & 2.2 & 313 & 287 & 0 & 508 & 5072 & 1125 & 441 & 159 & 0.715 \\
\hline 79 & 7305 & 175 & 52 & 12 & 1 & 3.4 & 863 & 2 & 52638 & 14795 & 0.0057 & $\begin{array}{l}0.9760 \\
\end{array}$ & 0.2971 & 3.5 & 285 & 301 & 0 & 510 & 5079 & 11 & 400 & 162 & 0.713 \\
\hline 9 & 7305 & 177 & 61 & 12 & 1 & 2.9 & 863 & 13 & 52744 & 18019 & 0.0056 & 0.9758 & 0.3446 & 3.4 & 295 & 298 & 0 & 540 & 5059 & 11 & 387 & 160 & 0.667 \\
\hline 95 & $\begin{array}{l}7305 \\
77305\end{array}$ & 199 & $\begin{array}{l}46 \\
41\end{array}$ & 34 & 1 & 4.3 & 855 & 1 & 52782 & $\begin{array}{l}13623 \\
12150\end{array}$ & 0.0050 & 0.9728 & $\begin{array}{l}0.2312 \\
0.2505\end{array}$ & 1.1 & 296 & 265 & 0 & 524 & $\begin{array}{l}4989 \\
5078\end{array}$ & 1182 & 425 & 185 & 0.777 \\
\hline 86 & $\begin{array}{l}7305 \\
77305\end{array}$ & $\begin{array}{l}158 \\
182\end{array}$ & $\begin{array}{l}41 \\
59\end{array}$ & 22 & 1 & $\begin{array}{l}3.9 \\
31\end{array}$ & $\begin{array}{l}865 \\
851\end{array}$ & 7 & 53143 & $\begin{array}{l}13152 \\
15589\end{array}$ & 0.0063 & 0.9784 & $\begin{array}{l}0.2595 \\
0.342\end{array}$ & $\begin{array}{l}2.1 \\
25\end{array}$ & 321 & $\begin{array}{l}336 \\
392\end{array}$ & 0 & $\begin{array}{l}534 \\
532\end{array}$ & 5078 & 1142 & 403 & 148 & 0.753 \\
\hline $\begin{array}{l}20 \\
23\end{array}$ & $\begin{array}{l}7305 \\
7305\end{array}$ & $\begin{array}{l}182 \\
174\end{array}$ & $\begin{array}{l}59 \\
44\end{array}$ & $\begin{array}{l}16 \\
29\end{array}$ & $\begin{array}{l}1 \\
1\end{array}$ & $\begin{array}{l}3.1 \\
4.0\end{array}$ & $\begin{array}{l}851 \\
894\end{array}$ & $\begin{array}{l}1 \\
0\end{array}$ & $\begin{array}{l}53160 \\
53315\end{array}$ & $\begin{array}{l}15583 \\
1258\end{array}$ & 0.0055 & $\begin{array}{l}0.9751 \\
0.076\end{array}$ & $\begin{array}{l}0.3242 \\
0.2529\end{array}$ & $\begin{array}{l}2.5 \\
14\end{array}$ & $\begin{array}{l}264 \\
285\end{array}$ & $\begin{aligned} 292 \\
306\end{aligned}$ & $\begin{array}{l}0 \\
0\end{array}$ & $\begin{array}{l}532 \\
551\end{array}$ & 5045 & $\begin{array}{l}1156 \\
1215\end{array}$ & 408 & 164 & 0.686 \\
\hline 43 & $\begin{array}{l}7305 \\
7305\end{array}$ & 168 & 53 & 25 & 1 & 3.2 & $\begin{array}{l}894 \\
869\end{array}$ & 0 & $\begin{array}{l}533415 \\
53498\end{array}$ & $\begin{array}{l}12538 \\
14822\end{array}$ & $\begin{array}{l}0.0057 \\
0.0060\end{array}$ & $\begin{array}{l}0.9762 \\
0.9770\end{array}$ & $\begin{array}{l}0.2529 \\
0.3155\end{array}$ & $\begin{array}{l}1.4 \\
1.7\end{array}$ & $\begin{array}{l}285 \\
280\end{array}$ & $\begin{array}{l}306 \\
318\end{array}$ & 0 & $\begin{array}{l}511 \\
532\end{array}$ & $\begin{array}{l}5042 \\
5009\end{array}$ & $\begin{array}{l}1215 \\
1184\end{array}$ & $\begin{array}{l}376 \\
427\end{array}$ & $\begin{array}{l}161 \\
153\end{array}$ & $\begin{array}{l}0.757 \\
0.697\end{array}$ \\
\hline 6 & 7305 & 177 & 54 & 16 & 1 & 3.3 & 868 & 3 & 53635 & 15287 & 0.0056 & 0.9758 & 0.3051 & 2.6 & 283 & 303 & 0 & 515 & 5134 & 1126 & 369 & 161 & 0.706 \\
\hline $\begin{array}{l}0 \\
29\end{array}$ & 7305 & 183 & $\begin{array}{l}54 \\
50\end{array}$ & $\begin{array}{l}10 \\
26\end{array}$ & 1 & $\begin{array}{l}3.3 \\
3.7\end{array}$ & 862 & 0 & $\begin{array}{l}54064 \\
54064\end{array}$ & 15761 & 0.0055 & $\begin{array}{l}0.9748 \\
0\end{array}$ & 0.2732 & $\begin{array}{l}2.0 \\
1.5\end{array}$ & 315 & 295 & 0 & 517 & 5017 & 1243 & $\begin{array}{l}509 \\
357\end{array}$ & 171 & 0.737 \\
\hline 52 & 7305 & $\begin{array}{l}169 \\
169\end{array}$ & 55 & 27 & 1 & $\begin{array}{l}3.1 \\
3.1\end{array}$ & 873 & 4 & 54253 & 15110 & 0.0059 & 0.9769 & 0.3254 & 1.6 & 275 & 321 & 0 & 531 & 502 & 1167 & 429 & 156 & 0.687 \\
\hline 53 & 7305 & 180 & 53 & 15 & 1 & $\begin{array}{l}3.1 \\
3.4\end{array}$ & $\begin{array}{l}907 \\
907\end{array}$ & $\begin{array}{l}4 \\
1\end{array}$ & 54257 & 15965 & 0.0056 & 0.9754 & $\begin{array}{l}0.02944 \\
0.2944\end{array}$ & 2.7 & 301 & 301 & 0 & 52 & 5066 & 1155 & $\begin{array}{l}399 \\
399\end{array}$ & 162 & 0.716 \\
\hline 61 & 7305 & 192 & 48 & 29 & 1 & 4.0 & 959 & 3 & 54276 & 15090 & 0.0052 & 0.9737 & 0.2500 & 1.3 & 314 & 283 & 0 & 533 & 4957 & 1229 & 407 & 179 & 0.759 \\
\hline 83 & 7305 & 171 & 49 & 20 & 1 & 3.5 & 885 & 0 & 54420 & 15910 & 0.0058 & 0.9766 & 0.2865 & 2.1 & 325 & 318 & 0 & 514 & 5006 & 1247 & 379 & 159 & 0.725 \\
\hline
\end{tabular}




\begin{tabular}{|c|c|c|c|c|c|c|c|c|c|c|c|c|c|c|c|c|c|c|c|c|c|c|c|}
\hline 13 & 7305 & 175 & 48 & 17 & 1 & 3.6 & 952 & 3 & 54530 & 15301 & 0.0057 & 0.9760 & 0.2743 & 2.5 & 319 & 312 & 0 & 541 & 5047 & 1121 & 437 & 159 & 0.737 \\
\hline 32 & 7305 & 182 & 48 & 30 & 1 & 3.8 & 866 & 1 & 54575 & 13159 & 0.0055 & 0.9751 & 0.2637 & 1.3 & 274 & 300 & 0 & 526 & 5056 & 1176 & 376 & 171 & 0.746 \\
\hline 30 & 7305 & 185 & 61 & 16 & 1 & 3.0 & 897 & 0 & 54717 & 18505 & 0.0054 & 0.9747 & 0.3297 & 2.5 & 303 & 296 & 0 & 513 & 5033 & 1157 & 427 & 175 & 0.681 \\
\hline 3 & 7305 & 204 & 59 & 23 & 1 & 3.5 & 898 & 1 & 54965 & 15593 & 0.0049 & 0.9721 & 0.2892 & 1.6 & 264 & 269 & 0 & 509 & 5011 & 1148 & 454 & 183 & 0.719 \\
\hline 54 & 7305 & 180 & 47 & 30 & 1 & 3.8 & 861 & 2 & 55215 & 14148 & 0.0056 & 0.9754 & 0.2611 & 1.4 & 301 & 307 & 0 & 534 & 5105 & 1130 & 367 & 169 & 0.749 \\
\hline 51 & 7305 & 161 & 44 & 39 & 1 & 3.7 & 868 & 2 & 55230 & 12175 & 0.0062 & 0.9780 & 0.2733 & 1.2 & 277 & 343 & 0 & 526 & 5113 & 1111 & 408 & 147 & 0.740 \\
\hline 24 & 7305 & 172 & 48 & 28 & 1 & 3.6 & 869 & 1 & 56062 & 12065 & 0.0058 & 0.9765 & 0.2791 & 1.5 & 251 & 326 & 0 & 509 & 5086 & 1182 & 374 & 154 & 0.733 \\
\hline 82 & 7305 & 168 & 47 & 20 & 1 & 3.6 & 865 & 5 & 56203 & 13562 & 0.0060 & 0.9770 & 0.2798 & 2.2 & 289 & 335 & 0 & 530 & 5012 & 1254 & 353 & 156 & 0.733 \\
\hline 97 & 7305 & 192 & 58 & 18 & 1 & 3.3 & 876 & 2 & 56527 & 15254 & 0.0052 & 0.9737 & 0.3021 & 2.1 & 263 & 294 & 0 & 529 & 4996 & 1209 & 398 & 173 & 0.708 \\
\hline 70 & 7305 & 179 & 46 & 27 & 1 & 3.9 & 899 & 1 & 56563 & 12266 & 0.0056 & 0.9755 & 0.2570 & 1.5 & 267 & 316 & 0 & 522 & 5057 & 1187 & 376 & 163 & 0.754 \\
\hline 50 & 7305 & 156 & 46 & 38 & 1 & 3.4 & 898 & 2 & 56675 & 11554 & 0.0064 & 0.9786 & 0.2949 & 1.2 & 251 & 363 & 0 & 533 & 4993 & 1197 & 435 & 147 & 0.720 \\
\hline 5 & 7305 & 183 & 40 & 20 & 1 & 4.6 & 860 & 0 & 58064 & 13549 & 0.0055 & 0.9749 & 0.2186 & 2.0 & 339 & 317 & 0 & 525 & 5040 & 1198 & 368 & 174 & 0.792 \\
\hline 44 & 7305 & 192 & 59 & 25 & 1 & 3.3 & 891 & 1 & 58728 & 15143 & 0.0052 & 0.9737 & 0.3073 & 1.5 & 257 & 306 & 0 & 530 & 5023 & 1219 & 361 & 172 & 0.704 \\
\hline 39 & 7305 & 207 & 49 & 17 & 1 & 4.2 & 866 & 0 & 58967 & 16782 & 0.0048 & 0.9717 & 0.2367 & 2.1 & 342 & 285 & 0 & 505 & 5082 & 1130 & 399 & 189 & 0.772 \\
\hline 15 & 7305 & 175 & 49 & 22 & 1 & 3.6 & 871 & 3 & 59138 & 13580 & 0.0057 & 0.9760 & 0.2800 & 1.9 & 277 & 338 & 0 & 524 & 5001 & 1203 & 420 & 157 & 0.733 \\
\hline 49 & 7305 & 187 & 48 & 20 & 1 & 3.9 & 871 & 0 & 59314 & 15205 & 0.0053 & 0.9744 & 0.2567 & 2.0 & 317 & 317 & 0 & 529 & 5031 & 1243 & 328 & 174 & 0.755 \\
\hline 77 & 7305 & 207 & 61 & 24 & 1 & 3.4 & 869 & 0 & 59461 & 18859 & 0.0048 & 0.9717 & 0.2947 & 1.5 & 309 & 287 & 0 & 556 & 4952 & 1169 & 441 & 187 & 0.715 \\
\hline 25 & 7305 & 193 & 59 & 16 & 1 & 3.3 & 871 & 2 & 59651 & 17653 & 0.0052 & 0.9736 & 0.3057 & 2.4 & 299 & 309 & 0 & 515 & 5024 & 1193 & 390 & 183 & 0.706 \\
\hline 1 & 7305 & 146 & 34 & 27 & 1 & 4.3 & 1105 & 6 & 59819 & 10369 & 0.0068 & 0.9800 & 0.2329 & 1.9 & 305 & 410 & 0 & 514 & 5071 & 1210 & 373 & 137 & 0.785 \\
\hline 34 & 7305 & 174 & 45 & 27 & 1 & 3.9 & 867 & 4 & 60087 & 13779 & 0.0057 & 0.9762 & 0.2586 & 1.6 & 306 & 345 & 0 & 524 & 5010 & 1217 & 388 & 166 & 0.755 \\
\hline 21 & 7305 & 187 & 57 & 22 & 1 & 3.3 & 869 & 1 & 60096 & 15959 & 0.0053 & 0.9744 & 0.3048 & 1.8 & 280 & 321 & 0 & 540 & 4933 & 1243 & 409 & 180 & 0.707 \\
\hline 60 & 7305 & 177 & 48 & 38 & 1 & 3.7 & 866 & 2 & 60203 & 11819 & 0.0056 & 0.9758 & 0.2712 & 1.1 & 246 & 340 & 0 & 547 & 5005 & 1199 & 390 & 164 & 0.742 \\
\hline 35 & 7305 & 194 & 58 & 27 & 1 & 3.3 & 904 & 2 & 60212 & 16174 & 0.0052 & 0.9734 & 0.2990 & 1.4 & 279 & 310 & 0 & 558 & 5003 & 1107 & 465 & 172 & 0.712 \\
\hline 8 & 7305 & 185 & 46 & 19 & 1 & 4.0 & 880 & 0 & 60931 & 15304 & 0.0054 & 0.9747 & 0.2486 & 2.1 & 333 & 329 & 0 & 511 & 5115 & 1165 & 343 & 171 & 0.763 \\
\hline 57 & 7305 & 199 & 59 & 34 & 1 & 3.4 & 871 & 1 & 61443 & 16864 & 0.0050 & 0.9728 & 0.2965 & 1.1 & 286 & 309 & 0 & 527 & 5008 & 1188 & 396 & 186 & 0.715 \\
\hline 65 & 7305 & 204 & 43 & 43 & 1 & 4.7 & 881 & 1 & 61807 & 14301 & 0.0049 & 0.9721 & 0.2108 & 0.8 & 333 & 303 & 0 & 549 & 5046 & 1097 & 431 & 182 & 0.799 \\
\hline 22 & 7305 & 169 & 37 & 39 & 1 & 4.6 & 910 & 0 & 61950 & 11150 & 0.0059 & 0.9769 & 0.2189 & 1.1 & 301 & 367 & 0 & 540 & 4935 & 1283 & 386 & 161 & 0.795 \\
\hline 68 & 7305 & 184 & 50 & 18 & 1 & 3.7 & 871 & 1 & 62145 & 15503 & 0.0054 & 0.9748 & 0.2717 & 2.2 & 310 & 338 & 0 & 531 & 5074 & 1125 & 404 & 171 & 0.741 \\
\hline 80 & 7305 & 202 & 54 & 26 & 1 & 3.7 & 916 & 2 & 62426 & 14073 & 0.0050 & 0.9723 & 0.2673 & 1.4 & 261 & 309 & 0 & 497 & 5055 & 1145 & 421 & 187 & 0.744 \\
\hline 28 & 7305 & 192 & 60 & 25 & 1 & 3.2 & 872 & 3 & 62545 & 16498 & 0.0052 & 0.9737 & 0.3125 & 1.5 & 275 & 326 & 0 & 489 & 5119 & 1128 & 391 & 178 & 0.700 \\
\hline 12 & 7305 & 187 & 49 & 21 & 1 & 3.8 & 869 & 1 & 62601 & 13236 & 0.0053 & 0.9744 & 0.2620 & 1.9 & 270 & 335 & 0 & 528 & 5026 & 1193 & 383 & 175 & 0.750 \\
\hline 67 & 7305 & 174 & 49 & 21 & 1 & 3.6 & 866 & 3 & 62787 & 15076 & 0.0057 & 0.9762 & 0.2816 & 2.0 & 308 & 361 & 0 & 533 & 5044 & 1136 & 426 & 166 & 0.733 \\
\hline 96 & 7305 & 184 & 44 & 18 & 1 & 4.2 & 903 & 2 & 63090 & 13990 & 0.0054 & 0.9748 & 0.2391 & 2.2 & 318 & 343 & 0 & 544 & 5091 & 1102 & 399 & 169 & 0.774 \\
\hline 31 & 7305 & 192 & 52 & 22 & 1 & 3.7 & 900 & 1 & 63286 & 15034 & 0.0052 & 0.9737 & 0.2708 & 1.7 & 289 & 330 & 0 & 498 & 5067 & 1229 & 332 & 179 & 0.741 \\
\hline 10 & 7305 & 186 & 47 & 22 & 1 & 4.0 & 881 & 3 & 65107 & 14246 & 0.0054 & 0.9745 & 0.2527 & 1.8 & 303 & 350 & 0 & 517 & 5042 & 1186 & 388 & 172 & 0.761 \\
\hline 46 & 7305 & 210 & 46 & 31 & 1 & 4.6 & 912 & 1 & 65330 & 12541 & 0.0048 & 0.9713 & 0.2190 & 1.1 & 273 & 311 & 0 & 523 & 5067 & 1143 & 382 & 190 & 0.791 \\
\hline 63 & 7305 & 188 & 41 & 23 & 1 & 4.6 & 866 & 0 & 65827 & 11350 & 0.0053 & 0.9743 & 0.2181 & 1.7 & 277 & 350 & 0 & 530 & 5078 & 1182 & 340 & 175 & 0.795 \\
\hline 89 & 7305 & 240 & 64 & 29 & 1 & 3.8 & 872 & 1 & 68600 & 18882 & 0.0042 & 0.9671 & 0.2667 & 1.0 & 295 & 286 & 0 & 532 & 5097 & 1077 & 378 & 221 & 0.743 \\
\hline 37 & 7305 & 196 & 47 & 60 & 1 & 4.2 & 871 & 1 & 71545 & 11923 & 0.0051 & 0.9732 & 0.2398 & 0.6 & 254 & 365 & 0 & 542 & 4890 & 1303 & 389 & 181 & 0.775 \\
\hline 85 & 7305 & 199 & 48 & 29 & 1 & 4.1 & 903 & 2 & $\begin{array}{l}72428 \\
75122\end{array}$ & 15621 & 0.0050 & 0.9728 & 0.2412 & 1.3 & 325 & 364 & 0 & 505 & 4983 & 1184 & 445 & 188 & 0.773 \\
\hline $\begin{array}{r}75 \\
45\end{array}$ & $\begin{array}{l}7305 \\
7330\end{array}$ & $\begin{array}{l}223 \\
232\end{array}$ & 62 & $\begin{array}{l}27 \\
38\end{array}$ & 1 & $\begin{array}{l}3.6 \\
47\end{array}$ & $\begin{array}{l}869 \\
888\end{array}$ & $\begin{array}{l}1 \\
2\end{array}$ & $\begin{array}{l}75133 \\
76121\end{array}$ & $\begin{array}{l}17762 \\
172085\end{array}$ & $\begin{array}{l}0.0045 \\
\end{array}$ & 0.9695 & $\begin{array}{l}0.2780 \\
0.211\end{array}$ & $\begin{array}{l}1.2 \\
0.8\end{array}$ & $\begin{array}{l}286 \\
251\end{array}$ & 337 & 0 & $\begin{array}{l}545 \\
513\end{array}$ & $\begin{array}{l}4970 \\
509\end{array}$ & 1088 & $\begin{array}{l}495 \\
318\end{array}$ & $\begin{array}{l}207 \\
21\end{array}$ & 0.735 \\
\hline $\begin{array}{l}45 \\
99\end{array}$ & $\begin{array}{l}7305 \\
7305\end{array}$ & $\begin{array}{l}232 \\
225\end{array}$ & $\begin{array}{l}49 \\
52\end{array}$ & $\begin{array}{l}38 \\
25\end{array}$ & $\begin{array}{l}1 \\
1\end{array}$ & $\begin{array}{l}4.7 \\
4.3\end{array}$ & $\begin{array}{l}888 \\
868\end{array}$ & $\begin{array}{l}2 \\
2\end{array}$ & $\begin{array}{l}766121 \\
76696\end{array}$ & $\begin{array}{l}\text { 122285 } \\
16087\end{array}$ & $\begin{array}{l}0.00033 \\
0.0044\end{array}$ & $\begin{array}{l}0.9982 \\
0.9692\end{array}$ & $\begin{array}{l}0.2112 \\
0.2311\end{array}$ & $\begin{array}{l}0.8 \\
1.3\end{array}$ & $\begin{array}{l}251 \\
309\end{array}$ & $\begin{array}{l}328 \\
341\end{array}$ & $\begin{array}{l}0 \\
0\end{array}$ & $\begin{array}{l}513 \\
528\end{array}$ & $\begin{array}{l}5068 \\
5060\end{array}$ & $\begin{array}{l}1194 \\
1125\end{array}$ & $\begin{array}{l}318 \\
384\end{array}$ & $\begin{array}{l}212 \\
208\end{array}$ & $\begin{array}{l}0.800 \\
0.781\end{array}$ \\
\hline Minimum & & 127 & 33 & 10 & 1 & 2.5 & 500 & 0 & 3294 & 90 & 0.0042 & 0.9671 & 0.2108 & 0.6 & 219 & 231 & 0 & 489 & 4890 & 1073 & 318 & 116 & 0.617 \\
\hline Average & & 173 & 49 & 23 & 1 & 3.6 & 875 & 2 & 53426 & 13903 & 0.0059 & 0.9763 & 0.2865 & 2.1 & 283 & 308 & 0 & 525 & 5038 & 1186 & 397 & 159 & 0.725 \\
\hline Maximum & & 240 & 65 & 60 & 1 & 4.7 & 1105 & 13 & 76696 & 18882 & 0.0079 & 0.9826 & 0.3931 & 5.0 & 342 & 410 & 0 & 558 & 5181 & 1303 & 495 & 221 & 0.800 \\
\hline Std.dev & & 23.4 & 6.6 & 8.2 & 0 & 0.5 & 48.3 & 2.2 & 9041.4 & 2066.2 & 0.0008 & 0.0032 & 0.0388 & 0.9 & 27.2 & 31.3 & 0.0 & 14.5 & 52.4 & 48.1 & 34.5 & 21.7930 & 0.039 \\
\hline
\end{tabular}


Scenerio NScenario 13c CSIROMk2b B11 with 5\% additional WEMPs savings $\square$ Higher population projection and Climate Change effect

\begin{tabular}{ll} 
Date: & $19 / 10 / 2007$ \\
Simulation & $8: 01: 23 \mathrm{PM}$ \\
\hline
\end{tabular}

$\begin{array}{lll}\text { Simulation } & \text { 8:49:14 PM } \\ \text { Elapsed Til } & 47.85 \text { Minutes } & \\ & \end{array}$

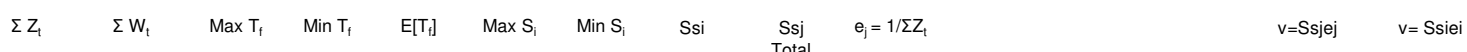

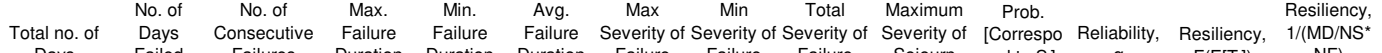

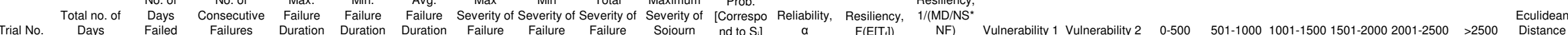

\begin{tabular}{|c|c|c|c|c|c|c|c|c|c|c|c|c|c|c|c|c|c|c|c|c|c|c|}
\hline & & & & & & & & & & & & & & & & & & & & & & \\
\hline 7305 & 567 & 116 & 53 & 1 & 4.9 & 1878 & 1 & 311068 & 54127 & 0.0018 & 0.9224 & 0.2046 & 0.243 & 467 & 549 & 0 & -181 & 2732 & 5735 & 3744 & 543 & 0.829 \\
\hline 7305 & 551 & 141 & 64 & 1 & 3.9 & 1862 & 2 & 261745 & 60085 & 0.0018 & 0.9246 & 0.2559 & 0.207 & 426 & 475 & 0 & -81 & 2808 & 5688 & 3667 & 527 & $\begin{array}{l}0.772 \\
0.799\end{array}$ \\
\hline 7305 & 629 & 147 & 51 & 1 & 4.3 & 1880 & 0 & 327750 & 70611 & 0.0016 & 0.9139 & 0.2337 & 0.228 & 480 & 521 & 0 & -108 & 2765 & 5630 & 3647 & 592 & 0.799 \\
\hline 7305 & 509 & 119 & 54 & 1 & 4.3 & 1875 & 2 & 239181 & 57838 & 0.0020 & 0.9303 & 0.2338 & 0.266 & 486 & 470 & 0 & -297 & 2612 & 5736 & 3907 & 490 & 0.792 \\
\hline 7305 & 527 & 113 & 55 & 1 & 4.7 & 1865 & 8 & 303287 & 56273 & 0.0019 & 0.9279 & 0.2144 & 0.252 & 498 & 575 & 0 & -216 & 2664 & 5760 & 3838 & 507 & 822 \\
\hline 7305 & 518 & 128 & 31 & 1 & 4.0 & 1876 & 2 & 284603 & 61269 & 0.0019 & 0.9291 & 0.2471 & 0.455 & 479 & 549 & 0 & -158 & 2731 & 5749 & 3799 & 493 & 0.788 \\
\hline 7305 & 537 & 127 & 48 & 1 & 4.2 & 1762 & 0 & 258236 & 55198 & 0.0019 & 0.9265 & 0.2365 & 0.283 & 435 & 481 & 0 & -188 & 2681 & 5710 & 3824 & 506 & 0.791 \\
\hline $\begin{array}{l}7305 \\
7305\end{array}$ & 560 & 123 & 58 & 1 & 4.6 & 1875 & 1 & 292509 & 58779 & 0.0018 & 0.9233 & 0.2196 & 0.225 & 478 & 522 & 0 & -169 & 2765 & 5726 & 3728 & 532 & 811 \\
\hline $\begin{array}{l}7305 \\
705\end{array}$ & 568 & 127 & 39 & 1 & 4.5 & 1865 & 1 & $\begin{array}{l}301688 \\
32201\end{array}$ & 57703 & 0.0018 & 0.9222 & 0.2236 & 0.330 & 454 & 531 & 0 & -168 & 2725 & 5671 & 3741 & 544 & 809 \\
\hline $\begin{array}{l}7305 \\
7305\end{array}$ & $\begin{array}{l}552 \\
552\end{array}$ & $\begin{array}{l}102 \\
128\end{array}$ & $\begin{array}{l}59 \\
49\end{array}$ & 1 & $\begin{array}{l}5.4 \\
4.4\end{array}$ & 1924 & 4 & $\begin{array}{r}323109 \\
\end{array}$ & 50324 & 0.0018 & 0.9244 & 0.1848 & 0.224 & 493 & 585 & 0 & -300 & 2675 & 5767 & $\begin{array}{l}3830 \\
3730\end{array}$ & 534 & $\begin{array}{l}0.852 \\
0.786\end{array}$ \\
\hline 7305 & $\begin{array}{l}2522 \\
565\end{array}$ & $\begin{array}{l}128 \\
116\end{array}$ & $\begin{array}{l}46 \\
56\end{array}$ & $\begin{array}{l}1 \\
1\end{array}$ & $\begin{array}{l}4.1 \\
4.9\end{array}$ & $\begin{array}{l}1890 \\
1929\end{array}$ & $\begin{array}{l}1 \\
0\end{array}$ & $\begin{array}{r}269109 \\
309769\end{array}$ & $\begin{array}{l}57028 \\
54840\end{array}$ & 0.0019 & 0.9285 & 0.2452 & 0.304 & $\begin{array}{l}446 \\
473\end{array}$ & $\begin{array}{l}516 \\
548\end{array}$ & 0 & -84 & $\begin{array}{r}2759 \\
2690\end{array}$ & $\begin{array}{l}5658 \\
5714\end{array}$ & $\begin{array}{l}3738 \\
3802\end{array}$ & $\begin{array}{l}499 \\
535\end{array}$ & $\begin{array}{l}0.786 \\
0.828\end{array}$ \\
\hline 7305 & 543 & 114 & 52 & 1 & $\begin{array}{l}4.9 \\
4.8\end{array}$ & 1898 & $\begin{array}{l}0 \\
2\end{array}$ & 296930 & $\begin{array}{l}44840 \\
49363\end{array}$ & $\begin{array}{l}0.0018 \\
0.0018\end{array}$ & $\begin{array}{l}0.9227 \\
0.9257\end{array}$ & $\begin{array}{l}0.2053 \\
0.2099\end{array}$ & $\begin{array}{l}0.231 \\
0.259\end{array}$ & $\begin{array}{l}4 / 3 \\
433\end{array}$ & $\begin{array}{l}548 \\
547\end{array}$ & $\begin{array}{l}0 \\
0\end{array}$ & $\begin{array}{l}-214 \\
-187\end{array}$ & $\begin{array}{l}2690 \\
2707\end{array}$ & $\begin{array}{l}5714 \\
5674\end{array}$ & $\begin{array}{l}3802 \\
3780\end{array}$ & $\begin{array}{l}535 \\
524\end{array}$ & $\begin{array}{l}0.828 \\
0.823\end{array}$ \\
\hline 7305 & 521 & 120 & 43 & 1 & 4.3 & 1883 & 0 & 272501 & 53977 & 0.0019 & 0.9287 & 0.2303 & 0.326 & 450 & 523 & 0 & -135 & 2755 & 5727 & 3780 & 494 & 0.801 \\
\hline 7305 & 539 & 117 & 39 & 1 & 4.6 & 1879 & 1 & 325183 & 59905 & 0.0019 & 0.9262 & 0.2171 & 0.348 & 512 & 603 & 0 & -184 & 2695 & 5724 & 3810 & 523 & 0.823 \\
\hline 7305 & 542 & 125 & 74 & 1 & 4.3 & 1920 & 2 & 263799 & 54115 & 0.0018 & 0.9258 & 0.2306 & 0.182 & 433 & 487 & 0 & -205 & 2741 & 5714 & 3782 & 508 & 0.797 \\
\hline 7305 & 539 & 113 & 45 & 1 & 4.8 & 1872 & 1 & 277746 & 54347 & 0.0019 & 0.9262 & 0.2096 & 0.301 & 481 & 515 & 0 & -198 & 2698 & 5705 & 3817 & 509 & 0.820 \\
\hline 7305 & 552 & 128 & 31 & 1 & 4.3 & 1882 & 1 & 282939 & 61107 & 0.0018 & 0.9244 & 0.2319 & 0.427 & 477 & 513 & 0 & -124 & 2784 & 5715 & 3693 & 527 & 0.799 \\
\hline 7305 & 563 & 111 & 77 & 1 & 5.1 & 1963 & 5 & 289652 & 49875 & 0.0018 & 0.9229 & 0.1972 & 0.169 & 449 & 514 & 0 & -287 & 2680 & 5756 & 3819 & 542 & 0.832 \\
\hline 7305 & 545 & 120 & 60 & 1 & 4.5 & 1856 & 3 & 286567 & 55048 & 0.0018 & 0.9254 & 0.2202 & 0.223 & 459 & 526 & 0 & -96 & 2794 & 5724 & 3678 & 513 & 811 \\
\hline 7305 & 603 & 123 & 39 & 1 & 4.9 & 1877 & 1 & 336822 & 58806 & 0.0017 & 0.9175 & 0.2040 & 0.311 & 478 & 559 & 0 & -156 & 2740 & 5645 & 3688 & 585 & 831 \\
\hline 7305 & 577 & 111 & 61 & 1 & 5.2 & 1964 & 3 & 314807 & 56523 & 0.0017 & 0.9210 & 0.1924 & 0.208 & 509 & 546 & 0 & -239 & 2694 & 5772 & 3764 & 556 & 0.840 \\
\hline 7305 & 542 & 113 & 65 & 1 & 4.8 & 1909 & 1 & 278682 & 47346 & 0.0018 & 0.9258 & 0.2085 & 0.207 & 419 & 514 & 0 & -212 & 2725 & 5708 & 3780 & 512 & 0.821 \\
\hline $\begin{array}{l}7305 \\
7305\end{array}$ & $\begin{array}{l}515 \\
555\end{array}$ & 111 & 50 & 1 & 4.6 & 1874 & 2 & $\begin{array}{r}274898 \\
318719\end{array}$ & $\begin{array}{l}56233 \\
5706\end{array}$ & 0.0019 & 0.9295 & 0.2155 & 0.284 & 507 & $\begin{array}{l}534 \\
577\end{array}$ & 0 & -142 & 2760 & 5741 & 3770 & 490 & $\begin{array}{l}0.816 \\
0.833\end{array}$ \\
\hline $\begin{array}{l}7305 \\
7305\end{array}$ & $\begin{array}{l}552 \\
558\end{array}$ & 112 & 38 & 1 & 4.9 & 1909 & 1 & $\begin{array}{r}318719 \\
300582\end{array}$ & $\begin{array}{l}57063 \\
55959\end{array}$ & 0.0018 & & 0.2029 & 0.348 & 509 & $\begin{array}{l}577 \\
511\end{array}$ & 0 & -204 & 2680 & 5705 & 3793 & 534 & $\begin{array}{l}0.833 \\
0.829\end{array}$ \\
\hline 7305 & $\begin{array}{l}588 \\
528\end{array}$ & $\begin{array}{l}118 \\
116\end{array}$ & $\begin{array}{l}60 \\
51\end{array}$ & $\begin{array}{l}1 \\
1\end{array}$ & $\begin{array}{l}5.0 \\
4.6\end{array}$ & $\begin{array}{l}1861 \\
1872\end{array}$ & $\begin{array}{l}2 \\
2\end{array}$ & $\begin{array}{l}\begin{array}{l}000582 \\
274120\end{array} \\
2712\end{array}$ & $\begin{array}{l}56951 \\
57179\end{array}$ & $\begin{array}{l}0.0017 \\
0.0019\end{array}$ & $\begin{array}{l}0.9195 \\
0.9277\end{array}$ & $\begin{array}{l}0.2007 \\
0.2197\end{array}$ & $\begin{array}{l}0.207 \\
0.271\end{array}$ & $\begin{array}{l}483 \\
493 \\
493\end{array}$ & $\begin{array}{l}511 \\
519\end{array}$ & $\begin{array}{l}0 \\
0\end{array}$ & $\begin{array}{l}-201 \\
-199\end{array}$ & $\begin{array}{l}2762 \\
2707\end{array}$ & $\begin{array}{l}5694 \\
5736\end{array}$ & $\begin{array}{l}3696 \\
3801\end{array}$ & $\begin{array}{l}564 \\
505\end{array}$ & $\begin{array}{l}0.829 \\
0.811\end{array}$ \\
\hline 7305 & 569 & 121 & 55 & 1 & 4.7 & 1876 & 0 & 312723 & 56944 & 0.0018 & 0.9221 & 0.2127 & 0.233 & 471 & 550 & 0 & -193 & 2654 & 5686 & 3829 & 542 & 0.821 \\
\hline 7305 & 588 & 130 & 50 & 1 & 4.5 & 1875 & 1 & 307830 & 63270 & 0.0017 & 0.9195 & 0.2211 & 0.248 & 487 & 524 & 0 & -165 & 2775 & 5733 & 3698 & 559 & 0.811 \\
\hline 7305 & 577 & 114 & 46 & 1 & 5.1 & 1925 & 0 & 318785 & 61430 & 0.0017 & 0.9210 & 0.1976 & 0.275 & 539 & 552 & 0 & -273 & 2629 & 5739 & 3838 & 556 & 0.836 \\
\hline 7305 & 521 & 117 & 67 & 1 & 4.5 & 1949 & 2 & 319539 & 63363 & 0.0019 & 0.9287 & 0.2246 & 0.209 & 542 & 613 & 0 & -248 & 2603 & 5731 & 3922 & 503 & 0.816 \\
\hline 7305 & 505 & 110 & 38 & 1 & 4.6 & 1881 & 5 & 274408 & 55613 & 0.0020 & 0.9309 & 0.2178 & 0.381 & 506 & 543 & 0 & -280 & 2627 & 5735 & 3897 & 485 & 0.815 \\
\hline 7305 & 577 & 104 & 46 & 1 & 5.5 & 1895 & 1 & 311858 & 53431 & 0.0017 & 0.9210 & 0.1802 & 0.275 & 514 & 540 & 0 & -242 & 2633 & 5718 & 3819 & 560 & 851 \\
\hline 7305 & 538 & 115 & 47 & 1 & 4.7 & 1879 & 1 & 317801 & 58881 & 0.0019 & 0.9264 & 0.2138 & 0.289 & 512 & 591 & 0 & -175 & 2735 & 5677 & 3769 & 511 & 0.824 \\
\hline 7305 & 584 & 120 & 32 & 1 & 4.9 & 1920 & 0 & 312760 & 63544 & 0.0017 & 0.9201 & 0.2055 & 0.391 & 530 & 536 & 0 & -181 & 2659 & 5668 & 3774 & 562 & 27 \\
\hline 7305 & 563 & 116 & 56 & 1 & 4.9 & 1867 & 0 & 282127 & 56618 & 0.0018 & 0.9229 & 0.2060 & 0.232 & 488 & 501 & 0 & -261 & 2631 & 5689 & 3846 & 541 & 822 \\
\hline 7305 & 611 & 127 & 60 & 1 & 4.8 & 1881 & 1 & 349557 & 59257 & 0.0016 & 0.9164 & 0.2079 & 0.199 & 467 & 572 & 0 & -154 & 2760 & 5630 & 3670 & 583 & 329 \\
\hline $\begin{array}{l}7305 \\
705\end{array}$ & $\begin{array}{l}572 \\
554\end{array}$ & $\begin{array}{l}120 \\
114\end{array}$ & $\begin{array}{l}37 \\
71\end{array}$ & 1 & $\begin{array}{l}4.8 \\
4.8\end{array}$ & $\begin{array}{l}1873 \\
1876\end{array}$ & 2 & $\begin{array}{l}264658 \\
288971\end{array}$ & $\begin{array}{l}55261 \\
55451\end{array}$ & 0.0017 & $\begin{array}{l}0.9217 \\
0\end{array}$ & 0.2098 & 0.345 & $\begin{array}{l}461 \\
469\end{array}$ & $\begin{array}{l}463 \\
531\end{array}$ & 0 & -196 & $\begin{array}{l}2710 \\
2707\end{array}$ & 5662 & 3746 & 551 & 315 \\
\hline $\begin{array}{l}7305 \\
7305\end{array}$ & $\begin{array}{l}544 \\
489\end{array}$ & $\begin{array}{l}114 \\
115\end{array}$ & $\begin{array}{l}71 \\
41\end{array}$ & $\begin{array}{l}1 \\
1\end{array}$ & $\begin{array}{l}4.8 \\
4.3\end{array}$ & $\begin{array}{l}1876 \\
1538\end{array}$ & 1 & $\begin{array}{l}288971 \\
231172\end{array}$ & $\begin{array}{l}53454 \\
55195\end{array}$ & 0.0018 & 0.9255 & 0.2096 & $\begin{array}{l}0.189 \\
0364\end{array}$ & $\begin{array}{l}469 \\
445\end{array}$ & $\begin{array}{l}531 \\
474\end{array}$ & $\begin{array}{l}0 \\
0 \\
0\end{array}$ & $\begin{array}{l}-201 \\
-178\end{array}$ & $\begin{array}{l}2727 \\
272\end{array}$ & $\begin{array}{l}5745 \\
5739\end{array}$ & 3774 & 520 & $\begin{array}{l}0.822 \\
0.791\end{array}$ \\
\hline 7305 & $\begin{array}{l}8899 \\
477\end{array}$ & 113 & $\begin{array}{l}41 \\
28\end{array}$ & 1 & $\begin{array}{l}4.3 \\
4.2\end{array}$ & $\begin{array}{l}1538 \\
1907\end{array}$ & 1 & 246787 & 56495 & $\begin{array}{l}0.0020 \\
0.0021\end{array}$ & 0.9347 & $\begin{array}{l}0.2352 \\
0.2369\end{array}$ & $\begin{array}{l}0.364 \\
0.547\end{array}$ & $\begin{array}{l}445 \\
500\end{array}$ & $\begin{array}{l}4 / 4 \\
517\end{array}$ & 0 & $\begin{array}{l}-1 / 8 \\
-146\end{array}$ & 2764 & $\begin{array}{l}5 / 39 \\
5730\end{array}$ & $\begin{array}{l}3853 \\
3783\end{array}$ & $\begin{array}{l}465 \\
451\end{array}$ & $\begin{array}{l}0.991 \\
0.793\end{array}$ \\
\hline 7305 & 539 & 111 & 44 & 1 & 4.9 & 1871 & 2 & 285506 & 54125 & 0.0019 & 0.9262 & 0.2059 & 0.308 & 488 & 530 & 0 & -212 & 2640 & 5698 & 3851 & 517 & 0.825 \\
\hline 7305 & 618 & 129 & 60 & 1 & 4.8 & 1910 & 1 & 332266 & 61721 & 0.0016 & 0.9154 & 0.2087 & 0.197 & 478 & 538 & 0 & -139 & 2788 & 5709 & 3641 & 595 & 0.824 \\
\hline 7305 & 556 & 108 & 33 & 1 & 5.1 & 1929 & 1 & 320176 & 57657 & 0.0018 & 0.9239 & 0.1942 & 0.398 & 534 & 576 & 0 & -270 & 2658 & 5702 & 3809 & 537 & 0.841 \\
\hline 7305 & 550 & 109 & 66 & 1 & 5.0 & 1877 & 1 & 333863 & 49174 & 0.0018 & 0.9247 & 0.1982 & 0.2 & 451 & 607 & 0 & -23 & 2635 & 5696 & 3854 & 524 & 0.841 \\
\hline 7305 & 536 & 104 & 50 & 1 & 5.2 & 1916 & 0 & 341383 & 56158 & 0.0019 & 0.9266 & 0.1940 & 0.2 & 540 & 637 & 0 & -18 & 2725 & 5753 & 3768 & 519 & 0.848 \\
\hline 7305 & 523 & 116 & 62 & 1 & 4.5 & 1870 & 0 & 288319 & 55182 & 0.0019 & 0.9284 & 0.2 & 0.2 & 476 & 551 & 0 & -21 & 2679 & & & 505 & 0.812 \\
\hline 7305 & 573 & 117 & 43 & 1 & 4.9 & 1873 & 1 & 308704 & 61089 & 0.0017 & 0.9216 & 0.2 & 0.2 & 522 & 539 & 0 & -15 & 2675 & 5682 & 3773 & 542 & 0.828 \\
\hline 7305 & 587 & 113 & 87 & 1 & 5.2 & 1878 & 1 & 330701 & 50945 & 0.0017 & 0.9196 & 0.1 & & 451 & 563 & 0 & -259 & 2649 & 5687 & 3812 & 562 & 0.842 \\
\hline 7305 & $\begin{array}{l}585 \\
582\end{array}$ & 132 & $\begin{array}{l}43 \\
59\end{array}$ & 1 & 4.4 & $\begin{array}{l}1913 \\
1905\end{array}$ & 1 & 315385 & 61000 & 0.0017 & 0.9199 & 0.2 & 0.2 & 462 & 539 & 0 & -95 & 2838 & 5691 & 3609 & 567 & 0.808 \\
\hline 7305 & $\begin{array}{l}528 \\
584\end{array}$ & 116 & 52 & 1 & $\begin{array}{l}4.6 \\
51\end{array}$ & 1905 & 1 & 293230 & 48634 & 0.0019 & 0.9277 & 0.2197 & 0.266 & 419 & 555 & 0 & -235 & 2657 & 5752 & 3863 & $\begin{array}{l}494 \\
557\end{array}$ & 0.815 \\
\hline $\begin{array}{l}7305 \\
7305\end{array}$ & $\begin{array}{l}584 \\
573\end{array}$ & $\begin{array}{l}115 \\
117\end{array}$ & $\begin{array}{l}67 \\
41\end{array}$ & 1 & 5.1 & $\begin{array}{l}1878 \\
1876\end{array}$ & $\begin{array}{l}0 \\
1\end{array}$ & 309233 & 55901 & 0.0017 & 0.9201 & 0.1969 & 0.187 & $\begin{array}{l}486 \\
488\end{array}$ & $\begin{array}{l}530 \\
535\end{array}$ & 0 & -134 & $\begin{array}{l}2723 \\
2707\end{array}$ & 5712 & 3736 & 557 & 0.834 \\
\hline $\begin{array}{l}7305 \\
7305\end{array}$ & $\begin{array}{l}573 \\
528\end{array}$ & $\begin{array}{l}117 \\
105\end{array}$ & $\begin{array}{l}41 \\
56\end{array}$ & $\begin{array}{l}1 \\
1\end{array}$ & $\begin{array}{l}4.9 \\
5.0\end{array}$ & $\begin{array}{l}1876 \\
1876\end{array}$ & $\begin{array}{l}1 \\
2\end{array}$ & $\begin{array}{l}3066632 \\
3115332\end{array}$ & $\begin{array}{l}57044 \\
50598\end{array}$ & $\begin{array}{l}0.0017 \\
0.0019\end{array}$ & $\begin{array}{l}0.9216 \\
0\end{array}$ & $\begin{array}{l}0.2042 \\
0 \\
0.1989\end{array}$ & $\begin{array}{l}0.311 \\
0.247\end{array}$ & $\begin{array}{l}488 \\
482\end{array}$ & $\begin{array}{l}535 \\
590\end{array}$ & $\begin{array}{l}0 \\
0 \\
0\end{array}$ & $\begin{array}{l}-168 \\
-259\end{array}$ & $\begin{array}{l}2707 \\
2703\end{array}$ & 5648 & $\begin{array}{l}3739 \\
3851\end{array}$ & $\begin{array}{l}549 \\
507\end{array}$ & 0.8288 \\
\hline $\begin{array}{l}7305 \\
7305\end{array}$ & $\begin{array}{l}528 \\
562\end{array}$ & $\begin{array}{l}105 \\
140\end{array}$ & $\begin{array}{l}56 \\
45\end{array}$ & $\begin{array}{l}1 \\
1\end{array}$ & $\begin{array}{l}5.0 \\
4.0\end{array}$ & $\begin{array}{l}18 / 6 \\
1900\end{array}$ & $\begin{array}{l}2 \\
0\end{array}$ & $\begin{array}{l}\begin{array}{l}111533 \\
276380\end{array}\end{array}$ & $\begin{array}{l}50598 \\
60652\end{array}$ & $\begin{array}{l}0.0019 \\
0.0018\end{array}$ & $\begin{array}{l}0.92817 \\
0.9231\end{array}$ & $\begin{array}{l}0.19899 \\
0.2491\end{array}$ & $\begin{array}{l}0.244 \\
0.289\end{array}$ & $\begin{array}{l}482 \\
433\end{array}$ & $\begin{array}{l}590 \\
492\end{array}$ & $\begin{array}{l}0 \\
0\end{array}$ & $\begin{array}{l}-259 \\
-58\end{array}$ & $\begin{array}{l}2663 \\
2822\end{array}$ & $\begin{array}{l}5 / 30 \\
5690\end{array}$ & $\begin{array}{l}3851 \\
3650\end{array}$ & $\begin{array}{l}501 \\
530\end{array}$ & $\begin{array}{l}0.838 \\
0.780\end{array}$ \\
\hline 7305 & 544 & 125 & 45 & 1 & 4.4 & 1916 & 2 & 280880 & 55589 & 0.0018 & 0.9255 & 0.2298 & 0.298 & 445 & 516 & 0 & -198 & 2709 & 5707 & 3784 & 525 & 0.801 \\
\hline 7305 & 560 & 120 & 35 & 1 & 4.7 & 1874 & 1 & 319792 & 63830 & 0.0018 & 0.9233 & 0.2143 & 0.373 & 532 & 571 & 0 & -170 & 2720 & 5680 & 3751 & 541 & 0.822 \\
\hline 7305 & 541 & 123 & 59 & 1 & 4.4 & 1860 & 6 & 267901 & 58053 & 0.0018 & 0.9259 & 0.2274 & 0.229 & 472 & 495 & 0 & -226 & 2692 & 5702 & 3805 & 515 & 0.801 \\
\hline
\end{tabular}




\begin{tabular}{|c|c|c|c|c|c|c|c|c|c|c|c|c|c|c|c|c|c|c|c|c|c|c|c|}
\hline 59 & 7305 & 569 & 98 & 38 & 1 & 58 & 1877 & 2 & 334978 & 57673 & 00018 & 0.9221 & 0.1722 & 0.338 & 589 & 589 & 0 & -314 & 2659 & 5695 & 3819 & 549 & 0.864 \\
\hline 60 & 7305 & 572 & 124 & 59 & 1 & 4.6 & 1874 & 0 & 312782 & 57330 & 0.0017 & 0.9217 & 0.2168 & 0.216 & 462 & 547 & 0 & -168 & 2740 & 5670 & 3729 & 539 & 0.817 \\
\hline 61 & 7305 & 570 & 108 & 44 & 1 & 5.3 & 1868 & 2 & 298405 & 54194 & 0.0018 & 0.9220 & 0.1895 & 0.291 & 502 & 524 & 0 & -233 & 2630 & 5695 & 3838 & 539 & 0.841 \\
\hline 62 & 7305 & 591 & 132 & 38 & 1 & 4.5 & 1864 & 0 & 298559 & 56608 & 0.0017 & 0.9191 & 0.2234 & 0.325 & 429 & 505 & 0 & -119 & 2826 & 5636 & 3617 & 570 & 0.807 \\
\hline 63 & 7305 & 549 & 132 & 35 & 1 & 4.2 & 1868 & 0 & 307825 & 55791 & 0.0018 & 0.9248 & 0.2404 & 0.380 & 423 & 561 & 0 & -151 & 2761 & 5731 & 3744 & 522 & 0.796 \\
\hline 64 & 7305 & 495 & 112 & 32 & 1 & 4.4 & 1943 & 1 & 267395 & 54768 & 0.0020 & 0.9322 & 0.2263 & 0.461 & 489 & 540 & 0 & -206 & 2637 & 5686 & 3900 & 476 & 0.806 \\
\hline 65 & 7305 & 600 & 114 & 39 & 1 & 5.3 & 1865 & 1 & 314663 & 57587 & 0.0017 & 0.9179 & 0.1900 & 0.312 & 505 & 524 & 0 & -177 & 2753 & 5690 & 3667 & 582 & 0.841 \\
\hline 66 & 7305 & 584 & 97 & 52 & 1 & 6.0 & 1857 & 2 & 316362 & 52699 & 0.0017 & 0.9201 & 0.1661 & 0.241 & 543 & 542 & 0 & -312 & 2606 & 5717 & 3856 & 561 & 0.865 \\
\hline 67 & 7305 & 582 & 115 & 52 & 1 & 5.1 & 1875 & 1 & 323998 & 60567 & 0.0017 & 0.9203 & 0.1976 & 0.241 & 527 & 557 & 0 & -165 & 2723 & 5658 & 3729 & 560 & 0.837 \\
\hline 68 & 7305 & 614 & 112 & 58 & 1 & 5.5 & 1880 & 0 & 338287 & 53927 & 0.0016 & 0.9159 & 0.1824 & 0.205 & 481 & 551 & 0 & -257 & 2602 & 5680 & 3840 & 579 & 0.851 \\
\hline 69 & 7305 & 577 & 111 & 39 & 1 & 5.2 & 1913 & 1 & 322786 & 58927 & 0.0017 & 0.9210 & 0.1924 & 0.325 & 531 & 559 & 0 & -186 & 2727 & 5700 & 3727 & 551 & 0.842 \\
\hline 70 & 7305 & 578 & 125 & 66 & 1 & 4.6 & 1901 & 2 & 310110 & 51579 & 0.0017 & 0.9209 & 0.2163 & 0.191 & 413 & 537 & 0 & -192 & 2786 & 5702 & 3690 & 550 & 0.816 \\
\hline 71 & 7305 & 571 & 111 & 57 & 1 & 5.1 & 1862 & 7 & 285803 & 49250 & 0.0018 & 0.9218 & 0.1944 & 0.224 & 444 & 501 & 0 & -192 & 2700 & 5763 & 3783 & 549 & 0.834 \\
\hline 72 & 7305 & 573 & 128 & 43 & 1 & 4.5 & 1870 & 0 & 280672 & 60814 & 0.0017 & 0.9216 & 0.2234 & 0.296 & 475 & 490 & 0 & -83 & 2820 & 5677 & 3645 & 538 & 0.805 \\
\hline 73 & 7305 & 534 & 116 & 54 & 1 & 4.6 & 1878 & 0 & 295976 & 52694 & 0.0019 & 0.9269 & 0.2172 & 0.253 & 454 & 554 & 0 & -248 & 2688 & 5748 & 3827 & 514 & 0.817 \\
\hline 74 & $\begin{array}{l}7305 \\
70305\end{array}$ & 506 & $\begin{array}{l}109 \\
\end{array}$ & 35 & 1 & 4.6 & 1907 & 1 & $\begin{array}{r}277808 \\
2500\end{array}$ & 55262 & 0.0020 & 0.9307 & 0.2154 & 0.412 & 507 & $\begin{array}{l}549 \\
595\end{array}$ & 0 & $\begin{array}{l}-195 \\
-19\end{array}$ & 2687 & 5733 & $\begin{array}{l}3839 \\
\end{array}$ & $\begin{array}{l}491 \\
575\end{array}$ & 0.818 \\
\hline 75 & $\begin{array}{l}7305 \\
7305\end{array}$ & & $\begin{array}{l}123 \\
102\end{array}$ & $\begin{array}{l}45 \\
45\end{array}$ & 1 & $\begin{array}{l}4.9 \\
5.9\end{array}$ & 1900 & $\begin{array}{l}0 \\
1\end{array}$ & $\begin{array}{l}350484 \\
270707\end{array}$ & 65672 & 0.0017 & $\begin{array}{l}0.9180 \\
\end{array}$ & 0.2053 & $\begin{array}{l}0.271 \\
0\end{array}$ & $\begin{array}{l}534 \\
514\end{array}$ & $\begin{array}{l}585 \\
513\end{array}$ & 0 & $\begin{array}{r}-148 \\
\end{array}$ & $\begin{array}{l}2741 \\
2731\end{array}$ & $\begin{array}{l}5660 \\
5730\end{array}$ & 3688 & 575 & 0.832 \\
\hline $\begin{array}{l}76 \\
77\end{array}$ & $\begin{array}{l}1305 \\
7305\end{array}$ & $\begin{array}{l}544 \\
633\end{array}$ & $\begin{array}{l}102 \\
104\end{array}$ & $\begin{array}{l}45 \\
70\end{array}$ & $\begin{array}{l}1 \\
1\end{array}$ & $\begin{array}{l}5.3 \\
6.1\end{array}$ & $\begin{array}{l}1868 \\
1865\end{array}$ & $\begin{array}{l}1 \\
0\end{array}$ & $\begin{array}{l}\begin{array}{l}2799075 \\
358478\end{array}\end{array}$ & $\begin{array}{l}52432 \\
54986\end{array}$ & $\begin{array}{l}0.0018 \\
0.0016\end{array}$ & $\begin{array}{l}0.9255 \\
0\end{array}$ & $\begin{array}{l}0.1875 \\
0.1643\end{array}$ & $\begin{array}{l}0.298 \\
0.165\end{array}$ & $\begin{array}{l}514 \\
529\end{array}$ & $\begin{array}{l}513 \\
566\end{array}$ & 0 & $\begin{array}{r}-345 \\
-196\end{array}$ & $\begin{array}{l}2530 \\
2731\end{array}$ & $\begin{array}{l}5738 \\
575\end{array}$ & $\begin{array}{l}3947 \\
3563\end{array}$ & $\begin{array}{l}529 \\
613\end{array}$ & $\begin{array}{l}0.841 \\
0.870\end{array}$ \\
\hline 78 & 7305 & 542 & 124 & 58 & 1 & 4.4 & 1874 & 0 & 276655 & $\begin{array}{l}54986 \\
48030\end{array}$ & 0.0018 & $\begin{array}{l}0.91358 \\
0.9258\end{array}$ & $\begin{array}{l}0.162838 \\
0.288\end{array}$ & $\begin{array}{l}0.165 \\
0.232\end{array}$ & $\begin{array}{l}529 \\
387\end{array}$ & $\begin{array}{l}506 \\
510\end{array}$ & 0 & $\begin{array}{l}-196 \\
-158\end{array}$ & 2739 & 5702 & $\begin{array}{l}35635 \\
3768\end{array}$ & 513 & 0.801 \\
\hline 79 & 7305 & 585 & 110 & 42 & 1 & 5.3 & 1937 & 0 & 311962 & 55337 & 0.0017 & 0.9199 & 0.1880 & 0.297 & 503 & 533 & 0 & -145 & 2749 & 5708 & 3700 & 564 & 0.843 \\
\hline 80 & 7305 & 586 & 112 & 68 & 1 & 5.2 & 1966 & 5 & 350748 & 53668 & 0.0017 & 0.9198 & 0.1911 & 0.183 & 479 & 599 & 0 & -197 & 2729 & 5728 & 3711 & 568 & 0.847 \\
\hline 81 & 7305 & 577 & 131 & 42 & 1 & 4.4 & 1864 & 0 & 276793 & 64896 & 0.0017 & 0.9210 & 0.2270 & 0.301 & 495 & 480 & 0 & -124 & 2790 & 5690 & 3676 & 553 & 0.800 \\
\hline 82 & 7305 & 593 & 115 & 52 & 1 & 5.2 & 1890 & 1 & 342355 & 57370 & 0.0017 & 0.9188 & 0.1939 & 0.237 & 499 & 577 & 0 & -274 & 2622 & 5679 & 3822 & 571 & 0.842 \\
\hline 83 & 7305 & 545 & 99 & 36 & 1 & 5.5 & 1872 & 0 & 289672 & 49867 & 0.0018 & 0.9254 & 0.1817 & 0.372 & 504 & 532 & 0 & -288 & 2604 & 5694 & 3890 & 520 & 0.849 \\
\hline 84 & 7305 & 589 & 138 & 55 & 1 & 4.3 & 1869 & 1 & 284837 & 60649 & 0.0017 & 0.9194 & 0.2343 & 0.225 & 439 & 484 & 0 & -90 & 2869 & 5729 & 3595 & 570 & 0.794 \\
\hline 85 & 7305 & 648 & 117 & 56 & 1 & 5.5 & 1905 & 2 & 368860 & 59595 & 0.0015 & 0.9113 & 0.1806 & 0.201 & 509 & 569 & 0 & -228 & 2705 & 5685 & 3687 & 623 & 0.855 \\
\hline 86 & $\begin{array}{l}7305 \\
7\end{array}$ & 580 & 118 & 56 & 1 & 4.9 & 1864 & 0 & 297668 & 52661 & 0.0017 & 0.9206 & 0.2034 & 0.225 & 446 & 513 & 0 & -220 & 2688 & 5683 & 3777 & 555 & 0.826 \\
\hline 87 & 7305 & 492 & 110 & 60 & 1 & 4.5 & 1894 & 1 & 262729 & 46487 & 0.0020 & 0.9326 & 0.2236 & 0.247 & 423 & 534 & 0 & -155 & 2720 & 5774 & 3791 & 470 & 0.808 \\
\hline 88 & $\begin{array}{l}7305 \\
7305\end{array}$ & $\begin{array}{l}554 \\
558\end{array}$ & $\begin{array}{l}115 \\
110\end{array}$ & $\begin{array}{l}40 \\
54\end{array}$ & 1 & $\begin{array}{l}4.8 \\
51\end{array}$ & $\begin{array}{l}1872 \\
1\end{array}$ & 1 & $\begin{array}{r}284032 \\
314447\end{array}$ & $\begin{array}{l}56575 \\
5751\end{array}$ & 0.0018 & 0.9242 & $\begin{array}{l}0.2076 \\
\end{array}$ & 0.330 & $\begin{array}{l}492 \\
525\end{array}$ & $\begin{array}{l}513 \\
563\end{array}$ & ${ }_{0}^{0}$ & $\begin{array}{r}-130 \\
-230\end{array}$ & $\begin{array}{l}2826 \\
2745\end{array}$ & $\begin{array}{l}5789 \\
5792\end{array}$ & 3674 & 531 & 0.822 \\
\hline $\begin{array}{l}89 \\
90\end{array}$ & $\begin{array}{l}7305 \\
7305\end{array}$ & $\begin{array}{l}558 \\
571\end{array}$ & $\begin{array}{l}110 \\
141\end{array}$ & $\begin{array}{l}54 \\
38\end{array}$ & $\begin{array}{l}1 \\
1\end{array}$ & $\begin{array}{l}5.1 \\
40\end{array}$ & $\begin{array}{l}1971 \\
\end{array}$ & 0 & $\begin{array}{l}314247 \\
28615\end{array}$ & $\begin{array}{l}57751 \\
59531\end{array}$ & 0.0018 & $\begin{array}{l}0.9236 \\
0\end{array}$ & $\begin{array}{l}0.1971 \\
\end{array}$ & 0.242 & $\begin{array}{l}525 \\
42\end{array}$ & $\begin{array}{l}563 \\
502\end{array}$ & 0 & $\begin{array}{r}-230 \\
-105\end{array}$ & $\begin{array}{l}2745 \\
2720\end{array}$ & $\begin{array}{l}5762 \\
5637\end{array}$ & 3739 & 537 & 0.837 \\
\hline 91 & 7305 & 518 & $\begin{array}{l}411 \\
118\end{array}$ & $\begin{array}{l}38 \\
53\end{array}$ & 1 & $\begin{array}{l}4.0 \\
4.4\end{array}$ & $\begin{array}{l}9123 \\
1875\end{array}$ & $\begin{array}{l}0 \\
3\end{array}$ & $\begin{array}{l}2860713 \\
285719\end{array}$ & $\begin{array}{l}5953 / 7 \\
47865\end{array}$ & $\begin{array}{l}0.00018 \\
0.0019\end{array}$ & $\begin{array}{l}0.9278 \\
0.9291\end{array}$ & $\begin{array}{l}0.24296 \\
0.2278\end{array}$ & $\begin{array}{l}0.331 \\
0.266\end{array}$ & $\begin{array}{l}422 \\
406\end{array}$ & $\begin{array}{l}502 \\
552\end{array}$ & $\begin{array}{l}0 \\
0\end{array}$ & $\begin{array}{l}-105 \\
-200\end{array}$ & $\begin{array}{l}2729 \\
2661\end{array}$ & $\begin{array}{l}5737 \\
5710\end{array}$ & $\begin{array}{l}3 / 26 \\
3848\end{array}$ & $\begin{array}{l}545 \\
491\end{array}$ & $\begin{array}{l}0.183 \\
0.806\end{array}$ \\
\hline 92 & 7305 & 526 & 106 & 52 & 1 & 5.0 & 1871 & 4 & 297623 & 53403 & 0.0019 & 0.9280 & 0.2015 & 0.267 & 504 & 566 & 0 & -193 & 2744 & 5797 & 3793 & 509 & 0.833 \\
\hline 93 & 7305 & 509 & 110 & 47 & 1 & 4.6 & 1895 & 2 & 258095 & 50626 & 0.0020 & 0.9303 & 0.2161 & 0.305 & 460 & 507 & 0 & -181 & 2696 & 5713 & 3815 & 490 & 0.813 \\
\hline 94 & 7305 & 605 & 131 & 49 & 1 & 4.6 & 1865 & 1 & 305789 & 61594 & 0.0017 & 0.9172 & 0.2165 & 0.246 & 470 & 505 & 0 & -82 & 2791 & 5647 & 3636 & 574 & 0.813 \\
\hline 95 & 7305 & 527 & 102 & 42 & 1 & 5.2 & 1872 & 2 & 289240 & 52451 & 0.0019 & 0.9279 & 0.1935 & 0.330 & 514 & 549 & 0 & -304 & 2602 & 5727 & 3893 & 510 & 0.839 \\
\hline 96 & 7305 & 541 & 114 & 85 & 1 & 4.7 & 1946 & 2 & 299095 & 53135 & 0.0018 & 0.9259 & 0.2107 & 0.159 & 466 & 553 & 0 & -158 & 2746 & 5724 & 3737 & 520 & 0.823 \\
\hline 97 & 7305 & 532 & 119 & 65 & 1 & 4.5 & 1961 & 0 & 284358 & 53777 & 0.0019 & 0.9272 & 0.2237 & 0.211 & 452 & 535 & 0 & -156 & 2743 & 5740 & 3764 & 507 & 0.809 \\
\hline 98 & 7305 & 566 & 126 & 28 & 1 & 4.5 & 1876 & 2 & 311739 & 61759 & 0.0018 & 0.9225 & 0.2226 & 0.461 & 490 & 551 & 0 & -138 & 2790 & 5703 & 3676 & 550 & 0.812 \\
\hline 99 & 7305 & 565 & 121 & 66 & 1 & 4.7 & 1932 & 0 & 343208 & 54692 & 0.0018 & 0.9227 & 0.2142 & 0.196 & 452 & 607 & 0 & -231 & 2696 & 5734 & 3782 & 548 & 0.826 \\
\hline 100 & 7305 & 528 & 99 & 58 & 1 & 5.3 & 1904 & 2 & 283837 & 51366 & 0.0019 & 0.9277 & 0.1875 & 0.239 & 519 & 538 & 0 & -262 & 2650 & 5742 & 3858 & 507 & 0.844 \\
\hline Minimum & & 477 & 97 & 28 & 1 & 3.9 & 1538 & 0 & 231726 & 46487 & 0.0015 & 0.9113 & 0.1643 & 0.143 & 387 & 463 & 0 & -345 & 2530 & 5630 & 3595 & 451 & 0.772 \\
\hline Average & & 557 & 117 & 51 & 1 & 4.8 & 1886 & 1 & 300177 & 56139 & 0.0018 & 0.9237 & 0.2110 & 0.276 & 480 & 538 & 0 & -192 & 2711 & 5709 & 3770 & 534 & 0.822 \\
\hline Maximum & & 648 & 147 & 87 & 1 & 6.1 & 1971 & 8 & 368860 & 70611 & 0.0021 & 0.9347 & 0.2559 & 0.547 & 589 & 637 & 0 & -58 & 2869 & 5797 & 3947 & 623 & 0.870 \\
\hline Std.dev & & 32.6 & 9.9 & 12.1 & 0 & 0.4 & 46.7 & 1.5 & 26604.0 & 4420.1 & 0.0001 & 0.0045 & 0.0185 & 0.074 & 36.6 & 34.1 & 0 & 59 & 62 & 35 & 76 & 32 & 0.020 \\
\hline
\end{tabular}


Scenerio NScenario 14 CSIROMk2b B11 with 15\% additional WEMPs savings

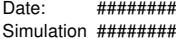

Simulation \#\#\#\#\#\#\#

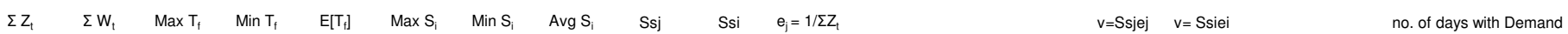

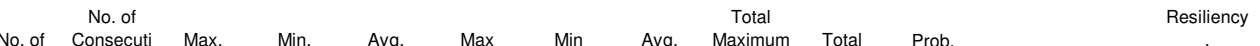

Total
Severity/n

\begin{tabular}{|c|c|c|c|c|c|c|c|c|c|c|c|c|c|c|c|c|c|c|c|c|c|c|c|c|c|}
\hline Trial No. & . & Fise & Earilures & 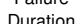 & rafuré & . & Finture & Filure & Frailum & SSivur & Failur & Wort tospo & $\alpha$ & F(ETTI) & NF) & ty 1 & ty? & & 501-1000 & & $1501-2000$ & 2001-2500 & & Distance & with fail \\
\hline 40 & $\begin{array}{l}\text { of Days } \\
7305\end{array}$ & $\begin{array}{l}\text { Falled } \\
139\end{array}$ & Falures & $\begin{array}{l}\text { Duration } \\
\quad 16\end{array}$ & $\begin{array}{l}\text { Duration } \\
1\end{array}$ & $\begin{array}{l}\text { Duration } \\
2.8\end{array}$ & $\begin{array}{c}\text { Failure } \\
590\end{array}$ & Failure & $\begin{array}{c}\text { a Failure } \\
219\end{array}$ & Sojourn & $\begin{array}{l}\text { Failure } \\
30408\end{array}$ & $\begin{array}{l}\left.\text { nd to } S_{j}\right] \\
0.072\end{array}$ & $\begin{array}{c}\alpha \\
0.9810\end{array}$ & $\begin{array}{l}\text {, FE(ETitif) } \\
0.3597\end{array}$ & $\begin{array}{c}\mathrm{NF}) \\
3\end{array}$ & 215 & $\begin{array}{l}\text { ty } 2 \\
219\end{array}$ & 0.500 & 630 & & 1191 & $\begin{array}{l}373000 \\
373\end{array}$ & $\begin{array}{c}>2500 \\
125\end{array}$ & $\begin{array}{l}\text { Distance } \\
06445\end{array}$ & $\begin{array}{c}\text { with failur } \\
219\end{array}$ \\
\hline 4 & 7305 & 129 & 47 & 20 & 1 & 2.7 & 852 & 0 & 247 & 11612 & 31826 & 0.0078 & 0.9823 & $\begin{array}{l}0.3643 \\
0.3643\end{array}$ & 3 & 247 & 247 & 0 & 648 & 4987 & 1146 & 409 & 115 & $\begin{array}{l}0.6450 \\
0.6435\end{array}$ & $\begin{array}{l}219 \\
247\end{array}$ \\
\hline 7 & 7305 & 153 & 50 & 33 & 1 & 3.1 & 749 & 2 & 246 & 11665 & 37633 & 0.0065 & 0.9791 & 0.3268 & 1 & 233 & 246 & 0 & 637 & 4925 & 1185 & 422 & 136 & 0.6807 & 246 \\
\hline 2 & 7305 & 145 & 52 & 17 & 1 & 2.8 & 841 & 0 & 263 & 12243 & 38099 & 0.0069 & 0.9802 & 0.3586 & 3 & 235 & 263 & 0 & 666 & 4926 & 1148 & 437 & 128 & 0.6502 & 263 \\
\hline 38 & $\begin{array}{l}7305 \\
7055\end{array}$ & $\begin{array}{l}140 \\
167\end{array}$ & 43 & 12 & 1 & 3.3 & 851 & 1 & 282 & 12527 & 39537 & 0.0071 & 0.9808 & 0.3071 & 4 & 291 & 282 & 0 & 662 & 4895 & 1185 & 435 & 128 & 0.7023 & 282 \\
\hline 76 & $\begin{array}{l}7305 \\
7055\end{array}$ & $\begin{array}{l}167 \\
167\end{array}$ & 56 & 13 & 1 & 3.0 & 846 & 4 & 241 & $\begin{array}{l}15162 \\
11702\end{array}$ & 40314 & 0.0060 & 0.9771 & 0.3353 & 3 & 271 & 241 & 0 & 625 & 5001 & 1133 & 397 & 149 & 0.6720 & 241 \\
\hline $\begin{array}{l}81 \\
84\end{array}$ & $\begin{array}{l}7305 \\
7305\end{array}$ & $\begin{array}{l}167 \\
157\end{array}$ & $\begin{array}{l}57 \\
53\end{array}$ & $\begin{array}{l}17 \\
20\end{array}$ & 1 & $\begin{array}{l}2.9 \\
3.9\end{array}$ & $\begin{array}{r}843 \\
848\end{array}$ & $\begin{array}{l}0 \\
2 \\
2\end{array}$ & $\begin{array}{l}247 \\
265\end{array}$ & $\begin{array}{l}15702 \\
17336\end{array}$ & $\begin{array}{l}41256 \\
41626\end{array}$ & $\begin{array}{l}0.0060 \\
0.0064\end{array}$ & 0.9771 & 0.3413 & 3 & $\begin{array}{l}275 \\
270\end{array}$ & $\begin{array}{l}247 \\
265\end{array}$ & 0 & 644 & $\begin{array}{l}4952 \\
4950\end{array}$ & $\begin{array}{l}1129 \\
1130\end{array}$ & $\begin{array}{l}431 \\
447\end{array}$ & $\begin{array}{l}149 \\
145\end{array}$ & 0.6664 & $\begin{array}{l}247 \\
265\end{array}$ \\
\hline $\begin{array}{l}84 \\
26\end{array}$ & $\begin{array}{l}7305 \\
705\end{array}$ & $\begin{array}{l}157 \\
174\end{array}$ & $\begin{array}{l}53 \\
49\end{array}$ & $\begin{array}{l}20 \\
20\end{array}$ & $\frac{1}{1}$ & $\begin{array}{l}3.0 \\
36\end{array}$ & $\begin{array}{l}848 \\
841\end{array}$ & $\begin{array}{l}2 \\
0\end{array}$ & $\begin{array}{l}265 \\
248\end{array}$ & $\begin{array}{l}14336 \\
13264\end{array}$ & $\begin{array}{l}41626 \\
43078\end{array}$ & $\begin{array}{l}0.0064 \\
0.0057\end{array}$ & $\begin{array}{l}0.9785 \\
0.9762\end{array}$ & $\begin{array}{l}0.3376 \\
0.2816\end{array}$ & $\begin{array}{l}2 \\
2\end{array}$ & $\begin{array}{l}270 \\
250\end{array}$ & $\begin{array}{l}265 \\
248\end{array}$ & $\begin{array}{l}0 \\
0\end{array}$ & $\begin{array}{l}633 \\
638\end{array}$ & $\begin{array}{l}4950 \\
4963\end{array}$ & $\begin{array}{l}1130 \\
1120\end{array}$ & $\begin{array}{l}447 \\
425\end{array}$ & $\begin{array}{l}145 \\
159\end{array}$ & $\begin{array}{l}0.6712 \\
0.7256\end{array}$ & $\begin{array}{l}265 \\
248\end{array}$ \\
\hline $\begin{array}{l}26 \\
16\end{array}$ & $\begin{array}{l}7305 \\
7305\end{array}$ & $\begin{array}{l}1 / 4 \\
169\end{array}$ & $\begin{array}{l}49 \\
46\end{array}$ & $\begin{array}{l}20 \\
16\end{array}$ & $\begin{array}{l}1 \\
1\end{array}$ & $\begin{array}{l}3.6 \\
3.7\end{array}$ & $\begin{array}{l}841 \\
887\end{array}$ & $\begin{array}{l}0 \\
0\end{array}$ & $\begin{array}{l}248 \\
259\end{array}$ & $\begin{array}{l}12264 \\
12011\end{array}$ & $\begin{array}{l}43078 \\
43687\end{array}$ & 0.0059 & $\begin{array}{l}0.9962 \\
0.9769\end{array}$ & $\begin{array}{l}0.2816 \\
0.2722\end{array}$ & $\begin{array}{l}2 \\
3\end{array}$ & $\begin{array}{l}250 \\
261\end{array}$ & $\begin{array}{l}248 \\
259\end{array}$ & 0 & $\begin{array}{l}638 \\
619\end{array}$ & $\begin{array}{l}4963 \\
4952\end{array}$ & $\begin{array}{l}1120 \\
1176\end{array}$ & $\begin{array}{l}425 \\
409\end{array}$ & $\begin{array}{l}159 \\
149\end{array}$ & $\begin{array}{l}0.7256 \\
0.7355\end{array}$ & $\begin{array}{l}248 \\
259\end{array}$ \\
\hline 41 & 7305 & 135 & 45 & 17 & 1 & $\begin{array}{l}3.1 \\
3.0\end{array}$ & 877 & 1 & 327 & 12780 & 44129 & $\begin{array}{l}0.0059 \\
0.0074\end{array}$ & 0.9815 & $\begin{array}{l}0.3333 \\
0.3722\end{array}$ & 3 & 284 & $\begin{array}{l}2599 \\
327\end{array}$ & 0 & $\begin{array}{l}623 \\
623\end{array}$ & $\begin{array}{l}4952 \\
4984\end{array}$ & 1204 & $\begin{array}{l}409 \\
376\end{array}$ & $\begin{array}{l}149 \\
118\end{array}$ & 0.6796 & $\begin{array}{l}259 \\
327\end{array}$ \\
\hline 58 & 7305 & 173 & 58 & 31 & 1 & 3.0 & 840 & 1 & 256 & 13917 & 44343 & 0.0058 & 0.9763 & 0.3353 & 1 & 240 & 256 & 0 & 643 & 4956 & 1162 & 385 & 159 & 0.6730 & $\begin{array}{l}327 \\
256\end{array}$ \\
\hline 17 & 7305 & 159 & 56 & 14 & 1 & 2.8 & 851 & 0 & 280 & 15394 & 44508 & 0.0063 & 0.9782 & 0.3522 & 3 & 275 & 280 & 0 & 647 & 4943 & 1145 & 429 & 141 & 0.6578 & 280 \\
\hline 72 & 7305 & 159 & 61 & 17 & 1 & 2.6 & 848 & 2 & 281 & 14555 & 44645 & 0.0063 & 0.9782 & 0.3836 & 3 & 239 & 281 & 0 & 667 & 4911 & 1142 & 438 & 147 & 0.6269 & 281 \\
\hline 18 & 7305 & 168 & 56 & 13 & 1 & 3.0 & 858 & 1 & 266 & 14710 & 44652 & 0.0060 & 0.9770 & 0.3333 & 3 & 263 & 266 & 0 & 641 & 4994 & 1092 & 424 & 154 & 0.6755 & 266 \\
\hline 27 & 7305 & 155 & 47 & 28 & 1 & 3.3 & 850 & 0 & 290 & 12713 & 44968 & 0.0065 & 0.9788 & 0.3032 & 2 & 270 & 290 & 0 & 613 & 5018 & 1140 & 395 & 139 & 0.7067 & 290 \\
\hline 71 & 7305 & 169 & 51 & 16 & 1 & 3.3 & 841 & 1 & 277 & 12904 & 46745 & 0.0059 & 0.9769 & 0.3018 & 3 & 253 & 277 & 0 & 642 & 4939 & 1126 & 445 & 153 & 0.7073 & 277 \\
\hline 93 & 7305 & 163 & 52 & 30 & 1 & 3.1 & 868 & 2 & 288 & 14992 & 46924 & 0.0061 & 0.9777 & 0.3190 & 1 & 288 & 288 & 0 & 669 & 4920 & 1206 & 358 & 152 & 0.6910 & 288 \\
\hline 88 & 7305 & 167 & 45 & 18 & 1 & 3.7 & 849 & 6 & 283 & $\begin{array}{l}13457 \\
13070\end{array}$ & 47188 & 0.0060 & 0.9771 & 0.2695 & 2 & 299 & 283 & 0 & 625 & 5036 & 1081 & 408 & 155 & 0.7396 & 283 \\
\hline 36 & $\begin{array}{l}7305 \\
7305\end{array}$ & $\begin{array}{l}163 \\
159\end{array}$ & 47 & 23 & 1 & 3.5 & 846 & 2 & 290 & $\begin{array}{l}12878 \\
18813\end{array}$ & 47263 & 0.0061 & 0.9777 & 0.2883 & 2 & $\begin{array}{l}274 \\
273\end{array}$ & 290 & 0 & 598 & 4994 & 1123 & 441 & 149 & 0.7214 & 290 \\
\hline $\begin{array}{c}56 \\
100\end{array}$ & $\begin{array}{l}7305 \\
7305\end{array}$ & $\begin{array}{l}159 \\
169\end{array}$ & $\begin{array}{l}47 \\
47\end{array}$ & $\begin{array}{l}24 \\
12\end{array}$ & 1 & $\begin{array}{l}3.4 \\
36\end{array}$ & $\begin{array}{l}884 \\
874\end{array}$ & $\begin{array}{l}6 \\
3\end{array}$ & $\begin{array}{l}298 \\
280\end{array}$ & $\begin{array}{l}12813 \\
15074\end{array}$ & $\begin{array}{l}47369 \\
47381\end{array}$ & $\begin{array}{l}0.0063 \\
0.0059\end{array}$ & $\begin{array}{l}0.9782 \\
0.9769\end{array}$ & $\begin{array}{l}0.2956 \\
0.2781\end{array}$ & $\begin{array}{l}2 \\
4\end{array}$ & $\begin{array}{r}273 \\
321\end{array}$ & $\begin{array}{l}298 \\
280\end{array}$ & $\begin{array}{l}0 \\
0\end{array}$ & $\begin{array}{l}619 \\
642\end{array}$ & $\begin{array}{l}4989 \\
4969\end{array}$ & $\begin{array}{l}1132 \\
1139\end{array}$ & $\begin{array}{l}419 \\
398\end{array}$ & $\begin{array}{l}146 \\
157\end{array}$ & $\begin{array}{l}0.7147 \\
0.7309\end{array}$ & $\begin{array}{l}298 \\
280\end{array}$ \\
\hline $\begin{array}{l}100 \\
55\end{array}$ & $\begin{array}{l}7305 \\
7305\end{array}$ & $\begin{array}{l}169 \\
151\end{array}$ & $\begin{array}{l}4 r \\
46\end{array}$ & $\begin{array}{l}12 \\
17\end{array}$ & $\begin{array}{l}1 \\
1\end{array}$ & $\begin{array}{l}3.6 \\
3.3\end{array}$ & $\begin{array}{l}874 \\
871\end{array}$ & $\begin{array}{l}3 \\
0\end{array}$ & $\begin{array}{l}280 \\
315\end{array}$ & $\begin{array}{l}15074 \\
12963\end{array}$ & $\begin{array}{l}47381 \\
47501\end{array}$ & $\begin{array}{l}0.0059 \\
0.0066\end{array}$ & $\begin{array}{l}0.9969 \\
0.9793\end{array}$ & $\begin{array}{l}0.2781 \\
0.3046\end{array}$ & $\begin{array}{l}4 \\
3\end{array}$ & $\begin{array}{l}321 \\
282\end{array}$ & $\begin{array}{l}280 \\
315\end{array}$ & $\begin{array}{l}0 \\
0\end{array}$ & $\begin{array}{l}642 \\
661\end{array}$ & $\begin{array}{l}4969 \\
4920\end{array}$ & $\begin{array}{l}1139 \\
1157\end{array}$ & 398 & $\begin{array}{l}157 \\
137\end{array}$ & 0.7309 & $\begin{array}{l}280 \\
315\end{array}$ \\
\hline 19 & 7305 & 161 & 44 & 26 & 1 & $\begin{array}{l}3.7 \\
3.7\end{array}$ & 922 & 0 & 295 & 12212 & 47570 & 0.0062 & 0.9780 & 0.2733 & 2 & 278 & 295 & 0 & 618 & 4971 & 1171 & 395 & 150 & 0.7366 & $\begin{array}{l}\begin{array}{l}315 \\
295\end{array}\end{array}$ \\
\hline 11 & 7305 & 167 & 52 & 18 & 1 & 3.2 & 864 & 1 & 292 & 14791 & 48732 & 0.0060 & 0.9771 & 0.3114 & 2 & 284 & 292 & 0 & 667 & 4903 & 1192 & 395 & 148 & 0.6988 & 292 \\
\hline 20 & 7305 & 171 & 58 & 14 & 1 & 2.9 & 836 & 1 & 287 & 14988 & 48995 & 0.0058 & 0.9766 & 0.3392 & 3 & 258 & 287 & 0 & 650 & 4975 & 1139 & 383 & 158 & 0.6711 & 287 \\
\hline 64 & 7305 & 159 & 53 & 11 & 1 & 3.0 & 906 & 0 & 310 & 15540 & 49265 & 0.0063 & 0.9782 & 0.3333 & 4 & 293 & 310 & 0 & 649 & 4923 & 1202 & 386 & 145 & 0.6784 & 310 \\
\hline 95 & 7305 & 180 & 49 & 17 & 1 & 3.7 & 849 & 0 & 275 & 15714 & 49501 & 0.0056 & 0.9754 & 0.2722 & 2 & 321 & 275 & 0 & 620 & 4993 & 1156 & 367 & 169 & 0.7365 & 275 \\
\hline 47 & 7305 & 190 & 51 & 17 & 1 & 3.7 & 849 & 1 & 261 & 13196 & 49545 & 0.0053 & 0.9740 & 0.2684 & 2 & 259 & 261 & 0 & 621 & 4919 & 1196 & 407 & 162 & .7394 & 261 \\
\hline 65 & 7305 & 193 & 66 & 14 & 1 & 2.9 & 845 & 2 & 257 & 18084 & 49602 & 0.0052 & 0.9736 & 0.3420 & 3 & 274 & 257 & 0 & 637 & 4978 & 077 & 440 & 173 & 6665 & 257 \\
\hline 23 & 7305 & 161 & 45 & 18 & 1 & 3.6 & 878 & 3 & 309 & 13762 & 49670 & 0.0062 & 0.9780 & 0.2795 & 3 & 306 & 309 & 0 & 633 & 4954 & 1162 & 405 & 151 & 7313 & 309 \\
\hline 8 & $\begin{array}{l}7305 \\
7055\end{array}$ & 166 & 47 & 11 & 1 & 3.5 & 853 & 4 & 302 & $\begin{array}{l}14586 \\
\end{array}$ & 50126 & 0.0060 & 0.9773 & 0.2831 & 4 & $\begin{array}{l}310 \\
250\end{array}$ & 302 & 0 & 630 & 4946 & 1152 & 423 & 154 & 7273 & 302 \\
\hline 62 & $\begin{array}{l}7305 \\
7305\end{array}$ & $\begin{array}{l}190 \\
169\end{array}$ & $\begin{array}{l}54 \\
50\end{array}$ & $\begin{array}{l}16 \\
13 \\
13\end{array}$ & 1 & $\begin{array}{l}3.5 \\
3.5\end{array}$ & $\begin{array}{l}843 \\
873\end{array}$ & $\begin{array}{l}0 \\
0\end{array}$ & $\begin{array}{l}264 \\
298\end{array}$ & $\begin{array}{l}13915 \\
19932\end{array}$ & $\begin{array}{l}50127 \\
50340\end{array}$ & $\begin{array}{l}0.0053 \\
0.059\end{array}$ & $\begin{array}{l}0.9740 \\
0.9769\end{array}$ & 0.2842 & $\begin{array}{l}2 \\
3\end{array}$ & $\begin{array}{l}258 \\
319\end{array}$ & $\begin{array}{l}264 \\
298\end{array}$ & 0 & $\begin{array}{l}646 \\
628\end{array}$ & $\begin{array}{l}4938 \\
4972\end{array}$ & $\begin{array}{l}1087 \\
1180\end{array}$ & $\begin{array}{l}470 \\
377\end{array}$ & $\begin{array}{l}164 \\
148\end{array}$ & $\begin{array}{l}0.7240 \\
0.7145\end{array}$ & $\begin{array}{l}264 \\
298\end{array}$ \\
\hline $\begin{array}{l}74 \\
90\end{array}$ & $\begin{array}{l}7305 \\
7305\end{array}$ & $\begin{array}{l}169 \\
164\end{array}$ & $\begin{array}{l}50 \\
52\end{array}$ & $\begin{array}{l}13 \\
25\end{array}$ & 1 & $\begin{array}{l}3.4 \\
32\end{array}$ & $\begin{array}{l}877 \\
890\end{array}$ & $\begin{array}{l}0 \\
3\end{array}$ & $\begin{array}{l}298 \\
309\end{array}$ & $\begin{array}{l}15932 \\
12475\end{array}$ & $\begin{array}{l}50340 \\
50677\end{array}$ & $\begin{array}{l}0.0059 \\
0.0061\end{array}$ & $\begin{array}{l}0.9769 \\
0.9775\end{array}$ & 0.2959 & 3 & $\begin{array}{l}319 \\
240\end{array}$ & $\begin{array}{l}298 \\
309\end{array}$ & 0 & 628 & $\begin{array}{l}4972 \\
4887\end{array}$ & $\begin{array}{l}1180 \\
1192\end{array}$ & $\begin{array}{l}377 \\
447\end{array}$ & $\begin{array}{l}148 \\
149\end{array}$ & $\begin{array}{l}0.7145 \\
0.6944\end{array}$ & $\begin{array}{l}298 \\
309\end{array}$ \\
\hline $\begin{array}{l}90 \\
39\end{array}$ & $\begin{array}{l}7305 \\
7305\end{array}$ & $\begin{array}{l}164 \\
185\end{array}$ & $\begin{array}{l}52 \\
51\end{array}$ & $\begin{array}{l}25 \\
16\end{array}$ & $\begin{array}{l}1 \\
1\end{array}$ & $\begin{array}{l}3.2 \\
3.6\end{array}$ & $\begin{array}{l}890 \\
852 \\
852\end{array}$ & $\begin{array}{l}3 \\
0\end{array}$ & $\begin{array}{l}309 \\
275\end{array}$ & $\begin{array}{l}12475 \\
15721\end{array}$ & $\begin{array}{l}50677 \\
50901\end{array}$ & $\begin{array}{l}0.0061 \\
0.0054\end{array}$ & $\begin{array}{l}0.9775 \\
0.9747\end{array}$ & $\begin{array}{l}0.3171 \\
0.2757\end{array}$ & 2 & $\begin{array}{l}240 \\
308\end{array}$ & $\begin{array}{l}309 \\
275\end{array}$ & $\begin{array}{l}0 \\
0\end{array}$ & $\begin{array}{l}630 \\
615\end{array}$ & $\begin{array}{l}4887 \\
5036\end{array}$ & $\begin{array}{l}1192 \\
1107\end{array}$ & $\begin{array}{l}447 \\
381\end{array}$ & $\begin{array}{l}149 \\
166\end{array}$ & 0.6944 & $\begin{array}{l}309 \\
275\end{array}$ \\
\hline 94 & 7305 & 181 & 53 & 27 & 1 & 3.4 & 845 & 4 & 283 & 15141 & 51160 & $\begin{array}{l}0.0054 \\
0.0055\end{array}$ & $\begin{array}{l}0.9752 \\
0.9752\end{array}$ & $\begin{array}{l}0.2928 \\
0.2928\end{array}$ & 1 & $\begin{array}{l}308 \\
286\end{array}$ & $\begin{array}{l}275 \\
283\end{array}$ & 0 & $\begin{array}{l}615 \\
637\end{array}$ & $\begin{array}{l}5036 \\
4913\end{array}$ & 1150 & $\begin{array}{l}381 \\
434\end{array}$ & $\begin{array}{l}166 \\
171\end{array}$ & $\begin{array}{l}0.7351 \\
0.7166\end{array}$ & $\begin{array}{l}275 \\
283\end{array}$ \\
\hline 33 & 7305 & 182 & 56 & 30 & 1 & 3.3 & 866 & 1 & 281 & 14782 & 51186 & 0.0055 & 0.9751 & 0.3077 & 1 & 264 & 281 & 0 & 614 & 4979 & 1122 & 420 & 170 & 0.7018 & $\begin{array}{l}283 \\
281\end{array}$ \\
\hline 29 & 7305 & 172 & 54 & 24 & 1 & 3.2 & 852 & 7 & 300 & 14980 & 51601 & 0.0058 & 0.9765 & 0.3140 & 2 & 207 & 300 & 0 & 639 & 4955 & 1110 & 437 & 164 & 0.6969 & 00 \\
\hline 87 & 7305 & 165 & 43 & 21 & 1 & 3.8 & 866 & 0 & 313 & 10471 & 51669 & 0.0061 & 0.9774 & 0.2606 & 2 & 244 & 313 & 0 & 664 & 504 & 1092 & 356 & 153 & 0.7503 & 13 \\
\hline 61 & 7305 & 187 & 55 & 28 & 1 & 3.4 & 847 & 2 & 277 & 15247 & 51887 & 0.0053 & 0.9744 & 0.29 & 1 & 27 & 27 & 0 & 63 & 49 & 11 & 423 & 7 & & 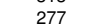 \\
\hline 52 & 7305 & 181 & 56 & 26 & 1 & 3.2 & 855 & 0 & 287 & 14629 & 51916 & 0.0055 & 0.9752 & 0.30 & 2 & 26 & 28 & 0 & 63 & 49 & 116 & 43 & 166 & 0.7005 & 87 \\
\hline 83 & 7305 & 176 & 48 & 24 & 1 & 3. & 85 & 5 & 29 & & 52367 & 0.0057 & 0.97 & & 2 & 31 & 29 & 0 & 63 & 49 & & 43 & 163 & & 88 \\
\hline 97 & 7305 & 168 & 51 & 17 & 1 & 3.3 & $91 \mathrm{~s}$ & 3 & 313 & 14 & 52629 & 0.0060 & 0.9770 & 6 & 3 & $28 \quad$ & 31 & 0 & 63 & & 11 & 39 & 152 & 0.7080 & 13 \\
\hline 24 & 7305 & 170 & 50 & 19 & 1 & 3.4 & 85 & 3 & 311 & & 528 & 0.0059 & 0.97 & & 2 & 26 & 31 & 0 & 63 & & 12 & 34 & 156 & & 11 \\
\hline 53 & 7305 & 175 & 54 & 16 & 1 & 3.2 & 853 & 1 & 304 & 155 & 53161 & 0.0057 & 0.9760 & 0.3 & 3 & $28 \quad$ & 30 & 0 & 62 & & 11 & 46 & 161 & & 304 \\
\hline 86 & 7305 & 167 & 49 & 23 & 1 & 3.4 & 43 & 6 & 319 & 13103 & 53254 & 0.0060 & 0.97 & 0. & 2 & 267 & 319 & 0 & 65 & 49 & 112 & 452 & 156 & & 319 \\
\hline 43 & 7305 & 171 & 56 & 24 & 1 & 3.1 & 879 & 0 & 312 & 14931 & 53371 & 0.0058 & 0.9766 & 0. & 2 & 26 & 312 & 0 & 627 & 49 & 11 & 458 & 149 & 44 & 312 \\
\hline 78 & 7305 & 164 & 40 & 43 & 1 & 4.1 & 851 & 1 & 328 & 10022 & 537 & 0.0061 & 0.9775 & 0. & 1 & 251 & 32 & 0 & 65 & 49 & 11 & 40 & 148 & 77 & 328 \\
\hline 98 & 7305 & 186 & 55 & 17 & 1 & 3.4 & 854 & 1 & 291 & 168 & 541 & 0.0054 & 0.9745 & 0.2 & 2 & 30 & 29 & 0 & 63 & 49 & 10 & 443 & 169 & 43 & 291 \\
\hline 79 & 730 & 181 & 60 & 12 & 1 & 3.0 & 900 & 1 & 300 & 143 & 54214 & 0.0055 & 0.9752 & 0.3 & 3 & 23 & 30 & 0 & 62 & $49 !$ & $107 \mathrm{C}$ & 440 & 167 & 0.6796 & 300 \\
\hline 48 & 730 & 168 & 45 & 17 & 1 & 3.7 & 852 & 0 & 323 & 141 & 54275 & 0.0060 & 0.9770 & 0.2 & 3 & 31 & 32 & 0 & 668 & 48 & 1168 & 419 & 161 & 0.7438 & 323 \\
\hline 42 & 730 & 164 & 50 & 21 & 1 & 3.3 & 850 & 0 & 333 & 154 & 54673 & 0.0061 & 0.9 & 0.3 & 2 & 30 & 333 & 0 & 62 & 49 & 116 & 414 & 152 & 0.7082 & 333 \\
\hline 69 & 730 & 186 & 62 & 25 & 1 & 3.0 & 882 & 2 & 296 & & 55119 & 0.0054 & 0.9 & 0.3 & 2 & 27 & 296 & 0 & 63 & 49 & 115 & 399 & 173 & 0.6776 & 296 \\
\hline 30 & 730 & 184 & 61 & 19 & 1 & 3.0 & 892 & 0 & 301 & 18629 & 55368 & 0.0054 & 0.9748 & 0.3315 & 2 & 30 & 301 & 0 & 646 & 4961 & 1117 & 412 & 169 & 0.6797 & 301 \\
\hline 6 & 7305 & 178 & 52 & 17 & 1 & 3.4 & 853 & 5 & 311 & $\begin{array}{l}15850 \\
17207\end{array}$ & 55384 & 0.0056 & 0.9756 & 0.2921 & 2 & 305 & 311 & 0 & 633 & 4969 & 1170 & 367 & 66 & 0.7191 & 311 \\
\hline 14 & 7305 & 158 & 44 & 19 & 1 & 3.6 & 860 & & 351 & 13707 & 55395 & 0.0063 & 0.9784 & 0.2785 & 2 & 312 & 351 & 0 & 613 & 4974 & 1165 & 408 & 145 & 0.7353 & 351 \\
\hline
\end{tabular}

Total no. Days ve Failure Failure Failure Severity of Severity of Severity of Severity of Severity of [Correspo Reliability, Resiliency 1/(MD/NS* Vulnerabili Vulnerabili $0.500-501-10001001-15001501-200020012500$ Eculidean 0. of days 


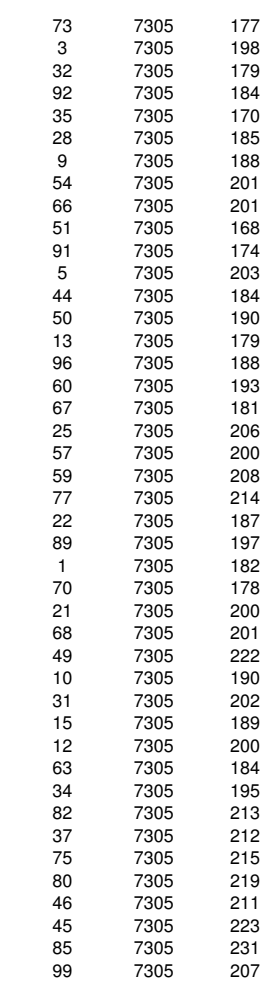

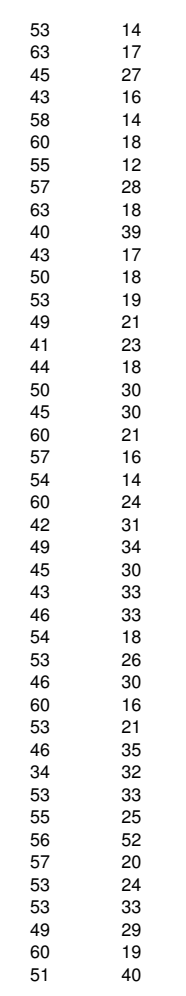

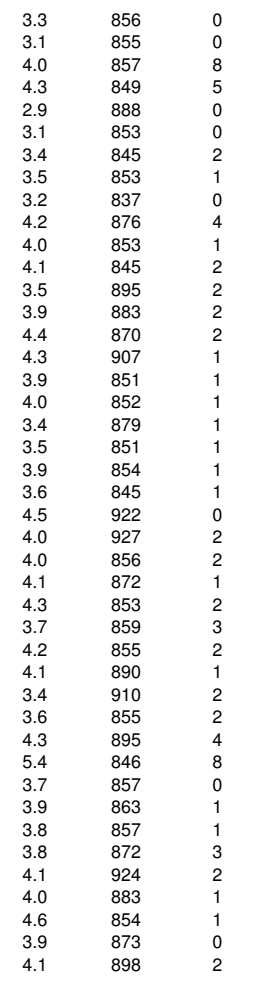

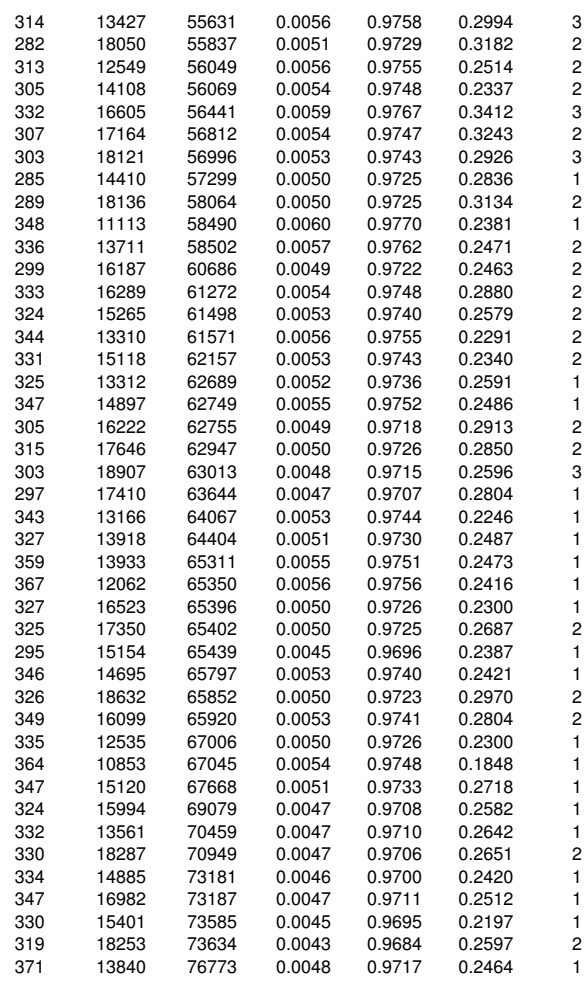

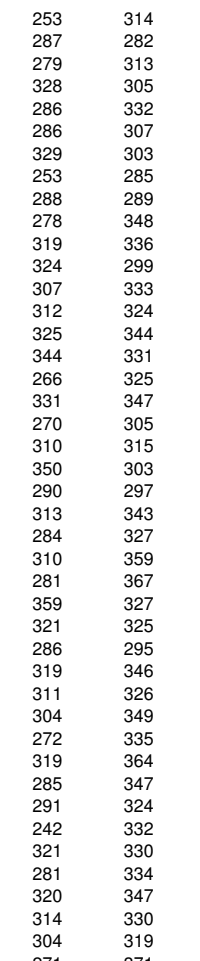

Minimum

$\underset{\substack{\text { Maximum } \\ \text { Std.dev }}}{\text { and }}$

$\begin{array}{llcl}2.6 & 590 & 0 & 219 \\ 3.5 & 861 & 2 & 304 \\ 5.4 & 927 & 8 & 371 \\ 0.5 & 36.8 & 1.8 & 30.9\end{array}$

$\begin{array}{llllll}10022 & 30408 & 0.0043 & 0.9684 & 0.1848 \\ 14658 & 54961 & 0.0056 & 0.9754 & 0.2875 \\ 14907 & 76773 & 0.0078 & 0.9823 & 0.3836\end{array}$

$\begin{array}{lllll}18907 & 76773 & 0.0078 & 0.9823 & 0.3836 \\ 1987.9 & 9569.6 & 0.0006 & 0.0028 & 0.0379\end{array}$

\begin{tabular}{|c|c|c|c|c|c|c|}
\hline & 5009 & 1115 & 394 & 166 & 0.7122 & 314 \\
\hline 602 & 4930 & 1150 & & 180 & 0.6916 & 282 \\
\hline 629 & 4957 & 1194 & 355 & 170 & 0.7594 & 313 \\
\hline 614 & 5026 & 1130 & 361 & 174 & 0.7763 & 305 \\
\hline 660 & 4887 & 1163 & 440 & 155 & 0.6725 & 332 \\
\hline 611 & 4914 & 1184 & 426 & 170 & 0.6872 & 307 \\
\hline 645 & 4947 & 1119 & 425 & 169 & 0.7182 & 303 \\
\hline 630 & 5010 & 1099 & 380 & 186 & 0.7260 & 285 \\
\hline 637 & 4943 & 1120 & 420 & 185 & 0.6968 & 89 \\
\hline 621 & 5010 & 1141 & 374 & 159 & 0.7749 & 48 \\
\hline 639 & 4930 & 1199 & 380 & 157 & 0.7652 & 36 \\
\hline 636 & 4967 & 1152 & 363 & 187 & 0.7636 & \\
\hline 644 & 5007 & $\begin{array}{l}1059 \\
1127\end{array}$ & 431 & $\begin{array}{l}164 \\
175\end{array}$ & $\begin{array}{l}0.7247 \\
0.753\end{array}$ & $\begin{array}{r}333 \\
324\end{array}$ \\
\hline 652 & $\begin{array}{l}4935 \\
4497\end{array}$ & $\begin{array}{l}1127 \\
1119\end{array}$ & $\begin{array}{l}416 \\
381\end{array}$ & $\begin{array}{l}175 \\
175\end{array}$ & $\begin{array}{l}0.7538 \\
0.7835\end{array}$ & $\begin{array}{l}324 \\
344\end{array}$ \\
\hline $\begin{array}{l}662 \\
644\end{array}$ & $\begin{array}{l}4927 \\
4969\end{array}$ & $\begin{array}{l}1169 \\
1115\end{array}$ & $\begin{array}{l}381 \\
363\end{array}$ & $\begin{array}{l}166 \\
174\end{array}$ & $\begin{array}{l}0.7835 \\
0.777\end{array}$ & $\begin{array}{l}344 \\
331\end{array}$ \\
\hline $\begin{array}{l}656 \\
656\end{array}$ & $\begin{array}{l}4909 \\
4928\end{array}$ & $\begin{array}{l}1150 \\
1142\end{array}$ & $\begin{array}{l}503 \\
402\end{array}$ & $\begin{array}{l}1 / 4 \\
177\end{array}$ & 0.7527 & $\begin{array}{l}331 \\
325\end{array}$ \\
\hline 630 & 4914 & 1172 & 419 & 170 & 0.7645 & 347 \\
\hline 632 & 4960 & 1116 & 412 & 185 & 0.7197 & 305 \\
\hline 633 & 4911 & 1171 & 406 & 184 & 0.7265 & 315 \\
\hline 620 & 4956 & 1147 & 391 & 191 & 0.7508 & 303 \\
\hline 671 & 4897 & 1095 & 448 & 194 & 0.7300 & 297 \\
\hline 647 & 4992 & 1100 & 390 & 176 & 0.7878 & 343 \\
\hline 639 & 5021 & 1078 & 383 & 184 & 0.7630 & 327 \\
\hline 628 & 4982 & 1140 & 383 & 172 & 0.7667 & 359 \\
\hline 631 & 4996 & 1094 & 414 & $\begin{array}{l}170 \\
170\end{array}$ & $\begin{array}{l}0.7729 \\
07815\end{array}$ & $\begin{array}{l}367 \\
327\end{array}$ \\
\hline 627 & 4883 & 1162 & $\begin{array}{l}443 \\
435\end{array}$ & $\begin{array}{l}190 \\
191\end{array}$ & $\begin{array}{l}0.7815 \\
0\end{array}$ & $\begin{array}{l}327 \\
325\end{array}$ \\
\hline $\begin{array}{l}622 \\
629\end{array}$ & $\begin{array}{l}4891 \\
4933\end{array}$ & $\begin{array}{l}1166 \\
1113\end{array}$ & $\begin{array}{l}435 \\
396\end{array}$ & $\begin{array}{l}191 \\
204\end{array}$ & $\begin{array}{l}0.7433 \\
0.7709\end{array}$ & $\begin{array}{l}325 \\
295\end{array}$ \\
\hline $\begin{array}{l}629 \\
620\end{array}$ & $\begin{array}{l}4933 \\
5000\end{array}$ & $\begin{array}{l}1143 \\
1123\end{array}$ & $\begin{array}{l}396 \\
382\end{array}$ & $\begin{array}{l}204 \\
180\end{array}$ & $\begin{array}{l}0.7109 \\
0\end{array}$ & $\begin{array}{l}295 \\
346\end{array}$ \\
\hline 611 & 4948 & $\begin{array}{l}1193 \\
1192\end{array}$ & $\begin{array}{l}382 \\
364\end{array}$ & $\begin{array}{l}100 \\
190\end{array}$ & 0.7155 & $\begin{array}{l}346 \\
326\end{array}$ \\
\hline 643 & 4919 & 1175 & 394 & 174 & 0.7334 & 349 \\
\hline 648 & 4928 & 1111 & 425 & 193 & 0.7821 & 335 \\
\hline 618 & 5007 & 1136 & 364 & 180 & 0.8285 & 364 \\
\hline 636 & 4952 & 1149 & 382 & 186 & 0.7418 & 347 \\
\hline 645 & 4924 & 1126 & 412 & 198 & 0.7536 & 324 \\
\hline 667 & 4850 & 1149 & 440 & 199 & 0.7483 & 332 \\
\hline 647 & 4874 & 1163 & 422 & 199 & 0.7472 & 330 \\
\hline 619 & 5014 & 1065 & 406 & 201 & 0.7703 & 334 \\
\hline 645 & 4978 & $\begin{array}{l}1125 \\
1112\end{array}$ & $\begin{array}{l}364 \\
272\end{array}$ & 193 & 0.7621 & $\begin{array}{r}347 \\
330\end{array}$ \\
\hline 645 & 4959 & $\begin{array}{l}1121 \\
101\end{array}$ & 372 & 208 & 0.7919 & 330 \\
\hline $\begin{array}{l}607 \\
640\end{array}$ & $\begin{array}{l}4977 \\
4952\end{array}$ & $\begin{array}{l}1059 \\
1149\end{array}$ & $\begin{array}{l}450 \\
368\end{array}$ & $\begin{array}{l}212 \\
196\end{array}$ & $\begin{array}{l}0.7518 \\
0.7686\end{array}$ & $\begin{array}{l}319 \\
371\end{array}$ \\
\hline 598 & 48 & 10 & 34 & 11 & 0.6269 & 219 \\
\hline 636 & 4955 & 1141 & 408 & 165 & 0.7233 & 304 \\
\hline 671 & 5040 & 1206 & 470 & 212 & 0.8285 & 371 \\
\hline 16.0 & 39.7 & 35.0 & 28.9 & 19.9 & 0.0388 & 31 \\
\hline
\end{tabular}


Scenerio N Scenario 14b CSIROMk2b B11 with 15\% additioanI WEMPs savings

Simulation $\quad 9: 11: 37$ PM

$\begin{array}{ll}\text { Simulation } & \text { 10:04:50 PM } \\ \text { Elapsed Tii } & 53.22 \text { Minutes }\end{array}$

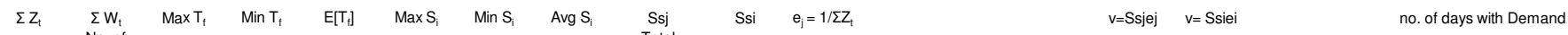

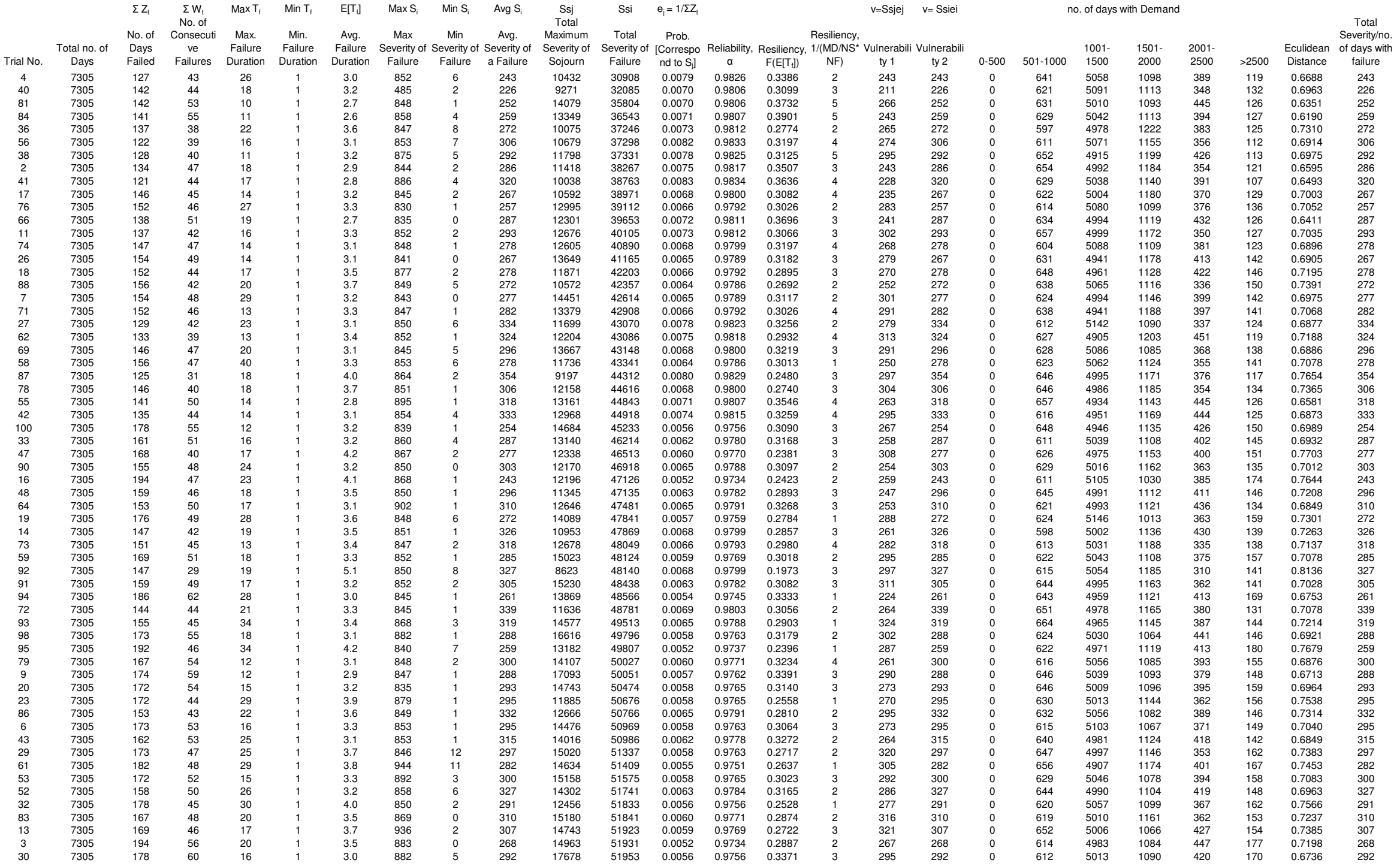




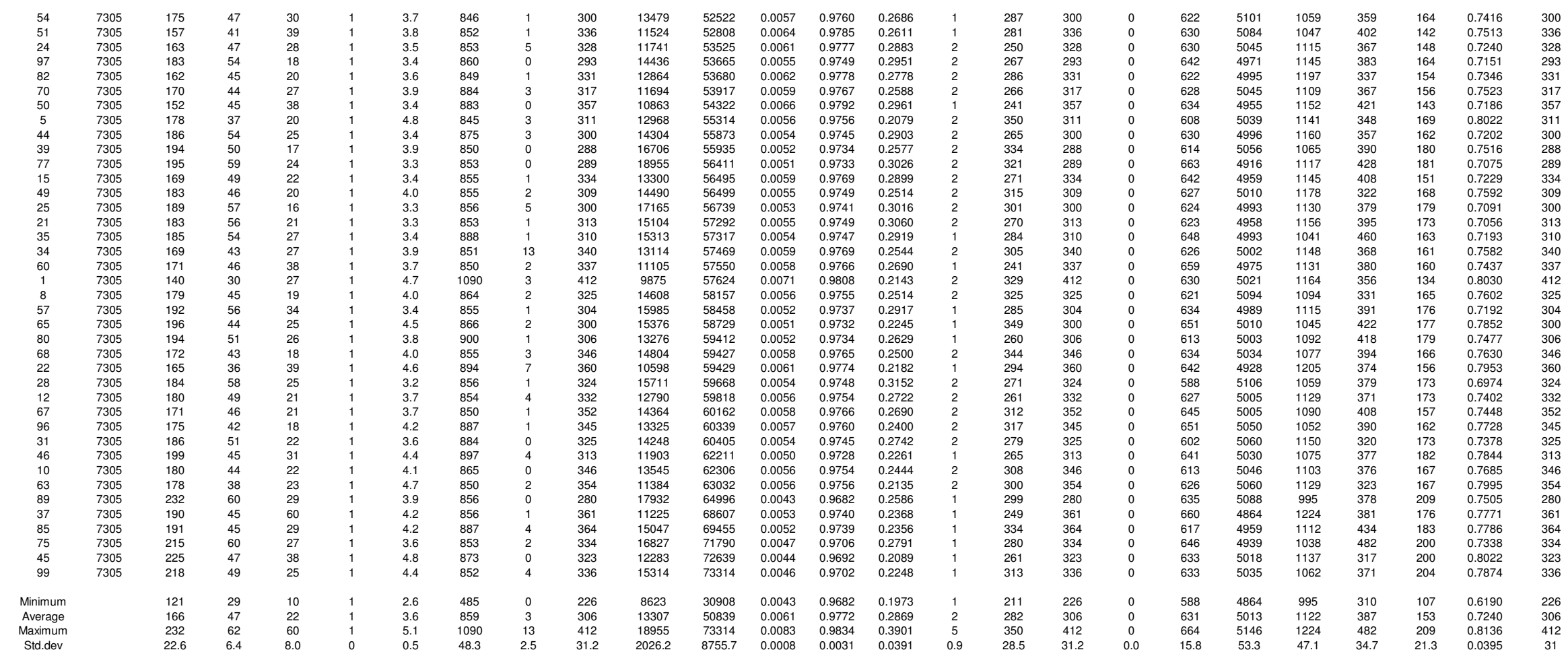


Scenerio N Scenario 14c CSIROMk2b B11 with 15\% additional WEMPs savings $\square$ Higher population projection and change of precipitation frequency of occurrence Date: 9/10/2007

Simulation $\quad$ 12:56:04 PM

Elapsed Til -1301.62 Minutes

\begin{tabular}{|c|c|c|c|c|c|c|c|c|c|c|c|c|c|c|}
\hline $\begin{array}{c}\sum Z_{\mathrm{t}} \\
\text { No. of } \\
\text { Days } \\
\text { Failed }\end{array}$ & $\begin{array}{c}\sum W_{t} \\
\text { No. of } \\
\text { Consecutive } \\
\text { Failures }\end{array}$ & $\begin{array}{l}\text { Max } T_{f} \\
\text { Max. } \\
\text { Failure } \\
\text { Duration }\end{array}$ & $\begin{array}{c}\text { Min } T_{f} \\
\text { Min. } \\
\text { Failure } \\
\text { Duration }\end{array}$ & $\begin{array}{c}E\left[T_{f}\right] \\
\text { Avg. } \\
\text { Failure } \\
\text { Duration }\end{array}$ & $\begin{array}{c}\operatorname{Max}_{\mathrm{S}} \\
\text { Max } \\
\text { Severity of } \\
\text { Failure }\end{array}$ & $\begin{array}{l}\text { Min } \mathrm{S}_{\mathrm{i}} \\
\quad \text { Min } \\
\text { Severity of } \\
\text { Failure }\end{array}$ & $\begin{array}{l}\text { Ssi } \\
\text { Total } \\
\text { Severity of } \\
\text { Failure }\end{array}$ & $\begin{array}{c}\text { Ssj } \\
\text { Total Maximum } \\
\text { Severity of } \\
\text { Sojourn }\end{array}$ & $\begin{array}{c}\mathrm{e}_{\mathrm{j}}=1 / \Sigma \mathrm{Z}_{\mathrm{t}} \\
\text { Prob. } \\
\text { [Correspo } \\
\left.\text { nd to } \mathrm{S}_{\mathrm{j}}\right]\end{array}$ & $\begin{array}{c}\text { Reliability, } \\
\alpha\end{array}$ & $\begin{array}{c}\text { Resiliency, } \\
F\left(E\left[T_{f}\right]\right)\end{array}$ & $\begin{array}{c}\text { Resiliency, } \\
\text { 1/(MD/NS*NF } \\
\text { ) }\end{array}$ & $\begin{array}{c}\mathrm{v}=\mathrm{Ssjej} \\
\text { Vulnerability } \\
1\end{array}$ & Vulnerability 2 \\
\hline 556 & 113 & 53 & 1 & 4.9 & 1862 & 1 & 302175 & 52319 & 0.0018 & 0.9239 & 0.2032 & 0.25 & 463 & 543 \\
\hline 541 & 138 & 34 & 1 & 3.9 & 1846 & 1 & 253067 & 59009 & 0.0018 & 0.9259 & 0.2551 & 0.40 & 428 & 468 \\
\hline 613 & 145 & 51 & 1 & 4.2 & 1863 & 2 & 317842 & 68653 & 0.0016 & 0.9161 & 0.2365 & 0.23 & 473 & 519 \\
\hline 496 & 113 & 54 & 1 & 4.4 & 1859 & 3 & 231198 & 56016 & 0.0020 & 0.9321 & 0.2278 & 0.27 & 496 & 466 \\
\hline 519 & 110 & 44 & 1 & 4.7 & 1849 & 0 & 294930 & 55516 & 0.0019 & 0.9290 & 0.2119 & 0.32 & 505 & 568 \\
\hline 506 & 124 & 31 & 1 & 4.1 & 1860 & 1 & 276458 & 59268 & 0.0020 & 0.9307 & 0.2451 & 0.47 & 478 & 546 \\
\hline 520 & 122 & 48 & 1 & 4.3 & 1746 & 1 & 249845 & 53230 & 0.0019 & 0.9288 & 0.2346 & 0.29 & 436 & 480 \\
\hline 543 & 121 & 48 & 1 & 4.5 & 1858 & 0 & 283751 & 57955 & 0.0018 & 0.9257 & 0.2228 & 0.28 & 479 & 523 \\
\hline 558 & 125 & 39 & 1 & 4.5 & 1849 & 1 & 292733 & 55702 & 0.0018 & 0.9236 & 0.2240 & 0.34 & 446 & 525 \\
\hline 543 & 103 & 59 & 1 & 5.3 & 1908 & 0 & 314374 & 49537 & 0.0018 & 0.9257 & 0.1897 & 0.23 & 481 & 579 \\
\hline 510 & 124 & 46 & 1 & 4.1 & 1874 & 1 & 260928 & 55044 & 0.0020 & 0.9302 & 0.2431 & 0.31 & 444 & 512 \\
\hline 551 & 116 & 47 & 1 & 4.8 & 1913 & 1 & 300939 & 54995 & 0.0018 & 0.9246 & 0.2105 & 0.28 & 474 & 546 \\
\hline 531 & 112 & 52 & 1 & 4.7 & 1882 & 2 & 288393 & 47803 & 0.0019 & 0.9273 & 0.2109 & 0.26 & 427 & 543 \\
\hline 506 & 120 & 43 & 1 & 4.2 & 1867 & 1 & 264345 & 52424 & 0.0020 & 0.9307 & 0.2372 & 0.34 & 437 & 522 \\
\hline 534 & 116 & 39 & 1 & 4.6 & 1863 & 2 & 316633 & 58055 & 0.0019 & 0.9269 & 0.2172 & 0.35 & 500 & 593 \\
\hline 525 & 121 & 74 & 1 & 4.3 & 1904 & 2 & 255335 & 52150 & 0.0019 & 0.9281 & 0.2305 & 0.19 & 431 & 486 \\
\hline 524 & 109 & 45 & 1 & 4.8 & 1855 & 0 & 269321 & 52936 & 0.0019 & 0.9283 & 0.2080 & 0.31 & 486 & 514 \\
\hline 532 & 122 & 31 & 1 & 4.4 & 1866 & 0 & 274296 & 59205 & 0.0019 & 0.9272 & 0.2293 & 0.44 & 485 & 516 \\
\hline 553 & 109 & 77 & 1 & 5.1 & 1947 & 2 & 280738 & 48151 & 0.0018 & 0.9243 & 0.1971 & 0.17 & 442 & 508 \\
\hline 524 & 111 & 60 & 1 & 4.7 & 1839 & 0 & 278064 & 53266 & 0.0019 & 0.9283 & 0.2118 & 0.23 & 480 & 531 \\
\hline 594 & 119 & 39 & 1 & 5.0 & 1860 & 1 & 327314 & 56886 & 0.0017 & 0.9187 & 0.2003 & 0.32 & 478 & 551 \\
\hline 564 & 112 & 60 & 1 & 5.0 & 1947 & 1 & 305733 & 55134 & 0.0018 & 0.9228 & 0.1986 & 0.22 & 492 & 542 \\
\hline 525 & 109 & 65 & 1 & 4.8 & 1893 & 1 & 270178 & 47818 & 0.0019 & 0.9281 & 0.2076 & 0.21 & 439 & 515 \\
\hline 504 & 109 & 50 & 1 & 4.6 & 1858 & 0 & 266804 & 54784 & 0.0020 & 0.9310 & 0.2163 & 0.29 & 503 & 529 \\
\hline 542 & 110 & 38 & 1 & 4.9 & 1892 & 1 & 310042 & 55880 & 0.0018 & 0.9258 & 0.2030 & 0.35 & 508 & 572 \\
\hline 572 & 114 & 60 & 1 & 5.0 & 1845 & 0 & 291325 & 56351 & 0.0017 & 0.9217 & 0.1993 & 0.21 & 494 & 509 \\
\hline 515 & 115 & 51 & 1 & 4.5 & 1856 & 1 & 265827 & 56218 & 0.0019 & 0.9295 & 0.2233 & 0.28 & 489 & 516 \\
\hline 550 & 112 & 55 & 1 & 4.9 & 1859 & 0 & 303850 & 55291 & 0.0018 & 0.9247 & 0.2036 & 0.24 & 494 & 552 \\
\hline 570 & 127 & 50 & 1 & 4.5 & 1859 & 1 & 298636 & 62184 & 0.0018 & 0.9220 & 0.2228 & 0.26 & 490 & 524 \\
\hline 569 & 115 & 46 & 1 & 4.9 & 1908 & 1 & 309682 & 61331 & 0.0018 & 0.9221 & 0.2021 & 0.28 & 533 & 544 \\
\hline 513 & 113 & 67 & 1 & 4.5 & 1933 & 1 & 311319 & 61554 & 0.0019 & 0.9298 & 0.2203 & 0.21 & 545 & 607 \\
\hline 500 & 110 & 38 & 1 & 4.5 & 1864 & 1 & 266421 & 53900 & 0.0020 & 0.9316 & 0.2200 & 0.38 & 490 & 533 \\
\hline 565 & 99 & 46 & 1 & 5.7 & 1878 & 3 & 302773 & 52191 & 0.0018 & 0.9227 & 0.1752 & 0.28 & 527 & 536 \\
\hline 524 & 115 & 47 & 1 & 4.6 & 1862 & 0 & 309341 & 58305 & 0.0019 & 0.9283 & 0.2195 & 0.30 & 507 & 590 \\
\hline 575 & 115 & 32 & 1 & 5.0 & 1904 & 3 & 303534 & 61675 & 0.0017 & 0.9213 & 0.2000 & 0.40 & 536 & 528 \\
\hline 552 & 116 & 56 & 1 & 4.8 & 1851 & 1 & 273286 & 56202 & 0.0018 & 0.9244 & 0.2101 & 0.24 & 485 & 495 \\
\hline 599 & 123 & 60 & 1 & 4.9 & 1864 & 0 & 339925 & 57305 & 0.0017 & 0.9180 & 0.2053 & 0.20 & 466 & 567 \\
\hline 556 & 117 & 37 & 1 & 4.8 & 1857 & 8 & 255666 & 53741 & 0.0018 & 0.9239 & 0.2104 & 0.36 & 459 & 460 \\
\hline 532 & 112 & 71 & 1 & 4.8 & 1860 & 0 & 280414 & 51732 & 0.0019 & 0.9272 & 0.2105 & 0.19 & 462 & 527 \\
\hline 477 & 115 & 41 & 1 & 4.1 & 1521 & 0 & 224083 & 49397 & 0.0021 & 0.9347 & 0.2411 & 0.37 & 430 & 470 \\
\hline 463 & 107 & 28 & 1 & 4.3 & 1891 & 0 & 239294 & 54939 & 0.0022 & 0.9366 & 0.2311 & 0.56 & 513 & 517 \\
\hline 528 & 107 & 44 & 1 & 4.9 & 1855 & 3 & 277053 & 52406 & 0.0019 & 0.9277 & 0.2027 & 0.31 & 490 & 525 \\
\hline 607 & 123 & 60 & 1 & 4.9 & 1894 & 0 & 322514 & 59727 & 0.0016 & 0.9169 & 0.2026 & 0.20 & 486 & 531 \\
\hline 547 & 108 & 33 & 1 & 5.1 & 1912 & 1 & 311391 & 57333 & 0.0018 & 0.9251 & 0.1974 & 0.40 & 531 & 569 \\
\hline 537 & 107 & 66 & 1 & 5.0 & 1860 & 0 & 325251 & 47606 & 0.0019 & 0.9265 & 0.1993 & 0.21 & 445 & 606 \\
\hline 525 & 100 & 50 & 1 & 5.3 & 1900 & 4 & 332953 & 54862 & 0.0019 & 0.9281 & 0.1905 & 0.28 & 549 & 634 \\
\hline 515 & 114 & 62 & 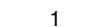 & 4.5 & 1853 & & 280098 & 54114 & 0.0019 & 0.9295 & 0.2214 & 0.23 & 475 & 544 \\
\hline
\end{tabular}




\begin{tabular}{|c|c|c|c|c|c|c|c|c|c|c|c|c|c|c|c|c|}
\hline 48 & 7305 & 551 & 113 & 43 & 1 & 4.9 & 1857 & 1 & 299727 & 60362 & 0.0018 & 0.9246 & 0.2051 & 0.31 & 534 & 544 \\
\hline 49 & 7305 & 574 & 111 & 87 & 1 & 5.2 & 1862 & 1 & 321447 & 49843 & 0.0017 & 0.9214 & 0.1934 & 0.15 & 449 & 560 \\
\hline 50 & 7305 & 575 & 132 & 43 & 1 & 4.4 & 1897 & 2 & 306166 & 59477 & 0.0017 & 0.9213 & 0.2296 & 0.30 & 451 & 532 \\
\hline 51 & 7305 & 511 & 113 & 52 & 1 & 4.5 & 1889 & 0 & 284952 & 46910 & 0.0020 & 0.9300 & 0.2211 & 0.27 & 415 & 558 \\
\hline 52 & 7305 & 568 & 112 & 67 & 1 & 5.1 & 1862 & 0 & 300060 & 54682 & 0.0018 & 0.9222 & 0.1972 & 0.19 & 488 & 528 \\
\hline 53 & 7305 & 559 & 110 & 28 & 1 & 5.1 & 1859 & 1 & 297627 & 56285 & 0.0018 & 0.9235 & 0.1968 & 0.47 & 512 & 532 \\
\hline 54 & 7305 & 517 & 104 & 56 & 1 & 5.0 & 1860 & 0 & 303216 & 49740 & 0.0019 & 0.9292 & 0.2012 & 0.25 & 478 & 586 \\
\hline 55 & 7305 & 547 & 139 & 45 & 1 & 3.9 & 1884 & 3 & 267582 & 58766 & 0.0018 & 0.9251 & 0.2541 & 0.30 & 423 & 489 \\
\hline 56 & 7305 & 532 & 126 & 45 & 1 & 4.2 & 1900 & 2 & 272321 & 54954 & 0.0019 & 0.9272 & 0.2368 & 0.31 & 436 & 512 \\
\hline 57 & 7305 & 550 & 117 & 35 & 1 & 4.7 & 1858 & 0 & 310980 & 61955 & 0.0018 & 0.9247 & 0.2127 & 0.38 & 530 & 565 \\
\hline 58 & 7305 & 530 & 124 & 59 & 1 & 4.3 & 1844 & 0 & 259380 & 57304 & 0.0019 & 0.9274 & 0.2340 & 0.23 & 462 & 489 \\
\hline 59 & 7305 & 558 & 97 & 38 & 1 & 5.8 & 1861 & 3 & 326019 & 57310 & 0.0018 & 0.9236 & 0.1738 & 0.34 & 591 & 584 \\
\hline 60 & 7305 & 553 & 120 & 59 & 1 & 4.6 & 1858 & 2 & 303859 & 55522 & 0.0018 & 0.9243 & 0.2170 & 0.22 & 463 & 549 \\
\hline 61 & 7305 & 548 & 100 & 44 & 1 & 5.5 & 1851 & 1 & 289526 & 52903 & 0.0018 & 0.9250 & 0.1825 & 0.30 & 529 & 528 \\
\hline 62 & 7305 & 579 & 126 & 38 & 1 & 4.6 & 1848 & 2 & 289313 & 55114 & 0.0017 & 0.9207 & 0.2176 & 0.33 & 437 & 500 \\
\hline 63 & 7305 & 530 & 132 & 35 & 1 & 4.0 & 1851 & 1 & 299266 & 54520 & 0.0019 & 0.9274 & 0.2491 & 0.39 & 413 & 565 \\
\hline 64 & 7305 & 481 & 111 & 32 & 1 & 4.3 & 1927 & 1 & 259657 & 54213 & 0.0021 & 0.9342 & 0.2308 & 0.47 & 488 & 540 \\
\hline 65 & 7305 & 589 & 114 & 39 & 1 & 5.2 & 1849 & 4 & 305218 & 56059 & 0.0017 & 0.9194 & 0.1935 & 0.32 & 492 & 518 \\
\hline 66 & 7305 & 578 & 95 & 52 & 1 & 6.1 & 1841 & 1 & 307138 & 51191 & 0.0017 & 0.9209 & 0.1644 & 0.24 & 539 & 531 \\
\hline 67 & 7305 & 571 & 115 & 52 & 1 & 5.0 & 1858 & 0 & 314845 & 59606 & 0.0018 & 0.9218 & 0.2014 & 0.25 & 518 & 551 \\
\hline 68 & 7305 & 594 & 111 & 58 & 1 & 5.4 & 1864 & 1 & 328655 & 53400 & 0.0017 & 0.9187 & 0.1869 & 0.21 & 481 & 553 \\
\hline 69 & 7305 & 557 & 110 & 39 & 1 & 5.1 & 1896 & 0 & 313753 & 59236 & 0.0018 & 0.9238 & 0.1975 & 0.34 & 539 & 563 \\
\hline 70 & 7305 & 562 & 118 & 66 & 1 & 4.8 & 1885 & 3 & 301042 & 49634 & 0.0018 & 0.9231 & 0.2100 & 0.20 & 421 & 536 \\
\hline 71 & 7305 & 561 & 105 & 57 & 1 & 5.3 & 1846 & 4 & 276783 & 47557 & 0.0018 & 0.9232 & 0.1872 & 0.23 & 453 & 493 \\
\hline 72 & 7305 & 557 & 124 & 43 & 1 & 4.5 & 1853 & 1 & 271686 & 60104 & 0.0018 & 0.9238 & 0.2226 & 0.30 & 485 & 488 \\
\hline 73 & 7305 & 523 & 110 & 54 & 1 & 4.8 & 1861 & 0 & 287578 & 50909 & 0.0019 & 0.9284 & 0.2103 & 0.26 & 463 & 550 \\
\hline 74 & 7305 & 494 & 109 & 35 & 1 & 4.5 & 1891 & 10 & 269861 & 54478 & 0.0020 & 0.9324 & 0.2206 & 0.42 & 500 & 546 \\
\hline 75 & 7305 & 585 & 121 & 45 & 1 & 4.8 & 1883 & 0 & 341091 & 64331 & 0.0017 & 0.9199 & 0.2068 & 0.28 & 532 & 583 \\
\hline 76 & 7305 & 540 & 102 & 45 & 1 & 5.3 & 1852 & 2 & 270455 & 52607 & 0.0019 & 0.9261 & 0.1889 & 0.30 & 516 & 501 \\
\hline 77 & 7305 & 621 & 103 & 54 & 1 & 6.0 & 1849 & 0 & 348474 & 54431 & 0.0016 & 0.9150 & 0.1659 & 0.22 & 528 & 561 \\
\hline 78 & 7305 & 524 & 116 & 58 & 1 & 4.5 & 1857 & 1 & 268231 & 47688 & 0.0019 & 0.9283 & 0.2214 & 0.24 & 411 & 512 \\
\hline 79 & 7305 & 577 & 110 & 42 & 1 & 5.2 & 1920 & 2 & 302715 & 53961 & 0.0017 & 0.9210 & 0.1906 & 0.30 & 491 & 525 \\
\hline 80 & 7305 & 579 & 108 & 68 & 1 & 5.4 & 1950 & 1 & 341458 & 51916 & 0.0017 & 0.9207 & 0.1865 & 0.19 & 481 & 590 \\
\hline 81 & 7305 & 565 & 127 & 42 & 1 & 4.4 & 1847 & 2 & 267758 & 63430 & 0.0018 & 0.9227 & 0.2248 & 0.31 & 499 & 474 \\
\hline 82 & 7305 & 581 & 113 & 52 & 1 & 5.1 & 1873 & 0 & 333007 & 55733 & 0.0017 & 0.9205 & 0.1945 & 0.24 & 493 & 573 \\
\hline 83 & 7305 & 535 & 100 & 36 & 1 & 5.4 & 1856 & 1 & 281143 & 48660 & 0.0019 & 0.9268 & 0.1869 & 0.38 & 487 & 526 \\
\hline 84 & 7305 & 579 & 136 & 55 & 1 & 4.3 & 1853 & 0 & 275537 & 59317 & 0.0017 & 0.9207 & 0.2349 & 0.23 & 436 & 476 \\
\hline 85 & 7305 & 634 & 110 & 56 & 1 & 5.8 & 1889 & 1 & 358687 & 57817 & 0.0016 & 0.9132 & 0.1735 & 0.21 & 526 & 566 \\
\hline 86 & 7305 & 562 & 112 & 56 & 1 & 5.0 & 1848 & 0 & 288640 & 52412 & 0.0018 & 0.9231 & 0.1993 & 0.23 & 468 & 514 \\
\hline 87 & 7305 & 480 & 106 & 60 & 1 & 4.5 & 1878 & 1 & 255034 & 45277 & 0.0021 & 0.9343 & 0.2208 & 0.25 & 427 & 531 \\
\hline 88 & 7305 & 543 & 113 & 40 & 1 & 4.8 & 1855 & 2 & 275329 & 55063 & 0.0018 & 0.9257 & 0.2081 & 0.34 & 487 & 507 \\
\hline 89 & 7305 & 548 & 110 & 54 & 1 & 5.0 & 1955 & 1 & 305475 & 56135 & 0.0018 & 0.9250 & 0.2007 & 0.25 & 510 & 557 \\
\hline 90 & 7305 & 556 & 141 & 38 & 1 & 3.9 & 1907 & 0 & 277717 & 58646 & 0.0018 & 0.9239 & 0.2536 & 0.35 & 416 & 499 \\
\hline 91 & 7305 & 507 & 113 & 53 & 1 & 4.5 & 1858 & 0 & 277551 & 46175 & 0.0020 & 0.9306 & 0.2229 & 0.27 & 409 & 547 \\
\hline 92 & 7305 & 517 & 101 & 52 & 1 & 5.1 & 1854 & 1 & 289328 & 51790 & 0.0019 & 0.9292 & 0.1954 & 0.27 & 513 & 560 \\
\hline 93 & 7305 & 498 & 105 & 47 & 1 & 4.7 & 1879 & 3 & 250096 & 48949 & 0.0020 & 0.9318 & 0.2108 & 0.31 & 466 & 502 \\
\hline 94 & 7305 & 590 & 128 & 49 & 1 & 4.6 & 1849 & 0 & 296303 & 59811 & 0.0017 & 0.9192 & 0.2169 & 0.25 & 467 & 502 \\
\hline 95 & 7305 & 518 & 100 & 42 & 1 & 5.2 & 1856 & 1 & 280941 & 51026 & 0.0019 & 0.9291 & 0.1931 & 0.34 & 510 & 542 \\
\hline 96 & 7305 & 529 & 116 & 85 & 1 & 4.6 & 1929 & 0 & 290569 & 51948 & 0.0019 & 0.9276 & 0.2193 & 0.16 & 448 & 549 \\
\hline 97 & 7305 & 522 & 116 & 65 & 1 & 4.5 & 1944 & 1 & 275989 & 51927 & 0.0019 & 0.9285 & 0.2222 & 0.22 & 448 & 529 \\
\hline 98 & 7305 & 558 & 121 & 28 & 1 & 4.6 & 1860 & 0 & 302815 & 59820 & 0.0018 & 0.9236 & 0.2168 & 0.47 & 494 & 543 \\
\hline 99 & 7305 & 556 & 118 & 66 & 1 & 4.7 & 1915 & 0 & 334289 & 52801 & 0.0018 & 0.9239 & 0.2122 & 0.20 & 447 & 601 \\
\hline 100 & 7305 & $\begin{array}{l}500 \\
520\end{array}$ & 100 & 58 & 1 & 5.2 & 1887 & 1 & 275497 & 49938 & 0.0019 & 0.9288 & 0.1923 & 0.24 & 499 & 530 \\
\hline Minimum & & 463 & 95 & 28 & 1 & 3.9 & 1521 & 0 & 224083 & 45277 & 0.0016 & 0.9132 & 0.1644 & 0.15 & 409 & 460 \\
\hline Average & & 545 & 115 & 50 & 1 & 4.8 & 1870 & 1 & 291419 & 54837 & 0.0018 & 0.9254 & 0.2109 & 0.29 & 480 & 535 \\
\hline Maximum & & 634 & 145 & 87 & 1 & 6.1 & 1955 & 10 & 358687 & 68653 & 0.0022 & 0.9366 & 0.2551 & 0.56 & 591 & 634 \\
\hline Std.dev & & 32.2 & 9.7 & 12.1 & 0 & 0.4 & 46.7 & 1.5 & 26233.0 & 4377.0 & 0.0001 & 0.0044 & 0.0190 & 0.08 & 37.0 & 33.9 \\
\hline
\end{tabular}


Appendix D

Optimization Results 


\begin{tabular}{cccccc}
\hline Improvement Cost, Z1 & $\mathrm{X} 1$ & $\mathrm{X} 2$ & $\mathrm{X3}$ & $\mathrm{X} 4$ & $\mathrm{X5}$ \\
\hline Cost(\$ in K) & $\$ 187$ & $\$ 196.40$ & $\$ 215$ & $\$ 1,098.0$ & 1695 \\
\hline System Performance, Z2 & & & & & \\
\hline Reliability & 0.9970 & 0.9970 & 0.9972 & 0.9991 & 0.9998 \\
Resiliency & 0.5480 & 0.5502 & 0.5540 & 0.6832 & 0.8380 \\
Vulnerability & 0.0760 & 0.0754 & 0.0750 & 0.0596 & 0.0250 \\
\hline Euclidean distances & 0.4584 & 0.4561 & 0.4523 & 0.3224 & 0.1639 \\
\hline
\end{tabular}

Cost and Performance Weight the same

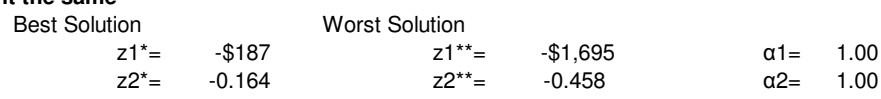

\begin{tabular}{|c|c|c|c|c|c|c|c|c|c|c|}
\hline Alternative Implementation & $\begin{array}{c}\text { Cost } \\
\mathrm{Z1} \\
\end{array}$ & $\begin{array}{c}\text { Performance } \\
\mathrm{Z2} \\
\end{array}$ & $\frac{z 1^{*}-z 1(x)}{z 1^{*}-z 1^{* *}}$ & $\frac{z 2^{*}-z 2(x)}{z 2^{*}-z 2^{* *}}$ & $\begin{array}{c}S= \\
\operatorname{Ls}(x)\end{array}$ & $\begin{array}{c}1 \\
\text { Rank } \\
\end{array}$ & $\begin{array}{c}\mathrm{S}= \\
\mathrm{Ls}(\mathrm{x}) \\
\end{array}$ & $\begin{array}{c}2 \\
\text { Rank } \\
\end{array}$ & $\begin{array}{c}\mathrm{S}= \\
\mathrm{Ls}(\mathrm{x})\end{array}$ & $\begin{array}{r}100 \\
\text { Rank } \\
\end{array}$ \\
\hline Alt. 1 & $-\$ 187$ & -0.45835 & 0.00 & 1.00 & 1.000 & 3 & 1.000 & 4 & 1.000 & 4 \\
\hline Alt. 2 & $-\$ 196$ & -0.45609 & 0.01 & 0.99 & 0.999 & 2 & 0.985 & 3 & 0.463 & 3 \\
\hline Alt. 3 & $-\$ 215$ & -0.45231 & 0.02 & 0.98 & 0.998 & 1 & 0.960 & 2 & 0.126 & 2 \\
\hline Alt. 4 & $-\$ 1,098$ & -0.32237 & 0.60 & 0.54 & 1.142 & 5 & 0.655 & 1 & 0.000 & 1 \\
\hline Alt. 5 & $-\$ 1,695$ & -0.16393 & 1.00 & 0.00 & 1.000 & 3 & 1.000 & 4 & 1.000 & 4 \\
\hline
\end{tabular}

Cost weights more

$$
\begin{array}{rrrrrr}
\text { Best Solution } & \multicolumn{5}{c}{\text { Worst Solution }} \\
z 1^{*}= & -\$ 187 & z 1^{* *}= & -\$ 1,695 & \alpha 1= & 10.00 \\
z 2^{*}= & -0.164 & z 2^{* *}= & -0.458 & \alpha 2= & 1.00
\end{array}
$$

\begin{tabular}{|c|c|c|c|c|c|c|c|c|c|c|}
\hline Alternative Implementation & $\begin{array}{l}\text { Cost } \\
\mathrm{Z1}\end{array}$ & $\begin{array}{c}\text { Performance } \\
\text { Z2 }\end{array}$ & $\frac{z 1^{*}-z 1(x)}{z 1^{*}-z 1^{* *}}$ & $\frac{z 2^{*}-z 2(x)}{z 2^{*}-z 2^{\star *}}$ & $\begin{array}{c}\mathrm{S}= \\
\mathrm{Ls}(\mathrm{x})\end{array}$ & $\begin{array}{c}1 \\
\text { Rank }\end{array}$ & $\begin{array}{c}S= \\
L s(x)\end{array}$ & $\begin{array}{c}2 \\
\text { Rank }\end{array}$ & $\begin{array}{c}\mathrm{s}= \\
\mathrm{Ls}(\mathrm{x})\end{array}$ & $\begin{array}{r}100 \\
\text { Rank }\end{array}$ \\
\hline Alt. 1 & $-\$ 187$ & -0.45835 & 0.00 & 1.00 & 1.000 & 1 & 1.000 & 3 & 1.000 & 4 \\
\hline Alt. 2 & $-\$ 196$ & -0.45609 & 0.01 & 0.99 & 1.055 & 2 & 0.985 & 2 & 0.463 & 3 \\
\hline Alt. 3 & $-\$ 215$ & -0.45231 & 0.02 & 0.98 & 1.166 & 3 & 0.963 & 1 & 0.126 & 2 \\
\hline Alt. 4 & $-\$ 1,098$ & -0.32237 & 0.60 & 0.54 & 6.579 & 4 & 3.939 & 4 & 0.000 & 1 \\
\hline Alt. 5 & $-\$ 1,695$ & -0.16393 & 1.00 & 0.00 & 10.000 & 5 & 10.000 & 5 & 10.000 & 5 \\
\hline
\end{tabular}

Performance weights more

\begin{tabular}{|c|c|c|c|c|c|c|c|c|c|c|}
\hline Alternative Implementation & $\begin{array}{c}\text { Cost } \\
\text { Z1 }\end{array}$ & $\begin{array}{c}\text { Performance } \\
\text { Z2 } \\
\end{array}$ & $\frac{z 1^{*}-z 1^{(x)}}{z 1^{*}-z 1^{* *}}$ & $\frac{z 2^{*}-z 2(x)}{z 2^{*}-z 2^{\star *}}$ & $\begin{array}{c}\mathrm{S}= \\
\mathrm{Ls}(\mathrm{x})\end{array}$ & $\begin{array}{c}1 \\
\text { Rank } \\
\end{array}$ & $\begin{array}{c}\mathrm{S}= \\
\mathrm{Ls}(\mathrm{x})\end{array}$ & $\begin{array}{c}2 \\
\text { Rank } \\
\end{array}$ & $\begin{array}{c}S= \\
\operatorname{Ls}(x)\end{array}$ & $\begin{array}{r}100 \\
\text { Rank } \\
\end{array}$ \\
\hline Alt. 1 & $-\$ 187$ & -0.45835 & 0.00 & 1.00 & 10.000 & 5 & 10.000 & 5 & 10.000 & 5 \\
\hline Alt. 2 & $-\$ 196$ & -0.45609 & 0.01 & 0.99 & 0.999 & 2 & 9.847 & 4 & 4.625 & 4 \\
\hline Alt. 3 & $-\$ 215$ & -0.45231 & 0.02 & 0.98 & 0.998 & 1 & 9.594 & 3 & 1.258 & 3 \\
\hline Alt. 4 & $-\$ 1,098$ & -0.32237 & 0.60 & 0.54 & 1.142 & 4 & 3.261 & 2 & 0.000 & 1 \\
\hline Alt. 5 & $-\$ 1,695$ & -0.16393 & 1.00 & 0.00 & 1.000 & 3 & 1.000 & 1 & 1.000 & 2 \\
\hline
\end{tabular}

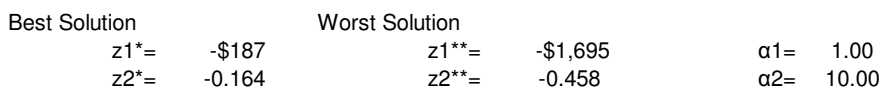

